

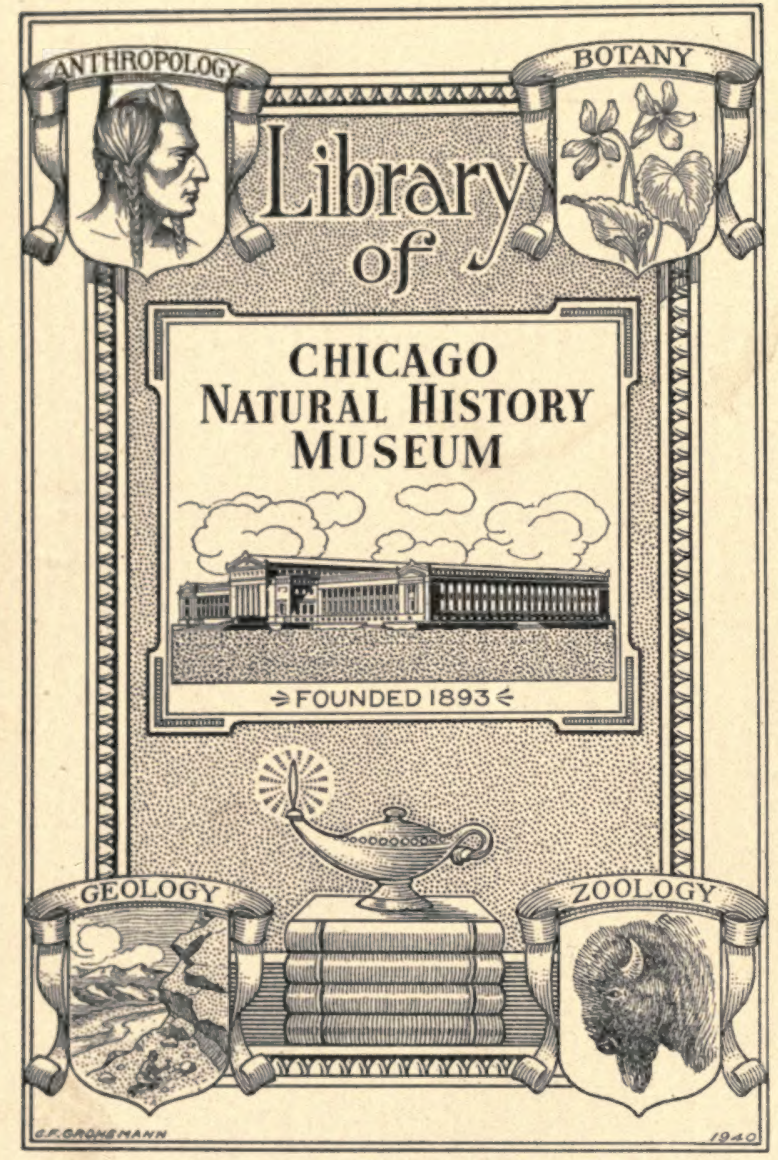








\section{Publications}

OF

\section{FIELD MUSEUM OF NATURAL HISTORY}

\section{ANTHROPOLOGICAL SERIES}

\section{Volume 30}

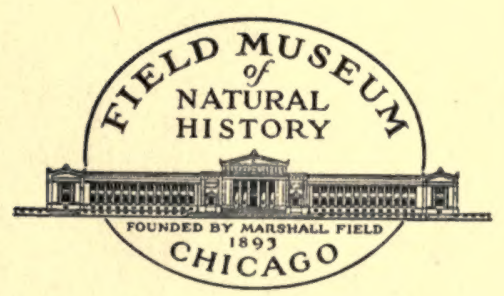

CHICAGO, U.S.A.

1940-1949 
Editors

PAUL S. MARTIN

LILLIAN A. ROSS 


\title{
THE ANTHROPOLOGY OF IRAQ
}

PART I, NUMBER 2

\section{THE LOWER EUPHRATES-TIGRIS REGION}

\author{
BY \\ HENRY FIELD \\ FORMERLY CURATOR OF PHYSICAL ANTHROPOLOGY
}

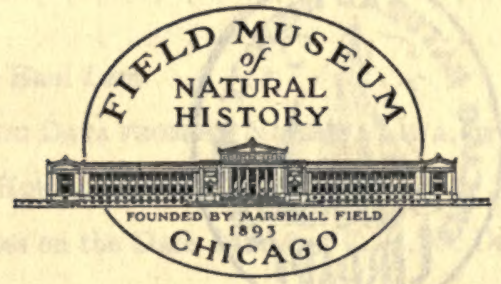

ANTHROPOLOGICAL SERIES

FIELD MUSEUM OF NATURAL HISTORY

VOLUME 30, PART I, NUMBER 2

JULY 8,1949

PUBLICATION 631 


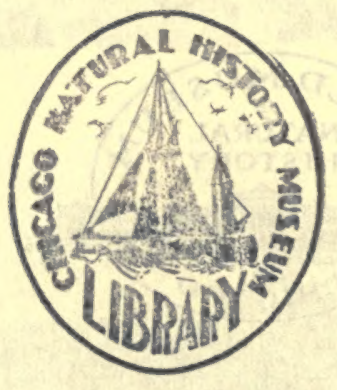

\section{4}

PRINTED IN THE UNITED STATES OF AMERICA

BY FIELD MUSEUM PRESS 


\section{CONTENTS}

PAGK

List of Illustrations . . . . . . . . . . . . . . 229

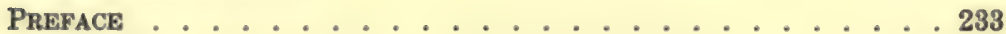

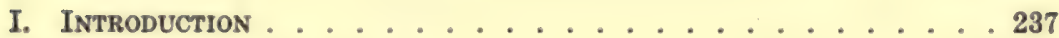

II. The LANd ANd the PeOPle . . . . . . . . . . . . . . 238

III. The Physical anthropology of the Al bu Muhammad, the Al

SAWAAd, AND THE SUBbA . . . . . . . . . . . 262

Al bu Muhammad ................... 263

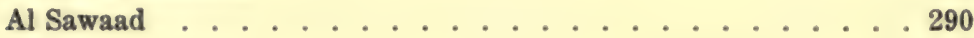

Subba . . . . . . . . . . . . . . 301

Notes on the Bani Lam ................... 328

IV. Anthropometric Data from An Nasiriya Liwa, by Winifred Smeaton 331

V. Arabs of the Hor al Hawiza, by E. S. Drower . . . . . . . . . 368

APPENDix: Notes on the Date Palm, by V.H.W.Dowson . . . . . 407

BibliograpHY .................... 412

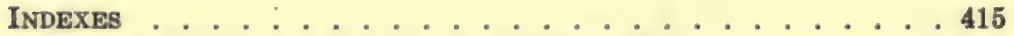

Al bu Muhammad Tribesmen Illustrated in Plates . . . . . . . 415

Al Sawaad Tribesmen Illustrated in Plates . . . . . . . . 416

Subba Males Illustrated in Plates . . . . . . . . . . . 416

Subba Females Illustrated in Plates . . . . . . . . . . . . . 416

General ................. 417 



\section{LIST OF ILLUSTRATIONS}

\section{PLATES}

49. Sheikh Falih as Saihud, Paramount Sheikh of the Al bu Muhammad tribe.

50. Sheikh Falih as Saihud's camp. Fig. 1. Brick guest-house. Fig. 2. Sheikh Falih and his tribesmen.

51. Sheikh Falih as Saihud's camp. Fig. 1. Spearing fish. Fig. 2. A large boat.

52. Sheikh Khazal ibn Falih's guest hut, constructed of 150 reed mats.

53. Interior of Sheikh Khazal ibn Falih's guest hut.

54. Framework of a reed hut.

55. Demolition of house at Sheikh Khazal ibn Falih's camp. Fig. 1. Household furniture. Fig. 2. Raised bed.

56. Beidha. Fig. 1. Interior of council house. Fig. 2. Sheikh Falih as Saihud entering boat.

57. Beidha. Fig. 1. Village. Fig. 2. Pits to keep buffaloes from rubbing against council house.

58, 59. Views of Beidha.

60. Weaving at Sheikh Falih as Saihud's camp.

61. Sheikh Falih as Saihud's camp. Fig. 1. Weaver smoking pipe. Fig. 2. Spinning wheel.

62. Al bu Muhammad tribesmen. Fig. 1. Shuwair, once Mandean, with astrological name of Zahrun bar Sharhat; now Moslem, poet, professional mourner, and eccentric affecting female dress. Fig. 2. Man with hoop and whorl.

63. Al bu Muhammad camp. Fig. 1. Women with whorls at Sheikh Khazal ibn Falih's camp. Fig. 2. Fireplace and coffee pots at Beidha.

64. Rice bins at Sheikh Khazal ibn Falih's camp.

65. Al bu Muhammad tribeswomen. Fig. 1. Milling rice in a quern. Fig. 2. Making butter in a swinging, goatskin churn.

66. Pounding grain at Sheikh Khazal ibn Falih's camp.

67. Al bu Muhammad camp. Fig. 1. Making bread by slapping uncooked dough against oven wall. The dough basin is in the foreground. Fig. 2. Baking bread.

68. Al bu Muhammad camp. Fig. 1. Plough. Fig. 2. Woman potter making a clay oven.

69. Al bu Muhammad camp. Fig. 1. Man making a reed mat. Fig. 2. Woman churning butter.

70. Sheikh Khazal ibn Falih's camp. Fig. 1. Cattle pen next to house. Fig. 2. Buffaloes in a wallow.

71. Milking sheep and cattle at camp of Sheikh Khazal ibn Falih.

72. Sheikh Khazal ibn Falih and his daughter.

73. Jewelry of an Al bu Muhammad woman.

74. Al bu Muhammad camp. Fig. 1. Irrigation by the arawi method. Fig. 2. Smoking a water pipe of a type common in the marshes. 
75. Al bu Muhammad camp. Fig. 1. Woman eating a rush. Fig. 2. Bundle of rushes.

76. Al bu Muhammad camp. Fig. 1. Relaxation after Ashura. Singing to snapping of fingers and drumming of feet. Fig. 2. Breast-beating for the dead. Professional mourner leaping in air.

77. Al bu Muhammad camp. Fig. 1. A tortoise duel. Fig. 2. The death grip.

78. Al bu Muhammad camp. Fig. 1. Large white pelican (Pelecanus crispus). Fig. 2. Young wild boar.

79-91. Al bu Muhammad classic Mediterranean types.

92-96. Al bu Muhammad classic Mediterranean plus convex-nosed types.

97-104. Al bu Muhammad Atlanto-Mediterranean types.

105-115. Al bu Muhammad Atlanto-Mediterranean plus convex-nosed types.

116-118. Al bu Muhammad mesocephals.

119-123. Al bu Muhammad sub-brachycephalic or brachycephalic Mediterranean types.

124-128. Al bu Muhammad Armenoid brachycephals.

129-133. Al bu Muhammad miscellaneous brachycephals.

134-136. Al bu Muhammad Negroid types.

137. Al bu Muhammad Mongoloid types.

138. Al bu Muhammad Australoid types.

139, 140. Al bu Muhammad aberrant types.

141. Boats at Halfaya.

142-144. Boat-building at Halfaya.

145. Al bu Muhammad boats. Fig. 1. Primitive type of craft, made of reed bundles. Fig. 2. A hunting expedition.

146. Al bu Muhammad boats. Fig. 1. Boats at Sheikh Khazal's camp. Fig. 2. Lighters on the Shatt al Arab.

147. Large boat at Al Qurna, at junction of Tigris and Euphrates rivers.

148. Subbi iron-worker near Sheikh Khazal ibn Falih's camp.

149-154. Al Sawaad classic Mediterraneans with either straight or convex noses.

155-159. Al Sawaad Atlanto-Mediterraneans.

160-164. Al Sawaad brachycephals.

165, 166. Al Sawaad sub-brachycephalic Armenoids.

167. Amara. Fig. 1. Subba sheikhs. Fig. 2. Subbi smith working on golden coffee set made for King Ghazi's coronation.

168. Subba sheikhs at Amara.

169-173. Subba Iranian Plateau dolichocephals.

174, 175. Subbi at Amara.

176. Subba Iranian Plateau dolichocephals.

177-180. Subba Iranian Plateau low mesocephals.

181-190. Subba Iranian Plateau high mesocephals.

191-194. Subba Iranian Plateau sub-brachycephals.

195-201. Subba high mesocephals.

202-205. Subba brachycephals plus Iranian Plateau type. 
206. Subba Jewish and North European types.

207, 208. Subba of aberrant types.

209-215. Subba women.

216,217 . Subba children.

218. Leveling the ground in rice field.

219. Sowing rice.

220. Shatt al Arab. Fig. 1. Abu al Khasib Creek, which irrigates about five thousand acres. Fig. 2. Stacking baled licorice root.

221. Shatt al Arab. Fig. 1. Digging in alfalfa between rows of palms. Fig. 2. Splitting into sprigs the staminate inflorescences of date palm.

222. Shatt al Arab. Fig. 1. Carrying harvested dates. Fig. 2. Pruning frond bases of date palm.

223. Shatt al Arab. Fig. 1. Sprigs of staminate blossoms of date palm. Fig. 2. Pruning fronds of date palm.

224. Shatt al Arab. Fig. 1. Spikes of unripened dates: left, with web caused by date mite; right, undamaged. Fig. 2. Spraying dairi palm with nicotine.

225. Tomb of Imam, near Al Qurna. Fig. 1. General view. Fig. 2. Part of decorations on inside of dome.

226. Brick kiln of ziggurat type near Al Qurna.

227. Samawa from the air.

228. Stone trough, ornamented with scene showing madhif type of building.

\section{TEXT FIGURES}

PAGR

11. Iron spear-points and fish-hooks used by Al bu Muhammad fishermen . 378

12. Ground plan of Al bu Muhammad council house . . . . . . . . 383

13. North and south elevations of Al bu Muhammad council house . . . . 383

14. Cross section of fireplace in Al bu Muhammad council house . . . . . 389

\section{MAPS}

1. Lower Euphrates-Tigris region . . . . . . . . . . . . . . 236

2. Route of Expedition east and southeast of Amara . . . . . . . . 239 



\section{PREFACE}

On April 1, 1934, the Field Museum Anthropological Expedition to the Near East, under my leadership, and financed by Mr. Marshall Field, began work in Baghdad. The first four and one-half months of the anthropometric survey were spent in Iraq. In addition, botanical, geological, and zoological specimens were collected. Anthropometric data were also obtained in Iran (Field, 1939) and among the North Osetes and Yezidis of the Caucasus, U.S.S.R.

Mr. Richard Martin, formerly Curator of Near Eastern Archaeology at Field Museum, was in charge of collecting zoological specimens and also accompanied me throughout the Expedition in the capacity of photographer.

Lady Drower ("E. S. Stevens"), the author of the "Folktales of Iraq" and other books, accompanied the Expedition to the Hor al Hawiza in order to record notes on the life and customs of the Al bu Muhammad tribesmen. Lady Drower, who has lived for many years in Iraq, is an accomplished linguist both in Arabic and in Mandean. The results obtained during part of April, 1934, are recorded by her in Chapter $\mathrm{V}$.

Miss Winifred Smeaton, now Mrs. Homer Thomas, was refused permission by Sheikh Falih as Saihud to measure any of the Al bu Muhammad women. Miss Smeaton, therefore, assisted Lady Drower and at the same time compiled extensive notes on tattooing and its significance among these marsh-dwellers.

Mr. Khedoory Muallim, whose services were lent to the Expedition by Dr. J. Sinderson of the Royal College of Medicine in Baghdad, collected birds in the marshes of the Chahala district.

Mr. Albert Meymourian, entomologist of the Rustam Agricultural Experimental Farm at Hinaidi near Baghdad, collected insects in the marshes east of Amara.

Mr. S. Y. Showket, of Basra, acted in the valuable capacity of interpreter. His knowledge of English, Arabic, Kurdish, Persian, and Chaldean, combined with his instinctive finesse in dealing with recalcitrant subjects, made him an invaluable member of the Expedition. Some of the photographs were taken by him.

Mr. Yusuf Lazar, an Assyrian, was in charge of collecting herbarium specimens and insects.

Our special gratitude must be recorded to our gracious host, Sheikh Falih as Saihud (Pl. 49), Paramount Sheikh of the great 
Al bu Muhammad tribe. Sheikh Khazal ibn Falih (Pl. 72) guided and escorted us for two weeks in the Hor al Hawiza.

Our letters of introduction from the Minister of the Interior to the Mutasarrif and Chief of Police of the Amara Liwa literally opened the road into the Hor al Hawiza. Their genuine interest in our work was an important factor in our success. Ten Amara policemen were assigned to the Expedition by the Mutasarrif, since few foreigners have ever been propelled in a boat (mashhuf) within the confines of this great marsh. Each member of the Expedition was ordered to take at least one police officer in uniform whenever he left camp within the marshes. The Chief of Police in Amara stated that the physical characters of the $\mathrm{Al}$ bu Muhammad and the Al Sawaad were different. Consequently, we visited Halfaya in order to obtain a series of fifty Al Sawaad tribesmen. We were assisted most ably by the Chief of Police in Halfaya.

Since full acknowledgments of assistance have been given in Part I, No. 1, I shall not repeat them here.

I wish to thank Miss Elizabeth Reniff, my former research assistant, who worked on this report both at Field Museum and at Harvard.

The typing was done by Miss Ethel Brady, who arranged the statistical tables, and by Mr. Theodore Scully, who typed the remainder of the manuscript and assisted with the final checking of the report. He also calculated some of the tables.

I also gratefully acknowledge the aid of Miss Lillian A. Ross, Associate Editor of Scientific Publications, in seeing the manuscript through the press.

My wife has generously assisted in the proofreading.

Mr. Richard A. Martin drew the sketch map of the route taken by members of the Expedition east and southeast of Amara. In addition he made text figures 12-14, based on personal observation and measurements of the largest Al bu Muhammad council house.

The general map of the Lower Tigris-Euphrates region (p. 236) was drawn by Mr. Peter Gerhard, a volunteer assistant, who checked some of the place names in the text.

Grateful acknowledgment must be made to Lady Drower for the photographs that have been used in the following plates: Pls. 52, 54, 62 (Fig. 2), 64, 65-68, 69 (Fig. 1), 70 (Fig. 2), 74, and 76.

Plates 218-224 are from photographs by Mr. V. H. W. Dowson and Plate 228 is from the British Museum. 
The place names conform to the spelling adopted by the Permanent Committee on Geographical Names of the Royal Geographical Society in London. As the question of orthography is by no means settled and many names are not yet included in the published lists of the Society, standard practice as adopted by the most recent British map-makers has been used.

For the sake of ocular euphony, throughout this report the English article has been inserted in front of tribal names such as the $\mathrm{Al} \mathrm{bu} \mathrm{Muhammad,} \mathrm{although} \mathrm{this} \mathrm{is} \mathrm{technically} \mathrm{incorrect.}$ Similarly, the plurals of many Arabic words have been anglicized by adding the letter $s$ to the singular form, i.e., mashufs instead of mashahuf.

Except in Chapter V (pp. 368-406) all diacritical marks have been omitted because the Arabic words and the names of tribal Sections and Sub-sections were recorded only as phonetic transliterations. Lady Drower, however, made a special effort to record accurate transliterations of Arabic terms in use among the $\mathrm{Al}$ bu Muhammad tribesmen. For this reason in Chapter V the majority of the diacritical marks have been retained.

This manuscript was completed during 1941, but publication was delayed by World War II. A few recent references have been added to the Bibliography. 


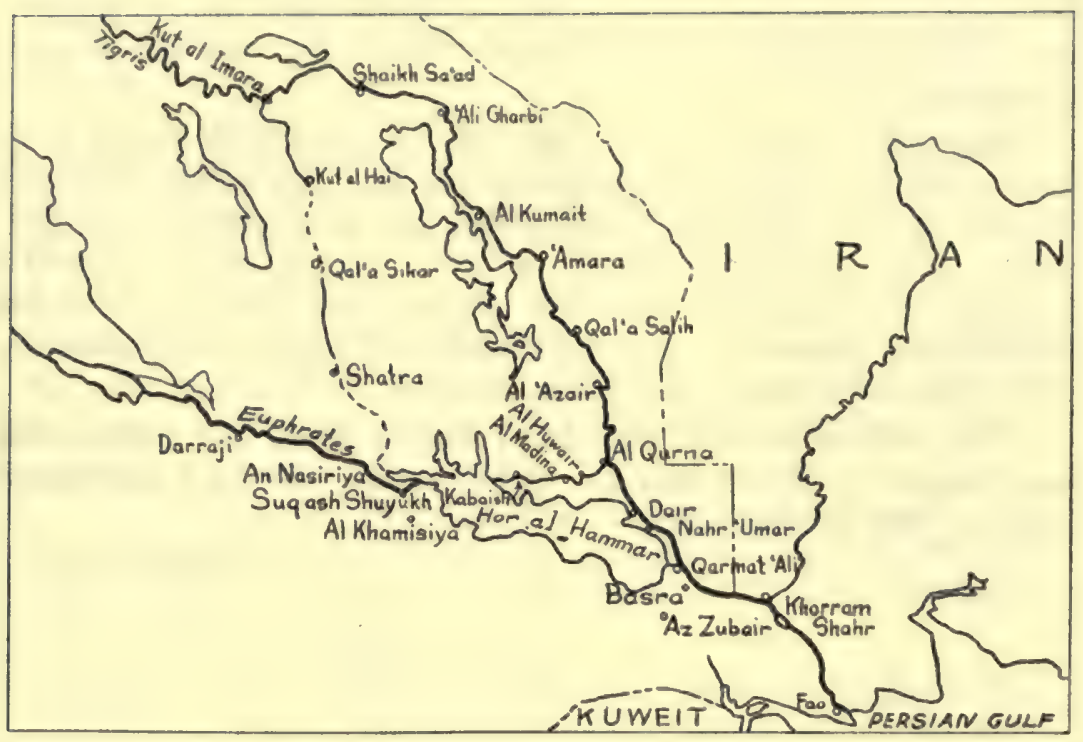

MAP 1. Lower Euphrates-Tigris region. 


\title{
THE ANTHROPOLOGY OF IRAQ
}

\author{
PART I, NUMBER 2 \\ THE LOWER EUPHRATES-TIGRIS REGION
}

\section{INTRODUCTION}

This report, based on the anthropometric data obtained in April, 1934, is concerned with the physical characters of the peoples of the Lower Euphrates-Tigris region of Iraq.

Chapter II deals briefly with the boundaries, physical geography, climate, flora, fauna, and recent historical outline of this area.

In Chapter III are included the anthropometric data on the Al bu Muhammad, Al Sawaad, and Subba, together with some notes on the Bani Lam.

Lady Drower (née E. S. Stevens), whose able contribution on the Marsh Arabs appears in Chapter V, has resided in Baghdad for nearly twenty years. She has devoted the major part of her efforts toward a study of the Mandeans or Subba, the famous silver-workers of Iraq.

In 1934, I invited Lady Drower to accompany the Expedition to the marshes lying east and southeast of Amara, an area known as the Hor al Hawiza. Lady Drower's special assignment was to collect information on the $\mathrm{Al} \mathrm{bu} \mathrm{Muhammad} \mathrm{Marsh} \mathrm{Arabs} \mathrm{and} \mathrm{to} \mathrm{record}$ their Arabic words and phrases, particularly those that differed from those in general use in central and northern Iraq.

Chapter IV deals with the anthropometric data on 125 men and 40 women obtained during March, 1935, in the Royal Hospital at An Nasiriya by Dr. Winifred Smeaton. These data form a most welcome addition because they are the only figures available for this area of southern Iraq.

The Appendix contains notes on the date palm (Phoenix dactylifera) by Mr. V. H. W. Dowson.

Reports on the Hemiptera and Orthoptera have already been published by the Museum (see China, 1938, and Uvarov, 1938).

Indexes of the individual numbers and plate numbers of the $\mathrm{Al}$ bu Muhammad, Al Sawaad, and Subba males and females have been prepared for the convenience of the reader. 


\section{THE LAND AND THE PEOPLE'}

Boundaries.-This region is divided into three parts: the Lower Euphrates, the northern Tigris (from Al Qurna northward), and the southern Tigris (from Al Qurna to Failiya).

The northern and western boundaries of this area run from Bagh-i-Shahi, on the Iranian-Iraq frontier, in a straight line to three miles south of Kut al Hai, crossing the Tigris at Sheikh Saad. Formerly the Shatt al Gharraf joined the Euphrates at An Nasiriya, but the southern portion of this channel silted up and the natural line of flow developed from three miles north of Shatra in a southeasterly direction along the Shatt al Bada.

The Euphrates River, flowing from Darraji into the Shatt al Arab, forms the southern boundary. The eastern boundary follows the Iranian-Iraq frontier in a southerly direction from Bagh-iShahi to Failiya, meeting the Euphrates River at the Shatt al Arab.

Physical Features.-This area constitutes part of the great alluvial plain of Iraq. With the exception of the isolated Jebel Sanam, approximately twenty miles south of $\mathrm{Az}$ Zubair, and the Arabian Desert, which rise 508 and 100 feet respectively, there is no place higher than forty-six feet above sea level. 'The Shatt al Gharraf, three miles downstream of Kut al Hai, approximates this with an altitude of forty-five feet. Suq ash Shuyukh lies at ten feet above sea level, An Nasiriya at fifteen, Shatra reaches thirty, and Qala Sikar only thirty-nine feet, so that the effect of the tide is felt as far up the Euphrates as Kabaish. The eastern and northern boundaries have an altitude ranging from five feet above sea level at Failiya to forty-six feet at Sheikh Saad, an insignificant difference over a distance of 263 miles.

The physical features of this area graduate from arid, unproductive desert into lands suitable for the grazing of camels and sheep, into fertile and cultivated areas dependent upon controlled irrigation, and into marsh land, which in its turn merges into a vast expanse of open water.

To the east of An Nasiriya the Euphrates River splits into many channels, which find their way into the Hor al Hammar, bordered, especially to the north, by vast marshes dense with reeds growing to a maximum height of twenty feet. The Euphrates has two main

1 The greater part of the information contained in this chapter is based on data obtained prior to 1930 , although in 1934 every effort was made to check the accuracy of the statements. 


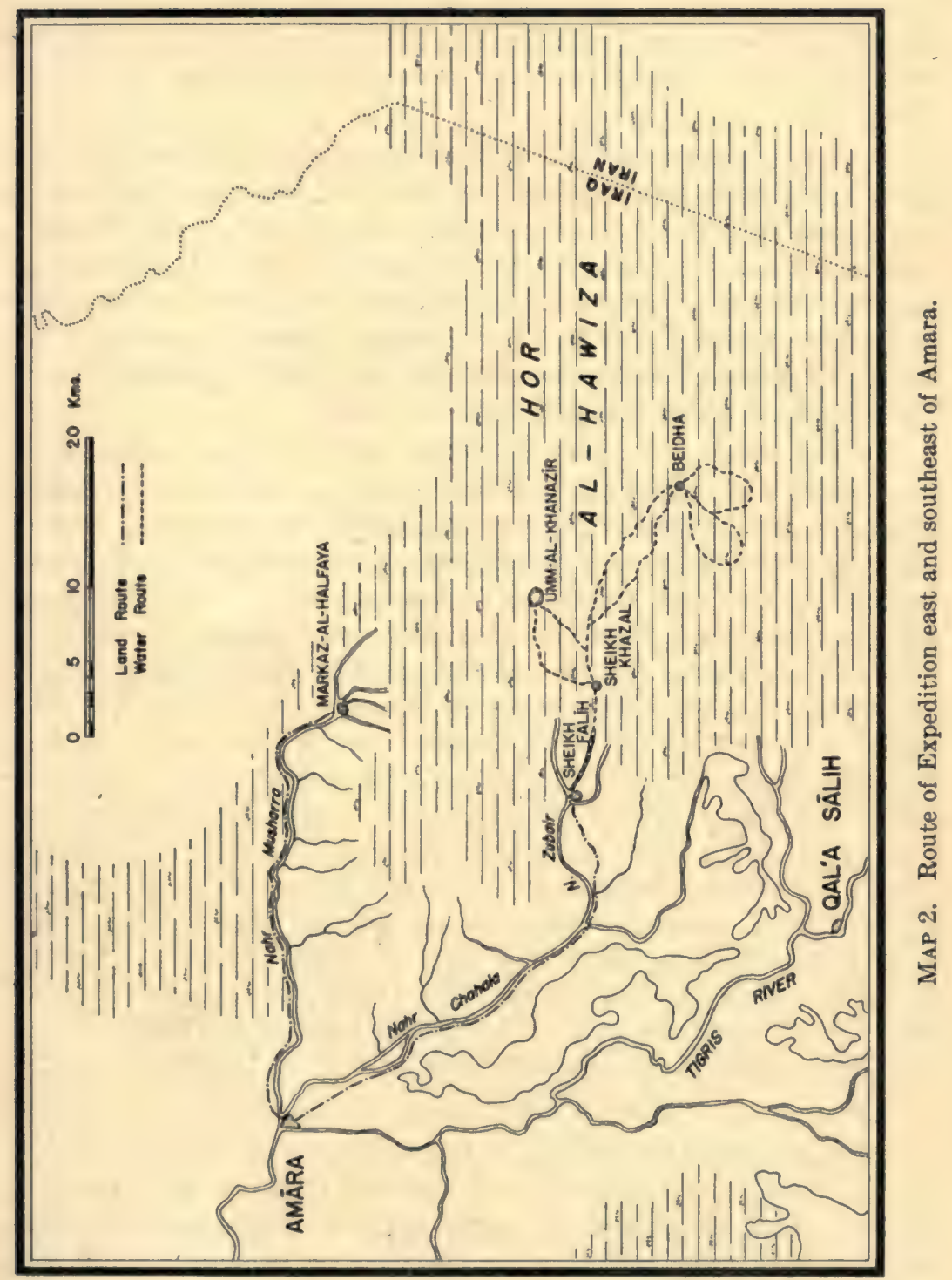


channels. The old waterway, passing Kabaish at the eastern end of the Hor al Hammar, joins the Tigris at Al Qurna. This channel is used by steamers. The new course winds through the shallow expanse of open water lying to the north of the Basra-An Nasiriya Railway, finally finding its main outlet into the Shatt al Arab at Qarmat Ali.

A considerable quantity of water from the Tigris reaches the Lower Euphrates via the Shatt al Hai, which takes off at Kut al Imara and flows down to three miles south of Kut al Hai, where it is also known as the Shatt al Gharraf until it becomes the Euphrates near An Nasiriya. The amount of water in the Gharraf is dependent on the level of the Tigris at Kut al Imara. Except for pools, which become brackish, the channel runs dry by September and remains waterless until the end of December or later.

To the north and south the Tigris River divides and irrigates this region, which would otherwise be desert as barren as the Nefud. The soil near the Tigris is free-working and, like calcareous loam, is inclined to be salty in the depressions. In the area north of Amara, land is irrigated only two miles inland on either bank of the river. Beyond stretches a desert covered with scrub useful only for fuel. The reaches between Amara and Al Qurna are intersected by numerous canals, providing the district with some of the richest rice fields in Iraq and creating extensive marshes, which deprive the Tigris of sufficient water for easy navigation. Below Al Qurna, however, and to the east of where the Tigris and Euphrates meet and form the Shatt al Arab, desert again predominates, although for the greater part of the distance between Al Qurna and Khorram Shahr (formerly Muhammera), especially below Basra, the left bank is fringed with date palms stretching inland to a depth of almost two miles. Between Basra and Khorram Shahr some 90,000 date trees are cultivated on long islands, which lie so close to the left bank of the Shatt al Arab that they appear to form part of the mainland (cf. Dowson, 1921-23).

Drainage from the Kurdish hills to the north, by a number of streams such as the Great Zab, the Little Zab, and the Diyala, provides the Tigris with more water and silt than are found in the Euphrates. Below Amara the Tigris is much reduced by numerous canals, which carry a great portion of its water into extensive swamps, thus rendering the reach between Qala Salih and Al Uzair, known as "the Narrows," almost unnavigable in the low water season. A large proportion of this water returns into the Tigris, upstream from Al Qurna. 
The waters of the Euphrates join those of the Tigris partly at Al Qurna, forty-six miles above Basra, and partly at Qarmat Ali, five miles above Basra. Together they form the Shatt al Arab, a fine river 1,200 yards wide and navigable as far as the Al Qurna bar for ocean-going steamers.

The Shuwaiyib River, three and one-half miles below Al Qurna, drains the Hor al Hawiza. This great belt of marshes, which lies a few miles east of the Tigris between Al Qurna and Qala Salih, is fed by streams from the Iranian hills, chief of which is the Karkheh. The Shuwaiyib enters the Shatt al Arab from the northeast, but the country near the mouth is flooded in spring or after rain. The two rivers are connected by the Ruta Creek, which enters the Tigris near Pear Drop Bend, just below a conspicuous group of palms about ten miles above Al Qurna. The upper course of the Shuwaiyib is lost in the marshes to the north.

Ruta Creek has a maximum width of thirty feet but its average width is about one-third of this figure. The depth remains constant.

Extending east toward the Hor al Adhaim (Azem) is the Michiriya Canal, about two miles above Qala Salih. The Majar al Kabir Canal, which runs southwest to the Hor al Hammar, about sixty miles distant, is unnavigable for flyboats.

The Majar as Saghir joins the Hor Umm Tafra with the Hor al Hammar.

Running southwest across the marshes, the Abu Tabr Canal, six and one-quarter miles south of Amara, is believed to lead eventually to the Hor al Hammar, a distance of about fifty miles. It is also unnavigable for flyboats.

Immediately above Amara, the Chahala and Musharra canals, which have a single mouth at the north end of the town, flow into the Hawiza marshes, the Musharra running in an easterly and the Chahala in a southeasterly direction. Except for small launches, both are unnavigable, the Chahala because of its regulator and the Musharra through lack of water.

From March to the end of June, when the Euphrates and Tigris are in flood, it is estimated that 4,000 square miles are inundated and covered mostly by "sheet water," the borders and shallower portions of which are marsh, thickly grown with reeds and intersected by many channels known only to the local inhabitants.

After the rivers subside these marshes become dry land, but the shallower "sheet water" becomes a marsh. The deeper water remains as permanent lakes of which the most important are the 
Hor al Hammar, Sadifa, Abu Ajul, Ghamuga, Al Hassuna, Tallya, and Butaniya.

The remainder of the country is either desert or cultivated land.

Rate of Land Formation.-According to early Sumerian records on cuneiform tablets, Eridu, the modern Abu Shahrain, twentythree miles southwest of An Nasiriya, was one of the oldest cities of Sumeria. Shortly after its foundation Eridu became a flourishing port ${ }^{1}$ on the Persian Gulf. It is described in cuneiform texts as "standing on the shore of the sea." The mounds of Eridu, surrounded by desert, now lie some 160 miles distant from the Persian Gulf.

From early texts it is possible to trace roughly the northern limit of the Persian Gulf at the dawn of the historical period. It appears to have extended from the Arabian Plateau, where the coast line ran approximately due north, to Eridu, and crossed the Euphrates about eleven miles northwest of An Nasiriya; thence it ran just south of Shatra and continued in a general northeasterly direction to the Tigris, turning southeast below the Elamite hills of Khuzistan (formerly Arabistan).

These figures and other data suggest the rates at which, from time to time, the land has advanced southward at the head of the Persian Gulf. This advance is due to the accumulation of sediment brought down in suspension by the Tigris, the Euphrates, and the Karun and deposited on the sea bed when the current is checked as the Shatt al Arab reaches open water. Thus, for example, the location of Eridu, a sea port about 4000 B.C., indicates a rate of advance of 121 feet per annum. Khorram Shahr, a port in the time of Alexander the Great, is now fifty miles from the sea. In this case the rate of advance was 113 feet per annum.

Recent tests have shown that the rate of advance is approximately ninety feet per annum. This gradual reduction in the rate of formation of the land is to be expected because, as the delta increases in length, the slope of the river bed becomes more level, thereby reducing the velocity of the current on which the amount of sediment brought down in suspension depends.

Climate.-Irrigation and marsh water may lower or raise temperatures. After the spring floods, Al Qurna, for example, is surrounded by extensive marshes. Consequently, the presumed maximum

1 On December 29, 1939, Mr. Frederick Richardson informed me that on the basis of his geological survey of southern Iraq this statement is incorrect. His results will appear in an Oriental Institute Publication. 
temperature is lowered and the minimum raised during May and June. Both temperatures, especially the minimum, are decreased during August and September.

\begin{tabular}{|c|c|c|c|c|c|}
\hline \multicolumn{6}{|c|}{ AVERAGE MINIMUM AND MAXIMUM TEMPERATURES IN 1918} \\
\hline Place & May & June & July . & August & September \\
\hline $\begin{array}{l}\text { Amara.. } \\
\text { Al Qurna }\end{array}$ & $\begin{array}{l}70-94 \\
75-92\end{array}$ & $\begin{array}{l}75-102 \\
77-97\end{array}$ & $\begin{array}{l}79-110 \\
77-103\end{array}$ & $\begin{array}{l}78-109 \\
72-105\end{array}$ & $\begin{array}{l}74-107 \\
68-105\end{array}$ \\
\hline
\end{tabular}

January is the coldest month, July or August the hottest. As in all semi-arid regions, the range in temperature is wide. Although $115^{\circ}$ is normal at Basra during the summer, the highest recorded temperature was $129^{\circ}$ during July, 1921. On the other hand, frost is often experienced in the cold season, the minimum recorded temperature being $23.7^{\circ}$ in January. Bitterly cold winds sweeping down from the Pusht-i-Kuh make the atmosphere of the Amara district appear far colder than farther south.

During August and September, the date-ripening season, the wind comes from the south, bringing with it a moist atmosphere. Mosquitoes and sand-flies are very numerous in these months. The normal speed of the wind rarely exceeds three miles per hour, although sudden gales are not unknown.

The rainy season begins in November, reaching its zenith in December and January. Except in years when the rain starts late, or is below the average, little falls after the middle of April. The average amount of rain in the district near Amara is thirteen inches over a period of thirty days, while south of Al Qurna not more than ten inches fall over the same period. Hail is rarely encountered in these parts. Snow has never been recorded.

Mirage.-Between April and September, mirage is to be seen everywhere in the desert from about 10.00 to 16.00 hours. Mirage makes that part of the desert between the observer and the sun appear like water, and exaggerates the size of objects. It is impossible to distinguish anything clearly either in or beyond the mirage, which appears 600 or 800 yards from the observer.

Grazing.- Shortly after the first rains have fallen, usually in December, large areas of the previously brown desert become green with grass, affording good grazing for sheep and cattle until the end of May. At that time, except for the scrub (shok) upon which the camels feed, the desert is barren.

The best cattle in this area are found in the region north of Amara, and especially in the Ali Gharbi district, where the quality of sheep is probably as good as that found in other parts of Iraq. Horses 
and cows are of average quality, although some good breeds of horses are seen in this area. Transport camels are found only north of Amara, while buffaloes live chiefly in the marshes between Qala Salih and Al Qurna, and cows in the Al Qurna district.

Agriculture.-The Tigris area, like the greater part of Iraq, is essentially agricultural. There are no manufacturing industries, and the only trade is with Baghdad, Basra, and Iran. A great deal of the commerce is local, taking the form of buying, selling, and interchanging the various products of the land. The Amara Liwa is famed chiefly for its rice fields, although wheat and barley are also grown extensively, the latter in the districts north of Amara and the former between Amara and Qala Salih, where the land irrigated by the Chahala, Butaira, and Majar al Kabir canals is the richest. Farther south, cultivation of fruit and vegetables is the main form of agriculture.

The products of the country comprise wheat, barley, rice, millet (gowari), mash, sesame (simsim), tomatoes, lady's-fingers, brinjals, lettuce, cucumbers, cabbages, melons, onions, turnips, radishes, carrots, beans, spinach, pumpkins, beetroot, cauliflower, dates, grapes, apples, apricots, plums, pomegranates, limes, figs, nectarines, pears, oranges, grasses (shuraib, fluih, thail), alfalfa, and Egyptian clover.

Both winter and summer crops are grown. The winter crops of wheat and barley are cultivated in the districts north of Amara, the proportion being six tons of barley to one ton of wheat. Rice is the most important summer crop. All the rice fields are to be found in the marsh land between Amara and Azair. Maize is sown with the rice; sesame is grown chiefly at Ali Gharbi, but is also found in small quantities between Ali Gharbi and Butaira. With the exception of wheat and barley, which are sown from November to January and harvested from May to June, the grains are sown from March to June and harvested in September.

Wheat and barley are sown broadcast while rice may be grown on the silt deposited in the marshes during the floods (afi), or planted in small pots (harfi) and transplanted in June (shital).

The method of watering rice called shitwi depends upon rain for moisture after ploughing and upon floods for generation and growth. There is another system known as saifi, involving canals and a succession of reed and mud dams (haml, sing.) that raise the level of the water sufficiently to flood the rice fields.

All vegetables are grown between the Butaira Canal and Kassareh. During the War (1914-18) the cultivation of European 
vegetables was encouraged, and the demand for these has increased the production. Vegetables are planted by the natives in the following seasons:

Spring.--Lady's-fingers, brinjals, lettuce, melons, and onions.

Autumn.-Cabbages, turnips, carrots, beans, beetroot, and cauliflower.

Autumn and Spring.-Tomatoes, cucumbers, radishes, spinach, and pumpkins.

Vegetables are almost always irrigated by lift, in contrast to the flow system used for grain. The most common machines for this purpose are pumps (tabia or mutbah), i.e. basket scoops worked by two men; a charid, worked by a horse, which draws water up in skins so that it can be distributed by small watercourses (ahliyahs); a naur similar to a Persian water-wheel, which can be worked by one man, i.e. a long pole fixed to a horizontal bar, weighted at one end by earth covered with sacking, while at the other end is a bucket or skin.

A large variety of fruits is grown in the gardens at Amara, Qala Salih, and Al Qurna, but, with the exception of dates, only in very small quantities. To provide sufficient moisture there are many irrigation pumps. The charid is employed throughout this region.

Alfalfa, which is plentiful in this district, is sown very lightly in September after the land is watered so that the seeds sink in with the water. The best grasses are usually found between Ali Gharbi and Amara.

Forage crops show rapid growth during the winter, but do not progress in summer when a shortage of grazing is usually felt. At this period the herds migrate from the left bank above Amara to the foothills of the Pusht-i-Kuh. The strong sun and dry air render the successful growth of really nutritive forage crops difficult during these months. In places where water is available, alfalfa is easily grown, yielding a supply of green forage and at the same time improving the soil. If the river rises early, the grass is cut in May and the quality is better.

Agricultural implements are very primitive, chiefly because they are sufficient for the purpose of the Arab and entail no expense. Those used in this area, almost all of which are manufactured by the blacksmiths of Amara, consist of:

(1) An Arab plough (fiddan) made of two shafts, at the end of which is fixed a bent piece of wood with an iron head, shaped like a 
curved arrow. The head is put into the ground from six to ten inches, according to the moisture and smoothness of the earth; two oxen, guided by one man, draw this plough.

(2) A curved saw (minjal) with a wooden handle, used for harvesting. Although he has a slow method of cutting the crops, the Arab shows great skill and dexterity, holding the stalks in one hand and cutting with the other (cf. Field, 1935a, Fig. 37).

(3) A five-pronged, wooden fork, used for winnowing barley. After the barley has been threshed by bullocks trampling over the straw, the bhossa is separated from the grain by means of this fork.

(4) A long-handled shovel (misha) with a footrest above the blade to press the shovel into the ground. This is used by Arabs throughout Iraq.

(5) Axes and curved knives, used for cutting trees.

Among insect pests is the locust (jirad), which attacks wheat, barley, tomatoes, lady's-fingers, melons, and cucumbers. There are two kinds: the Abu Dubailah ("father of an elbow," so-named because of its shape) become numerous during years of heavy rain; and the locust of Nejd (jirad Najdi) appears about once every ten years and at different seasons of the year. Because of their destructiveness, locusts ${ }^{1}$ are believed by Mohammedans to be the revenge of Allah.

There are several varieties of ants: a red ant (humairah) destroys rice; a white ant (irahah) eats maize and mash; a white ant (zaluntah) eats vegetables and rice; a small red and black flying ant (ikhzail) destroys barley, wheat, and rice. In addition to the insects the natives are sometimes pestered by tortoises (Pl. 77), which eat the roots of the rice.

Trees.-With the exception of those bearing fruit, only two varieties of trees, safsaf and gharab, are found in this district. Both have a life of approximately fifty years. The safsaf is a kind of willow, growing on river banks or in gardens, whose wood is used in making beams for roofs, and ploughs. Gharab, the Euphrates poplar, is used in the manufacture of planks, beams, mashufs, and also as fuel; its leaves are boiled to produce a yellow dye.

${ }^{1}$ In March, 1928, during excavations conducted by the Field MuseumOxford University Joint Expedition at Jemdet Nasr, which lies eighteen miles northeast of Kish, we were plagued with a swarm of locusts. In mid-afternoon the sky became gray and finally almost dark, some time before sunset. The flight lasted from 15.00 hours to 04.00 hours on the following day. We were invited to eat fried locusts, a local delicacy. They were stripped of their wings and cooked over smouldering camel dung. They tasted like shrimps. When daylight came, millions of locusts covered the ground, which appeared to be literally crawling with tired locusts. Not a blade of early spring grass nor a leaf of camel'sthorn (hatab) remained. 
Minerals.-Extensive salt bands at Qala Salih and Musharra have yielded, individually, as high as 150,000 kilograms a year. In less abundant quantities, salt is also produced at Amara, Sirut, and Sayyid Nur. Bands of inferior quality exist in other parts of the area and it is thought that at a depth of not more than six feet both banks of the river between Amara and Al Qurna would yield this mineral. Large and deep wells are sunk until salt water of an amber color appears. This water is drawn into salt pans and allowed to evaporate until the salt crust, about half an inch thick, forms on the surface. This muddy salt is then removed, washed in clear salt water, and spread out to dry on reed mats.

From a chemical point of view the percentage of lime is most striking. The soils contain a high percentage of valuable ingredients such as nitrogen, phosphoric acid, and potash.

Gemento, similar to gypsum (juss), is present at Duwairij. At present little use is made of this, except for experiments and local requirements such as burning it and plastering graves, although the Arabs use it as a substitute for mortar.

Bricks are made in numerous places. The largest production comes from the Harta Nahiya near Qarmat Ali. At one time there were twenty-five kilns, employing 250 men. Each large kiln (Pl. 226) can produce 30,000 to 40,000 bricks in an eight-day shift. There are kilns also at An Nasiriya, Shatra, Qala Sikar, Suwaiq, Karradi, and Suq ash Shuyukh.

Ghee is tinned at Shatra.

Industries.-In the Lower Euphrates-Tigris region, the men, excluding those who are merchants, after the age of sixteen usually follow some profession. Listed in order of social prominence they may become government servants, cultivators (fallahin), planters $(t a a b)$, boatmen, dealers in reeds and mats, fishermen both in salt and in fresh water, buffalo breeders, weavers, or coolies.

The weaving of woolen abas at Al Qurna, Shatra, and especially at Suq ash Shuyukh, where the men do the weaving, forms one of the more important manufactures of southern Iraq. Lengths of cloth are exported to Al Kuwait and Al Khamisiya for sale.

Boat-building is carried out to some extent on the banks of the Shatt al Arab, but the most famous boat builders in the country are the Mandeans. They construct all types of river craft from mahailahs down to small mashufs. Al Huwair and Khas have great reputations as boat-building localities; both are situated on the Euphrates between Al Madina and Al Qurna (Pls. 141-144). 
Among native craft (Pls. 145-147) are the following:

Mahailah or Safinah.- These boats are found everywhere from Fao to Baghdad. They vary in length from thirty to eighty feet, with a beam of from ten to twenty-five feet open, but with a poop in the larger types, and one mast provided with a lateen and staysail. The safinahs, built in Baghdad, are coated with bitumen. When wind or stream is adverse they are either poled or towed by a rope from the top of the mast. From ten to a hundred tons of cargo can be carried. The draught of a loaded safinah is from three and onehalf to four and one-half feet. The crews vary from three to eight men, and a large safinah can carry up to sixty passengers. The smaller safinahs are generally known as mahailahs.

Balam.-The Basra type of this boat is about twenty feet long by three feet across, and long and narrow in shape. It can be rowed or sailed, but is more generally towed or punted.

Mashuf.-This is a canoe of reeds or thin wood covered with bitumen. The length is from fifteen to eighteen feet, the boat being easily and rapidly propelled by one man, who sits as low and as far aft as possible and uses a paddle. A large mashuf (Pl. 145, Fig. 2) can carry from four to six men with a second paddler in the bow.

Quffah.-The gufa, rarely seen below Baghdad, is a coracleshaped craft peculiar to Iraq. This type of craft is of very ancient origin, being frequently depicted on Chaldean and Assyrian reliefs. It is a strong wickerwork basket, thickly coated with bitumen. In appearance the gufa is a hollow spheroid, four to five feet in diameter, with the central portion of the top removed. The gufa is propelled by two men with paddles, and will carry four or five passengers; a very large gufa can carry as many as twenty people.

The manufacture of mats, baskets, and other articles from the marsh reeds in this area is mostly carried out by the Bani Asad and Madina tribesmen, whose marshy habitats to the east of the Hor al Hammar are eminently suited to the industry. Reeds are of three kinds: chaulan, bardi, and qassab. All are good food for cattle when the plants are young and tender. Chaulan is used for the manufacture of soft mats (bassir); qassab is used for coarse mats (buwari); bardi and qassab make good fuel and are much used in brick kilns. From the reed mats the Arabs build their mat huts ${ }^{1}$ (saraif). Reeds and mats are collected on the rivers, formed into rafts (garah), and floated down to their destination.

${ }^{3}$ For building of reed huts see Journal of American Oriental Society, March, 1939 , vol. 59 , No. 1, p. 109 and references in footnote 3. 
History.-The Muntafiq Confederation is a powerful tribal league that occupies an area in the Lower Euphrates-Tigris region from Darraji to Kabaish, extending as far north as Kut al Hai on the Shatt al Gharraf.

In 1920, the link between the various units of the league was no more than a common recognition of the now nominal paramount authority of the Sadun. They, the ruling family of the Muntafiq, are descended from Mani, one of the Sherifs of Mecca, who, about A.D. 1600, fled to the Euphrates to escape the consequences of a feud. Mani married a daughter of the ruling family of the Bani Malik and had a son by her named Shabib. The Bani Malik were attacked and heavily defeated by the Ajwad, Mani himself being killed. The Bani Malik made their escape into Nejd and took Shabib with them, since he was the grandson of their own sheikh. After an exile of three years, the Bani Malik, reinforced from Central Arabia and led by Shabib, fell upon and almost exterminated the Ajwad, who were encamped at Safwan. A few men and a total of forty women are said to have been all that were spared. Shabib thus, by virtue of his military powers, became leader of the Bani Malik and overlord of the Ajwad, this combination becoming so powerful that it was joined by the Bani Said, a tribe of the Jazira. These three divisions formed the Muntafiq league.

Up to about 1870 , the Muntafiq tribes under the Sadun were almost independent of Turkish rule. They paid tribute but no rent to the Sadun.

History records that the Tigris has always been divided into two distinct parts: the northern, stretching from Al Qurna northward, inhabited some 400 years ago solely by the Bani Rabiah tribe, whose territory is now on the Shatt al Gharraf, and many of whose former sections are with the Bani Lam; and the southern, from Al Qurna to Failiya, the home of the Chaab.

The tribes of the lower Tigris district, the descendants of the original families of Al bu Muhammad, Bani Lam, Azairij, Al Sawaad, and Sudan tribes, originate from Yuarib's line, while the Bani Rabiah, from whom spring the Al bu Darraj, the Chaab, Bani Malik, and Bani Asad, can be traced back to Abir.

In 926 A.H., Sulaiman, the ninth Sultan of Turkey, conquered Iraq from Mosul to Fao, and for the first time introduced Turkish government into the country. Then the land now inhabited by the Bani Lam was owned by the Buwaish, a section of the Bani Rabiah, which later resided at Ahwaz under the Sheikh of 
Muhammera. ${ }^{1}$ The chief of the Buwaish, Mulla Barkat, sometimes known as Mubarak, was king of Hawiza and sole owner of the lands from Kut al Imara to Hawiza, on the left bank of the Tigris, while the right bank was in the possession of the Muntafiq. It was during Mulla Barkat's reign that Barrak, one of the grandsons of Lam, migrated to Hawiza and settled as a subject of Mulla Barkat. Later Barrak's son, Hafidh, having quarreled with Mulla Barkat, fought and defeated him with the assistance of the Chaab, Darraj, Khazraj, and Hallaf sections of the Bani Rabiah. From that day these four sections became subjects of the Bani Lam, and the Bani Rabiah were expelled from these lands, part taking refuge in Iran and the remainder on the Shatt al Gharraf, where the greater portion of the tribe still resides.

A century later Muhammad, the founder of the Al bu Muhammad, migrated to the Chahala and was accepted as a subject of the Bani Lam, whose position remained the same until Faisal al Khalifah, of the Al bu Muhammad, attacked and defeated them, seizing the districts of Javrah and Thulthain. From this date quarrels were of frequent occurrence between the two tribes, until the Turkish Government sent troops, under the command of Muhammad Pasha, to restore peace, an object that he attained without fighting by dividing the district equally between the two tribes.

For many years the Bani Lam and the Al bu Muhammad lived in comparative peace side by side, each transferring its hatred of the other to the Turkish Government. In 1908, war again broke out between the Al bu Muhammad and the Bani Lam. Under the leadership of Ghadhban ibn Bunaiyah, the Bani Lam were supported by the Sudan, an ancient tribe that migrated 200 years ago from the district of Hilla, and by the Al Sawaad and Azairij, both of which claim origin from the same tribe, Bani Himyar. The Al bu Darraj, an offshoot of the Bani Rabiah, allied itself with the Al bu Muhammad. The Bani Lam were victorious and seized the lands from $\mathrm{Al}$ Kumait to Majar as Saghir, but the Turkish government interfered and made alterations in the distribution of the lands that were resented by both tribes and resulted in a combined attack on the Turkish troops stationed in the town of Amara. The tribes were defeated, and Ghadhban, the Bani Lam chief, was dismissed and his lands reapportioned. At the outbreak of the War in 1914, Ghadhban was recalled and made Commandant of the Arab forces under

${ }^{1}$ Although by order of the Shah, Muhammera has been changed to Khorram Shahr, the term Sheikh of Muhammera has been retained throughout this historical summary. 
Muhammad Pasha Daghestani at Ahwaz, remaining loyal to the Turks until the fall of Amara in 1915, after which, at the head of the Bani Lam, he supported the Turks or British according to the swing of the pendulum of success.

Toward the end of the sixteenth century the whole district from Al Qurna to Fao, on the left bank of the Shatt al Arab, was governed by the Bani Amir, a section of the Chaab, a tribe of Quraish, in Arabia. This section ruled for 150 years until the powerful Muntafiq defeated them and seized their property. The Chaab, who are said to have come from the western shores of the Gulf, were at the time residing in Persian territory, and, seizing their opportunity, took the lands and settled in these parts. While on the Shatt al Arab they followed the profession of pirates, and in spite of their coming frequently into collision with the East India Company, they managed to remain supreme within their own territories. Being within both Persian and Ottoman boundaries, they found themselves under Persian and Turkish rule, but with the exception of paying tribute to the Shah, they were virtually independent and appeared frequently in the troubled annals of Lower Iraq as allies of both Persia and Turkey.

At the beginning of the nineteenth century, a section of the Chaab, Al Muhaisin, emerged as rivals, on account of the murder of the brother of Hajji Jabir, of the Muhaisin section, by a Chaab Chief. Hajji Jabir, father of Sheikh Khazal, the Sheikh of Muhammera, at the head of Al Muhaisin, attacked and defeated the Chaab, but they reorganized their forces and not only turned the tables on the Al Muhaisin, but also took Hajji Jabir prisoner to Persia. He made terms with the Persian Government at Tehran, and was allowed to return to Khorram Shahr, when he again attacked and defeated the Chaab and became chief of the whole district. His rule of the tribe continued from 1819 to 1881, during which period he gradually increased their numbers by admitting foreign sections who agreed to submit to his rule. His son, Sheikh Mizal, succeeded him, but was not so well disposed toward the British. He was, however, hated by the tribe and finally assassinated in 1897 . Khazal, his younger brother, became, by tribal election, Sheikh of Al Muhaisin.

Many types of tribal conditions are represented in the Lower Euphrates-Tigris district, although there are no distinct divisions between these classes.

(1) The settled tribal area is inhabited by the Muntafiq and the Al Jazair confederations. 
(2) The nomadic tribal areas comprise certain wandering tribes to the west and east of the Gharraf and the Beduin tribes in the Shamiya, to the south of the Basra-Darraji Railway, who wander into this area.

(3) The semi-tribal area lies near Al Qurna and in the vast marsh area to the northwest, west, and southwest.

(4) The non-tribal area extends from the vicinity of Al Qurna down to Fao.

Settled Tribal Areas.- Tribes are administered through their own sheikhs. The sheikhship normally passes from father to son or at least remains in the family, unless the administration has a special reason for making a change.

Although the majority of rural settled Arabs have a regular tribal organization such as that of the Abuda or the Bani Asad, there are many thousands who belong to so mixed a community that tribal ties have become entirely or almost entirely extinct. Such conditions are found in the highly civilized areas and among the population of the date gardens on the banks of the Shatt al Arab downstream from Basra. This population is either pastoral or agricultural or a combination of both.

The Muntafiq is not a "tribe" but a large, loose confederation of Arab tribes. The Muntafiq tribesman is either a settled cultivator (hadhr) or a shepherd (shawiya), who uses the donkey as a means of transport in place of the camel preferred by the Beduin.

The Muntafiq fall into three main divisions: the Ajwad, the Bani Malik (colloq. Malich), and the Bani Said. Of these the Ajwad had the least cohesion. The Bani Malik, also loosely united, were divided into two main confederations known as the Mujarrah and the Bani Khaiqan. The Bani Said were the most compact and corresponded more closely to a tribal group.

In the case of a gathering of all the Muntafiq, as for example, the tribal concentration at Shuaiba (colloq. Shaiba) in 1915, the various tribes grouped themselves into their respective divisions. Normally, however, these three main divisions were merely nominal.

The Al Jazair, a confederation of settled tribes, some of whom are Muntafiq, are located in the vicinity of the Hor al Hammar. It is probable that at one time the whole of the $\mathrm{Al}$ Jazair was Muntafiq, for local tradition places this confederation as Bani Malik by origin. Presumably, it was only when the links that bound the Muntafiq together weakened with the waning authority of the Sadun that the sections east of Kabaish detached themselves. 
The tribes composing the Al Jazair were the Muntafiq groups of the Bani Asad, Al Husaini, Bani Hutait, Ibadah, and Bani Musharraf, and the non-Muntafiq Bani Mansur.

The Arabs, who live in towns, are looked down upon by their rural brethren as being merchants and generally contemptible. Under such conditions men, each of whom belongs by origin to a separate tribe, are found living together. The result is that the population soon becomes so mixed that no tribal bonds remain.

The Nomadic Tribal Areas.-These tribes, which included the Dhafir and the Ajman, were pastoral tent dwellers, breeding either camels or sheep, and donkeys, from which they obtained their livelihood. They were tribally organized. The tribes in the Shamiya were dependent to a very great extent for supplies on the "Desert Ports" such as Az Zubair and Al Khamisiya.

The Semi-Tribal Area.-This is the connecting link between the tribal areas under sheikhs and the non-tribal areas under the mudirs of nahiyas. Al Madina, for instance, was not a tribe but a nahiya, being, however, under a sheikh and not a mudir. The Budur and the Bani Said were also examples of this group.

The assimilation of the nomad to the life of a settled cultivator is not immediate. Indeed, in many cases a tribe in the process of settlement might revert to its original nomadic condition because of quarrels with neighboring tribes or failure of crops. Thus, the seminomadic tribes could be distinguished from the truly settled cultivators by their far greater dependency on live stock.

The Non-Tribal Area.-This may be said to extend from Dair southward to Fao. The great date-garden district was inhabited by a population that had become so mixed, because of the advent of settlers who had migrated from the north and from districts on the left bank of the Shatt al Arab, that tribal conditions were often nonexistent. There was no large tribal organization; in many cases there were small communities of tribesmen who, to some extent, maintained their tribal connections, but those tribal ties were gradually becoming less cohesive.

The Madan.--In the vast marsh area, the settled districts that are situated along the river and canal banks run back into the marshes where they have no definite limits. The marshes are inhabited by Madan, a general term that includes all those marsh dwellers who, although organized tribally in a small way, have no cohesion on a large scale. They are fishermen, reed gatherers, and breeders of buffaloes, often without fixed habitation, and are accustomed, with 
the subsiding floods, to come down to the pasturage near the river and canals.

No Madan sheikh has much influence except over his own small unit; the groups fall under the authority of whichever sheikh administers the territory in which, or on the borders of which, they happen to be. Frequently they wander from the domain of one sheikh into that of another. The distinction between Madan and non-Madan is indefinite and appears to be one of calling rather than of race. No anthropometric data were available.

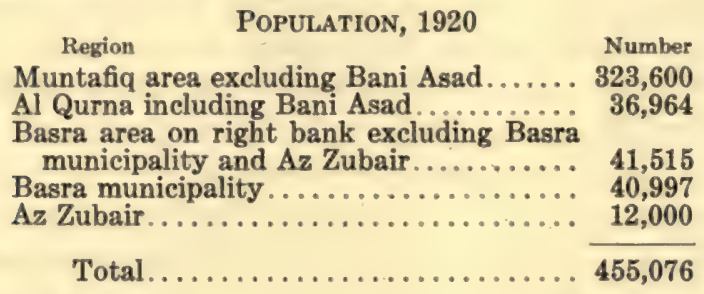

Muntafiq Division (excluding Bani Asad)

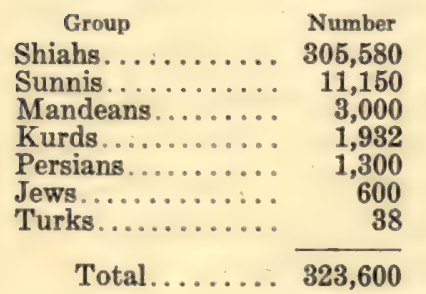

Three Nahiyas of Basra Division

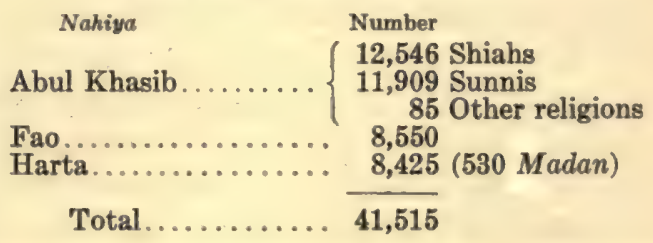

Number

12,546 Shiahs
8,550
Harta............... 8,425 (530 Madan)
Total.......... 41,515

Of the above, 29 per cent were men, 34 per cent women, and 37 per cent children.

\begin{tabular}{|c|c|c|c|}
\hline \multicolumn{4}{|c|}{ Basra Municipality } \\
\hline District & Number & Religion & Number \\
\hline Basra town. & 20,680 & Christians... & 2,057 \\
\hline Municipal villages. & 13,181 & 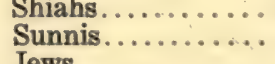 & $\begin{array}{r}25,813 \\
6,620\end{array}$ \\
\hline Ashar. & 7,136 & 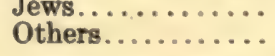 & $\begin{array}{r}6,288 \\
219\end{array}$ \\
\hline Total & 40,997 & Total. . & 40,997 \\
\hline
\end{tabular}

Although the majority of the population of this area were Shiah Arabs, the following were Sunnis:

(1) The Sadun Family.

(2) The Manna Family.

(3) The Shamiya Beduin tribes and others mentioned as Sunnis in the Tribal Lists. 
(4) The population of Az Zubair.

(5) Part of the population of Al Khamisiya and some of the townsmen of An Nasiriya and Suq ash Shuyukh.

There were also some Christians, Jews, Subba (Mandeans), Kurds, Persians, and Turks.

The Sadun, or the titular ruling family of the Muntafiq, are Sunnis; the tribesmen of the Muntafiq are, with very few exceptions, Shiahs.

Although the sedentary and "Donkey Beduin" tribes of Iraq are, for the most part, of good Arab stock and can claim descent from the best old blood of Arabia, they have lost caste by settling down and becoming Shiahs, being now despised by the genuine Beduin, who will not intermarry with them.

The Sadun, however, who have lived in Lower Iraq since the sixteenth century, are in a separate category. Descended from the family of the Sherif of Mecca, Sunni to this day, and Beduin in their manner of life, they are accepted as equals by the pure Arabs of Arabia.

The Shiah tribesmen are hospitable and can not, in any way, be said to be fanatical. They take a practical view of life and are ready to adopt new ideas, such as modern methods in agriculture, if it is proved to them that the new way is an improvement on the old.

The Sunni tribesmen vary little in characteristics from the Shiahs. The Sadun, as befits their calling, are more dignified and straightforward than the Shiahs or Sunnis.

The Jews are not popular among the Arabs and are generally looked down upon as the local money makers, except in large towns such as Basra, where the Jews are an influential community and civilization has altered original ideas.

\section{Population According to Religious Denominations}

(From Boesch, 1989)

\begin{tabular}{|c|c|c|c|c|c|c|c|}
\hline Region of Liva & Sunnis & Shiahs & Christians & Jews & Subba & Others & Totals \\
\hline Tigris*....... & 4,000 & 288,800 & 200 & 2,000 & 500 & 0 & 295,500 \\
\hline Amara & 4,497 & 255,995 & 229 & 2,540 & 0 & 1,972 & 265,233 \\
\hline Basra ... & 53,752 & 182,381 & 4,150 & 7,260 & 0 & 378 & $248,812 \dagger$ \\
\hline Muntafiq ........ & 3,337 & 221,545 & 55 & 555 & 0 & 1,734 & 227,226 \\
\hline Southern Desert.... & 2,000 & 18,000 & 0 & 0 & 0 & 0 & 20,000 \\
\hline
\end{tabular}

*These figures were not taken from Boesch.

†This figure is incorrect; the total is 247,921.

The Christians of the Tigris region, most of whom live in Amara, may be divided into two classes, Chaldeans and Syrians. Chal- 
deans are to be found in many towns between Mosul and Basra. The majority, however, live in Mosul, the headquarters of the Patriarch of Babylon. There were about twenty houses of Syrians in Amara. With the exception of the Armenians all Christians are Roman Catholies.

Population.-The lower reaches of the Tigris are inhabited almost solely by Arabs, who have migrated from Central Arabia. Other nationalities are to be found in the larger towns on the river banks, but with the exception of a few Iranis, never in the outlying districts. Similarly, nearly all the tribesmen are Shiahs, Sunnis being found only among the better-class townspeople, while small numbers of other religious denominations have settled in the towns for commercial or other reasons.

The population of the Lower Euphrates-Tigris region consists of Arabs, Kurds and Lurs, Iranis, Subba, and Jews.

Arabs.-They derive their origin from Central Arabia and trace their descent to Qahtan, who is called the founder of the Arab race and after whom the Bani Qahtan tribe in Arabia was named. Although of the same basic Proto-Mediterranean stock as the Beduin, their long sojourn in Iraq has produced outward changes. Physically, they have profited by the improved conditions of living and are a contrast to the slender, half-starved Beduin of the desert. They suffer, however, from a loss of prestige, since the Beduins prohibit intermarriage.

Iranis.-Considering the proximity of Irani territory one finds the number of settled Iranis (Persians) in this area strangely small, totaling not more than 1,500. The Bani Lam claim a few in one of the smaller sections, the Nodah Ali, who are all Iranis by birth, while farther south, Iranis from Hawiza are occasionally to be found working among the tribes. Some Iranis also make their living in Amara as merchants and artisans.

Kurds.-They are divided into two classes, pure Kurds and Failiyah, sometimes called Irani "Kurds" or Lurs.

The pure Kurds emigrated from the Daudi, Jaf, Talabani, and Hamawand tribes, and also from Sulaimaniya and Kirkuk, settling for the most part in Amara. They intermarry with the Arabs and refuse to acknowledge the Failiyah as Kurds.

The Failiyah Lurs, the majority of whom are coolies, came from the Pusht-i-Kuh in Iran (cf. Hassan Kuli Khan tribe of Lurs of Pusht-i-Kuh in Field 1939a.). Half Kurd, half Iranian, they speak a broken dialect that is intelligible to both races. They comprise 
a large part of the total population of Ali Gharbi, which trades extensively with the Pusht-i-Kuh. In Amara, all are employed as coolies to coal boats. At Qala Sikar and Karradi they practice cultivation on the Gharraf. They rarely intermarry with the Arabs.

Subba (Mandeans).--During the past 1,500 years, the Subba have been connected with this area. According to one tradition they lived originally in Iran, but were driven out by the Sun and Fire worshipers of that country, settling in Chahar Riz, which lies between Band-i-Bazugan on the left bank of the Shatt al Tib and the Pusht-i-Kuh. Here the Iranis again molested them and they fled, some to Hawiza and some to the Euphrates marshes in the district of Suq ash Shuyukh. The Iranis endeavored to obliterate all traces of their religion and burnt all the holy books they found at Chahar Riz. About 500 years later, however, one of these was discovered buried at that place, and the modern Subba holy books trace their origin to this volume.

About sixty years ago, part of the Subba from the Euphrates left with the intention of settling in Kut al Imara. In 1928 they formed a colony, which numbered about 500 persons. A few Subba also came from Hawiza. They are famed chiefly as gold- and silversmiths (Pl. 167, Fig. 2), carpenters, iron-workers (Pl. 148), and mashuf makers.

In 1920, the Subba had headquarters at Suq ash Shuyukh and lived also at An Nasiriya, Kabaish, Bani Said, Khas, Al Hassan, Hakkam, Bani Khaiqan, Basra, and Bani Muslim. (For description of their cults, customs, magic legends, and folklore see Drower, 1937.)

Jews.-With the exception of about 200 Jews in Ali Gharbi and Qala Salih, the whole Jewish population of the area lived in Amara, having moved there from Baghdad and Basra when Amara came into prominence as a commercial town. They are engaged chiefly in trade, especially wool, grain, and money changing. On the whole they are a group isolated by both Christians and Arabs.

According to the 1919 census figures, the population of the towns in the Tigris district was 295,500, divided as follows: Arabs, 284,000; Kurds and Lurs, 8,000; Iranis, 1,500; Jews, 2,000. Of the total population the approximate percentage of men, women, and children was 30 per cent, 40 per cent, and 30 per cent, respectively.

In the western and southern part of the Lower Euphrates area no census figures are available. Wherever possible, data have been compiled on the important towns along the Euphrates. 
An Nasiriya.-Built by Nasir Pasha about the year 1867. This town is situated on the left bank of the Euphrates and, being lowlying, relies for its protection from the floods of the Euphrates on the important Abu Jidahah bund, which is upstream on the left bank. Nasir Pasha wished to build the town on higher ground farther downstream but was overruled by Sadun Pasha. In order to protect the town from destruction by floods, further extensive bunds, often twenty feet in height, were constructed on both banks. The town was surrounded by a wall eight feet high, constructed in 1915.

The main building was the old Turkish Sarai, which was exceptionally well built. In 1920 An Nasiriya, which measured 1,650 by 570 yards, had about one thousand brick houses. The bazaar was well stocked and the streets were unusually broad and straight.

The population of An Nasiriya in 1920 was as follows: Arabs, 4,742; Jews, 521; Christians, 21; Mandeans (Subba), 633; Persians, 300; Turks, 23; Lurs (Pusht-i-Kuh), 281; Indians, 2. The population was divided into 2,073 adult males, 2,761 adult females, and 1,689 children under sixteen years of age.

Qala Sikar.- Situated on the left bank of the Shatt al Gharraf between Kut al Hai and Shatra, the town consisted of 400 brick houses, 100 mud dwellings, and 200 shops in the bazaar. In 1920 the population was composed of two-thirds Arabs and one-third Lurs from Pusht-i-Kuh, Iran. Fruit and vegetable gardens flourished for 600 yards downstream from the town. According to local information, up to about 1860 the land around the Gharraf was the haunt of the lion and the wild pig. The few inhabitants were almost entirely Beduin. A local character, named Sikar, built a fort on the present site of Qala Sikar. Eventually recognized by the Sadun as Governor of the district, Sikar was a man of energy who brought merchants from Baghdad and many Lurs to settle in the district. Qala Sikar has been twice flooded and rebuilt. It flourished until forty years ago when the trade routes and surroundings became insecure. Large numbers of inhabitants therefore left Qala Sikar and settled in Karradi and elsewhere.

Al Qurna.-This town stands on the bank of the Tigris just upstream from its junction with the old Euphrates channel. During 1920 the population numbered 1,941, composed of 1,841 Shiahs and 100 Sunnis. Ocean steamers of a draught varying from ten to fifteen feet, dependent on the height of the river and the state of the tide, can reach Al Qurna at all seasons of the year from Basra, but actually 
seldom proceed farther north than Maqil, where all the berthing facilities exist. All river steamers can proceed up the Tigris during any season and also up the Euphrates as far as Kabaish (colloq. Chabaish), and beyond to upstream from Darraji, provided the channel through the Hor al Hammar is sufficiently dredged. The interior waterways of the marshes are, generally speaking, not navigable by any craft except mashufs.

Shatra.- Situated mostly on the right bank of the Shatt al Shatra, this town stands three miles downstream of the take-off of the Bada channel. The distance by road to An Nasiriya is about thirty-five miles. In 1920 the population was 5,500, including 5,160 Shiahs, 200 Persians, 120 Sunnis, 10 Jews, and 10 Mandeans (Subba). The majority of the houses were of burnt brick. The town, which is surrounded by a fortified wall eight feet high, with ruined towers at intervals of 400 yards, is divided by the Shatt al Shatra.

Almost every man of the Shiah inhabitants is connected with either the Sinajir or the Al bu Shamkhi sections of the Abuda. These two sections fought each other in 1917. The Al bu Shamkhi were beaten, their houses in the northern part of the town wrecked. By May, 1920, many of them had been rebuilt. According to local history, Shatra was founded about 1872. With the building of bazaars and houses it grew rapidly. A brisk trade with Baghdad and growth as a grain center made it into a "Little Baghdad," the most important town on the Shatt al Gharraf.

Suq ash Shuyukh.-This circular town stands among date palm groves on the right bank of the main Euphrates channel, one and one-half miles downstream from where the Akaika channel takes off. This channel was closed by means of a bund four miles down from the main river. In 1920 the town, which lies seventeen miles in a direct line southeast of An Nasiriya, had a population of 8,830 , of which 5,000 lived in the town itself and 3,000 in the gardens immediately outside. About 800 Mandeans (Subba) lived on the left bank opposite the town. Prior to 1867, when An Nasiriya was built, Suq ash Shuyukh was the old Sadun capital of the Muntafiq. The town became divided into two antagonistic factions: the Hathar, who are Shiahs, consisting of two-thirds of the population, and the Najada, who are Sunnis.

Az Zubair.-Situated thirteen miles southwest of Basra, this town became one of the "Desert Ports" where the Beduin caravans called to replenish their stock of supplies and clothing. In this manner Az Zubair developed into a distributing center for the trade 
between the western desert and Basra. In 1920 the population was about 12,000 , all of whom were Sunnis.

The Desert and the Sown.-Probably in no other part of Iraq is the process of gradual change from the desert Arab to the settled cultivator, with the resultant disintegration of the tribal system, better exemplified than on the lower reaches of the Tigris from Kut al Imara to Khorram Shahr. It is well known that all tribes that migrated to Iraq did so with the intention of settling as cultivators on its fertile land, but in this respect none have taken to the land as much as these tribes of the Tigris, for the obvious reason that the country in which they settled is cut off from the Beduins and the semi-settled tribes of the Muntafiq by the Euphrates, while the foothills of Iran prohibit migrations.

The nomad, therefore, is not to be found in this area, and today the only tribe to retain any of its original characteristics is the seminomadic Bani Lam. They used to migrate across the border into Iran in search of grazing.

The remaining tribes are sedentary and dwell in villages of reed huts, some cultivating their crops and gardens, while others, who have settled in the marshes, breed buffaloes and make reed mats, which they sell to merchants of the neighboring towns.

Among these sedentary people there is a tendency to disregard their tribal ties and settle where cultivation is best. A rice grower cares little whether he works under an Al bu Muhammad, Azairij, or an $\mathrm{Al}$ Sawaad sheikh. To the south, at the junction of the Tigris and Euphrates, tribes such as the Nashwah and Muzaira have long cast off all connection with their original group and have named themselves after the place in which they have settled. On the left bank of the Shatt al Arab, between Al Qurna and Khorram Shahr, the greater part of the land is inhabited by the Al Muhaisin, a collection of foreign tribes that came there for the purpose of cultivation. Considering themselves subjects of the Sheikh of Muhammera, they attached themselves to the Al Muhaisin section of the Chaab, which they found there on their arrival. Although now known as the $\mathrm{Al}$ Muhaisin tribe, they are in reality no more than cultivators of the date gardens.

As far south as Qala Salih the lands are divided into estates (muqata'as), the sheikh of each being selected from the reigning family of the tribe in that particular district. Tribal policy is largely directed by these chiefs, who hold their office usually, but not of 
necessity, through inheritance. The paramount sheikh no longer exists; the sheikhs hold themselves directly responsible to the Government. 


\section{THE PHYSICAL ANTHROPOLOGY OF THE AL BU MUHAMMAD, THE AL SAWAAD, AND THE SUBBA}

Introduction.-The anthropometric methods and technique have been described in detail in the Iran Report (Field, 1939, pp. 287-289). It seems, however, desirable to republish the list of abbreviations employed in this chapter.

\section{List of ANTHRopometric AbBreviations}

$\mathrm{B}=$ head breadth

$\mathrm{B}^{\prime}=$ minimum frontal diameter

$\mathbf{B}^{\prime} / \mathbf{B}=$ fronto-parietal index

$B^{\prime} / J=z y g o-f r o n t a l$ index

$\mathrm{B} / \mathrm{L}=$ cephalic index

Big. B.=bigonial breadth

Biz. B.= bizygomatic breadth

C.I. = cephalic index

E.B.=ear breadth

$\mathrm{EB} / \mathrm{EL}=$ ear index

E.I. $=$ ear index

E.L. $=$ ear length

F.P.I. =fronto-parietal index

G.B.= greatest breadth

G.H. = total facial height

$\mathrm{G}^{\prime} \mathrm{H}=$ upper facial height

$\mathrm{GH} / \mathrm{J}=$ facial index

$\mathbf{G}^{\prime} \mathbf{H} / \mathbf{J}=$ upper facial index
Go-Go=bigonial breadth

Go-Go/J = zygo-gonial index

G.O.L.=glabello-occipital length

$\mathrm{J}=$ bizygomatic breadth

$\mathrm{L}=$ glabello-occipital length

L.L.= lower limb length

M.F.D.=minimum frontal diameter

N.B. = nasal breadth

N.H. $=$ nasal height

$\mathrm{NB} / \mathrm{NH}=$ nasal index

N.I. = nasal index

R.S.H. = relative sitting height

S.H. = sitting height

T.F.H. = total facial height

T.F.I. = total facial index

U.F.H. = upper facial height

U.F.I. = upper facial index

Zyg.fr.I. = zygo-frontal index

Zyg.go.I.= zygo-gonial index

This chapter will include the data obtained on the Al bu Muhammad, the Al Sawaad, and the Subba.

A detailed description of the life and customs of the $\mathrm{Al} \mathrm{bu}$ Muhammad has also been prepared by Lady Drower (Chapter V). Miss Winifred Smeaton was not allowed to make anthropometric measurements on the women, but she was permitted to make a study of tattooing and its significance. Mr. Richard Martin took the photographs of the racial types as well as a large series depicting the life in these marshes.

Entomological specimens for Field Museum and for Rustam Agricultural Experimental Farm at Hinaidi near Baghdad were collected by Albert Meymourian, who was lent to the Expedition by the Department of Agriculture in Baghdad. Mr. Khedoory Muallim, who was attached to the Expedition by the Royal College of Medicine in Baghdad, prepared the bird skins. Mr. S. Y. Showket acted as our general assistant and interpreter, and Mr. Yusuf Lazar 
collected the plants and some of the animals. In addition, the Chief of Police in Amara kindly sent ten policemen as escorts.

\section{The AL BU Muhammad}

In southern Iraq, both sides of the Tigris River are marshy. To the southeast of Amara and almost due east of Qala Salih lies the Hor al Hawiza, which covers the territory eastward as far as the Iraq-Iran boundary. Since we did not visit the western marsh we can deal only with the physical characters of the Al bu Muhammad tribesmen of the Hor al Hawiza, and with the Al Sawaad, who live near Halfaya. These two tribal groups, together with the Al Sudan, the Uzairij, and the Bani Lam, form the principal tribesmen of the eastern marshes.

The Al Sawaad live in the district south of Halfaya, north of the Sudan tribesmen. They are said to be darker in skin color and taller in stature than their neighbors.

The Bani Lam, a sheep-owning tribe, are still semi-nomadic. They have had constant feuds with the Al bu Muhammad, who are their equals in power and fame.

The Al bu Muhammad live beside the banks of the Chahala River and its main tributaries, the $\mathrm{Az}$ Zubair, the Adil, and the Taiah. They live also on islands scattered throughout the Hor al Hawiza and the Hor umr Sauan. These Marsh Arabs are often called Madan, which means that they are settled tribes and not nomads. The term, however, should apply only to the Marsh Arabs (Muntafiq) living to the west and southwest of Amara. The Al bu Muhammad are cultivators, fishermen, hunters, and makers of reed mats, which they use for the construction of their houses and as articles of commerce. They are one of the most powerful tribes of the Tigris. According to their own account they are descended from the Zubaid, who dwell beside the Tigris below Baghdad. An ancestor named Muhammad, from whom they take their name, migrated from the Zubaid district to the Hafira Canal opposite Qala Salih ten generations ago. The tribe has since expanded over the canals and marshes on either side of the Tigris between Amara and Al Uzair (Ezra's Tomb).

Muhammad found a small tribe called Al Furaijat in this district. The Sheikh of the Furaijat married Muhammad's sister and Muhammad married the Sheikh's daughter, whose three sons, Amla, Abbud, and Shudaiyid, gave rise to the present three sections of the $\mathrm{Al}$ bu Muhammad: Al Amla, Al Abbud, and Al Shadda. 
The Al Amla is frequently known as the $\mathrm{Al}$ bu Muhammad Section, because it is the senior of the three. Within this Section are the four ruling families (Baits) ${ }^{1}$ of the $\mathrm{Al}$ bu Muhammad, namely, the Baits Wadi, Khalifah, Yasir, and Saihud.

There has always been some confusion between Baits and Sections. Baits refer to families or houses. Originally the three houses of Muhammad's sons were called Baits. Eventually as the families increased, the original Baits became known as Sections and the ruling house as a Bait, named after the father or grandfather of the local sheikh. Confusion of the two terms developed when the $\mathrm{Al}$ Amla Section was called Bait Chuwaimil after a distinguished greatgrandson of Muhammad. At one period the ruling house of this Section was named after him. Descended from Chuwaimil were the four important sheikhs: Wadi, Khalifah, Yasir, and Saihud. Bait Chuwaimil was therefore divided into four Baits, from which are descended the present ruling houses of the $\mathrm{Al}$ bu Muhammad and all of the Al Amla Section. These Baits were named after the sheikhs, the name Bait Chuwaimil thus ceasing to exist except as a former ruling house of the Al Amla Section.

From this it will be seen that the Al Amla Section contains the royal house of the $\mathrm{Al} \mathrm{bu} \mathrm{Muhammad} \mathrm{and} \mathrm{for} \mathrm{that} \mathrm{reason} \mathrm{has} \mathrm{some-}$ times been called the Al bu Muhammad Section, while the other two Sections, whose descendants are unknown, have retained their original names, their Sub-sections only being called after the sons of Abbud and Shudaiyid.

The members of the Al Amla Section cultivate the rich rice lands at the tails of the canals. They do not move beyond their tribal district, but within its limits they transfer freely from one farm to another.

The Al Abbud are also mainly cultivators, scattered throughout the territory of the $\mathrm{Al}$ bu Muhammad. 'They intermingle with the Al Amla Section and the tribesmen work side by side.

The Al Shadda, chiefly marshmen of no settled habitation, live among the marshes between Qala Salih and Al Uzair. They do not mingle with the other Sections and are occupied in breeding buffaloes and making reed mats.

In addition, many Sections of foreign tribes have become subjects of the $\mathrm{Al} \mathrm{bu} \mathrm{Muhammad.} \mathrm{These} \mathrm{tribes} \mathrm{live} \mathrm{and} \mathrm{work} \mathrm{with}$

I The plural has been anglicized for the sake of convenience. In Arabic the plural is pronounced "beaut," as in beauty. 
both the Al Amla and the Al Abbud, but have attached themselves to the former.

Vital Statistics and Age.-Despite the inherent difficulties in attempting to obtain figures relating to the size of families, the $\mathrm{Al}$ bu Muhammad tribesmen disclose these data more readily than other groups in Iraq.

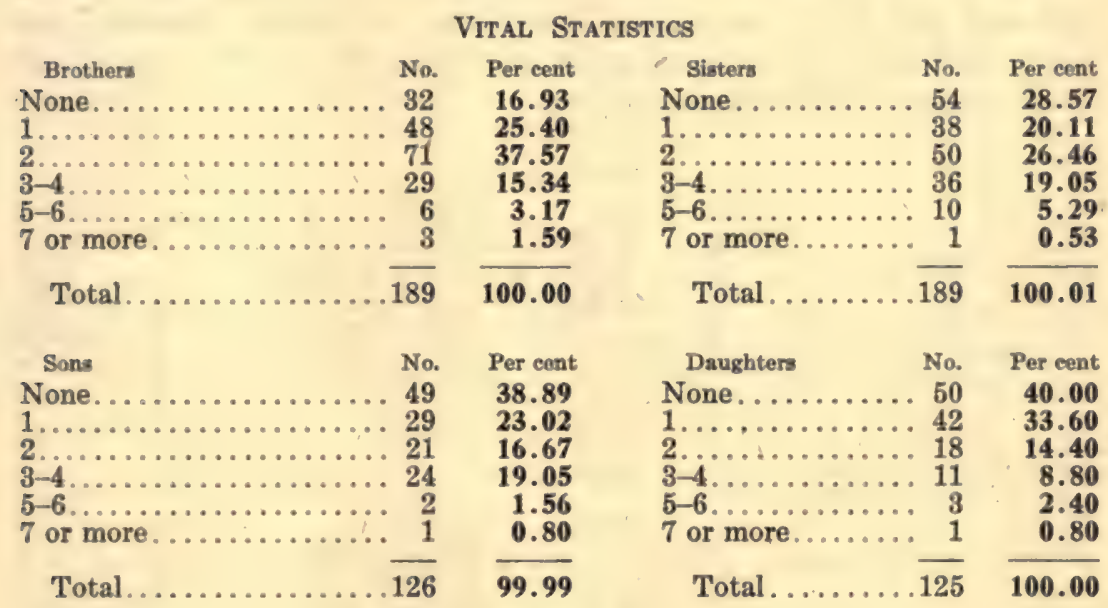

Age Distribution

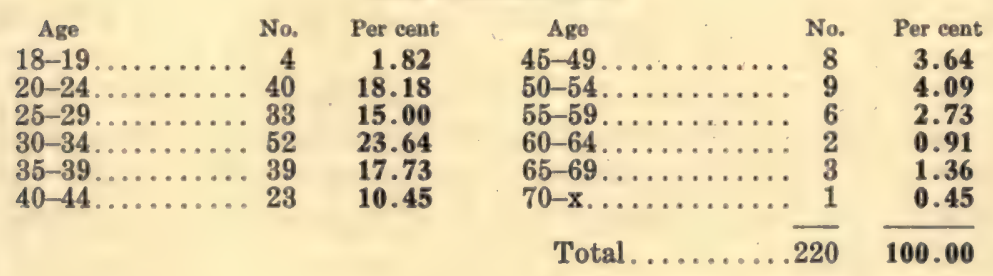

\section{MORPHOLOGICAL CHARACTERS OF AL BU MUHAMMAD TRIBESMEN}

Skin.-The color was darker than that of the average Arab of the Kish area. Individually it ranged from that of a typical southern European to very dark brown. The constant exposure to the weather combined with the intense reflection of the sun off the water darkened the skin. Furthermore, while poling their vessels through the marshes their bodies were semi-naked, often nude, so that they became tanned through constant sunburn.

Nos. 894 and 938 had very dark skins. Nos. 914,925 , and 930 possessed dark skins, in addition to Nos. 747, 752, 794, 797, 805, 843, 901, all of whom had Negro blood. Both Mongoloid and Negroid 
blood were evidenced in Nos. 797 and 833 . No. 894 had typical Marsh Arab features but distinct Negroid blood in his very dark brown skin color, curly-frizzly hair, and lip characteristics: integumental, double plus, membranous, plus, and lip seam, plus.

Hair.-Head hair was very abundant. However, abnormal hairiness of the body was not recorded, and the general impression retained was that these $\mathrm{Al}$ bu Muhammad tribesmen possessed less than the average amount of body hair observed on the Arabs of the Kish area or on the Dulaimis.

\begin{tabular}{|c|c|c|c|c|c|}
\hline & & $\mathrm{H}$ & & & \\
\hline Color & No. & Per cent & Form & No. & Per cent \\
\hline Black ........... & 39 & 21.79 & Straight. . & 0 & \\
\hline Very dark brown....... & 17 & 9.50 & Very low waves.... & 2 & 1.10 \\
\hline Dark brown......... & 92 & 51.40 & Low waves........ & $16 \overline{4}$ & 90.61 \\
\hline 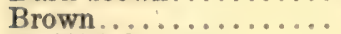 & 0 & ... & Deep waves. & 5 & 2.76 \\
\hline Reddish brown....... & 0 & & Curly-frizzly . . . . . . & 10 & 5.52 \\
\hline Light brown.......... & 1 & 0.56 & Woolly........... & 0 & $\ldots$. \\
\hline 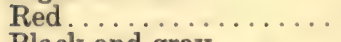 & 0 & & & & \\
\hline Black and gray ......... & 25 & $\begin{array}{r}2.23 \\
13.97\end{array}$ & Total........... & 181 & 99.99 \\
\hline Light brown and gray. . & 0 & & Texture & No. & Per cent \\
\hline 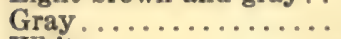 & 1 & 0.56 & Coarse...... & 35 & 18.82 \\
\hline 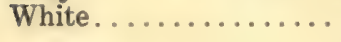 & 0 & $\ldots \ldots$ & Medium coarse..... & 4 & 2.15 \\
\hline Total. . & 179 & 100.01 & $\begin{array}{l}\text { Medium fine....... } \\
\text { Fine .............. }\end{array}$ & $\begin{array}{r}139 \\
4 \\
4\end{array}$ & $\begin{array}{r}74.73 \\
2.15 \\
2.15\end{array}$ \\
\hline & & & Total . .......... & 186 & 100.00 \\
\hline
\end{tabular}

Eyes.-The majority of the individuals had blue-brown eyes. In these cases the pigmentation was brown but there was a definite element of blue color present. This was not due to arcus senilis, although the concentration of blue color was generally present in an outer ring.

In No. 820 the blue ring was almost absent and in No. 841 the color effect of the blue-brown was blue. Nos. 901 and 947 had sharply delineated blue-ringed eyes.

Twenty-two individuals had blue-brown eyes. These men had brown eyes with a marked blue element not only as an outer ring but also throughout the iris. Of these, in No. 801 blue predominated, with the remainder a light green. No. 764 had exceptionally light blue-brown eyes. Six individuals (3.18 per cent) had green-brown eyes; No. 832 was also blue-ringed. No. 745 had light brown eyes, No. 774 blue-gray, and No. 949 blue-green. Only six individuals (3.18 per cent), Nos. $843,845,849,910,944$, and 950 , had dark brown eyes. 
Half of the group possessed homogeneous irides, the remainder being either zoned (36.26 per cent) or rayed (14.29 per cent). Since there were so many mixed eyes this high percentage of homogeneous irides seems most improbable and should therefore not be taken as correct. The majority (88.65 per cent) of the sclera were clear.

\begin{tabular}{|c|c|c|c|c|c|}
\hline & & & EYES & & \\
\hline Color & No. & Per cent & Iris & No. & Per cent \\
\hline Black. & 0 & & Homogeneous............ & 90 & 49.45 \\
\hline Dark brown.... & 6 & 3.18 & 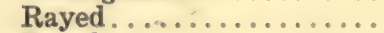 & 26 & 14.29 \\
\hline Blue-brown..... & 152 & 80.42 & Zoned................. & 66 & 36.26 \\
\hline Blue-brown..... & 22 & 11.64 & & & \\
\hline Green-brown .... & 6 & 3.18 & Total. & 182 & 100.00 \\
\hline Green-brown.... & 0 & ... & & & \\
\hline Gray-brown..... & 0 & $\ldots$ & Selera & No. & Per cent \\
\hline Blue........... & 0 & $\ldots$ & Clear. & 164 & 88.65 \\
\hline Gray.......... & 0 & & Yellow. & 1 & 0.54 \\
\hline Light brown.... & 1 & 0.53 & Speckled. & 10 & 5.41 \\
\hline Blue-gray....... & 1 & 0.53 & 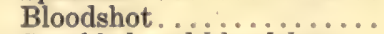 & 9 & 4.86 \\
\hline Blue-green . ..... & $\hat{1}$ & 0.53 & Speckled and bloodshot... & 1 & 0.54 \\
\hline Total......... & 189 & 100.01 & Yellow and bloodshot...... & 0 & $\cdots$ \\
\hline & & & Total. & 185 & 100.00 \\
\hline
\end{tabular}

The eyes, or more properly the eye-slits, were horizontal as in Europeans.

The average condition of the eyes was considerably better than that of the Arabs of the Kish area but not up to the standard of the members of the Iraq Army, studied at Hilla in 1928. There was only one case of total blindness, No. 736; three, Nos. 779, 814, and 823 , were blind in the left eye. No. 836 had poor eyes, with a cataract in his left eye. Both eyes were very poor in Nos. 735 and 907, and poor in Nos. 855, 871, and 937. The left eye of No. 773 appeared normal, but the right eye was almost closed and his vision was poor. Nos. 778 and 870 had the right eye out of alignment; both eyes of No. 778 were poor. No. 895 was slightly cross-eyed and had a poor right eye while No. 845 had a poor left eye.

Nose.-On the basis of my Iran report, the nose form suggests the presence of two racial elements: the straight-nosed Iraqo-Mediterranean dolichocephal and the convex-nosed Iranian Plateau dolichocephal. When the geographical position of the Hor al Hawiza is taken into account, this blending of Mediterranean racial types is to be expected.

The men with flaring alae possessed Negro blood. Three men (Nos. 930, 938, and 942) had double plus, and three (Nos. 820, 821, and 935) had nasal tips. 


\begin{tabular}{|c|c|c|c|c|c|}
\hline \multicolumn{6}{|c|}{ Nose } \\
\hline Profile & No. & Per cent & Winga & No. & Per cent \\
\hline Wavy. & 3 & 1.60 & Compressed... & 23 & 12.30 \\
\hline Straight......... & 106 & 56.38 & Compressed-medium .... & 19 & 10.16 \\
\hline Concave.......... & 6 & 3.19 & Medium.............. & 90 & 48.13 \\
\hline Convex........... & 65 & 34.57 & Medium flaring. . . . . . . & 42 & 22.46 \\
\hline Concavo-convex... & 8 & 4.26 & 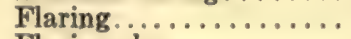 & 13 & 6.95 \\
\hline Total. & 188 & 100.00 & ing prus............. & & $\cdots \cdots$ \\
\hline & & & Total............... & 187 & 100.00 \\
\hline
\end{tabular}

Mouth.-Five men (Nos. 833, 840, 859, 894, and 901) had double plus lip eversion.

Teeth and Musculature.-While Nos. 813 and 815 had very uniform teeth, Nos. 834 and 806 had irregular front teeth. No. 809 had two large front teeth. No. 878 had his left upper incisor missing. In No. 856 the lower front teeth showed considerable wear.

TEETH

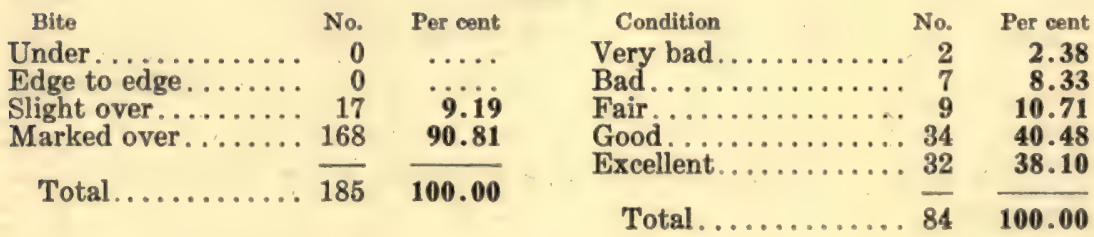

\section{MUSCULATURE}

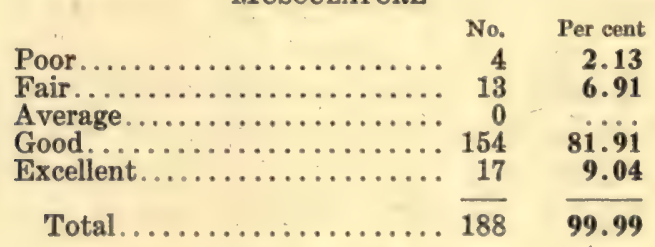

Branding Scars.-No. 946 had a scar (chawi or kawi) on the outside of the right forearm, where a spear-wound had been inflicted during a fight. The branding stopped the bleeding. No. 811 had a scar on the right wrist and No. 823 had three on the right arm. Nos. 821 and 891 each had a large scar on the left temple.

Tattooing.-Only twenty-five of the tribesmen examined were not tattooed.

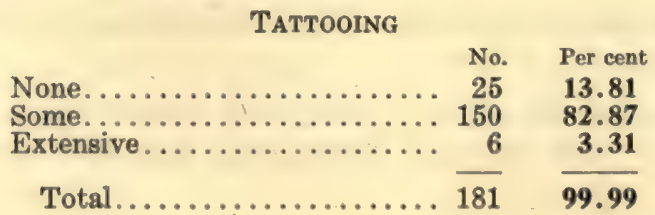


Henna.-No. 946 had henna on his hands and nails because he had been married two weeks before.

Health.-Only twelve men (6.39 per cent) were recorded as being in fair or poor health.

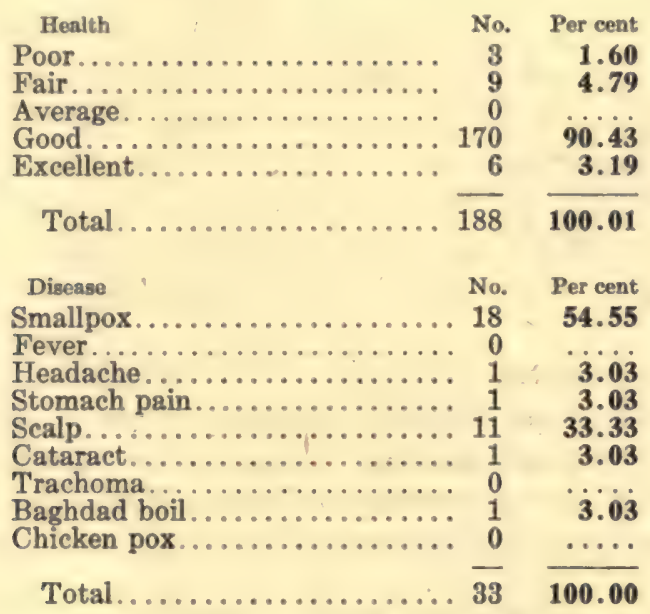

Special Observations.-No. 859 had a pronounced supraorbital torus combined with considerable prognathism.

\section{SUMMARY}

The statistics compiled on 221 members of the Al bu Muhammad tribe reveal that the majority possessed dark hair, medium to coarse in texture, with low waves. The eyes were brown, often with an outer bluish ring. The sclera were clear while the iris varied in character. The nose was straight but there was a concavo-convex element in the population. The nasal wings showed considerable variation although the majority were in the medium-compressed group. Among the individuals observed the average age was 34.04 years while the greatest number came within the 20-40 age groups.

\section{STATISTICAL ANALYSES OF AL BU MUHAMMAD TRIBESMEN}

Stature and Sitting Height.-Average stature (220 men) was 166.71 (range 143.0-187.0). These dwellers in the marshes east of Amara were slightly taller than the average for Southwestern Asia. Seventythree tribesmen were unusually tall. No. 806 was omitted. 


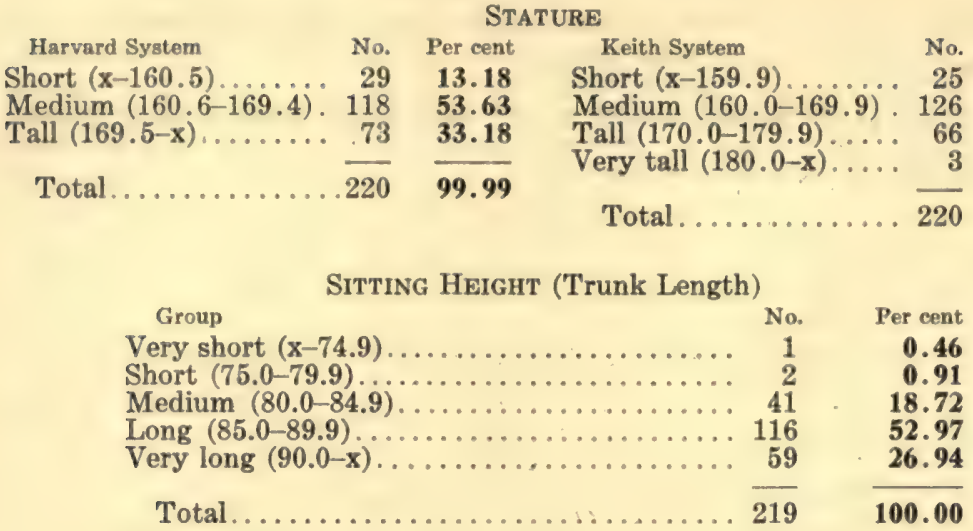

Head Measurements and Indices. - The minimum frontal diameter (mean 113.02) and the head breadth (mean 145.75) were wide. The minimum frontal diameter seems to be unusually large and should probably be reduced by at least $2 \mathrm{~mm}$. In the two very narrow groups there was only one individual.

\section{Minimum Frontal Diameter}

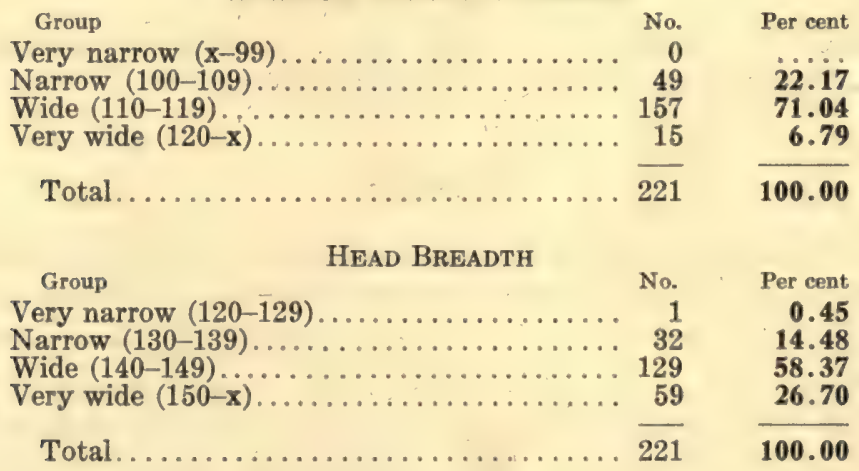

\section{Cephalic Index}

\begin{tabular}{|c|c|c|c|c|c|}
\hline \multirow{2}{*}{$\begin{array}{l}\text { Harvard System } \\
\text { Dolichocephalic . . . . . } \\
(\mathrm{x}-76.5)\end{array}$} & No. & Per cent & Keith System & No. & $\begin{array}{r}\text { Per cent } \\
1.36\end{array}$ \\
\hline & 81 & 36.65 & $\begin{array}{l}\text { Ultradolichocephalic... } \\
(x-70.0)\end{array}$ & 3 & 1.36 \\
\hline $\begin{array}{r}\text { Mesocephalic } \\
\quad(76.6-82.5)\end{array}$ & 116 & 52.49 & $\begin{array}{c}\text { Dolichocephalic....... } \\
(70.1-75.0)\end{array}$ & 45 & 20.36 \\
\hline $\begin{array}{l}\text { Brachycephalic........ } \\
(82.6-\mathrm{x})\end{array}$ & 24 & 10.86 & $\begin{array}{l}\text { Mesocephalic ........ } \\
(75.1-79.9)\end{array}$ & 117 & 52.94 \\
\hline Total & 221 & 100.00 & $\begin{array}{c}\text { Brachycephalic ........ } \\
(80.0-84.9)\end{array}$ & 40 & \\
\hline & & & $\begin{array}{l}\text { Ultrabrachycephalic... } \\
\quad(85.0-x)\end{array}$ & 8 & 3.6 \\
\hline & & & & 221 & 100.00 \\
\hline
\end{tabular}


The mean cephalic index was 77.94 (with range $68-88$ ). While both groupings of cephalic indices include about half of the series as mesocephals, the threefold and fivefold classifications show considerable divergence. The three (1.36 per cent) ultradolichocephals $(x-70.0)$ show a remarkable variation in head form within this group, indicating a stock composed of at least two elements.

Facial Measurements and Indices.-The bizygomatic breadth was medium narrow (mean 135.45) and the bigonial breadth was extremely narrow (mean 104.94). Since the breadth of the head and forehead was wide, the face tended to be ovoid or triangular. The upper part of the facial length (mean 70.55) showed extreme variation. The total facial height (mean 121.75) follows a similar frequency pattern.

Facial Measurements and Indices

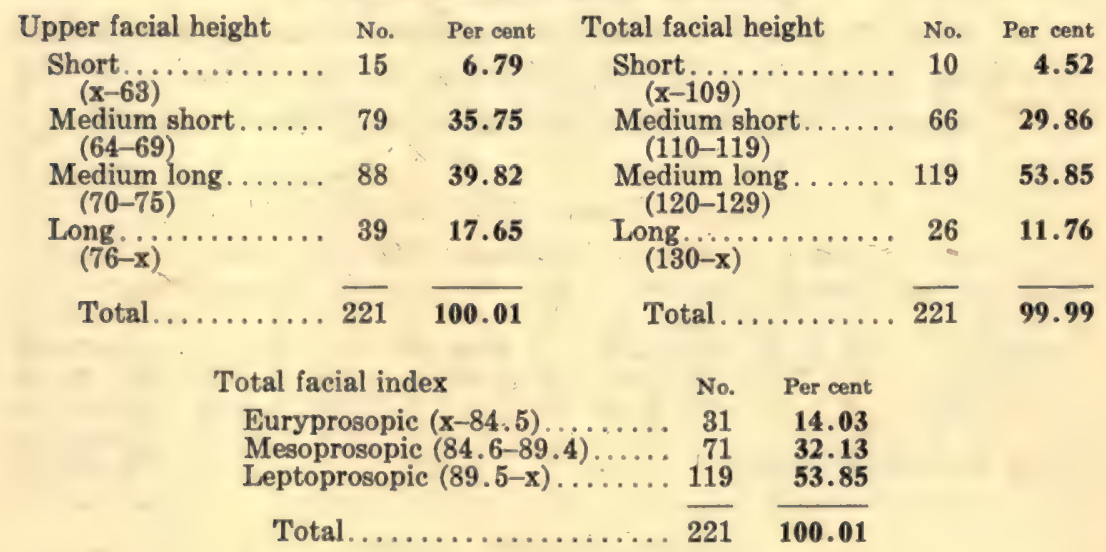

Nasal Measurements and Indices.-The nose was short (mean 52.98 ) and narrow (mean 34.85) with an index of 66.02 .

Nasal Measurements and Indices

\begin{tabular}{|c|c|c|c|c|c|}
\hline Nasal beight & No. & Per cent & Nasal width & No. & Per cent \\
\hline $\begin{array}{l}\text { Short } \\
(x-49)\end{array}$ & 55 & 24.89 & $\begin{array}{l}\text { Very narrow. . . . . . } \\
(\mathrm{x}-29)\end{array}$ & 9 & 4.07 \\
\hline$\underset{(50-59)}{\text { Medium }} \ldots \ldots \ldots$ & 148 & 66.97 & $\begin{array}{l}\text { Medium narrow..... } \\
(30-35)\end{array}$ & 125 & 56.56 \\
\hline$\underset{(60-x)}{\operatorname{Long}} \cdots \cdots \cdots \cdots$ & 18 & 8.14 & 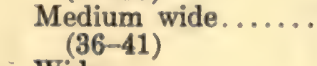 & 76 & 34.39 \\
\hline Total. & 221 & 100.00 & $\begin{array}{l}\text { Wide } \ldots . . . . . . . . . . \\
(42-x)\end{array}$ & 11 & 4.98 \\
\hline & & & Total. & 221 & 100.00 \\
\hline
\end{tabular}




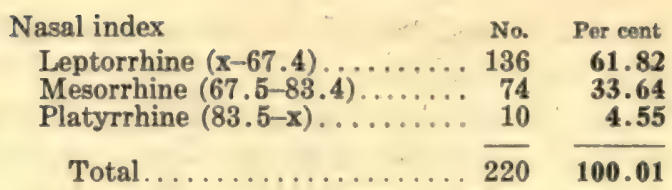

\section{SUMMARY}

The Al bu Muhammad tribesmen were medium to tall in stature and long in trunk length, with a face triangular as a result of a wide head and forehead, a medium or narrow bizygomatic breadth but a very narrow bigonial breadth. In cephalic index this group was mesocephalic with both dolichocephalic and brachycephalic elements present. The nose was short and narrow. These marshdwelling Arabs were medium tall, mesocephalic, leptoprosopic, and leptorrhine.

In order to furnish additional statistical data for comparison with those in my Iran Report and those in Part I, No. 1, of The Anthropology of Iraq, the following tables have been calculated:

\begin{tabular}{|c|c|c|c|c|c|c|c|c|c|c|c|}
\hline \multirow{3}{*}{ Standing height } & \multicolumn{8}{|c|}{ SitTing HEIght (Trunk Length) } & & \multirow{2}{*}{\multicolumn{2}{|c|}{ Totals }} \\
\hline & \multicolumn{2}{|c|}{$900-\mathrm{x}$} & \multicolumn{2}{|c|}{$899-850$} & \multicolumn{2}{|c|}{$849-800$} & \multicolumn{2}{|c|}{$799-750$} & $749-x$ & & \\
\hline & No. & $\%$ & No. & $\%$ & No. & $\%$ & No. & $\%$ & No. \% & No. & $\%$ \\
\hline $1800-x$ & 3 & 1.37 & 0 & & 0 & & 0 & $\ldots$ & $0 \ldots$ & 3 & 1.37 \\
\hline $99-17$ & 391 & 17.81 & 24 & 10.9 & 2 & 0.91 & 0 & & $0 \ldots$ & 65 & \\
\hline $99-16$ & 17 & 7.76 & 85 & 38.81 & 23 & 10.5 & 1 & 0.46 & $0 \ldots$ & 126 & 57. \\
\hline$x-1599 \ldots$ & 0 & & 7 & 3.20 & 16 & 7.31 & 1 & 0.46 & 10.46 & 25 & 11.43 \\
\hline Nos. 806 and & 883 & omitte & & & & & & & & 219 & 100.01 \\
\hline
\end{tabular}

\section{Minimum Frontal Diameter}

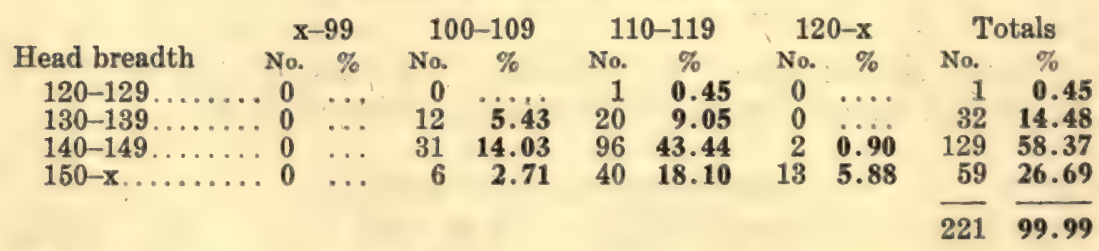

Bizygomatic BreadTh

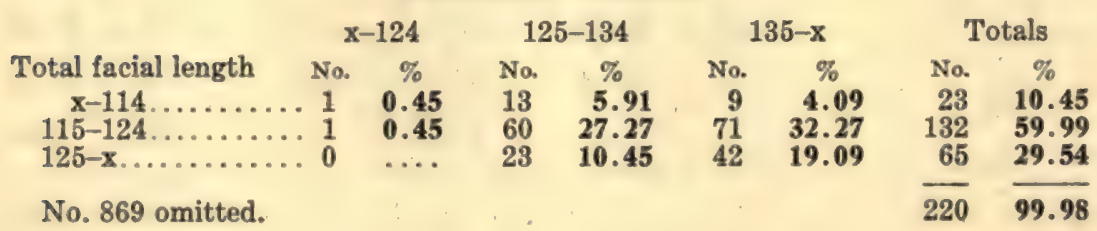


UPPER Facial LENGTH

$\begin{array}{lllllll}\mathrm{x}-63 & 64-69 & 70-75 & 76-81 & 82-\mathrm{x} & \text { Totals }\end{array}$

Total facial length No. $\%$ No. $\%$ No. $\%$ No. $\%$ No. $\%$ No. $\%$

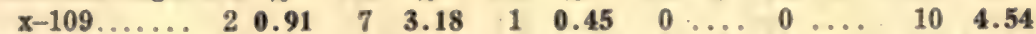

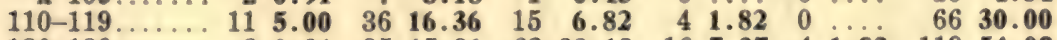

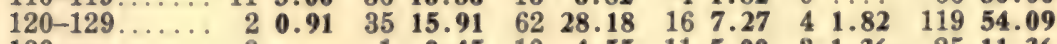

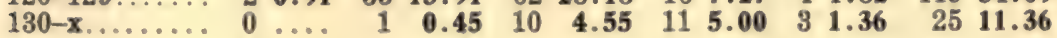

$\overline{220} \overline{99.99}$

\section{Nasal Breadth}

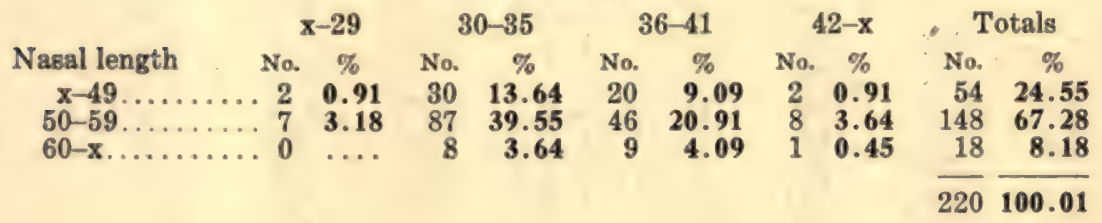

\section{Measurements and Indices of Al bu Muhammad Tribesmen}

\begin{tabular}{|c|c|c|c|c|c|}
\hline Mesaurements & No. & Range & Mean & S.D. & C.v. \\
\hline Age ........ & 220 & $18-70$ & $34.05 \pm 0.48$ & $10.50 \pm 0.34$ & $30.84 \pm 0.99$ \\
\hline Stature.... & 220 & $143-187$ & $166.71 \pm 0.29$ & $6.36 \pm 0.20$ & $3.82 \pm 0.12$ \\
\hline Sitting height. & 219 & $72-98$ & $87.79 \pm 0.18$ & $3.84 \pm 0.12$ & $4.37 \pm 0.14$ \\
\hline Head length. . & 221 & $167-205$ & $187.26 \pm 0.26$ & $5.82 \pm 0.19$ & $3.11 \pm 0.10$ \\
\hline Head breadth. & 221 & $126-164$ & $145.75 \pm 0.26$ & $5.76 \pm 0.18$ & $3.95 \pm 0.13$ \\
\hline \multicolumn{6}{|l|}{ Minimum frontal } \\
\hline Bizygomatic diameter. & 221 & $120-149$ & $135.45 \pm 0.23$ & $5.05 \pm 0.16$ & $3.73 \pm 0.12$ \\
\hline Bigonial diameter. . . . & 221 & $86-129$ & $104.94 \pm 0.26$ & $5.76 \pm 0.18$ & $5.49 \pm 0.18$ \\
\hline Total facial height.... & 221 & $100-144$ & $121.75 \pm 0.30$ & 0.21 & 0.17 \\
\hline I height... & 221 & $50-\varepsilon$ & .24 & .17 & .24 \\
\hline Nasal height. . . . . . . . & 220 & $40-71$ & $52.98 \pm 0.23$ & $5.00 \pm 0.16$ & $9.44 \pm 0.30$ \\
\hline Nasal breadth. . & 220 & $25-51$ & $34.85 \pm 0.17$ & $3.75 \pm 0.12$ & $10.76 \pm 0.35$ \\
\hline Ear length. . & 221 & $44-75$ & $58.98 \pm 0.25$ & $5.52 \pm 0.18$ & $9.36 \pm 0.30$ \\
\hline Ear breadth........ & 221 & $23-43$ & $32.19 \pm 0.14$ & & \\
\hline \multicolumn{6}{|l|}{ Ind } \\
\hline Relative sitting height & 219 & $48-57$ & $52.78 \pm 0.07$ & $1.64 \pm 0.05$ & $3.11 \pm 0.10$ \\
\hline Cephalic........... & 221 & $68-$ & $77.94 \pm 0.17$ & $3.69 \pm 0.12$ & $4.73 \pm 0.15$ \\
\hline Fronto-parietal . . . . . & 221 & $69-86$ & $77.62 \pm 0.14$ & $3.18 \pm 0.10$ & $4.10 \pm 0.13$ \\
\hline Zygo-frontal. & 221 & $72-95$ & $83.26 \pm 0.14$ & $3.00 \pm 0.10$ & $3.60 \pm 0.12$ \\
\hline Zygo-gonial & 221 & 63-92 & $77.35 \pm 0.18$ & $3.99 \pm 0.13$ & $5.16 \pm 0.17$ \\
\hline Total facial. & 221 & $75-109$ & $90.05 \pm 0.25$ & $5.45 \pm 0.17$ & $6.05 \pm 0.19$ \\
\hline Upper facial. . & 221 & $43-66$ & $52.13 \pm 0.18$ & $4.05 \pm 0.13$ & $7.77 \pm 0.25$ \\
\hline Nasal.... & 220 & 44-95 & $66.02 \pm 0.42$ & $9.16 \pm 0.29$ & $13.87 \pm 0.45$ \\
\hline Ear.................. & 221 & $37-76$ & $55.02 \pm 0.27$ & $5.92 \pm 0.19$ & $10.76 \pm 0.35$ \\
\hline
\end{tabular}


Vital Statistics* of Al bu Muhammad Tribesmen

\begin{tabular}{|c|c|c|c|c|c|c|}
\hline Number & Age & Married & Sons & Daughters & Brotherw & Sisters \\
\hline 764 & 40 & 1 & 3,1 & 1,0 & 1,1 & 3,0 \\
\hline 765 & 25 & 1 & 0,0 & 0,0 & 2,0 & 2,0 \\
\hline 766 & 30 & 1 & 0,0 & 0,1 & 2,1 & 3,0 \\
\hline 767 & 35 & 2 & 4,0 & 2,0 & 1,1 & 2,0 \\
\hline 768 & 25 & 0 & & & 2,1 & 3,0 \\
\hline 769 & 35 & 1 & 1,1 & 1,0 & 2,1 & 2,0 \\
\hline 770 & 35 & 1 & 2,1 & 0,0 & 0,0 & 1,0 \\
\hline 771 & 30 & 1 & 1,1 & 0,0 & 0,3 & 3,2 \\
\hline 772 & 22 & 0 & & & 2,0 & 1,0 \\
\hline 773 & 33 & 1 & 1,0 & 2,0 & 1,1 & 0,0 \\
\hline 774 & 25 & 0 & & & 2,0 & 2,3 \\
\hline 775 & 35 & 1 & 2,0 & 0,0 & 2,0 & 2,0 \\
\hline 776 & 30 & 1 & 1,0 & 0,2 & 3,0 & 2,0 \\
\hline 777 & 40 & 1 & 0,0 & 4,1 & 3,0 & 2,0 \\
\hline 778 & 35 & 1 & 1,0 & 1,1 & 2,0 & 3,0 \\
\hline 779 & 20 & 0 & $\ldots$ & $\ldots$ & 0,1 & 0,1 \\
\hline 780 & 20 & 0 & $\ldots$ & $\ldots$ & 1,0 & 0,1 \\
\hline 781 & 35 & 0 & $\ldots$ & $\cdots$ & 1,0 & 0,0 \\
\hline 782 & 20 & 0 & $\ldots$ & $\ldots$ & 2,0 & 2,0 \\
\hline 783 & 35 & 1 & 2,1 & 1,0 & 2,0 & 4,0 \\
\hline 784 & 30 & 1 & 1,0 & 0,0 & 2,0 & 1,0 \\
\hline 785 & 50 & 1 & 2,0 & 1,0 & 2,0 & 3,0 \\
\hline 786 & 25 & 0 & $\ldots$ & $\ldots$ & 2,0 & 0,0 \\
\hline 787 & 25 & 0 & $\ldots$ & $\ldots$ & 1,0 & 0,0 \\
\hline 788 & 45 & 1 & 2,0 & 1,0 & 2,0 & 0,0 \\
\hline 789 & 33 & 1 & 0,0 & 0,0 & 1,0 & 1,0 \\
\hline 790 & 20 & 0 & & & 0,0 & 2,0 \\
\hline 791 & 30 & 1 & 0,0 & 1,0 & 1,0 & 2,0 \\
\hline 792 & 30 & 0 & $\ldots$ & $\ldots$ & 0,1 & 2,0 \\
\hline 793 & 30 & 1 & 1,0 & 0,1 & 1,1 & 3,2 \\
\hline 794 & 32 & 1 & 0,0 & 0,0 & 1,0 & 1,0 \\
\hline 795 & 30 & 1 & 0,0 & 0,0 & 3,0 & 1,0 \\
\hline 796 & 35 & 1 & 1,0 & 0,0 & 1,0 & 0,0 \\
\hline 797 & 22 & 0 & $\ldots$ & $\ldots$ & 2,0 & 0,0 \\
\hline 798 & 35 & 1 & 1,0 & 1,0 & 2,0 & 3,0 \\
\hline 799 & 33 & 0 & $\ldots$ & $\ldots$ & 0,0 & 0,0 \\
\hline 800 & 30 & 1 & 0,0 & 2,0 & 2,0 & 0,0 \\
\hline 801 & 23 & 0 & & & 2,0 & 0,0 \\
\hline 802 & 35 & 1 & 0,0 & 0,2 & 2,0 & 3,0 \\
\hline 803 & 25 & 1 & 1,0 & 0,0 & 0,0 & 0,0 \\
\hline 804 & 50 & 0 & $\ldots$ & $\ldots$ & 1,0 & 1,2 \\
\hline 805 & 35 & 1 & 2,2 & 1,0 & 1,0 & 1,0 \\
\hline 806 & 25 & 0 & & & 0,0 & 0,0 \\
\hline 807 & 35 & 1 & 0,0 & 1,0 & 2,0 & 2,0 \\
\hline 808 & 35 & 1 & $5, s$ & 1,8 & 1,0 & 0,0 \\
\hline 809 & 40 & 1 & 2,2 & 2,2 & 0,0 & 0,2 \\
\hline 810 & 32 & 1 & 0,0 & 0,0 & 0,1 & 0,1 \\
\hline 811 & 40 & 1 & 1,0 & 2,0 & 2,3 & 3,2 \\
\hline
\end{tabular}

* Italicized numbers refer to deceused relatives. 
Physical ANTHROPOLOGY

Vital Statistics* of Al bu Muhammad Tribesmen

\begin{tabular}{|c|c|c|c|c|c|c|}
\hline Number & Age & Married & Sons & Daughters & Brothers & Sisters \\
\hline 812 & 35 & 1 & 2,1 & 1,0 & 2,0 & 1,1 \\
\hline 813 & 18 & 0 & & $\ldots$ & 2,0 & 2,1 \\
\hline 814 & 34 & 1 & 0,0 & 1,0 & 1,0 & 1,0 \\
\hline 815 & 22 & 0 & & & 2,0 & 0,0 \\
\hline 816 & 25 & 1 & 0,0 & 1,0 & 2,1 & 0,0 \\
\hline 817 & 20 & 1 & $\ldots$ & $\ldots$ & 2,0 & 2,0 \\
\hline 818 & 22 & 0 & $\ldots$ & $\ldots$ & 2,1 & 0,3 \\
\hline 819 & 32 & 1 & 0,0 & 1,0 & 0,0 & 0,0 \\
\hline 820 & 35 & 1 & 2,0 & 1,1 & 0,2 & 2,0 \\
\hline 821 & 32 & 1 & 0,0 & 1,0 & 2,1 & 1,1 \\
\hline 822 & 65 & 1 & 2,3 & 0,0 & 1,4 & 0,4 \\
\hline 823 & 46 & 1 & 1,8 & 1,8 & 1,0 & 2,0 \\
\hline 824 & 40 & 1 & 1,1 & 1,0 & 0,0 & 1,1 \\
\hline 825 & 35 & 1 & 1,0 & 0,0 & 1,5 & 1,2 \\
\hline 826 & 40 & 1 & 0,0 & 0,0 & 0,2 & 1,1 \\
\hline 827 & 40 & 1 & 1,0 & 1,1 & 1,1 & $1, s$ \\
\hline 828 & 20 & 0 & $\ldots$ & $\ldots$ & 2,0 & 2,0 \\
\hline 829 & 22 & 0 & $\ldots$ & $\ldots$ & 1,0 & 0,0 \\
\hline 830 & 30 & 0 & $\ldots$ & $\ldots$ & 0,0 & 2,0 \\
\hline 831 & 40 & 1 & 2,0 & 0,0 & 1,0 & 2,0 \\
\hline 832 & 20 & 0 & $\ldots$ & $\ldots$ & 2,0 & 1,0 \\
\hline 833 & 20 & 0 & & & 1,0 & 0,0 \\
\hline 834 & 35 & 1 & 0,0 & 0,0 & 2,0 & 1,0 \\
\hline 835 & 35 & 1 & 0,0 & 0,0 & 0,0 & 2,0 \\
\hline 836 & 65 & 1 & 2,2 & 1,0 & 2,2 & 1,2 \\
\hline 837 & 55 & 1 & 2,2 & 1,2 & 1,2 & 2,1 \\
\hline 838 & 23 & 1 & 1,0 & 0,1 & 3,1 & $2, s$ \\
\hline 839 & 40 & 1 & 4,0 & 0,0 & 2,0 & 3,1 \\
\hline 840 & 25 & 0 & & & 1,1 & 1,1 \\
\hline 841 & 30 & 1 & 1,0 & 0,1 & 0,1 & 0,1 \\
\hline 842 & 20 & 0 & $\ldots$ & $\ldots$ & 2,0 & 1,1 \\
\hline 843 & 35 & 1 & 2,0 & 1,0 & 2,0 & 0,0 \\
\hline 844 & 30 & 1 & 1,0 & 0,0 & 0,0 & 1,0 \\
\hline 845 & 25 & 0 & & & 1,0 & 1,0 \\
\hline 846 & 40 & 1 & 1,2 & 1,0 & 1.4 & 1,0 \\
\hline 847 & 45 & 1 & 0,0 & 1,0 & 2,0 & 1,0 \\
\hline 848 & 35 & 1 & 1,0 & 1,0 & 1,0 & 0,0 \\
\hline 849 & 40 & 1 & 3,0 & 1,2 & 1,0 & 2,0 \\
\hline 850 & 20 & 0 & $\ldots$ & $\ldots$ & 2,0 & 1,0 \\
\hline 851 & 20 & 0 & & 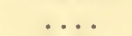 & 3,0 & 2,0 \\
\hline 852 & 55 & 1 & 2,0 & 0,0 & 1,0 & 0,0 \\
\hline 853 & 28 & 1 & 2,0 & 1,0 & 1,0 & 0,0 \\
\hline 854 & 20 & 0 & $\ldots$ & & 1,1 & 1,0 \\
\hline 855 & 45 & 1 & 2,0 & 0,0 & 1,0 & 1,0 \\
\hline 856 & 50 & 1 & 4,0 & 4,0 & 1,1 & 2,0 \\
\hline 857 & 20 & 0 & $\ldots$ & & 3, 0 & 3,0 \\
\hline 858 & 30 & 1 & 1,0 & 1,0 & 1,0 & 2,0 \\
\hline 859 & 28 & 1 & 2,0 & 0,2 & 1,1 & 2,0 \\
\hline
\end{tabular}

* Italicized numbers refer to decensed relatives. 
Vital Statistics* of Al bu Muhammad Tribesmen

\begin{tabular}{|c|c|c|c|c|c|c|}
\hline Number & Age & Married & Sons & Daughters & Brothers & Sisters \\
\hline 860 & 20 & 1 & 0,0 & 1,0 & 2,0 & 2,0 \\
\hline 861 & 25 & 1 & 1,0 & 2,0 & 1,1 & 4,2 \\
\hline 862 & 22 & 0 & $\ldots$ & $\ldots$ & 1,2 & 0,0 \\
\hline 863 & 22 & 0 & $\ldots$ & $\ldots$ & 2,0 & 0,0 \\
\hline 864 & 30 & 0 & $\ldots$ & $\ldots$ & 1,0 & 1,0 \\
\hline 865 & 25 & 0 & $\ldots$ & $\ldots$ & 2,0 & 2,0 \\
\hline 866 & 35 & 0 & $\ldots$ & $\ldots$ & 3,0 & 2,0 \\
\hline 867 & 30 & 0 & $\ldots$ & $\ldots$. & 1,1 & 2,0 \\
\hline 868 & 35 & 1 & 0,0 & 0,0 & 2,1 & 2,0 \\
\hline 869 & 38 & 1 & 0,0 & 0,0 & 1,0 & 2,0 \\
\hline 870 & 30 & 1 & 0,0 & 1,0 & 2,0 & 2,0 \\
\hline 871 & 35 & 1 & 0,0 & 1,0 & 2,0 & 1,0 \\
\hline 872 & 27 & 0 & $\ldots$ & $\ldots$ & 0,2 & 2,3 \\
\hline 873 & 35 & 1 & 1,2 & 2,0 & 0,0 & 1,0 \\
\hline 874 & 25 & 1 & 0,0 & 0,0 & 2,0 & 1,0 \\
\hline 875 & 55 & 1 & 0,2 & 1,3 & 0,1 & 0,0 \\
\hline 876 & 35 & 1 & 0,0 & 0,0 & 2,0 & 0,0 \\
\hline 877 & 30 & 0 & & $\ldots$ & 1,0 & 0,1 \\
\hline 878 & 30 & 1 & 0,0 & 0,0 & 1,0 & 0,0 \\
\hline 879 & 25 & 0 & $\ldots$ & $\ldots$ & 2,0 & 0,0 \\
\hline 880 & 56 & 1 & $1, s$ & 0,4 & 0,2 & 0,2 \\
\hline 881 & 20 & 0 & $\ldots$ & $\ldots$ & 2,0 & 2,0 \\
\hline 882 & 27 & 1 & 1,0 & 0,0 & 1,3 & 0,0 \\
\hline 883 & 35 & 1 & 1,0 & 0,1 & 0,1 & 3,0 \\
\hline 884 & 25 & 0 & $\ldots$ & $\ldots$ & 2,0 & 4,0 \\
\hline 885 & 20 & 1 & 0,0 & 0,0 & 2,1 & 1,0 \\
\hline 886 & 40 & 2 & 1,1 & 1,10 & 1,1 & 3,0 \\
\hline 887 & 22 & 0 & $\ldots$ & $\ldots$ & 3,2 & 2,0 \\
\hline 888 & 35 & 1 & 0,0 & 0,0 & 1,4 & 0,0 \\
\hline 889 & 50 & 1 & 1,2 & 2,2 & 1,2 & 0,1 \\
\hline 890 & 30 & 0 & & $\ldots$ & 0,10 & 0,5 \\
\hline 891 & 40 & 1 & 2,0 & 0,2 & 0,0 & 3,0 \\
\hline 892 & 25 & 0 & $\ldots$ & $\ldots$ & 1,1 & 2,2 \\
\hline 893 & 20 & 1 & 2,0 & 0,0 & 3,1 & 2,0 \\
\hline 894 & 35 & 1 & 0,8 & 1,3 & 1,6 & 4,6 \\
\hline 895 & 35 & 0 & $\ldots$ & $\ldots$ & 2,0 & 0,0 \\
\hline 896 & 50 & 1 & 2,0 & 0,5 & 2,0 & 4,0 \\
\hline 897 & 33 & 1 & 2,0 & 2,0 & 1,0 & 3,0 \\
\hline 898 & 23 & 0 & $\ldots$ & $\ldots$ & 1,0 & 2,3 \\
\hline 899 & 25 & 0 & $\ldots$ & $\ldots$ & 2,1 & 1,1 \\
\hline 900 & 25 & 0 & $\ldots$ & $\ldots$ & 1,1 & 2,3 \\
\hline 901 & 35 & 3 & 4,1 & 2,1 & 1,2 & 2,1 \\
\hline 902 & 33 & 0 & & $\ldots$ & 1,0 & 2,8 \\
\hline 903 & 35 & 1 & 1,0 & 0,0 & 1,0 & 0,0 \\
\hline 904 & 35 & 1 & 0,0 & 2,0 & 1,1 & 4,0 \\
\hline 905 & 20 & 0 & $\ldots$ & $\ldots$ & 0,0 & 1,0 \\
\hline 906 & 20 & 1 & 0,0 & 1,0 & 2,0 & 0,0 \\
\hline 907 & 65 & 1 & 1,3 & 1,0 & 0,2 & 0,0 \\
\hline
\end{tabular}

* Italicized numbers refer to deceased relatives. 
Physical ANTHRopology

\section{Vital Statistics* of Al bu Muhammad Tribesmen}

\begin{tabular}{|c|c|c|c|c|c|c|}
\hline Number & Age & Married & Sons & Daughters & Brothers & Sisters \\
\hline 908 & 30 & 0 & & & 1,0 & 0,0 \\
\hline 909 & 28 & 1 & 0,0 & 1,0 & 2,0 & 1,1 \\
\hline 910 & 25 & 0 & $\ldots$ & $\ldots$ & 3,0 & 3,0 \\
\hline 911 & 18 & 0 & $\ldots$ & $\ldots$ & 0,0 & 2,0 \\
\hline 912 & 18 & 0 & $\ldots$ & & 0,0 & 2,0 \\
\hline 913 & 25 & 1 & 0,0 & 0,0 & 0,0 & 0,0 \\
\hline 914 & 30 & 0 & $\ldots$ & $\ldots$ & 0,2 & 0,0 \\
\hline 915 & 18 & 0 & $\ldots$ & $\ldots$ & 0,0 & 0,0 \\
\hline 916 & 40 & 1 & 0,0 & 1,0 & 0,1 & 0,1 \\
\hline 917 & 45 & 1. & 0,0 & 1,0 & 0,0 & 0,0 \\
\hline 918 & 23 & 1 & 0,0 & 0,0 & 0,0 & 0,0 \\
\hline 919 & 40 & 1 & 0,0 & 1,0 & 0,0 & 0,0 \\
\hline 920 & 65 & 1 & 1,3 & 0,0 & 0,0 & 0,0 . \\
\hline 921 & 20 & 0 & $\ldots$ & $\ldots$ & 0,0 & 0,0 \\
\hline 922 & 20 & 0 & $\ldots$ & $\ldots$ & 0,0 & 1,0 \\
\hline 923 & 40 & 0 & $\ldots$ & $\ldots$ & 0,0 & 0,0 \\
\hline 924 & 40 & 1 & 1,0 & 0,0 & 0,0 & 0,0 \\
\hline 925 & 20 & 0 & $\ldots$ & & 1,0 & 0,0 \\
\hline 926 & 40 & 1 & 0,0 & 0,0 & 0,0 & 0,0 \\
\hline 927 & 30 & 0 & $\ldots$ & $\ldots$ & 0,0 & 0,0 \\
\hline 928 & 30 & 1 & 0,0 & 1,0 & 0,0 & 0,0 \\
\hline 929 & 35 & 1 & 1,0 & 0,0 & 0,0 & 0,0 \\
\hline 930 & 60 & 1 & 1,0 & 2,0 & 1,0 & 1,0 \\
\hline 931 & 40 & 1 & 0,0 & 0,0 & 0,0 & 0,0 \\
\hline 932 & 55 & 0 & $\ldots$ & $\cdots$ & 0.0 & 0,0 \\
\hline 933 & 50 & 1 & 1,2 & 2,3 & 2,0 & 1,0 \\
\hline 934 & 45 & 1 & 1,2 & 2,0 & 2,0 & 1,0 \\
\hline 935 & 35 & 1 & 0,0 & 0,0 & 1,0 & 0,0 \\
\hline 936 & 33 & 1 & 0,0 & 0,0 & 1,2 & 1,2 \\
\hline 937 & 40 & 1 & 4,0 & 1,0 & 2,0 & 2,0 \\
\hline 938 & 40 & 1 & 1,0 & 1,0 & 4,0 & 2,0 \\
\hline 939 & 30 & 1 & 0,0 & 0,0 & 2,0 & 4,0 \\
\hline 940 & 30 & 1 & 0,0 & 0,0 & 4,3 & 2,0 \\
\hline 941 & 45 & 1 & 1,0 & 0,0 & 2,0 & 1,0 \\
\hline 942 & 50 & 1 & 2,0 & 1,0 & 1,0 & 1,0 \\
\hline 943 & 30 & 1 & 1,0 & 0,0 & 1,0 & 0,0 \\
\hline 944 & 20 & 0 & $\ldots$ & $\cdots$ & 1,0 & 3,0 \\
\hline 945 & 40 & $2 \dagger$ & 2,0 & 3,0 & 3,1 & 0,2 \\
\hline 946 & 25 & 2 & 1,0 & 0,0 & 2,0 & 1,0 \\
\hline 947 & 30 & 1 & 1,0 & 0,0 & 1,0 & 3,0 \\
\hline 948 & 28 & 1 & 0,0 & 2,0 & 1,0 & 1,1 \\
\hline 949 & 45 & 1 & 3,0 & 1,0 & 0,0 & 4,0 \\
\hline 950 & 23 & 0 & $\ldots$ & $\ldots$ & 2,0 & 2,0 \\
\hline 951 & 20 & 0 & & $\cdots$ & 1,0 . & 0,0 \\
\hline 952 & 35 & 1 & 1,0 & 1,0 & 1,0 & 3,0 \\
\hline 953 & 32 & 1 & 0,0 & 0,0 & 3,0 & 1,0 \\
\hline
\end{tabular}

* Italicized numbers refer to deceased relatives.

† No. 945 had two sons and two daughters by his firat wife. 
MEASUREMENTS

\begin{tabular}{|c|c|c|c|c|c|c|c|c|c|c|c|c|}
\hline No. & Age & Stature & SH & L & B & $B^{\prime}$ & $\mathbf{J}$ & go-go & GH & $G^{\prime} \mathbf{H}$ & $\mathrm{NH}$ & NB \\
\hline 733 & 22 & 1710 & 942 & 188 & 151 & 118 & 142 & 102 & 122 & 82 & 60 & 35 \\
\hline & 30 & 1700 & 892 & 186 & & 111 & 138 & 103 & 12 & 73 & 57 & \\
\hline 3 & 70 & 1656 & 827 & 182 & 4 & 115 & 138 & 98 & 12 & 73 & 59 & 3 \\
\hline 36 & 60 & 1630 & 829 & 193 & 13 & 108 & 139 & 98 & 12 & 83 & & \\
\hline 737 & 30 & 1697 & 890 & 183 & 14 & 108 & 131 & 104 & 11 & 63 & & \\
\hline 3. & 30 & 1730 & & 199 & & 113 & 133 & 104 & & 74 & 51 & \\
\hline 3 & 20 & 1673 & 865 & 184 & 14 & 109 & 133 & 10 & 12 & 75 & 52 & \\
\hline & 30 & 1656 & & 178 & & 114 & 143 & 10 & 12 & 73 & 56 & \\
\hline & 25 & 1680 & 850 & 183 & & 109 & 135 & 10 & 12 & 73 & 57 & \\
\hline & 25 & 1757 & 895 & 187 & & 111 & 142 & 11 & 12 & 76 & 61 & \\
\hline & 30 & 1758 & 915 & 186 & 15 & 106 & 140 & 11 & 11 & 74 & 54 & \\
\hline & 40 & 169 & & 184 & & 107 & 13 & 10 & & & 49 & \\
\hline & 35 & 172 & 90 & 184 & & 118 & 140 & 10 & 12 & & 53 & \\
\hline & & & 901 & 191 & 14 & 115 & 14 & 11 & 12 & & 52 & \\
\hline & 30 & 16 & 87 & 188 & & 110 & 13 & 10 & & & 48 & \\
\hline & 30 & 168 & 87 & $18^{\prime}$ & & 11 & 13 & 10 & & 7 & 55 & \\
\hline & 35 & 16 & & 19 & & 11 & & 9 & & 7 & 46 & \\
\hline & 30 & 175 & 941 & 19 & 15 & 12 & 14 & 104 & & 8 & 68 & \\
\hline & 50 & 15 & 87 & 18 & 14 & 11 & 13 & 9 & & 7 & & \\
\hline & 25 & 166 & 895 & 19 & 15 & 112 & 13 & 10 & 12 & 7 & 55 & \\
\hline & 30 & 17 & 90 & 19 & & 10 & 13 & 10 & & & & \\
\hline & 25 & 175 & 895 & 20 & 15 & 11 & 13 & 11 & & $7 \%$ & 58 & \\
\hline & 30 & & 86 & 18 & 14 & 11 & 13 & 10 & 13 & 7 & 55 & \\
\hline & 50 & 16 & 85 & 19 & & 12 & 13 & 10 & 13 & 7 & 58 & \\
\hline & 30 & 15 & 82 & 18 & 14 & 11. & 13 & 10 & 12 & 68 & 50 & \\
\hline & 30 & 16 & 88 & 18 & & 11 & 13 & 10 & 18 & 7 & 54 & \\
\hline & 35 & 17 & 93 & 18 & 14 & 11 & 13 & 10 & 12 & 72 & 52 & \\
\hline & 30 & & & & & & & & & & & \\
\hline & 20 & 1623 & 831 & 189 & 13 & 10 & 12 & 10 & 12 & 5 & 45 & \\
\hline & 25 & & 88 & 18 & & & & 9 & 12 & & & \\
\hline & 25 & 166 & 875 & 18 & & 118 & 14 & 10 & 13 & 73 & 56 & \\
\hline & 40 & 17 & 90 & 18 & & & 14 & & & & & \\
\hline & 25 & 15 & 82 & 18 & & 11 & & 10 & 1) & & 49 & \\
\hline & 30 & & 88 & & & & 13 & 10 & 12 & & 57 & \\
\hline & 35 & & 915 & & & 11 & 13 & 10 & & 7 & $52^{*}$ & \\
\hline & 25 & 16 & 90 & 18 & & 11 & 12 & 9 & & 6 & 46 & \\
\hline & 35 & 16 & 8 & & & & & 10 & & & & \\
\hline & 35 & 16 & 82 & 18 & & 11 & 13 & 11 & & 6 & $4^{\prime}$ & \\
\hline & 30 & & 8 & & & & & & & & & \\
\hline & 22 & & $8:$ & 17 & & 10 & 13 & 9 & 18 & & 5 & \\
\hline & 33 & & & & & & 12 & 9 & & & 4 & \\
\hline & 25 & & & & & 11 & 14 & 11 & 11 & & & \\
\hline & 35 & & & & & & 13 & & & & & \\
\hline & 30 & & 9 & & & & 14 & & & & & \\
\hline & 40 & & & & & & & & & & & \\
\hline & 35 & & 85 & & & & 13 & 10 & & & 44 & \\
\hline & 20 & & & & & & 13 & 9 & & & & \\
\hline & 20 & & 84 & & & & & 10 & & & 5 & \\
\hline & 35 & & & & & & & 10 & & & & \\
\hline & 20 & & & & & & & & & $6^{\prime}$ & 51 & \\
\hline & 35 & & & & & & & & & & & \\
\hline & 30 & & 9 & & & 10 & 13 & & & 7 & 51 & \\
\hline & 50 & & & & & 11 & & & & 7 & & \\
\hline & 25 & & & & & & & & & 6 & 47 & \\
\hline & 25 & 162 & & 18 & & 108 & 128 & 100 & 122 & 68 & 46 & \\
\hline
\end{tabular}

* Should be omitted because of broken nose. 


\section{INDICES}

\begin{tabular}{|c|c|c|c|c|c|c|c|c|c|c|c|}
\hline No. & EL & EB & RSH & B/L & $B^{\prime} / B$ & $\mathbf{G H} / \mathbf{J}$ & $\mathbf{G}^{\prime} \mathbf{H} / \mathbf{J}$ & $\mathrm{NB} / \mathrm{NH}$ & EB/EL & $80-\mathrm{go} / \mathrm{J}$ & $\mathbf{B}^{\prime} / \mathbf{J}$ \\
\hline 733 & 54 & 34 & 55.1 & 80.3 & 78.2 & 85.9 & 57.8 & 58.3 & 62.9 & 71.8 & 83.1 \\
\hline 734 & 67 & 34 & 52.5 & 81.2 & 73.5 & & 52.9 & & 50.8 & 74.6 & 80.4 \\
\hline 735 & 71 & 34 & 50.0 & 79.1 & 79.9 & 88.4 & 52.9 & 55.9 & 47.9 & 71.0 & 83.3 \\
\hline 736 & 73 & 38 & 50.9 & 69.9 & 80.0 & 89.2 & 59.7 & 55.9 & 52.1 & 70.5 & 77.7 \\
\hline 737 & 57 & 33 & 52.4 & 77.6 & 76.1 & 87.8 & 48.1 & & 57.9 & 79.4 & 82.4 \\
\hline 738 & 64 & 33 & 51.6 & 71.9 & 79.0 & 100.0 & 55.6 & 64.7 & 51.6 & 78.2 & 85.0 \\
\hline 73 & 54 & 30 & 51.7 & 77.7 & 76.2 & 96.2 & 56.4 & 57.7 & 55.6 & 81.2 & 82.0 \\
\hline 74 & 61 & 32 & 53.1 & 86.5 & 74.0 & 88.8 & 51.0 & 58.9 & 52.5 & 75.5 & 79.7 \\
\hline 74 & 61 & 30 & 50.6 & 83.1 & 71.7 & 92.6 & 54.1 & 61.4 & 49.2 & 79.3 & 80.7 \\
\hline 74 & 56 & 31 & 50.9 & 82.9 & 71.6 & 88.0 & 53.5 & 59.0 & 55.4 & 77.5 & 78.2 \\
\hline 74 & 58 & 34 & 52.0 & 81.7 & 69.7 & 85.0 & 52.9 & 66.7 & 58.6 & 78.6 & 75.7 \\
\hline & 58 & 38 & 51.9 & 79.4 & 73.3 & 79.3 & 48.2 & 79.6 & 65.5 & 74.8 & 79.3 \\
\hline 74 & 65 & 34 & 52.1 & 83.7 & 76.6 & 86.4 & 49.3 & 73.6 & 52.3 & 72.9 & \\
\hline & 54 & 34 & 54.3 & 76.4 & 78.8 & 86.4 & 52.1 & 50.0 & 63.0 & 80.7 & 82.1 \\
\hline $74^{\prime}$ & 58 & 30 & 52.0 & 79.3 & 73.8 & 91.0 & 54.1 & 79.2 & 51.7 & 82.0 & 82.7 \\
\hline & 66 & 36 & 52.0 & 75.9 & 81.0 & 99.3 & 56.7 & 63.6 & 54.6 & 79.1 & 85.8 \\
\hline $74 !$ & 66 & 37 & 53.5 & 71.9 & 83.3 & 98.5 & 63.0 & 78.3 & 56.1 & 70.2 & 85.8 \\
\hline & 64 & 36 & 53.5 & 81.4 & 77.9 & 93.8 & & 57.4 & 56.3 & 71.2 & \\
\hline 75 & 74 & 40 & 54.5 & 78.7 & 81.3 & 94.8 & 59.0 & 64.9 & 54.1 & 72.4 & 87.3 \\
\hline & 53 & 31 & 53.9 & 78.1 & 74.7 & 90.4 & 52.9 & 72.7 & 58.5 & 76.5 & 82.4 \\
\hline 75 & 54 & 33 & 52.9 & 78.1 & 72.0 & 94.1 & 54.4 & 61.3 & 61.1 & 78.7 & 79.4 \\
\hline & 53 & 31 & 51.1 & 75.5 & 77.5 & 97.8 & 56.6 & 62.1 & 58.5 & 80.9 & 86.0 \\
\hline 75 & 54 & 38 & 52.2 & 78.4 & 76.6 & 94.9 & 53.6 & 58.2 & 70.4 & 76.1 & \\
\hline 75 & 63 & 34 & $52 . \overline{8}$ & 76.1 & 80.0 & 94.9 & 55.8 & 69.0 & 54.0 & 73.9 & 87.0 \\
\hline & 64 & 34 & 53.7 & 77.4 & 79.2 & 90.3 & & 74.0 & & 75.4 & \\
\hline 7 & 64 & 34 & 53.0 & 73.9 & 81.3 & 93.2 & 54.9 & 55.6 & 53.1 & 81.2 & 85.0 \\
\hline & 52 & 34 & 54.2 & 79.7 & 77.9 & 89.1 & & 76 & & 74.5 & \\
\hline 7 & 56 & 31 & 51.8 & 80.4 & 71.7 & 93.4 & 52.2 & 68.0 & 55.4 & 73.5 & 80.2 \\
\hline & 64 & 31 & 51.2 & 73.0 & 75.4 & 96.0 & 43.2 & 64.4 & & 82.4 & .2 \\
\hline 76 & 54 & 30 & 54.6 & 79.0 & 76.9 & 90.5 & 55.5 & 62.9 & 55. & 71.5 & 5 \\
\hline 76 & 51 & 34 & 52.5 & 82.4 & 76.6 & 93.0 & .0 & 55.4 & 66 . & 73.4 & .5 \\
\hline & 68 & 33 & 51.7 & 86.2 & 76.5 & 79.7 & 48.0 & 65.5 & 48.5 & 69.6 & 8 \\
\hline 7 & 60 & 33 & 53.6 & 77.5 & 78.6 & 89.5 & 48.1 & 75.5 & 55 & 75.2 & 5.7 \\
\hline & 60 & 33 & 55 & 82.1 & 76. & 96.2 & & 63.2 & & 76.9 & 3.1 \\
\hline & 64 & 33 & 51 . & 74.9 & 81.1 & 91.7 & 55.6 & $78.9^{*}$ & 51 & 80.5 & 7.2 \\
\hline & 60 & 31 & 53.5 & 74.9 & 80 & 93.7 & & & & & \\
\hline 76 & 55 & 30 & 52.6 & 74.0 & 85.9 & 91.4 & 50.8 & 61.5 & 54.6 & 78.9 & 85.9 \\
\hline & 62 & 37 & 50.2 & & 74 & & & 80 & & & \\
\hline & 61 & 28 & 51.3 & 74.9 & 78.6 & 97.6 & 59.2 & 61.8 & 45.9 & 79.2 & \\
\hline & 52 & 30 & 51 & 85.2 & 72.0 & 92.5 & & 61.4 & & 72.9 & \\
\hline & 66 & 33 & 52.8 & 73.6 & 79. & 90.7 & & & & 75.2 & \\
\hline & 56 & 32 & & & 75 & 83.6 & & 61.8 & 57 & 81.4 & \\
\hline & 62 & 30 & 53.8 & 78.5 & & & & & & 78.9 & \\
\hline & 66 & 38 & 51.2 & 78.8 & 79 & & & 68.5 & & 87.5 & \\
\hline & 63 & 33 & 52.2 & & & & & & & & .0 \\
\hline & 58 & 31 & 53.7 & & 75 & 93 & & 84.1 & & 79.4 & \\
\hline & 53 & 27 & 51.2 & 75 & & & & 76.7 & & 73.9 & \\
\hline & 54 & 30 & 51. & 86 & 72 & 88 & & 56.9 & 55 & 78.6 & \\
\hline & 53 & 30 & 54 & 73 & & 94 & & & & & \\
\hline & 56 & 33 & 52 & 78 & 74 & 86 & 48 & 60.8 & 58 & 73.7 & \\
\hline & 65 & 35 & 52 & 79. & & & & & & & \\
\hline & 62 & 30 & 54 & 74. & 78 & 87.8 & & 66.7 & & -80.9 & \\
\hline & 67 & 35 & & & & & & 60.3 & & & \\
\hline & 62 & 30 & 51.1 & 75 & 78 & 88. & 48 & 76.6 & 48.4 & 82.7 & \\
\hline & 66 & 30 & 50.9 & 76.6 & 75 & 95.3 & 53.1 & 76.1 & 53.6 & 78.1 & \\
\hline
\end{tabular}

* Should be omitted because of broken nove. 
Measurements

\begin{tabular}{|c|c|c|c|c|c|c|c|c|c|c|c|}
\hline Age & Stature & SH & $\mathbf{L}$ & B & $\mathrm{B}^{\prime}$ & $\mathbf{J}$ & go-go & GH & $\mathbf{G}^{\prime} \mathbf{H}$ & NH & NB \\
\hline 788 & 1685 & 897 & 188 & 154 & 111 & 144 & 103 & 123 & 67 & 55 & 31 \\
\hline 33 & 1691 & 895 & 186 & 145 & 108 & 133 & 102 & 126 & 85 & 58 & 36 \\
\hline 20 & 1450 & 745 & 184 & 142 & 110 & 131 & 102 & 106 & 64 & 49 & 31 \\
\hline 791 & 1648 & 845 & 201 & 153 & 114 & 138 & 109 & 124 & 73 & 56 & 30 \\
\hline 792 & 1720 & 855 & 187 & 151 & 113 & 138 & 108 & 118 & 69 & 55 & 35 \\
\hline 793 & 1538 & 835 & 180 & 146 & 108 & 131 & 101 & 122 & 66 & 50 & 26 \\
\hline 794 & 1762 & 934 & 184 & 148 & 116 & 133 & 95 & 129 & 67 & 46 & 42 \\
\hline 795 & 1647 & 865 & 184 & 145 & 113 & 133 & 104 & 123 & 67 & 51 & 34 \\
\hline 796 & 1596 & 815 & 193 & 137 & 114 & 133 & 103 & 122 & 79 & 61 & 33 \\
\hline 22 & 1640 & 865 & 191 & 144 & 114 & 134 & 107 & 122 & 70 & 54 & 37 \\
\hline 798 & 1718 & 901 & 185 & 141 & 112 & 128 & 105 & 122 & 67 & 45 & 32 \\
\hline 33 & 1627 & 835 & 176 & 145 & 107 & 134 & 98 & 114 & 67 & 45 & 32 \\
\hline 800 & 1711 & 905 & 188 & 150 & 110 & 134 & 102 & 122 & 70 & 53 & 33 \\
\hline 23 & 1730 & 919 & 201 & 158 & 122 & 147 & 118 & 122 & 71 & 51 & 33 \\
\hline 35 & 1634 & 885 & 183 & 145 & 113 & 138 & 108 & 120 & 68 & 45 & 33 \\
\hline 25 & 1732 & 915 & 187 & 152 & 113 & 134 & 103 & 131 & 76 & 57 & 33 \\
\hline 50 & 1765 & 963 & 188 & 138 & 111 & 135 & 106 & 127 & 75 & 53 & 33 \\
\hline 35 & 1870 & 985 & 190 & 151 & 121 & 144 & 107 & 126 & 75 & 54 & 45 \\
\hline 25 & & & 192 & 157 & 118 & 140 & 104 & 126 & 78 & 60 & 33 \\
\hline 35 & 1656 & 928 & 186 & 141 & 109 & 127 & 102 & 122 & 70 & 51 & 35 \\
\hline 35 & 1726 & 865 & 188 & 143 & 114 & 134 & 97 & 137 & 82 & 60 & 35 \\
\hline 40 & 1640 & 898 & 192 & 148 & 116 & 137 & 104 & 115 & 68 & 46 & 41 \\
\hline 32 & 1710 & 920 & 185 & 138 & 118 & 133 & 103 & 132 & 72 & 54 & 29 \\
\hline 40 & 1630 & 865 & 186 & 144 & 107 & 137 & 114 & 121 & 70 & 56 & 39 \\
\hline 35 & 1730 & 914 & 187 & 146 & 115 & 136 & 108 & 116 & 73 & 58 & \\
\hline 18 & 1610 & 815 & 185 & 146 & 106 & 126 & 98 & 118 & 68 & 45 & 35 \\
\hline 34 & 1585 & 857 & 187 & 157 & 120 & 140 & 109 & 122 & 65 & 48 & 31 \\
\hline 22 & 1693 & 908 & 193 & 148 & 110 & 132 & 103 & 126 & 76 & 51 & 31 \\
\hline 25 & 1586 & 830 & 182 & 152 & 108 & 132 & 107 & 120 & 71 & 52 & 32 \\
\hline 20 & 1612 & 862 & 180 & 149 & 113 & 136 & 105 & 124 & 70 & 51 & 36 \\
\hline 22 & 1700 & 911 & 182 & 151 & 114 & 134 & 103 & 124 & 76 & 51 & 28 \\
\hline 32 & 1597 & 875 & 185 & 147 & 107 & 133 & 108 & 109 & 65 & 46 & 30 \\
\hline 35 & 1760 & 905 & 189 & 147 & 113 & 132 & 108 & 135 & 75 & 58 & 31 \\
\hline 32 & 1760 & 947 & 187 & 148 & 116 & 138 & 108 & 133 & 78 & 53 & 33 \\
\hline 65 & 1602 & 792 & 183 & 147 & 115 & 136 & 113 & 128 & 82 & 59 & 35 \\
\hline 46 & 1714 & 945 & 188 & 15 & 116 & 142 & 105 & 128 & 77 & 60 & 36 \\
\hline 40 & 1640 & 870 & 192 & 136 & 116 & 133 & 93 & 128 & 72 & 47 & 35 \\
\hline 35 & 1682 & 845 & 188 & 141 & 117 & 134 & 97 & 113 & 61 & 52 & -34 \\
\hline 40 & 1695 & 860 & 198 & 142 & 112 & 132 & 101 & 127 & 76 & 52 & 33 \\
\hline 40 & 1660 & 855 & 193 & 150 & 116 & 147 & 111 & 123 & 71 & 52 & 37 \\
\hline 20 & 1505 & 832 & 170 & 137 & 104 & 133 & 107 & 116 & 68 & 52 & 34 \\
\hline 22 & 1572 & 815 & 181 & 143 & 109 & 133 & 96 & 113 & 67 & 50 & 31 \\
\hline 25 & 1652 & 848 & 199 & 148 & 111 & 137 & 113 & 118 & 67 & 53 & 35 \\
\hline 40 & 1635 & 895 & 198 & 15 & 115 & 140 & 105 & 128 & 72 & 55 & \\
\hline 20 & 1570 & 808 & 185 & 15 & 115 & 136 & 101 & 107 & 66 & 45 & \\
\hline 20 & 1614 & 866 & 190 & 153 & 121 & 141 & 112 & 123 & 74 & 52 & 36 \\
\hline 35 & 1705 & 855 & 179 & 14 & 111 & 133 & 106 & 111 & 65 & 42 & \\
\hline 35 & 1690 & 905 & 185 & 13 & 112 & 133 & 98 & 12 & 76 & 57 & 31 \\
\hline 55 & 1660 & 88 & 19 & 14 & 110 & 137 & 107 & 12 & 72 & 55 & 33 \\
\hline 55 & 1640 & 85 & 18 & 14 & 11 & 145 & 120 & 144 & 85 & 65 & 38 \\
\hline 23 & 1713 & 88 & 18 & 14 & 11 & 13 & 101 & 12 & 72 & 50 & 37 \\
\hline 40 & 1690 & 87 & 19 & 14 & 117 & 142 & 117 & 122 & 72 & 54 & 30 \\
\hline 25 & 1710 & & 18 & 14 & 11 & 13 & 94 & 101 & 65 & 46 & 37 \\
\hline 30 & 1543 & 81 & $17 \varepsilon$ & 13 ? & 111 & 128 & 100 & 10 & 56 & 42 & 36 \\
\hline 20 & 1645 & 88 & 191 & 14 & 107 & 137 & 104 & 113 & 67 & 54 & 30 \\
\hline 35 & 1710 & & 191 & 155 & 124 & 144 & 108 & 117 & 65 & 52 & 49 \\
\hline
\end{tabular}




\section{INDICES}

\begin{tabular}{|c|c|c|c|c|c|c|c|c|c|c|c|}
\hline No. & EL & EB & RSH & $\mathrm{B} / \mathrm{L}$ & $\mathbf{B}^{\prime} / \mathbf{B}$ & GH/J & $\mathbf{G}^{\prime} \mathbf{H} / \mathbf{J}$ & $\mathrm{NB} / \mathrm{NH}$ & EB/EL & go-go/J & $\mathbf{B}^{\prime} / \mathbf{J}$ \\
\hline 788 & 51 & 30 & 53.2 & 81.9 & 72.1 & 85.4 & 46.5 & 56.4 & 58.8 & 71.5 & 77.1 \\
\hline 789 & 66 & 33 & $52 . \overline{9}$ & 78.0 & 74.5 & & 63.9 & 62.1 & 50.0 & 76.7 & 81.2 \\
\hline 790 & 63 & 30 & 51.4 & 77.2 & 77.5 & 80.9 & 48.9 & 63.3 & 47.6 & 77.9 & 84.0 \\
\hline 791 & 55 & 30 & 51.3 & 76.1 & 74.5 & 89.9 & 52.9 & 53.6 & 54.5 & 79.6 & 82.6 \\
\hline 792 & 60 & 31 & 49.7 & 80.8 & 74.8 & 85.5 & 50.0 & 63.6 & 51.7 & 78.3 & 81.9 \\
\hline 793 & 62 & 30 & 54.3 & 81.1 & 74.0 & 93.1 & 50.4 & 52.0 & 48.4 & 77.1 & 82.4 \\
\hline 794 & 62 & 24 & 53.0 & 80.4 & 78.4 & 97.0 & 50.4 & 91.3 & 38.7 & 71.4 & 87.2 \\
\hline 795 & 61 & 35 & 52.5 & 78.8 & 77.9 & 92.5 & 50.4 & 66.7 & 57.4 & 78.2 & 85.0 \\
\hline 796 & 63 & 33 & 51.1 & 71.0 & 83.2 & 91.7 & 59.4 & 54.1 & 52.4 & 77.4 & 85.7 \\
\hline 797 & 58 & 32 & 52.7 & 75.4 & 79.2 & 91.0 & 52.2 & 68.5 & 55.2 & 79.9 & 85.1 \\
\hline 798 & 50 & 32 & 52.4 & 76.2 & 79.4 & 95.3 & 52.3 & 71.1 & 64.0 & 82.0 & 87.5 \\
\hline 799 & 54 & 28 & 51.5 & 82.4 & 73.8 & 85.1 & 50.0 & 71.1 & 51.9 & 73.1 & 79.9 \\
\hline 800 & 63 & 31 & 52.9 & 79.8 & 73.3 & 91.0 & 52.2 & 62.3 & 49.2 & 76.1 & 82.1 \\
\hline 80. & 60 & 30 & 53.1 & 78.6 & 77.2 & 83.0 & 48.3 & 64.7 & 50.0 & 80.3 & 83.0 \\
\hline 802 & 58 & 30 & 54.2 & 79.2 & 77.9 & 86.9 & 49.3 & 73.3 & 51.7 & 78.3 & 81.9 \\
\hline 803 & 59 & 35 & 52.8 & 81.3 & 74.3 & 97.8 & 56.7 & 57.9 & 59.3 & 76.9 & 84.3 \\
\hline 804 & 57 & 27 & 54.5 & 73.4 & 80.4 & 94.1 & 55.6 & 62.3 & 47.4 & 78.5 & 82.2 \\
\hline 805 & 62 & 33 & 52.7 & 79.5 & 80.1 & 87.5 & 52.1 & 83.3 & 53.2 & 74.3 & 84.0 \\
\hline 806 & 59 & 26 & & 81.8 & 75.2 & 90.0 & 55.7 & 55.0 & 44.1 & 74.3 & 84.3 \\
\hline $80 ?$ & 55 & 26 & 56.0 & 75.8 & $77 . \overline{3}$ & 96.1 & 55.1 & 68.6 & 47.3 & 80.3 & 85.8 \\
\hline 80 & 60 & 42 & 50.1 & 76.1 & 79.7 & 102.2 & 61.2 & 58.3 & & 64.9 & 85.1 \\
\hline 809 & 65 & 36 & 54.8 & 77.1 & 78.4 & 83.9 & 49.6 & 89.1 & 55.4 & 75.9 & 84.7 \\
\hline & 66 & 35 & 53.8 & 74.6 & 85.5 & 99.3 & 54.1 & 53.7 & 53.0 & 77.4 & 88.7 \\
\hline 811 & 58 & 34 & 53.1 & 77.4 & 74.3 & 88.3 & 51.1 & 69.6 & 58.6 & 83.2 & 78.1 \\
\hline & 56 & 33 & 52.8 & 78.1 & 78.8 & 85.3 & 53.7 & 53.4 & 58.9 & 79.4 & 84.5 \\
\hline 81 & 53 & 31 & 50.6 & 78.9 & 72.6 & 93.7 & 54.1 & .77 .8 & 58.5 & 77.8 & 84.1 \\
\hline & 54 & 34 & 54.1 & 83.9 & 76.4 & 87.1 & 46.4 & 64.6 & 63.0 & 77.9 & 85.7 \\
\hline & 60 & 33 & 53.3 & 77.1 & 74.3 & 95.5 & 57.6 & 60.8 & 55.0 & 78.0 & 83.3 \\
\hline & 54 & 31 & 52.3 & 83.5 & 71.1 & 90.9 & 53.8 & 61.5 & 57.4 & 81.1 & 81.8 \\
\hline & 54 & 28 & 53.5 & 82.8 & 75.8 & 91.2 & 51.5 & 70.6 & 51.9 & 77.2 & 83.1 \\
\hline 8 & 58 & 30 & 53.6 & 83.0 & 75.5 & 92.5 & 56.7 & 54.9 & 51.7 & 76.9 & 85.1 \\
\hline & 57 & 32 & 54.8 & 79.5 & 72.8 & 82.0 & 48 & 65.2 & & 81.2 & 80.5 \\
\hline & 58 & 34 & 51.4 & 78.6 & 76.9 & 102.3 & 56.8 & 53.5 & 58.6 & 81.8 & 85.6 \\
\hline & 60 & 36 & 53.8 & 79.1 & 78.4 & 96.4 & & 62.3 & 60 & 78.3 & 84.1 \\
\hline 82 & 68 & 30 & 49.4 & 80.3 & 78.2 & 94.1 & 60.3 & 59.3 & 44.1 & 83.1 & 84.6 \\
\hline & 74 & 34 & & 80.3 & 76.8 & 90.1 & & 60.0 & 45.9 & 73.9 & 81.7 \\
\hline & 62 & 35 & 53. & 70.8 & 85.3 & 96.2 & & 74.5 & 56.5 & 69.9 & 87.2 \\
\hline & 52 & 34 & 50.2 & 75.5 & 82. & 84.3 & & 65.4 & 65.4 & 72.4 & 87.3 \\
\hline & 53 & 30 & 50. & 71.7 & & 96.2 & & & & & 84.9 \\
\hline & 57 & 28 & 51.5 & 77.7 & 77.3 & 83.7 & 48.3 & 71.2 & 49.1 & 75.5 & 78.9 \\
\hline & 65 & 34 & 55. & 80.6 & & 87.2 & & & & & 78.2 \\
\hline & 53 & 31 & 51. & 79.0 & 76.2 & 85.0 & & 62.0 & 58.5 & 72.2 & $81 . \overline{9}$ \\
\hline & 67 & 32 & & 74.4 & & & & 66.0 & & & 81.0 \\
\hline & 64 & 32 & & 76.8 & 75 . & 91. & & 63.6 & 50 & 75.0 & 82.1 \\
\hline & 55 & 30 & & 82.7 & & 78.7 & & 77.8 & & 74.3 & 84.6 \\
\hline & 54 & 28 & 53. & 80.5 & & 87.2 & & 69.2 & & 79.4 & 85.8 \\
\hline & 50 & 33 & & 79.9 & & 88.5 & & 85.7 & 66 & 79.7 & 83.5 \\
\hline & 57 & 30 & & 75.1 & & 96.2 & & & & 73.7 & 84.2 \\
\hline & 71 & 35 & & & & $90 . \overline{5}$ & & 60.0 & 49.3 & 78.1 & \\
\hline & 70 & 33 & & 78.7 & & 99.8 & & 58.5 & 47.1 & 82.8 & \\
\hline & 52 & 33 & & 78.2 & 75 & 90.3 & 53 & 74.0 & 63.5 & 75.4 & \\
\hline & 68 & 35 & & 76.2 & & 85.9 & & & & & 82.4 \\
\hline & 56 & 30 & & $78 . \overline{5}$ & 77. & 76.5 & 49 & 80.4 & 53.6 & 71.2 & 83.3 \\
\hline & 63 & 33 & & 77.0 & & & & & & 78.1 & 86.7 \\
\hline & 58 & 32 & 53. & 77.0 & 72 . & 82.5 & 48.9 & 55.6 & 55.2 & 75.9 & 78.1 \\
\hline & 50 & 30 & 51.5 & 81.1 & 80.0 & 81.8 & 45.1 & 94.3 & 60.0 & 75.0 & 86.1 \\
\hline
\end{tabular}


Measurements

\begin{tabular}{|c|c|c|c|c|c|c|c|c|c|c|c|c|}
\hline No. & Age & Stature & SH & $\mathbf{L}$ & B & $\mathbf{B}^{\prime}$ & $\mathbf{J}$ & go-go & GH & $\mathbf{G}^{\prime} \mathbf{H}$ & NH & NB \\
\hline 844 & 30 & 1690 & 871 & 188 & 144 & 110 & 134 & 106 & 118 & 78 & 61 & 30 \\
\hline 845 & 25 & 1682 & 883 & 191 & 144 & 114 & 131 & 110 & 125 & 76 & 59 & 35 \\
\hline 846 & 40 & 1734 & 930 & 187 & 140 & 111 & 131 & 111 & 121 & 71 & 55 & 34 \\
\hline 847 & 45 & 1750 & 885 & 185 & 147 & 114 & 137 & 111 & 134 & 78 & 53 & 32 \\
\hline 848 & 35 & 1640 & 875 & 193 & 153 & 113 & 138 & 110 & 124 & 75 & 60 & 34 \\
\hline 849 & 40 & 1666 & 880 & 182 & 140 & 111 & 133 & 107 & 133 & 79 & 57 & 44 \\
\hline 850 & 20 & 1605 & 858 & 187 & 142 & 115 & 136 & 100 & 116 & 74 & 58 & 33 \\
\hline 851 & 20 & 1659 & 845 & 194 & 145 & 114 & 136 & 101 & 124 & 71 & 53 & 35 \\
\hline 852 & 55 & 1674 & 870 & 192 & 153 & 115 & 138 & 109 & 125 & 74 & 3 & 37 \\
\hline 853 & 28 & 1652 & 885 & 183 & 150 & 114 & 139 & 96 & 115 & 65 & 48 & 32. \\
\hline 854 & 20 & 1655 & 869 & 187 & 149 & 113 & 123 & 96 & 118 & 66 & 48 & 31 \\
\hline 855 & 45 & 1568 & 820 & 190 & 138 & 107 & 126 & 104 & 133 & 81 & 59 & 31 \\
\hline 856 & 50 & 1732 & 931 & 184 & 151 & 121 & 141 & 115 & 119 & 65 & 43 & 38 \\
\hline 857 & 20 & 1692 & 825 & 190 & -144 & 117 & 135 & 103 & 114 & 62 & 46 & 31 \\
\hline 858 & 30 & 1734 & 863 & 184 & 148 & 106 & 131 & 105 & 121 & 71 & 54 & 32 \\
\hline 859 & 28 & 1662 & 905 & 191 & 154 & 111 & 142 & 101 & 120 & 70 & 47 & 31 \\
\hline 86 & 20 & 1650 & 855 & 188 & 140 & 109 & 136 & 100 & 116 & 62 & 52 & 30 \\
\hline 861 & 25 & 1770 & 939 & 195 & 147 & 113 & 134 & 101 & 117 & 68 & 54 & 35 \\
\hline 86 & 22 & 1610 & 915 & 190 & 141 & 108 & 133 & 103 & 125 & 68 & 54 & 40 \\
\hline 863 & 22 & 1613 & 850 & 178 & 142 & 106 & 130 & 101 & 114 & 66 & 51 & 30 \\
\hline 86 & 30 & 1610 & 868 & 180 & 136 & 115 & 139 & 106 & 126 & 67 & 50 & 30 \\
\hline 865 & 25 & 1710 & 849 & 195 & 141 & 113 & 133 & 107 & 119 & 76 & 57 & 35 \\
\hline 866 & 35 & 1613 & 872 & 179 & 143 & 117 & 134 & 105 & 119 & 74 & 55 & 32 \\
\hline 867 & 30 & 1682 & 849 & 188 & 147 & 116 & 143 & 101 & 121 & 68 & 51 & 37 \\
\hline 868 & 35 & 1660 & 885 & 190 & 142 & 116 & 135 & 101 & 121 & 67 & 51 & 34 \\
\hline 86 & 38 & 1690 & 891 & 175 & 135 & 105 & 126 & 106 & & 81 & 58 & 35 \\
\hline 870 & 30 & 1702 & 930 & 188 & 143 & 115 & 139 & 109 & 116 & 64 & 46 & 31 \\
\hline 87 & 35 & 1737 & 878 & 200 & 136 & 115 & 140 & 111 & 131 & 76 & 59 & 38 \\
\hline 872 & 27 & 1657 & 872 & 194 & 148 & 113 & 139 & 113 & 113 & 78 & 59 & 40 \\
\hline 87 & 35 & 1703 & 890 & 191 & 138 & 115 & 143 & 107 & 131 & 73 & & 34 \\
\hline 874 & 25 & 1650 & 855 & 185 & 144 & 113 & 136 & 108 & 120 & 64 & 52 & 37 \\
\hline 87 & 55 & 1702 & 905 & 187 & 151 & 11 & 137 & 110 & 11 & 68 & & 35 \\
\hline 87 & 35 & 1640 & 897 & 185 & 147 & 113 & 137 & 107 & 123 & 69 & 51 & 32 \\
\hline 87 & 30 & 1770 & 950 & 190 & 143 & 109 & 137 & 110 & 127 & 73 & 56 & 33 \\
\hline 87 & 30 & 1607 & 835 & 185 & 153 & 114 & 141 & 105 & 115 & 71 & 56 & 33 \\
\hline 87 & 25 & 1694 & 909 & 178 & 147 & 114 & 138 & 107 & 107 & 66 & & 26 \\
\hline 10 & 56 & 1703 & 915 & 184 & 144 & 111 & 135 & 107 & 133 & 78 & 5 & 36 \\
\hline 88 & 20 & 1687 & 895 & 187 & 144 & 113 & 132 & 102 & 117 & 64 & 51 & 31 \\
\hline & 27 & 1660 & 892 & 185 & 144 & 114 & 130 & 104 & 122 & 68 & 49 & 31 \\
\hline & 35 & 1750 & & 18 & 141 & 11 & 133 & 98 & 120 & 68 & 47 & 44 \\
\hline & 25 & 1633 & 909 & 183 & 146 & 105 & 130 & 100 & 114 & 62 & 44 & 31 \\
\hline & 20 & 1626 & 876 & 186 & 157 & 122 & 142 & 116 & 121 & 67 & 51 & 36 \\
\hline & 40 & 1652 & 84 & & 148 & 121 & 143 & 113 & 120 & 61 & 44 & 35 \\
\hline & 22 & 1567 & 815 & 184 & 135 & 111 & 133 & 104 & 117 & 62 & 4 & 37 \\
\hline & 35 & 1632 & 875 & 183 & 144 & 116 & 14 & 111 & 127 & 74 & & 30 \\
\hline & 50 & 1590 & 835 & 190 & 149 & 113 & 138 & 105 & 117 & 67 & & 35 \\
\hline 80 & 30 & 1642 & 84 & 188 & 140 & 110 & 133 & 111 & 126 & 70 & 53 & 33 \\
\hline & 40 & 1670 & 906 & 185 & 147 & $11:$ & 138 & 102 & 110 & 64 & 46 & 27 \\
\hline & 25 & 1743 & 905 & 181 & 156 & 114 & 138 & 104 & 124 & 71 & 50 & 36 \\
\hline & 20 & 1710 & 845 & 203 & 141 & 11 & 133 & 104 & 123 & 69 & 57 & 33 \\
\hline & 35 & 1666 & 926 & 190 & 137 & 118 & 136 & 113 & 121 & 64 & 46 & 35 \\
\hline & 35 & 1650 & 87 & 19 & 145 & 11 & 140 & 108 & 124 & 7 & 54 & 34 \\
\hline & 50 & 1562 & 85 & 179 & 148 & 10 & 13 & 95 & 120 & 68 & 48 & 35 \\
\hline & 33 & 16 & 93 & 18 & 147 & 10 & 132 & 97 & 120 & 72 & 50 & 33 \\
\hline & 23 & 1720 & 895 & 189 & 147 & 118 & 142 & 110 & 123 & 74 & 56 & 34 \\
\hline
\end{tabular}




\section{INDICES}

\begin{tabular}{|c|c|c|c|c|c|c|c|c|c|c|c|}
\hline o. & EL & EB & RSH & B/L & $\mathbf{B}^{\prime} / \mathbf{B}$ & $\mathbf{G H} / \mathbf{J}$ & $\mathbf{G}^{\prime} \mathbf{H} / \mathbf{J}$ & $\mathrm{NB} / \mathrm{NH}$ & EB/EL & go-go/J & $\mathbf{B}^{\prime} / \mathrm{J}$ \\
\hline 844 & 58 & 30 & 51.5 & 76.6 & 76.4 & 88.1 & 58.2 & 49.2 & 51.7 & 79.1 & 82.1 \\
\hline & 56 & 33 & 52.5 & 75.4 & 79.2 & & & & & & \\
\hline & 61 & 40 & 53.6 & 74.9 & 79.3 & 92.4 & & 61.8 & & & \\
\hline & 53 & 35 & 50.6 & 79.5 & 77.6 & 97.8 & & & & & \\
\hline & 67 & 37 & 53.4 & 79.3 & 73.9 & 89.9 & & & & & \\
\hline & 64 & 33 & 52. & 81.4 & 79.4 & 100.0 & & & & & \\
\hline & 48 & 35 & 53.5 & 75.9 & 81.1 & 85 & & 56.9 & & & \\
\hline & 52 & 28 & 50. & 74.8 & 78.7 & & & & & & \\
\hline & 65 & 38 & 52.0 & 79.7 & 75.2 & 90.6 & 53.6 & 58.7 & & & \\
\hline & 63 & 30 & & 82.0 & 76.1 & 82.7 & 46.8 & 66.6 & & & \\
\hline & 60 & 30 & 52.5 & 79.7 & 75.9 & 95.9 & 53.6 & 64.7 & & 77 & \\
\hline & 56 & 33 & 52. & 72.6 & 77.6 & 105.2 & 64.3 & 52.6 & & & \\
\hline & 56 & 38 & 53.8 & 82.1 & 80.2 & 84. & 46.1 & 88.4 & 67. & & \\
\hline & 60 & 35 & 48.8 & 75.9 & 81.4 & & & 67.4 & & & \\
\hline & 54 & 30 & 49.8 & 80.4 & 71.6 & 92. & 54.1 & 59.2 & 55 & 80.2 & \\
\hline & 65 & 35 & 54.4 & 80.6 & 72.1 & & 49.3 & 65.9 & & & \\
\hline & 54 & 35 & 51.8 & 74.5 & 77.9 & 85.3 & & 57.7 & & & \\
\hline & 66 & 37 & 53. & 75.4 & 76.9 & & & 64.8 & & 75.4 & \\
\hline & 62 & 32 & 56. & 74.2 & 76.6 & & & & & 77.4 & \\
\hline & 57 & 31 & 52.7 & 79.8 & 74 & 87. & 50.8 & 58.8 & 54.4 & 77.7 & \\
\hline & 52 & 33 & 53.9 & 75.6 & & & & & & & \\
\hline & 52 & 26 & 49.7 & 72.3 & 80 & 89 & 57.1 & 61.4 & 50.0 & 80.5 & \\
\hline & 58 & 31 & & & & & & & & & \\
\hline & 58 & 32 & 50.5 & 78.2 & 78 & 84 & 47 & 72.6 & 55.2 & & \\
\hline & 54 & 24 & & 74.7 & & 89.6 & & & & & \\
\hline & 58 & 37 & 52.7 & 77.2 & 77.8 & & & 60.3 & & & \\
\hline & 57 & 32 & 54.6 & 76.1 & 80.4 & 83.5 & & .4 & & & \\
\hline & 64 & 35 & 50.6 & 68.0 & 84 & 93.6 & & 64.4 & & & \\
\hline & 62 & 33 & & 76.3 & & 81 & & 67.8 & & & \\
\hline & 62 & 35 & 52.3 & 72.3 & 83.3 & 91 & & & & & \\
\hline & 58 & 28 & 51.8 & 77.8 & & 88. & & & & & \\
\hline & 62 & & & & & & & & & & \\
\hline & 57 & 31 & 54.7 & 79.5 & 76 & & & 62.7 & & 78.1 & \\
\hline & 61 & & & & & & & & & & \\
\hline & 53 & 33 & & 82.7 & & & & 58. & & & \\
\hline & 52 & 27 & & & & & & & & & \\
\hline & 64 & 32 & & 78 & & & & 65. & & & \\
\hline & 52 & & & 77 & & & & & & & \\
\hline & 67 & 32 & & & & & & & & & \\
\hline & 71 & 35 & & & & & & & & & \\
\hline & 51 & 30 & 55.7 & & & & & & & & \\
\hline & 50 & 31 & 53.9 & & & & & & & & \\
\hline & 63 & 34 & 51.4 & & & & & & & & \\
\hline & 57 & 30 & 52.0 & 73 & & & & 77 & & & \\
\hline & 59 & & & & & & & & & & \\
\hline & 55 & 31 & & 78.4 & & & & & & & \\
\hline & 61 & & & & & & & & & & \\
\hline & 61 & 30 & & & & & & & & & \\
\hline & 53 & 31 & & & & & & & & & \\
\hline & 57 & 33 & 49 & & & & & & & & \\
\hline & 55 & 35 & & & & & & & & & \\
\hline & 66 & 37 & & & & & & & & & \\
\hline & 46 & 30 & & 82 & & & & & & & \\
\hline & 62 & 38 & & 78 & & & & & & & \\
\hline & & 33 & & 77.8 & 80.3 & 86.6 & & 60.7 & 60.0 & 77.5 & \\
\hline
\end{tabular}




\section{Measurements}

\begin{tabular}{|c|c|c|c|c|c|c|c|c|c|c|c|c|}
\hline No. & Age & Stature & SH & L. & B & $\mathbf{B}^{\prime}$ & $\mathbf{J}$ & go-go & $\mathbf{G H}$ & $\mathbf{G}^{\prime} \mathbf{H}$ & NH & NB \\
\hline 899 & 25 & 1700 & 865 & 185 & 151 & 118 & 141 & 115 & 128 & 78 & 58 & 35 \\
\hline 900 & 25 & 1710 & 887 & 186 & 137 & 110 & 134 & 112 & 120 & 68 & 48 & 37 \\
\hline 901 & 35 & 1704 & 915 & 197 & 158 & 121 & 148 & 116 & 129 & 68 & 52 & 44 \\
\hline 902 & 33 & 1604 & 865 & 180 & 143 & 111 & 136 & 107 & 117 & 66 & 49 & 32 \\
\hline 903 & 35 & 1594 & 845 & 199 & 143 & 107 & 129 & 99 & 120 & 64 & 45 & 38 \\
\hline 904 & 35 & 1640 & 875 & 190 & 147 & 118 & 138 & 105 & 122 & 66 & 56 & 31 \\
\hline 905 & 20 & 1686 & 872 & 178 & 154 & 118 & 146 & 102 & 126 & 72 & 57 & 32 \\
\hline 906 & 20 & 1673 & 863 & 188 & 151 & 122 & 140 & 104 & 118 & 67 & 58 & 37 \\
\hline 907 & 65 & 1710 & 881 & 186 & 143 & 111 & 137 & 108 & 108 & 70 & 55 & 38 \\
\hline 908 & 30 & 1745 & 915 & 201 & 144 & 115 & 133 & 105 & 120 & 66 & 50 & 37 \\
\hline 909 & 28 & 1652 & 925 & 184 & 147 & 115 & 135 & 105 & 120 & 74 & 57 & 36 \\
\hline 910 & 25 & 1690 & 873 & 180 & 147 & 108 & 130 & 110 & 115 & 66 & 49 & 32 \\
\hline 911 & 18 & 1553 & 855 & 187 & 142 & 107 & 129 & 86 & 120 & 68 & 56 & 25 \\
\hline 912 & 18 & 1483 & 755 & 180 & 138 & 107 & 122 & 98 & 108 & 64 & 51 & 37 \\
\hline 913 & 25 & 1630 & 901 & 190 & 140 & 108 & 135 & 104 & 117 & 72 & & 34 \\
\hline 914 & 30 & 1640 & 885 & 185 & 142 & 115 & 140 & 104 & 12 & 72 & & 34 \\
\hline 915 & 18 & 1640 & 885 & 184 & 138 & 108 & 128 & 97 & 110 & 60 & 48 & 36 \\
\hline 916 & 40 & 1605 & 855 & 189 & 138 & 107 & 129 & 96 & 11 & 78 & 54 & 34 \\
\hline 917 & 45 & 1665 & 873 & 193 & 150 & 113 & 135 & 116 & 131 & 78 & 62 & 35 \\
\hline 918 & 23 & 1742 & 937 & 186 & 145 & 111 & 133 & 107 & 130 & 74 & 58 & 34 \\
\hline 919 & 40 & 1657 & 865 & 200 & 153 & 118 & 140 & 115 & 12 & 76 & 5 & 36 \\
\hline 920 & 65 & 1643 & 829 & 188 & 143 & 113 & 139 & 107 & 123 & 66 & 53 & 32 \\
\hline 921 & 20 & 1644 & 855 & 185 & 147 & 113 & 138 & 10 & 11 & 60 & 48 & 31 \\
\hline 922 & 20 & 1650 & 880 & 178 & 147 & 113 & 130 & 102 & 118 & 67 & 56 & 37 \\
\hline 923 & 40 & 1695 & 870 & 190 & 140 & 11 & 136 & 102 & 12 & 74 & 57 & 41 \\
\hline 924 & 40 & 1645 & 830 & 186 & 145 & 113 & 128 & 103 & 119 & 65 & 48 & 34 \\
\hline 925 & 20 & 1610 & 837 & 178 & 138 & 111 & 132 & 110 & 11 & 67 & 50 & 34 \\
\hline 926 & 40 & 1592 & 865 & 185 & 134 & 108 & 132 & 105 & 11 & 63 & 47 & 35 \\
\hline 927 & 30 & 1685 & 890 & 187 & 142 & 110 & 136 & 107 & 12 & 71 & 57 & 31 \\
\hline 928 & 30 & 1580 & 812 & 18 & 149 & 114 & 134 & 102 & 11 & 62 & 48 & 34 \\
\hline 929 & 35 & 1723 & 889 & 197 & 138 & 114 & 138 & 107 & 12 & 67 & 54 & 36 \\
\hline 930 & 60 & 173 & 96 & 19 & 15 & 11. & 144 & 10 & 12 & 73 & 6 & 40 \\
\hline 931 & 40 & 1710 & 900 & 176 & 152 & 11 & 139 & 102 & 118 & 72 & 50 & 37 \\
\hline 932 & 55 & 17 & 87 & 19 & & 11 & 13 & 10 & 12 & 76 & & 42 \\
\hline 93 & 50 & 161 & 895 & 18 & 146 & 12. & 132 & 122 & 12 & 73 & 60 & 38 \\
\hline 93 & 45 & 153 & 80 & 19 & 14 & 11 & 13 & 111 & 12 & 6 & & 37 \\
\hline & 35 & 165 & 81 & 18 & 14 & 111 & 132 & 98 & & 67 & 48 & 37 \\
\hline & 33 & 1656 & 85 & 19 & 13 & 11 & 126 & 104 & & 71 & & 34 \\
\hline & 40 & 168 & 88 & 18 & 14 & 11 & 13 & 10 & 11. & 69 & 52 & 37 \\
\hline & 40 & 1760 & 94 & 18. & 15 & 113 & 132 & 10 & & 74 & 5 & 43 \\
\hline & 30 & 167 & 88 & 19 & & 11 & 137 & 11 & & 79 & 66 & 37 \\
\hline & 30 & 1632 & 85 & 18 & 13 & 11 & 128 & 97 & & 72 & 57 & 37 \\
\hline & 45 & 16 & 91 & 19 & 14 & 11 & 13 ? & 104 & & & & 42 \\
\hline & 50 & 1580 & & 18 & 14 & 11 & 141 & 98 & & 72 & 5 & 42 \\
\hline & 30 & 160 & 85 & 19 & & 11 & 13 & 10 & & 68 & 52 & 38 \\
\hline & 20 & 1727 & 88 & 17 & & 11 & 13 & 11 & & 68 & 5 & 37 \\
\hline & 40 & 184 & 92 & 18 & & 11 & 13 & 10 & & 7 & & \\
\hline & 25 & 173 & 91 & 19 & & 11. & 132 & 10 & & 72 & 5. & \\
\hline & 30 & 165 & & 18 & & 108 & 141 & 11 & & 7 & 53 & \\
\hline & 28 & 1657 & 88 & 19 & & 11 & 13 & 10 & & 72 & 62 & \\
\hline & 45 & 1710 & & 18 & & 118 & 125 & 10 & & 68 & 49 & \\
\hline & 23 & 1743 & & 18 & & 116 & 140 & 10 & & 69 & 51 & \\
\hline & 20 & 167 & & 18 & 14 & 11 & 131 & 10 & & 72 & 52 & 36 \\
\hline & 38 & 173 & & 19 & & 11 & 140 & 10 & & 70 & 50 & \\
\hline & & 1660 & & 193 & & 116 & 137 & 103 & & 74 & 63 & \\
\hline
\end{tabular}




\section{INDICES}

No. EL EB RSH B/L $\quad B^{\prime} / B \quad G H / J \quad G \quad H / J \quad N B / N H \quad E B / E L \quad$ go-go/J $\quad B^{\prime} / \mathbf{J}$

$\begin{array}{llllllllllll}899 & 58 & 34 & 50.9 & 81.8 & 78.2 & 90.8 & 55.3 & 60.3 & 58.6 & 81.6 & 83.7\end{array}$

$\begin{array}{llllllllllll}900 & 58 & 33 & 51.9 & 73.7 & 80.3 & 89.6 & 50.8 & 77.1 & 56.9 & 76.1 & 82.1 \\ 901 & 60 & 34 & 53.7 & 80.2 & 76.6 & 87.2 & 45.9 & 84.6 & 56.7 & 78.4 & 81.8\end{array}$

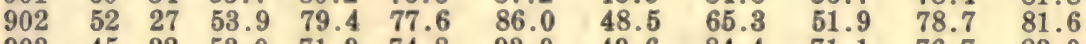

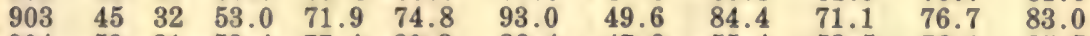

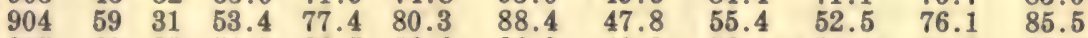

$\begin{array}{llllllllllll}905 & 60 & 37 & 51.7 & 86.5 & 76.6 & 86.3 & 49.3 & 56.1 & 61.7 & 69.9 & 80.8\end{array}$

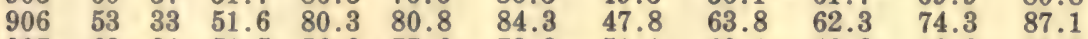

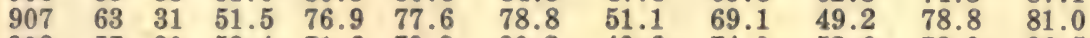

$\begin{array}{llllllllllll}908 & 57 & 30 & 52.4 & 71.6 & 79.9 & 90.2 & 49.6 & 74.0 & 52.6 & 78.9 & 86.5\end{array}$

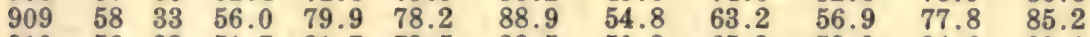

$\begin{array}{llllllllllll}910 & 56 & 33 & 51.7 & 81.7 & 73.5 & 88.5 & 50.8 & 65.3 & 58.9 & 84.6 & 83.1\end{array}$

$\begin{array}{llllllllllll}911 & 46 & 32 & 55.1 & 75.9 & 75.4 & 93.0 & 52.7 & 44.6 & 69.6 & 66.7 & 82.9\end{array}$

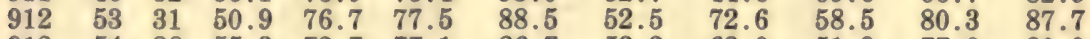

$\begin{array}{llllllllllll}913 & 54 & 28 & 55.3 & 73.7 & 77.1 & 86.7 & 53.3 & 63.0 & 51.9 & 77.0 & 80.0\end{array}$

$\begin{array}{llllllllllll}915 & 55 & 30 & 54.0 & 75.0 & 78.3 & 85.9 & 46.9 & 75.0 & 54.6 & 75.8 & 84.4\end{array}$

$\begin{array}{llllllllllll}916 & 56 & 34 & 53.3 & 73.0 & 77.5 & 91.5 & 60.5 & 63.0 & 60.7 & 74.4 & 82.9\end{array}$

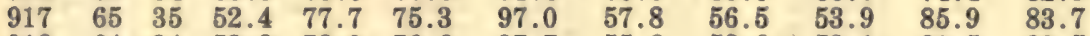

$\begin{array}{llllllllllll}918 & 64 & 34 & 53.8 & 78.0 & 76.6 & 97.7 & 55.6 & 58.6 & 53.1 & 80.5 & 83.5\end{array}$

$\begin{array}{llllllllllll}919 & 60 & 36 & 52.2 & 76.5 & 77.1 & 91.4 & 54.3 & 62.1 & 60.0 & 82.1 & 84.3\end{array}$

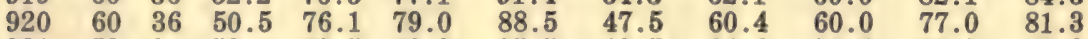

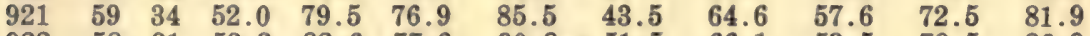

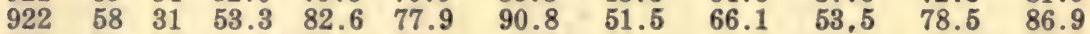

$\begin{array}{llllllllllll}923 & 57 & 30 & 51.3 & 73.7 & 80.7 & 91.2 & 54.4 & \mathbf{7 1 . 9} & \mathbf{5 2 . 6} & \mathbf{7 5 . 0} & 83.1\end{array}$

$\begin{array}{llllllllllll}924 & 53 & 26 & 50.5 & 78.0 & 77.9 & 93.0 & 50.8 & 70.8 & 49.1 & 80.5 & 88.3\end{array}$

$\begin{array}{llllllllllll}925 & 52 & 30 & 52.0 & 77.5 & 80.4 & 85.6 & 50.8 & 68.0 & 57.7 & 83.3 & 84.1\end{array}$

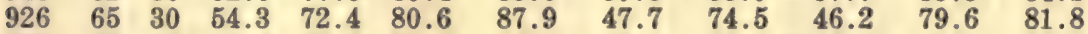

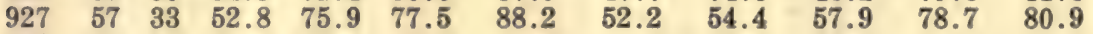

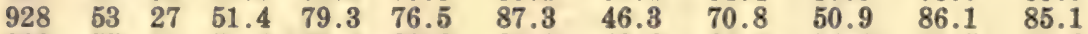

$\begin{array}{llllllllllll}929 & 55 & 30 & 51.6 & 70.1 & 82.6 & 87.0 & 48.6 & 66.7 & 54.6 & 77.5 & 82.6\end{array}$

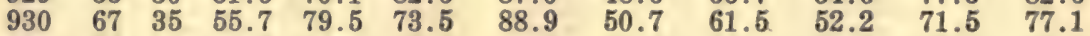

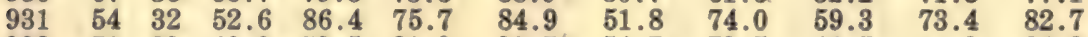

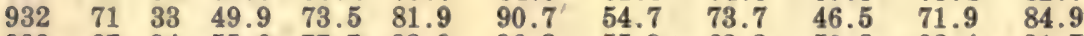

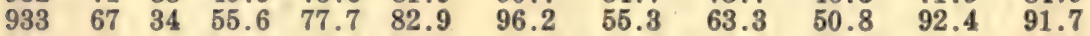

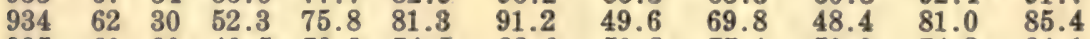

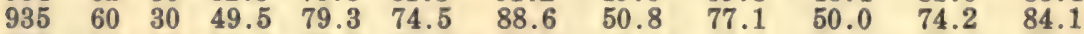

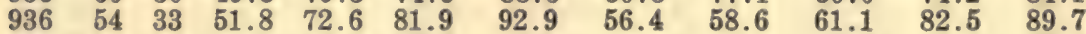

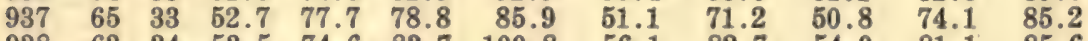

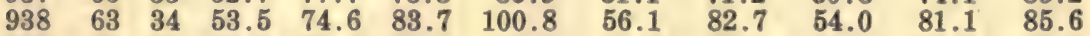

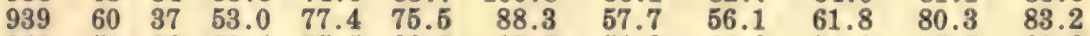

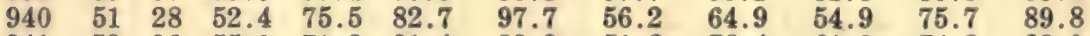

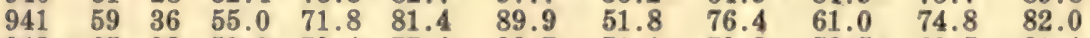

$\begin{array}{llllllllllll}942 & 65 & 38 & 53.0 & 79.4 & 77.4 & 88.7 & 51.1 & 79.3 & 58.5 & 69.5 & 80.1\end{array}$

$\begin{array}{llllllllllll}943 & 51 & 33 & 53.5 & 75.3 & 79.0 & 94.7 & 51.9 & 73.1 & 64.7 & 79.4 & 86.3\end{array}$

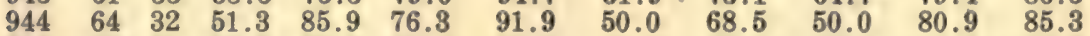

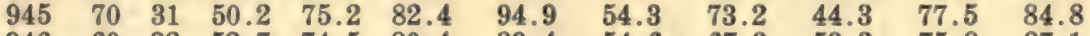

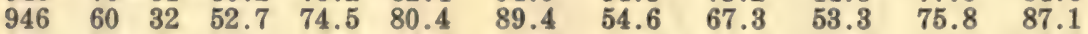

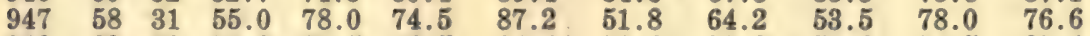

$\begin{array}{llllllllllll}948 & 62 & 32 & 53.2 & 80.5 & 76.5 & 94.4 & 52.6 & 53.2 & 51.6 & 74.5 & 85.4\end{array}$

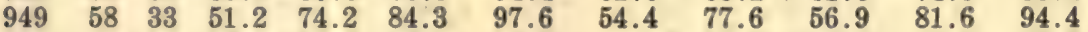

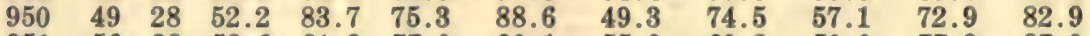

$\begin{array}{llllllllllll}951 & 56 & 28 & 52.6 & 81.3 & 77.0 & 90.1 & 55.0 & 69.2 & 50.0 & \mathbf{7 7 . 9} & 87.0\end{array}$

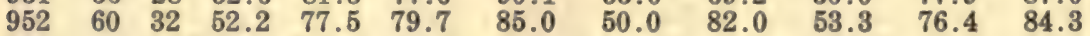

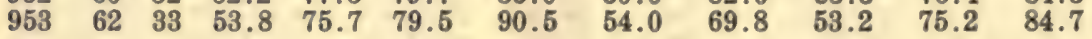


Morphological Characters of Al bu Muhammad Tribesmen

\begin{tabular}{|c|c|c|c|c|c|c|c|c|}
\hline \multirow[b]{2}{*}{ No. } & \multicolumn{3}{|c|}{ EAus } & \multicolumn{3}{|c|}{ EYES } & \multicolumn{2}{|c|}{ NOSE } \\
\hline & Form & Texture & Color & Color & Sclera & Iris & Profile & Wings \\
\hline 765 & $1 \mathrm{w}$ & coarse & black & bl-br & clear & zon & conv & m-fll \\
\hline 766 & $1 \mathrm{w}$ & medium & $\mathrm{dk}$ br & bl-br & blood & hom & conv & medium \\
\hline 767 & $1 \mathrm{w}$ & medium & $\mathrm{dk}$ br & bl-br & clear & zon & & \\
\hline 768 & $1 \mathrm{w}$ & medium & $\mathrm{v} d \mathrm{dk}$ br & bl-br & clear & hom & str & m-f \\
\hline 769 & l w & medium & $\mathrm{dk}$ br & bl-br & clear & zon & conv & medium \\
\hline 770 & $c-f$ & medium & black & bl-br & clear & zon & conv & m-fl \\
\hline & $1 \mathrm{w}$ & coarse & black & bl-br & $\begin{array}{l}\text { speck- } \\
\text { blood }\end{array}$ & ray & str & comp \\
\hline 772 & $1 \mathrm{w}$ & medium & dk br & bl-br & clear & hom & str & medium \\
\hline 773 & $1 \mathrm{w}$ & medium & $\mathrm{dk}$ br & bl-br & clear & hom & conc & medium \\
\hline 774 & $1 \mathrm{w}$ & medium & $\mathrm{dk}$ br & bl-gray & clear & ray & str & medium \\
\hline 775 & I w & medium & dk br & bl-br & clear & hom & str & cp-m \\
\hline 776 & $1 \mathrm{w}$ & medium & $\mathrm{dk}$ br & bl-br & clear & hom & str & $\mathrm{m}-\mathrm{fl}$ \\
\hline 777 & l w & medium & $\mathrm{dk}$ br & bl-br & clear & zon & conv & cp-m \\
\hline 778 & $1 \mathrm{w}$ & medium & br, gray & bl-br & clear & zon & str & medium \\
\hline 779 & $1 \mathrm{w}$ & medium & & bl-br & clear & hom & str & medium \\
\hline 780 & $1 \mathrm{w}$ & medium & dk br & bl-br & clear & hom & conv & cp-m \\
\hline 781 & $\therefore$ & medium & $\mathrm{dk}$ br & bl-br & clear & zon & str & flar \\
\hline 782 & $1 \mathrm{w}$ & medium & $\mathbf{v}$ dk br & bl-br & clear & hom & str & medium \\
\hline 783 & $1 \mathrm{w}$ & medium & br, gray & bl-br & clear & hom & str & m-fl \\
\hline 784 & $d w$ & medium & dk br & bl-br & & $\ldots$ & str & medium \\
\hline 785 & $1 \mathrm{w}$ & medium & br, gray & gr-br & clear & ray & str & medium \\
\hline 786 & l w & medium & dk br & bl-br & clear & hom & str & medium \\
\hline 787 & $1 \mathrm{w}$ & medium & $\mathrm{dk}$ br & gr-br & clear & ray & str & medium \\
\hline 788 & $1 \mathrm{w}$ & medium & br, gray & bl-br & clear & hom & str & comp \\
\hline 789 & l w & medium & dk br & bl-br & clear & hom & conv & medium \\
\hline 790 & $1 \mathrm{w}$ & medium & $\mathrm{dk}$ br & bl-br & clear & hom & conv & nedium \\
\hline 791 & $1 \mathrm{w}$ & medium & $\mathrm{dk}$ br & bl-br & clear & zon & str & medium \\
\hline 792 & $1 \mathrm{w}$ & medium & $\mathrm{dk}$ br & bl-br & clear & hom & str & \\
\hline 793 & l w & medium & $\mathrm{dk}$ br & $\mathrm{bl}-\mathrm{br}$ & clear & hom & str & medium \\
\hline 794 & $c-1$ & coarse & black & bl-br & clear & hom & str & \\
\hline 795 & $1 \mathrm{w}$ & medium & $\mathrm{dk}$ br & bl-br & clear & hom & str & medium \\
\hline 796 & $1 \mathrm{w}$ & medium & $\mathrm{dk}$ br & bl-br & clear & hom & conv & medium \\
\hline 797 & $1 \mathrm{w}$ & coarse & $\mathrm{v}$ dk br & bl-br & clear & hom & str & m-fl \\
\hline 798 & $1 \mathrm{w}$ & medium & $\mathrm{dk}$ br & bl-br & clear & zon & conv & medium \\
\hline 795 & $1 \mathrm{w}$ & medium & $\mathrm{dk}$ br & bl-br & clear & hom & str & medium \\
\hline 800 & $1 \mathrm{w}$ & medium & $\mathrm{dk}$ br & & clear & hom & conv & cp-m \\
\hline 801 & d w & medium & $\mathrm{dk}$ br & bl-br & & & str & $m-f 1$ \\
\hline & $1 \mathrm{w}$ & medium & $\mathrm{dk}$ br & bl-br & clear & hom & str & comp \\
\hline & & & & & & $\mathbf{z o}$ & str & medium \\
\hline 804 & $1 \mathrm{w}$ & medium & br, gray & $b l$-br & clear & hom & str & medium \\
\hline 80 & $c-f$ & medium & $\mathrm{v} \mathrm{dk}$ br & bl-br & blood & hom & $c-c$ & \\
\hline 806 & l w & medium & $\mathrm{dk}$ br & bl-br & clear & hom & str & medium \\
\hline $80^{\circ}$ & $c-f$ & medium & dk br & bl-br & clear & hom & str & \\
\hline 80 & $1 \mathrm{w}$ & medium & dk br & bl-br & clear & hom & str & medium \\
\hline 80 & $1 \mathrm{w}$ & medium & br, gray & bl-br & clear & hom & str & flar \\
\hline 810 & $1 \mathrm{w}$ & medium & br, gray & bl-br & clear & hom & conv & cp-m \\
\hline 81. & d w & medium & dk br & bl-br & clear & hom & $c-c$ & $m-f l$ \\
\hline 81 & $1 \mathrm{w}$ & medium & dk br & gr-br & clear & hom & conv & \\
\hline 81 & $1 \mathrm{w}$ & medium & $\mathrm{dk}$ br & bl-br & clear & zon & $\ldots$ & medium \\
\hline 81 & $1 \mathrm{w}$ & medium & $\mathrm{dk}$ br & bl-br & clear & $\ldots$ & str & medium \\
\hline & $1 \mathrm{w}$ & medium & dk br & bl-br & clear & zon & str & m-fl \\
\hline & $1 \mathrm{w}$ & medium & $\mathrm{dk}$ br & bl-br & clear & zon & str & medium \\
\hline & $1 \mathrm{w}$ & medium & dk br & bl-br & clear & zon & str & medium \\
\hline & l w & medium & dk br & bl-br & clear & hom & str & medium \\
\hline & $1 \mathrm{w}$ & medium & dk br & bl-br & clear & zon & conv & medium \\
\hline
\end{tabular}


Morphological Characters of Al bu Muhammad Tribesmen

\begin{tabular}{|c|c|c|c|c|c|c|c|c|}
\hline \multirow{3}{*}{$\begin{array}{l}\text { No. } \\
820\end{array}$} & \multicolumn{3}{|c|}{ HAIR } & \multicolumn{3}{|c|}{ हหरू } & \multicolumn{2}{|c|}{ Nosts } \\
\hline & Form & Texture & Color & Color & Sclera & Irls & Profile & Wings \\
\hline & l w & medium & br, gray & bl-br & clear & zon & conv & medium \\
\hline 821 & $1 w$ & medium & dk br & bl-br & clear & hom & conv & $m-f$ \\
\hline 822 & $c-f$ & medium & gray & & yellow & zon & $\operatorname{con} \mathrm{v}$ & $m-f l$ \\
\hline 823 & l w & medium & dk br & bl-br & blood & hom & conv & medium \\
\hline 824 & $1 \mathrm{w}$ & medium & br, gray & bl-br & clear & zon & conv & medium \\
\hline 825 & l w & medium & v dk br & bl-br & clear & zon & str & medium \\
\hline 826 & $1 \mathrm{w}$ & medium & dk br & bl-br & clear & hom & str & medium \\
\hline 827 & $1 \mathrm{w}$ & medium & dk br & bl-br & clear & & $c-c$ & m-fl \\
\hline 828 & l w & medium & black & bl-br & clear & hom & conv & medium \\
\hline 829 & & medium & $\mathrm{v} d \mathrm{dk}$ br & & clear & hom & c-e & medium \\
\hline 830 & I w & medium & dk br & bl-br & clear & hom & str & ep-m \\
\hline 831 & I w & medium & br, gray & bl-br & clear & hom & conv & medium \\
\hline 832 & $1 \mathrm{w}$ & fine & dk br & $\mathrm{gr}-\mathrm{br}$ & clear & hom & wavy & m-fl \\
\hline 833 & $1 \mathrm{w}$ & medium & black & bl-br & clear & hom & cone & m-fl \\
\hline 834 & $1 \mathrm{w}$ & medium & dk br & bl-br & clear & zon & conv & medium \\
\hline 835 & I w & medium & br, gray & $b l-b r$ & clear. & hom & str & medium \\
\hline 836 & $c-f$ & coarse & br, gray & bl-br & blood & zon & conv & medium \\
\hline 837 & l w & coarse & br, gray & $b l-b r$ & clear & zon & conv & flar \\
\hline 838 & $1 \mathrm{w}$ & coarse & black & bl-br & clear & hom & conv & comp \\
\hline 839 & $1 \mathrm{w}$ & medium & dk br & bl-br & clear & hom & conv & medium \\
\hline 840 & $1 \mathrm{w}$ & medium & $\mathrm{dk}$ br & bl-br & clear & zon & str & $m-f l$ \\
\hline 841 & $1 \mathrm{w}$ & medium & dk br & bl-br & clear & zon & cone & medium \\
\hline 842 & I w & medium & dk br & bl-br & clear & hom & conv & medium \\
\hline 843 & $c-f$ & coarse & black & dk br & clear & hom & cone & flar. \\
\hline 844 & I w & medium & dk br & $\mathrm{gr}-\mathrm{br}$ & blood & zon & str & medium \\
\hline 845 & l w & fine & $\mathrm{v} d \mathrm{k}$ br & & clear & hom & str & m-fl \\
\hline 846 & I w & coarse & black & bl-br & clear & hom & conv & $m-f l$ \\
\hline 47 & $1 \mathrm{w}$ & medium & br, gray & bl-br & clear & zon & conv & comp \\
\hline 48 & I w & medium & dk br & bl-br & clear & ray & conv & medium \\
\hline 849 & l w & medium & br, gray & $\mathrm{dk}$ br & clear & hom & str & flar \\
\hline 850 & v l w & medium & dk br & bl-br & clear & hom & str & medium \\
\hline 51 & $1 \mathrm{w}$ & medium & $\mathrm{dk}$ br & bl-br & clear & hom & str & medium \\
\hline & $1 \mathrm{w}$ & medium & dk br & gr-br & clear & ray & $c-c$ & medium \\
\hline 58 & $1 \mathrm{w}$ & medium & $\mathrm{v}$ dk br & bl-br & clear & zon & conv & medium \\
\hline & $\mathrm{l} \mathrm{w}$ & medium & dk br & & clear & hom & str & medium \\
\hline 85 & $1 \mathrm{w}$ & medium & $\mathrm{dk}$ br & bl-br & clear & hom & conv & comp \\
\hline & $1 \mathrm{w}$ & coarse & black & bl-br & clear & hom & str & medium \\
\hline 35 & $e-f$ & coarse & black & bl-br & clear & ray & str & medium \\
\hline & $1 \mathrm{w}$ & medium & dk br & bl-br & clear & ray & conv & comp \\
\hline 15 & l w & medium & dk br & bl-br & clear & zon & str & cp-m \\
\hline 86 & l $w$ & m-fine & v dk br & bl-br & clear & ray & conv & cp-m \\
\hline 67 & $1 \mathrm{w}$ & coarse & v dk br & bl-br & clear & hom & conv & comp \\
\hline 36 & $w$ & medium & black & bl-br & clear & hom & str & flar \\
\hline $0^{\circ}$ & $1 \mathrm{w}$ & medium & $\mathbf{v} \mathrm{dk}$ br & bl-br & clear & hom & conv & medium \\
\hline & $1 \mathrm{w}$ & c-med & dk br & bl-br & clear & hom & str & medium \\
\hline & $1 \mathrm{w}$ & c-med & dk br & bl-br & clear & hom & conv & medium \\
\hline 16 & $d w$ & medium & dk br & bl-br & clear & hom & conv & comp \\
\hline & l w & coarse & black & bl-br & clear & zon & conv & $\mathrm{m}-\mathrm{fl}$ \\
\hline & $\mathrm{v} 1 \mathrm{w}$ & medium & br, gray & bl-br & clear & ray & conv & medium \\
\hline 7 & $1 \mathrm{w}$ & fine & br, gray & & clear & hom & str & comp \\
\hline 87. & $1 \mathrm{w}$ & medium & $\mathrm{dk}$ br & bl-br & clear & hom & str & comp \\
\hline & $1 \mathrm{w}$ & coarse & black & bl-br & clear & zon & str & medium \\
\hline & $1 \mathrm{w}$ & medium & black & bl-br & clear & & str & m-fl \\
\hline & l w & medium & dk br & $b l$-br & clear & zon & str & cp-m \\
\hline & w & medium & black & $b l$-br & clear & hom & conv & medium \\
\hline & $1 \mathrm{w}$ & medium & blk, gray & bl-br & clear & hom & str & medium \\
\hline & $1 \mathrm{w}$ & medium & black & bl-br & clear & zon & str & cp-m \\
\hline & d w & medium & $\mathrm{dk}$ br & bl-br & clear & hom & str & cp-m \\
\hline
\end{tabular}


Morphological Charactirs of Al bu Muhammad Tribesmen

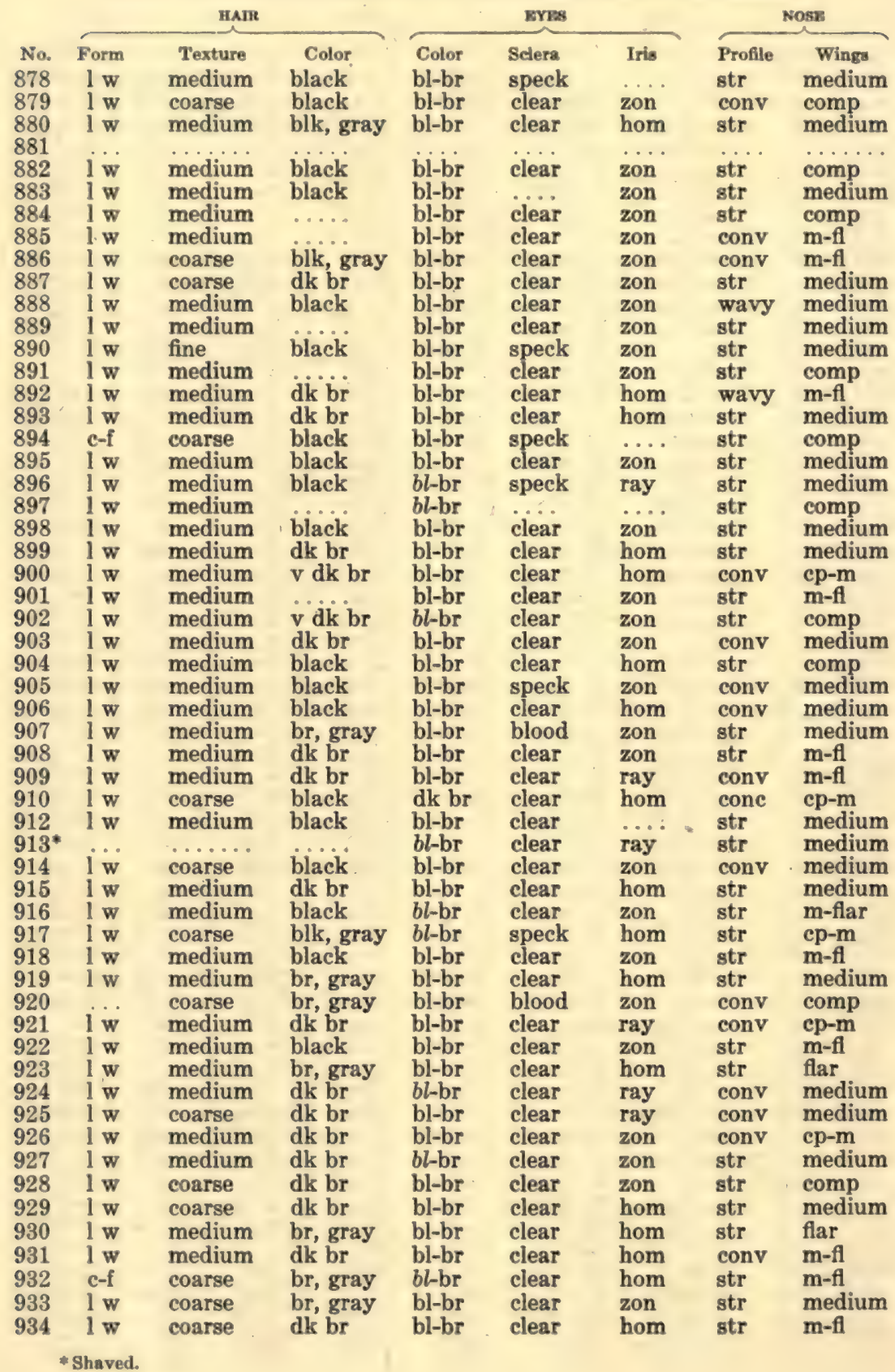


Morphological Characters of Al bu Muhammad Tribesmbe

\begin{tabular}{|c|c|c|c|c|c|c|c|c|}
\hline \multirow{3}{*}{ No. } & \multirow[b]{2}{*}{ Form } & \multicolumn{2}{|l|}{ FaTR } & \multicolumn{3}{|c|}{ EYES } & \multicolumn{2}{|c|}{ Nose } \\
\hline & & Texture & Color & Color & Selera & Iris & Profile & Wings \\
\hline & $1 \mathrm{w}$ & c-med & $\mathrm{v}$ dk br & bl-br & clear & hom & str & $m-f l$ \\
\hline 936 & $\mathrm{l} w$ & coarse & $\mathrm{dk}$ br & bl-br & speck & ray & conv & $m-f$ \\
\hline 937 & $\mathrm{l} w$ & medium & $\mathrm{dk}$ br & $\mathrm{bl}-\mathrm{br}$ & speck & hom & conv & medium \\
\hline 938 & & coarse & black & bl-br & clear & zon & conv & flar \\
\hline 939 & $1 \mathrm{w}$ & medium & $\mathrm{v} \mathrm{dk} \mathrm{br}$ & $\mathrm{bl}-\mathrm{br}$ & clear & hom & str & cp-m \\
\hline 940 & $1 \mathrm{w}$ & c-med & $\mathrm{v} d \mathbf{d k r}$ & bl-br & clear & hom & $c-c$ & $m-f l$ \\
\hline 941 & & coarse & $\mathrm{v} d \mathrm{dk}$ br & bl-br & blood & ray. & str & $m-f$ \\
\hline 942 & $1 \mathrm{w}$ & coarse & br, gray & bl-br & clear & ray & str & flar \\
\hline 943 & $1 \mathrm{w}$ & medium & dk br & bl-br & clear & ray & conv & $\mathrm{m}-\mathrm{fl}$ \\
\hline 944 & I w & medium & $\mathrm{dk} \mathrm{br}$ & $\mathrm{dk} \mathrm{br}$ & clear & ray & conv & medium \\
\hline 945 & $\mathrm{l} w$ & coarse & black & bl-br & blood & ray & conv & $\mathrm{m}-\mathrm{fl}$ \\
\hline 946 & I w & coarse & $\mathrm{dk}$ br & bl-br & clear & zon & str & cp-m \\
\hline 947 & $1 \mathrm{w}$ & m-fine & dk br & bl-br & clear & hom & $c-c$ & cp-m \\
\hline 948 & i w & medium & $\mathrm{dk}$ br & bl-br & clear & hom & conv & $m-f$ \\
\hline 949 & $1 \mathrm{w}$ & medium & lt br & $\mathrm{bl}-\mathrm{gr}$ & clear & ray & str & medium \\
\hline 950 & I w & m-fine & $\mathrm{dk} b \mathrm{r}$. & $\mathrm{dk} \mathrm{br}$ & speck & ray & $c-c$ & m-f \\
\hline & $1 \mathrm{w}$ & coarse & dk br & bl-br & speck & ray & conv & medium \\
\hline & $1 \mathrm{w}$ & & & $\begin{array}{l}b]-b r \\
b l-b r\end{array}$ & clear & zon & cone & m-f \\
\hline & $1 \mathrm{w}$ & m-fine & dk br & bl-br & clear & hom & str & flar \\
\hline
\end{tabular}

\section{NOTES ON AL BU MUHAMMAD FEMALES}

On April 22, 1934, Miss Smeaton examined and measured three women at Sheikh Khazal's camp. Measurements of these women were taken at the request of one of the sheikhs.

No. 1004.-Birthplace, Amara. Although only about thirty years of age, she had been married six times but was childless. She was tattooed on the arms, back, and thighs. The color of the skin was darker than that of most Arabs. The hair had low waves, was medium in texture, and dark brown in color, possibly due to the application of henna. The color of the eyes was dark brown, the sclera clear, and the rim of the rayed iris slightly darker than the iris itself. The nasal profile was straight, with a depressed nasal tip and flaring nasal wings. No teeth had been lost and the occlusion was slightly over. The teeth were in very good condition.

No. 1005.-Birthplace, Al Uzair (Ezra's Tomb). Twenty to twenty-two years old. She had married at puberty, had two sons living and two dead, two daughters living and one dead. She also had two sisters living. Her chin, hands, feet, and body were elaborately tattooed. Her skin was very clear and light in color and her cheeks rosy. She used no powder. Her hair had low waves, was medium in texture, and dark brown in color. Her large eyes were green brown, with clear sclera and rayed iris with a darker rim. The 
nasal profile was slightly concave, the nasal tip medium in thickness, the nasal wings were medium, the nasal septum was inclined down. The general musculature was good; the square face and chin were fat, and the thighs heavy. Her health was consistently good.

No. 1006.-Birthplace, Ghuraib. About forty years old. She had borne seven children, four boys and three girls, all of whom were living. She had one brother and two sisters living, and one brother dead. She was tattooed on the brow, chin, and arms. The color of the skin was darker than the average. The hair had low waves, was coarse in texture, and dark brown in color. The eyes were dark brown with clear sclera and a rayed iris. The nasal profile was straight with medium wings.

Morphological Characters of Al bu Muhammad Females

\begin{tabular}{|c|c|c|c|c|c|c|c|c|}
\hline \multirow[b]{2}{*}{ No. } & \multicolumn{3}{|c|}{ HAIR } & \multicolumn{3}{|c|}{ WYES } & \multicolumn{2}{|c|}{ NOSE } \\
\hline & Form & Texture & Color & Color & Sclera & Iris & Profile & Wings \\
\hline $\begin{array}{l}1004 \\
1005 \\
1006\end{array}$ & $\begin{array}{l}l w \\
l w w \\
d w\end{array}$ & $\begin{array}{l}\text { medium } \\
\text { medium } \\
\text { coarse }\end{array}$ & $\begin{array}{l}\text { dk br } \\
\text { dk br } \\
\text { dk br }\end{array}$ & $\begin{array}{l}\mathrm{dk} \text { br } \\
\mathrm{gr}-\mathrm{br} \\
\mathrm{dk} \text { br }\end{array}$ & $\begin{array}{l}\text { clear } \\
\text { clear } \\
\text { clear }\end{array}$ & ray & $\begin{array}{l}\text { str } \\
\text { cone } \\
\text { str }\end{array}$ & $\begin{array}{l}\text { flar } \\
\text { medium } \\
\text { medium }\end{array}$ \\
\hline
\end{tabular}

\begin{tabular}{|c|c|c|c|c|c|c|c|c|c|c|c|c|}
\hline \multirow[b]{2}{*}{ No. } & \multicolumn{12}{|c|}{ Measurements } \\
\hline & Age & Stature & SH & I & B & $\mathbf{B}^{\prime}$ & $\boldsymbol{J}$ & go-go & GH & $\mathbf{G}^{\prime} \mathbf{H}$ & NH & NB \\
\hline 1004 & 30 & & & 182 & 143 & 96 & 130 & 87 & 108 & 72 & 51 & \\
\hline 1005 & 21 & 1568 & 805 & 176 & 151 & 102 & 131 & 92 & 104 & 70 & 52 & \\
\hline 1006 & 40 & 1579 & 810 & 186 & 146 & 102 & 129 & 89 & 107 & 69 & 46 & \\
\hline
\end{tabular}

\section{INDICES}

$\begin{array}{llllllllll}\text { No. EL EB RSH } & \text { B/L } & B^{\prime} / B & \text { GH } / J & G^{\prime} H / J & \text { NB/NH } & \text { EB } / E L & \text { go-go/J } & B^{\prime} / J\end{array}$

$\begin{array}{llllllllllll}1004 & 67 & 34 & \ldots & 78.6 & 67.1 & 83.1 & 55.4 & 70.6 & 55.2 & 66.9 & 73.9\end{array}$

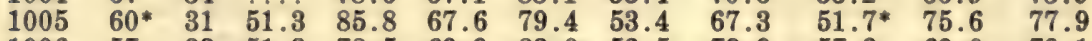

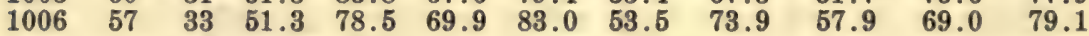

* Stretched slightly from heavy earrings.

\section{THE AL SAWAAD}

The Al Sawaad is a sedentary tribe scattered among the rice fields on the right bank of the Musharra Canal. Most of the tribesmen live in the marshes near Halfaya, which lies about twenty miles east of Amara. They tend cattle and cultivate the soil. As a result of their small numerical strength they are overshadowed in importance by the Bani Lam and the $\mathrm{Al}$ bu Muhammad.

The tribe is said to be descended from the Bani Himyar and is of the same origin as the Al Azairij. Some tribesmen claim that the name Sawaad is an incorrect interpretation of their original section, the Saad, so-called after one of their ancestors. 
Definite physical differences between the $\mathrm{Al}$ bu Muhammad and the Al Sawaad tribesmen were described by the Chief of Police in Amara. Since we had obtained anthropometric statistics on the former it was thought desirable to obtain a comparative series on a group of the Al Sawaad. With considerable difficulty and only through the co-operation of the local Chief of Police at Halfaya was it possible to induce fifty tribesmen to offer themselves for study. A superficial examination indicated that the $\mathrm{Al}$ Sawaad had lighter skin color than the Al bu Muhammad. The general shape of the face also appeared squarer, probably because of unusual development of the masseter muscles, which tended to increase the bigonial breadth.

Other observations, however, resembled closely those made on the $\mathrm{Al}$ bu Muhammad tribesmen. The hair was almost black in color and medium-coarse in texture, with low waves. The eyes were very dark brown, the sclera clear, and the greater number of the irides were either homogeneous or zoned. The nose was straight with medium-compressed wings although the medium-flaring element was present.

Vital Statistics.-It was impossible to obtain information on vital statistics but the parents of all these individuals were members of the Al Sawaad tribe, who lived in the Halfaya district.

Age.-The average age for the fifty men was 33.50 (range 20-64). About half of the individuals were between 20 and 29 years of age.

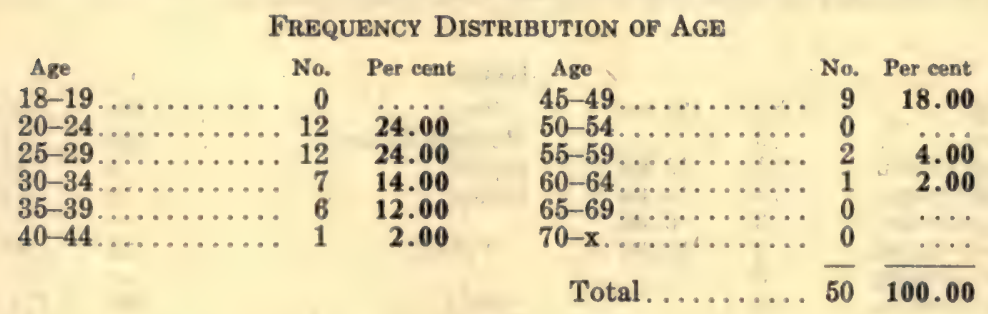

\section{MORPHOLOGICAL CHARACTERS OF AL SAWAAD TRIBESMEN}

Skin.-The color was lighter than that of the Al bu Muhammad tribesmen and about the same as that of the Arabs of the Kish area. Individually it ranged from that of a typical western European to dark brown. The skin color was slightly lighter than we had anticipated, since these tribesmen lead an agricultural and pastoral existence, which should tend to give the skin a weather-beaten appearance. 
Hair.- The hair color varied from dark brown to black, which I now think should have been classified as very dark brown. Twentythree hair samples were obtained.

\begin{tabular}{|c|c|c|c|c|c|}
\hline \multicolumn{6}{|c|}{ HAIR } \\
\hline Colot & No. & Per cent & Form & No. & Per cent \\
\hline Black. & 35 & 77.78 & Straight..... & 0 & $\therefore .$. \\
\hline Very dark brown...... & 0 & $\ldots$. & Very low waves.... & 0 & \\
\hline Dark brown............ & 2 & 4.44 & Low waves......... & 41 & 91.11 \\
\hline Brown ............. & 0 & .... & Deep waves. & 4 & 8.89 \\
\hline Reddish brown.. & 0 & $\ldots$. & Curly-frizzaly... & 0 & $\ldots \ldots$ \\
\hline Light brown ....... . & 0 & $\ldots \ldots$ & Woolly........... & 0 & $\ldots$. \\
\hline $\operatorname{Red} \ldots \ldots \ldots \ldots$ & 0 & & & & \\
\hline Black and gray..... & 5 & 11.11 & Total & 45 & 100.00 \\
\hline Light brown and gray.... & 0 & & Texture & No. & Per cent \\
\hline 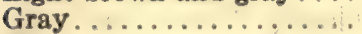 & 1 & 2.22 & Coarse ........... & 8 & 17.78 \\
\hline White $\ldots \ldots \ldots \ldots \ldots$ & 0 & $\ldots$ & Coarse-medium .... & 0 & \\
\hline Total. & 45 & 99.99 & Medium-fine $\cdots$ & 0 & 77.78 \\
\hline & & & Fine............ & 2 & 4.44 \\
\hline & & & Total ......... & 45 & 100.00 \\
\hline
\end{tabular}

Head hair was abundant. There appeared to be an average amount of face and body hair.

Eyes.-The majority of the eyes were dark brown or blue-brown. Eleven men (22 per cent) had either blue-brown or green-brown eyes. The blue and green elements indicate submerged blondism. The iris was either homogeneous or zoned. The six rayed irides could only have been recorded on the light eyes.

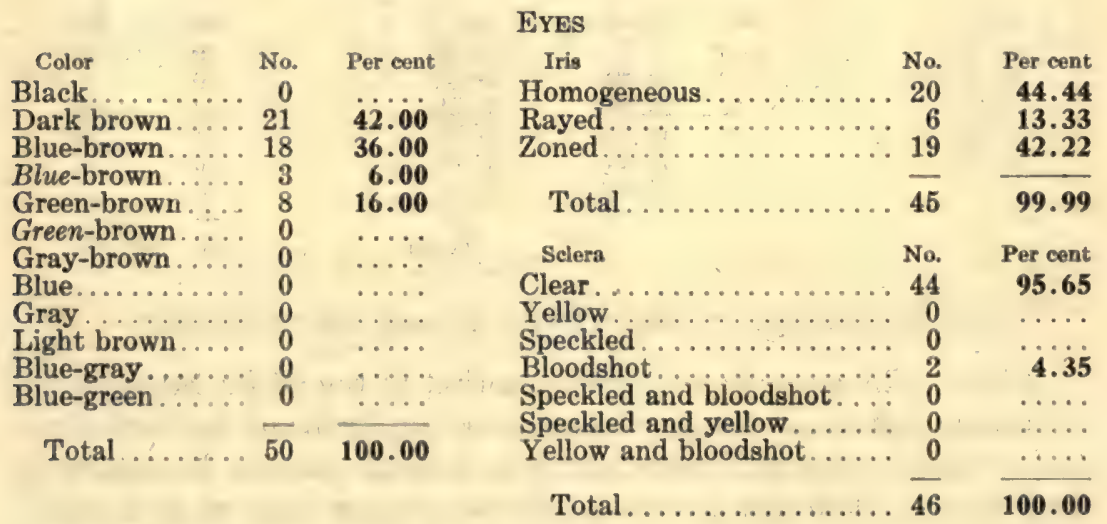

Nos. 957, 977, and 988 had blue-brown eyes. No. 984 was blind in the left eye; No. 985 was blind in the right eye as a result of a 
bad cataract; and No. 993 had a small cataract forming near the inner orbital margin of the right eye.

Nose.-The nasal profile was either straight or convex. The presence of alae recorded as flaring or flaring plus in two men indicates the presence of Negro blood. Four men had thicker than average nasal tip thickness and one man was recorded in the double plus group.

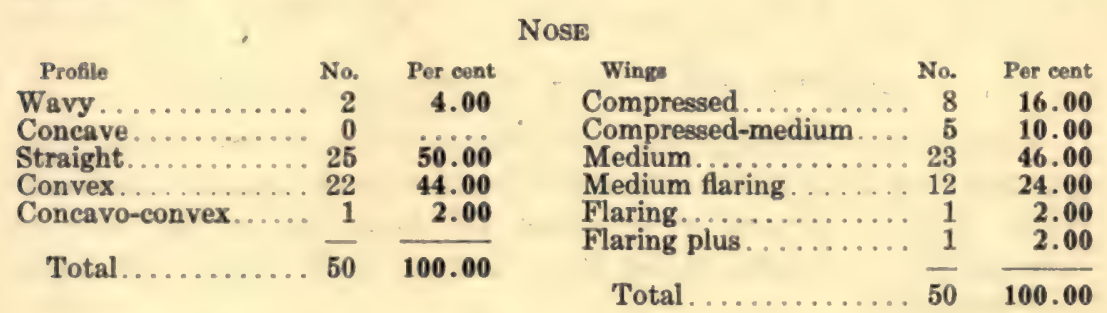

Mouth.-The lips varied in thickness from average (Nos. 966 and 972) to broad (Nos. 996 and 1000) and everted (No. 1003). No. 955 was a mouth-breather.

Teeth.-The occlusion was recorded as marked-over in every case. I now think this should have been slight-over instead of marked-over. The teeth were extra good in Nos. 954, 962, 963, 971-973, 977, 978, 996, and 1002. No. 968 had fair teeth, Nos. 956, 989, and 991 were in poor condition, while No. 957 had very poor teeth. No. 961 had good teeth but the front teeth were irregular.

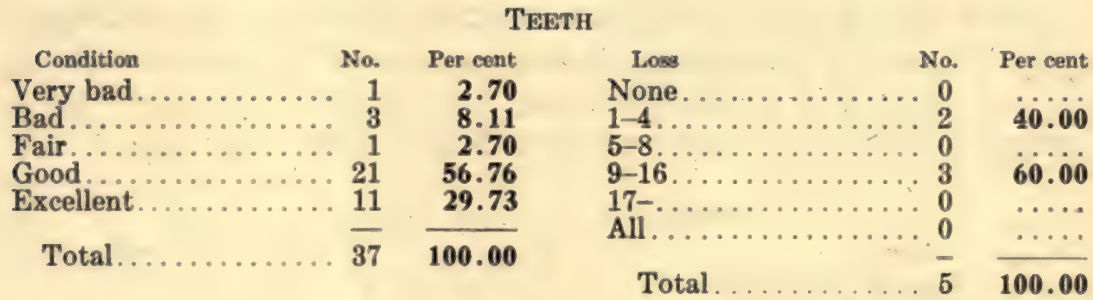

The general condition of the teeth was good or excellent.

Disease.-Nos. 959, 992, and 997 had smallpox scars.

Branding Scars.-No. 958 had a chawi (kawi) scar on his left wrist.

Tattooing.-Forty-five men ( 89.13 per cent) bore tattooed designs. Five men were recorded as having none. 
Musculature.-In general, this was either good or excellent.

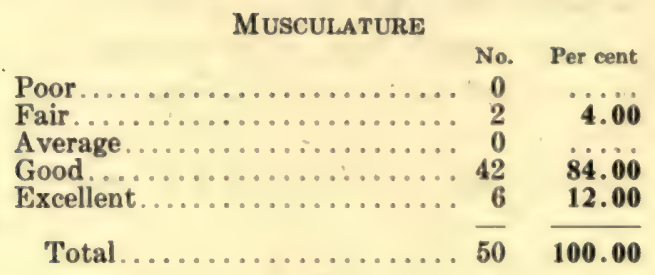

\section{STATISTICAL ANALYSES OF AL SAWAAD TRIBESMEN}

The size of this group (50) does not warrant statistical deductions, but the care with which the individuals were selected by the local police and the general composition of the group would seem to indicate that averages taken from a large series would not differ very markedly.

Stature and Sitting Height (Trunk Length).-Although the individuals in this group exhibit a relatively narrow age range within the young adult categories, the majority were medium in stature (160.0-170.0).

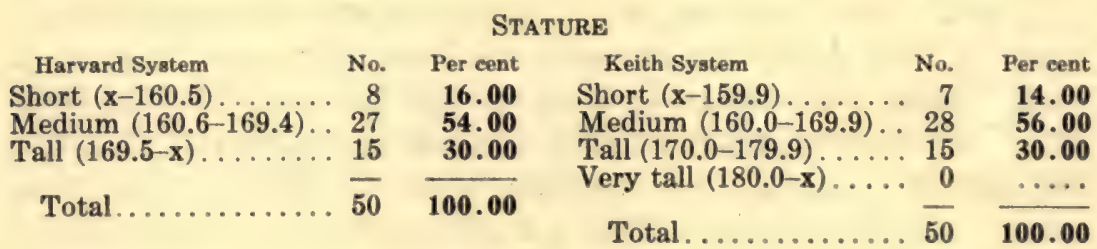

Both classificatory systems group the individuals almost identically. The wide range suggests the presence of two racial elements. It was surprising to find so many men over 169.5, since this is several points above the average for Southwestern Asia.

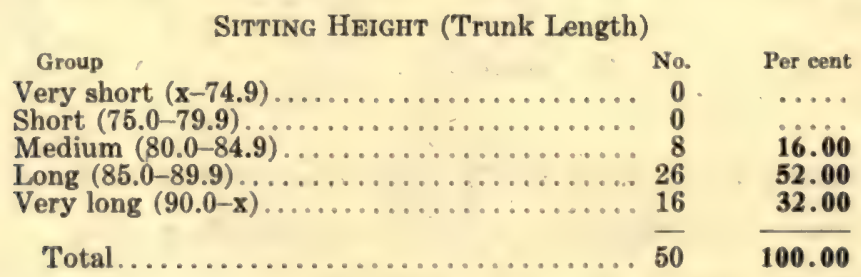

Head Measurements and Indices.-According to the Harvard system the majority (54 per cent) were mesocephalic with a tendency toward dolichocephaly. The additional divisions of the Keith 
system reveal a different frequency distribution. The ultradolichocephalic and ultrabrachycephalic elements indicate the presence of two racial stocks, a supposition already formulated on the basis of the almost equal percentages of straight and convex noses. The round-headed individuals are the most significant, since dolichocephaly and mesocephaly were anticipated in this area. At the same time, it must be noted that the ultrabrachycephalic Bakhtiaris live but 200 air miles from the eastern confines of the Hor al Hawiza.

\section{Minimum Frontal Diameter}

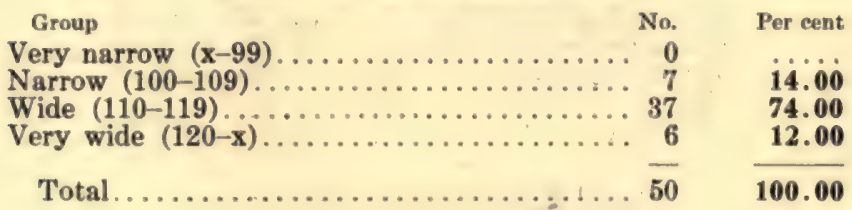

\section{HeAd BREADTh}

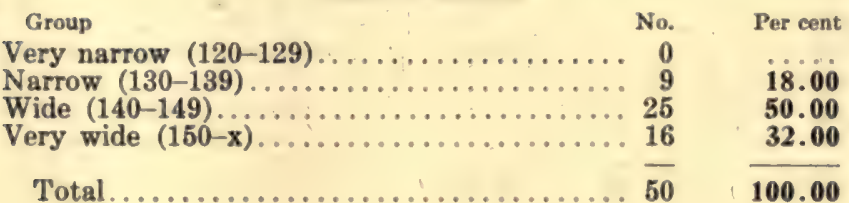

\section{Cepphalic Index}

\begin{tabular}{|c|c|c|c|c|c|}
\hline Keith System & No. & Per cent & Harvard Syatem & No. & Per cent \\
\hline $\begin{array}{l}\text { Ultradolichocephalic.... } \\
(x-70.0)\end{array}$ & 1 & 2.00 & $\begin{array}{l}\text { Dolichocephalic ........ } \\
(\mathrm{x}-76.5)\end{array}$ & 16 & 32.00 \\
\hline $\begin{array}{c}\text { Dolichocephalic....... } \\
(70.1-75.0)\end{array}$ & 11 & 22.00 & $\begin{array}{l}\text { Mesocephalic. . . . . . . } \\
\quad(76.6-82.5)\end{array}$ & 27 & $\mathbf{5 4 . 0 0}$ \\
\hline $\begin{array}{l}\text { Mesocephalic. . . . . . } \\
\text { (75.1-79.9) }\end{array}$ & 20 & 40.00 & $\begin{array}{l}\text { Brachycephalic......... } \\
\quad(82.6-\mathrm{x})\end{array}$ & 7 & 14.00 \\
\hline $\begin{array}{l}\text { Brachycephalic. . . . . } \\
\text { (80.0-84.9) } \\
\text { Ultrabrachycephalic. . }\end{array}$ & 15 & $\begin{array}{r}30.00 \\
6.00\end{array}$ & Total. & $\overline{50}$ & 100.00 \\
\hline
\end{tabular}
$(85.0-\mathrm{x})$

Total...........5 50

100.00

Facial and Nasal Measurements and Indices.-It is remarkable that despite seven men with short upper faces there were none in the short $(x-109)$ total facial height division. Both facial heights indicate the presence of two racial elements, since there is such wide dispersion. The index classifies half of the group into the leptoprosopic category, with only five men (10 per cent) in the euryprosopic division. 


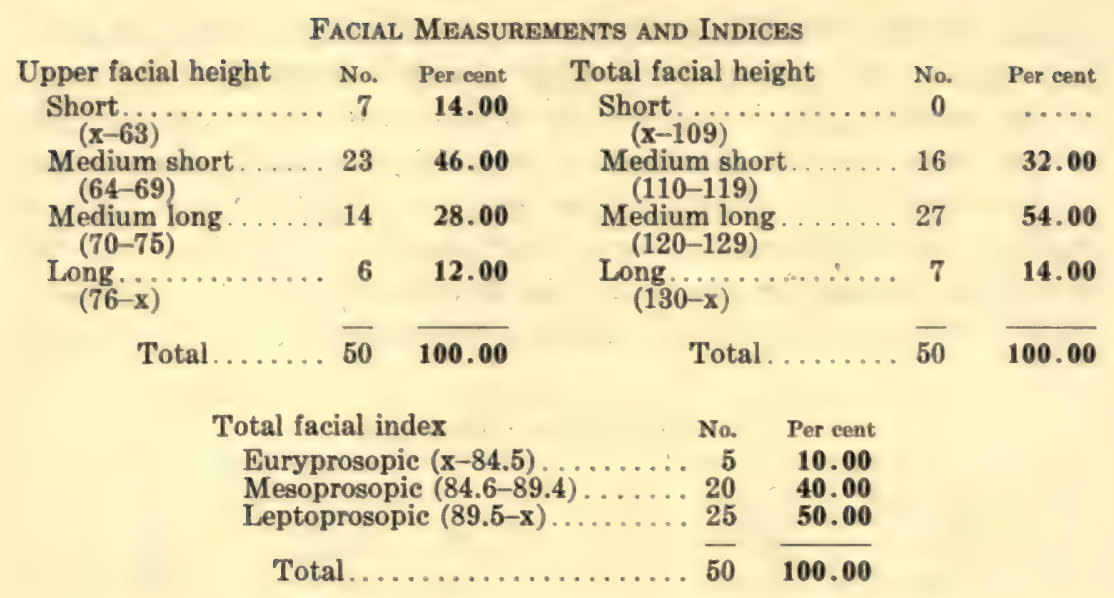

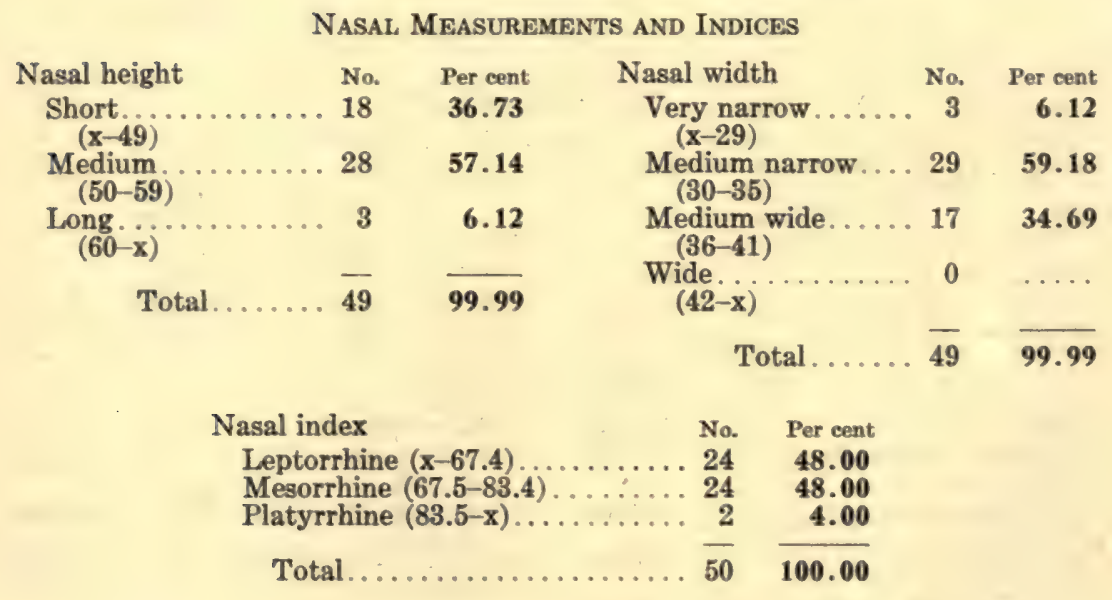

\section{SUMMARY}

In this young group of fifty $\mathrm{Al}$ Sawaad tribesmen the skin was medium dark brown; the hair was very dark brown with low waves and medium in texture; the eyes were dark brown or blue-brown, the iris was homogeneous or zoned, and the sclera were clear; the nose was either straight or convex with widely divergent alae; the teeth, musculature, and health were good or excellent; the stature was medium to tall; the trunk varied from medium to very long, which would account for the increase in stature; the head and forehead were wide; the face tended to be long; and the cephalic index was mesocephalic (78.30) with extreme variations. 
The Al Sawaad tribesmen therefore appear to be composed of both straight-nosed and convex-nosed dolichocephals together with a brachycephalic admixture. No significant deductions can be drawn, since the series of fifty tribesmen does not warrant them.

In order to furnish additional statistical data for comparison with those of my Iran Report and those in Part I, No. 1, of The Anthropology of Iraq, the following tables have been calculated:

Sitring Height (Trunk Length)

\begin{tabular}{|c|c|c|c|c|c|c|c|c|c|c|c|c|}
\hline \multirow[b]{2}{*}{ Standing height } & \multicolumn{2}{|c|}{$900-x$} & \multicolumn{2}{|c|}{$899-850$} & \multicolumn{2}{|c|}{$849-800$} & \multicolumn{2}{|c|}{$799-750$} & \multicolumn{2}{|c|}{$749-x$} & \multicolumn{2}{|c|}{ Totals } \\
\hline & No. & $\%$ & No. & $\%$ & No. & $\%$ & No. & $\%$ & No. & $\%$ & No. & $\%$ \\
\hline $1800-\mathrm{x} \ldots$ & 0 & & 0 & & 0 & $\ldots$ & 0 & & 0 & $\ldots$ & 0 & \\
\hline $1799-1700$. & 7 & 14.00 & 8 & 16.00 & 0 & & 0 & .. & 0 & $\ldots$ & 15 & 30. \\
\hline $1699-1600$. & 9 & 18.00 & 18 & 36.00 & 1 & 2.00 & 0 & & 0 & & 28 & 56. \\
\hline $\mathrm{x}-1599$ & 0 & $\ldots$. & 0 & $\ldots \ldots$ & 7 & 14.00 & 0 & & 0 & $\ldots$ & 7 & 14.00 \\
\hline
\end{tabular}

\section{Minimum Frontal Diameter}

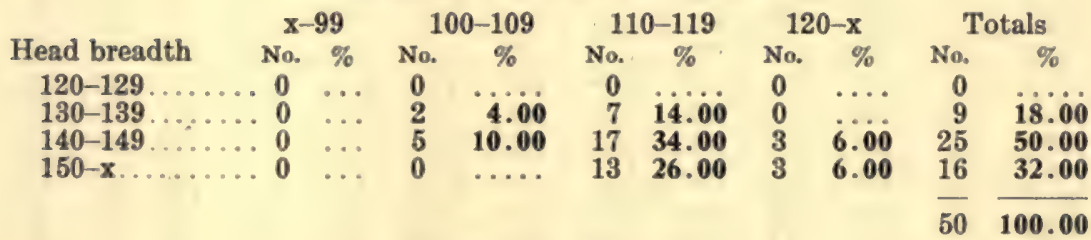

BIZYGoMATIC BREADTH

\begin{tabular}{|c|c|c|c|c|c|c|c|c|}
\hline \multirow{5}{*}{$\begin{array}{l}\text { Total facial length } \\
\quad x-114 \ldots \ldots \\
115-124 \ldots \ldots \\
125-x \ldots \ldots\end{array}$} & \multicolumn{2}{|c|}{$x-124$} & \multicolumn{2}{|c|}{$125-134$} & \multicolumn{2}{|c|}{$135-x$} & \multicolumn{2}{|c|}{ Totals } \\
\hline & No. & $\%$ & No. & $\%$ & No. & $\%$ & No. & $\%$ \\
\hline & .0 & & 1 & 2.00 & 1 & 2.00 & 2 & 4. \\
\hline & . 1 & 2.00 & 11 & 22. & 18 & 36.00 & 30 & 60. \\
\hline & 0 & , & 6 & 12.00 & 12 & 24.00 & 18 & 36. \\
\hline
\end{tabular}

UPPER FACIAL LENGTH

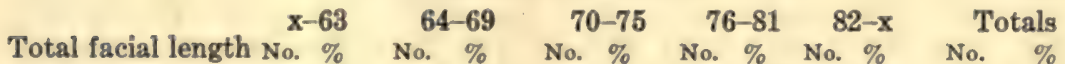

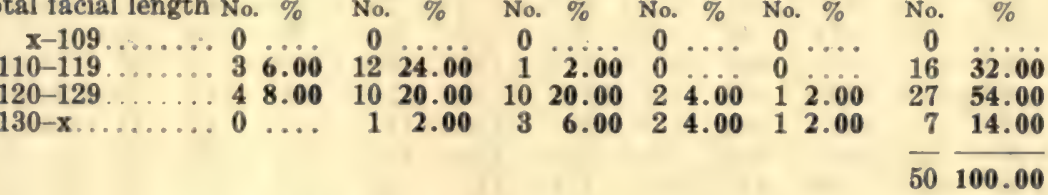

NASAL WidTh

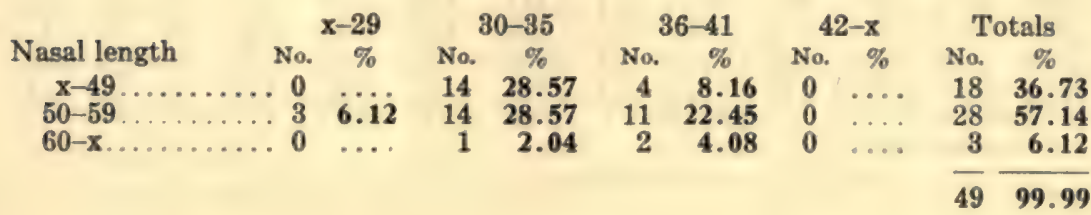


Measurements

\begin{tabular}{|c|c|c|c|c|c|c|c|c|c|c|c|c|}
\hline No. & Age & Stature & SH & L & B & $\mathrm{B}^{\prime}$ & J & go-go & GH & $\mathbf{G}^{\prime} \mathbf{H}$ & NH & NB \\
\hline 954 & 22 & 1755 & 929 & 200 & 148 & 110 & 143 & 113 & 134 & 74 & 53 & 35 \\
\hline 955 & 40 & 1565 & 840 & 185 & 148 & 118 & 137 & 114 & 119 & 67 & 50 & 30 \\
\hline 956 & 45 & 1640 & 906 & 190 & 164 & 113 & 140 & 105 & 127 & 87 & 63 & 33 \\
\hline 957 & 55 & 1657 & 856 & 188 & 144 & 105 & 135 & 111 & 121 & 73 & 53 & 37 \\
\hline 958 & 25 & 1640 & 872 & 179 & 147 & 115 & 132 & 105 & 126 & 77 & 58 & 32 \\
\hline 959 & 20 & 1660 & 861 & 179 & 138 & 115 & 134 & 107 & 115 & 60 & 41 & 32 \\
\hline 960 & 25 & 1530 & 829 & 185 & 135 & 111 & 128 & 98 & 119 & 65 & 44 & 30 \\
\hline 961 & 20 & 1680 & 875 & 187 & 153 & 113 & 132 & 105 & 124 & 66 & 44 & 30 \\
\hline 962 & 25 & 1691 & 856 & 191 & 144 & 122 & 143 & 106 & 122 & 63 & 46 & 35 \\
\hline 963 & 22 & 1634 & 875 & 182 & 152 & 114 & 135 & 104 & 116 & 65 & 50 & 36 \\
\hline 964 & 45 & 1730 & 895 & 187 & 147 & 108 & 138 & 107 & 121 & 67 & 50 & 34 \\
\hline 965 & 45 & 1683 & 848 & 187 & 146 & 113 & 134 & 108 & 134 & 75 & 56 & 29 \\
\hline 966 & 20 & 1663 & 908 & 182 & 133 & 105 & 126 & 103 & 123 & 68 & 52 & 27 \\
\hline 967 & 25 & 1663 & 900 & 182 & 148 & 117 & 138 & 107 & 120 & 64 & 45 & 31 \\
\hline 968 & 45 & 1701 & 878 & 187 & 146 & 108 & 121 & 103 & 123 & 68 & 49 & 32 \\
\hline 969 & 45 & 1640 & 910 & 185 & 151 & 118 & 135 & 108 & 125 & 72 & 55 & 35 \\
\hline 970 & 30 & 1674 & 870 & 194 & 144 & 109 & 130 & 110 & $142^{*}$ & 67 & 50 & 30 \\
\hline 971 & 25 & 1678 & 858 & 188 & 150 & 115 & 138 & 98 & 123 & 78 & 57 & 36 \\
\hline 972 & 22 & 1746 & 970 & 185 & 155 & 117 & 144 & 117 & 128 & 70 & 52 & 37 \\
\hline 973 & 30 & 1650 & 880 & 183 & 143 & 113 & 131 & 106 & 114 & 61 & 41 & 35 \\
\hline 974 & 33 & 1712 & 953 & 193 & 144 & 115 & 135 & 108 & 126 & 66 & 48 & 33 \\
\hline 975 & 35 & 1778 & 949 & 193 & 149 & 119 & 143 & 114 & 120 & 65 & $45 \ddagger$ & $42 \ddagger$ \\
\hline 976 & 20 & 1585 & 837 & 185 & 154 & 111 & 136 & 108 & 115 & 61 & 45 & 34 \\
\hline 977 & 25 & 1745 & 898 & 187 & 152 & 118 & 140 & 116 & 121 & 75 & 60 & 36 \\
\hline 978 & 25 & 1644 & 895 & 190 & 142 & 114 & 130 & 107 & 128 & 70 & 53 & 34 \\
\hline 979 & 25 & 1637 & 865 & 183 & 133 & 113 & 130 & 114 & 115 & 65 & 49 & 35 \\
\hline 980 & 25 & 1710 & 895 & 185 & 155 & 118 & 142 & 116 & 116 & 66 & 50 & 35 \\
\hline 981 & 35 & 1683 & 929 & 189 & 150 & 111 & 137 & 107 & 113 & 66 & 45 & 35 \\
\hline 982 & 30 & 1590 & 845 & 179 & 153 & 115 & 139 & 105 & 115 & 66 & 46 & 37 \\
\hline 983 & 20 & 1796 & 922 & 194 & 143 & 114 & 133 & 111 & 115 & 68 & 50 & 37 \\
\hline 984 & 35 & 1711 & 880 & 180 & 140 & 108 & 130 & 97 & 119 & 68 & 50 & 36 \\
\hline 985 & 45 & 1745 & 920 & 187 & 148 & 119 & 138 & 109 & 136 & 79 & 53 & 31 \\
\hline 986 & 23 & 1610 & 900 & 177 & 136 & 115 & 133 & 102 & 117 & 68 & 51 & 36 \\
\hline 987 & 23 & 1690 & 892 & 186 & 161 & 120 & 140 & 111 & 127 & 63 & 44 & 35 \\
\hline 988 & 60 & 1740 & 895 & 198 & 138 & 111 & 133 & 106 & 135 & 86 & 64 & 36 \\
\hline 989 & 55 & 1602 & 867 & 181 & 136 & 105 & 130 & 103 & 131 & 75 & 49 & 33 \\
\hline 990 & 45 & 1722 & 878 & 199 & 148 & 117 & 138 & 114 & 127 & 63 & 49 & 38 \\
\hline 991 & 45 & 1655 & 885 & 197 & 148 & 118 & 139 & 115 & 123 & 74 & 55 & 38 \\
\hline 992 & 35 & 1580 & 837 & 176 & 139 & 114 & 126 & 103 & 118 & 67 & 49 & 33 \\
\hline 993 & 34 & 1614 & 868 & 186 & 149 & 118 & 137 & 105 & 124 & 61 & 56 & 37 \\
\hline 994 & 25 & 1574 & 848 & 190 & 147 & 111 & 131 & 110 & 115 & 71 & 52 & 33 \\
\hline 995 & 25 & 1666 & 878 & 184 & 139 & 113 & 134 & 106 & 124 & 73 & 58 & 36 \\
\hline 996 & 45 & 1675 & 908 & 185 & 152 & 121 & 142 & 106 & 128 & 71 & 53 & 31 \\
\hline 997 & 35 & 1735 & 895 & 195 & 160 & 124 & 148 & 108 & 126 & 67 & 48 & 36 \\
\hline 998 & 33 & 1575 & 846 & 188 & 144 & 114 & 137 & 105 & 122 & 66 & 48 & 37 \\
\hline 999 & 20 & 1667 & 865 & 184 & 143 & 115 & 137 & 104 & 128 & 74 & 54 & 33 \\
\hline 1000 & 35 & 1680 & 907 & 193 & 151 & 114 & 141 & 120 & 122 & 68 & 55 & 38 \\
\hline 1001 & 20 & 1676 & 870 & 193 & 155 & 118 & 139 & 108 & 119 & 68 & 53 & 33 \\
\hline 1002 & 25 & 1720 & 915 & 178 & 145 & 120 & 139 & 104 & 121 & 71 & 53 & 26 \\
\hline 1003 & 30 & 1670 & 910 & 197 & 144 & 120 & 140 & 104 & 130 & 76 & 54 & 31 \\
\hline
\end{tabular}


INDICES

\begin{tabular}{|c|c|c|c|c|c|c|c|c|c|c|c|}
\hline No. & EL & EB & RASH & B/L & $\mathbf{B}^{\prime} / \mathbf{B}$ & GH/J & $G^{\prime} \mathrm{H} / \mathrm{J}$ & $\mathrm{NB} / \mathrm{NH}$ & EB/EL & go-go/J & $\mathbf{B}^{\prime} / \mathbf{J}$ \\
\hline 954 & 55 & 32 & 52.9 & 74.0 & 74.3 & 93.7 & 51.7 & 66.0 & 65.4 & 79.0 & 76.9 \\
\hline 955 & & & 53.6 & 80.0 & 79.7 & 86.8 & 48.9 & 60.0 & & 83.2 & 86.1 \\
\hline 956 & 58 & 31 & 55.2 & 86.3 & 68.9 & 90.7 & 62.1 & 52.4 & 53.4 & 75.0 & 80.7 \\
\hline 957 & 64 & 33 & 51.6 & 76.6 & 72.9 & 96.8 & 58.4 & 69.8 & 51.6 & 88.8 & 84.0 \\
\hline 958 & 50 & 28 & 53.1 & 82.1 & 78.2 & 95.7 & 58.4 & 55.1 & 64.0 & 79.5 & 87.1 \\
\hline 959 & 52 & 30 & 51.8 & 77.1 & 83.3 & 85.8 & 44.7 & 78.0 & 57.7 & 79.8 & 85.8 \\
\hline 960 & 62 & 38 & 54.2 & 72.9 & 82.2 & 92.9 & 50.8 & 68.2 & 61.3 & & 86.7 \\
\hline 961 & 56 & 30 & 52.1 & 81.8 & 73.8 & 93.9 & 50.0 & 68.1 & 53. & 79. & 85.6 \\
\hline 962 & 52 & 30 & 50.6 & 75.4 & 84.7 & 85.3 & 44.0 & 76.1 & 57.7 & 74.1 & 85.3 \\
\hline 963 & 62 & 33 & 53.5 & 83.5 & 75.0 & 85.9 & 48.1 & 72.0 & 53.2 & 77.0 & 84.4 \\
\hline 964 & 58 & 35 & 51.7 & 78.6 & 73.4 & 87.7 & 48.5 & 68.0 & 61.7 & 77.5 & 78.2 \\
\hline 965 & 60 & 37 & 50.4 & 78.1 & 77.4 & 100.0 & 55.9 & 51.7 & 61.7 & 80.6 & 84.3 \\
\hline 966 & 56 & 36 & 54.6 & 73.1 & 78.9 & 97.6 & & & & & \\
\hline 967 & 55 & 30 & 54.1 & 81.3 & 79.0 & 86.9 & 46.4 & 68.9 & 54.5 & 77.5 & 84.8 \\
\hline 968 & 66 & 37 & 51.6 & 78.3 & 73.9 & 93.9 & 51.9 & 65.3 & 56.1 & 78.6 & 82.4 \\
\hline 969 & 55 & 33 & 55.4 & 81.6 & 78.1 & 92.6 & 53.3 & 63.6 & 60.0 & 80.0 & 87.4 \\
\hline 970 & 57 & 31 & 51.9 & 74.2 & 75.7 & $109.2^{*}$ & 51.5 & 60.0 & 54.4 & 84.6 & 83.8 \\
\hline 971 & 55 & 35 & 51.1 & 79.7 & 76.6 & 89.1 & 56.5 & 63.1 & 63.6 & 71.0 & 83.3 \\
\hline 972 & 51 & 34 & 55.5 & 83.8 & 75.4 & 88.8 & 48.6 & 71.1 & 66. & 81.2 & 81.2 \\
\hline 973 & 57 & 30 & 53.3 & 78.1 & 79 & 87.0 & 46.6 & & & .9 & 86.2 \\
\hline 974 & 61 & 40 & 55.6 & 74.6 & 79.8 & 93.3 & 48.8 & 68.7 & 65.5 & 80.0 & 85.2 \\
\hline 975 & 56 & 35 & 53.3 & 77.2 & 79.8 & 83.9 & 45.4 & $93.3 \ddagger$ & 62.5 & 79.7 & 83.2 \\
\hline 976 & 52 & 31 & 52.8 & 83.2 & 72.1 & 84.5 & 44.8 & 75.5 & 59.6 & 79.4 & 81.6 \\
\hline 977 & 62 & 34 & 51.4 & 81.2 & 77.6 & 86.4 & 53.5 & 60.0 & 54.8 & 82.8 & 84.3 \\
\hline 978 & 60 & 30 & 54.4 & 74.7 & 80.3 & 98.5 & & & & 3 & 87.7 \\
\hline 979 & 55 & 35 & 52.8 & 72. & & & 0.0 & & & & 86.9 \\
\hline 980 & 55 & 35 & 52.3 & 83.8 & 76.1 & 81.7 & 46.4 & 70.0 & 63.6 & 81.7 & 83.1 \\
\hline 981 & 55 & 32 & 55.2 & 79.3 & 74.0 & 82.4 & 48.2 & 77.7 & 58.2 & 78.1 & 81.0 \\
\hline 982 & 62 & 35 & 53.1 & 85.4 & 75.1 & 82.7 & 47.5 & 80.4 & 56.4 & 75.5 & 82.7 \\
\hline 983 & 57 & 33 & 51.3 & 73.7 & 79.7 & 86.4 & 51.1 & 74.0 & 57.9 & 83.4 & 85.7 \\
\hline 984 & 56 & 28 & 51.4 & 77.7 & 77.1 & 91.5 & 52.3 & 72.0 & 50.0 & 74.6 & 83.1 \\
\hline 985 & 64 & 37 & 52.7 & 79.1 & & 98.5 & & & & & 86.2 \\
\hline 986 & 53 & 30 & 55.9 & 76 & 84 & 87.9 & & & & & 86.4 \\
\hline 987 & 53 & 34 & 52.8 & 86.5 & 74.5 & 90.7 & 45.0 & 79.5 & 64.1 & 79.3 & 85.7 \\
\hline 988 & 70 & 38 & 51.4 & 69.6 & 80.4 & 101.5 & 64.6 & 56.2 & 54.3 & 79.7 & 83.4 \\
\hline 989 & 61 & 36 & 54.1 & 75.1 & 77.1 & 100.8 & 57.7 & 67.3 & 59.0 & 79.2 & 80.8 \\
\hline 990 & 64 & 35 & 50.9 & 74.3 & 79.0 & 92.0 & 45.6 & 77.5 & 54.6 & 82.6 & 84.7 \\
\hline 991 & 67 & 37 & 53.4 & 75.1 & 79.7 & 88.5 & 53.2 & 69.0 & 51. & 82.7 & 84.9 \\
\hline 992 & 54 & 30 & 52.9 & 78.9 & 82 & 93.6 & 53.2 & & & & 90.4 \\
\hline 993 & 57 & 32 & 53.7 & 80.1 & 79.1 & 90.5 & 44.5 & & & & 86.1 \\
\hline 994 & 61 & 36 & 53.8 & 77.4 & 75.5 & 87.8 & 54.2 & 63.4 & 59.0 & 3.9 & 84.7 \\
\hline 995 & 57 & 31 & 52.7 & 75.5 & 81.3 & 92.5 & 54.4 & 62.1 & 54.4 & 79.1 & 84.3 \\
\hline 996 & 65 & 40 & 54.2 & 82.1 & 79.6 & 90.1 & 50.0 & 58.5 & 61.5 & 74.6 & 85.2 \\
\hline 997 & 66 & 38 & 51.5 & 82.0 & 77.5 & 85.1 & 45.3 & 75.0 & 57.5 & 72.9 & 83.7 \\
\hline 998 & 51 & 33 & 53.7 & 76.6 & & 89.0 & 48.1 & 77.1 & & 76.6 & 83.2 \\
\hline 999 & 53 & 32 & 51.8 & 72.3 & 80.4 & 93.4 & 54.0 & 61.1 & 60.4 & 75.9 & 83.9 \\
\hline 1000 & 66 & 37 & 53.9 & 78.2 & 75.5 & 86.5 & 48.2 & 69.1 & 56.1 & 85.1 & 80.8 \\
\hline 1001 & 58 & 32 & 51.9 & 80.3 & 76.1 & 85.6 & 48.9 & 62.2 & 60.3 & 77.7 & 84.9 \\
\hline 1002 & 54 & 32 & 53.2 & 81.4 & 82.8 & 87.0 & 51.1 & 49.1 & 59.2 & 74.8 & 86.3 \\
\hline 03 & & 34 & 54.4 & 73.1 & 83.3 & 92.8 & 54.3 & 57.4 & 50.7 & 74.3 & 85.7 \\
\hline
\end{tabular}

* Probably too high.

$\ddagger$ Should be omitted because the noee was broken. 
Morphological Characters of Al SawaAd Tribesmen

\begin{tabular}{|c|c|c|c|c|c|c|c|c|}
\hline \multirow[b]{2}{*}{ No. } & \multicolumn{3}{|c|}{ HAIR } & \multicolumn{3}{|c|}{ EYks } & \multicolumn{2}{|c|}{ Noss: } \\
\hline & Form & Texture & Color & Color & Selera & Iris & Profile & Wings \\
\hline 954 & $1 \mathrm{w}$ & medium & black & dk br & $\therefore \ldots$ & & str & cp-m \\
\hline $955^{*}$ & & & & dk br & clear & hom & conv & medium \\
\hline 956 & $1 \mathrm{w}$ & medium & blk, gray & bl-br & clear & hom & str & medium \\
\hline & $\ldots$ & $\ldots \ldots$ & & $b l$-br & clear & zon & conv & m-fl \\
\hline 958 & l w & medium & black & $\mathrm{dk}$ br & clear & hom & conv & medium \\
\hline 959 & $1 \mathrm{w}$ & medium & black & $\mathrm{dk}$ br & clear & hom & $c-c$ & flar \\
\hline 960 & $1 \mathrm{w}$ & medium & black & bl-br & clear & zon & str & medium \\
\hline 961 & $1 \mathrm{w}$ & medium & black & gr-br & clear & ray & conv & medium \\
\hline 962 & $1 \mathrm{w}$ & medium & dk br & $\mathrm{dk}$ br & clear & hom & str & medium \\
\hline 963 & $1 \mathrm{w}$ & medium & black & $\mathrm{dk} b r$ & clear & hom & conv & medium \\
\hline 964 & $1 \mathrm{w}$ & medium & blk, gray & dk br & & $\ldots$ & conv & medium \\
\hline 965 & I w & coarse & blk, gray & gr-br & clear & zon & conv & comp \\
\hline 966 & $\mathrm{~d} w$ & coarse & black & gr-br & clear & zon & conv & comp \\
\hline 967 & $1 \mathrm{w}$ & medium & black & dk br & clear & ray & str & $m-f i$ \\
\hline 968 & $1 \mathrm{w}$ & medium & br, gray & bl-br & clear & hom & conv & comp \\
\hline 969 & I $w$ & medium & br, gray & bl-br & clear & zon & str & medium \\
\hline 970 & $1 \mathrm{w}$ & coarse & black & bl-br & clear & hom & str & comp \\
\hline 971 & $1 \mathrm{w}$ & medium & black & bl-br & clear & hom & str & medium \\
\hline 972 & d w & medium & black & gr-br & clear & ray & wavy & m-fl \\
\hline 973 & $1 \mathrm{w}$ & medium & black & dk br & clear & hom & str & medium \\
\hline 974 & $d w$ & medium & black & $g r-b r$ & clear & zon & str & medium \\
\hline 975 & $1 \mathrm{w}$ & medium & black & dk br & clear & hom & str & flar. \\
\hline 976 & $d w$ & medium & dk br & dk br & clear & hom & str & cp-m \\
\hline 977 & $1 \mathrm{w}$ & medium & black & $b l-b r$ & $\because \cdots$ & $\therefore$ & str & medium \\
\hline 978 & $1 \mathrm{w}$ & coarse & black & bl-br & clear & hom & str & medium \\
\hline 979 & $1 \mathrm{w}$ & coarse & black & bl-br & clear & zon & str & $m-f l$ \\
\hline 980 & $1 \mathrm{w}$ & fine & black & bl-br & clear & zon & str & medium \\
\hline 981 & $1 \mathrm{w}$ & medium & black & dk br & clear & zon & conv & medium \\
\hline 982 & $1 \mathrm{w}$ & coarse & black & dk br & clear & zon & conv & medium \\
\hline 983 & $1 \mathrm{w}$ & medium & black & dk br & clear & zon & conv & m-fl \\
\hline 984 & $\mathrm{lw}$ & medium & blk, gray & dk br & clear & zon & conv & comp \\
\hline 985 & $1 \mathrm{w}$ & fine & blk, gray & bl-br & clear & ray & wavy & medium \\
\hline 986 & $1 \mathrm{w}$ & medium & black & bl-br & clear & zon & str - & m-fl \\
\hline 987 & $1 \mathrm{w}$ & medium & black & $\mathrm{dk}$ br & clear & zon & str & medium \\
\hline 988 & $1 \mathrm{w}$ & medium & gray & $b l-b r$ & blood & ray & conv & m-flar \\
\hline $989^{*}$ & $\ldots$ & $\ldots \ldots \ldots$ & $\ldots$ & bl-br & clear & hom & conv & cp-m \\
\hline $990^{*}$ & $\cdots$ & $\therefore \ldots \ldots$ & & dk br & clear & hom & conv & medium \\
\hline 991 & $1 \mathrm{w}$ & coarse & black & dk br & clear & zon & conv & m-fl \\
\hline 992 & I w & medium & black & $d k$ br & clear & zon & str & medium \\
\hline 993 & $1 \mathrm{w}$ & medium & black & bl-br & blood & $\ldots$ & str & comp \\
\hline 994 & $1 \mathrm{w}$ & medium & black & $\mathrm{dk}$ br & clear & zon & conv & m-fl \\
\hline 995 & $1 \mathrm{w}$ & medium & black & $g r-b r$ & clear & hom & str & medium \\
\hline 996 & $1 \mathrm{w}$ & medium & black & bl-br & & $\ldots$ & str & $\mathrm{cp}-\mathrm{m}$ \\
\hline 997 & $1 \mathrm{w}$ & medium & black & $\mathrm{dk}$ br & clear & zon & str & comp \\
\hline 998 & $1 \mathrm{w}$ & medium & black & bl-br & clear & hom & conv & m-fl \\
\hline 999 & $1 \mathrm{w}$ & coarse & black & gr-br & clear & ray & str & medium \\
\hline 1000 & l w & medium & black & bl-br & clear & hom & conv & $m-f l$ \\
\hline 1001 & l w & medium & black & gr-br & clear & zon & conv & $m-f l$ \\
\hline $002^{*}$ & $\therefore$. & & & bl-br & clear & hom & str & $\mathrm{cp-m}$ \\
\hline 1003 & $1 \mathrm{w}$ & medium & black & bl-br & clear & hom & conv & comp \\
\hline
\end{tabular}




\section{Measurements and Indices of Al SaWaAd Tribesmen}

\begin{tabular}{|c|c|c|c|c|c|}
\hline Measurements & No. & Range & Mean & S.D. & c.v. \\
\hline Age $\ldots . . .$. & 50 & $20-64$ & $33.50 \pm 1.03$ & $10.80 \pm 0.73$ & $32.24 \pm 2.17$ \\
\hline Stature. & 50 & $152-181$ & $166.98 \pm 0.55$ & $5.73 \pm 0.39$ & $3.43 \pm 0.23$ \\
\hline Sitting height. & 50 & $81-98$ & $88.78 \pm 0.30$ & $3.15 \pm 0.21$ & $3.55 \pm 0.24$ \\
\hline Head length. . & 50 & $176-202$ & $187.26 \pm 0.56$ & $5.82 \pm 0.39$ & $3.11 \pm 0.21$ \\
\hline Head breadth. & 50 & $126-164$ & $145.96 \pm 0.65$ & $6.81 \pm 0.46$ & $4.67 \pm 0.31$ \\
\hline Minimum frontal & & & & & \\
\hline diameter. . ........ & 50 & 105-124 & $114.66 \pm 0.41$ & $4.32 \pm 0.29$ & $3.77 \pm 0.25$ \\
\hline Bizygomatic diameter & 50 & $120-149$ & $135.90 \pm 0.47$ & $4.90 \pm 0.33$ & $3.61 \pm 0.24$ \\
\hline Bigonial diameter.... & 50 & $94-121$ & $107.74 \pm 0.48$ & 0.34 & $4.68 \pm 0.32$ \\
\hline Total facial height... & 50 & $110-144$ & $123.10 \pm 0.61$ & $6.35 \pm 0.43$ & $5.16 \pm 0.35$ \\
\hline Upper facial height.... & 50 & $60-89$ & $69.50 \pm 0.55$ & 0.39 & $8.27 \pm 0.56$ \\
\hline Nasal height....... & 49 & $40-67$ & $51.38 \pm 0.47$ & $4.92 \pm 0.34$ & $9.58 \pm 0.65$ \\
\hline Nasal breadth. & 49 & $25-39$ & $33.71 \pm 0.30$ & 0.21 & $9.17 \pm 0.62$ \\
\hline Ear length. & 50 & $48-75$ & .53 & 0.37 & 9.44 \\
\hline Ear breadth. & 49 & $26-40$ & $54 \pm 0.30$ & $3.12 \pm 0.21$ & $9.30 \pm 0.57$ \\
\hline Indie & & & & & \\
\hline Relative sitting height. & 50 & $50-57$ & $53.06 \pm 0.15$ & $1.60 \pm 0.11$ & $3.02 \pm 0.20$ \\
\hline & 50 & & & & \\
\hline Fronto-parietal. & 50 & $69-86$ & $77.86 \pm 0.32$ & $3.39 \pm 0.23$ & $4.35 \pm 0.29$ \\
\hline Zygo-f & 50 & & & & $2.95 \pm 0.20$ \\
\hline Zygo-gc & 50 & $69-\varepsilon+r-1$ & $79.24 \pm 0.35$ & $3.63 \pm 0.24$ & $4.58 \pm 0.31$ \\
\hline Total facial. & 50 & 80-109 & $90.40 \pm 0.52$ & & $6.08 \pm 0.41$ \\
\hline Upper facial. & 50 & $43-66$ & $50.66 \pm 0.47$ & $4.89 \pm 0.33$ & $9.65 \pm 0.65$ \\
\hline Nasal. . . . . . & 49 & & $67.06 \pm 0.56$ & $8.24 \pm 0.56$ & $12.29 \pm 0.84$ \\
\hline Ear $\ldots \ldots \ldots$ & 49 & $50-66$ & $50.02 \pm 0.43$ & $4.48 \pm 0.31$ & $8.96 \pm 0.61$ \\
\hline
\end{tabular}

\section{The SUBBA}

Lady Drower (see Bibliography) has published a very detailed account of the history, religion, customs, folklore, and magic of the Mandeans or Subba of Iraq and Iran. The reader is referred to this standard work and to the references listed by Curzon (vol. 2, p. 306, footnote 1).

In 1892, Curzon (vol. 2, p. 305) wrote: “At Dizful, at Shushter, at Hawizeh, and at Mohammerah, are still to be found a few relics of the interesting and obscure community known as the Sabians, frequently miscalled the Christians of St. John. In former days the sectaries of this faith were very numerous in Mesopotamia; and in the seventeenth century Petis de la Croix reported 10,000 in Busrah alone. Even in 1840 Layard found 300 to 400 families in Shushter; but in 1877 Schindler only heard of 50 families on Persian soil, and of not more than 500 families elsewhere."

Birthplaces.-The following individuals gave these places of birth: Amara (Nos. 2888-2919), Halfaya (2927-2964), Majar near Amara (No. 2965), Qala Salih (Nos. 2966-2978), and the Chahala district (Nos. 2920-2926). No. 2979 had no birthplace recorded although it was probably Qala Salih. 
Vital Statistics.-Unreliable as these figures must be, the general trends are probably correct. Since the Subba are a deeply religious group with whom honesty is a moving, guiding principle, unusual credence can be placed in these figures.

\section{Vital STATISTICS}

\begin{tabular}{|c|c|c|c|c|}
\hline Brothers & Per cent & Sisters & No. & Per cent \\
\hline 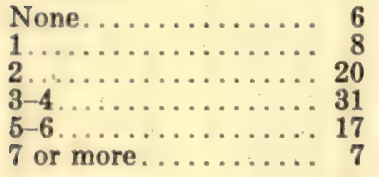 & $\begin{array}{r}6.74 \\
8.99 \\
22.47 \\
34.83 \\
19.10 \\
7.87\end{array}$ & 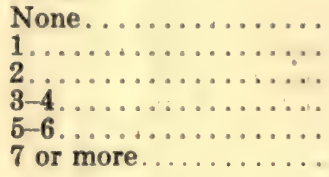 & $\begin{array}{r}11 \\
17 \\
13 \\
32 \\
9 \\
7\end{array}$ & $\begin{array}{r}12.36 \\
19.10 \\
14.61 \\
35.96 \\
10.11 \\
7.87\end{array}$ \\
\hline Total......... & 100.00 & Total .............. & 89 & 100.01 \\
\hline Sons & Per cent & Daughters & No. & Per cent \\
\hline 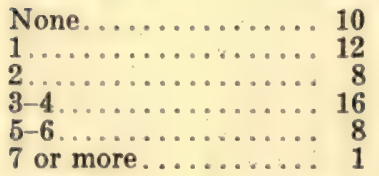 & $\begin{array}{r}18.18 \\
21.82 \\
14.55 \\
29.09 \\
14.55 \\
1.82\end{array}$ & 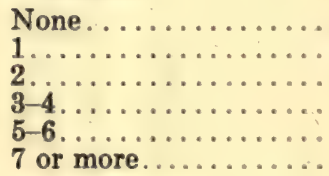 & $\begin{array}{r}9 \\
17 \\
8 \\
17 \\
1 \\
3\end{array}$ & $\begin{array}{r}16.36 \\
30.91 \\
14.55 \\
30.91 \\
1.82 \\
5.45\end{array}$ \\
\hline Total......... 55 & 100.01 & Total .............. & 55 & 100.00 \\
\hline
\end{tabular}

The number of brothers and sisters recorded indicate very large families. When the age groups are taken into account, namely that 27.78 per cent were twenty-four years of age or below, the number of children is also large.

The reason for these unusually high figures in an Iraqi group is almost certainly correlated with a low incidence of infant mortality, the result of ritual ablutions and cleanliness.

No. 2898 is the son of No. 2888 . No. 2897 is the brother of No. 2892.

Age.-The mean for ninety Subba was 36.70. About half of the group were from 20-34 years of age. Nos. 2974 and 2975 were omitted.

\section{Frequency Distribution of Age}

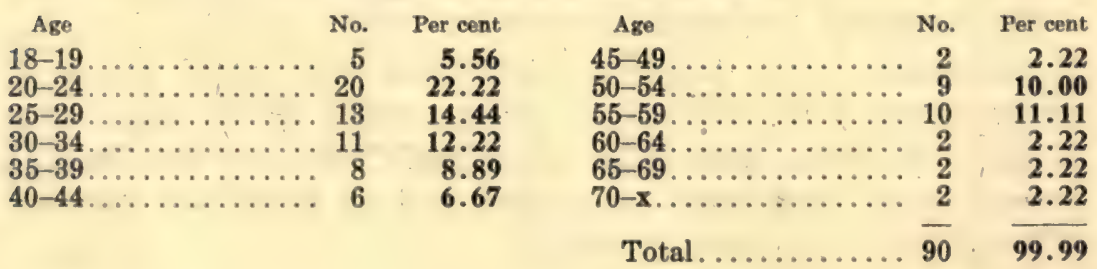




\section{MORPHOLOGICAL CHARACTERS OF SUBBA}

Skin.-The color varied from medium light (northern European) to light tawny brown. In general, the Subba were considerably lighter in skin color than the Arabs of central and southern Iraq. Among those whom we were able to observe, the exposed parts of the body were darker than the unexposed. Individuals who were bald and whose heads were always covered by a kaffyah were often as light in pigmentation as northern Europeans. There were few examples of the weather-beaten skin that is characteristic of the $\mathrm{Al}$ bu Muhammad tribesmen and the Beduins of northwestern Iraq.

Hair.-The Subba are distinguished from all other peoples in Iraq by the quantity of head, face, and body hair. The color varied from dark brown to black. It is probable, however, that the majority of the individuals recorded with black hair should have been classified in the very dark brown category. The rufous element was not caused by the application of henna. No Subbi possessed light hair. Gray hair was seldom noticed before the fortieth year, but in late middle age grayness was as a rule advanced.

Beards were very much in fashion, the result of religious ritual. No. 2920 (Pls. 188, 189) had a heavy beard. Although No. 2895 had dark brown hair, his beard was reddish brown. No. 2900 had a very white beard. No. 2953 had a black and reddish brown mustache.

In general, the hair was low wavy, but one man (No. 2921) was recorded in the curly-frizzly group.

\begin{tabular}{|c|c|c|c|c|c|}
\hline \\
\hline Color & No. & Per cent & Form & No. & Per cent \\
\hline Black.......... & 34 & 39.08 & Straight........... & 0 & \\
\hline Very dark brown ....... & 7 & 8.05 & Very low waves..... & 0 & \\
\hline Dark brown ......... & 12 & 13.79 & Low waves......... & 71 & 89.87 \\
\hline Brown $\ldots \ldots \ldots \ldots \ldots$ & 0 & & Deep waves.... . . . . . & 7 & 8.86 \\
\hline Reddish brown........ & 5 & 5.75 & Curly-frizzly ......... & 1 & 1.27 \\
\hline Light brown............ & 0 & $\ldots$. & Woolly............. & 0 & $\ldots \ldots$ \\
\hline Black and gray ............. & 22 & 25.29 & Total ............ & 79 & 100.00 \\
\hline $\begin{array}{l}\text { Dark brown and gray.... } \\
\text { Light brown and gray. . }\end{array}$ & $\begin{array}{l}1 \\
0\end{array}$ & 1.15 & Texture & No. & Per cent \\
\hline 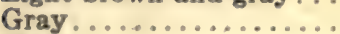 & 5 & 5.75 & Coarse.... & 26 & 32.50 \\
\hline White............... & 1 & 1.15 & Medium-coarse..... & 8 & 10.00 \\
\hline Total........ & 87 & 100.01 & Medium-fine......... & 3 & 3.75 \\
\hline & & & Total ........... & 80 & 100.00 \\
\hline
\end{tabular}


Eyes.-The light colors suggest submerged blondism.

\begin{tabular}{|c|c|c|c|c|c|}
\hline & & & EYES & & \\
\hline Color & No. & Per cent & Iris & No. & Per cent \\
\hline Black.......... & 0 & & Homogeneous. . & 47 & 54.02 \\
\hline Dark brown..... & 5 & 5.56 & Rayed........ & 4 & 4.60 \\
\hline Blue-brown...... & 66 & 73.33 & Zoned. & 36 & 41.38 \\
\hline Blue-brown...... & 14 & 15.56 & & - & \\
\hline Green-brown . . . . & 4 & 4.44 & Total & 87 & 100.00 \\
\hline Green-brown ...... & 0 & 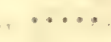 & Sclera & No. & Per cent \\
\hline $\begin{array}{l}\text { Gray-brown ...... } \\
\text { Blue.......... }\end{array}$ & $\begin{array}{l}0 \\
0\end{array}$ & $\cdots \cdots$ & Clear. . & 78 & 88.64 \\
\hline Gray.......... & 0 & & Yellow. & 0 & \\
\hline Light brown.... . . & 1 & 1.11 & Speckled. . & 6 & 6.82 \\
\hline Blue-gray....... & 0 & $\ldots$. & Bloodshot. . . . . . . . . . . & 3 & 3.41 \\
\hline Blue-green...... & 0 & $\ldots$. & Speckled and bloodshot. ... & 1 & 1.14 \\
\hline Total & 90 & 100.00 & Yellow and bloodshot....... & 0 & $\cdots \cdots$ \\
\hline & & & Total $\ldots \ldots \ldots \ldots$ & 88 & 100.01 \\
\hline
\end{tabular}

Although five individuals (Nos. 2891, 2892, 2894, 2922, 2967) had dark brown eyes, the majority (73.33 per cent) had blue-brown eyes. Fourteen individuals had blue-brown eyes, and four (Nos. $2895,2919,2944,2954$ ) had green-brown eyes. No. 2976 had light brown eyes.

In general, the Subba had excellent eyes. No. 2902 attributed this to "their eating so much fish." No. 2948 had poor vision. A large white spot in the center of the pupil reduced the vision of No. 2916 to one half. No. 2921 was blind in the right eye because of a cataract that formed as a result of a flake of silver entering the eye during work.

Nose.-Thirty per cent were convex. Our observations have already indicated that this distinction is one of the most important racial criteria in Southwestern Asia. Therefore, we find two racial elements present among the Subba.

\begin{tabular}{|c|c|c|c|c|c|}
\hline \multirow{2}{*}{ Profile } & \multirow[b]{2}{*}{ No. } & \multicolumn{2}{|c|}{ Nose } & \multirow[b]{2}{*}{ No. } & \multirow[b]{2}{*}{ Per cent } \\
\hline & & Per cent & Wings & & \\
\hline Wavy... & 3 & 3.33 & Compressed ........ & 14 & 15.56 \\
\hline Concave. & 1 & 1.11 & Compressed-medium. & 16 & 17.78 \\
\hline Straight.......... & 48 & 53.33 & Medium............ & 35 & 38.89 \\
\hline Convex............ & 27 & 30.00 & Medium flaring. ....... & 16 & 17.78 \\
\hline Concavo-convex... & 11 & 12.22 & Flaring...$\ldots \ldots \ldots$ & 9 & 10.00 \\
\hline & 90 & 99.99 & $\cdots \cdots \cdot$ & 0 & $\cdots \cdots$ \\
\hline & & & Total. . & 90 & 100.01 \\
\hline
\end{tabular}

There were slightly more Subba with narrow than wide alae. Although nine men (10 per cent) possessed flaring nostrils, they did not appear to have Negroid blood. The general impression 
retained was that the Subba possessed large, straight noses, which grew broad with advancing years.

Mouth and Teeth.-The lips showed normal eversion. The teeth presented the normal occlusion of Europeans in only 22.89 per cent of the group. The remainder, with only one exception, were recorded as having marked-over occlusion. This may be due to a general trend in the reduction of the size of the palate, the result of special food eaten by the Subba, whose diet and ritualistic ablutions form an important part of their religious expressions.

Although it was not always possible to obtain statistical data on the dental condition and the number of teeth lost, the figures recorded reveal a singular discrepancy. The few teeth lost indicate fairly good dentition.

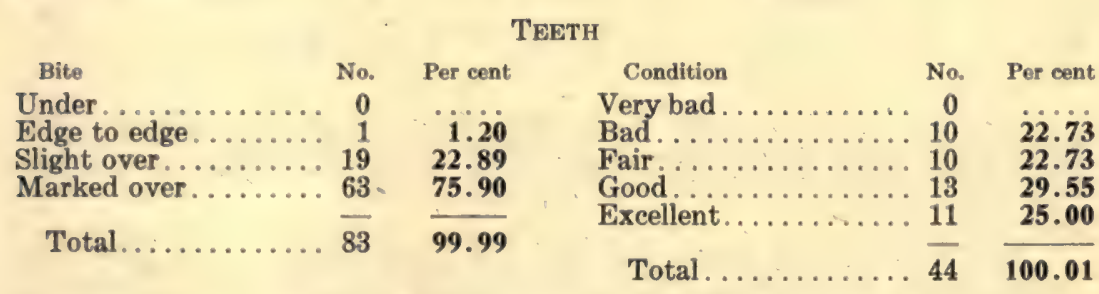

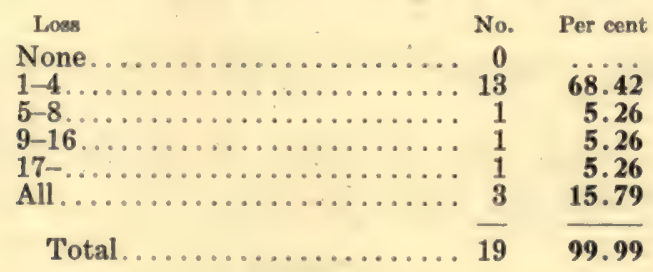

The individual condition of the teeth was as follows: excellent, Nos. 2898, 2899, 2901, 2907, 2908, 2940, 2951, 2963, 2965, 2971, and 2972; good, Nos. 2891, 2895-2897, 2902, 2911, 2924, 2927, 2929, 2942, 2962, 2967, and 2979; fair, Nos. 2888, 2890, 2903, 2914, 2915, 2928, 2934, 2966, 2969, and 2978; bad, Nos. 2912, 2917, 2933, 2941, 2946, 2957, 2960, 2968, 2970, and 2977. No. 2936 had irregular front teeth. The following had lost teeth: one to four, Nos. 2923, 2925, 2930, 2931, 2934, 2944, 2945, 2950, 2954, 2958-2960, 2978; five to eight, No. 2961; nine to sixteen, No. 2941; seventeen, No. 2922; and all, Nos. 2889, 2900, and 2906.

Musculature and Health.-The health statistics were almost identical with those obtained on the muscular development. 
In general musculature Nos. 2891, 2893, 2902, 2937, and 2968 were excellent, and Nos. 2941, 2948, and 2975 were fairly well developed.
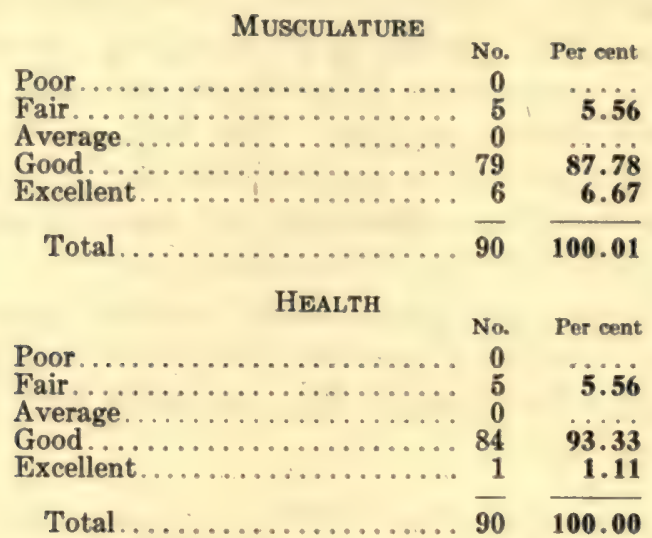

Disease.-Fifteen men (Nos. 2894, 2899, 2912, 2915, 2918, 2927 , $2933,2938,2939,2940,2951,2955,2957,2962$, and 2969) bore smallpox scars.

No. 2955 had a large boil on the right hand. No. 2964 had disease scars on the head as well as many pimples (hab shabab) on the face.

Cauterization.-No chawi (kawi) scars were recorded on the entire group.

Tattooing.-Nine (10 per cent) of ninety individuals were tattooed, but in no case was it extensive.

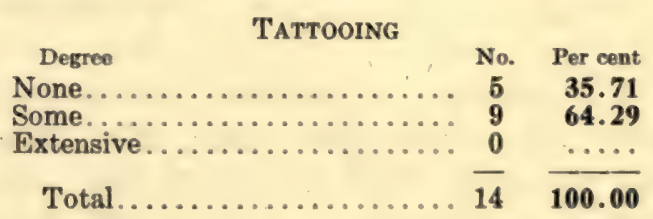

Despite the fact that only fourteen men appear to have been recorded, I am confident that each man was examined and that there should have been eighty-one individuals instead of only five in the untattooed category. The following persons bore tattooed marks: Nos. 2897, 2901, 2906, 2917, 2934, 2941, 2953, 2957, and 2959.

Henna.-No. 2955 had applied henna to his fingernails and hands in order to toughen the palms for a fishing trip.

Anomalies.-No. 2939 lisped. 


\section{STATISTICAL ANALYSES OF SUBBA MALES}

Stature.-The average standing height was 166.23 , which is close to the mean for Southwestern Asia. According to both classificatory systems, about half of the individuals fall into the medium grouping. There are present, however, both tall (170.0-179.9) and short $(x-159.9)$ elements. It is important to find two very tall (180.0-x) men among the Subba, who are differentiated from the Arabs of Iraq by being taller in stature. Nos. 2974 and 2975 were omitted.

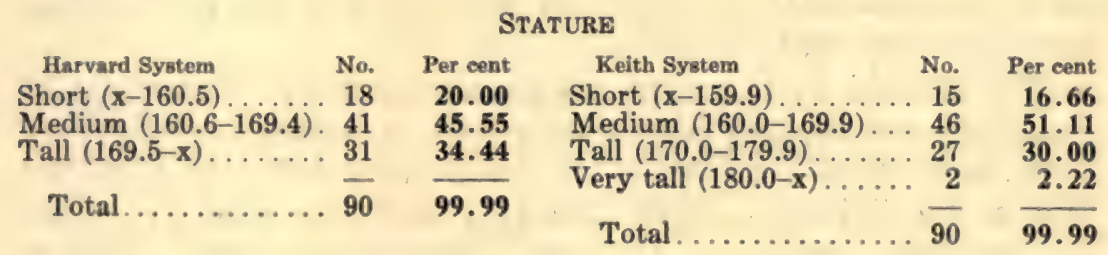

Sitting Height (Trunk Length).- The average sitting height was 88.57 (range 80-98). It is remarkable that seventy-two men (79.99 per cent) were above 85.0 in trunk length. Nos. 2974 and 2975 were omitted. The relative sitting height was 53.30 (range 48.0 $57.0)$.

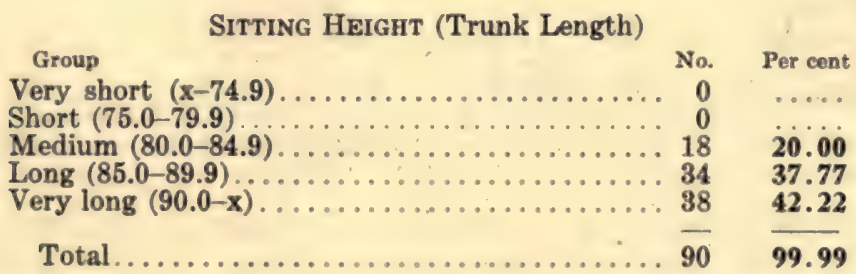

Minimum Frontal Diameter.-Nos. 2974, 2975, and 2979 were omitted.

\section{Minimum Frontal Diameter}

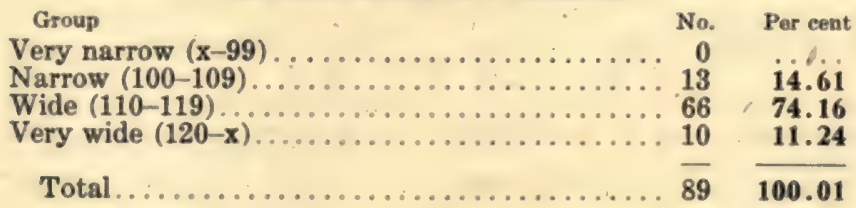

Head Breadth.-The average maximum diameter was 145.75 (range 135-158). Nos. 2926, 2974, and 2975 were omitted. 


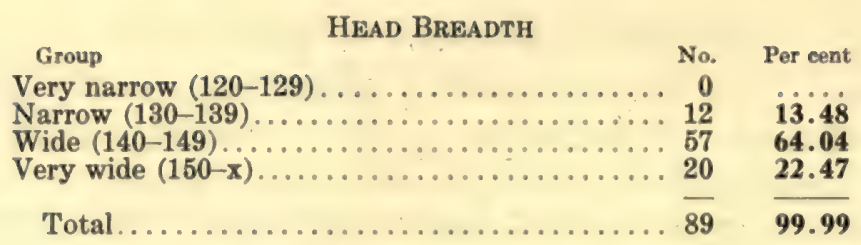

Cephalic Index.-According to both the Harvard and the Keith systems, the majority of the Subba fell into the mesocephalic category. 'The threefold Harvard system reveals twenty-five (28.09 per cent) dolichocephals $(x-76.5)$ and eleven (12.36 per cent) in the brachycephalic $(82.6-\mathrm{x})$ group.

The fivefold Keith system discloses an entirely different set of groupings, with the exception of the central or mesocephalic division. There were 28.09 per cent in the group $80-\mathrm{x}$ and only 17.97 per cent in the division $x-75.0$. The fact that there were five ultrabrachycephals $(85.0-x)$ and one ultradolichocephal $(x-70.0)$ indicates the presence of two racial elements. In both series, No. 2926 was omitted.

\begin{tabular}{|c|c|c|c|c|c|}
\hline \multicolumn{6}{|c|}{ CEPhalic Index } \\
\hline Harvard System & No. & Per cent & Keith System & No. & Per cent \\
\hline Dolichocephalic. & 25 & 28.09 & Ultradolichocephalic. . . & 1 & 1.12 \\
\hline $\begin{array}{c}\text { Mesocephalic... } \\
(76.6-82.5)\end{array}$ & 53 & 59.55 & $\begin{array}{c}\text { Dolichocephalic . . . . } \\
(70.1-75,0)\end{array}$ & 15 & 16.85 \\
\hline Brachycephalic. & 11 & 12.36 & Mesocephalic ......... & 48 & 53.93 \\
\hline Total..... & 89 & 100.00 & $\begin{array}{c}\text { Brachycephalic ....... } \\
(80.0-84.9)\end{array}$ & 20 & 22.47 \\
\hline & & & $\begin{array}{l}\text { Ultrabrachycephalic.. } \\
(85.0-x)\end{array}$ & 5 & 5.62 \\
\hline & & & Total......... & 89 & 99.99 \\
\hline
\end{tabular}

Facial Measurements and Indices.-The wide divergence in these measurements and indices suggests racial admixture. In the facial height series, No. 2907 was omitted.

\section{Facial Measurements and Indices}

\begin{tabular}{|c|c|c|c|c|c|}
\hline Upper facial height & No. & Per cent & Total facial height & No. & Per cent \\
\hline$\underset{(x-63)}{\operatorname{Short}} \ldots \ldots \ldots \ldots$ & 4 & 4.44 & ${ }_{(x-1009)}^{\text {Short }} \ldots \ldots \ldots$ & 3 & 3.37 \\
\hline $\begin{array}{l}\text { Medium short. ..... } \\
(64-69)\end{array}$ & 22 & 24.44 & $\begin{array}{l}\text { Medium short....... } \\
\quad(110-119)\end{array}$ & 27 & 30.33 \\
\hline $\begin{array}{l}\text { Medium long...... } \\
\quad(70-75)\end{array}$ & 25 & 27.78 & $\begin{array}{l}\text { Medium long. . . . . . } \\
\quad(120-129)\end{array}$ & 42 & 47.19 \\
\hline $\begin{array}{l}\text { Long } \ldots \ldots \ldots \\
(76-x)\end{array}$ & 39 & 43.33 & $\begin{array}{l}\text { Long } \ldots \ldots \ldots \ldots \\
(130-x)\end{array}$ & 17 & 19.10 \\
\hline Total. & 90 & 99.99 & Total. & 89 & 99.99 \\
\hline
\end{tabular}




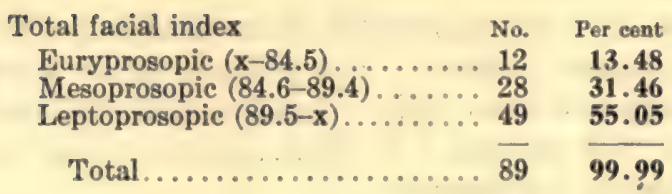

Nasal Measurements and Indices.-The wide range of variation indicates mixed racial stocks. Although the platyrrhine Subbi (No. 2960) had an index of 90, there was no evidence of Negro blood.

\begin{tabular}{|c|c|c|c|c|c|c|}
\hline \multirow{2}{*}{ Nasal height } & \multicolumn{5}{|c|}{ Nasal Measurements and INDices } & \multirow[b]{2}{*}{ Per cent } \\
\hline & No. & Per eent & \multicolumn{2}{|c|}{ Nasal width } & No. & \\
\hline Short & 13 & 14.44 & \multicolumn{2}{|c|}{$\underset{(\mathrm{x}-29)}{\text { Very narrow }} . \ldots \ldots$} & 2 & 2.22 \\
\hline Medium & 48 & 53.33 & \multicolumn{2}{|c|}{$\underset{(30-35)}{\text { Medium narrow...... }}$} & 45 & 50.00 \\
\hline $\begin{array}{l}\text { Long. . } \\
(60-\mathrm{x})\end{array}$ & $\ldots 29$ & 32.22 & \multicolumn{2}{|c|}{ 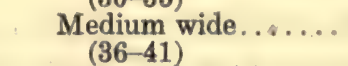 } & 38 & 42.22 \\
\hline Total... & $\ldots \ldots . \overline{90}$ & 99.99 & \multicolumn{2}{|c|}{$\begin{array}{l}\text { Wide. } \\
(42-\mathrm{x})\end{array}$} & 5 & 5.55 \\
\hline & & 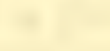 & \multicolumn{2}{|c|}{ Total... } & 90 & 99.99 \\
\hline \multicolumn{3}{|c|}{$\begin{array}{l}\text { Nasal index } \\
\text { Leptorrhine }(x-67.4) \ldots \\
\text { Mesorrhine }(67.5-83.4) \\
\text { Platyrrhine }(83.5-x) \ldots\end{array}$} & $\begin{array}{rr} & \text { No. } \\
\ldots \quad & 69 \\
\cdots \quad & 20 \\
\ldots \quad & 1\end{array}$ & $\begin{array}{c}\text { Per cent } \\
76.67 \\
22.22 \\
1.11\end{array}$ & & \\
\hline \multicolumn{3}{|c|}{ Total. . } & 90 & 100.00 & & \\
\hline
\end{tabular}

\section{SUMMARY}

The ninety Subba of the middle-aged group were light in skin color and extremely hirsute, with very dark brown hair, which had low waves and medium texture. The eyes were brown, with definite traces of submerged blondism. The nasal profile was either straight or convex but the alae showed extreme variation. The teeth presented no unusual features except perhaps for the tendency to overbite occlusion. The musculature and health of the group seemed extremely good.

In stature the Subba were tall, the result of long trunks. The head and forehead were wide, although the bizygomatic breadth (136.05) was not unusually large. The bigonial breadth (104.66) was exceptionally narrow so that the face tended to have an ovoid or even triangular appearance. Since the upper and total facial heights were long, the cephalic index (78.39) is misleading unless examined in relation to the Keith classificatory system (p. 308). There appeared to be both dolichocephalic and brachycephalic elements present. 
Analyses of the morphological characters and the statistical data reveal that the Subba are not a single racial stock as might have been anticipated from their unusual quantity of head, face, and body hair, their tall stature, and their apparent isolation, resulting from strict religious segregation.

We are forced to conclude that there are at least four elements present: straight-nosed; convex-nosed; dolichocephalic; and brachycephalic.

When we examine the statistical and morphological data in conjunction with the photographs, we find that a definite number of the Subba can be classified as members of the Iranian Plateau Race. On the other hand, the brachycephals may be the bearers of blondism into this group.

Despite the variation in form of the head and of the nasal profile, there is a greater degree of homogeneity among the Subba than would be anticipated from the anthropometric data. This may be due to the hirsuteness of all Subba males, a feature that distinguishes them from all other racial, cultural, linguistic, or religious groups in Iraq. The only possible exception to this statement is that the Yezidis possess a far greater quantity of body hair than the Arabs or Beduins of Iraq.

Several Subba, particularly No. 2888 (Pls. 174, 175) resembled the hairy Ainu, the aboriginal inhabitants of Japan. Dr. Hooton and I, therefore, compared the Subba of Iraq with a series of Ainu. Statistically and morphologically, with the exception of the similarity of hairy face and body hair, there was no resemblance.

On the basis of my data, I believe that the Subba are connected racially with western Iran.

The Subba can be distinguished either by appearance, culture, religion, or language from the following groups in Iraq: Arab, Beduin, Kurd, Yezidi, Chaldean, Assyrian, Turkoman, or Jew.

Their affinities are with the peoples of Iran rather than with any groups in the southern, central, or northern sections of Iraq.

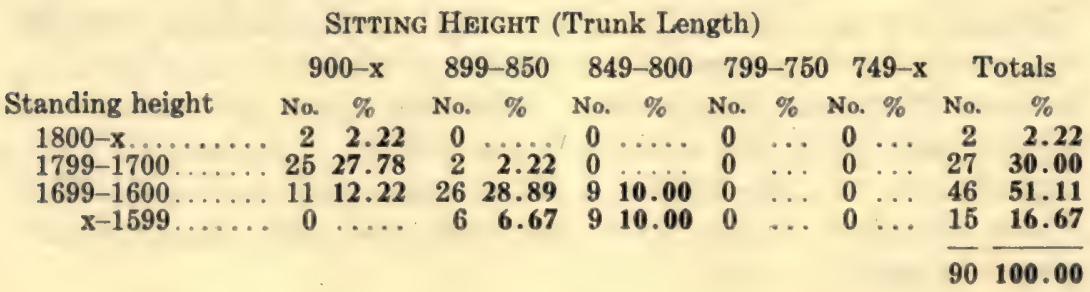


Mrnimum Frontal Diameter

\begin{tabular}{|c|c|c|c|c|c|c|c|c|c|c|}
\hline \multirow[b]{2}{*}{ Head breadth } & \multicolumn{2}{|c|}{$x-99$} & \multicolumn{2}{|c|}{$100-109$} & \multicolumn{2}{|c|}{$110-119$} & \multicolumn{2}{|c|}{$120-x$} & \multicolumn{2}{|c|}{ Totals } \\
\hline & No. & $\%$ & No. & $\%$ & No. & $\%$ & No. & $\%$ & No. & $\%$ \\
\hline $120-129 \ldots$ & 0 & $\ldots$ & 0 & & 0 & & 0 & ... & 0 & \\
\hline $130-139$ & 0 & $\ldots$ & 2 & 2.25 & 10 & 11.24 & 0 & & 12 & 13.49 \\
\hline $140-149$ & 0 & $\ldots$ & 11 & 12.36 & 44 & 49.44 & 2 & 2.25 & 67 & 64.05 \\
\hline $150-x \ldots$ & $\mathbf{0}$ & $\ldots$ & 0 & $\ldots \ldots$ & 12 & 13.48 & 8 & 8.99 & 20 & 22.47 \\
\hline
\end{tabular}

\section{Bizygomatic Breadth}

\begin{tabular}{|c|c|c|c|c|c|c|c|c|}
\hline \multirow{5}{*}{$\begin{array}{r}\text { Total facial length } \\
x-114 \ldots \ldots \ldots \\
115-124 \ldots \ldots \\
125-x \ldots \ldots\end{array}$} & \multicolumn{2}{|c|}{$x-124$} & \multicolumn{2}{|c|}{$125-134$} & \multicolumn{2}{|c|}{$135-x$} & \multicolumn{2}{|c|}{ Totals } \\
\hline & N & $\%$ & No. & $\%$ & No. & $\%$ & No. & $\%$ \\
\hline & . 1 & 1.12 & 9 & 10.11 & 4 & 4.49 & 14 & 15.72 \\
\hline & c & $\ldots$ & 11 & 12.36 & 26 & 29.21 & 37 & 41.57 \\
\hline & c & $\ldots$ & 12 & 13.48 & 26 & 29.21 & 38 & 42.69 \\
\hline & & & & & & & 89 & 99.98 \\
\hline
\end{tabular}

\section{UPPER Facial LENGTH}

$\begin{array}{llllll}\mathrm{x}-68 & 64-69 & 70-75 & 76-81 & 82-\mathrm{x} & \text { Totals }\end{array}$

Total fac. length No. $\%$ No. $\%$ No. $\%$ No. $\%$ No. $\%$ No. $\%$

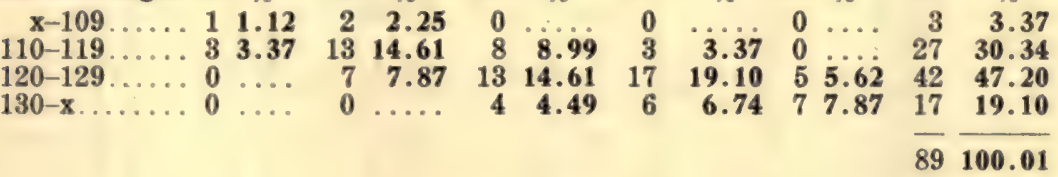

\section{NASAL WIDTH}

\begin{tabular}{|c|c|c|c|c|c|c|c|c|c|c|}
\hline \multirow{5}{*}{$\begin{array}{r}\text { Nasal length } \\
x-49 \ldots \\
50-59 \ldots \\
60-x \ldots\end{array}$} & \multicolumn{2}{|c|}{$x-29$} & \multicolumn{2}{|c|}{ 30-35 } & \multicolumn{2}{|c|}{$36-41$} & \multicolumn{2}{|c|}{$42-x$} & \multicolumn{2}{|c|}{ Totals } \\
\hline & No. & $\%$ & No. & $\%$ & - No. & $\%$ & No. & $\%$ & No. & $\%$ \\
\hline & 0 & & 11 & 12.22 & 2 & 2.22 & 0 & & 13 & 14. \\
\hline & 1 & 1.11 & 25 & 27. & 20 & 22. & 2 & 2.2 & 48 & \\
\hline & 1 & 1.11 & 9 & 10.00 & 16 & 17.78 & 3 & 3.33 & 29 & 32.22 \\
\hline
\end{tabular}

Vital Statistics* of Subba Males

\begin{tabular}{|c|c|c|c|c|c|c|}
\hline Number & Age & Married & Sons & Daughters & Brothers & Sisters \\
\hline 2888 & 60 & 1 & 1,0 & $\quad 4,0$ & 0,6 & 1,0 \\
\hline 2889 & 59 & 1 & 1,0 & 1,0 & 4,0 & 0,0 \\
\hline 2890 & 47 & 1 & 2,0 & 3,0 & & \\
\hline 2891 & 34 & 1 & 0,0 & 2,0 & 1,0 & 4,0 \\
\hline 2892 & 25 & $\overline{0}$ & & & 7,0 & 1, \\
\hline 2893 & 42 & 1 & 3,0 & 3,0 & 3,1 & 1, \\
\hline 2894 & 20 & $\overline{0}$ & & & 3,0 & 0,0 \\
\hline 2895 & 24 & 1 & 0,0 & 0,0 & 7,0 & 1 , \\
\hline 2896 & 35 & 1 & 0,0 & 0,0 & 2,0 & 2 , \\
\hline 2897 & 19 & 0 & & & 7,0 & 1,0 \\
\hline 2898 & 92 & 1 & 1,0 & 2,0 & 0,0 & 4,2 \\
\hline 2899 & 33 & 0 & & & 4,0 & 3,0 \\
\hline 2900 & 55 & 1 & 8,0 & 1,0 & 3,0 & 3,0 \\
\hline 2901 & 23 & 0 & & & 1,0 & 3,0 \\
\hline 2902 & 27 & 1 & 0,0 & 0,0 & 0,1 & 3 , \\
\hline 2903 & 33 & 1 & 0,0 & 1,0 & 1,4 & 3,2 \\
\hline
\end{tabular}

* Italicized numbers reler to decened relatives. 
Vital Statistics* of Subba Males

\begin{tabular}{|c|c|c|c|c|c|c|}
\hline Number & Age & Married & Sons & Daughters & Brothers & Sisters \\
\hline 2904 & 29 & 1 & 0,0 & 0,0 & 5,0 & 7,3 \\
\hline 2905 & 26 & 1 & 0,0 & 1,0 & 2,3 & 0,0 \\
\hline 2906 & 59 & 1 & 1,4 & 4,0 & 3,0 & 0,0 \\
\hline 2907 & 26 & 0 & & & 5,2 & 7,4 \\
\hline 2908 & 22 & 0 & 0,0 & 0,0 & 3,1 & 0,1 \\
\hline 2909 & 34 & 1 & 1,0 & 1,0 & 0,3 & 1,1 \\
\hline 2910 & 30 & 0 & $\ldots$ & $\ldots$ & 0,2 & 1,2 \\
\hline 2911 & 20 & 0 & $\ldots$ & $\ldots$ & 3,1 & 2,2 \\
\hline 2912 & 20 & 0 & $\ldots$ & $\ldots$ & 3,3 & 0,0 \\
\hline 2913 & 21 & 0 & $\ldots$ & $\ldots$ & 1,1 & 4,3 \\
\hline 2914 & 20 & 0 & . & $\therefore$ & 2,2 & 1,2 \\
\hline 2915 & 42 & 1 & 2,0 & 1,0 & 0,0 & 0,0 \\
\hline 2916 & 20 & 0 & 0,0 & 0,0 & 5,2 & 2,1 \\
\hline 2917 & 65 & 1 & 4,0 & 3,0 & 1,0 & 2,1 \\
\hline 2918 & 30 & 1 & 0,1 & 0,0 & 3,0 & 2,2 \\
\hline 2919 & 38 & 1 & 3,0 & 1,0 & 0,1 & 1,1 \\
\hline 2920 & 50 & 1 & 1,0 & 1,1 & 0,0 & 3,0 \\
\hline 2921 & 56 & 1 & 1,2 & 2,2 & 4,1 & 2,0 \\
\hline 2922 & 60 & 1 & 2,2 & 2,1 & 1,8 & 2,1 \\
\hline 2923 & 70 & 1 & 2,3 & 3,1 & 1,1 & 3,1 \\
\hline 2924 & 30 & 0 & & & 2,4 & 2,4 \\
\hline 2925 & 39 & 2 & 2,0 & 4,3 & 4,0 & 1,1 \\
\hline 2926 & 30 & 1 & $\ldots$ & 1,0 & 1,2 & 2,1 \\
\hline 2927 & 24 & 0 & & $\because \cdots$ & 2,2 & 2,2 \\
\hline 2928 & 35 & 1 & 0,4 & 2,1 & 0,0 & 1,2 \\
\hline 2929 & 22 & 0 & $\ddot{i} \ddot{\theta}$ & $\ddot{0} \ddot{g}$ & 3,2 & 2,1 \\
\hline 2930 & 50 & 1 & 1,2 & 0,2 & 1,1 & 1,2 \\
\hline 2931 & 55 & 1 & 3,2 & 2,2 & 4,2 & 2,2 \\
\hline 2932 & 54 & 1 & 2,1 & 3,0 & 2,1 & 4,0 \\
\hline 2933 & 22 & 0 & $\ldots$ & $\ldots$ & 2,0 & 1,0 \\
\hline 2934 & 25 & 0 & $\ldots$ & & 3,0 & 1,0 \\
\hline 2935 & 28 & 1 & 1,0 & 0,0 & 1,1 & 2,0 \\
\hline 2936 & 39 & 1 & 4,2 & 0,1 & 3,1 & 3,0 \\
\hline 2937 & 37 & 1 & 4,1 & 0,0 & 2,1 & 1,0 \\
\hline 2938 & 19 & 0 & $\ldots$ & $\ldots$ & 2,0 & 2,2 \\
\hline 2939 & 30 & 0 & $\ldots$ & $\ldots$ & 2,1 & 2,2 \\
\hline 2940 & 25 & 0 & $\cdots$ & & 2,2 & 2,0 \\
\hline 2941 & 55 & 1 & 0,1 & 2,0 & 5,2 & 0,2 \\
\hline 2942 & 25 & 0 & $\ldots$ & $\ldots$ & 2,0 & 2,0 \\
\hline 2943 & 22 & 0 & & & 1,2 & 1,1 \\
\hline 2944 & 30 & 1 & 0,0 & 0,0 & 1,4 & 2,0 \\
\hline 2945 & 50 & 1 & 4,0 & 1,0 & 5,0 & 0,0 \\
\hline 2946 & 22 & 0 & & & 3,0 & 1,0 \\
\hline 2947 & 26 & 1 & 1,0 & 1,0 & 2,0 & 4,2 \\
\hline 2948 & 70 & 1 & 1,0 & 6,0 & 2,1 & 0,0 \\
\hline 2949 & 55 & 1 & 3,0 & 4,3 & 0,2 & 4,1 \\
\hline 2950 & 55 & 1 & 1,0 & 2,1 & 0,0 & 3,1 \\
\hline 2951 & 20 & 0 & & & 3,1 & 1,0 \\
\hline 2952 & 55 & 1 & 3,1 & 1,3 & 1,1 & 0,0 \\
\hline 2953 & 40 & 1 & 3,0 & 3,0 & 1,0 & 1,0 \\
\hline 2954 & 51 & 1 & 0,2 & 2,1 & 1,1 & 0,0 \\
\hline 2955 & 20 & 0 & & & 4,1 & 5,2 \\
\hline 2956 & 40 & 1 & 2,1 & 0,2 & 1,1 & 2,1 \\
\hline 2957 & 40 & 1 & 2,0 & 1,0 & 3,2 & 2,1 \\
\hline 2958 & 50 & 1 & 4,2 & 5,3 & 4,1 & 3,2 \\
\hline 2959 & 40 & 1 & 2,1 & 3,1 & 0,2 & 1,2 \\
\hline 2960 & 45 & 1 & 3,0 & 2,0 & 2,1 & 2,1 \\
\hline 2961 & 54 & 1 & 3,2 & 3,1 & 0,2 & 1,0 \\
\hline
\end{tabular}

* Italicized numbera refer to deceased relatives. 
Vital statistics* of Subba Males

\begin{tabular}{|c|c|c|c|c|c|c|}
\hline Number & Age & Married & Sona & Daughters & Brothers & Sisters \\
\hline 2962 & 18 & 0 & $\ldots$ & $\ldots$ & 2,1 & 5,1 \\
\hline 2963 & 25 & 0 & $\ldots$ & $\ldots$ & 2,0 & 1,0 \\
\hline 2964 & 18 & 0 & $\ldots$ & $\ldots$ & 1,0 & 1,0 \\
\hline 2965 & 24 & 0 & & & 0,0 & 1,0 \\
\hline 2966 & 34 & 1 & 2,0 & 1,0 & 2,0 & 7,0 \\
\hline 2967 & 23 & 0 & $\ldots$ & & 6,0 & 0,0 \\
\hline 2968 & 55 & 1 & $5,-$ & $2,-$ & 1,6 & 1,5 \\
\hline 2969 & 29 & 1 & 1,0 & 0,0 & 4,0 & 3,0 \\
\hline 2970 & 50 & 1 & 2,0 & 1,0 & 6,0 & 1,0 \\
\hline 2971 & 18 & 0 & $\ldots$ & $\ldots$ & 3,0 & 7,0 \\
\hline 2972 & 20 & 0 & & & 2,0 & 2,0 \\
\hline 2973 & 54 & 1 & 2,0 & 1,0 & 1,0 & 3,0 \\
\hline 2974 & $71 \dagger$ & 1 & 0,0 & 2,0 & 0,0 & 0,0 \\
\hline 2975 & $16 \dagger$ & 0 & & & 4,0 & 2,0 \\
\hline 2976 & 68 & 1 & 3,0 & 1,0 & 2,0 & 3,0 \\
\hline 2977 & 23 & 0 & & & 4,1 & 2,0 \\
\hline 2978 & 38 & 0 & 0,0 & 1,0 & 0,4 & 2,1 \\
\hline 2979 & 25 & 0 & $\ldots$ & $\ldots$ & 3,0 & 7,0 \\
\hline
\end{tabular}

* Italicized numbers refer to decensed relatives.

+Omitted from the averagea because of age.

Measurements and Indices of Subba Males

\begin{tabular}{|c|c|c|c|c|c|}
\hline Messurements & No. & Range & Mean & S.D. & C.v. \\
\hline Age $\ldots \ldots \ldots \ldots \ldots$ & 90 & $18-70$ & $36.70 \pm 1.06$ & $14.90 \pm 0.75$ & $40.60 \pm 2.04$ \\
\hline Stature..... . & 90 & 149-184 & $166.23 \pm 0.47$ & $6.66 \pm 0.33$ & $4.01 \pm 0.20$ \\
\hline Sitting height. . . . . . . & 90 & $80-98$ & $88.57 \pm 0.28$ & $3.99 \pm 0.20$ & $4.50 \pm 0.23$ \\
\hline Head length....... & 90 & 173-199 & $186.00 \pm 0.41$ & $5.82 \pm 0.29$ & $3.13 \pm 0.16$ \\
\hline Head breadth. & 89 & $135-158$ & $145.75 \pm 0.36$ & $5.13 \pm 0.26$ & $3.52 \pm 0.18$ \\
\hline \multicolumn{6}{|l|}{ Minimum frontal } \\
\hline Bizygomatic diameter & 90 & $120-149$ & $136.05 \pm 0.43$ & $6.05 \pm 0.30$ & $4.45 \pm 0.22$ \\
\hline Bigonial diameter.... & 89 & $82-121$ & $104.66 \pm 0.42$ & $5,88 \pm 0.30$ & $5.62 \pm 0.28$ \\
\hline Total facial height. . . & 89 & 105-139 & $122.75 \pm 0.53$ & $7.40 \pm 0.37$ & $6.03 \pm 0.30$ \\
\hline Upper facial height... & 90 & $60-89$ & $74.15 \pm 0.48$ & $6.75 \pm 0.34$ & $9.10 \pm 0.46$ \\
\hline Nasal height......... & 90 & $44-75$ & $56.78 \pm 0.45$ & $6.36 \pm 0.32$ & $11.20 \pm 0.56$ \\
\hline Nasal breadth . . . . . . & 90 & $25-48$ & $35.54 \pm 0.28$ & $3.96 \pm 0.20$ & $11.14 \pm 0.56$ \\
\hline ggth......... & 90 & $48-79$ & $61.14 \pm 0.37$ & $5.24 \pm 0.26$ & 8.5 \\
\hline Ear breadth........... & 90 & $23-49$ & $33.51 \pm 0.26$ & $3.72 \pm 0.19$ & $11.10 \pm 0.56$ \\
\hline \multicolumn{6}{|l|}{ Indioes } \\
\hline Relative sitting height & 90 & $48-57$ & $53.30 \pm 0.12$ & $1.62 \pm 0.08$ & $3.04 \pm 0.15$ \\
\hline Cephalic............ & 89 & 68-91 & $78.39 \pm 0.29$ & $4.05 \pm 0.20$ & $5.17 \pm 0.26$ \\
\hline Fronto-parietal. . . . & 88 & $72-92$ & $78.79 \pm 0.24$ & $3.30 \pm 0.17$ & $4.18 \pm 0.21$ \\
\hline Zygo-frontal......... & 88 & $76-99$ & $84.18 \pm 0.23$ & $3.16 \pm 0.16$ & $3.75 \pm 0.19$ \\
\hline Zygo-gonial. . . . . . . . & 89 & $66-89$ & $77.05 \pm 0.30$ & $4.17 \pm 0.21$ & $5.41 \pm 0.27$ \\
\hline Total facial....... & 89 & 75-109 & $90.50 \pm 0.41$ & $5.75 \pm 0.29$ & $6.35 \pm 0.32$ \\
\hline Upper facial. . & 90 & $43-66$ & $54.68 \pm 0.33$ & $4.65 \pm 0.23$ & $8.50 \pm 0.43$ \\
\hline Nasal....... & 90 & 40-91 & $63.34 \pm 0.54$ & $7.64 \pm 0.38$ & $12.06 \pm 0.61$ \\
\hline Ear.. & 90 & $37-72$ & $55.34 \pm 0.41$ & $5.76 \pm 0.29$ & $10.41 \pm 0.52$ \\
\hline
\end{tabular}




\section{Measurements}

\begin{tabular}{|c|c|c|c|c|c|c|c|c|c|c|c|c|}
\hline No. & Age & Stature & SH & L & B & $\mathbf{B}^{\prime}$ & $\mathbf{J}$ & go-go & GH & $\mathrm{G}^{\prime} \mathrm{H}$ & NH & NB \\
\hline 2888 & 60 & 1575 & 820 & 196 & 138 & 117 & 140 & 105 & 131 & 88 & 67 & 39 \\
\hline 2889 & 59 & 1660 & 880 & 186 & 147 & 120 & 141 & 97 & $128^{*}$ & $82^{*}$ & 65 & 43 \\
\hline 2890 & 47 & 1642 & 864 & 189 & 139 & 115 & 133 & 100 & 130 & 84 & 64 & 41 \\
\hline 2891 & 34 & 1720 & 965 & 195 & 148 & 114 & 138 & 109 & 127 & 83 & 67 & 41 \\
\hline 2892 & 25 & 1823 & 946 & 195 & 151 & 121 & 138 & 110 & 135 & 85 & 68 & 37 \\
\hline 2893 & 42 & 1713 & 921 & 185 & 143 & 116 & 135 & 102 & 128 & 81 & 64 & 32 \\
\hline 2894 & 20 & 1660 & 905 & 178 & 141 & 117 & 136 & 99 & 118 & 75 & 61 & 34 \\
\hline 2895 & 24 & 1625 & 835 & 192 & 138 & 117 & 135 & 98 & 125 & 73 & 58 & 46 \\
\hline 2896 & 35 & 1720 & 930 & 188 & 145 & 116 & 133 & 115 & 111 & 69 & 56 & 41 \\
\hline 2897 & 19 & 1700 & 920 & 183 & 155 & 115 & 141 & 108 & 129 & 85 & 74 & 35 \\
\hline 2898 & 32 & 1660 & 885 & 180 & 147 & 111 & 136 & 108 & 123 & 76 & 54 & 35 \\
\hline 2899 & 33 & 1665 & 860 & 175 & 143 & 116 & 136 & 101 & 126 & 79 & 59 & 36 \\
\hline 2900 & 55 & 1741 & 935 & 193 & 155 & 126 & 145 & 106 & $128^{*}$ & $79 *$ & 66 & 44 \\
\hline 2901 & 23 & 1675 & 927 & 187 & 146 & 118 & 143 & 114 & 124 & 71 & 53 & 35 \\
\hline 2902 & 27 & 1766 & 970 & 185 & 145 & 118 & 135 & 108 & 123 & 72 & 56 & 35 \\
\hline 2903 & 33 & 1650 & 925 & 189 & 147 & 115 & 134 & 91 & 122 & 70 & 52 & 33 \\
\hline 2904 & 29 & 1636 & 852 & 184 & 146 & 116 & 137 & 108 & 119 & 73 & 56 & 37 \\
\hline 2905 & 26 & 1632 & 865 & 184 & 147 & 114 & 138 & 98 & 114 & 67 & 53 & 38 \\
\hline 2906 & 59 & 1730 & 911 & 186 & 141 & 115 & 143 & 103 & $128^{*}$ & $81^{*}$ & 64 & 37 \\
\hline 2907 & 26 & 1717 & 938 & 179 & 153 & 118 & 138 & & & 80 & 62 & 37 \\
\hline 2908 & 22 & 1637 & 866 & 184 & 143 & 117 & 137 & 98 & 108 & 62 & 52 & 37 \\
\hline 2909 & 34 & 1624 & 847 & 196 & 137 & 110 & 126 & 110 & 118 & 67 & 52 & 35 \\
\hline 2910 & 30 & 1740 & 906 & 187 & 147 & 115 & 136 & 95 & 131 & 75 & 57 & 31 \\
\hline 2911 & 20 & 1726 & 935 & 174 & 135 & 112 & 129 & 105 & 113 & 73 & 56 & 38 \\
\hline 2912 & 20 & 1650 & 810 & 175 & 151 & 113 & 128 & 97 & 110 & 62 & 48 & 33 \\
\hline 2913 & 21 & 1735 & 920 & 178 & 144 & 115 & 136 & 103 & 118 & 65 & 46 & 31 \\
\hline 2914 & 20 & 1650 & 880 & 184 & 148 & 113 & 131 & 104 & 120 & 73 & 57 & 34 \\
\hline 2915 & 42 & 1684 & 859 & 178 & 151 & 127 & 141 & 106 & 123 & 78 & 61 & 41 \\
\hline 2916 & 20 & 1702 & 915 & 186 & 147 & 114 & 128 & 102 & 121 & 68 & 52 & 36 \\
\hline 2917 & 65 & 1615 & 842 & 190 & 139 & 108 & 141 & 107 & 118 & 74 & 52 & 33 \\
\hline 2918 & 30 & 1743 & 913 & 186 & 154 & 121 & 138 & 107 & 127 & 78 & 64 & 35 \\
\hline 2919 & 38 & 1800 & 915 & 187 & 140 & 117 & 136 & 110 & 126 & 71 & 52 & 36 \\
\hline 2920 & 50 & 1711 & 933 & 188 & 144 & 115 & 134 & 104 & 130 & 80 & 60 & 33 \\
\hline 2921 & 56 & 1594 & 845 & 189 & 144 & 108 & 132 & 109 & 135 & 76 & 55 & 40 \\
\hline 2922 & 60 & 1554 & 838 & 182 & 156 & 111 & 141 & 107 & 124 & 75 & 52 & 41 \\
\hline 2923 & 70 & 1492 & 819 & 185 & 148 & 106 & 123 & 98 & 110 & 77 & 48 & 37 \\
\hline 2924 & 30 & 1600 & 845 & 198 & 144 & 108 & 131 & 108 & 134 & 73 & 54 & 36 \\
\hline 2925 & 39 & 1576 & 859 & 174 & 141 & 117 & 136 & 100 & 123 & 86 & 57 & 34 \\
\hline 2926 & 30 & 1690 & 878 & 183 & (121) & 118 & 140 & 103 & 132 & 84 & 65 & 38 \\
\hline 2927 & 24 & 1582 & 860 & 188 & 148 & 111 & 134 & 105 & 122 & 69 & 51 & 37 \\
\hline 2928 & 35 & 1583 & 865 & 190 & 151 & 113 & 137 & 105 & 118 & 79 & 54 & 34 \\
\hline 2929 & 22 & . 1660 & 885 & 186 & 141 & 114 & 133 & 108 & 118 & 67 & 47 & 35 \\
\hline 2930 & 50 & 1663 & 900 & 183 & 144 & 113 & 130 & 105 & 120 & 67 & 48 & 30 \\
\hline 2931 & 55 & 1694 & 915 & 188 & 140 & 114 & 133 & 108 & 129 & 72 & 58 & 36 \\
\hline 29 & 54 & 1695 & 923 & 187 & 144 & 114 & 140 & 117 & 137 & 83 & 58 & 36 \\
\hline & 22 & 1633 & 902 & 188 & 146 & $133 t$ & 136 & 99 & 115 & 63 & 45 & 34 \\
\hline
\end{tabular}

* Shortened because edentulous.

† Questionable. 


\section{INDICES}

\begin{tabular}{|c|c|c|c|c|c|c|c|c|c|c|c|}
\hline No. & EL & EB & RSH & B/L & $\mathbf{B}^{\prime} / \mathbf{B}$ & GH/J & $\mathbf{G}^{\prime} \mathbf{H} / \mathbf{J}$ & $\mathrm{NB} / \mathrm{NH}$ & EB/EL & go-go/J & $\mathbf{B}^{\prime} / \mathbf{J}$ \\
\hline 2888 & 61 & 33 & 52.1 & 70.4 & 84.8 & 93.6 & 62.8 & 58.2 & 54.1 & 75.0 & 83.6 \\
\hline 2889 & 64 & 32 & 53.0 & 79.0 & 81.6 & 90.8 & 58.1 & 66.2 & 50.0 & 68.8 & 85.1 \\
\hline 2890 & 61 & 30 & 52.6 & 73.5 & 82.3 & 97.8 & 63.1 & 64.1 & 49.2 & 75.2 & 86.5 \\
\hline 2891 & 53 & 33 & 56.1 & 75.9 & 77.0 & 92.1 & 60.1 & 61.2 & 62.3 & 79.1 & 82.6 \\
\hline 392 & 69 & 34 & 51.9 & 77.4 & 80.2 & 97.8 & 61.6 & 54.4 & 49.3 & 79.2 & 87.7 \\
\hline 2893 & 58 & 28 & 53.7 & 77.4 & 81.1 & 94.9 & 60.0 & 50.0 & 48.3 & 75.6 & 85.9 \\
\hline 2894 & 60 & 27 & 54.5 & 79.2 & 83.0 & 86.7 & 55.1 & 55.7 & 45.0 & 72.8 & 86.0 \\
\hline 2895 & 57 & 32 & 51.3 & 71.9 & 84.8 & 92.6 & 54.1 & 79.3 & 56.2 & 72.6 & 86.7 \\
\hline $2 \xi$ & 64 & 34 & 54.0 & 77.2 & 80.0 & 83.5 & 51.9 & 73.2 & 53.1 & 86.5 & 87.3 \\
\hline 397 & 64 & 38 & 54.1 & 84.7 & 74.2 & 91.5 & 60.2 & 47.3 & 59.4 & 76.6 & 81.6 \\
\hline 2898 & 61 & 34 & 53.3 & 81.7 & 75.5 & 90.4 & 55.9 & 64.8 & 55.7 & 79.4 & 81.6 \\
\hline 2899 & 60 & 31 & 51.6 & 81.7 & 81.1 & 92.6 & 58.1 & 61.0 & 51.7 & 74.3 & 85.3 \\
\hline 2900 & 77 & 41 & 53.7 & 80.3 & 81.3 & 88.3 & 54.5 & 66.7 & 53.2 & 73.1 & 86.9 \\
\hline 2901 & 65 & 30 & 55.3 & 78.1 & 80.8 & 86.7 & 49.6 & 66.0 & 46.2 & 79.7 & 82.5 \\
\hline 2902 & 66 & 34 & 54.9 & 78.4 & 81.5 & 91.2 & 53.4 & 62.5 & 51.5 & 80.0 & 87.4 \\
\hline 2903 & 54 & 30 & 56.1 & 77.8 & 78.2 & 91.0 & 52.3 & 63.5 & 55.5 & 67.9 & 85.9 \\
\hline 2904 & 57 & 33 & 52.1 & 79.4 & 79.5 & 86.9 & 53.3 & 66.0 & 57.8 & 78.8 & 84.6 \\
\hline 290 & 56 & 29 & 53.0 & 79.9 & 77.5 & 82.6 & 48.6 & 71.6 & 51.8 & 71.0 & 82.6 \\
\hline 2906 & 57 & 34 & 52.7 & 75.8 & 81.5 & 89.5 & 56.6 & 57.8 & 59.6 & 72.0 & 80.4 \\
\hline 2907 & 63 & 33 & 54.6 & 85.5 & 77.1 & & & 58.7 & 52.4 & & \\
\hline 2908 & 65 & $25 \ddagger$ & 52.9 & 77.7 & 81.8 & 78.8 & 45.3 & 71.1 & $38.4 \ddagger$ & 71.6 & 85.4 \\
\hline 2909 & 57 & 34 & 52.2 & 69.9 & 80.3 & 93.7 & 53.2 & 67.3 & 59.6 & 87.4 & 87.4 \\
\hline 2910 & 59 & 32 & 52.1 & 78.6 & 78.2 & 96.4 & 55.2 & 54.4 & 54.2 & 69.8 & 84.5 \\
\hline 2911 & 58 & 32 & 54.2 & 77.6 & 83.0 & 87.6 & 56.6 & 67.9 & 55.2 & 81.4 & 86.8 \\
\hline 2912 & 52 & 31 & 49.1 & 86.2 & 74.9 & 85.9 & 48.4 & 68.8 & 59.6 & 75.8 & 88.3 \\
\hline 291 & 63 & 31 & 53.0 & 80.9 & 79.9 & 86.9 & 47.8 & 67.4 & 49.2 & 75.8 & 84.5 \\
\hline 291 & 50 & 28 & 53. & 80.5 & 76.4 & 91.6 & 55 & 59.6 & & 79.4 & 86.3 \\
\hline 2915 & 60 & 34 & 51.0 & 84.8 & 84.1 & 87.2 & 55.3 & 67.2 & 56.6 & 75.2 & 90.0 \\
\hline 2916 & 57 & 33 & 53.3 & 79.0 & 77.6 & 94.5 & 53.1 & 69.2 & 57.9 & 79.7 & 89.1 \\
\hline 2917 & 62 & 34 & 52.2 & 73.1 & 77.8 & 83.6 & 52.5 & 63.4 & 54.8 & 75.9 & 76.6 \\
\hline 2918 & 53 & 38 & 52.4 & 82.8 & 78.5 & 92.0 & 56.5 & 54.7 & 71.7 & 77.5 & 87.7 \\
\hline 2919 & 56 & 30 & 50.8 & 74.9 & 83.5 & 92.7 & 52.2 & 69.2 & 53.6 & 80.9 & 86.0 \\
\hline 2920 & 56 & 30 & 54.5 & 77.6 & 79.9 & 97.0 & 59.7 & 55.0 & & 77.6 & 85.9 \\
\hline 292 & 63 & 33 & 53.0 & 76.2 & 75.0 & 102.3 & 57.6 & 72.8 & 52.4 & 82.6 & 81.9 \\
\hline 2922 & 68 & 44 & 53.9 & 85.7 & 71.7 & 88.0 & 53.2 & 78.8 & 64.6 & 75.9 & 78.6 \\
\hline 2923 & 56 & 34 & 54.9 & 80.0 & 71.6 & 89.5 & 62.6 & 77.1 & 60.7 & 79.7 & 86.1 \\
\hline 2924 & 71 & 33 & 52.8 & 72.7 & 75.0 & 102.3 & 55.8 & 66.7 & 46.4 & 82.5 & 82.5 \\
\hline 2925 & 64 & 34 & 54.5 & 81.0 & 83.0 & 90.5 & 63.3 & 59.6 & 53.1 & 73.5 & 86.0 \\
\hline 292 & 62 & 32 & 52.0 & & & 94.3 & 60.0 & 58.4 & 51.6 & 73.6 & 84.2 \\
\hline 2927 & 54 & 33 & 54.4 & 78.7 & 75.0 & 91.0 & 51.5 & 72.5 & 61.1 & 78.4 & 82.9 \\
\hline 29 & 66 & 36 & 54.6 & 80.0 & 74.9 & 86.1 & 57.7 & 62.9 & 54.5 & 76.6 & 83.2 \\
\hline 29 & 64 & 37 & 53.3 & 75.8 & 80.9 & 88.7 & 50.4 & 74.5 & 57.8 & 81.2 & 85.0 \\
\hline 293 & 66 & 37 & 54.1 & 78.6 & 78.5 & 92.3 & 51.5 & 62.5 & 56.0 & 80.8 & 86.4 \\
\hline 293 & 68 & 47 & 54.0 & 74.5 & 81.4 & 97.0 & 54.2 & 62.0 & 69.1 & 81.2 & 85.8 \\
\hline & 64 & 36 & 54.5 & 77.0 & 79.2 & 97.9 & 59.3 & 62.1 & 56.3 & 83.6 & 81.4 \\
\hline & & 32 & 55.2 & 77.6 & & 84.5 & 46.4 & 75.5 & 52.4 & 72.8 & 97.9 \\
\hline
\end{tabular}




\section{MeAsurements}

\begin{tabular}{|c|c|c|c|c|c|c|c|c|c|c|c|}
\hline No. & Age & Stature & SH & L & B & $\mathbf{B}^{\prime}$ & $\mathbf{J}$ & go-go & GH & $\mathbf{G}^{\prime} \mathbf{H}$ & NH \\
\hline 2934 & 25 & 1644 & 915 & 188 & 135 & 110 & 132 & 96 & 125 & 68 & 49 \\
\hline 2935 & 28 & 1653 & 896 & 189 & 148 & 113 & 138 & 113 & 120 & 66 & 51 \\
\hline 2936 & 39 & 1650 & 875 & 182 & 150 & 110 & 141 & 108 & 113 & 67 & 48 \\
\hline 37 & 37 & 1620 & 867 & 188 & 141 & 109 & 132 & 107 & 126 & 77 & 57 \\
\hline 938 & 19 & 1540 & 808 & 183 & 144 & 113 & 136 & 102 & 122 & 69 & 46 \\
\hline 2939 & 30 & 1790 & 918 & 195 & 148 & 118 & 142 & 104 & 125 & 73 & 52 \\
\hline 940 & 25 & 1640 & 892 & 187 & 155 & 118 & 141 & 113 & 125 & 73 & 50 \\
\hline 2941 & 55 & 1620 & 892 & 182 & 142 & 108 & 141 & 105 & 118 & 68 & 57 \\
\hline 2942 & 25 & 1695 & 875 & 178 & 142 & 111 & 138 & 104 & 119 & 72 & 56 \\
\hline 2943 & 22 & 169 & 895 & 181 & 145 & 113 & 134 & 104 & 113 & 67 & 50 \\
\hline 44 & 30 & 1600 & 862 & 185 & 148 & 115 & 140 & 106 & 133 & 70 & 53 \\
\hline 45 & 50 & 1558 & 875 & 185 & 146 & 107 & 128 & 102 & 110 & 68 & 53 \\
\hline 46 & 22 & 1522 & 818 & 183 & 145 & 111 . & 132 & 98 & 114 & 64 & 48 \\
\hline 47 & 26 & 1580 & 817 & 182 & 141 & 111 & 131 & 105 & 117 & 63 & 48 \\
\hline 2948 & 70 & 1613 & 840 & 194 & 139 & 110 & 134 & 103 & 114 & 68 & 58 \\
\hline 2949 & 55 & 1597 & 892 & 197 & 141 & 108 & 127 & 97 & 128 & 78 & 5 \\
\hline 2950 & 55 & 1713 & 895 & 189 & 139 & 114 & 131 & 104 & 129 & 80 & 60 \\
\hline 951 & 20 & 1704 & 955 & 178 & 155 & 115 & 143 & 106 & 107 & 65 & 50 \\
\hline 2952 & 55 & 1686 & 859 & 195 & 151 & 114 & 145 & 109 & 133 & 79 & 66 \\
\hline 53 & 40 & 1734 & 917 & 199 & 154 & 117 & 137 & 118 & 119 & 74 & 58 \\
\hline 54 & 51 & 154 & 855 & 188 & 137 & 107 & 128 & 107 & 126 & 73 & 53 \\
\hline 2955 & 20 & 167 & 885 & 183 & 140 & 106 & 128 & 104 & 125 & 69 & 47 \\
\hline 295 & 40 & $16 ?$ & 887 & 179 & 138 & 110 & 126 & 98 & 134 & 77 & 55 \\
\hline 2957 & 40 & 169 & 915 & $19^{\prime}$ & 150 & 113 & 141 & 101 & 126 & 80 & 57 \\
\hline 2958 & 50 & 1754 & 975 & 194 & 145 & 113 & 142 & 111 & 13 & 86 & 63 \\
\hline 2959 & 40 & 1657 & 890 & 183 & 157 & 120 & 145 & 10 & 123 & 77 & 65 \\
\hline 2960 & 45 & 1650 & 840 & 186 & 138 & 113 & 125 & 107 & 115 & 68 & 50 \\
\hline 61 & 54 & 161 & 855 & 186 & 142 & 107 & 128 & 102 & 113 & 66 & 55 \\
\hline & 18 & & 915 & 185 & 147 & 111 & 129 & 9 & 124 & 76 & 58 \\
\hline 3 & 25 & & 828 & 19 & 148 & 113 & 134 & 111 & 122 & 70 & 53 \\
\hline 2964 & 18 & 1656 & 870 & 176 & 142 & 108 & 124 & 92 & 107 & 68 & 45 \\
\hline 2965 & 24 & 1595 & 841 & 184 & 146 & 115 & 135 & 101 & 135 & 82 & 62 \\
\hline 2966 & 34 & 1715 & 925 & 19 & 154 & 117 & 145 & 115 & 119 & 77 & 65 \\
\hline 2967 & 23 & 1743 & 912 & 19 & 145 & 116 & 136 & 10 & 131 & 74 & 60 \\
\hline 296 & 55 & 174 & 92 & 18 & 153 & 121 & 139 & 11 & 122 & 85 & 64 \\
\hline 296 & 29 & & 825 & 180 & 143 & 121 & 138 & 10 & 121 & 81 & 61 \\
\hline & 50 & & 86 & 18 & 147 & 116 & 140 & 10 & 122 & 78 & 64 \\
\hline 971 & 18 & 1650 & 908 & 187 & 148 & 117 & 140 & 101 & 129 & 74 & 60 \\
\hline 2972 & 20 & 1686 & 902 & 181 & 150 & 118 & 147 & 11 & 118 & 73 & 57 \\
\hline 2973 & 54 & 1598 & 801 & 181 & 141 & 107 & 125 & (85) & 131 & 81 & 64 \\
\hline $1974^{*}$ & 71 & 1652 & 866 & 185 & 147 & 118 & 137 & 104 & 118 & 73 & 54 \\
\hline & 16 & 174 & 873 & 185 & 144 & 115 & 137 & 108 & 128 & 80 & 62 \\
\hline & 68 & & 880 & 192 & 150 & 124 & 143 & 101 & 132 & 81 & 66 \\
\hline & 23 & & 95 & 18 & 146 & 118 & 144 & 107 & 118 & 70 & 51 \\
\hline & 38 & & 906 & 183 & 149 & 114 & 137 & 10 & 129 & 81 & 62 \\
\hline . & 25 & 1760 & 920 & 188 & 148 & $\ldots$ & 146 & 107 & 124 & 76 & .58 \\
\hline
\end{tabular}

* Omitted from the averages because of age. 


\section{INDICES}

\begin{tabular}{|c|c|c|c|c|c|c|c|c|c|c|c|}
\hline No. & EL & EB & RSH & B/L & $\mathbf{B}^{\prime} / \mathbf{B}$ & $\mathrm{GH} / \mathrm{J}$ & $\mathbf{G}^{\prime} \mathbf{H} / \mathbf{J}$ & $\mathrm{NB} / \mathrm{NH}$ & EB/EL & $\mathrm{go}-\mathrm{go} / \mathrm{J}$ & $B^{\prime} / J$ \\
\hline 2934 & 61 & 35 & 55.6 & 71.4 & 81.5 & 94.6 & 51.6 & 67.4 & 57.4 & 72.7 & 83.4 \\
\hline 35 & 60 & 33 & 54.2 & & 76.4 & & & & & & \\
\hline 36 & 52 & 33 & 52.5 & 82.4 & 3.4 & & & & & & \\
\hline 37 & 59 & 37 & 53.5 & 75.0 & 7 & & & & & & \\
\hline 38 & 61 & 36 & & 78.6 & & & & & 59 & & 3. \\
\hline 9 & 56 & 34 & 1.3 & 75.9 & 9.6 & 0 & & & & & 3. \\
\hline 0 & 65 & 34 & 4.4 & 2.9 & & & & & & & \\
\hline 41 & 67 & 36 & & & & & & & & & \\
\hline 42 & 63 & 35 & 51.6 & & & & & & & & \\
\hline 3 & 60 & 32 & 52.9 & 80.1 & 77 & & & & & & \\
\hline & 64 & 33 & 3.9 & & & & & & & & 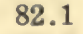 \\
\hline & 62 & 44 & .1 & & & & & & & & \\
\hline & 60 & 37 & 53.7 & 9.2 & & & & & & & \\
\hline 47 & 51 & 30 & 51.7 & & & & & & & & \\
\hline 8 & 68 & 34 & 52. & & & & & & & & \\
\hline 14 & 74 & 36 & & & & & & & & & . \\
\hline & 58 & 32 & .2 & & & & & & & & . \\
\hline & 60 & 36 & 6.0 & 7.0 & .2 & & & & & & \\
\hline & 64 & 30 & & 77.4 & & & & & & & \\
\hline & 58 & 33 & 52.9 & & & & & & & & \\
\hline & 64 & 33 & & & & & & & & & \\
\hline & 64 & 29 & & & & & & & & & \\
\hline & 56 & 30 & .0 & .1 & & & & & & & \\
\hline & 60 & 33 & 4.1 & & & & & & & & \\
\hline & 62 & 38 & & & & & & & & & \\
\hline & 61 & 37 & & & & & & & & & \\
\hline & 65 & 40 & & & & & & & & & \\
\hline & 55 & 35 & & & & & & & & & \\
\hline & 61 & 35 & & & & & & & & & \\
\hline & 60 & 3 & & .1 & & & & & & & \\
\hline & 50 & 27 & & & & & & & & & \\
\hline & 57 & 34 & & & & & & & & & \\
\hline & 56 & 32 & & & & & & & & & \\
\hline & 63 & 34 & & & & & & & & & \\
\hline & 72 & 33 & & & & & & & & & \\
\hline & 58 & 35 & & & & & & .2 & & & \\
\hline & 55 & 34 & 52.3 & & & & & & & & \\
\hline & 64 & 35 & & & & & & & & & \\
\hline & 58 & 32 & & & & & & & & & \\
\hline & 61 & 34 & & & & & & & & & \\
\hline & 55 & 31 & & 79 & & & & & & & \\
\hline & 58 & 26 & & & & & & & & & \\
\hline & 63 & 30 & & 78.1 & & & & & & & \\
\hline & 58 & 30 & & 79.4 & 80.8 & & & & & & \\
\hline & 58 & 31 & 51.6 & 81.4 & 76.5 & 94.2 & & 48.4 & 53.5 & & \\
\hline & 66 & 33 & 52.2 & 78.7 & & 84.9 & 52.1 & 62.1 & 50.0 & 73.3 & \\
\hline
\end{tabular}


Morphological Characters of Subba Males

\begin{tabular}{|c|c|c|c|c|c|c|c|c|}
\hline \multirow[b]{2}{*}{ No. } & \multicolumn{3}{|c|}{ HAIR } & \multicolumn{3}{|c|}{ EYISS } & \multicolumn{2}{|c|}{ NOSE } \\
\hline & Form & Texture & Color & Color & Sclers & Iris & Profile & Wings \\
\hline 2888 & $1 \mathrm{w}$ & medium & gray & bl-br & speck & zon & str & flar \\
\hline 2889 & l w & c-med & gray & bl-br & speck & zon & str & flar \\
\hline 2890 & i w & coarse & blk, gray & bl-br & clear & hom & conv & cp-m \\
\hline 2891 & l w & coarge & black & $\mathrm{dk} b r$ & clear & hom & str & cp-m \\
\hline 2892 & $\mathrm{l} w$ & c-med & $\mathrm{dk} \mathrm{br}$ & $\mathrm{dk}$ br & clear & hom & conv & comp \\
\hline 2893 & l w & coarse & blk, gray & bl-br & speck & hom & wavy & cp-m \\
\hline 2894 & l w & coarse & black & $\mathrm{dk}$ br & clear & hom & str & $m-f l$ \\
\hline 2895 & $\mathrm{l} w$ & c-med & $\mathrm{dk}$ br & gr-br & clear & hom & str & flar \\
\hline 2896 & $1 \mathrm{w}$ & coarse & black & bl-br & clear & hom & str & flar \\
\hline 2897 & l w & coarse & black & bl-br & clear & hom & conv & cp-m \\
\hline 2898 & $1 \mathrm{w}$ & coarse & black & bl-br & clear & hom & str & medium \\
\hline 2899 & $1 \mathrm{w}$ & c-med & dk br & bl-br & speck & hom & conv & $\mathrm{m}-\mathrm{fl}$ \\
\hline 2900 & $1 \mathrm{w}$ & medium & blk, gray & bl-br & clear & zon & str & medium \\
\hline 2901 & $1 \mathrm{w}$ & m-fine & red br & bl-br & clear & hom & $c-c$ & medium \\
\hline 2902 & & coarse & blk, gray & bl-br & clear & ray & conv & $m-f$ \\
\hline 2903 & $1 \mathrm{w}$ & c-med & red br & bl-br & clear & zon & str & medium \\
\hline 2904 & $1 \mathrm{w}$ & medium & $\mathrm{dk}$ br & bl-br & clear & hom & str & $m-f$ \\
\hline $2905^{*}$ & & & black & bl-br & clear & zon & str & flar \\
\hline 2906 & I w & coarse & blk, gray & $\mathrm{bl}-\mathrm{br}$ & speck & hom & str & $m-f l$ \\
\hline 2907 & $d w$ & coarse & black & bl-br & clear & zon & conv. & medium \\
\hline 2908 & $1 \mathrm{w}$ & coarse & black & bl-br & clear & hom & conv & medium \\
\hline 2909 & $1 \mathrm{w}$ & coarse & red br & bl-br & clear & zon & wavy & m-fl \\
\hline $2910^{*}$ & & & $\mathrm{v}$ dk br & bl-br & clear & hom & conv & comp \\
\hline 2911 & d w & medium & $\mathbf{v ~ d k ~ b r}$ & bl-br & clear & hom & str & flar \\
\hline 2912 & $1 \mathrm{w}$ & medium & $\mathrm{v}$ dk br & bl-br & clear & ray & conc & $m-f l$ \\
\hline 2913 & d w & fine & $\mathbf{v}$ dk br & bl-br & clear & hom & conv & comp \\
\hline 2914 & $d w$ & coarse & black & bl-br & clear & hom & conv & medium \\
\hline 2915 & $1 \mathrm{w}$ & coarse & blk, gray & bl-br & clear & hom & str & flar \\
\hline 2916 & $1 \mathrm{w}$ & c-med & $\mathrm{v}$ dk br & bl-br & clear & hom & conv & medium \\
\hline 2917 & $\mathrm{l} w$ & medium & gray & bl-br & clear & zon & str & comp \\
\hline 2918 & $1 \mathrm{w}$ & medium & black & bl-br & clear & zon & str & comp \\
\hline $2919^{*}$ & $\ldots$ & ........ & red br & $\mathrm{gr}-\mathrm{br}$ & clear & zon & str & $\mathrm{cp}-\mathrm{m}$ \\
\hline $2920^{*}$ & $\ldots$ & & & bl-br & blood & zon & conv & medium \\
\hline 2921 & $c-f$ & coarse & br, gray & bl-br & clear & zon & conv & $m-f l$ \\
\hline 2922 & $1 \mathrm{w}$ & medium & gray & $\mathrm{dk}$ br & clear & & str & $c p-m$ \\
\hline 2923 & $1 \mathrm{w}$ & medium & white & bl-br & clear & hom & str & comp \\
\hline 2924 & $1 \mathrm{w}$ & coarse & $\mathrm{dk}$ br & bl-br & clear & hom & $c-c$ & $m-f$ \\
\hline 2925 & $\mathrm{l} \mathrm{w}$ & medium & blk, gray & $b l$-br & clear & hom & str & cp-m \\
\hline $2926^{*}$ & & & & bl-br & clear & hom & conv & medium \\
\hline 2927 & l w & coarse & black & & clear & hom & conv & cp-m \\
\hline 2928 & $\mathrm{l} w$ & medium & black & bl-br & clear & zon & str & medium \\
\hline 2929 & l w & medium & black & bl-br & clear & zon & $c-c$ & medium \\
\hline 2930 & $1 \mathrm{w}$ & medium & black & bl-l & clear & hom & conv & medium \\
\hline 2931 & $1 \mathrm{w}$ & coarse & blk, gray & $b l-b r$ & clear & hom & str & cp-m \\
\hline $2932^{*}$ & & & blk, gray & bl-br & clear & hom & conv & medium \\
\hline 2933 & l w & fine & black & bl-br & clear & hom & $c-c$ & medium \\
\hline 2934 & $1 \mathrm{w}$ & coarse & black & & clear & ray & conv & comp \\
\hline 2935 & $1 \mathrm{w}$ & medium & black & & clear & hom & str & medium \\
\hline 2936 & $1 \mathrm{w}$ & medium & black & bl-br & clear & zon & str & comp \\
\hline 2937 & $1 \mathrm{w}$ & medium & black & & clear & zon & str & comp \\
\hline 2938 & $\mathrm{l} w$ & medium & black & bl-br & clear & zon & str & medium \\
\hline 2939 & $d w$ & medium & $\mathrm{dk}$ br & bl-br & clear & zon & str & medium \\
\hline & $1 \mathrm{w}$ & medium & $\mathrm{v}$ dk br & bl-br & clear & zon & str & comp \\
\hline & & & blk, gray & bl-br & clear & zon & str & comp \\
\hline 2942 & I w & medium & black & bl-br & clear & zon & str & medium \\
\hline 2943 & $l_{1} w$ & medium & black & bl-br & clear & hom & $c-c$ & medium \\
\hline
\end{tabular}


Morphological Characters of Subba Males

\begin{tabular}{|c|c|c|c|c|c|c|c|c|}
\hline \multirow[b]{2}{*}{ Na. } & \multicolumn{3}{|c|}{ burn } & \multicolumn{3}{|c|}{ EYres } & \multicolumn{2}{|c|}{ Nosss } \\
\hline & Form & Texture & Color & Color & Sclera & Iris & Profile & Wingm \\
\hline 2944 & $1 \mathrm{w}$ & medium & red br & $\mathrm{gr}-\mathrm{br}$ & clear & zon & conv & medium \\
\hline $2945^{*}$ & & & black & bl-br & clear & zon & str & medium \\
\hline 2946 & $1 \mathrm{w}$ & fine & dk br & $b l-b r$ & clear & ray & str & medium \\
\hline 2947 & $1 \mathrm{w}$ & medium & $\mathrm{v} d \mathrm{k}$ br & bl-br & clear & $20 n$ & str & medium \\
\hline 2948 & $1 \mathrm{w}$ & coarse & gray & bl-br & blood & hom & str & cp-m \\
\hline 2949 & $1 \mathrm{w}$ & medium & blk, gray & $b l-b r$ & & & str & medium \\
\hline 2950 & $1 \mathrm{w}$ & coarse & blk, gray & bl-br & clear & hom & str & ep-m \\
\hline 2951 & l $w$ & coarse & $\mathrm{dk}$ br & bl-br & clear & zon & str & medium \\
\hline 2952 & l $w$ & medium & blk, gray & bl-br & clear & hom & str & comp \\
\hline 2953 & I w & medium & blk, gray & $b l-b r$ & & $\ldots$ & str & medium \\
\hline 2954 & $1 \mathrm{w}$ & medium & blk, gray & $\mathrm{gr}-\mathrm{br}$ & clear & zon & conv & comp \\
\hline 2955 & l w & medium & dk br & bl-br & clear & hom & $c-c$ & cp-m \\
\hline 2956 & $1 \mathrm{w}$ & medium & black & bl-br & clear & zon & str & medium \\
\hline 2957 & $1 \mathrm{w}$ & medium & black & bl-br & clear & hom & str & medium \\
\hline 2958 & $\operatorname{lw}$ & medium & black & $b l$-br & clear & zon & conv & cp-m \\
\hline 2959 & $d w$ & medium & blk, gray & bl-br & clear & zon & str & medium \\
\hline 2960 & $1 \mathrm{w}$ & medium & blk, gray & $b l-b r$ & clear & zon & conv & flar \\
\hline 2961 & $1 \mathrm{w}$ & medium & blk, gray & bl-br & clear & zon & $c-c$ & medium \\
\hline 2962 & l w & medium & black & bl-br & clear & hom & $c-c$ & m-fl \\
\hline 2963 & $1 \mathrm{w}$ & medium & dk br & bl-br & clear & zon & $c-c$ & cp-m \\
\hline 2964 & $1 \mathrm{w}$ & medium & dk br & bl-br & clear & hom & str & $m-f$ \\
\hline 2965 & $1 \mathrm{w}$ & medium & black & bl-br & clear & hom & str & m-fl \\
\hline $2966^{*}$ & $\ldots$ & ....... & black & bl-br & clear & hom & str & medium \\
\hline 2967 & $1 \mathrm{w}$ & m-fine & dk br & dk br & clear & zon & str & m-fl \\
\hline 2968 & $1 \mathrm{w}$ & coarse & blk, gray & bl-br & clear & hom & str & comp \\
\hline 2969 & $1 \mathrm{w}$ & coarse & black & bl-br & clear & hom & conv & m-fl \\
\hline 2970 & $1 \mathrm{w}$ & coarse & blk, gray & bl-br & speck & hom & conv & m-fl \\
\hline 2971 & I w & medium & black & bl-br & clear & zon & wavy & medium \\
\hline 2972 & d w & c-med & black & bl-br & clear & zon & str & flar \\
\hline 2973 & $1 \mathrm{w}$ & medium & blk, gray & bl-br & clear & zon & conv & cp-m \\
\hline $2974 \ddagger$ & $1 \mathrm{w}$ & c-med & blk, gray & bl-br & clear & zon & $c-c$ & m-fl \\
\hline $2975 \ddagger$ & $1 \mathrm{w}$ & fine. & dk br & bl-br & clear & hom & str & medium \\
\hline 2976 & $1 \mathrm{w}$ & c-med & blk, gray & It br & blood & hom & conv & medium \\
\hline & $1 \mathrm{w}$ & m-fine & black & bl-br & clear & hom & $c-c$ & m-fl \\
\hline 0 & $\because \cdots$ & & & bl-br & sp-bl & hom & conv & cp-m \\
\hline 2979 & l w & coarse & black & bl-br & clear & hom & $c-c$ & medium \\
\hline
\end{tabular}

* Shaved.

¥Omitted from the averages because of age.

\section{INDIVIDUALS OMITTED FROM THE STATISTICAL SERIES}

Ten individuals were omitted from the series of averages because of age: Nos. 2980, 2982, 2988, and 2989 from Amara; Nos. 2994, 2995, 2997, 3000, and 3004 from Halfaya; and No. 3011 from Umm Saraidah.

Demography.-No. 2982 was a sister of No. 2985. No. 2988 was a daughter of No. 2987 (female) and No. 2908 (male).

Head and Facial Form.-Nos. 2994 and 3011 had very low foreheads. No. 2989 had a broader face than the average. 
Hair.-The majority had dark brown hair. Two had black and one brown-gray hair. With the exception of one individual with coarse-medium hair, the texture was either medium or fine. Three individuals had straight hair, five low wavy, and one very low wavy hair.

Eyes.-Six individuals had blue-brown and four dark brown eyes. The sclera was clear except in Nos. 2995 and 3011, both of whom had bloodshot eyes. The iris was rayed in five individuals, zoned in three, and homogeneous in one. Nos. 2982, 2988, and 2989 had blue-ringed eyes.

Nose.-Only one individual had a convex profile; two had a concave profile; the remainder were straight. The alae were compressed in two individuals, flaring in four, and medium in four. No. 3004 had a depressed nasal tip. No. 2980 wore a nose-ring (khazzamah).

Teeth.-Five individuals had a marked-over occlusion. Two had an edge-to-edge and two a slight-over bite. Nos. 2980, 2997, 3004, and 3011 had suffered no loss of teeth, but No. 2995 had plus caries and had lost from 9 to 16 teeth. The condition of the teeth was good in Nos. 2980, 2988, 2989, and 3004. No. 2982 had excellent teeth. No. 2994 had very white teeth, while those of No. 2997 were slightly discolored and those of No. 3011 were discolored.

Musculature and Health.-Nos. 2980, 2994, 3000, and 3004 were recorded as good in both categories.

Disease.-No. 2989 bore smallpox scars. No. 2994 had scars from Baghdad boils on her right cheek. The eyes of No. 2995 were in such bad condition that they would scarcely open.

Tattooing.-Nos. 2997, 3004, and 3011 had some tattooing.

\section{Subba Females}

Despite the small size (23) of the group, these figures, which were obtained by Miss Winifred Smeaton, are extremely important.

Nos. 2980, 2982, 2988, 2989, 2994, 2995, 2997, 3000, 3004, and 3011 have been omitted throughout the following discussions.

Birthplaces.-Amara, Nos. 2981 and 2983-2987; Chahala, Nos. 2990 and 2991; Halfaya, Nos. 2992, 2993, 2996, 2998, 2999, 30013003, and 3005; Qala Salih, Nos. 3008 and 3009; Huwaiza, No. 3006; Muhammera (Iran), No. 3007; and from a settled tribe living in a reed village near the Subba, No. 3010. The birthplace for No. 3012 was not given. 
Vital Statistics.-The families were unusually large, coincident with a very high death rate, particularly among the males. The number of brothers (21), sisters (21), sons (16), and daughters (17) was remarkably constant.

\section{Vital Statistics}

\begin{tabular}{|c|c|c|c|c|c|}
\hline 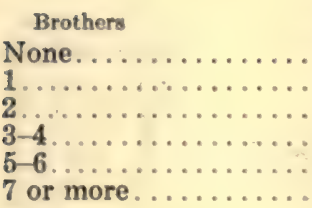 & $\begin{array}{r}\text { No. } \\
1 \\
1 \\
7 \\
8 \\
5 \\
0\end{array}$ & $\begin{array}{r}\text { Por cent } \\
4.55 \\
4.55 \\
31.82 \\
36.36 \\
22.73 \\
7\end{array}$ & 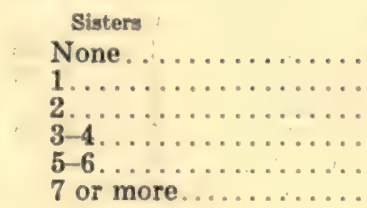 & $\begin{array}{r}\text { No. } \\
1 \\
1 \\
5 \\
9 \\
5 \\
1\end{array}$ & $\begin{array}{r}\text { Per cent } \\
4.55 \\
4.55 \\
22.73 \\
40.91 \\
22.73 \\
4.55\end{array}$ \\
\hline Total........... & 22 & 100.01 & Total........... & 22 & 100.02 \\
\hline 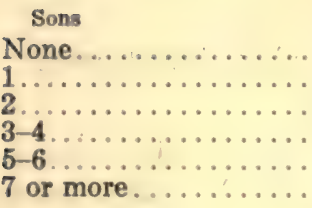 & $\begin{array}{r}\text { No. } \\
3 \\
4 \\
1 \\
5 \\
4 \\
2\end{array}$ & $\begin{array}{r}\text { Per cent } \\
15.79 \\
21.05 \\
5.26 \\
26.32 \\
21.05 \\
10.53\end{array}$ & 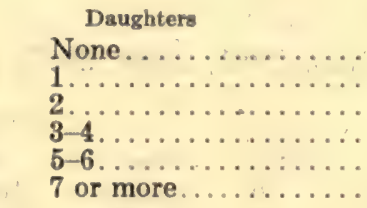 & $\begin{array}{r}\text { No. } \\
2 \\
4 \\
3 \\
4 \\
4 \\
2\end{array}$ & $\begin{array}{l}\text { Per cent } \\
10.53 \\
21.05 \\
15.79 \\
21.05 \\
21.05 \\
10.53\end{array}$ \\
\hline Total.......... & 19 & 100.00 & 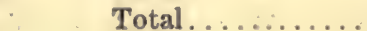 & 19 & 100.00 \\
\hline
\end{tabular}

Nos. 2981 and 2984 were sisters whose mother was No. 3007. The relationship of No. 2985 to No. 2982 and of No. 2986 to No. 2987 was that of a sister. No. 2987 was mother of No. 2988 and wife of No. 2908. No. 3007 was also mother of No. 2907 (male).

Head Form.-No. 2990 had a low brow that sloped backward. Nos. 2993, 3005, 3008, and 3009 had a low and No. 3010 a very low brow. No. 3006 had a high vaulted head.

Age.-The average age was 35.05 (range 18-64). Nine girls were less than twenty-five years of age.

Age Distribution

\begin{tabular}{|c|c|c|c|c|c|}
\hline Age & No. & Per cent & Age & No. & Per cent \\
\hline 18-19. & 2 & 8.70 & 45-49. & 1 & 4.34 \\
\hline $20-24$. & .7 & 30.43 & $50-54 \ldots$ & 3 & 13.04 \\
\hline 25-29. & . 1 & 4.35 & $55-59 \ldots$ & 0 & \\
\hline $30-34$. & .2 & 8.70 & 60-64. & 2 & 8.70 \\
\hline 35-39. & . 2 & 8.70 & 65-69. & 0 & $\ldots \ldots$ \\
\hline 40-44. & 3 & 13.04 & $70-x$. & 0 & $\ldots \ldots$ \\
\hline & & & Total. & 23 & 100.00 \\
\hline
\end{tabular}

MORPHOLOGICAL CHARACTERS OF SUBBA FEMALES

Hair.-The majority (82.61 per cent) had low wavy hair. 


\begin{tabular}{|c|c|c|c|c|c|}
\hline \multicolumn{6}{|c|}{ HaIR } \\
\hline Color & No. & Per cent & Form & No. & Per cent \\
\hline Black... & 7 & 30.43 & Straight.......... & 3 & 13.04 \\
\hline Very dark brown........ & 1 & $4.35^{\circ}$ & Very low waves.... & 1 & 4.35 \\
\hline Dark brown............ & . 11 & 47.83 & Low waves........ & 19 & 82.61 \\
\hline Brown $\ldots \ldots \ldots \ldots \ldots$ & . 0 & ..... & Deep waves........ & 0 & .... \\
\hline Reddish brown..$\ldots \ldots \ldots$ & 0 & $\ldots \ldots$ & Curly-frizzly....... & 0 & $\ldots$. \\
\hline Light brown ............ & 0 & ..... & Woolly........... & 0 & $\cdots \cdots$ \\
\hline 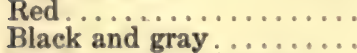 & $\begin{array}{l}0 \\
1\end{array}$ & 4.35 & Total & 23 & 100.00 \\
\hline Dark brown and gray.... & 2 & 8.70 & Texture & No. & Per cent \\
\hline Light brown and gray.... & 0 & & Coarse.. & 2 & 8.70 \\
\hline Gray and red brown ...... & 1 & 4.35 & Coarse-medium ... & 0 & \\
\hline 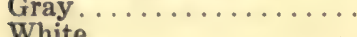 & 0 & $\cdots \cdots$ & Medium ......... & 12 & 52.17 \\
\hline 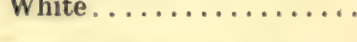 & 0 & $\cdots \cdot$ & Medium-fine. . . . . . . & 1 & 4.35 \\
\hline Total & 23 & 100.01 & & 8 & 34.78 \\
\hline & & & Total & 23 & 100.00 \\
\hline
\end{tabular}

Eyes.-Nos. 2981, 2986, 2987, and 3010 had blue-ringed eyes.

\begin{tabular}{|c|c|c|c|c|c|}
\hline Color & No. & Per cent & Iris & No. & Per cent \\
\hline Black. & 0 & & Homogeneous... & 3 & 13.64 \\
\hline Dark brown ...... & 7 & 30.43 & Rayed........ & 12 & 54.55 \\
\hline Blue-brown ....... & 11 & 47.83 & Zoned. & 7 & 31.82 \\
\hline Blue-brown....... & 1 & 4.35 & & & \\
\hline Green-brown .... & 1 & 4.35 & Total & 22 & 100.01 \\
\hline Green-brown ...... & 2 & 8.70 & Sclera & No. & Per cent \\
\hline Gray-brown...... & $\begin{array}{l}1 \\
0\end{array}$ & 4.35 & Clear. & 12 & 52.17 \\
\hline Blue............ & $\begin{array}{l}0 \\
0\end{array}$ & $\cdots \cdots$ & Yellow . & 2 & 8.70 \\
\hline 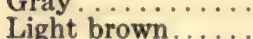 & $\begin{array}{l}0 \\
0\end{array}$ & …․ & Speckled. & 0 & \\
\hline Blue-gray .......... & 0 & $\cdots \cdots$ & Bloodshot. . , , . . . . & 9 & 39.13 \\
\hline Blue-green. . . . . . & 0 & $\ldots \ldots$ & Speckled and bloodshot. & 0 & $\ldots$. \\
\hline & & & Yellow and bloodshot....... & 0 & $\cdots \cdots$ \\
\hline & & & Total ............. & - 23 & 100.00 \\
\hline
\end{tabular}

Nose.-No. 3012 had a double plus and No. 2998 a plus nasal tip. In Nos. 2992 and 3008 the tip was depressed. No. 2993 had a nasal tip that was crooked to the right.

\begin{tabular}{|c|c|c|c|c|c|}
\hline \multirow[b]{2}{*}{ Profile } & \multicolumn{4}{|c|}{ Nose } & \multirow[b]{2}{*}{ Per cent } \\
\hline & No. & Per cent & Wings & No. & \\
\hline Wavy... & 0 & & Compressed........... & 5 & 21.74 \\
\hline Concave. & 2 & 8.70 & Compressed-medium .... & 1 & 4.35 \\
\hline Straight.. & 12 & 52.17 & Medium ........ & 9 & 39.13 \\
\hline Convex.............. & 8 & 34.78 & Medium-flaring. . . . . . . & 1 & 4.35 \\
\hline Concavo-convex..... & 1 & 4.35 & 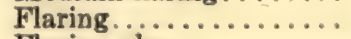 & 7 & 30.43 \\
\hline Total & 23 & 100.00 & & & \\
\hline
\end{tabular}

Teeth.-Five individuals (Nos. 2986, 2987, 2998, 3010, and 3012) showed slight wear and two (Nos. 3001 and 3006) had caries. No. 
3009 had crooked teeth and No. 3002 had very crooked, uneven teeth. No. 3003 and her children had poor teeth. No. 2986 showed wear, especially on the upper incisors. No. 2984 had a gold tooth.

\begin{tabular}{|c|c|c|c|c|c|c|c|}
\hline \multirow{2}{*}{ Bite } & \multicolumn{4}{|c|}{ ТЕЕтн } & \multirow[b]{2}{*}{$\therefore$} & \multirow[b]{2}{*}{ No. } & \multirow[b]{2}{*}{ Per cent } \\
\hline & & $\mathrm{Na}$ & Per cent & Condition & & & \\
\hline \multirow{4}{*}{$\begin{array}{l}\text { Under ...... } \\
\text { Edge-to-edge } \\
\text { Slight over.. } \\
\text { Marked over. }\end{array}$} & ........ & 0 & & Very bad. & $\ldots \ldots$ & 0 & \\
\hline & $\ldots \ldots$ & 3 & 17.64 & Bad.... & 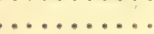 & 3 & 17.64 \\
\hline & $\ldots \ldots$ & 8 & 47.06 & Fair.... & & 1 & 5.88 \\
\hline & $\ldots \ldots$ & 6 & 35.29 & Good... & $\ldots \ldots \ldots \ldots$ & 9 & 52.94 \\
\hline \multirow{8}{*}{ Total..... } & & 17 & 09.99 & Excellent. & $\ldots \ldots \ldots \ldots$ & & \\
\hline & & & (2) & Total. & $\ldots \ldots$ & 17 & 99.99 \\
\hline & Loses & & & No. & Per cent & & \\
\hline & None. . & $\ldots$ & $\cdots \cdots$ & $\ldots \ldots 8$ & 42.11 & & \\
\hline & $5-8 \ldots$ & & & $\begin{array}{ll}\cdots & 10 \\
\ldots & 0\end{array}$ & 52.03 & & \\
\hline & $9-16 \ldots$ & & 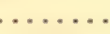 & $\ldots \ldots$ & 5.26 & & \\
\hline & $17-\ldots$ & & & $\because \cdots \cdots$ & $\cdots \cdots$ & & \\
\hline & Total. & • & & $\ldots \ldots 19$ & 100.00 & & \\
\hline
\end{tabular}

Musculature.-The general musculature of eleven women was good; in one individual it was poor.

Health.-One woman was in poor health and eleven were in good health.

Disease.-Nos. 2981, 2984, and 3009 bore smallpox scars. No. 2992 had disease scars on the face. No. 3001 had lost her right eye. To "relieve headaches" Nos. 2993 and 3005 each wore a piece of bone and two coral beads in their left ear.

Tattooing.-Twelve women out of twenty were tattooed despite the fact that it was forbidden (haram). Among the Subba women of Halfaya, many individuals were tattooed.

\section{STATISTICAL ANALYSES OF SUBBA FEMALES}

Stature.-The average was 152.61 (range 143.0-163.0).

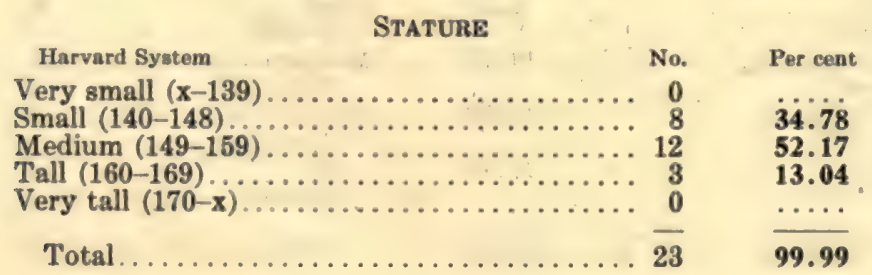




\section{Sitring Height (Trunk Length)}

Group

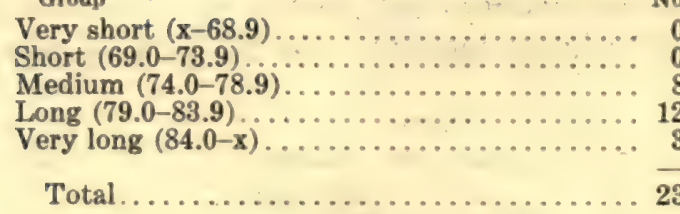

No. Per cent

-....

34.78

52.17

13.04

$23 \quad 99.99$

\section{Minimum Frontal Diameter}

Group

No.

Per cent

Very narrow $(x-99) \ldots \ldots \ldots \ldots \ldots \ldots .8$

34.78

Narrow $(100-109) \ldots . . . . . . . . . . . . . . .14$

60.87

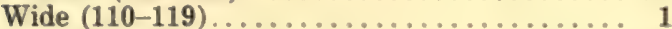

Very wide $(120-\mathbf{x}) \ldots \ldots \ldots \ldots \ldots \ldots \ldots$

4.35

Total

23

100.00

\section{Head Breadth}

Group

No. Per cent

Very narrow $(120-129) \ldots \ldots \ldots \ldots \ldots \ldots \ldots . . \ldots$

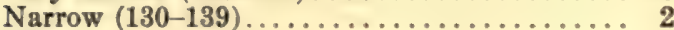

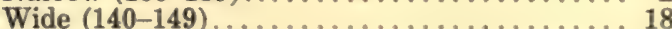

Very wide $(150-\mathrm{x}) \ldots \ldots \ldots \ldots \ldots \ldots . . . . .$.

8.70

78.26

13.04

Total

100.00

\section{Cephalic Index}

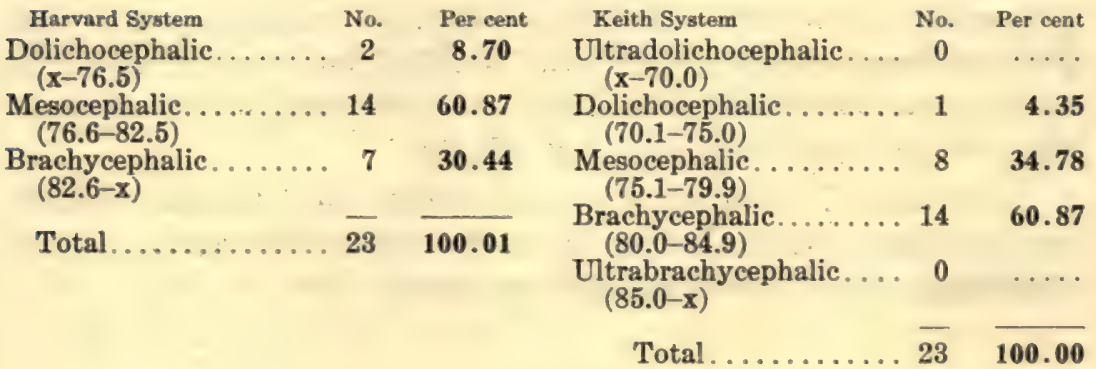

Facial Measurements and Indices

\begin{tabular}{|c|c|c|c|c|c|}
\hline $\begin{array}{l}\text { Upper facial height } \\
\text { Short. }\end{array}$ & No. & $\begin{array}{r}\text { Per cent } \\
4.35\end{array}$ & $\begin{array}{l}\text { Total facial height } \\
\text { Short }\end{array}$ & $\begin{array}{r}\text { No. } \\
9\end{array}$ & $\begin{array}{r}\text { Per cent } \\
39.13\end{array}$ \\
\hline${ }_{(x-63)}^{\text {Short }} \cdots \cdots \cdots$ & & & ${ }_{(x-109)}^{\text {Short }} \cdots \cdots$ & & \\
\hline $\begin{array}{c}\text { Medium short. . . . . . } \\
(64-69)\end{array}$ & 9 & 39.13 & $\begin{array}{c}\text { Medium short. ....... } \\
(110-119)\end{array}$ & 13 & 56.52 \\
\hline $\begin{array}{l}\text { Medium long. . . . . . . } \\
\quad(70-75)\end{array}$ & 8 & 34.78 & $\begin{array}{l}\text { Medium long } \ldots \ldots \\
\quad(120-129)\end{array}$ & 1 & 4.35 \\
\hline${ }_{(76-x)}^{\text {Long }} \ldots \ldots$ & 5 & 21.74 & $\begin{array}{l}\text { Long } \ldots \ldots \ldots \ldots \\
\quad(130-x)\end{array}$ & 0 & - \\
\hline Total. & 2 & 100.00 & Total . ... & 23 & 100.00 \\
\hline
\end{tabular}




\begin{tabular}{|c|c|c|}
\hline Total facial index & No. & Per cent \\
\hline $\begin{array}{l}\text { Euryprosopic }(x-84.5) \ldots \ldots \ldots \\
\text { Mesoprosopic }(84.6-89.4) \ldots \ldots \\
\text { Leptoprosopic }(89.5-x) \ldots \ldots\end{array}$ & $\begin{array}{r}5 \\
8 \\
10\end{array}$ & $\begin{array}{l}21.74 \\
34.78 \\
43.48\end{array}$ \\
\hline Total. & 23 & 100.00 \\
\hline
\end{tabular}

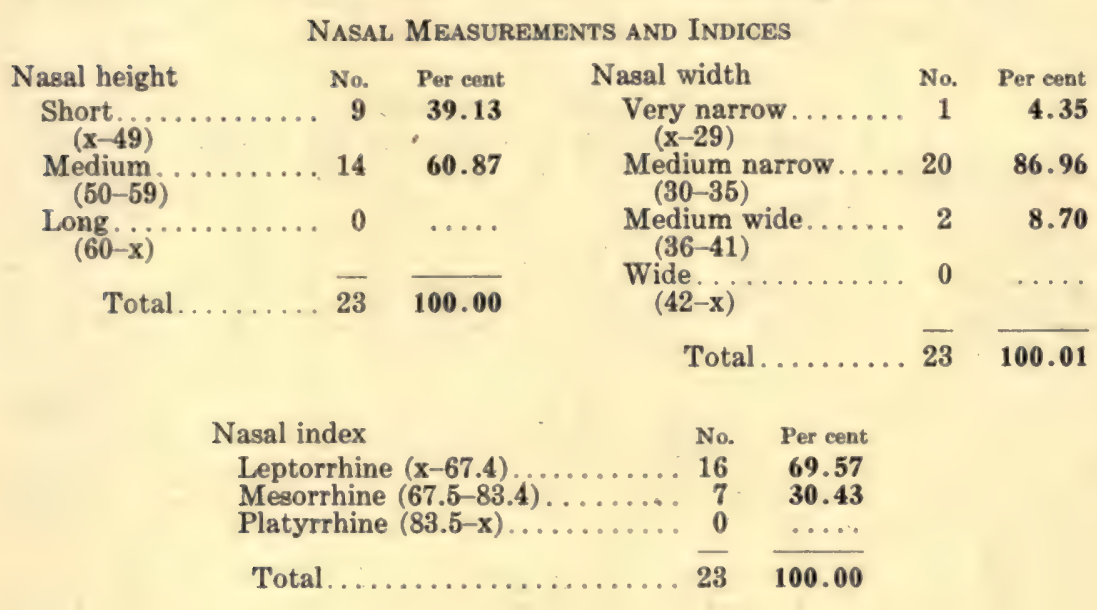

\section{SUMMARY}

The Subba women possessed more delicate features than their neighbors. Some of the young girls were attractive and pretty. The two main elements present are an oval-faced, almost straight-nosed type, and a square-faced, convex-nosed type. The former is represented by No. 2982 (Pl. 209), the latter by No. 3012 (Pl. 215).

The hair was dark brown with low waves and either medium or fine in texture. The eyes were brown with rayed or zoned irides and clear or bloodshot sclera. The nose was either straight or convex with a great variation in size of alae, ranging from compressed to flaring. Approximately half of the group had normal occlusion; the majority were in good condition. The muscular development and general health were good. The majority bore tattooed designs.

The stature was medium small but the trunk length was medium long, indicating that the legs tended to be short. The forehead was narrow but the head was wide. The cephalic index was brachycephalic (80.0-84.9), there being only one woman in the dolichocephalic (70.1-75.0) group. The upper facial height showed considerable variation from medium short to long, but the total facial height was medium short or short. The facial index was therefore incon- 
sistent, the majority being in the leptoprosopic category. The nose was medium or short in height and medium narrow in width. The nasal index was leptorrhine, with about one-third of the series in the mesorrhine division.

The Subba are short in stature, brachycephalic, straight or convex-nosed, leptorrhine, and leptoprosopic.

\begin{tabular}{|c|c|c|c|c|c|c|c|c|c|c|}
\hline \multirow[b]{3}{*}{ Standing height } & \multicolumn{7}{|c|}{ Sitting Height (Trunk Length) } & \multirow[b]{2}{*}{$689-x$} & \multirow{2}{*}{\multicolumn{2}{|c|}{ Totals }} \\
\hline & \multirow{2}{*}{$\begin{array}{c}840-x \\
\text { No. \% }\end{array}$} & \multicolumn{2}{|c|}{$790-839$} & \multicolumn{2}{|c|}{$740-789$} & \multicolumn{2}{|c|}{$690-739$} & & & \\
\hline & & & $\%$ & & $\%$ & No. & $\%$ & No. $\%$ & No. & $\%$ \\
\hline $1880-x \ldots \ldots$ & $0 \ldots$ & 0 & $\ldots \ldots$ & 0 & $\ldots$. & 0 & $\ldots$ & $0 \ldots$ & $\mathbf{0}$ & $\ldots$ \\
\hline $1700-1870$. & $0 \ldots$ & 0 & & 0 & $\ldots$. & 0 & ... & $0 \ldots$ & 0 & \\
\hline-1690. & 28.70 & & 4.35 & 0 & & 0 & $\ldots$ & $0 \ldots$ & $\mathbf{3}$ & 13.05 \\
\hline $490-1590$ & 14.35 & & 34.78 & & 13.04 & 0 & $\cdots$ & ... & 12 & 52.17 \\
\hline $1400-1480$. & $0 \ldots$ & 3 & 13.04 & 5 & 21.74 & 0 & $\cdots$ & $\ldots$ & 8 & 34.78 \\
\hline $\mathrm{x}-1390$ & $0 \ldots$ & 0 & $\cdots \cdots$ & 0 & $\cdots$ & 0 & $\cdots$ & $0 \ldots$ & 0 & $\therefore . .$. \\
\hline & & & & & & & & & 23 & 100.00 \\
\hline
\end{tabular}

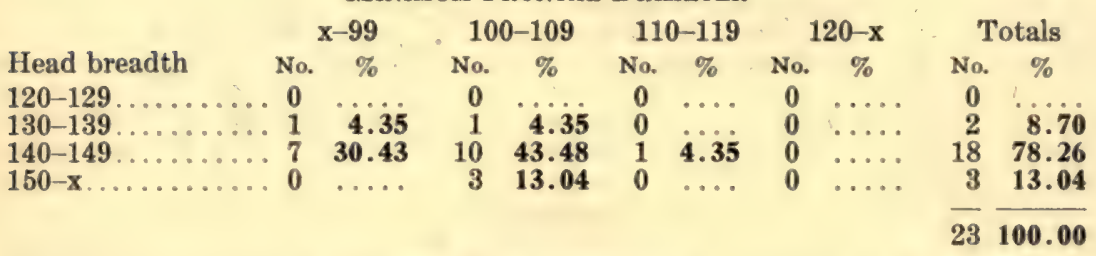

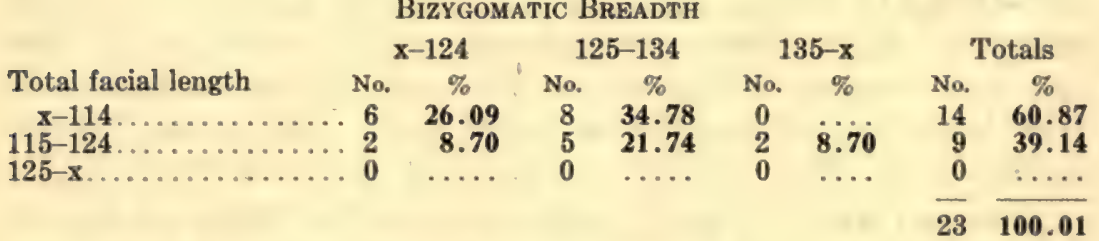

UPPER FACIAL LENGTH

\begin{tabular}{|c|c|c|c|c|c|c|c|c|c|c|c|c|}
\hline & & -63 & & $34-69$ & & 70-75 & & $6-81$ & & $2-x$ & & otals \\
\hline Total facial length & No. & $\%$ & No. & $\%$ & No. & $\%$ & No. & $\%$ & No. & $\%$ & No. & $\%$ \\
\hline$x-109 \ldots \ldots \ldots$ & 1 & 4.35 & 5 & 21.78 & 3 & 13.04 & 0 & & 0 & $\ldots$ & 9 & 39.17 \\
\hline $10-1$ & 0 & $\ldots$ & 4 & 17.39 & 5 & 21.74 & 4 & 17.39 & 0 & & 13 & 56.5 \\
\hline $120-129$ & 0 & $\ldots$ & 0 & $\ldots \ldots$ & 0 & $\ldots \ldots$ & 1 & 4.35 & 0 & $\ldots$ & 1 & 4.35 \\
\hline 30-x. & 0 & $\cdots$ & 0 & $\ldots$. & 0 & $\ldots$ & 0 & $\ldots$. & 0 & $\cdots$ & 0 & $\ldots \ldots$ \\
\hline
\end{tabular}

NASAL WIDTH

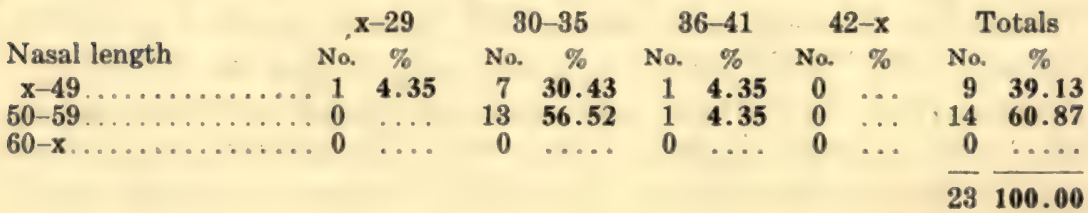


Measurfments and Indices of Subba Females

\begin{tabular}{|c|c|c|c|c|c|}
\hline Measurements & No. & Range & Mean & & \\
\hline Age $\ldots . . . \ldots$ & 23 & $18-64$ & $35.05 \pm 1.98$ & $14.05 \pm 1.40$ & $40.09 \pm 3.99$ \\
\hline Stature...... & 23 & $143-163$ & $152.61 \pm 0.75$ & $5.31 \pm 0.53$ & $3.48 \pm 0.35$ \\
\hline Sitting height. & 23 & $72-89$ & $79.90 \pm 0.49$ & $3.48 \pm 0.35$ & $4.36 \pm 0.43$ \\
\hline Head length.. & 22 & $170-187$ & $177.81 \pm 0.63$ & $4.35 \pm 0.44$ & $2.45 \pm 0.25$ \\
\hline Head breadth. & 22 & $135-152$ & $143.08 \pm 0.51$ & $3.57 \pm 0.36$ & $2.50 \pm 0.25$ \\
\hline Min. frontal diam.... & 23 & $93-112$ & $101.82 \pm 0.61$ & $4.36 \pm 0.43$ & $4.28 \pm 0.43$ \\
\hline Bizygomatic diameter & 23 & $120-139$ & $126.55 \pm 0.62$ & $4.40 \pm 0.44$ & $3.48 \pm 0.35$ \\
\hline Bigonial diameter.... & 22 & $74-105$ & $94.42 \pm 0.92$ & $6.40 \pm 0.65$ & $6.78 \pm 0.69$ \\
\hline Total facial height... & 23 & $100-124$ & $111.55 \pm 0.80$ & $5.70 \pm 0.57$ & $5.11 \pm 0.51$ \\
\hline Upper facial height. & 23 & $60-79$ & $70.50 \pm 0.64$ & $4.55 \pm 0.45$ & $6.45 \pm 0.64$ \\
\hline Nasal height....... & 23 & $44-59$ & $51.06 \pm 0.59$ & $4.20 \pm 0.42$ & $8.23 \pm 0.82$ \\
\hline Nasal breadth & 23 & $28-39$ & $32.90 \pm 0.26$ & $1.86 \pm 0.18$ & \pm 0.56 \\
\hline Ear length... & 22 & $56-71$ & $62.22 \pm 0.56$ & $3.92 \pm 0.40$ & $6.30 \pm 0.64$ \\
\hline $\begin{array}{c}\text { Ear breadth. ........ } \\
\text { Indices }\end{array}$ & 23 & $29-40$ & $33.39 \pm 0.36$ & $2.55 \pm 0.25$ & $7.64 \pm 0.76$ \\
\hline Relative sitting height & 23 & $50-57$ & $52.42 \pm 0.19$ & $1.38 \pm 0.14$ & $2.63 \pm 0.26$ \\
\hline Cephalic ........... & 22 & $74-85$ & $80.31 \pm 0.41$ & $2.85 \pm 0.29$ & $3.55 \pm 0.36$ \\
\hline Fronto-parietal. ... & 23 & & $70.90 \pm 0.44$ & $3.12 \pm 0.31$ & $4.40 \pm 0.44$ \\
\hline Zygo-frontal... & 23 & $72-87$ & $80.82 \pm 0.39$ & $2.80 \pm 0.28$ & $3.46 \pm 0.34$ \\
\hline Zygo-gonial. & 22 & $60-80$ & $74.77 \pm 0.63$ & $4.41 \pm 0.45$ & $5.90 \pm 0.60$ \\
\hline Total facial. & 23 & $80-99$ & $88.50 \pm 0.64$ & $4.55 \pm 0.45$ & $5.14 \pm 0.51$ \\
\hline Upper facial. & 23 & $46-66$ & $56.27 \pm 0.56$ & $3.96 \pm 0.39$ & $7.04 \pm 0.70$ \\
\hline Nasal. . . . . . & 23 & $56-79$ & $65.66 \pm 0.69$ & $4.92 \pm 0.49$ & $7.49 \pm 0.75$ \\
\hline Ear... & 22 & $41-64$ & $53.94 \pm 0.66$ & $4.56 \pm 0.46$ & $8.45 \pm 0.86$ \\
\hline
\end{tabular}

\section{Vital Statistics* of Subba Females}

\begin{tabular}{|c|c|c|c|c|c|c|c|}
\hline Number & Age & Married & Years & Sons & Daughters & Brothers & Sisters \\
\hline 2981 & 20 & 0 & $\cdots$ & $\ldots$ & ... & 5,0 & 6,0 \\
\hline $2982 \dagger$ & 15 & 0 & & & & 1,1 & 2,8 \\
\hline 2983 & 30 & 1 & 18 & 2,1 & 3,1 & 1,1 & 2,0 \\
\hline 2984 & 23 & 1 & 2 & 0,0 & 0,0 & 5,0 & 6,1 \\
\hline 2985 & 18 & 0 & & & & 1 , & \\
\hline 2986 & 50 & 1 & 30 & 4,8 & 0,1 & 0,2 & 3,0 \\
\hline 2987 & 40 & 1 & 28 & 1,4 & 4,1 & 0,2 & 3,0 \\
\hline $2988 \dagger$ & 12 & 0 & $\cdots$ & $\cdots$ & $\cdots$ & 1,4 & 3,0 \\
\hline $2989 \dagger$ & 16 & 0 & $\cdots$ & $\cdots$ & $\cdots$ & 2,3 & 3,1 \\
\hline 2990 & 19 & 0 & & & & $2, s$ & 1,1 \\
\hline 2991 & 22 & 1 & 6 & 1,0 & 1,0 & 4,1 & 0,0 \\
\hline 2992 & 22 & 0 & 29 & 34 & 3 & & 4,1 \\
\hline $\begin{array}{l}2993 \\
2994 \dagger\end{array}$ & $\begin{array}{l}40 \\
14\end{array}$ & $\begin{array}{l}1 \\
0\end{array}$ & 29 & 0,4 & 0,8 & 2,1 & 3,4 \\
\hline $2995 \dagger$ & 80 & 1 & . & 1,3 & $1, s$ & 0,5 & 2,8 \\
\hline 2996 & 20 & 1 & 10 & 1,0 & 1,0 & 2,0 & 3,0 \\
\hline $2997 \dagger$ & 15 & 0 & .. & & & 2,1 & 1,1 \\
\hline $2998^{\circ}$ & 40 & 1 & $\because$ & 4,2 & 4,8 & & 3,1 \\
\hline 2999 & 20 & 1 & 5 & 0,0 & 2,0 & 4,2 & 1,1 \\
\hline $3000 \dagger$ & 12 & 0 & $\cdots$ & & & & 2,1 \\
\hline 3001 & 60 & 1 & $\because$ & 2,2 & 2,0 & 2,0 & 0,2 \\
\hline 3002 & 21 & 1 & 6 & 0,0 & 0,1 & 2,1 & 3,1 \\
\hline 3003 & 38 & 1 & .. & 3,1 & 4,1 & 1,2 & 4,5 \\
\hline $\begin{array}{l}3004 \dagger \\
3005\end{array}$ & $\begin{array}{l}14 \\
28\end{array}$ & 0 & $\cdots$ & 01 & $A$ & & 1,4 \\
\hline 3006 & 32 & 1 & $\because$ & 3,1 & 1,4 & 0 & 1,0 \\
\hline 3007 & 50 & 1 & $\because$ & 2,0 & 2,0 & 0,3 & 3, 0 \\
\hline 3008 & 50 & 1 & 12 & 3,3 & 2,1 & 0,0 & 0,0 \\
\hline & 35 & 1 & 15 & 4,1 & 0,4 & 3,1 & 1,2 \\
\hline 301 & 45 & 1 & $\cdots$ & 0,1 & 0,0 & $0, s$ & 1,2 \\
\hline $\begin{array}{l}30111 \\
3012\end{array}$ & 60 & $\begin{array}{l}0 \\
1\end{array}$ & $\because$ & 8,1 & 3,2 & 3,0 & 3,0 \\
\hline
\end{tabular}

† Omitted from averages becaune of age. 
Measurements of Subba Females

\begin{tabular}{|c|c|c|c|c|c|c|c|c|c|c|c|c|}
\hline No. & Age & Stature & SH & L & B & $\mathbf{B}^{\prime}$ & $\mathbf{J}$ & 150-go & GH & $\mathrm{G}^{\prime} \mathrm{H}$ & NH & NB \\
\hline $2980^{*}$ & 14 & 1527 & 794 & 171 & 139 & 105 & 124 & 90 & 105 & 68 & 50 & 34 \\
\hline 2981 & 20 & 1580 & 870 & 175 & 144 & 106 & 132 & 103 & 117 & 74 & 56 & 34 \\
\hline $2982^{*}$ & 15 & 1568 & 821 & 176 & 144 & 101 & 127 & 93 & 108 & 68 & 47 & 30 \\
\hline 2983 & 30 & 1539 & 778 & 182 & 144 & 100 & 121 & 95 & 112 & 72 & 52 & 34 \\
\hline 2984 & 23 & 1618 & 844 & 178 & 141 & 111 & 135 & 100 & 124 & 78 & 55 & 38 \\
\hline 2985 & 18 & 1567 & 796 & 177 & 146 & 106 & 125 & 93 & 102 & 64 & 48 & 31 \\
\hline 2986 & 50 & 1534 & 798 & 179 & 150 & 105 & 132 & 98 & 115 & 69 & 52 & 32 \\
\hline 2987 & 40 & 1542 & 821 & 176 & 143 & 103 & 129 & 100 & 11 & 77 & 54 & 31 \\
\hline $2988^{*}$ & 12 & 1445 & 743 & 176 & 146 & 100 & 124 & 92 & 113 & 69 & 46 & 30 \\
\hline 989* & 16 & 1541 & 748 & 183 & 150 & 108 & 132 & 94 & 10 & 57 & 40 & 33 \\
\hline 2990 & 19 & 1609 & 848 & 174 & 137 & 97 & 125 & 87 & 114 & 69 & 52 & 32 \\
\hline 2991 & 22 & 1470 & 768 & 176 & 148 & 100 & 127 & 88 & 102 & 60 & 46 & 2 \\
\hline 2992 & 22 & 1546 & 800 & 170 & 144 & 102 & 124 & 88 & 110 & 73 & 54 & 5 \\
\hline 2993 & 40 & 1483 & 791 & 176 & 143 & 97 & 121 & 90 & 109 & 70 & 50 & 32 \\
\hline $2994^{*}$ & 14 & 1506 & 799 & 169 & 145 & 103 & 125 & 92 & 97 & 58 & 41 & 4 \\
\hline $2995^{*}$ & 80 & 1329 & 700 & 178 & 151 & 99 & 118 & & 110 & 66 & 52 & 34 \\
\hline 96 & 20 & 1464 & 752 & 176 & 143 & 108 & 129 & 102 & 105 & 67 & 47 & \\
\hline $2997^{*}$ & 15 & 1502 & 805 & 169 & 145 & 100 & 125 & 96 & 115 & 74 & 52 & 32 \\
\hline 299 & 40 & 1533 & 76 & 187 & 143 & 97 & 120 & 96 & 10 & 74 & 49 & \\
\hline 2999 & 20 & 1499 & 780 & 171 & 142 & 102 & 128 & 93 & 111 & 68 & 44 & 3 \\
\hline $3000^{*}$ & 12 & 1467 & 76 & 166 & 130 & 92 & 117 & 86 & 10 & 64 & 51 & \\
\hline 3001 & 60 & 1484 & 794 & 181 & 150 & 104 & 129 & & 109 & 73 & 57 & 35 \\
\hline 3002 & 21 & 1620 & 837 & 185 & 145 & 101 & 121 & 92 & 118 & 79 & 55 & \\
\hline & 38 & 1571 & 817 & 182 & 140 & 98 & 120 & 93 & 117 & 70 & 50 & 33 \\
\hline $3004^{*}$ & 14 & 1496 & 744 & 176 & 140 & 100 & 123 & 99 & 110 & 70 & 52 & \\
\hline & 28 & 1461 & 771 & 184 & 138 & 104 & 125 & 97 & 117 & 74 & 50 & 32 \\
\hline 3006 & 32 & 1455 & 830 & 177 & 140 & 93 & 122 & 76 & 107 & 66 & 45 & \\
\hline & 50 & 1517 & 798 & 176 & 142 & 99 & 127 & 94 & 119 & 76 & 56 & \\
\hline 30 & 50 & 1451 & 74 & 175 & 143 & 102 & 123 & (97) & 102 & 67 & 48 & \\
\hline & 35 & 148 & 77 & 170 & 141 & 94 & 126 & 94 & 110 & 69 & 46 & \\
\hline & 45 & 1549 & 80 & 179 & 141 & 98 & 128 & 99 & 10 & 66 & 47 & \\
\hline & 16 & 15 & 81 & 173 & 141 & 97 & 126 & 91 & 106 & 63 & 43 & 1 \\
\hline & 60 & $15^{\circ}$ & 82 & (182 & 152 & 109 & 136 & 105 & 119 & 76 & 57 & \\
\hline
\end{tabular}

* Omitted from averages because of age.

† Did not remove headdress.

\section{NOTES ON THE BANI LAM}

The Bani Lam are a numerous and important tribe, who cultivate the wheat and barley fields on either side of the Tigris. Their territory extends to the Iranian frontier from the neighborhood of Badra to Hawiza. In the early months of the year, the tribe is to be found chiefly in the grazing lands below the Iranian foothills.

The Bani Lam are divided into innumerable sections, only one of which, the Nusairi, is purely Bani Lam. The other sections are made up of foreign tribes, chiefly Bani Rabiah and Iranian, who from time to time have joined and finally become subjects of the Bani Lam. The Nusairi Section is divided into small groups, all of which have been named after the descendants of Nusairi's and Nasar's sons. The chiefs of the tribe have always been selected from four Baits: Madhkur, Arar, Jandal, and Abdul Khan. Unlike 


\section{INDICES OF SUbBa Females}

\begin{tabular}{|c|c|c|c|c|c|c|c|c|c|c|c|}
\hline No. & EL & EB & RSH & $B / L$ & $\mathbf{B}^{\prime} / \mathbf{B}$ & GH/J & $\mathbf{G}^{\prime} \mathbf{H} / \mathbf{J}$ & $\mathrm{NB} / \mathrm{NH}$ & EB/EL & go-go/J & $B^{\prime} / J$ \\
\hline 2980 & 59 & 30 & 51.9 & 81.3 & 75.5 & 84.7 & 54.8 & 68.0 & 50.9 & 72.6 & 84.7 \\
\hline 2981 & 61 & 30 & 55.1 & 82.3 & 73.6 & 88.6 & 56.1 & 60.6 & 49.1 & 78.0 & \\
\hline 2982 & 60 & 35 & 52.4 & 81.4 & 70.1 & 85.0 & 53.6 & 63.8 & 58.3 & 73.2 & 79.5 \\
\hline 2983 & 64 & 30 & 50.5 & 79.1 & 69.5 & 92.5 & 59.5 & 65.4 & 46.8 & 78.5 & 82.6 \\
\hline 2984 & 64 & 33 & 52.2 & 79.1 & 78.7 & 91.9 & 57.8 & 69.1 & 51.6 & 74.0 & 82.2 \\
\hline 2985 & 60 & 31 & 50.8 & 82.5 & 72.6 & 84.8 & 51.2 & 64.5 & 51.6 & 74.4 & 84.9 \\
\hline 2986 & 65 & 40 & 52.0 & 83.9 & 70.0 & 87.1 & 52.3 & 61.5 & 61.5 & 74.3 & 79.5 \\
\hline 2987 & 57 & 35 & 53.2 & 81.2 & 72.0 & 90.0 & 59.7 & 57.4 & 61.4 & 77.5 & 79.9 \\
\hline 2988 & 55 & 34 & 51.4 & 83.0 & 68.5 & 91.1 & 55.6 & 65.1 & 61.7 & 74.1 & 80 \\
\hline 2989 & 60 & 30 & 48.5 & 82.0 & 72.0 & 75.7 & 43.2 & 82.5 & 50.0 & 71.2 & 81.9 \\
\hline 2990 & 58 & 32 & 52.7 & 78.7 & 70.8 & 91.2 & 55.2 & 61.5 & 55.2 & 69.6 & 77.6 \\
\hline 2991 & 61 & 32 & 52.2 & 84.1 & 67.6 & 80.3 & $47 . \overline{2}$ & 69.6 & 52.5 & 69.3 & 78.7 \\
\hline 2992 & 59 & 31 & 51.7 & 84.7 & 70.8 & 88.7 & 58.9 & 64.8 & 52.5 & 71.0 & .3 \\
\hline 2993 & $59 \dagger$ & $34 \dagger$ & 53.3 & 81.3 & 67.8 & 90.1 & 57.9 & 64.0 & 57.6 & 74.4 & 80.2 \\
\hline 2994 & 55 & 31 & 53.0 & 85.8 & 71.0 & 77.6 & 46.4 & 82.9 & 56.4 & 73.6 & .4 \\
\hline 2995 & 64 & 34 & 52.6 & 84.8 & 65.6 & 93.2 & 55.9 & 65.4 & 53.1 & & .9 \\
\hline 2996 & 60 & 32 & 51.3 & 81.3 & 75.5 & 81.4 & 51.9 & 76.6 & 53.3 & 79.1 & 83.7 \\
\hline 2997 & 60 & 32 & 53.6 & 85.8 & 69.0 & & & & & 6.8 & \\
\hline 2998 & 67 & 35 & 49.9 & 76.5 & 67.8 & 90.8 & 61.7 & 67.4 & 52.2 & 80.0 & 80.8 \\
\hline 2999 & 69 & 29 & 52.0 & 83.0 & 71.8 & 86 & 53.1 & 75.0 & 42.0 & 72.7 & .7 \\
\hline 3000 & 57 & 30 & 52.1 & 78.3 & 70.8 & 86.3 & 54.7 & 60.8 & 52.6 & 73.5 & 8.6 \\
\hline 3001 & $69 \ddagger$ & 37 & 53.5 & 82.9 & 69.3 & 84 & 56. & 61.4 & 53.6 & & \\
\hline 3002 & $(65)$ & 34 & 51.6 & 78.4 & 69.7 & 97.5 & 65.3 & 60.0 & & 76.0 & \\
\hline 3003 & 60 & 33 & 52.0 & 76.9 & 70.0 & 97.5 & 58.3 & 66.0 & 55.0 & 77.5 & \\
\hline 3004 & 61 & 36 & 51.1 & 79.6 & 71.4 & & & 59.6 & & 80.5 & \\
\hline 3005 & 58 & 31 & 52.7 & 75.0 & 75.4 & 93.6 & 59.2 & 64.0 & 53. & 77.6 & \\
\hline 300 & 67 & 35 & 57.0 & 79.1 & 66.4 & 87 & & 64.4 & & 62.3 & \\
\hline 3007 & 66 & 36 & 52.6 & 80.6 & 69.6 & 93.6 & 59. & 60.6 & 54.5 & 74.0 & 78.0 \\
\hline 300 & 59 & 35 & 51.3 & 81.7 & 71.3 & 82. & & 68.8 & 59.3 & 78.9 & 82.9 \\
\hline 300 & 56 & 33 & 52.4 & 82.9 & 66.7 & 87.3 & 54. & 71.7 & 58.9 & 74.6 & 74 \\
\hline & 64 & 34 & 51.7 & 78.8 & 69.5 & 82 & & 70.1 & 53.1 & 77.4 & \\
\hline 301 & 62 & 32 & 53.7 & 81.5 & 68.8 & 84 & 50.0 & 72.1 & 51.6 & 72.2 & 77.0 \\
\hline 3012 & 62 & 35 & 53.4 & 83.5 & 71.7 & 87.5 & 55.9 & 57.9 & 56.5 & 77.2 & 80.2 \\
\hline
\end{tabular}

† Right ear measured.

$\$$ Ear lobe atretched by earrings.

those of the $\mathrm{Al} \mathrm{bu}$ Muhammad, the Baits have retained their original names.

They relate that some twelve generations back, Barrak, son of Mufarrij and one of the grandsons of Lam ibn Harithah, from whom they take their name and who was a chief of the Qahtan tribe of the Hejaz, migrated with his son, Hafidh al Lami, to Iraq and settled in Hawiza. Mubarak, chief of the Hawiza district, welcomed them as his guests and subjects. After a time Hafidh had a quarrel with Mubarak, resulting in an outbreak of war. Hafidh, who had earned for himself a reputation for justice, was supported by some of the present foreign tribes of the Bani Lam (Chaab, Darraj, Khazraj, and Hallaf). These were subjects of the Bani Rabiah, whose seat was between Kut al Imara and Al Qurna. Hafidh was victorious and after his occupation of the land the Bani Rabiah used to come yearly 


\section{Morphological Characters of Subba Females}

\begin{tabular}{|c|c|c|c|c|c|c|c|c|}
\hline \multirow{4}{*}{$\begin{array}{l}\text { No. } \\
2980^{*} \\
2981\end{array}$} & \multicolumn{3}{|c|}{ HAIR } & \multicolumn{3}{|c|}{ EYRes } & \multicolumn{2}{|c|}{ NOSIS } \\
\hline & Form & Texture & Color & Color & Sclera & Iris & Profile & Wings \\
\hline & str & c-med & $\mathrm{dk}$ br & $\mathrm{dk}$ br & clear & ray & str & flar \\
\hline & $1 \mathrm{w}$ & m-fine & $\mathrm{dk} b \mathrm{r}$ & $\mathrm{dk} b \mathrm{br}$ & yellow & zon & conv & comp \\
\hline $2982^{*}$ & l w & medium & black & $\mathrm{dk}$ br & clear & zon & conv & comp \\
\hline 2983 & $1 \mathrm{w}$ & fine & dk br & $\mathrm{dk}$ br & clear & zon & str & $\mathrm{m}-\mathrm{fl}^{2}$ \\
\hline 2984 & $1 \mathrm{w}$ & medium & $\mathrm{dk} \mathrm{br}$ & $\mathrm{gr}-\mathrm{br}$ & clear & zon & str & medium \\
\hline 2985 & l w & fine & $\mathrm{dk}$ br & $\mathrm{dk}$ br & clear & zon & conv & comp \\
\hline 2986 & v l w & fine & $\mathrm{dk}$ br & $\mathrm{dk}$ br & blood & zon & conv & comp \\
\hline 2987 & l w & fine & black & gray-br & blood & ray & eonv & ep-m \\
\hline $2988^{*}$ & str & fine & $\mathrm{dk}$ br & $\mathrm{dk}$ br & clear & zon & str & medium \\
\hline $2989^{*}$ & $1 \mathrm{w}$ & fine & $\mathrm{dk}$ br & $\mathrm{dk}$ br & clear & zon & cone & medium \\
\hline 2990 & str & coarse & black & bl-br . & clear & ray & str & flar \\
\hline 2991 & $1 \mathrm{w}$ & medium & $\mathrm{dk}$ br & $\mathrm{dk}$ br & clear & ray & cone & medium \\
\hline 2992 & str & medium & $\mathrm{dk}$ br & $\mathrm{bl}-\mathrm{br}$ & blood & ray & str & flar \\
\hline 2993 & $1 \mathrm{w}$ & medium & black & bl-br & clear & ray & str & medium \\
\hline $2994^{*}$ & $\mathrm{l} w$ & fine & black & $\mathrm{bl}-\mathrm{br}$ & clear & ray & cone & flar \\
\hline $2995 *$ & & medium & br, gray & bl-br & blood & & str & comp \\
\hline 2996 & str & medium & black & $\mathrm{dk} \mathrm{br}$ & clear & ray & str & flar \\
\hline $2997^{*}$ & str & medium & $\mathrm{dk}$ br & $\mathrm{bl}-\mathrm{br}$ & clear & ray & str & medium \\
\hline 2998 & $1 \mathrm{w}$ & medium & $\mathrm{dk}$ br & bl-br & clear & $\ldots$ & $c-c$ & flar \\
\hline 2999 & $1 \mathrm{w}$ & fine & black & bl-br & clear & ray & conv & flar \\
\hline $3000^{*}$ & I w & fine & $\mathrm{dk}$ br & bl-br & clear & hom & str & flar \\
\hline 3001 & $1 \mathrm{w}$ & coarse & br, gray & bl-br & clear & ray & conv & medium \\
\hline 3002 & l w & medium & $\mathrm{dk}$ br & bl-br & blood & hom & str & medium \\
\hline 3003 & $\mathrm{l} w$ & fine & dk br & bl-br & clear & ray & str & medium \\
\hline $3004^{*}$ & v l w & fine & $\mathrm{dk}$ br & bl-br & clear & ray & str & medium \\
\hline 3005 & l w & medium & black & $g r-b r$ & blood & ray & cone & comp \\
\hline 3006 & $\mathrm{l}$ w & fine & $\mathrm{dk}$ br & $g r-b r$ & clear & ray & str & medium \\
\hline & i w & medium & red br, gray & $\mathrm{bl}$-br & yellow & zon & conv & medium \\
\hline 3008 & $1 \mathrm{w}$ & medium & blk, gray & bl-br & blood & hom & str & flar \\
\hline & $1 \mathrm{w}$ & fine & black & bl-br & blood & ray & str & flar \\
\hline & $\mathrm{l} \mathrm{w}$ & medium & $\mathrm{v} \mathrm{dk} \mathrm{br}$ & $\mathrm{dk}$ br & blood & zon & str & medium \\
\hline $011 *$ & I w & medium & $\mathrm{dk}$ br & $\mathrm{bl}-\mathrm{br}$ & blood & ray & str & fiar \\
\hline & $1 \mathrm{w}$ & medium & br, gray & bl-br & blood & hom & conv & comp \\
\hline
\end{tabular}

* Omitted from averages because of age.

to collect their revenue. Hafidh, however, refused to pay. In the war that ultimately broke out, Hafidh and his subjects defeated the Bani Rabiah and they became the sole owners of the land, which included the Amara district and part of the Muntafiq. Hafidh had two sons, from whom the pure Bani Lam stock originated.

Circumstances did not allow us to obtain anthropometric data on the Bani Lam. On April 27, 1934, however, we paid a brief visit to the black tents of Sheikh Shabib of the Hamra sub-tribe of the Bani Lam near Halfaya. As we sipped black coffee we were informed that the tribal mark (wasm) on the camels of the Balasim was two short parallel lines on each side of the right eye. The Khafaya cut a v-shaped piece out of the right ear, and the Ghanan split the camel's ear in two parts. (For additional information on the Bani Lam see Field, 1939a.) 


\section{WiniFred SMEATON²}

The An Nasiriya male series, examined during March, 1935, in the prison, includes townsmen and men of uncertain tribes from An Nasiriya, Suq ash Shuyukh, Qalat Sikar, Karradi, and Bat-ha, and members of settled tribes, fallahin and madan, from the Muntafiq Liwa generally, or an area roughly from Rumaitha on the Euphrates and a corresponding point on the western branch of the Euphrates down through An Nasiriya to Suq ash Shuyukh and Chabaish on the Hor al Hammar and north along the river that flows south from Kut al Imara under the name of Hai, Gharraf, and Shatra as far as Hai. This series comprises 109 individuals, including one townsman from An Nasiriya who was measured in the Royal Hospital at Baghdad.

The total number measured in An Nasiriya prison was 125 individuals.

Tribe or Birthplace.-The following information was recorded on each individual.

In this chapter minor variations in the spellings of tribal and place names occur.

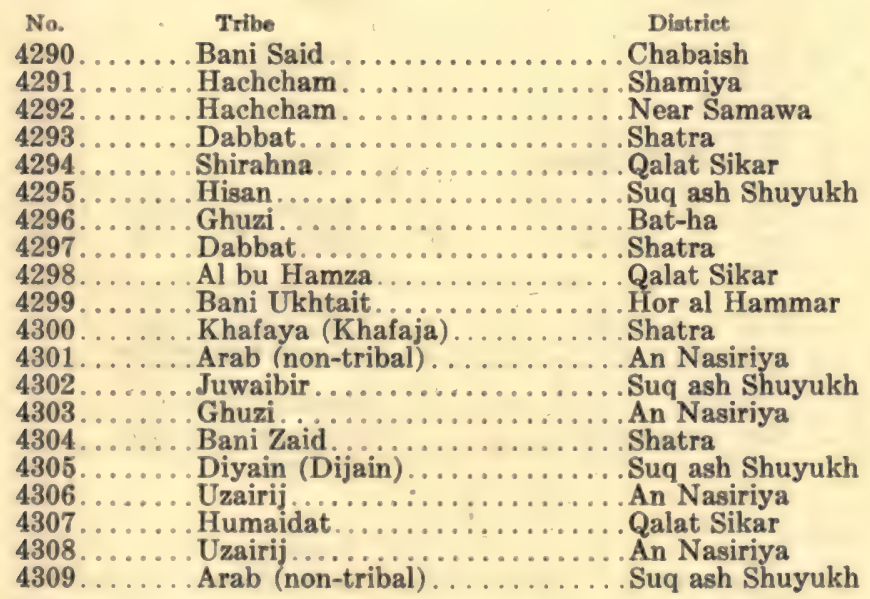

1 Now Muntafiq.

2 Member of Field Museum Anthropological Expedition to the Near East, 1934. This group forms a welcome addition to our series from Iraq, particularly since they are the only anthropometric data available from the An Nasiriya Liwa. (H.F.) 


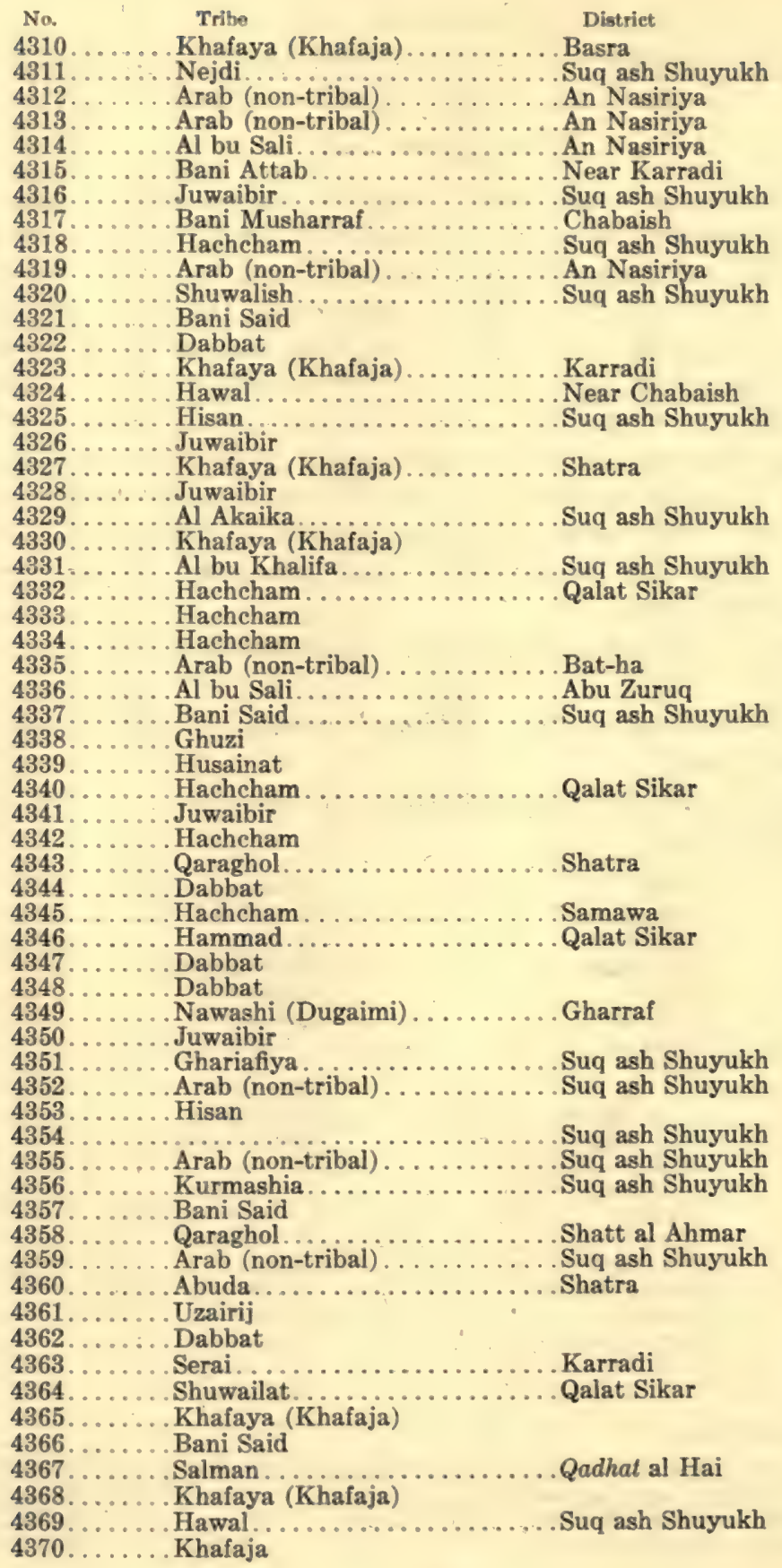




\begin{tabular}{|c|c|c|}
\hline \multirow{2}{*}{\multicolumn{3}{|c|}{$\begin{array}{l}\text { Tribe } \\
\text { Khafaja }\end{array}$}} \\
\hline & & \\
\hline 4372 & Arab (non-tribal) & ... Qalat Sikar \\
\hline 4373 & Khafaja & \\
\hline 4374 & Badr & \\
\hline 4375 & Khafaja & \\
\hline 4376 & Khafaja & \\
\hline 4377 & Khafaja & \\
\hline 4378 & Khafaja & \\
\hline 4379 & Marshadi...... & $\ldots . . .$. Qalat Sikar \\
\hline 4380 & Dabbat & \\
\hline 4381 & Al Khalil........ & .......... An Nasiriya \\
\hline 4382 & Juwaibir & \\
\hline 4383 & Zaiyad & \\
\hline 4384 & Khafaja.... & ... Suq ash Shuyukh \\
\hline 4385 & Bani Said........ & ......... Suq ash Shuyukh \\
\hline 4386 & Dabbat & \\
\hline 4387 & Shuwailat,. & Qalat Sikar \\
\hline 4388 & Khafaja & \\
\hline 4389 & Khafaja & \\
\hline 4390 & Khafaja & \\
\hline 4391 & Majid... & ... Suq ash Shuyukh \\
\hline 4392 & Husainat & \\
\hline 4393 & Husainat & \\
\hline 4394 & Khafaja & \\
\hline 439 & Shadud. & ......... Suq ash Shuyukh \\
\hline 439 & Khafaja. . & ......... Mushakhil (tribal section) \\
\hline & Hachcham ..... & . . . . . . . . Suq ash Shuyukh \\
\hline & . Arab (non-tribal) & . . . . . . . An Nasiriya \\
\hline
\end{tabular}

Age.-The mean age was 31.54 (range 15-75). This group, selected by most random sampling, should be fairly representative of the peoples of this area.

Age Distribution

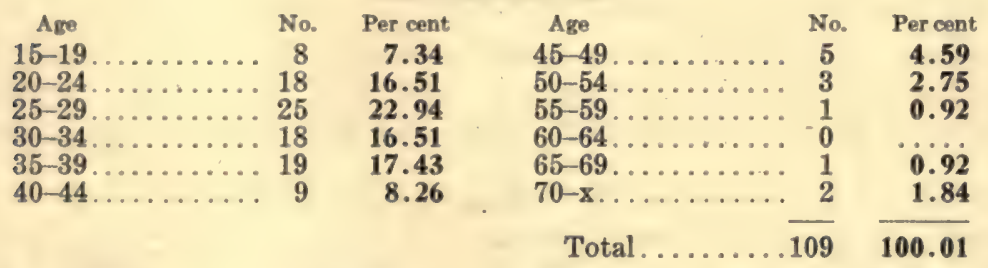

Vital Statistics.-Unreliable as these figures must be, because of the fear, superstitious beliefs, and innate reticence in confiding family matters to foreigners, the general trends are of value.

Vital Statistics

\begin{tabular}{|c|c|c|c|c|c|}
\hline Sons & No. & Per cent & Daughters & No. & Per cent \\
\hline None. & 17 & 34.00 & None..... & 17 & 34.69 \\
\hline & 18 & 36.00 & & 17 & 34.69 \\
\hline 2. & 10 & 20.00 & & 10 & 20.41 \\
\hline ......... & 4 & 8.00 & $3-4$ & 4 & 8.16 \\
\hline $5-6 \ldots \ldots \ldots \ldots$ & 1. & 2.00 & $5-6, \ldots \ldots \ldots \ldots$ & 1 & 2.04 \\
\hline 7 or more........ & 0 & $\ldots$ & 7 or more......... & 0 & $\cdots \cdots$ \\
\hline Total. & 50 & 100.00 & Total. . & 49 & 99.99 \\
\hline
\end{tabular}


About one-third of the group disclaimed any sons or daughters. There were thirty-three male children and thirty-two females. No. 4386 had two children but the sex was not recorded. No. 4381 was married but the number of children was uncertain.

\section{MORPHOLOGICAL CHARACTERS OF AN NASIRIYA MALES}

Physical Appearance.-No. 4299 was recorded as a good type, but No. 4359 was described as a poor specimen. No. 4322 had pointed ears. No. 4313 was very thin, while No. 4330 had a prison pallor and appeared pathetic. No. 4358 had a ridge above the nape of his neck. No. 4396 was recorded as an "absolute Mephistopheles."

Head Form.-No. 4295 had a flat occiput. No. 4319 had an extremely high vault and No. 4392 had a flat area on the occiput.

Supra-orbital Ridges.-No. 4347 had very well-developed supraorbital ridges; those of Nos. 4291, 4376, and 4391 were well developed.

Facial Form.-No. 4352 had a narrow face and prominent malars. No. 4367 had a small face.

Prognathism.-Nos. 4392 and 4298 had facial prognathism, No. 4355 had alveolar prognathism, and Nos. 4356 and 4358 were indicated as having some degree of prognathism.

Negroid Admixture.-No. 4356, with a large admixture of Negroid blood, had everted lips, prognathism, and, although his head was shaven, probably had frizzly hair. No. 4298 was indicated as having possibly a slight admixture of Negroid blood.

Skin.-No. 4351 had a slightly florid and fairer complexion than that of the other individuals. Nos. 4337, 4338, 4358, and 4373 had dark and Nos. 4364, 4367, 4385, and 4392 had very dark skins.

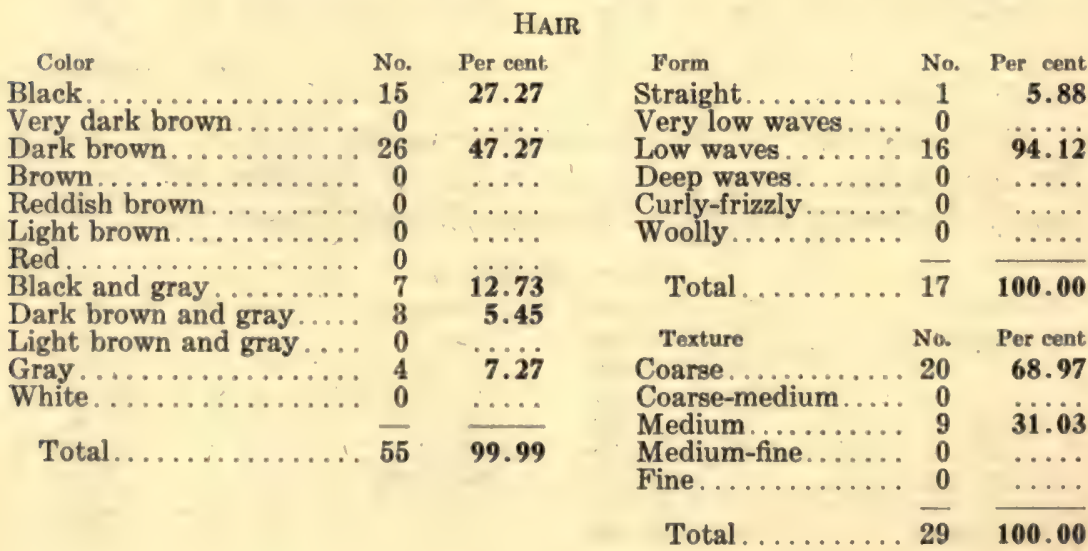


Hair.- Twenty-one men or more than 18 per cent had mustaches. Five men wore beards. No. 4390 had a beard lighter than his head hair. The beard of No. 4392 was deep wavy and coarse, although his hair was fine.

Eyes.-The eyes of No. 4315 were so badly filmed that the eye color was not discernible. The eyes of No. 4358 were slightly filmed, and those of No. 4307 were filmed. No. 4305 had bluish filmed eyes. The right eye of No. 4398 was filmed. Nos. 4293 and $4342(?)$ had filmed spots in their left eyes. No. 4293 said he could see well.

Nos. 4380, 4384, and 4398 had lost their right eyes. No. 4307 had his left eye turned inward and No. 4347 was cross-eyed.

No. 4353 had very small and No. 4391 deep-set and small eyes. No. 4332 had a white spot in the retina of his eye, while No. 4359 had maturation in his eyes.

Twenty individuals had blue-ringed eyes, while twelve had darker rings around the iris. Nos. 4321, 4324, 4329, and 4429 had gray-ringed eyes.

\begin{tabular}{|c|c|c|c|c|}
\hline & & & EYes & \\
\hline Color & No. & Per cent & Sclera & Per cent \\
\hline Black..... . & 1 & 0.93 & Clear. . & 26.21 \\
\hline Dark brown....... & 95 & 87.96 & Yellow.. & 5.83 \\
\hline Blue-brown........ & 0 & ..... & Speckled. . & \\
\hline Blue-brown........ & 0 & & Bloodshot. . . . . . . . . & 62.14 \\
\hline Green-brown ...... & 4 & 3.70 & Speckled and bloodshot. & 1.94 \\
\hline Green-brown....... & 0 & & Speckled and yellow...... & \\
\hline Gray-brown ........ & 5 & 4.63 & Yellow and bloodshot.... & 3.88 \\
\hline Blue............. & 0 & $\ldots$. & & \\
\hline Gray............ & 0 & $\ldots$. & $\ldots \ldots \ldots .103$ & 100.00 \\
\hline Light brown...... & 3 & 2.78 & & \\
\hline Blue-gray ......... & 0 & $\ldots$ & & \\
\hline Blue-green........ & $\mathbf{0}$ & $\ldots \ldots$ & & \\
\hline Total. & 108 & 100.00 & & \\
\hline
\end{tabular}

Nose.-Nos. 4355 and 4378 had short noses and No. 4366 a very short nose. The noses of Nos. 4347 and 4363 were small. While the nasal bridge of No. 4394 was high and narrow and that of No. 4316 high, No. 4338 had a low and broad bridge. His nose was swollen and sore. No. 4359 had a long and No. 4380 a long and narrow nose. The noses of Nos. 4305 and 4318 were broad throughout, while that of No. 4336 was broad only above the alae. Nos. $4306,4307,4310,4314$, and 4315 had broad noses. Those of Nos. 4313 and 4332 were very broad.

The variability in the nasal profile, in the width of the nasal alae, and in the elevation of the nasal tip suggests that at least two distinct elements are present in this assorted group of individuals from the An Nasiriya Liwa. 


\begin{tabular}{|c|c|c|c|c|c|c|}
\hline \multicolumn{7}{|c|}{ Nose } \\
\hline Profile & No. & Per cent & Wings & & No. & Per cent \\
\hline Wavy... & $\ldots 0$ & & \multicolumn{2}{|c|}{ Compressed . ............ } & 12 & 11.11 \\
\hline Straight. & $\ldots .22$ & 20.18 & \multicolumn{2}{|c|}{ Compressed-medium.... } & 6 & 5.55 \\
\hline Concave. & $\ldots \ldots 25$ & 22.94 & \multicolumn{2}{|c|}{ Medium...$\ldots \ldots \ldots$} & 46 & 42.59 \\
\hline Convex.. & $\ldots \ldots 48$ & 44.04 & \multirow{2}{*}{\multicolumn{2}{|c|}{ Medium-flaring . . . . . . . }} & 13 & 12.04 \\
\hline \multicolumn{2}{|c|}{ Concavo-convex..... 14} & 12.84 & & Flaring plus $\ldots \ldots \ldots$ & 31 & 28.70 \\
\hline \multirow{9}{*}{ Total . } & 109 & 100.00 & & & & $\cdots$ \\
\hline & & & Total ... & & 108 & 99.99 \\
\hline & \multicolumn{2}{|c|}{ Tip Elevation } & No. & Per cent & & \\
\hline & \multirow{2}{*}{\multicolumn{2}{|c|}{ Elevated.......... }} & $\ldots 88$ & 18.60 & & \\
\hline & & & $\ldots \ldots$ & 11.63 & & \\
\hline & \multicolumn{2}{|c|}{ Horizontal........ } & $\ldots \ldots \ldots 0$ & & & \\
\hline & \multicolumn{2}{|c|}{ Slightly depressed. . } & $\ldots \ldots \ldots 17$ & 39.53 & & \\
\hline & \multicolumn{2}{|c|}{ Depressed....... } & $\ldots \ldots 13$ & 30.23 & & \\
\hline & \multicolumn{2}{|l|}{ Total } & $\ldots \ldots 43$ & 99.99 & & \\
\hline
\end{tabular}

Description of Nasal Septum

No.
4290
4291
4292
4293
4294
4295
4296
4297
4298
4299
4300
4301
4302
4303
4304
4305
4306
4307
4308
4309
4310
4311
4312
4313
4314
4315
4316
4317
4318
4319
4320
4321
4322
4323
4324
4325
4326
4327
4328

No.

4290

4291

4293

4294

4295

4296

4297

4299

4300

4301

302

4304

4305

4306

4307

4309

4310

4311

4312

4314

4315

4316

4317

4319

4320

4321

4322

323

4325

4327

4328

Septum
conc
str
str
conv
conv
conv
conv
conv
str
str
str
str
str
str
conv
str
conv
str
str
str
str
str
str
str
str
conv
str
conv
..$~$
str
conv
str
conv
conv
str

Inclination

slight up

slight up

up

up

up

up

up

up

up

down

up

slight up

up

up

slight down

up

up

up

up

up

slight up

.......

slight up

slight up

slight up

slight up

up

.......

$\ldots \ldots$

slight up

up

up

up

down

slight up
11.11

5.55

28.70

99.99
Elevation

dep

slight elev

slight dep

slight dep

slight dep

elev

elev

dep

elev

dep

dep

slight elev slight dep elev

elev

dep

slight elev slight dep

dep

dep

slight dep

dep

slight dep slight dep

dep

dep

slight elev elev

slight dep slight dep slight dep slight dep

dep

slight dep

slight elev slight dep elev

dep

slight dep 


$\begin{array}{cccl}\text { No. } & \text { Septum } & \text { Inclination } & \text { Elevation } \\ 4329 & \text { conv } & \text { up } & \text { slight dep } \\ 4330 & \text { conv } & \text { up } & \text { dep } \\ 4331 & \text { conv } & \text { up } & \text { elev } \\ 4332 & \text { conv } & \text { down } & \text { slight dep } \\ 4398 & \text { conv } & \text { up } & ?\end{array}$

Teeth.-The number of individuals with malocclusion indicates unusual variation in the size of the mandible.

TEETH

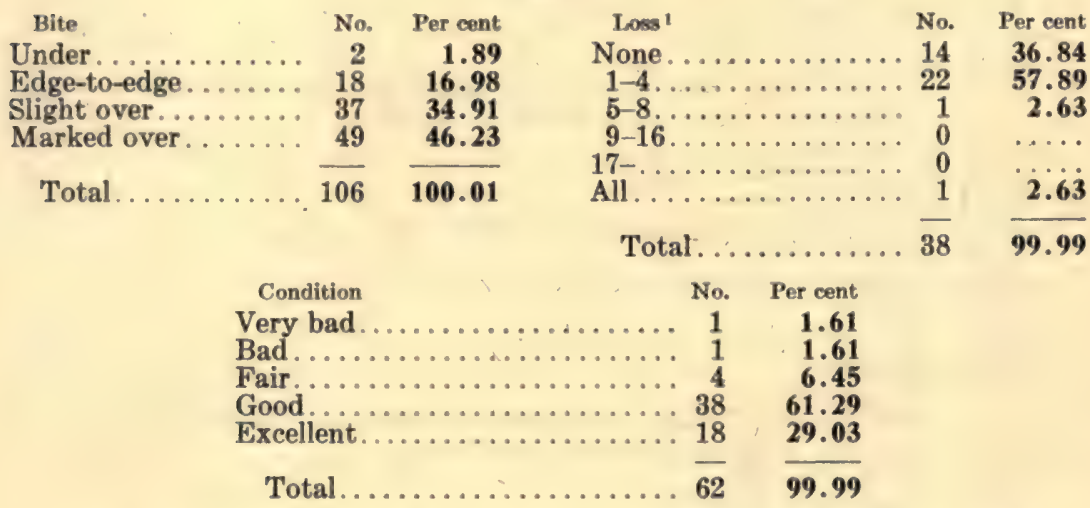

The following table records observations, eruption, and in some cases the teeth lost by the individuals.

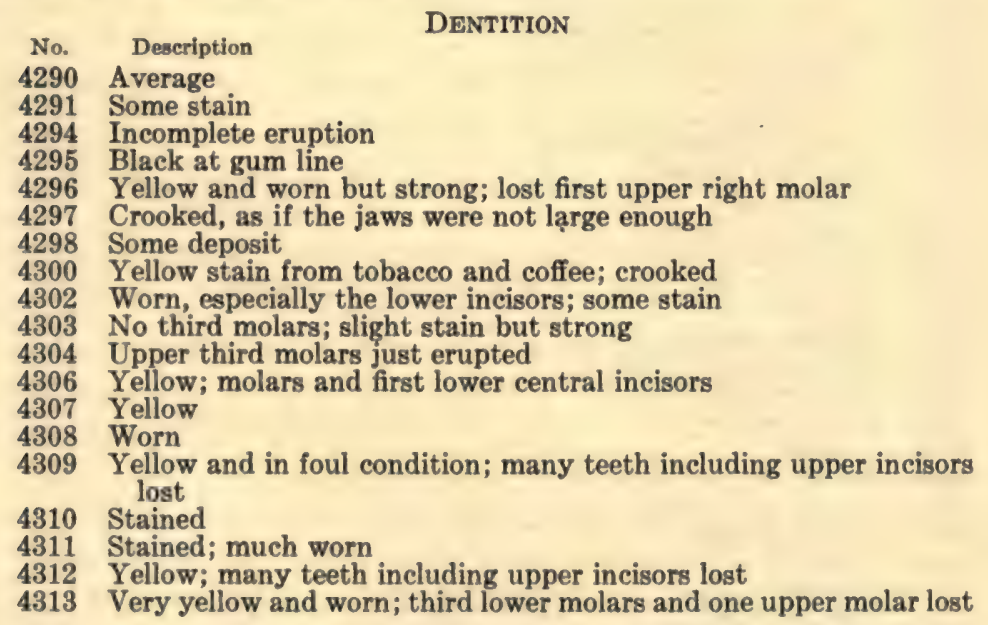

1 Individuals recorded as having lost many, several, or some teeth were not included in the table on loss. They were as follows: many, Nos. 4308-4310, 4312, 4315,4359 , and 4392; several, Nos. 4307, 4311, 4317, 4318, 4338, 4339, and 4364; and some, Nos. 4337 and 4397. 


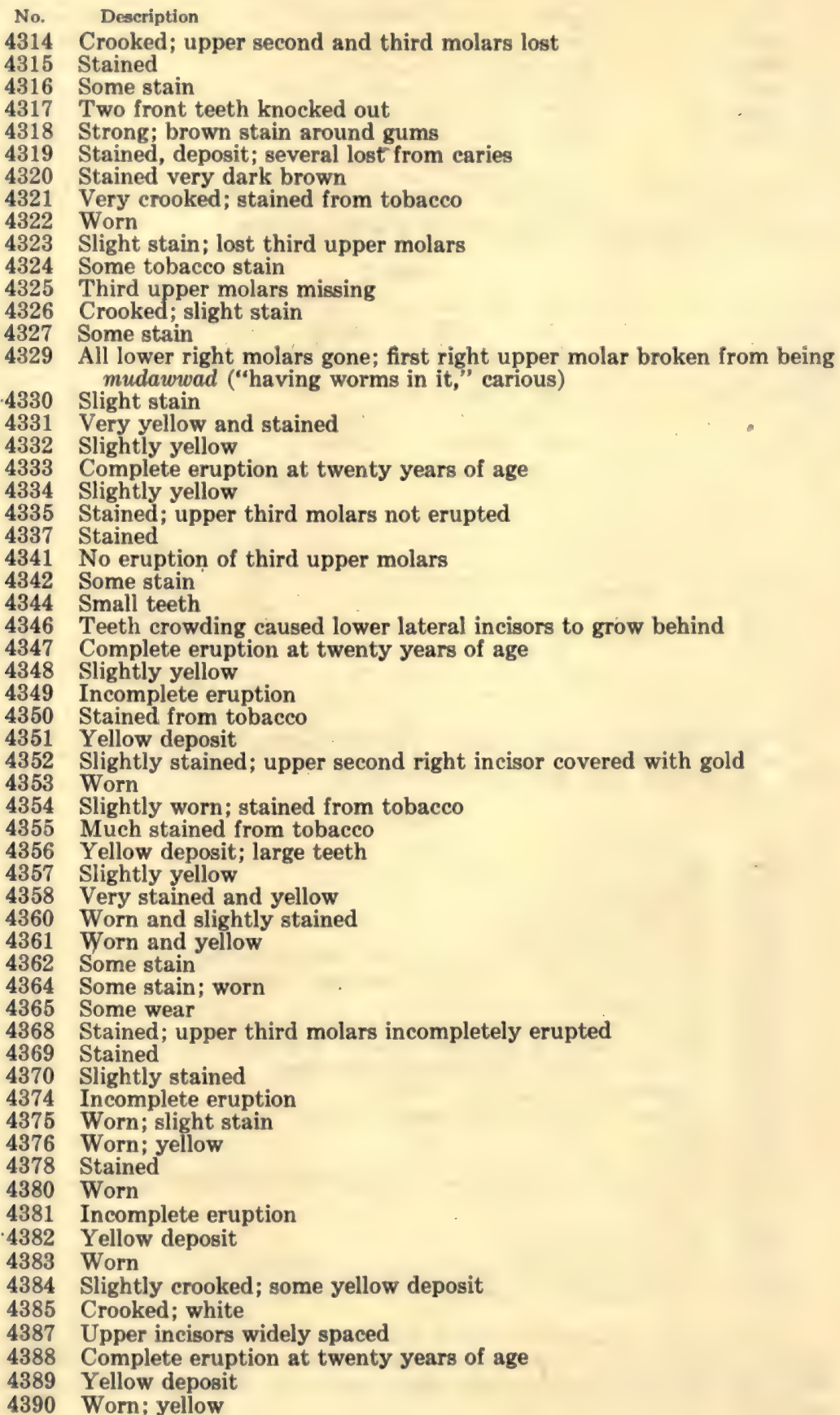




$\begin{array}{cl}\text { No. } & \text { Deseription } \\ 4391 & \text { Stained } \\ 4392 & \text { Black stain } \\ 4393 & \text { Stained } \\ 4395 & \text { Yellow } \\ 4396 & \text { Yellow } \\ 4397 & \text { White } \\ 4398 & \text { Much deposit; worn; three gold-capped }\end{array}$

Health.-Health was recorded for only one individual; No. 4290, good.

Disease.-Fourteen individuals (Nos. 4292, 4294, 4295, 4303, $4314,4323,4343,4345,4347,4352,4371,4381,4388$, and 4389) had smallpox scars. No. 4293 had ringworm. No. 4415 had a scar from a "Baghdad boil" on his right cheek while No. 4353 had a bad boil(?) above the right side of his lip. No. 4374 had scalp disease, probably favus, and No. 4398 had scurf on his scalp.

No. 4354 had a mark on the back of the right hand from opening a blood vessel. In the An Nasiriya Liwa a treatment for stomach pains is to take blood from the hand and let it drop into hot water; certain individuals (whether male or female was not clear) can then diagnose whether the pain is caused by excess of meat or fat in the digestive tract.

No. 4357 had a white spot on the right wrist. The following reason was ascribed: when his mother was pregnant she did not eat curds $(r \bar{b} b a)$ and kept scratching her wrist on this spot. As a direct result the boy was born with this mark on his wrist. The observer believed that the spot was due to a lack of pigmentation.

Cauterization.- These Arabs of the An Nasiriya Liwa believe that circular scars caused by branding or cauterization relieve pain and in some cases give strength to the part of the body thus treated; for example, head pains can be relieved and strength increased in the arm through this rather crude and excessively painful method.

These marks are called chawi or more correctly kawi. For the sake of simplicity and convenience, the letter $s$ has been added to form the Anglicized plural.

The group was divided almost equally into those who bore chawi marks and those who did not. The latter consisted of the following fifty-six individuals: Nos. 4290-4295, 4297, 4299, 43004303, 4305, 4306, 4308-4311, 4314, 4316, 4318, 4319, 4321, 4323, $4325,4326,4334,4335,4337,4338,4340,4342$, 4344, 4347-4349, 4352 , 4354, 4359, 4365-4367, 4370, 4372-4374, 4376, 4378, 4382$4384,4386,4387$, and $4389-4391$. 
Tattooing.-Among the 109 men examined eighty-five (77.98 per cent) bore tattooed designs. The following individuals were not tattooed: Nos. 4294, 4295, 4301, 4309, 4311, 4315, 4316, 4328, 4334, 4336, 4337, 4339, 4354, 4355, 4365, 4369, 4370, 4379, 4385, 4392, 4394,4396 , and 4398.

\section{STATISTICAL ANALYSES OF 109 AN NASIRIYA MALES}

There now remains the task of grouping the total series of An Nasiriya males according to the Harvard and Keith classificatory systems for stature, sitting height (trunk length), minimum frontal diameter, head breadth, cephalic index, nasal height, nasal breadth, and nasal index.

Stature.-These inhabitants of the An Nasiriya Liwa were medium to tall according to both systems. There is remarkably little difference in the groupings. The average stature was 167.17, which is slightly higher than the average for Southwestern Asia. Slightly more than half of the group fell into the medium group according to both the Harvard and the Keith classificatory systems. About one-third were tall (169.5-179.9) although no man was in the very tall $(180.0-\mathrm{x})$ class.

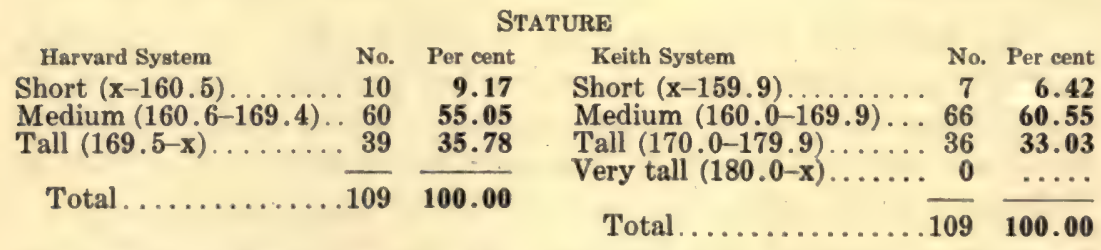

Sitting Height (Trunk Length).-The relative sitting height index of 50.86 together with the stature groupings reveal that the tendency to shortness in trunk length is more than compensated by the increase in leg length. On the basis of the trunk length groups, the stature should be short to medium and not medium to tall as is the case.

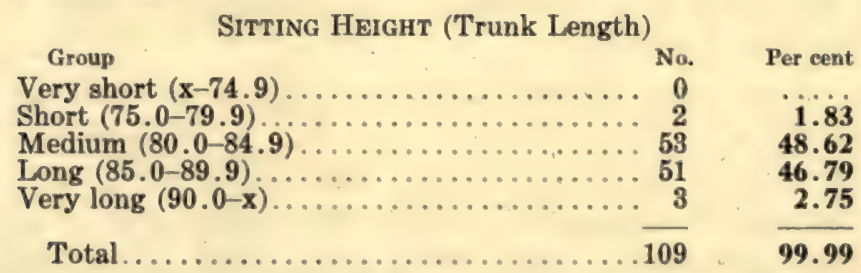

Minimum Frontal Diameter.-The mean was 104.49, a low figure for this general area. 


\begin{tabular}{|c|c|c|}
\hline Group & Minimum Frontal Diameter & Per cent \\
\hline Tery narrow $(x-9$ & 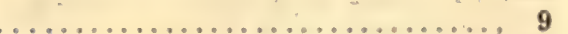 & 8.26 \\
\hline $100-109$ & $\ldots .88$ & 80.73 \\
\hline Wide (110-119). & . 12 & 11.01 \\
\hline Very wide $(120-x)$ & $\cdots \ldots \ldots \ldots \ldots \ldots \ldots$ & \\
\hline Total.......... & 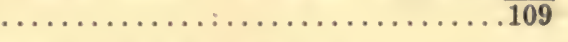 & 100.00 \\
\hline
\end{tabular}

Head Breadth.-The mean for this measurement was 148.39, which indicates a tendency toward broadness. The mean head length was 189.88 , which is short for this part of the world.

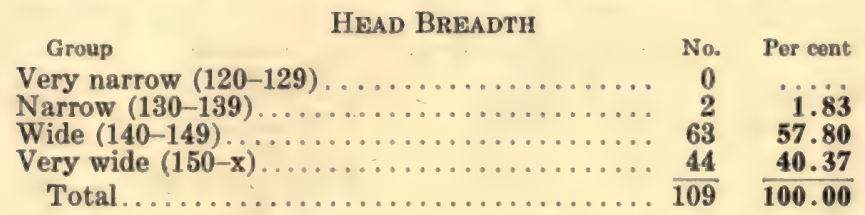

Cephalic Index.-The Harvard and the Keith systems show somewhat different arrangements.

The mean cephalic index was 78.19. Therefore the peoples of the An Nasiriya Liwa were mesocephals with both brachycephalic and dolichocephalic elements, indicating a mixed population.

Cephalic Index

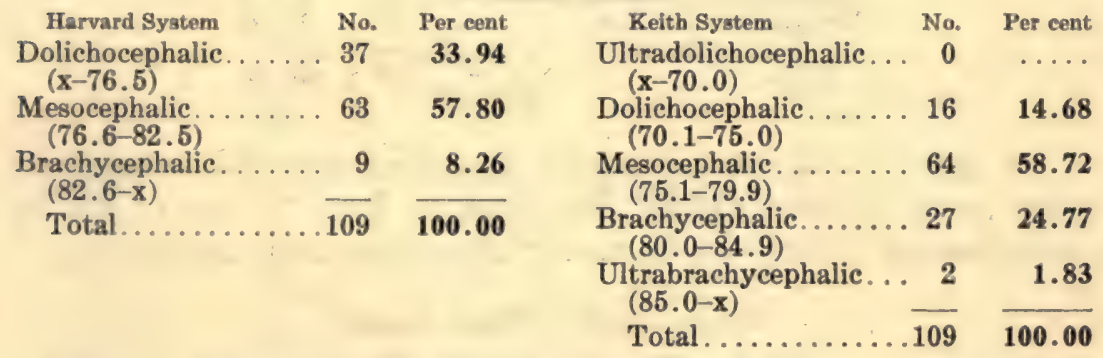

Facial Measurements and Indices.-The mean upper facial height was 71.40. The mean total facial length was 118.30. Thus the lower part of the face tended to be short. This disharmony resulted in a wide diffusion of the total facial indices.

\section{Facial Measurements and Indices}

\begin{tabular}{|c|c|c|c|c|c|}
\hline Tpper facial height & No. & Per cent & Total facial height & No. & Per cent \\
\hline 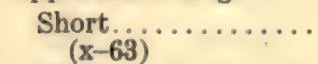 & 3 & 2.75 & Short $_{(x-109)} \cdots \cdots$ & 6 & $\mathbf{5 . 5 0}$ \\
\hline Medium short. . . . . & 31 & 28.44 & $\begin{array}{l}\text { Medium short....... } \\
(110-119)\end{array}$ & 57 & 52.29 \\
\hline $\begin{array}{l}\text { Medium long. ....... } \\
\quad(70-75)\end{array}$ & 57 & 52.29 & im long . . . . . & 43 & 39.45 \\
\hline $\begin{array}{l}\text { Long. } \\
\quad(76-\mathrm{x})\end{array}$ & 18 & 16.51 & $\begin{array}{l}\text { Long } \\
(130-x)\end{array}$ & 3 & 2.75 \\
\hline Total & 10 & 99.99 & Total & 109 & \\
\hline
\end{tabular}


1 Total facial index No. Per eent

Euryprosopic $(x-84.5) \ldots \ldots \ldots .30$
Mesoprosopic $(84.6-89.4) \ldots \ldots .42$
Leptoprosopic $(89.5-x) \ldots \ldots \ldots .37$
Total.....................

Nasal Measurements and Indices.-The means were length 50.10, breadth 37.03 and nasal index 74.19. The thirteen individuals in the platyrrhine classification suggest the presence of Negroid blood.

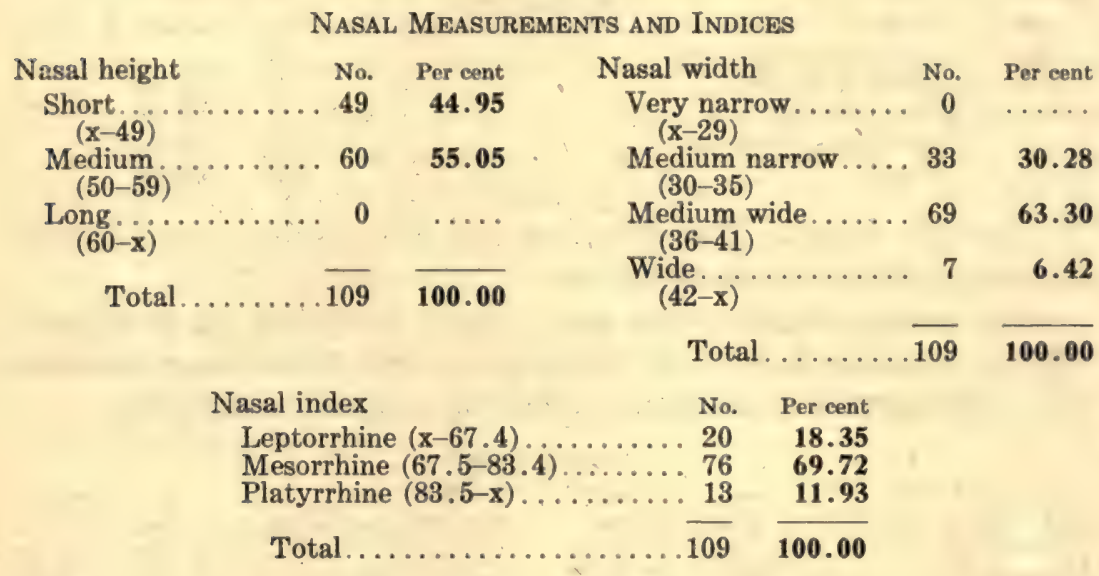

In order to furnish additional statistical data for comparison with those of Field (1939) and those in Part I, No. 1, of The Anthropology of Iraq, the following tables have been calculated:

SitTing Height (Trunk Length)

\begin{tabular}{|c|c|c|c|c|c|c|c|c|c|c|}
\hline \multirow{6}{*}{$\begin{array}{r}\text { Standing height } \\
1800-\mathrm{x} \\
1799-1700 \ldots \\
1699-1600 \ldots \\
\mathrm{x}-1599 \ldots\end{array}$} & $900-x$ & \multicolumn{2}{|c|}{$899-850$} & \multicolumn{2}{|c|}{$849-800$} & $799-750$ & \multicolumn{2}{|c|}{$749-x$} & \multicolumn{2}{|c|}{ Totals } \\
\hline & No. $\%$ & No. & $\%$ & No. & $\%$ & No. $\%$ & No. & $\%$ & No. & $\%$ \\
\hline & 0 & & & 0 & $\ldots$ & $\ldots$. & 0 & $\ldots$ & 0 & \\
\hline & 714.00 & 8 & 16.00 & 0 & & 0 & 0 & $\ldots$ & 15 & 30.00 \\
\hline & 918.00 & 18 & 36.00 & 1 & 2.00 & $\ldots$ & 0 & $\ldots$ & 28 & 56.00 \\
\hline & $0 \ldots \ldots$ & 0 & $\ldots .$. & 71 & 14.00 & $\ldots$ & 0 & $\ldots$ & 7 & 14.00 \\
\hline
\end{tabular}

Minimum Frontal Diameter

\begin{tabular}{|c|c|c|c|c|c|c|c|c|c|c|}
\hline \multirow[b]{2}{*}{ Head breadth } & \multicolumn{2}{|c|}{$x-99$} & \multicolumn{2}{|c|}{$100-109$} & \multicolumn{2}{|c|}{$110-119$} & \multicolumn{2}{|c|}{$120-x$} & \multicolumn{2}{|c|}{ Totals } \\
\hline & No. & $\%$ & No. & $\%$ & No. & $\%$ & No. & $\%$ & No. & $\%$ \\
\hline $120-129 \ldots$ & .0 & $\ldots$. & 0 & & 0 & & 0 & & 0 & \\
\hline $130-139$. & 0 & $\ldots$ & 2 & 4.00 & 7 & 14.00 & 0 & & 9 & 18.00 \\
\hline $140-149$. & 0 & $\ldots$ & $\overline{5}$ & 10.00 & 17 & 34.00 & 3 & 6.00 & 25 & 50.00 \\
\hline $150-x \ldots$ & 0 & $\ldots$ & 0 & $\ldots \ldots$ & 13 & 26.00 & 3 & 6.00 & 16 & 32.00 \\
\hline & & & & & & & & & 50 & 100.00 \\
\hline
\end{tabular}


Bizygomatc BREadth

$\mathrm{x}-124 \quad 125-134 \quad 135-\mathrm{x} \quad$ Totals

\begin{tabular}{|c|c|c|c|c|c|c|c|}
\hline 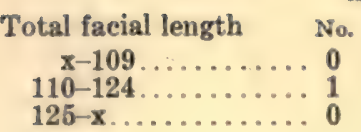 & 2.00 & $\begin{array}{r}\text { No. } \\
1 \\
11 \\
6\end{array}$ & $\begin{array}{r}\% \\
2.00 \\
22.00 \\
12.00\end{array}$ & $\begin{array}{r}\text { No. } \\
1 \\
18 \\
12\end{array}$ & $\begin{array}{r}\% \\
2.00 \\
36.00 \\
24.00\end{array}$ & $\begin{array}{r}\text { No. } \\
2 \\
30 \\
18\end{array}$ & $\begin{array}{r}\% \\
4.00 \\
60.00 \\
36.00\end{array}$ \\
\hline & & & & & & 50 & 100.00 \\
\hline
\end{tabular}

\section{UPPER Facial Length}

$$
\begin{array}{llllll}
\mathrm{x}-63 \quad 64-69 & 70-75 & 76-81 & 82-\mathrm{x} & \text { Totals }
\end{array}
$$

Total facial length No. $\%$ No. $\%$ No. $\%$ No. $\%$ No. $\%$ No. $\%$

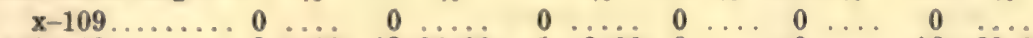

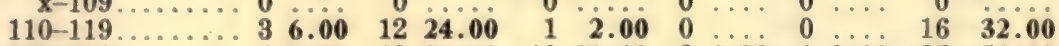

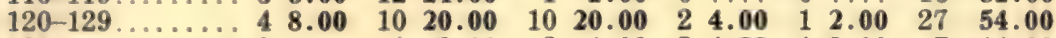

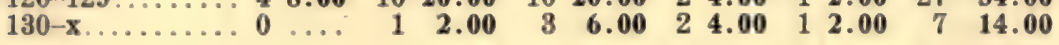

$50 \overline{100.00}$

\section{NASAL WIDTH}

\begin{tabular}{|c|c|c|c|c|c|c|c|c|c|c|}
\hline \multirow{5}{*}{$\begin{array}{r}\text { Nasal length } \\
x-49 \ldots \\
50-59 \ldots \\
60-x \ldots\end{array}$} & \multicolumn{2}{|c|}{$x-29$} & \multicolumn{2}{|c|}{$30-35$} & \multicolumn{2}{|c|}{$36-41$} & \multicolumn{2}{|c|}{$42-x$} & \multicolumn{2}{|c|}{ Totals } \\
\hline & No. & $\%$ & No. & $\%$ & No. & $\%$ & No. & $\%$ & No. & $\%$ \\
\hline & 0 & & 14 & 28.57 & 4 & 8.16 & 0 & $\ldots$ & 18 & 36.73 \\
\hline & 3 & 6.12 & 14 & 28.57 & 11 & 22.45 & 0 & $\ldots$ & 28 & 57.14 \\
\hline & 0 & $\ldots$ & 1 & 2.04 & 2 & 4.08 & 0 & $\ldots$ & 3 & 6.12 \\
\hline & & & & & & & & & 49 & 99.99 \\
\hline
\end{tabular}

\section{Vital Statistics* of AN Nasiriya Males}

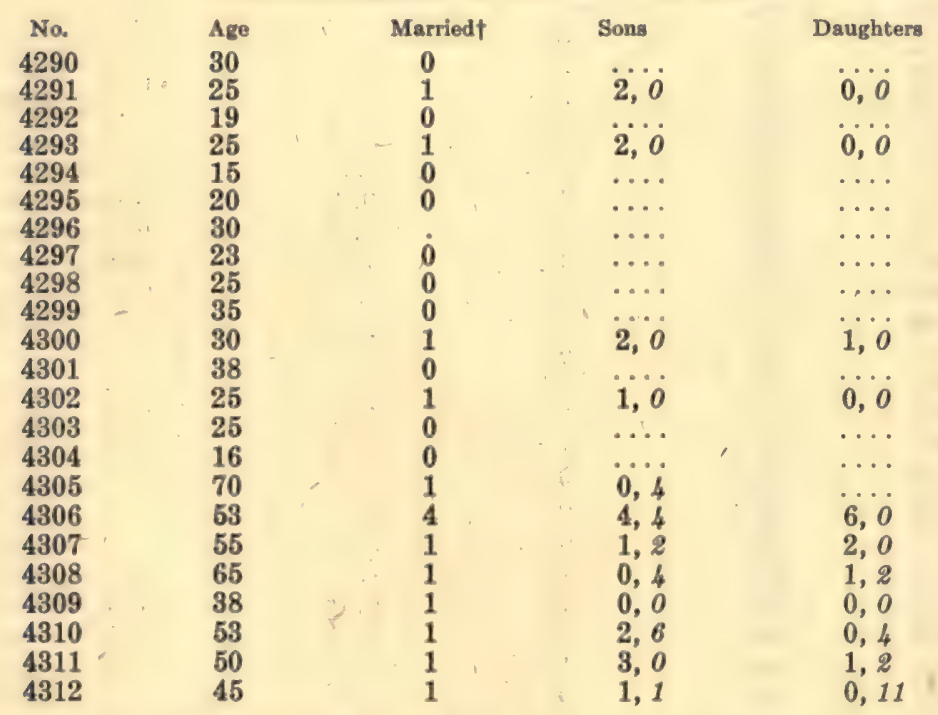

* Italicized numbers refer to deceased children.

† Since so many individuals claimed to be unmarried, an unusual condition among the tribal Arabs, Lady Drower questioned the veracity of their assertions. 
Vital Statistics* of AN Nasiriya Males

\begin{tabular}{|c|c|c|c|c|}
\hline No. & Age & Married & Sons & Daughters \\
\hline 4313 & 48 & 1 & 5,2 & 1,2 \\
\hline 4314 & 48 & 1 & 4,0 & 2,1 \\
\hline 4315 & 75 & 1 & 1,0 & 2,0 \\
\hline 4316 & 21 & 0 & $\ldots$ & $\ldots$ \\
\hline 4317 & 25 & 0 & $\ldots$ & $\cdots$ \\
\hline 4318 & 38 & 1 & 0,0 & 0,0 \\
\hline 4319 & 35 & 1 & 0,0 & $\ldots$ \\
\hline 4320 & 40 & 1 & 1,3 & 2,2 \\
\hline 4321 & 25 & 1 & 1,0 & 1,0 \\
\hline 4322 & 28 & 0 & $\ldots$ & $\ldots$ \\
\hline 4323 & 21 & 1 (2 mos.) & $\ldots$ & $\ldots$ \\
\hline 4324 & 20 & 0 & $\ldots$ & $\ldots$ \\
\hline 4325 & 19 & 0 & $\ldots$ & $\ldots$ \\
\hline 4326 & 25 & 0 & $\because \cdots$ & $\cdots$ \\
\hline 4327 & 32 & 1 & 1 & $\cdots$ \\
\hline 4328 & 25 & 0 & $\cdots$ & $\because \cdots$ \\
\hline 4329 & 32 & 1 & 2,0 & 2,0 \\
\hline 4330 & 33 & 1 & 0,0 & 2,0 \\
\hline 4331 & 35 & 1 & 2,1 & 1,0 \\
\hline 4332 & 32 & 0 & $\ldots$ & $\ldots$ \\
\hline 4333 & 20 & 1 & 0,0 & 0,0 \\
\hline 4334 & 43 & 1 & 1,0 & 3,0 \\
\hline 4335 & 19 & 0 & $\ldots$ & $\ldots$ \\
\hline 4336 & 27 & 0 & $\ldots$ & $\ldots$ \\
\hline 4337 & 40 & 0 & $\ldots$ & $\cdots$ \\
\hline 4338 & 28 & 1 & 0,0 & 3,0 \\
\hline 4339 & 27 & 1 & 1,0 & 0,0 \\
\hline 4340 & 25 & & $\ldots$ & $\ldots$ \\
\hline 4341 & 21 & 0 & $\ldots$ & $\ldots$ \\
\hline 4342 & 25 & 0 & $\ldots$ & $\ldots$ \\
\hline 4343 & 25 & 0 & $\ldots$ & $\therefore$. \\
\hline 4344 & 23 & 0 & $\ldots$ & $\cdots$ \\
\hline 4345 & 30 & 0 & $\cdots$ & $\cdots$ \\
\hline 4346 & 30 & 1 & 0,0 & 0,0 \\
\hline 4347 & 20 & 1 & 2,0 & 0,0 \\
\hline 4348 & 22 & 1 & 1,0 & 0,0 \\
\hline 4349 & 18 & 0 & $\ldots$ & $\ldots$ \\
\hline 4350 & 22 & 0 & $\therefore$ & $\cdots$ \\
\hline 4351 & 22 & 0 & $\ldots$ & $\cdots$ \\
\hline 4352 & 30 & 0 & $\because \cdots$ & $\ddot{0}$ \\
\hline 4353 & 38 & 3 & 1,0 & 0,0 \\
\hline 4354 & $\cdot 28$ & 1 & 0,0 & 0,0 \\
\hline 4355 & 38 & 0 & $\ldots$ & $\cdots$ \\
\hline 4356 & 30 & 0 & $\ldots$ & $\cdots$ \\
\hline 4357 & 25 & 0 & $\ldots$ & $\because \cdots$ \\
\hline 4358 & 38 & 1 & $\ldots$ & 3 \\
\hline 4359 & 35 & 1 & 0,0 & 0,0 \\
\hline 4360 & 40 & 1 & 2,0 & 2,0 \\
\hline 4361 & 40 & 1 & 0,0 & 1,0 \\
\hline 4362 & 28 & 0 & $\ldots$ & $\cdots$ \\
\hline 4363 & 25 & 0 & $\ldots$ & $\ldots$ \\
\hline 4364 & 40 & 0 & $\ldots$ & $\ldots$ \\
\hline
\end{tabular}


DATA From AN NASIRIYa LiWA

Vital Statistics* of AN Nasiriya Males

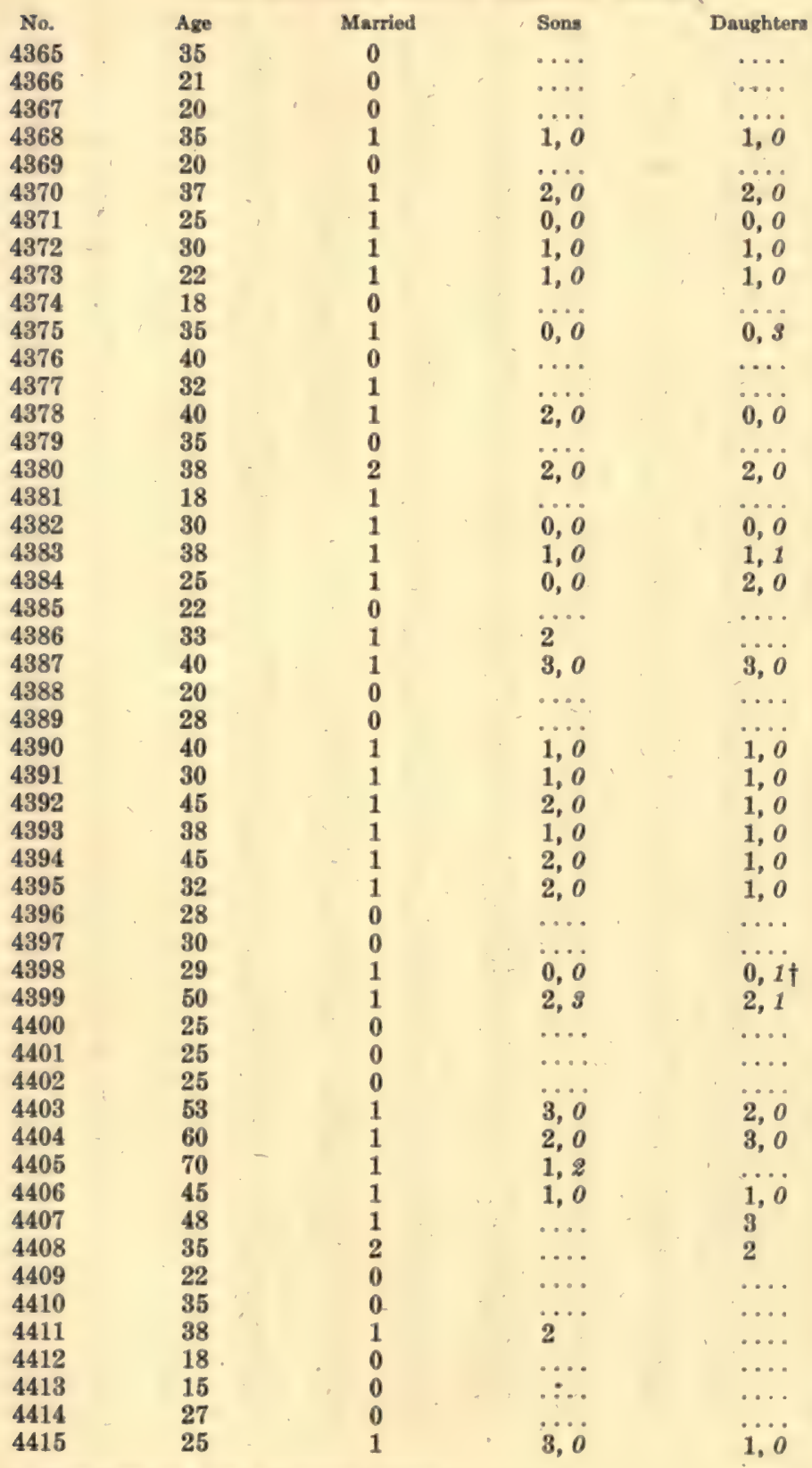

* Italicized numbera refer to deceased children.

1 Miscarriage. 
MeAsurements

\begin{tabular}{|c|c|c|c|c|c|c|c|c|c|c|c|c|}
\hline No. & Age & Stature & SH & L & B & $\mathbf{B}^{\prime}$ & $\mathbf{J}$ & go-go & GH & $\mathrm{G}^{\prime} \mathrm{H}$ & $\mathrm{NH}$ & NB \\
\hline 4290 & 30 & 1656 & 846 & 188 & 148 & 104 & 136 & 101 & 118 & 72 & 54 & 38 \\
\hline 4291 & 25 & 1620 & 827 & 179 & 151 & 101 & 135 & 106 & 120 & 71 & 49 & 32 \\
\hline 4292 & 19 & 1672 & 845 & 186 & 143 & 103 & 135 & 101 & 111 & 68 & 49 & 35 \\
\hline 4293 & 25 & 1640 & 858 & 185 & 145 & 103 & 136 & 103 & 118 & 71 & 52 & 36 \\
\hline $4294^{*}$ & 15 & 1651 & 861 & 194 & 153 & 105 & 133 & 106 & 110 & 69 & 49 & 38 \\
\hline 4295 & 20 & 1702 & 866 & 178 & 137 & 101 & 126 & 95 & 101 & 65 & 47 & 35 \\
\hline 4296 & 30 & 1653 & 824 & 194 & 151 & 103 & 137 & 100 & 113 & 66 & 48 & 36 \\
\hline 4297 & 23 & 1667 & 872 & 183 & 145 & 105 & 133 & 100 & 124 & 73 & 53 & 38 \\
\hline 4298 & 25 & 1645 & 874 & 188 & 143 & 104 & 133 & 103 & 129 & 78 & 54 & 34 \\
\hline 4299 & 35 & 1694 & 891 & 197 & 148 & 106 & 138 & 102 & 123 & 73 & 51 & 38 \\
\hline 4300 & 30 & 1641 & 846 & 189 & 154 & $(110)+$ & 138 & 105 & 122 & 75 & 52 & 40 \\
\hline 4301 & 38 & 1707 & 915 & 189 & 154 & 108 & 143 & 101 & 124 & 73 & 49 & 38 \\
\hline 4302 & 25 & 1645 & 861 & 181 & 153 & 102 & 137 & 96 & 118 & 72 & 51 & 38 \\
\hline 4303 & 25 & 1717 & 859 & 184 & 147 & 103 & 132 & 104 & 110 & 66 & 48 & 10 \\
\hline $4304^{*}$ & 16 & 1620 & 826 & 188 & 142 & 100 & 128 & 93 & 115 & 68 & 48 & 37 \\
\hline 4305 & 70 & 1605 & 836 & 191 & 141 & 103 & 134 & 105 & (100) & (60) & 54 & 10 \\
\hline 4306 & 53 & 1565 & 839 & 188 & 148 & 99 & 137 & 110 & 112 & 68 & 47 & 39 \\
\hline 4307 & 55 & 1710 & 870 & 191 & 145 & 104 & 134 & 95 & 123 & 76 & 51 & 37 \\
\hline 4308 & 65 & 1660 & 798 & 195 & 154 & 109 & 142 & 108 & 117 & 75 & 48 & \\
\hline 4309 & 38 & 1560 & 809 & 180 & 148 & 101 & 133 & 103 & (118) & (69) & 53 & 34 \\
\hline 4310 & 53 & 1674 & 867 & 193 & 154 & 106 & 140 & 100 & 115 & 69 & 48 & \\
\hline 4311 & 50 & 1651 & 803 & $187 \ddagger$ & 158 & 99 & 133 & 93 & 128 & 78 & 54 & 7 \\
\hline 4312 & 45 & 1649 & 861 & 188 & 146 & 101 & 135 & 102 & (111) & (64) & & \\
\hline 4313 & 48 & 1762 & 890 & 185 & 157 & 107 & 131 & 101 & 125 & 82 & 6 & 35 \\
\hline 431 & 48 & 1721 & 865 & 192 & 145 & 102 & 132 & 108 & 112 & 69 & & \\
\hline $4315 *$ & 75 & 1688 & 830 & 188 & 15 & 104 & 150 & 117 & 126 & 75 & 57 & 39 \\
\hline 4316 & 21 & 1592 & 831 & 188 & 150 & 106 & 136 & 105 & 124 & 74 & & 36 \\
\hline 4317 & 25 & 1724 & 850 & 188 & 144 & 107 & 137 & 104 & 112 & 68 & 44 & 37 \\
\hline 431 & 38 & 1650 & 858 & 193 & 15 & 102 & 138 & 109 & 120 & 73 & 46 & \\
\hline 4319 & 35 & 1686 & 807 & 190 & 14 & 105 & 131 & 104 & 122 & 72 & 46 & 36 \\
\hline 432 & 40 & 1741 & 895 & 196 & 15 & 109 & 135 & 115 & 127 & 79 & 51 & 40 \\
\hline 432 & 25 & 1615 & 817 & 180 & 15 & 103 & 135 & 98 & 113 & 67 & 47 & 33 \\
\hline 432 & 28 & 1609 & 806 & 180 & 14 & 97 & 130 & 93 & 120 & 76 & 55 & 36 \\
\hline 432 & 21 & 1637 & 862 & 191 & 14 & 107 & 135 & 96 & 120 & 73 & 53 & 35 \\
\hline 432 & 20 & 1692 & 899 & 175 & 14 & 95 & 121 & 93 & 119 & 67 & 47 & \\
\hline 432 & 19 & 1712 & 838 & 180 & 14 & 105 & 13 & 108 & 114 & 68 & 46 & \\
\hline 4326 & 25 & 1703 & 863 & 184 & 16 & 110 & 139 & 107 & 117 & 67 & 45 & 35 \\
\hline & 32 & 1696 & 860 & 192 & & 105 & 13 & 10 & 118 & 74 & & 0 \\
\hline 432 & 25 & 1656 & 856 & 185 & 14 & 102 & 130 & 110 & 114 & 65 & 44 & 38 \\
\hline 432 & 32 & 1726 & & 186 & & 102 & 13 & 10. & & & & \\
\hline 433 & 39 & 1741 & 885 & 201 & 18 & 114 & 146 & 111 & 117 & 69 & 48 & 41 \\
\hline & 35 & 1639 & 83 & 188 & & 98 & & 94 & 11 & 75 & 50 & 8 \\
\hline 43 & 32 & 1691 & 86 & 199 & 14 & 107 & 138 & 101 & 119 & 70 & 48 & \\
\hline 433 & 20 & 1645 & & 19 & & 102 & 138 & 101 & & & & \\
\hline 433 & 43 & 1753 & 87 & 18 ? & 15 & 105 & 139 & 104 & 12 & 77 & & \\
\hline & 19 & 171 & & 187 & 14 & 101 & 1 & 95 & 12 & 75 & & \\
\hline 43 & 27 & 163 & 81 & 187 & 14 & 100 & & 94 & 12 & & & \\
\hline & 40 & 170 & & 19 & & 107 & & 102 & 12 & 77 & & \\
\hline 43 & 28 & 166 & & 19 & & 108 & & $10^{\circ}$ & 12 & & & \\
\hline & 27 & 171 & & 19 & & 114 & 1. & 111 & 122 & & 48 & \\
\hline 434 & 25 & 1750 & 87 & 18 & & 106 & 18 & 106 & 11 & 72 & & \\
\hline & 21 & 165 & & 17 & 14 & 102 & 133 & 98 & 11 & 66 & 48 & \\
\hline 43 & 25 & 1636 & 83 & 19 & & 110 & 13 & 95 & 10 & & & \\
\hline & 25 & 176 & & 19 & & 11 & 18 & 103 & 119 & 73 & & \\
\hline 43 & 23 & 164 & 82 & 182 & & 10 & 12 & 99 & 114 & 70 & & \\
\hline & 30 & 168 & 862 & 193 & 14 & 106 & 136 & 107 & 118 & 72 & 3 & 39 \\
\hline & 30 & 1771 & 860 & 199 & 154 & 115 & 139 & 105 & 130 & $7 \overline{5}$ & 52 & \\
\hline
\end{tabular}

* Omitted from means.

† Measurement affected because of dagger wound.

† Oceiput flat. 
INDICES

\begin{tabular}{|c|c|c|c|c|c|c|c|c|c|c|c|}
\hline No. & EL & EB & RSH & B/L & $\mathbf{B}^{\prime} / \mathbf{B}$ & $\mathbf{G H} / \mathbf{J}$ & $G^{\prime} H / J$ & $\mathrm{NB} / \mathrm{NH}$ & EB/EL & $\mathrm{go-go} / \mathrm{J}$ & $\mathbf{B}^{\prime} / \mathbf{J}$ \\
\hline 4290 & 59 & 34 & 51.1 & 78.7 & 70.3 & 86.8 & 52.9 & 70.4 & 57.6 & 74.3 & 76.5 \\
\hline 4291 & 59 & 33 & 51.0 & 84.4 & 66.9 & 88.9 & 52.6 & 65.3 & 55.9 & 78.5 & 74.8 \\
\hline 4292 & 66 & 38 & 50.5 & 76.9 & 72.0 & 82.2 & 50.4 & 71.4 & 57.6 & 74.8 & 76.3 \\
\hline 4293 & 59 & 35 & 52.3 & 78.4 & 71.0 & 86.8 & 52.2 & 69.2 & 59.3 & 75.7 & 75.7 \\
\hline 4294 & 61 & 38 & 52.2 & 78.9 & 68.6 & 82.7 & 51.9 & 77.6 & 62.3 & 79.7 & 78.9 \\
\hline 4295 & 62 & 36 & 50.9 & 77.0 & 73.7 & 80.2 & 51.6 & 74.5 & 58.1 & 75.4 & 80.2 \\
\hline 4296 & 64 & 36 & 49.8 & 77.8 & 68.2 & 82.5 & 48.2 & 75.0 & 56.3 & 73.0 & 75.2 \\
\hline 4297 & 67 & 38 & 52.3 & 79.2 & 72.4 & 93.2 & 54.9 & 71.7 & 56.7 & 75.2 & 78.9 \\
\hline 4298 & 66 & 36 & 53.1 & 76.1 & 72.7 & 97.0 & 58.6 & 63.0 & 54.5 & 77.4 & 78.2 \\
\hline 4299 & 65 & 40 & 52.6 & 75.1 & 71.6 & 89.1 & 52.9 & 74.5 & 61.5 & 73.9 & 76.8 \\
\hline 4300 & 61 & 35 & 51.6 & 81.5 & 71.4 & 88.4 & 54.3 & 76.9 & 57.4 & 76.1 & 80.0 \\
\hline 4301 & 62 & 30 & 53.6 & 81.5 & 70.1 & 86.7 & 51.0 & 77.6 & 48.4 & 70.6 & 75.5 \\
\hline 4302 & 67 & 35 & 52.3 & 84.5 & 66.7 & 86.1 & 52.6 & 74.5 & 52.2 & 70.1 & 74.5 \\
\hline 4303 & 58 & 32 & 50.0 & 79.9 & 70.1 & 83.3 & 50.0 & 83.3 & 55.2 & 78.8 & 78.0 \\
\hline 430 & 59 & 33 & 51.0 & 75.5 & 70.4 & 89.8 & 53.1 & 77.1 & 55.9 & 72.7 & 78.1 \\
\hline 4305 & 68 & 36 & 52.1 & 73.8 & 73.0 & 74.6 & 44.8 & 74.1 & 52.9 & 78.4 & 76.9 \\
\hline 4306 & 72 & 36 & 53.6 & 78.7 & 66.9 & 81.8 & 49.6 & 83.0 & 50.0 & 80.3 & 72.3 \\
\hline 4307 & 65 & 36 & 50.9 & 75.9 & 71.7 & 91.8 & 56.7 & 72.5 & 55.4 & 70.9 & 77.6 \\
\hline 4308 & 72 & 36 & 48.1 & 79.0 & 70.8 & 82.4 & 52.8 & 85.4 & 50.0 & 76.1 & 76.8 \\
\hline 4309 & 67 & 39 & 51.9 & 82.2 & 68.2 & 88.7 & 51.9 & 64.2 & 58.2 & 77.4 & 75.9 \\
\hline 4310 & 67 & 38 & 51.8 & 79.8 & 68.8 & 82.1 & 49 & 72.9 & 56.7 & 71.4 & 75.7 \\
\hline 43. & 67 & 33 & 48.6 & 84.5 & 62.7 & 96.2 & & 68.5 & 49.3 & 69.9 & \\
\hline 4312 & 57 & 33 & 52.2 & 77.7 & 69.2 & 82.2 & 47.4 & 77.8 & 7.9 & 75.6 & 74.8 \\
\hline & 66 & 38 & 50.5 & 84.9 & 68.2 & 95.4 & & & .6 & & \\
\hline 4314 & 68 & 36 & 50.3 & 75.5 & 70.3 & 84.8 & 52.3 & 72.0 & 52.9 & 81.8 & 77.3 \\
\hline & 69 & 33 & 49.2 & 81.4 & 68 & & & 68.4 & 47.8 & & \\
\hline 4316 & 65 & 35 & 52.2 & 79.8 & 70.7 & 91.2 & 54.4 & 69.2 & 53.8 & 77.2 & 77.9 \\
\hline 431 & 63 & 34 & 49 & 76.6 & 74.3 & & & 84.1 & .0 & & \\
\hline 4318 & 68 & 39 & 52.0 & 80.0 & 66.2 & 87.0 & 52.9 & 89.1 & 57.4 & 79.0 & 73.9 \\
\hline 431 & 71 & 34 & 47.9 & 74.2 & 74.5 & 93.1 & & 78 & 47.9 & 79.4 & \\
\hline 432 & 68 & 40 & 51.4 & 76.5 & 72.7 & 94.1 & & 78.4 & 58.8 & 85.2 & 80.7 \\
\hline 432 & 57 & 35 & 50.6 & 83.9 & 68.2 & 83.7 & 49.6 & 70.2 & 61.4 & 72.6 & 76.3 \\
\hline 432 & 64 & 37 & 50.1 & 78.3 & 68.8 & 92.3 & & 65.5 & 57.8 & 71.5 & \\
\hline 432 & 62 & 38 & 52.7 & 76.4 & 73.3 & 88.9 & 54.1 & 66.0 & 61.3 & 71.1 & \\
\hline 432 & 63 & 36 & 53.1 & 80.6 & 67.4 & & & & 57.1 & 76.9 & \\
\hline 432 & 64 & 37 & 48.9 & 82.2 & 70.9 & 85.7 & 51.1 & 82.6 & 57.8 & 81.2 & 78.9 \\
\hline 432 & 62 & 35 & 50.7 & 85.3 & 70 & & & 77.8 & & 77.0 & \\
\hline 432 & 63 & 36 & 50.7 & 78.1 & 70.0 & 88.7 & 55.6 & 75.5 & 57.1 & 75.9 & \\
\hline 432 & 62 & 33 & 51.7 & 77.3 & & & & & & & \\
\hline 4329 & 65 & 41 & 51.7 & 76.9 & 71.3 & 92.4 & 58.0 & 57.1 & 63.1 & 77.1 & 77.9 \\
\hline 433 & 63 & 36 & & & 71 & & & & .1 & .0 & \\
\hline 433 & 63 & 35 & 50.8 & 71.8 & 72.6 & 95.9 & 61.0 & 76.0 & 55.6 & 76.4 & \\
\hline 433 & 68 & 38 & 51.3 & 73. & 72 & & & & .9 & 73.2 & \\
\hline 433 & 60 & 36 & 51.2 & 76.3 & 70.3 & & 42.8 & 81.8 & 60.0 & 73.2 & \\
\hline 4 & 64 & 36 & 49.6 & 83.1 & 66 & & & 64.3 & 56.3 & 74.8 & \\
\hline 433 & 59 & 34 & 49.9 & 75.9 & & & & & & & \\
\hline 433 & 65 & 36 & 50.1 & & 68 & & 56.3 & 64.8 & 55.4 & & \\
\hline & 62 & 33 & 51.2 & 80. & 69 & & & & & 75.6 & \\
\hline 4 & 61 & 35 & 49.8 & 74. & 73 & & & & 57 & 77.0 & \\
\hline & 63 & 35 & 48.7 & & 73 & & & & & 77.6 & \\
\hline $43^{5}$ & 61 & 33 & & 81 & 70 & & 52.6 & 60.4 & 54.1 & 77.4 & \\
\hline & 64 & 33 & 50. & 81 & 70 & & & & & 73.7 & \\
\hline & 64 & 35 & 51.0 & 75. & 74. & 80 & 48.5 & 89.4 & 54.7 & 70.9 & \\
\hline & 65 & 36 & & & 75 & & & & & 75.2 & \\
\hline 43 & 62 & 34 & 49.9 & & 67 & 90 & 55 & 70 & & & \\
\hline & 59 & 36 & 51.2 & 75.6 & & & & & & & \\
\hline & 69 & & 48.6 & 77.4 & 74.7 & 93.5 & 54.0 & 67.3 & 52.2 & 75.5 & \\
\hline
\end{tabular}


Measurements

\begin{tabular}{|c|c|c|c|c|c|c|c|c|c|c|c|c|}
\hline No. & Age & Stature & SH & L & B & $\mathbf{B}^{\prime}$ & $\mathbf{J}$ & go-go & GH & $\mathbf{G}^{\prime} \mathbf{H}$ & NH & NB \\
\hline 4347 & 20 & 1779 & 895 & 193 & 156 & 108 & 140 & 105 & 124 & 74 & 50 & 35 \\
\hline 4348 & 22 & 1718 & 858 & 190 & 143 & 106 & 131 & 100 & 112 & 64 & 46 & 36 \\
\hline 4349 & 18 & 1693 & 863 & 183 & 149 & 104 & 139 & 105 & 121 & 72 & 50 & 37 \\
\hline 4350 & 22 & 1632 & 821 & 190 & 145 & 110 & 128 & 100 & 115 & 69 & 48 & 34 \\
\hline 4351 & 22 & 1670 & 870 & 185 & 143 & 107 & 131 & 96 & 121 & 75 & 53 & 36 \\
\hline 4352 & 30 & 1684 & 836 & 189 & 140 & 97 & 128 & 97 & 115 & 70 & 47 & 39 \\
\hline 4353 & 38 & 1642 & 889 & 189 & 151 & 108 & 142 & 105 & 116 & (75) & 51 & (46) \\
\hline 4354 & 28 & 1749 & 898 & 189 & 146 & 103 & 138 & (109) & 127 & 79 & 54 & 39 \\
\hline 4355 & 38 & 1706 & 855 & 188 & 142 & 104 & 130 & 103 & 122 & 75 & 50 & 40 \\
\hline 4356 & 30 & 1692 & 839 & 194 & 156 & 107 & 140 & 106 & 121 & 67 & 47 & 43 \\
\hline 4357 & 25 & 1669 & 870 & 187 & 151 & 105 & 137 & 110 & 113 & 66 & 48 & 37 \\
\hline 4358 & 38 & 1751 & 887 & 204 & 150 & 108 & 141 & 100 & 136 & 77 & 50 & 43 \\
\hline 4359 & 35 & 1738 & 847 & 190 & 148 & 102 & 128 & 98 & 118 & 76 & 52 & 38 \\
\hline 4360 & 40 & 1654 & 872 & 198 & 147 & 106 & 130 & 107 & 126 & 76 & 53 & 38 \\
\hline 4361 & 40 & 1700 & 874 & 203 & 151 & 106 & 140 & 111 & 128 & 76 & 54 & 36 \\
\hline 4362 & 28 & 1726 & 878 & 185 & 146 & 103 & 135 & 104 & 124 & 75 & (54) & 37 \\
\hline 4363 & 25 & 1609 & 818 & 198 & 142 & 105 & 135 & 94 & 107 & 63 & 47 & 37 \\
\hline 4364 & 40 & 1687 & 849 & 194 & 145 & 111 & 138 & 106 & 130 & 75 & 50 & 39 \\
\hline 4365 & 35 & 1707 & 870 & 190 & 152 & 114 & 145 & 102 & 123 & 74 & 54 & 38 \\
\hline 4366 & 21 & 1715 & 838 & 194 & 146 & 105 & 135 & 99 & 118 & 65 & 44 & 6 \\
\hline 4367 & 20 & 1622 & 822 & 183 & 157 & 103 & 132 & 97 & 109 & 64 & 45 & 35 \\
\hline 4368 & 35 & 1615 & 806 & 193 & 150 & 99 & 132 & 105 & 115 & 71 & 49 & 38 \\
\hline 4369 & 20 & 1700 & 917 & 183 & 148 & 106 & 144 & 103 & 113 & 67 & 46 & 37 \\
\hline 4370 & 37 & 1689 & 831 & 194 & 147 & 101 & 132 & 94 & 126 & 76 & 53 & 37 \\
\hline 4371 & 25 & 1563 & 831 & 189 & 149 & 100 & 132 & 102 & 115 & 71 & 46 & 37 \\
\hline 4372 & 30 & 1624 & 836 & 192 & 144 & 101 & 133 & 96 & 122 & 71 & 48 & 32 \\
\hline 4373 & 22 & 1612 & 813 & 188 & 156 & 106 & 137 & 101 & 112 & 70 & 48 & 39 \\
\hline 4374 & 18 & 1710 & 861 & 193 & 144 & 104 & 130 & 102 & 113 & 68 & 48 & 36 \\
\hline 4375 & 35 & 1630 & 832 & 200 & 154 & 105 & 136 & 109 & 120 & 74 & 47 & 37 \\
\hline 4376 & 40 & 1759 & 908 & 204 & 153 & 106 & 145 & 110 & 124 & 77 & 53 & 36 \\
\hline 4377 & 32 & 1619 & 800 & 184 & 151 & 110 & 143 & 106 & 114 & 72 & 47 & 42 \\
\hline 4378 & 35 & 1637 & 846 & 194 & 156 & 101 & 138 & 103 & 117 & 70 & 47 & 41 \\
\hline 4379 & 35 & 1697 & 858 & 193 & 148 & 106 & 137 & 91 & 11 & 66 & 47 & 37 \\
\hline 4380 & 38 & 1692 & 863 & 191 & 141 & 102 & 132 & 101 & 118 & 73 & 49 & 34 \\
\hline 4381 & 18 & 1723 & 851 & 192 & 14 & 104 & 133 & 104 & 11 & 72 & 53 & \\
\hline 4382 & 30 & 1676 & 842 & 193 & 15 & 109 & 146 & 112 & 119 & 71 & 50 & 34 \\
\hline 4383 & 38 & 1587 & 819 & 191 & 14 & 102 & 133 & 105 & 11 & 66 & 49 & \\
\hline 4384 & 25 & 1725 & 843 & 189 & 14 & 103 & 134 & 102 & 125 & 72 & 51 & 40 \\
\hline 4385 & 22 & 1615 & 835 & 191 & 15 & 104 & 135 & 107 & 118 & 71 & 50 & 6 \\
\hline 4386 & 33 & 1761 & 861 & 191 & 15 & 98 & 137 & 104 & 115 & 71 & 51 & 40 \\
\hline 4387 & 40 & 1725 & 847 & 19 & 14 & 100 & 137 & 106 & 11 & 68 & $\begin{array}{l}46 \\
\end{array}$ & 38 \\
\hline 4388 & 20 & 1654 & 813 & & 15 & 102 & 131 & 100 & 11 & 71 & 50 & 6 \\
\hline 438 & 28 & 1673 & 830 & & 14 & 102 & 133 & 98 & 11 & 73 & 48 & \\
\hline 439 & 40 & 1674 & 82 & 194 & & 109 & 137 & 106 & 120 & 72 & 50 & 42 \\
\hline 439 & 30 & 1601 & 808 & 19 & 14 & 106 & 139 & 102 & 120 & 73 & 52 & 39 \\
\hline 439 & 45 & 1600 & 80 & & & 101 & 135 & 105 & 12 & 79 & 53 & \\
\hline 439 & 38 & 1652 & 8 & 193 & & 107 & 137 & 102 & 120 & 75 & 58 & \\
\hline 439 & 45 & 1620 & 83 & & & 101 & 129 & 102 & 11 & 71 & 57 & 39 \\
\hline 43 ? & 32 & 1629 & 8( & 15 & 14 & 108 & 144 & 105 & 12 & 72 & 50 & 7 \\
\hline 439 & 28 & 1631 & 82 & 19 & & 113 & 13 & 93 & & 70 & 49 & \\
\hline 43 ? & 30 & 1528 & 77 & 18 & 15 & 98 & 130 & 100 & 11 & 70 & 52 & 34 \\
\hline & 29 & 1567 & 83 & & 14 & 107 & 140 & 110 & & 74 & 52 & \\
\hline & 50 & 1681 & 84 & 19 & 14 & 103 & 135 & 106 & 12 & 76 & 54 & 31 \\
\hline & & 1698 & & 18 & 14 & 102 & 135 & 102 & & 70 & 48 & 33 \\
\hline & 05 & 1706 & 9 & 18 & 14 & 102 & 142 & 110 & 11 & 71 & 53 & 41 \\
\hline & & 1570 & & & & 103 & 13 & 110 & 120 & 72 & 55 & \\
\hline & 5 & 1665 & & & 14 & 100 & 138 & 102 & (122) & (72) & 49 & \\
\hline & & 1579 & & & 14 & 109 & 136 & 109 & & 67 & 48 & 33 \\
\hline 440 & 7 & 1585 & & 179 & 136 & 94 & 127 & 97 & (109) & (66) & 50 & \\
\hline
\end{tabular}

* Omitted from means. 
INDICES

\begin{tabular}{|c|c|c|c|c|c|c|c|c|c|c|c|}
\hline No. & EL & EB & RSH & B/L & $\mathbf{B}^{\prime} / \mathbf{B}$ & GH/J & $\mathbf{G}^{\prime} \mathbf{H} / \mathbf{J}$ & $\mathrm{NB} / \mathrm{NH}$ & EB/EL & $\mathrm{g} 0-\mathrm{go} / \mathrm{J}$ & $\mathbf{B}^{\prime} / \mathbf{J}$ \\
\hline 4347 & 63 & 37 & 50.3 & 80.8 & 69.2 & 88.6 & 52.9 & 70.0 & 58.7 & 75.0 & 77.1 \\
\hline 4348 & 67 & 37 & 49.9 & 75.3 & 74.1 & 85.5 & 48.9 & 78.3 & 55.2 & 76.3 & 80.9 \\
\hline 4349 & 62 & 33 & 51.0 & 81.4 & 69.8 & 87.1 & 51.8 & 74.0 & 53.2 & 75.5 & 74.8 \\
\hline 4350 & 56 & 35 & 50.3 & 76.3 & 75.9 & 89.8 & 53.9 & 70.8 & 62.5 & 78.1 & 85.9 \\
\hline 4351 & 65 & 35 & 52.1 & 77.3 & 74.8 & 92.4 & 57.3 & 67.9 & 53.8 & 73.3 & 81.7 \\
\hline 4352 & 64 & 33 & 49.6 & 74.1 & 69.3 & 89.8 & 54.7 & 83.0 & 51.6 & 75.8 & 75.8 \\
\hline 4353 & 65 & 36 & 54.1 & 79.9 & 71.5 & 81.7 & 52.8 & 90.2 & 55.4 & 73.9 & 76.1 \\
\hline 4354 & 66 & 34 & 51.3 & 77.2 & 70.5 & 92.0 & 57.2 & 72.2 & 51.5 & 79.0 & 74.6 \\
\hline 4355 & 63 & 37 & 50.1 & 75.5 & 73.2 & 93.8 & 57.7 & 80.0 & 58.7 & 79.2 & \\
\hline 4356 & 63 & 34 & 49.6 & 80.4 & 68.6 & 86.4 & 47.9 & 91.5 & & 75.7 & 76.4 \\
\hline 4357 & 62 & 32 & 52.1 & 80.7 & 69.5 & 82.5 & 48.2 & 77.1 & 51.6 & 80.3 & 76.6 \\
\hline 4358 & 71 & 35 & 50.7 & 73.5 & 72.0 & 96.5 & 54.6 & 86.0 & 49.3 & 70.9 & 76.6 \\
\hline 4359 & 71 & 42 & 48.7 & 77.9 & 68.9 & 92.2 & 59.4 & 73.1 & 59.2 & 76.6 & 80.0 \\
\hline 4360 & 65 & 40 & 52.7 & 74.2 & 72.1 & 96.9 & 58.5 & 71.7 & 61.5 & 82.3 & 81.5 \\
\hline 4361 & 59 & 36 & 51.4 & 74.4 & 70.2 & 91.4 & 54.3 & 66.7 & 61.0 & 79.3 & 75.7 \\
\hline 4362 & 63 & 33 & 50.9 & 78.9 & 70.5 & 91.9 & 55.6 & 68.5 & 52.4 & 77.0 & 76.3 \\
\hline 4363 & 57 & 34 & 50.8 & 71.7 & 73.9 & 79.3 & 46.7 & 78.7 & 59.6 & 69.6 & 77.8 \\
\hline 4364 & 68 & 39 & 50.3 & 74.7 & 76.6 & 94.2 & 54.3 & 78.0 & 57.4 & 76.8 & .4 \\
\hline 4365 & 65 & 38 & 48.7 & 80.0 & 75.0 & 84.8 & 51.0 & 70.4 & 58.5 & 70.3 & 78.6 \\
\hline 4366 & 62 & 35 & 48.9 & 75.3 & 71.9 & 87.4 & 48.1 & 81.8 & 56.5 & 73.3 & 77.8 \\
\hline 4367 & 53 & 36 & 50.7 & 85.8 & 65.6 & 82.6 & 48.5 & 77.8 & 67.9 & 73.5 & 78.0 \\
\hline 4368 & 61 & 36 & 49.9 & 77.7 & 66.0 & 87.1 & 53.8 & 77.6 & 59.0 & 79.5 & 75.0 \\
\hline 4369 & 65 & 35 & 53.9 & 80.9 & 71.6 & 78.5 & 46.5 & 80.4 & 3.8 & 71.5 & 73.6 \\
\hline 4370 & 68 & 33 & 49.2 & 75.8 & 68.7 & 95.5 & 51.7 & 69.8 & 48.5 & 71.2 & 76.5 \\
\hline 4371 & 56 & 35 & 53.2 & 78.8 & 67.1 & 87.1 & 53.8 & 80.4 & 62.5 & 77.3 & 5.8 \\
\hline 4372 & 57 & 28 & 51.5 & 75.0 & 70.1 & 91.7 & 53.4 & 66.7 & 49.1 & 72.2 & 75.9 \\
\hline 4373 & 60 & 36 & 50.4 & 83.0 & 67.9 & 81.8 & 51.1 & 81.3 & 60.0 & 73.7 & 77.4 \\
\hline 4374 & 66 & 36 & 50.4 & 74.6 & 72.2 & 86.9 & 52.3 & 75.0 & 54.5 & 78.5 & 80.0 \\
\hline 4375 & 59 & 34 & 51.0 & 77.0 & 68.2 & 88.2 & 54.4 & 78.7 & 57.6 & 80.1 & 77.2 \\
\hline 4376 & 66 & 41 & 51.6 & 75.0 & 69.3 & 85.5 & 53.1 & 67.9 & 62.1 & 75.9 & 73.1 \\
\hline 4377 & 60 & 34 & 49.4 & 82.1 & 72.8 & 79.7 & 50.3 & 89.4 & 56.7 & 74.1 & 76.9 \\
\hline 4378 & 65 & 34 & 51.7 & 80.4 & 64.7 & & 50.7 & 87.2 & 52.3 & 74.6 & 3.2 \\
\hline 4379 & 61 & 36 & 50.6 & 76.7 & 71.6 & 84.7 & 48.2 & 78.7 & 59.0 & 66.4 & 77.4 \\
\hline 438 & 65 & 39 & 51.0 & 73.8 & 72.3 & & 55.3 & 69.4 & & 76.5 & 77.8 \\
\hline 4381 & 65 & 33 & 49.4 & 76.0 & 71.2 & 85.7 & 54.1 & 71.7 & 50.8 & 78.2 & 78.2 \\
\hline & 66 & 33 & 50.2 & 81.3 & 69.4 & & 48.6 & 68.0 & & 76.7 & \\
\hline 4383 & 65 & 34 & 51.6 & 76.4 & 69.9 & 85.0 & 49.6 & 71.4 & 52.3 & 78.9 & 76.7 \\
\hline & 61 & 38 & 48.9 & 77. & 70 & & & & & 76.1 & \\
\hline 438 & 63 & 33 & 51.7 & 79.1 & 68.9 & 87.4 & 52.6 & 72.0 & 52.4 & 79.3 & 7.0 \\
\hline 43 & 70 & 35 & 48.9 & 78 & 65 & & & & & 75.9 & \\
\hline 438 & 65 & 35 & 49.1 & 73.2 & 70.4 & 82.5 & 49.6 & 82.6 & & 77.4 & 3.0 \\
\hline 43 & 64 & 37 & 49.2 & & 67 & & & 72.0 & & 76.3 & \\
\hline 438 & 64 & 31 & 49.6 & 75.9 & 70.3 & & 1.9 & 72.9 & & 73.7 & .7 \\
\hline 43 & 68 & 38 & 49.3 & 76.8 & 73.2 & & & 84.0 & & 77.4 & \\
\hline $43 ?$ & 61 & 34 & 50. & 78 & 71 & & & & & 73.4 & \\
\hline $43 !$ & 66 & 35 & 50.1 & 75.5 & 69 & & & 66.0 & & 77.8 & \\
\hline 43 & 60 & 36 & 52.1 & 77.7 & 71. & & & & & 74.5 & \\
\hline 43 & 56 & 32 & 51.8 & 79.6 & 68. & & & 68.4 & & & \\
\hline & 67 & 35 & 52.9 & 76.4 & 72 & & & & & 72.9 & \\
\hline & 59 & 34 & 50.6 & 77. & 76.9 & & & 71.4 & 57.6 & 66.9 & \\
\hline & 56 & 34 & 50. & 79.9 & 64 & & & & & 76.9 & \\
\hline & 66 & 33 & 53. & 78.8 & 71 & & 52.9 & 65.4 & & 78.6 & \\
\hline & 61 & 38 & 50.3 & 75 & 71 & & & & & 78.5 & \\
\hline 44 & 61 & 35 & 54.1 & 81 & 68 & & 51.9 & 68.8 & & 75.6 & \\
\hline & 65 & 35 & 53. & 78.8 & 68 & & & & & 77.5 & \\
\hline & 59 & 35 & 51. & 78. & 71. & & 54 & 63 & & 82.7 & \\
\hline & 58 & 34 & 52.6 & & 70 & & & & & 73.9 & \\
\hline & 65 & 32 & 50.3 & 82.5 & $74 . ?$ & 80 & 49.3 & 68.8 & 49 & 80.1 & \\
\hline & 66 & 36 & 50.0 & 76.0 & 69.1 & 85.8 & 52.0 & 62.0 & 54.5 & 76.4 & 74.0 \\
\hline
\end{tabular}


Measurements

\begin{tabular}{|c|c|c|c|c|c|c|c|c|c|c|c|}
\hline No. Age & Stature & SH & L. & B & $\mathbf{B}^{\prime}$ & J & go-go & GH & $\mathbf{G}^{\prime} \mathbf{H}$ & NH & NB \\
\hline $4406 * 45$ & 1690 & 845 & 186 & 137 & 101 & 133 & 110 & 122 & 76 & 53 & 31 \\
\hline $4407 * 48$ & 1695 & 831 & 197 & 150 & 110 & 138 & 109 & 131 & 81 & 59 & 37 \\
\hline $4408 * 35$ & 1615 & 803 & 185 & 155 & 111 & 140 & 108 & 124 & 75 & 55 & \\
\hline $4409 * 22$ & 1633 & 824 & 183 & 143 & 110 & 139 & 104 & 107 & 63 & 43 & 34 \\
\hline $4410 * 35$ & 1727 & 851 & 190 & 152 & 101 & 137 & & 120 & 74 & 53 & 12 \\
\hline $4411 * 38$ & 1630 & 817 & 193 & 146 & 107 & 138 & 103 & 125 & 76 & 54 & 44 \\
\hline $4412 * 18$ & 1571 & 83. & 193 & 145 & 102 & 132 & 98 & 112 & 64 & 43 & 37 \\
\hline $4413 * 15$ & 1615 & 822 & 192 & 147 & 104 & 133 & 98 & 120 & 65 & 47 & \\
\hline $4414 * 27$ & 1701 & 850 & 193 & 150 & 98 & 132 & 97 & 130 & 82 & 58 & 39 \\
\hline $4415 * 25$ & 1663 & 817 & 199 & 155 & 105 & 138 & 101 & 122 & 76 & 55 & \\
\hline
\end{tabular}

\section{INDICES}

\begin{tabular}{|c|c|c|c|c|c|c|c|c|c|c|c|}
\hline No. & EL & EB & RSH & B/L & $\mathbf{B}^{\prime} / \mathbf{B}$ & $\mathrm{GH} / J$ & $\mathrm{G}^{\prime} \mathbf{H} / \mathrm{J}$ & $\mathrm{NB} / \mathrm{NH}$ & EB/EL & $\mathrm{go}-\mathrm{go} / \mathrm{J}$ & $\mathbf{B}^{\prime} / \mathrm{J}$ \\
\hline 4406 & (59) & 32 & 50.0 & 73.7 & 73.7 & 91.7 & 57.1 & $\mathbf{5 8 . 5}$ & $(54.2)$ & 82.7 & 75.9 \\
\hline 4407 & 68 & 39 & 49.0 & 76.1 & 73.3 & 94.9 & 58.7 & 62.7 & 57.4 & 79.0 & 79.7 \\
\hline 4408 & 69 & 34 & 49.7 & 83.8 & 71.6 & 88.6 & 53.6 & 65.5 & 49.3 & 77.1 & 79.3 \\
\hline 4409 & 59 & 35 & 50.5 & 78.1 & 76.9 & 77.0 & 45.3 & 79.1 & 59.3 & 74.8 & \\
\hline 4410 & 69 & 36 & 49.3 & 80.0 & 66.4 & 87.6 & 54.0 & 79.2 & 52.2 & & \\
\hline 4411 & 66 & 38 & 50.1 & 75.6 & 73.3 & 90.6 & & 81.5 & 57.6 & 74.6 & \\
\hline 441 & 51 & 35 & 52.9 & 75 & 70 & 84.8 & & 86.0 & 68.6 & 74.2 & \\
\hline 44 & 57 & 33 & 50.9 & 76.6 & 70.7 & 90.2 & 48.9 & 76.6 & 57.9 & 73.7 & \\
\hline 44$]$ & 64 & 35 & 50.0 & 77. & 65. & & & & & 73.5 & \\
\hline 1 & 66 & 36 & 49.1 & 77. & & 88 & & & 54.5 & 73.2 & \\
\hline
\end{tabular}

\section{Morphological Characters of AN Nasiriya Males}

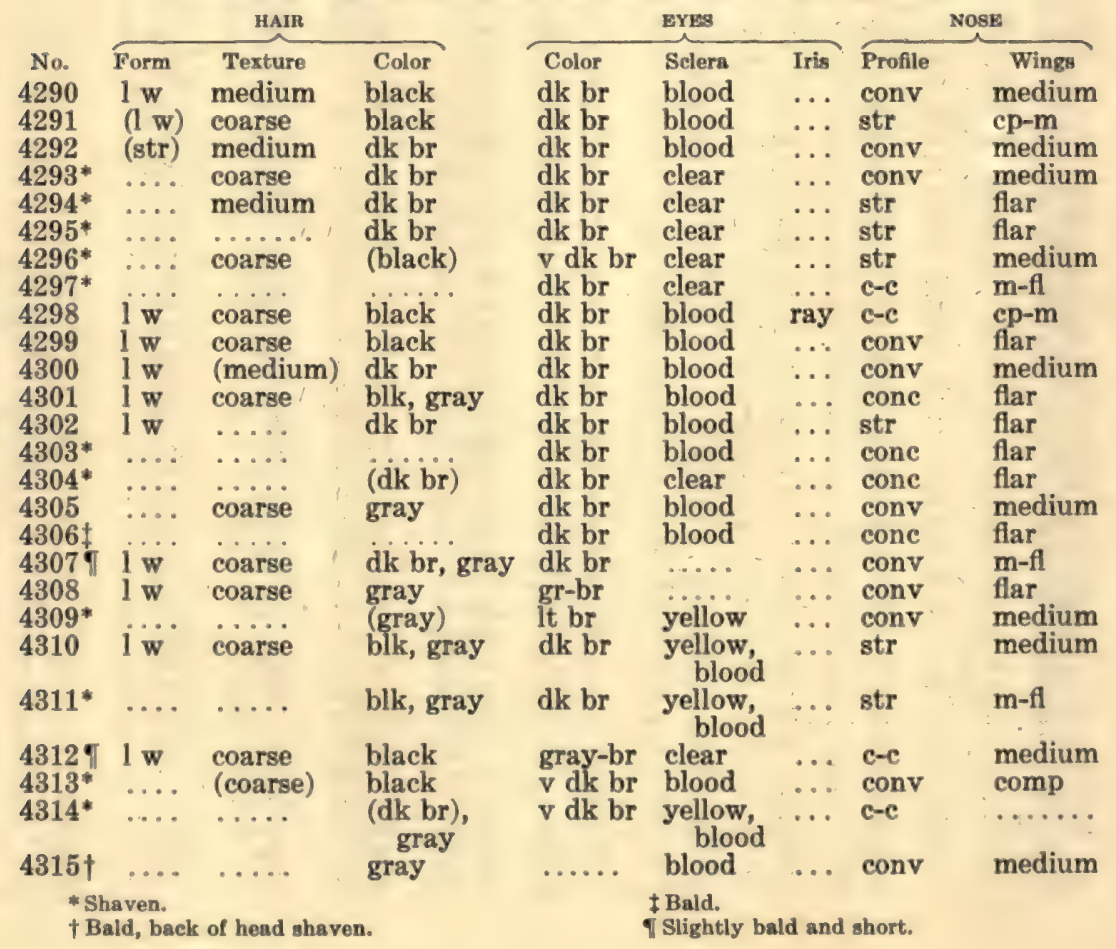


Morphological Characters of An Nasiriya Males

\begin{tabular}{|c|c|c|c|c|c|c|c|c|}
\hline \multirow[b]{2}{*}{ No. } & \multicolumn{3}{|c|}{ HAIR } & \multicolumn{3}{|c|}{ EYES } & \multicolumn{2}{|c|}{ NOSE } \\
\hline & Form & Texture & Color & Color & Sclera & Iris & Profile & Wings \\
\hline 4316 & $1 \mathrm{w}$ & & dk br & dk br & blood & $\cdots$ & conv & medium \\
\hline $4317^{*}$ & $\ldots$ & medium & $\mathrm{dk}$ br & $\mathrm{v}$ dk br & yellow & ... & conc & flar \\
\hline 4318 ๆ & $\ldots$ & coarse & black & $\mathrm{dk} b r$ & blood & $\cdots$ & conv & flar \\
\hline 4319 & $\ldots$ & coarse & dk br & $\mathrm{dk} b \mathrm{r}$ & blood & $\ldots$ & str & $m-f$ \\
\hline $4320^{*}$ & $\ldots$ & $\ldots \ldots$ & $\begin{array}{l}\text { dk br, } \\
\text { gray }\end{array}$ & dk br & clear & $\ldots$ & conv & flar \\
\hline 4321 & $\ldots$ & coarse & black & dk br & $\begin{array}{l}\text { yellow, } \\
\text { blood }\end{array}$ & $\ldots$ & conv & medium \\
\hline 4322 & $\ldots$ & $\cdots$ & (dk br) & dk br & yellow & $\ldots$ & conv & medium \\
\hline 4323* & $\ldots$ & $\ldots \ldots$ & (dk br) & dk br & clear & $\ldots$ & conv & medium \\
\hline 4324* & $\ldots$ & $\ldots \ldots$ & (dk br) & gray-br & blood & $\ldots$ & conv & comp \\
\hline 4325* & $\ldots$ & . & (dk br) & $\mathrm{v}$ dk br & clear & $\ldots$ & cone & flar \\
\hline $4326^{*}$ & $\ldots$ & (medium) & $\mathrm{dk}$ br & vk dk br & clear & $\cdots$ & cone & flar \\
\hline 4327 & $\cdots$ & $\ldots \ldots$ & (dk br) & dk br & $\begin{array}{l}\text { speck- } \\
\text { blood }\end{array}$ & $\cdots$ & conv & flar \\
\hline 4328 & & $\ldots \ldots$ & (dk br) & $\mathrm{dk}$ br & blood & $\cdots$ & str & flar \\
\hline $4329^{*}$ & $\ldots$. & ..... & (black) & $\mathrm{dk}$ br & clear & $\ldots$ & conv & comp \\
\hline 4330 & $\cdots$ & $\ldots$ & $(\mathrm{dk} b r)$ & $\mathrm{dk}$ br & blood & $\ldots$ & str & flar \\
\hline 4331 & $\cdots$ & $\cdots \cdots$ & (dk br) & $\mathrm{dk}$ br & & $\cdots$ & cone & $\mathrm{m}-\mathrm{fl}$ \\
\hline 4332 & $\cdots$ & $\cdots \cdots$ & (dk br) & $\mathrm{dk}$ br & yellow & $\ldots$ & cone & flar \\
\hline $\begin{array}{l}4338 \\
4334\end{array}$ & $\cdots$ & $\ldots$ & $\ldots \ldots$ & $\mathrm{dk}$ br & clear & $\cdots$ & $c-c$ & flar \\
\hline 4335 & $\mathrm{l} w$ & medium & $\mathrm{d} \mathbf{k} \overrightarrow{\mathrm{b} r}$ & $\begin{array}{l}\mathrm{gr}-\mathrm{br} \\
\mathrm{dk} \mathrm{br}\end{array}$ & $\begin{array}{l}\text { blood } \\
\text { clear }\end{array}$ & zon & $\begin{array}{l}\text { conv } \\
\text { conv }\end{array}$ & medium \\
\hline 336 & $\ldots \ldots$ & $\ldots$ & $\ldots \ldots$ & $\mathrm{dk}$ br & blood & $\cdots$ & conv & $\begin{array}{l}\text { comp } \\
\text { medium }\end{array}$ \\
\hline 4337 & $\ldots$ & $\ldots \ldots$ & $\therefore \cdots$ & $\mathrm{dk}$ br & blood & $\ldots$ & conv & comp \\
\hline 4338 & $\ldots$. & $\ldots$ & blk, gray & $\mathrm{dk}$ br & blood & $\ldots$ & $c-c$ & comp \\
\hline 4339 & $\cdots$ & $\ldots \ldots$ & $\ldots \ldots$ & $\mathrm{v} d \mathrm{dk}$ br & clear & $\ldots$ & cone & $\mathrm{m}-\mathrm{fl}^{\mathrm{s}}$ \\
\hline 4340 & $\cdots$ & $\cdots \cdots$ & $\ldots \ldots$ & dk br & blood & $\cdots$ & conv & comp \\
\hline 4341 & $\cdots$ & $\ldots$ & $\cdots \cdots$ & $\mathrm{dk}$ br & $\begin{array}{l}\text { speck- } \\
\text { blood }\end{array}$ & $\cdots$ & conv & $\mathrm{cp}-\mathrm{m}$ \\
\hline 4342 & $\cdots$ & $\therefore \ldots$ & $\cdots$ & $\mathrm{dk}$ br & clear & $\cdots$ & $c-c$ & \\
\hline $\begin{array}{l}4343 \\
4344\end{array}$ & $\cdots$ & $\cdots \cdots$ & $\ldots \ldots$ & $\mathrm{v}$ dk br & clear. & ... & c-c & medium \\
\hline $\begin{array}{l}4344 \\
4345\end{array}$ & $\cdots$ & $\cdots \cdots$ & black & $\mathrm{dk}$ br & blood & $\ldots$ & conc & medium \\
\hline $\begin{array}{l}4345 \\
4346\end{array}$ & $\ldots$ & $\ldots \cdots$ & $\begin{array}{l}\text { black } \\
\text { black }\end{array}$ & $\mathrm{v}$ dk br & blood & $\cdots$ & cone & m-fl \\
\hline 43478 & $\ldots$ & coarse & $\begin{array}{l}\text { black } \\
\text { black }\end{array}$ & lt br & blood & zon & str & medium \\
\hline $4348^{\circ}$ & $\ldots$ & $\ldots \ldots$ & black & $\mathrm{dk}$ br & clear & $\cdots$ & conv & medium \\
\hline 4349. & $\ldots \ldots$ & $\ldots \ldots$ & & $\begin{array}{l}\text { dk br } \\
\text { dk br }\end{array}$ & $\begin{array}{l}\text { clear } \\
\text { clear }\end{array}$ & $\cdots$ & conc & medium \\
\hline $4350 \&$ & $\ldots$ & coarse & black & $\mathrm{dk}$ br & $\begin{array}{l}\text { clear } \\
\text { blood }\end{array}$ & $\cdots$ & conv & medium \\
\hline 4351 & $\cdots$ & $\ldots \ldots$ & $\ldots \ldots$ & (gray-br) & blood & $\ldots$ & conc & comp \\
\hline 4352 & $\cdots$ & $\ldots \ldots$ & ...... & gray-br & blood & $\ldots$ & $c-c$ & flar \\
\hline 4353 & $\cdots$ & $\ldots \ldots$ & $\ldots \ldots$ & $\mathrm{dk}$ br & blood & $\ldots$ & conc & \\
\hline 4354 & $\cdots$ & $\because \ldots$ & ..... & black & blood & $\cdots$ & str & medium \\
\hline & $\cdots$ & $\ldots \ldots$ & ..... & dk br & blood & $\therefore$ & $\operatorname{conv}$ & flar \\
\hline $4356 \dagger$ & $\cdots$ & $\cdots \cdots$ & $\ldots \ldots$ & lt br & blood & $\cdots$ & conc & flar \\
\hline & $\cdots$ & $\ldots \ldots$ & ..... & dk br & yellow & $\cdots$ & conc & flar \\
\hline & $\cdots$ & $\ldots \ldots$ & ..... & v dk br & blood & $\cdots$ & str & m-fl \\
\hline & $\cdots$ & $\ldots$. & ...... & dk br & yellow & $\cdots$ & conc & medium \\
\hline & $\cdots$ & $\therefore \cdots$ & $\cdots \cdots$ & v dk br & blood & $\cdots$ & str & medium \\
\hline & $\cdots$ & $\cdots \cdots$ & ...... & gray-br & blood & $\ldots$ & conv & comp \\
\hline & $\cdots$ & $\ldots \ldots$ & ...... & v dk br & clear & $\cdots$ & conc & $\mathrm{cp}-\mathrm{m}$ \\
\hline & $\cdots$ & $\cdots \cdots$ & . $\therefore . .$. & dk br & blood & $\ldots$ & str & medium \\
\hline & $\therefore$. & $\ldots \ldots$ & ...... & dk br & blood & $\cdots$ & str & medium \\
\hline & $\cdots$ & $\ldots \ldots$ & ...... & dk br & blood & $\therefore$. & conv & medium \\
\hline
\end{tabular}

* Shaven.

I Rather bald.

6 Hair very short.

† Hair probably frizzly but shaven.

₹ Hair very thin probably because of disease. 
Morphological Characters of An Nasiriya Males

\begin{tabular}{|c|c|c|c|c|c|c|c|c|}
\hline \multirow[b]{2}{*}{ No. } & \multicolumn{3}{|c|}{ HAIR } & \multicolumn{3}{|c|}{ EYEg } & \multicolumn{2}{|c|}{ NOSE } \\
\hline & Form & Texture & Color & Color & Selera & Iris & Profile & Wings \\
\hline 4366 & $\ldots$ & $\ldots \ldots$ & $\ldots \ldots$ & $\mathrm{dk}$ br & blood & $\ldots$ & cone & flar \\
\hline 4367 & $\ldots$ & $\ldots \ldots$ & $\ldots \ldots$ & dk br & blood & $\ldots$ & conv & m-fl \\
\hline 4368 & $\ldots$ & $\ldots \ldots$ & $\ldots \ldots$ & gr-br & blood & zon & conv & medium \\
\hline 4369 & & $\ldots \ldots$ & $\therefore \ldots$ & dk br & blood & $\ldots$ & str. & $m-f$ \\
\hline $4370 \dagger$ & $(1 \mathrm{w})$ & coarse & blk, gray & v dk br & blood & $\ldots$ & cone & medium \\
\hline 4371 & $\cdots$ & $\ldots \ldots$ & $\ldots \ldots$ & dk br & clear & $\cdots$ & str & flar \\
\hline 4372 & $\ldots$ & $\ldots \ldots$ & $\ldots \ldots$ & dk br & blood & $\ldots$ & $c-c$ & $c p-m$ \\
\hline 4373 & $\cdots$ & $\cdots \cdots$ & $\ldots \ldots$ & dk br & clear & $\cdots$ & conv & $m-f l$ \\
\hline 4374 & $\ldots$ & (mejium) & $\mathrm{di} \mathrm{br}$ & v dk br & blood & $\ldots$ & conv & medium \\
\hline $4375 \pm$ & $\cdots$ & (medium) & dk br & v dk br & blood & $\cdots$ & str & m-fl \\
\hline $4376 \uparrow$ & $\cdots$ & coarse & dk br & v dk br & blood & $\cdots$ & conv & comp \\
\hline 4377 & $\because \cdots$ & $\cdots \cdots$ & $\dot{3 i} \cdots$ & v dk br & blood & $\cdots$ & cone & flar \\
\hline 4378 & I w & coarse & blk, gray & dk br & blood & $\cdots$ & str & flar \\
\hline 4379 & $\cdots$ & $\cdots$ & $\ldots \ldots$ & v dk br & blood & $\cdots$ & $c-c$ & medium \\
\hline 4380 & $\cdots$ & $\cdots \cdots$ & $\ldots \ldots$ & v dk br & & $\cdots$ & conv & comp \\
\hline 4381 & $\cdots$ & $\cdots \cdots$ & $\ldots \ldots$ & dk br & blood & $\ldots$ & conv & medium \\
\hline 4382 & $\cdots$ & $\ldots \ldots$ & $\cdots \cdots$ & dk br & clear & $\cdots$ & conv & medium \\
\hline 4383 & $\cdots$ & $\ldots \ldots$ & .... & dk br & blood & $\cdots$ & cone & $\mathrm{cp}-\mathrm{m}$ \\
\hline 4384 & $\therefore$. & $\ldots$ & $\ldots \ldots$ & $\mathrm{dk}$ br & $\therefore \cdots$ & $\cdots$ & str & flar \\
\hline 4385 & $\ldots$ & $\therefore \ldots$ & $\ldots \ldots$ & $v \mathrm{dk}$ br & blood & . & cone & medium \\
\hline 4386 ๆ & $\ldots$ & $\ldots \ldots$ & $\ldots \ldots$ & dlk br & blood & $\ldots$ & conv & medium \\
\hline 4387 & $\ldots$ & $\ldots \ldots$ & $\ldots \ldots$ & dk br & blood & $\ldots$ & $c-c$ & $m-f l$ \\
\hline 4388 & $\ldots$ & $\ldots \ldots$ & $\ldots \ldots$ & $\mathbf{v} \mathbf{d k}$ br & & $\ldots$ & conv & medium \\
\hline 4389 & $\ldots$ & $\ldots \ldots$ & $\therefore \ldots$ & dk br & blood & $\ldots$ & $c-c$ & medium \\
\hline $4390^{*}$ & $\ldots$ & $\ldots$ & dk br & $\mathbf{v} \mathrm{dk}$ br & blood & $\ldots$ & $c-c$ & flar \\
\hline 4391 & $\ldots$ & $\ldots \ldots$ & dk br & $\mathrm{dk}$ br & clear & $\cdots$ & conv & medium \\
\hline 4392 & $\ldots$ & $\ldots \ldots$ & $\therefore \cdots$ & $\mathrm{v}$ dk br & blood & $\ldots$ & conv & medium \\
\hline 4393 & $\ldots$ & $\ldots \ldots$ & blk, gray & dk br & blood & ... & conv & medium \\
\hline 4394 & $\ldots$ & $\ldots \ldots$ & black & dk br & blood & $\ldots$ & conv & medium \\
\hline 4395 & $\ldots$ & $\ldots \ldots$ & $\ldots \ldots$ & v dk br & blood & $\cdots$ & conc & medium \\
\hline 4396 & $\ldots$. & $\ldots \ldots$ & $\ldots \ldots$ & $\mathrm{gr}-\mathrm{br}$ & blood & $\ldots$ & conv & medium \\
\hline 4397 & $\cdots \cdots$ & $\cdots$ & $\because \cdots$ & $\mathrm{v}$ dk br & clear & $\cdots$ & str & comp \\
\hline 4398 & l w & medium & dk br & $\begin{array}{l}\text { dk br } \\
\text { (blk) }\end{array}$ & clear & $\cdots$ & conv & medium \\
\hline $4399^{*}$ & $\ldots$ & $\therefore \ldots$ & gray & dk br, gray & blood & $\ldots$ & conv & comp \\
\hline $4400^{*}$ & $\ldots$ & $\ldots \ldots$ & (dk br) & dk br & blood & . & str & $\mathrm{cp}-\mathrm{m}$ \\
\hline 4401 & $\ldots$ & coarse & $\mathrm{dk}$ br & dk br & blood & .. & conv & m-fl \\
\hline 4402 & $\therefore$. & $\ldots$ & black & $\mathrm{dk}$ br & yellow & $\ldots$ : & conv & medium \\
\hline 4403 & l w & medium & black & dk br & blood & $\ldots$ & conv & medium \\
\hline 4404 & $\ldots$ & medium & dk br & dk br & blood & ... & conv & comp \\
\hline 4405 & $\ldots$ & $\ldots \ldots$ & gray & dk br & & $\ldots$ & $c-c$ & comp \\
\hline 4406 & $\cdots$ & & dk br & dk br & blood & $\ldots$ & conv & comp \\
\hline 4407 & (str) & fine & blk, gray & dk br & blood & $\ldots$ & conv & $\mathrm{cp}-\mathrm{m}$ \\
\hline 4408 & $\ldots$ & $\cdots \cdots$ & $\ldots \ldots$ & dk br & blood & $\cdots$ & conv & comp \\
\hline 4409 & $\cdots$ & $\ldots$ & & dk br & blood & $\ldots$ & conv-str & flar \\
\hline 4410 & I w & coarse & black & dk br & blood & $\ldots$ & $c-c$ & flar \\
\hline 4411 & $\cdots$ & $\cdots \cdots$ & $\ldots \ldots$ & dk br & blood & $\ldots$ & str & flar \\
\hline 4412 & $\cdots$ & $\therefore \ldots$ & $\ldots \ldots$ & $\mathrm{v}$ dk br & yellow & $\ldots$ & cone & flar \\
\hline 4413 & & $\ldots$ & $\ldots \cdots$ & dk br & yellow & . & cone & medium \\
\hline 4414 & $1 \mathrm{w}$ & coarse & dk br & $\mathrm{dk}$ br & blood & $\ldots$ & conv & medium \\
\hline 4415 & $\ldots$ & $\ldots \ldots$ & $\ldots \ldots$ & lt br & clear & $\cdots$ & conv & comp \\
\hline & $\begin{array}{l}\text { ven. } \\
\text { ir shor }\end{array}$ & & $=$ & & & & & \\
\hline & very & & & & & & & \\
\hline & & & & & & & & \\
\hline
\end{tabular}




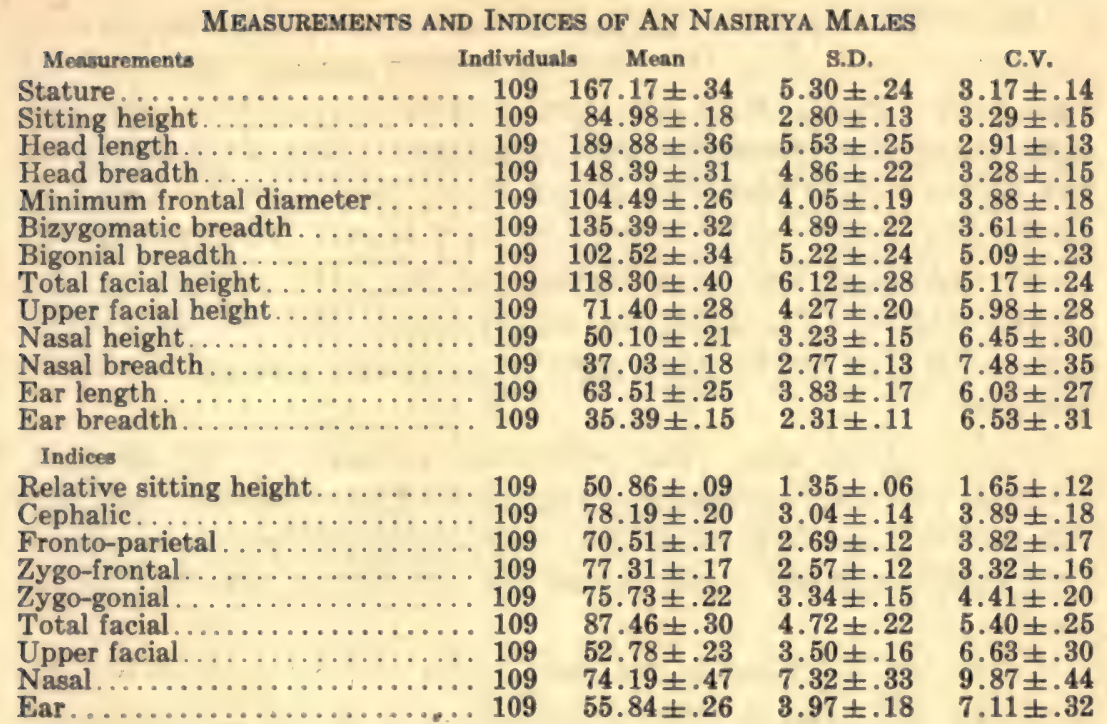

\section{INDIVIDUALS OMITTED FROM THE STATISTICAL SERIES}

Seventeen individuals were omitted because of origins too heterogeneous to form a comparable group. These included No. 4399 from Kut; Nos. 4400 and 4401 from An Najaf, the Al Baadwa and $\mathrm{Al}$ bu Shairuza respectively; No. 4402, a Husainat from Hammam Ali near Mosul; Nos. 4403-4406, Persians (now Iranis) from Isfahan, near Bender abu Shahr, Persia and Kermanshah respectively; No. 4407, a Persian gypsy; No. 4408, from Harta near Basra; No. 4409, a Sawaad from Halfaya; No. 4410, a Jubur from Baghdad Liwa; Nos. 4411 and 4412, Budur (shepherds) from An Nasiriya; No. 4413, a Sadun (Beduin) from Basra; No. 4414, a Juhaish from Hillah; and No. 4415, an Al Ubaid from Samarra.

Skin.--Nos. 4401 and 4414 had fair skins and No. 4409 a darker skin than the average.

Head Form.-No. 4406 had a high sloping vault with abstanding ears.

Hair.-Five individuals had dark brown hair. Nos. 4402, 4403, and 4410 had black hair. No. 4407 had black-gray and Nos. 4399 and 4405 gray hair. There were two individuals in the medium and three in the coarse categories of hair texture. No. 4407 had fine hair. Three individuals had low wavy hair, while one individual, No. 4407, had straight hair. Nos. 4399 and 4400 were shaven. No. 4410 had a mustache. 
Eyes.-The majority had dark brown eyes. No. 4412 had very dark brown eyes, while No. 4399 had gray-brown and No. 4415 had light brown eyes. With the exception of three yellow and one clear sclera, the remainder were bloodshot. Nos. 4403 and 4407 had darker rims around dark brown eyes. Nos. 4399 and 4415 had darker rims around gray-brown and light brown eyes respectively.

No. 4405 had both eyes filmed, and No. 4411 had his left eye slightly filmed. No. 4404 had deep set eyes and No. 4411 small eyes. The eyes of No. 4405 were very red and rheumy; his vision was poor.

Nose.-There were two individuals in each of the straight, concave, and concavo-convex categories. The remainder had convex profiles. Six individuals had compressed-medium nasal wings. Four individuals had medium, one medium-flaring, and four flaring alae.

While No. 4399 had a straight septum with an upward inclination, No. 4400 had a straight septum with a slightly downward inclination. Nos. 4399 and 4400 had depressed nasal tips. The nose of No. 4409 was short, of No. 4414 large, and that of No. 4399 had a high, narrow bridge.

Teeth.-The majority (Nos. 4402, 4404, 4406, 4407, and 44114414) had marked-over occlusion. Nos. 4399 and 4410 had edge-toedge and Nos. 4400, 4401, 4408, 4409, and 4415 had slight-over occlusion. Loss of teeth was indicated as none, Nos. 4401 and 4410; one to four, Nos. 4400 and 4402; some, No. 4406; many, Nos. 4399, 4403 (including the upper incisors), and 4407; and most, No. 4405. Eruption was incomplete in Nos. 4412 and 4413. The dental condition was recorded as fair, Nos. 4402 and 4408; good, Nos. 4412, 4414, and 4415; and very good, No. 4409.

DENTITION

$\begin{array}{cl}\text { No. } & \text { Description } \\ 4399 & \text { Much worn, yellow } \\ \mathbf{4 4 0 0} & \text { Very crooked, stained } \\ \mathbf{4 4 0 1} & \text { Caries } \\ \mathbf{4 4 0 4} & \text { Worn, yellow } \\ \mathbf{4 4 0 6} & \text { Bad deposit } \\ \mathbf{4 4 0 7} & \text { Stained } \\ \mathbf{4 4 0 8} & \text { Stained } \\ \mathbf{4 4 0 9} & \text { White } \\ \mathbf{4 4 1 0} & \text { Stained, slightly worn } \\ \mathbf{4 4 1 1} & \text { Slightly yellow } \\ \mathbf{4 4 1 2} & \text { Slightly stained } \\ \mathbf{4 4 1 4} & \text { Slightly yellow } \\ \mathbf{4 4 1 5} & \text { Slightly stained } \\ & \end{array}$


Prognathism.-No. 4412, with possible Negroid admixture, had slight alveolar prognathism.

Henna.-No. 4407 had used henna on his hair.

Tattooing.-Among the seventeen individuals, eleven were tattooed.

Branding.-Six individuals (Nos. 4399, 4402, 4409, 4410, 4412, and 4414) were branded.

\section{Miscellaneous Notes}

No. Description

4400 Thin, prison pallor

4404 Magician

4405 Four fingers of leit hand lost through fighting

4407 Described as kaulia (gypsy) but claims he is not

4409 Different appearance from others, darker skin and a very short face

4414 Different type, fairer; in chains!

4415 Driver, but tribe keeps sheep and cultivates

\section{Women Studied in An Nasiriya Hospital}

During March, 1935, forty women were also examined.

26 ARABS From Various LOCALITIES

No.
$4416-4417$
$4419-4424$
4425
4426
4427
4428
4429
4430
4431
4432
4433
4434
4435
4436
4438
4439
4440
4442
4443
4444

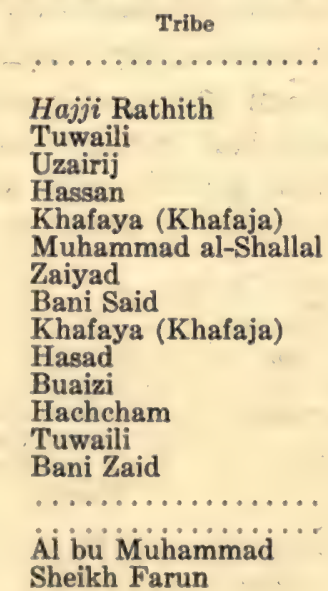

Locality
An Nasiriya
Near An Nasiriya
Near An Nasiriya
Hai
An Nasiriya
Near An Nasiriya
Suq ash Shuyukh
An Nasiriya
Shatra
Near An Nasiriya
Shamiya
Basra
Amara
Amara
Near Ad Diwaniya

Vital Statistics. - The figures available indicate relatively large families, particularly when the mean age was about thirty. No. 4421 was recorded as having two sons living, many dead, and one daughter living, many dead. 


\begin{tabular}{|c|c|c|c|c|c|}
\hline \multirow[b]{2}{*}{ Sons } & \multicolumn{3}{|c|}{ Vital Statistics } & \multirow[b]{2}{*}{ No. } & \multirow[b]{2}{*}{ Per cent } \\
\hline & No. & Per cent & Daughters & & \\
\hline None. & 5 & 23.81 & None..... & 5 & 23.81 \\
\hline & 10 & 47.62 & & 6 & 28.57 \\
\hline$\ldots \ldots$ & 2 & 9.52 & & 4 & 19.05 \\
\hline$\therefore \ldots \ldots \ldots$ & 4 & 19.05 & $3-4$ & 6 & 28.57 \\
\hline $5-6 \ldots \ldots \ldots \ldots$ & 0 & $\ldots \ldots$ & $5-6 \ldots \ldots$ & 0 & $\ldots \ldots$ \\
\hline 7 or more........ & 0 & $\cdots$. & 7 or more. & 0 & \\
\hline Total. & 21 & 100.00 & Total. & 21 & 100.00 \\
\hline
\end{tabular}

Age.-The mean was 29.90 , range $16-54$. Half of the individuals were below thirty.

\begin{tabular}{|c|c|c|c|c|c|}
\hline \multicolumn{6}{|c|}{ AGE DISTRIBUTION } \\
\hline Age & No. & Per cent & Age & No. & Per cent \\
\hline $17-19$ & 6 & 23.08 & $50-54$ & 1 & 3.85 \\
\hline $20-24$ & 3 & 11.54 & $55-59 \ldots$ & 0 & $\ldots$. \\
\hline $25-29$ & 4 & 15.38 & $60-64 \ldots \ldots$ & 0 & $\ldots .$. \\
\hline $30-34$ & 3 & 11.54 & $65-69 \ldots \ldots \ldots \ldots$ & 0 & $\ldots \ldots$ \\
\hline $35-39$ & 6 & 23.08 & $70-x \ldots \ldots \ldots \ldots$ & 0 & $\ldots \ldots$ \\
\hline $\begin{array}{l}40-44 \\
45-49\end{array}$ & $\begin{array}{l}2 \\
1\end{array}$ & $\begin{array}{l}7.69 \\
3.85\end{array}$ & Total. & 26 & 100.01 \\
\hline
\end{tabular}

\section{MORPHOLOGICAL CHARACTERS OF 26 AN NASIRIYA FEMALES}

Skin.-No. 4422 had a fairer skin than that of other tribeswomen. No. 4423 had light skin especially on the forehead. No. 4424, a Negroid admixture, had a pale brown skin with darker blotches. She was seven months pregnant and looked very ill.

Head Form.-No. 4421 had wide, high flat area on occiput.

Hair.-Nos. 4426, 4427, and 4434 had low-growing hair on the forehead. No. 4427 had some hair growing down to her eyebrows. No. 4429 had very matted hair and No. 4432 had thick hair. Nos. 4422 and 4439 had hair "plastered" with henna paste.

\begin{tabular}{|c|c|c|c|c|c|}
\hline Color & No. & Per cent & Form & No. & Per cent \\
\hline Black............... & 8 & 30.77 & Straight. . . . . . . . & 0 & \\
\hline Very dark brown ......... & 0 & & Very low waves.... & 4 & 16.67 \\
\hline Dark brown $\ldots . . . \ldots \ldots$ & 12 & 46.15 & Low waves........ & 17 & 70.83 \\
\hline Brown $\ldots \ldots \ldots \ldots \ldots \ldots$ & 0 & $\ldots$ & Deep waves... & 2 & 8.33 \\
\hline Reddish brown $\ldots \ldots \ldots$ & 0 & $\ldots$. & Curly-frizzly....... & 1 & 4.17 \\
\hline $\begin{array}{l}\text { Light brown............ } \\
\text { Red }\end{array}$ & 0 & $\ldots \ldots$ & Woolly........... & 0 & $\therefore .$. \\
\hline Black and gray ........... & $\begin{array}{l}0 \\
4\end{array}$ & 15.38 & Total. & 24 & 100.00 \\
\hline Dark brown and gray....... & 2 & 7.69 & & No. & Per cent \\
\hline $\begin{array}{l}\text { Light brown and gray ..... } \\
\text { Gray . . }\end{array}$ & 0 & $\cdots$ & Coarse..... & 7 & 28.00 \\
\hline 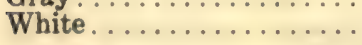 & 0 & $\cdots$ & Coarse-medium ..... & 0 & \\
\hline & & & Medium.... & 11 & 44.00 \\
\hline 10 ta. & 26 & 99.99 & $\begin{array}{l}\text { Medium-fine......... } \\
\text { Fine............ }\end{array}$ & $\frac{0}{7}$ & 28.00 \\
\hline & & & Total........... & 25 & 100.00 \\
\hline
\end{tabular}


Eyes.-Six women (Nos. 4420, 4429, 4431, 4432, 4435, and 4442) had blue-ringed irides, possibly the result of arcus senilis.

Nos. 4419, 4433, and 4443 had filmed eyes. No. 4419 claimed that she was unable to distinguish colors, while No. 4433, who had a bluish film over both eyes, had very poor vision.

\begin{tabular}{|c|c|c|c|c|c|}
\hline & & & EYES & & \\
\hline Color & No. & Per cent & Sclera & No. & Per cent \\
\hline Black........ & 1 & 4.17 & Clear. . & 7 & 30.43 \\
\hline Dark brown..... & 23 & 95.83 & Yellow. . & 5 & 21.74 \\
\hline Blue-brown ...... & 0 & $\ldots .$. & Speckled.... & 0 & \\
\hline Blue-brown ....... & 0 & $\ldots .$. & Bloodshot. ............ & 10 & 43.48 \\
\hline Green-brown..... & 0 & $\ldots \ldots$ & Speckled and bloodshot.... & 0 & \\
\hline Green-brown...... & 0 & $\ldots \ldots$ & Speckled and yellow....... & 0 & \\
\hline Gray-brown ...... & 0 & $\therefore \ldots$ & Yellow and bloodshot...... & 1 & 4.35 \\
\hline Blue........... & 0 & $\ldots .$. & & & \\
\hline Gray ........... & 0 & $\ldots \ldots$ & Total .......... & 23 & 100.00 \\
\hline Light brown...... & 0 & $\therefore \ldots$ & & & \\
\hline Blue-gray ......... & 0 & $\ldots \ldots$ & & & \\
\hline Blue-green. . ..... & 0 & $\because \cdots$ & & & \\
\hline Total......... & 24 & 100.00 & & & \\
\hline
\end{tabular}

Nose.-The nasal tip was either depressed (9) or elevated (7). No. 4424 had a slightly thicker than average nasal tip and No. 4433 was in the double plus category. Eight individuals had a convex and three a straight septum. The septum inclination was up in twelve individuals and down in four.

No. 4439 had a very small nose. No. 4425 had a small nose, especially at the tip. There was no nasion depression. No. 4422 had a very low nasal bridge.

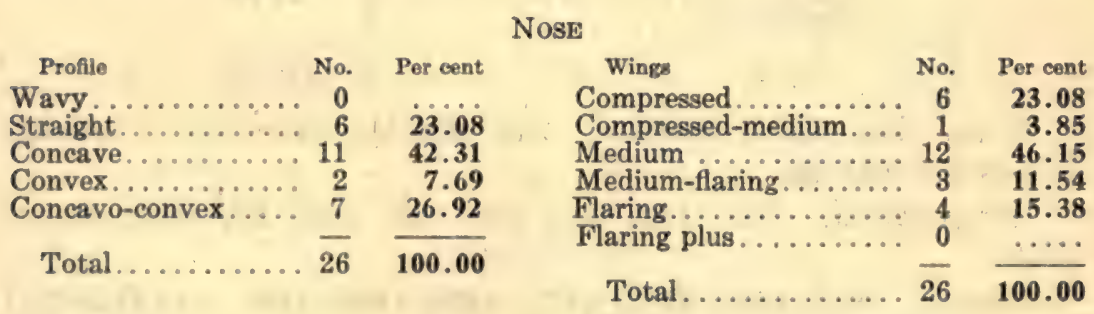

Teeth.-Nos. 4422, 4424, 4426, and 4430 had incomplete eruption. The dental condition was recorded as follows: good, Nos. 4424, 4428, 4431, 4432, and 4439; fair, Nos. 4422 and 4434; bad, No. 4417. Wear was slightly more than average in Nos. 4416, 4417, 4420, 4421, 4428, 4436, 4438, and 4444, and double plus in No. 4419. Some caries was present in Nos. 4423, 4426, 4427, 4429, 4431, 4434, and 4435 . 


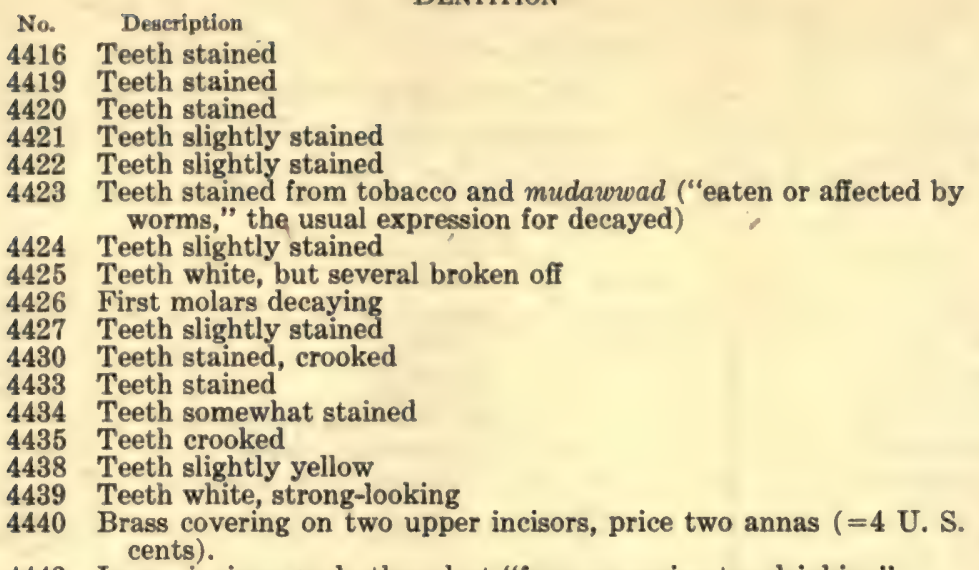

4416 Teeth stained

4419 Teeth stained

4420 Teeth stained

4421 Teeth slightly stained

4422 Teeth slightly stained

4423 Teeth stained from tobacco and mudawwad ("eaten or affected by

4424 Teeth slightly stained

4425 Teeth white, but several broken off

4426 First molars decaying

4427 Teeth slightly stained

4430 Teeth stained, crooked

4433 Teeth stained

4434 Teeth somewhat stained

4435 Teeth crooked

4438 Teeth slightly yellow

4439 Teeth white, strong-looking

\section{DENTITION}

4443 Lower incisors and others lost "from excessive tea-drinking"

4444 Teeth stained

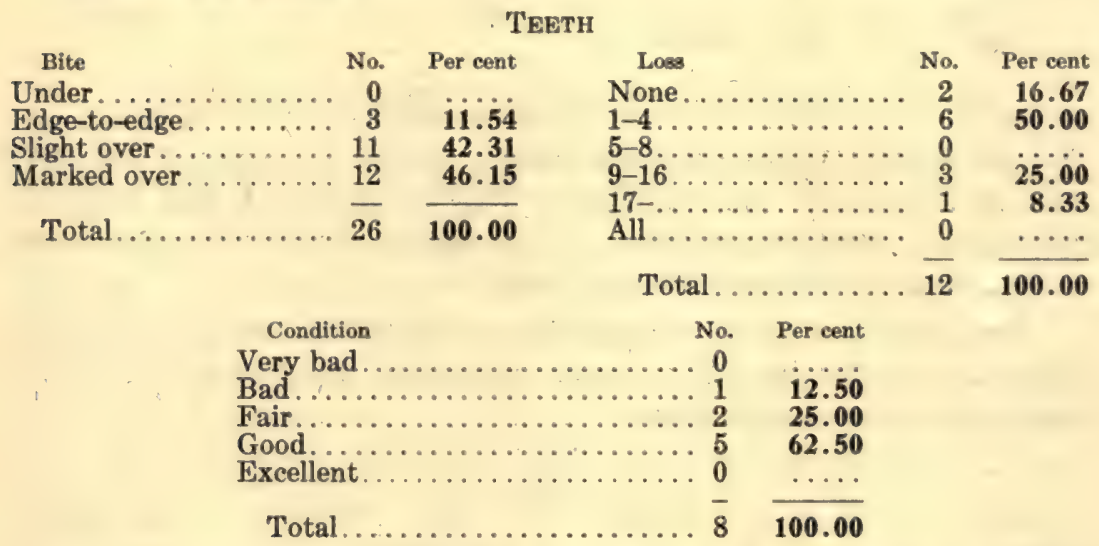

Lips.-No. 4424, Negroid, had slightly more than average eversion of the lips.

Prognathism.-Nos. 4427 and 4430 had some alveolar prognathism.

Henna.-Nos. 4422, 4423, 4427, 4428, 4433, 4439, and 4440 had applied henna to the hair.

Tattooing.-All the women bore tattooed designs, twenty-four extensively.

Branding.-No branding was recorded.

STATISTICAL ANALYSES OF AN NASIRIYA FEMALES

Stature.-The mean was 156.45 , range 146-169. 


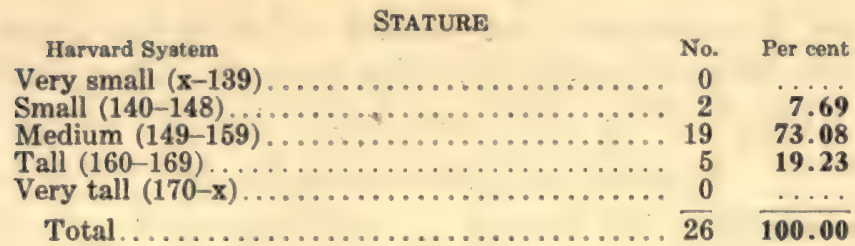

Sitting Height (Trunk Length).-The mean was 80.26, range $75-89$.

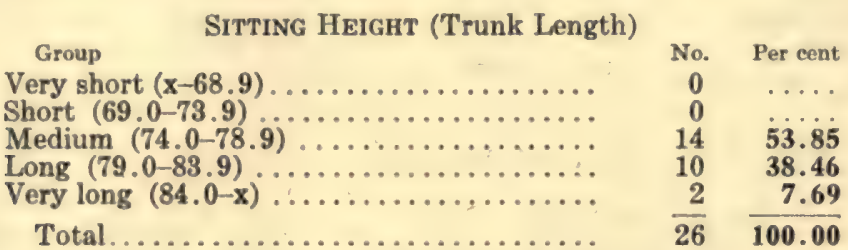

Head Measurements and Indices.-The mean head breadth was 140.80 (range 132-149). The mean minimum frontal diameter was 102.02 (range 93-112). The mean cephalic index was 77.64 (range 71-85).

\begin{tabular}{|c|c|c|}
\hline Group & No. & Per cent \\
\hline Very narrow $(x-129)$ & 0 & \\
\hline$\ldots \ldots$ & 9 & 36.00 \\
\hline $40-149$ & 16 & 64.00 \\
\hline Very wide $(150-x) \ldots .$. & 0 & $\ldots \ldots$ \\
\hline $\begin{array}{l}\text { Total } \ldots \ldots \ldots \ldots \ldots \ldots \ldots \ldots \ldots \\
\text { No. } 4432 \text { was omitted. }\end{array}$ & 25 & 100.00 \\
\hline Minimum Frontal Diameter & & \\
\hline Group & No. & Per cent \\
\hline Very narrow $(x-99)$ & 6 & 24.00 \\
\hline$\ldots \ldots$ & 18 & 72.00 \\
\hline ... & 1 & 4.00 \\
\hline Very wide $(120-x) \ldots$ & 0 & $\cdots$ \\
\hline Total. . & 25 & 100.00 \\
\hline
\end{tabular}

Cephalic Index

\begin{tabular}{|c|c|c|}
\hline Harvard Syatem & No. & Per cent \\
\hline $\begin{array}{c}\text { Dolichocephalic...... } \\
(x-76.5)\end{array}$ & 9 & \\
\hline $\begin{array}{l}\text { Mesocephalic } . . . . . \\
\quad(76.6-82.5)\end{array}$ & 15 & 60.00 \\
\hline $\begin{array}{l}\text { Brachycephalic....... } \\
(82.6-x)\end{array}$ & 1 & 4.00 \\
\hline Total. & & 100 \\
\hline
\end{tabular}

No. 4432 was omitted.

\begin{tabular}{|c|c|c|}
\hline Keith System & No. & Per cent \\
\hline $\begin{array}{l}\text { Ultradolichocephalic... } \\
\qquad(x-70.0)\end{array}$ & 0 & $\cdots \cdots$ \\
\hline $\begin{array}{c}\text { Dolichocephalic...... } \\
(70.1-75.0)\end{array}$ & 4 & 16.00 \\
\hline 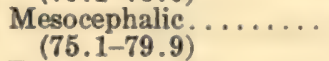 & 16 & 64.00 \\
\hline $\begin{array}{c}\text { Brachycephalic........ } \\
(80.0-84.9)\end{array}$ & 5 & 20.00 \\
\hline $\begin{array}{l}\text { Ultrabrachycephalic... } \\
\qquad(85.0-x)\end{array}$ & 0 & \\
\hline Total ........... & 25 & 100.00 \\
\hline
\end{tabular}


Facial Measurements and Indices.-The mean upper facial height was 66.60 (range 60-79). The mean total facial height was 107.60 (range 95-114). The mean index was 84.20 (range 76-95).

\section{Facial Measurements and Indices}

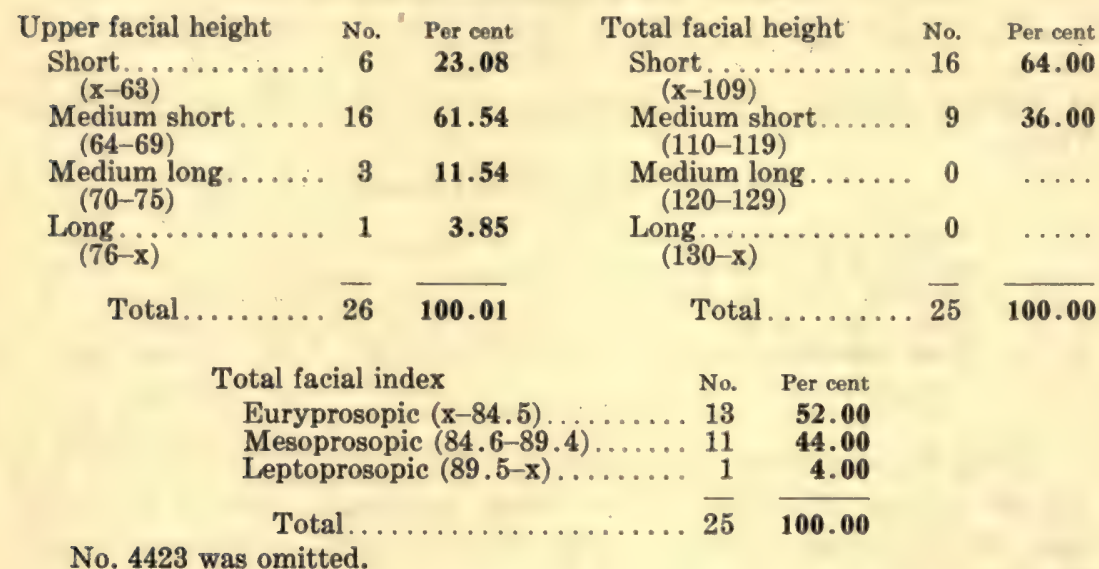

Nasal Measurements and Indices.-The mean nasal height was 46.26 (range 36-55). The mean width was 32.72 (range 28-42). The mean nasal index was 71.26 (range 56-91).

\begin{tabular}{|c|c|c|c|c|c|c|}
\hline \multicolumn{7}{|c|}{ Nasal Measurembents and Indices } \\
\hline Nasal height & No. & Per cent & \multirow{2}{*}{\multicolumn{2}{|c|}{$\begin{array}{l}\text { Nasal width } \\
\text { Very narrow........ } \\
(\mathrm{x}-29)\end{array}$}} & No. & Per cent \\
\hline Short ${ }_{(x-49)}$ & $\ldots 20$ & 76.92 & & & 2 & 8.00 \\
\hline$\underset{(50-59)}{\text { Medium }}$ & $\cdots$ & 23.08 & \multicolumn{2}{|c|}{$\begin{array}{l}\text { Medium narrow ..... } \\
(30-35)\end{array}$} & 21 & 84.00 \\
\hline $\begin{array}{l}\text { Long. . } \\
(60-\mathrm{x})\end{array}$ & $\cdots$ & $\cdots \cdots$ & \multicolumn{2}{|c|}{$\begin{array}{c}\text { Medium wide........ } \\
(36-41)\end{array}$} & 1 & 4.00 \\
\hline \multirow{3}{*}{ Total. } & & & \multicolumn{2}{|c|}{$\begin{array}{l}\text { Wide } \ldots \ldots \ldots \ldots \\
\qquad(42-x)\end{array}$} & 1 & 4.00 \\
\hline & & & \multicolumn{2}{|c|}{ Total . } & 25 & 100.00 \\
\hline & $\begin{array}{c}\text { Nasal index } \\
\text { Leptorrhin } \\
\text { Mesorrhin } \\
\text { Platyrrhin }\end{array}$ & $\begin{array}{l}(x-67.4) \\
(67.5-83 \\
(83.5-x)\end{array}$ & $\begin{array}{r}\text { No. } \\
8 \\
\therefore \quad 14 \\
3\end{array}$ & $\begin{array}{r}\text { Per cent } \\
32.00 \\
56.00 \\
12.00\end{array}$ & & ' \\
\hline \multicolumn{3}{|c|}{ Total... } & . 25 & 100.00 & & \\
\hline
\end{tabular}

The following tables have been added so that statistical comparisons can be made with the groups in Field (1939) and in Part I, No. 1, of The Anthropology of Iraq. 
Sitring HEight (Trunk Length)

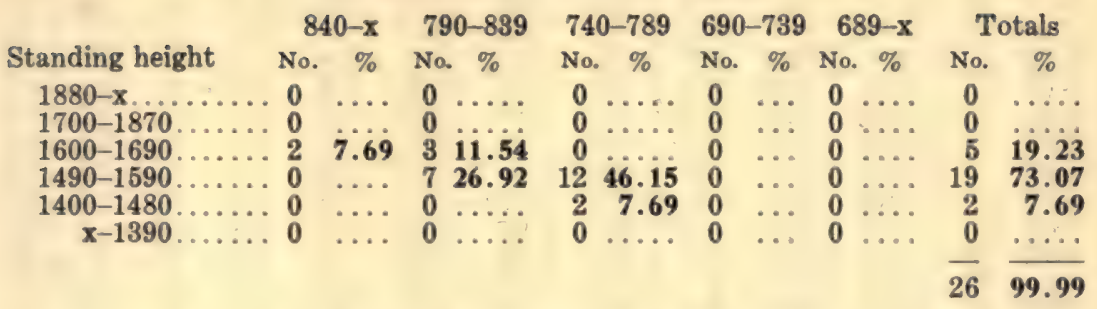

Minimum Frontal Diameter

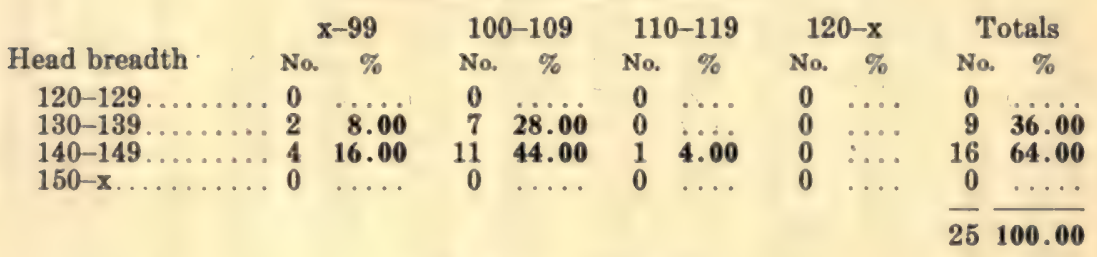

Bizygomatic Breadth

\begin{tabular}{|c|c|c|c|c|c|c|c|c|}
\hline \multirow[b]{2}{*}{ Total facial length } & \multicolumn{2}{|c|}{$x-124$} & \multicolumn{2}{|c|}{$125-134$} & \multicolumn{2}{|c|}{$135-x$} & \multicolumn{2}{|c|}{ Totals } \\
\hline & No. & $\%$ & No. & $\%$ & No. & $\%$ & No. & $\%$ \\
\hline & 5 & 20.00 & 20 & 80.00 & 0 & $\ldots$ & 25 & 100.00 \\
\hline $115-124$ & $\begin{array}{l}0 \\
0\end{array}$ & $\therefore \ldots$ & $\begin{array}{l}0 \\
0\end{array}$ & ..... & 0 & $\cdots$ & 0 & ...... \\
\hline & & & & & & & 25 & 100.00 \\
\hline
\end{tabular}

UPPER Facial Length

$\begin{array}{llllll}x-63 & 64-69 & 70-75 & 76-81 & 82-x & \text { Totals }\end{array}$

Total facial length No. $\%$ No. $\%$ No. $\%$ No. $\%$ No. $\%$ No. $\%$

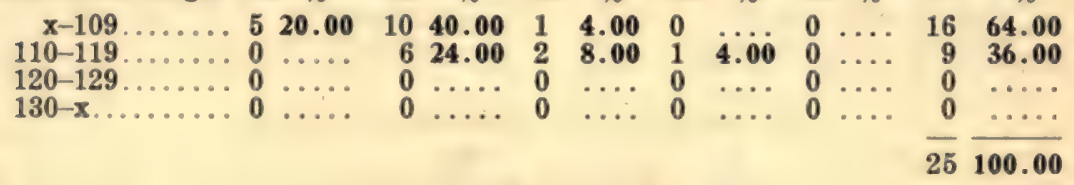

\section{NASAL WIDTH}

\begin{tabular}{|c|c|c|c|c|c|c|c|c|c|}
\hline \multirow{3}{*}{$\begin{array}{r}\text { Nasal length } \\
x-49 \ldots \\
50-59 \ldots \\
60-x \ldots \\
\end{array}$} & \multirow{2}{*}{$\begin{array}{r}x-29 \\
\text { No. } \%\end{array}$} & \multicolumn{2}{|c|}{$30-35$} & \multicolumn{2}{|c|}{$36-41$} & \multicolumn{2}{|c|}{$42-x$} & \multicolumn{2}{|c|}{ Totals } \\
\hline & & No. & $\%$ & No. & $\%$ & No. & $\%$ & No. & $\%$ \\
\hline & $\begin{array}{cc}1 & 4.00 \\
1 & 4.00 \\
0 & \ldots\end{array}$ & $\begin{array}{r}18 \\
3 \\
0\end{array}$ & $\begin{array}{l}72.00 \\
12.00 \\
\ldots \ldots\end{array}$ & $\begin{array}{l}1 \\
0 \\
0\end{array}$ & 4.00 & $\begin{array}{l}0 \\
1 \\
0\end{array}$ & 4.00 & $\begin{array}{r}20 \\
5 \\
0\end{array}$ & $\begin{array}{l}80.00 \\
20.00\end{array}$ \\
\hline & & & & & & & & 25 & 100.00 \\
\hline
\end{tabular}


Measurements of An Nasiriya Females

\begin{tabular}{|c|c|c|c|c|c|c|c|c|c|c|c|c|}
\hline No. & Age & Stature & SH & L & B & B $^{\prime}$ & $\mathbf{J}$ & go-go & GH & $\mathrm{G}^{\prime} \mathrm{H}$ & NH & NB \\
\hline 4416 & 40 & 1546 & 785 & 188 & 134 & 100 & 121 & 98 & 108 & 69 & 45 & 33 \\
\hline 4417 & 35 & 1591 & 818 & 183 & 136 & 103 & 130 & 104 & 111 & 66 & 48 & 37 \\
\hline $4418^{*}$ & 16 & 1576 & 805 & 183 & 141 & 102 & 124 & 93 & 104 & 61 & 42 & 31 \\
\hline 4419 & 50 & 1661 & 890 & 191 & 147 & 109 & 134 & 104 & 112 & 70 & 51 & 30 \\
\hline 4420 & 28 & 1541 & 789 & 174 & 144 & 101 & 130 & 100 & 108 & 66 & 46 & 34 \\
\hline 4421 & 38 & 1554 & 838 & 178 & 146 & 99 & 130 & 101 & 102 & 62 & 43 & 33 \\
\hline 4422 & 17 & 1595 & 834 & 175 & 141 & 110 & 130 & 94 & 103 & 61 & 39 & 35 \\
\hline 4423 & 18 & 1555 & 781 & 180 & 139 & & 121 & 96 & & 62 & 45 & 32 \\
\hline 4424 & 17 & 1656 & 813 & 181 & 142 & 102 & 131 & 96 & 114 & 69 & 45 & 32 \\
\hline 4425 & 30 & 1520 & 797 & 182 & 145 & 99 & 130 & 92 & 107 & 66 & 48 & 32 \\
\hline 4426 & 19 & 1693 & 805 & 181 & 136 & 95 & 120 & 92 & 105 & 66 & 43 & 29 \\
\hline 4427 & 22 & 1471 & 779 & 177 & 140 & 99 & 126 & 98 & 106 & 65 & 46 & 30 \\
\hline 4428 & 28 & 1583 & 796 & 180 & 141 & 102 & 127 & 90 & 110 & 70 & 52 & 34 \\
\hline 4429 & 38 & 1534 & 783 & 195 & 148 & 101 & 128 & 99 & 109 & 68 & 47 & 32 \\
\hline 4430 & 18 & 1525 & 785 & 176 & 134 & 101 & 126 & 92 & 103 & 61 & 37 & 32 \\
\hline 4431 & 30 & 1464 & 775 & 171 & 141 & 102 & 122 & 90 & 105 & 65 & 49 & 32 \\
\hline 4432 & 22 & 1526 & 784 & 168 & $(140) \&$ & 104 & 126 & 90 & 105 & 65 & 46 & 30 \\
\hline 4433 & 48 & 1540 & 771 & 190 & 139 & 104 & 128 & 100 & 114 & 77 & 50 & 35 \\
\hline $\mathbf{4 4 3 4}$ & 25 & 1577 & 813 & 176 & 135 & 100 & 128 & 92 & 109 & 70 & 5 & 29 \\
\hline 4435 & 20 & 1567 & 798 & 176 & 143 & 99 & 127 & 95 & 105 & 65 & 48 & 33 \\
\hline 443 & 35 & 1665 & 882 & 188 & 145 & 105 & 125 & 101 & 112 & 66 & 44 & 35 \\
\hline $4437^{*}$ & 15 & 1620 & 803 & 180 & 139 & 102 & 119 & 96 & 110 & 70 & 44 & 34 \\
\hline 443 & 35 & 1682 & 812 & 184 & 144 & 105 & 132 & 102 & 110 & 66 & & 34 \\
\hline 4439 & 33 & 1505 & 779 & 179 & 136 & 101 & 122 & 100 & 100 & 62 & 42 & 31 \\
\hline 444 & 18 & 1520 & 776 & 178 & 142 & 100 & 127 & 97 & 113 & 69 & 51 & \\
\hline$\triangle 44$ & 15 & 1521 & 774 & 171 & 144 & 100 & 124 & 92 & 106 & 68 & 47 & 35 \\
\hline & 35 & 1532 & 781 & 182 & 143 & 105 & 130 & 95 & 110 & 64 & 47 & 32 \\
\hline 4 & 40 & 1529 & 779 & 190 & 145 & 104 & 134 & 104 & $(108) \S$ & 68 & 5 & 42 \\
\hline & 25 & 1546 & 771 & 182 & 134 & 97 & 118 & 86 & 99 & 63 & 44 & 31 \\
\hline & 28 & 158 & 81 & 189 & 144 & 110 & 134 & 98 & 103 & 63 & 4 & 39 \\
\hline & 20 & 1439 & 75 & 191 & 139 & 97 & 124 & 88 & 102 & 63 & 46 & 33 \\
\hline & 30 & $14 \%$ & 70 & 18 & 140 & 100 & 124 & 89 & 104 & 65 & 43 & 31 \\
\hline & 17 & 1492 & 779 & 18 & 138 & 103 & 125 & 99 & 112 & 70 & 47 & 39 \\
\hline & 15 & 1526 & 77 & 18 & 140 & 101 & 128 & 102 & 114 & 69 & 45 & $(33) \dagger$ \\
\hline & 14 & 1560 & 80 & 18 & 135 & 100 & 12 & 98 & 107 & 65 & 44 & 38 \\
\hline & 14 & 151 & 75 & $17 \mathrm{t}$ & 13 & 102 & 11 & 88 & 104 & 62 & 45 & 30 \\
\hline & 29 & 155 & 82 & 178 & 136 & 104 & 12 & 92 & 101 & 61 & 41 & 33 \\
\hline & 16 & 15 ? & 78 & 16 & 14 & 101 & 12 & 95 & & 66 & 48 & 31 \\
\hline & 35 & 15 & 81 & 16 & 13 & 97 & 121 & 87 & & 73 & 49 & 32 \\
\hline 44 & 43 & 1512 & 770 & 182 & 135 & 97 & 127 & 98 & (107) & $(68) \ddagger$ & 49 & 34 \\
\hline
\end{tabular}

* Omitted from means.

†Nose stretched by nose ring.

$\ddagger$ Edentulous.

$\$$ Measurement uncertain.

\section{Mgasurements of An Nasiriya Frmales}

Measurements No. Range Mean S.D.

Age........... $26 \quad 16-54 \quad 29.90 \pm 1.3210 .00 \pm 0.94$

Stature......... $26 \quad 146-169 \quad 156.45 \pm 0.75 \quad 5.70 \pm 0.53$

Sitting height....... 26

Head length........ 26

Head breadth....... 25

Min. frontal diam..... 25

Bizygo. diam........ 26

Bigonial diameter.... 26

Total facial height... . 25

Upper facial height... 26

Nasal height........ 26

Nasal breadth . . . . . . 25

Ear length......... 26

Ear breadth.......... 26
$75-89$

167-196

132-149

93-112

115-134

86-105

95-114

60-79

36-55

28-42

48-71

26- 40
$80.26+0.38$

$181.05 \pm 0.85$

$140.80 \pm 0.61$

$102.02 \pm 0.51$

$127.60 \pm 0.56$

$96.58 \pm 0.60$

$107.60 \pm 0.55$

$66.60 \pm 0.48$

$46.26 \pm 0.51$

$32.72 \pm 0.38$

$59.82 \pm 0.64$

$32.76 \pm 0.37$
$2.91 \pm 0.27$

$6.39 \pm 0.60$

$4.50 \pm 0.43$

$3.80 \pm 0.36$

$4.25 \pm 0.40$

$4.52 \pm 0.42$

$4.10 \pm 0.39$

$3.65 \pm 0.34$

$3.84 \pm 0.36$

$2.85 \pm 0.27$

$4.84 \pm 0.45$
$2.76 \pm 0.26$
C.V.

$33.44 \pm 3.13$

$3.64 \pm 0.34$

$3.63 \pm 0.34$

$3.53 \pm 0.33$

$3.20 \pm 0.31$

$3.72 \pm 0.35$

$3.33 \pm 0.31$

$4.68 \pm 0.44$

$3.81 \pm 0.36$

$5.48 \pm 0.51$

$8.30 \pm 0.78$

$8.71 \pm 0.83$

$8.09 \pm 0.76$

$8.42 \pm 0.79$ 
Indices of AN NASIRIYA FemaLes

\begin{tabular}{|c|c|c|c|c|c|c|c|c|c|c|c|}
\hline No. & EL & EB & RSH & $B / L$ & $\mathbf{B}^{\prime} / \mathbf{B}$ & $\mathrm{GH} / \mathrm{J}$ & $\mathrm{G}^{\prime} \mathbf{H} / \mathbf{J}$ & $\mathrm{NB} / \mathrm{NH}$ & EB/EL & go-go/J & $B^{\prime} / J$ \\
\hline 4416 & 59 & 34 & 50.8 & 71.3 & 74.6 & 89.3 & 57.0 & 73.3 & 57.6 & 80.9 & 82.6 \\
\hline 4417 & 68 & 39 & 51.4 & 74.3 & 75.7 & 85.4 & 50.8 & 77.1 & 57.3 & 80.0 & 79.2 \\
\hline 4418 & 60 & 32 & 51.1 & 77.0 & 72.3 & 83.9 & 49.2 & 73.8 & 53.3 & 75.0 & 82.3 \\
\hline 4419 & 66 & 36 & 53.6 & 76.9 & 74.1 & 83.6 & 52.2 & 58.8 & 54.5 & 77.6 & 81.3 \\
\hline 4420 & 61 & 34 & 51.2 & 82.8 & 70.1 & 83.1 & 50.8 & 73.9 & 55.7 & 76.9 & 77.7 \\
\hline 4421 & 58 & 34 & 53.9 & 82.0 & 67.8 & 78.5 & 47.7 & 76.7 & 58.6 & 77.7 & 76.1 \\
\hline 4422 & 62 & 34 & 52.3 & 80.5 & 78.0 & 79.2 & 46.9 & 89.7 & 54.8 & 72.3 & 84.6 \\
\hline 4423 & 62 & 30 & 50.2 & 77.2 & & & 51.2 & 71.1 & 48.4 & 79.3 & \\
\hline 4424 & 61 & 31 & 49.1 & 78.5 & 71.8 & 87.0 & 52.7 & 71.1 & 50.8 & 73.3 & 77.8 \\
\hline 4425 & 51 & 32 & 52.4 & 79.7 & 68.3 & 82.3 & 50.8 & 66.7 & 62.7 & 70.8 & 76.1 \\
\hline 4426 & 57 & 30 & 47.5 & 75.1 & 69.8 & 87.5 & 55.0 & 67.4 & 52.6 & 76.6 & 79.3 \\
\hline 4427 & 53 & 30 & 52.9 & 79.1 & 70.7 & 84.1 & 51.6 & 65. & 56.6 & 77.8 & 78.6 \\
\hline 4428 & 62 & 30 & 50.3 & 78.3 & 72.4 & 86.6 & 55.1 & 65.4 & 48.4 & 70.8 & 80.2 \\
\hline 4429 & 64 & 35 & 51.0 & 75.9 & 68.2 & 85.1 & 53.1 & 68.1 & 54.7 & 77.3 & 78.8 \\
\hline 4430 & 57 & 28 & 51.4 & 76.1 & 75.4 & 81.7 & 48.4 & 86.5 & 49.1 & 73.0 & 30.1 \\
\hline 4431 & 54 & 30 & 52.9 & 82.5 & 72.3 & 86.1 & 53.3 & 65.3 & 55.6 & 73.8 & 83.6 \\
\hline 4432 & 68 & 30 & 51.3 & & & 83.3 & 51.6 & 65. & 51.7 & 71.4 & 82.5 \\
\hline 4433 & 68 & 36 & 50.1 & 73.2 & 74.8 & 89.1 & 60.1 & 70 & 52.9 & 78.1 & 81.2 \\
\hline 4434 & 60 & 32 & 51.6 & 76.7 & 74.1 & 85.1 & 54.7 & 58.0 & 53.3 & 71.9 & 78.1 \\
\hline 4435 & 59 & 32 & 50.9 & 81.2 & 69.2 & 82.7 & 51.2 & 68. & 54.2 & 74.8 & 77.9 \\
\hline 4436 & 65 & 36 & 52.9 & 77.1 & 72.4 & 89.6 & 52.8 & 79. & 55.4 & 80.8 & 84.0 \\
\hline 4437 & 58 & 26 & 49.6 & 78.3 & 73.4 & 92.4 & 58.8 & 77. & 44.8 & 80.7 & 85.7 \\
\hline 4438 & 57 & 33 & 48.2 & 78.3 & 72.9 & 83.3 & 50.0 & 70. & 57.9 & 77.3 & 79.5 \\
\hline 4439 & 58 & 32 & 51.8 & 75.9 & 74.2 & 81.9 & 50.8 & 73.8 & 55.2 & 81.9 & .8 \\
\hline 4440 & 57 & 30 & 51.1 & 79.7 & 70.4 & 88.9 & 54.3 & & & 76.3 & 3.7 \\
\hline 4441 & 55 & 30 & 50.9 & 84.2 & 69.4 & 85.5 & 54.8 & 74.5 & 54.5 & 74.2 & 80.6 \\
\hline 4442 & 56 & 35 & 50.9 & 78.6 & 73.4 & 84.6 & 49.2 & 68.1 & 62.5 & 73.1 & 80.8 \\
\hline 4443 & 65 & 35 & 50.9 & 76.3 & 71.7 & 80.6 & & 84.0 & 53.8 & 77.6 & 77.6 \\
\hline 4444 & 54 & 33 & 49.9 & 73.6 & 72.4 & 83.9 & 53.4 & 70.5 & 61.1 & 72.9 & 82.2 \\
\hline 4445 & & & 51.5 & 76.2 & 76.4 & 76.8 & 47.0 & 86.7 & & 73.1 & 82.1 \\
\hline 4446 & 62 & 32 & 52.5 & 72.7 & 69.8 & & & 71.7 & 51.6 & 70.9 & 8.2 \\
\hline 4447 & (59) & 30 & 49.2 & 75.7 & 71.4 & 83.9 & 52.4 & 72.1 & 50.8 & 71.8 & 80.6 \\
\hline 4448 & 55 & 32 & 51.8 & 76.2 & 74.6 & 89.6 & 56.0 & 82.9 & 58.2 & 79.2 & 2.4 \\
\hline 4449 & 55 & 26 & 51.0 & 77.8 & 72.1 & 89.1 & 53.9 & 73.3 & 47.3 & 79.7 & \\
\hline & 57 & 31 & 51.6 & 75.0 & 74.1 & 84.9 & 51.6 & & 54.4 & 77.8 & 79.3 \\
\hline 4451 & 57 & 32 & 50.1 & 77.8 & 74.5 & 87.4 & 52.1 & 66.7 & 56.1 & 73.9 & \\
\hline 4452 & 61 & 34 & 53.2 & 76.4 & 76.5 & 78.2 & 47.3 & 80.5 & 55.7 & 71.3 & 0.6 \\
\hline & 57 & 33 & 49.6 & & 69.6 & 85.6 & 52.8 & & 57.9 & 76.0 & \\
\hline 5 & 61 & 37 & 53.9 & 81.6 & 70.3 & 95.8 & 60.3 & 65.3 & 60.6 & 71.9 & 80. \\
\hline & 66 & 32 & 50.9 & 74.2 & 71.9 & 84.2 & 53.5 & 69.4 & 48.5 & 77.1 & 10.0 \\
\hline
\end{tabular}

\section{Indices of AN NASiRIYA Females}

Indices No. Range Mean s. D.

\begin{tabular}{|c|c|c|c|c|c|}
\hline $\begin{array}{l}\text { Relative sitting } \\
\text { height. }\end{array}$ & 26 & $48-55$ & $51.12 \pm 0.20$ & $1.54 \pm 0.14$ & $3.01+0.28$ \\
\hline Cephalic. . . . . . . . & 25 & $71-85$ & $77.64 \pm 0.40$ & $2.97 \pm 0.28$ & $3.83 \pm 0.37$ \\
\hline Fronto-parietal. & 24 & $66-80$ & $72.37 \pm 0.41$ & $3.00 \pm 0.29$ & $4.15 \pm 0.40$ \\
\hline Zygo-frontal.... & 25 & $76-87$ & $80.06 \pm 0.37$ & $2.76 \pm 0.26$ & $3.45 \pm 0.33$ \\
\hline Zygo-gonial. & 26 & $69-83$ & $76.00 \pm 0.48$ & $3.63 \pm 0.34$ & $4.78 \pm 0.45$ \\
\hline Total facial. & 25 & $76-95$ & $84.20 \pm 0.47$ & $3.50 \pm 0.33$ & $4.16 \pm 0.40$ \\
\hline Upper facial. & 26 & $46-60$ & $51.95 \pm 0.40$ & $3.00 \pm 0.28$ & $5.77 \pm 0.54$ \\
\hline Nasal. . . . . . . . . . . & 25 & $56-91$ & $71.26 \pm 1.06$ & $7.84 \pm 0.75$ & $11.00 \pm 1.05$ \\
\hline Ear. . & 26 & $45-64$ & $55.10 \pm 0.54$ & $4.12 \pm 0.39$ & $7.48 \pm 0.70$ \\
\hline
\end{tabular}




\section{Vital Statistics $\dagger$ of An Nasiriya Females}

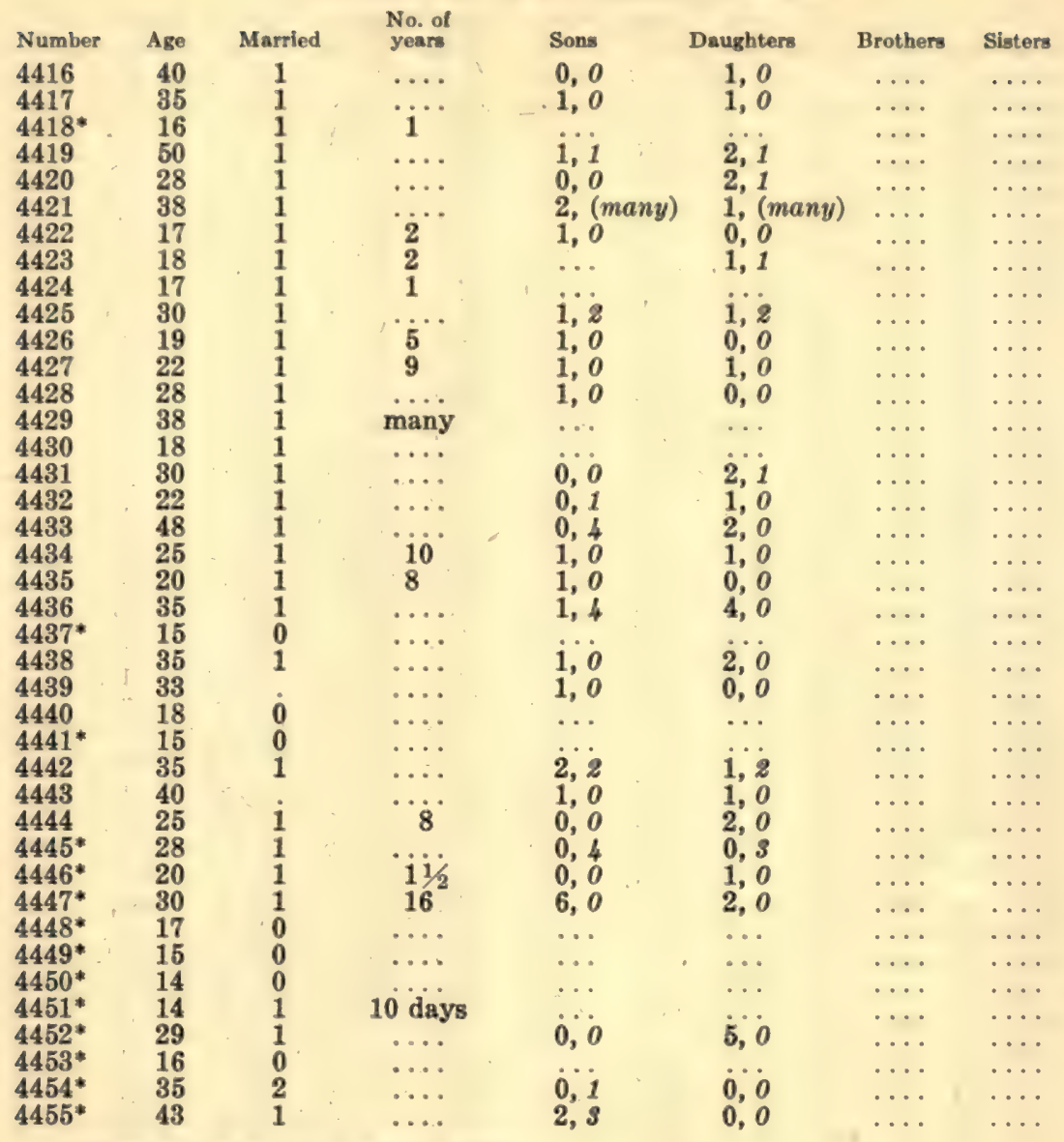

+ Italicized numbers refer to deceased children.

* Omitted from averages. 
Morphological Characters of An Nasiriya Framales

\begin{tabular}{|c|c|c|c|c|c|c|c|c|}
\hline & & HAIR & & & SYES & & & 886 \\
\hline No. & Form & Texture & Color & Color & Selera & Irin & Profile & Wings \\
\hline 4416 & $1 \mathrm{w}$ & medium & br-gray & $\mathrm{dk}$ br & blood & ... & $c-c$ & medium \\
\hline 4417 & l w & medium & & $\mathrm{dk}$ br & yellow & $\cdots$ & $c-c$ & medium \\
\hline $4418^{*}$ & v l w & fine & dk br & $\mathrm{dk}$ br & clear & $\cdots$ & cone & medium \\
\hline $\begin{array}{l}4419 \\
4420\end{array}$ & $1 \mathrm{w}$ & & $\begin{array}{l}\text { blk, gray } \\
\text { blk }\end{array}$ & $\mathrm{dk} b \mathrm{r}$ & clear & $\cdots$ & $c-c$ & comp \\
\hline $\begin{array}{l}4420 \\
4421\end{array}$ & $1 \mathrm{w}$ & medium & blk & $\mathrm{dk}$ br & yellow & $\cdots$ & $\begin{array}{l}\text { str } \\
\text { conce }\end{array}$ & $\begin{array}{l}\text { medium } \\
\text { flar }\end{array}$ \\
\hline 4422 & & & & & & $\ldots$ & cone & \\
\hline 4423 & $v$ l w & fine & $\mathrm{dk}$ br & $\mathrm{dk}$ br & yellow & $\cdots$ & $c-c$ & medium \\
\hline 4424 & $c-f$ & coar & $\mathrm{dk}$ br & dk br & od & $\ldots$ & cone & comp \\
\hline 4425 & $\mathrm{l} w$ & med & $\mathrm{dk}$ br & $\mathrm{dk}$ br & clear & $\cdots$ & cone & comp \\
\hline 4426 & $1 \mathrm{w}$ & medium & blk & $\mathrm{dk}$ & clear & $\ldots$ & str & $\begin{array}{c}\text { comp- } \\
\text { med }\end{array}$ \\
\hline 4427 & v l w & fine & $\mathrm{dk}$ br & $\mathrm{dk}$ br & blood & & str & medium \\
\hline & $1 \mathrm{w}$ & & & & & $\therefore$ & & medium \\
\hline 4429 & l w & fine & $\mathrm{dk}$ br & $\mathrm{dk}$ br & blood & $\ldots$ & cone & comp \\
\hline 4430 & $\mathrm{l} w$ & medium & $\mathrm{dk}$ br & d & & $\therefore$ & conc & \\
\hline 4431 & I w & coarse & blk & dk br & clear & $\ldots$ & conc & medium \\
\hline 4432 & $\mathrm{v} l \mathrm{w}$ & coarse & & dk & $\begin{array}{l}\text { yellow- } \\
\text { blood }\end{array}$ & $\cdots$ & str & medium \\
\hline 4433 & $1 \mathrm{w}$ & medium & br-gray & & & $\cdots$ & conc & med-fl \\
\hline 4434 & l w & medium & $\mathrm{dk} \mathrm{br}$ & $\mathrm{dk}$ br & blood & $\ldots$ & st & \\
\hline 4435 & l $w$ & coar & $\mathrm{dk}$ br & dk & & $\ldots$ & $c-c$ & l-fl \\
\hline 4436 & $1 \mathrm{w}$ & medium & blk & dk br & & $\ldots$ & cone & med-fl \\
\hline $4437^{*}$ & $1 \mathrm{w}$ & medium & dk br & dk & & $\ldots$ & conc & medium \\
\hline 4438 & I w & fine & blk, gray & dk br & & $\ldots$ & conv & medium \\
\hline 4439 & & fine & dk br & dk br & & $\ldots$ & cone & ap \\
\hline 4440 & v 1 w & fine & dk br & dk br & yellow & ... & conv & nedium \\
\hline $4441^{*}$ & $\mathrm{v} / \mathrm{w}$ & fine & dk br & dk br & & ... & cone & medium \\
\hline 4442 & $d w$ & coarse & blk, gray & dk br & clear. & $\ldots$ & conc & medium \\
\hline $4443^{2}$ & $1 \mathrm{w}$ & medium & blk, gray & dk br & blood & $\cdots$ & $c-c$ & flar \\
\hline $\begin{array}{l}4444 \\
4445^{*}\end{array}$ & $\begin{array}{l}d w \\
l w\end{array}$ & coarse & $\begin{array}{l}\text { dk br } \\
\text { blk }\end{array}$ & $\begin{array}{l}\text { dk br } \\
\text { dk br }\end{array}$ & $\begin{array}{l}\text { blood } \\
\text { blood }\end{array}$ & $\cdots$ & $\begin{array}{l}\text { str } \\
\text { str }\end{array}$ & $\begin{array}{l}\text { medium } \\
\text { flar }\end{array}$ \\
\hline $4446^{*}$ & v l w & coar & & $\mathrm{dk}$ br & cle & & conc & medium \\
\hline 444 & $d w$ & coarse & red-br & dk br & clear & ray & & medium \\
\hline & $1 \mathrm{w}$ & fine & $\mathrm{dk}$ br & dk & & $\ldots$ & cor & \\
\hline & $1 \mathrm{w}$ & medium & blk & & & & conc & \\
\hline & $1 \mathrm{w}$ & medium & blk & dk br & cles & ... & cone & \\
\hline & l $w$ & medium & brown & gray-br & clear & $\ldots$ & $c-c$ & medium \\
\hline & $1 \mathrm{w}$ & coarse & blk & dk br & yellow & $\cdots$ & cone & \\
\hline $4453^{*}$ & v l w & coarse & dk br & dk br & clear & $\ldots$ & str & comp \\
\hline $\begin{array}{l}4454^{*} \\
4455^{*}\end{array}$ & l w & $\begin{array}{l}\text { fine } \\
\text { fine }\end{array}$ & dk br & gray-br & clear & $\cdots$ & conv & comp \\
\hline & & & & & & $\ldots$ & str & med \\
\hline
\end{tabular}

* Omitted from means.

† Dark speckled.

\section{INDIVIDUALS OMITTED FROM THE STATISTICAL SERIES}

Four individuals were omitted because of age; these were No. 4418 (16) from An Nasiriya, No. 4437 (15) from the Al Uzairij tribe near An Nasiriya, No. 4441 (15) from Basra, and No. 4453 (16), a Subbi from An Nasiriya. The remaining group, omitted primarily because they came from diverse localities, consisted of No. 4445, a Dulaimi from Samarra; Nos. 4446 and 4447, Jews from Baghdad; Nos. 4448, 4449 (15), and 4450 (14), a gypsy (kaulia); No. 4451 (14), 
a Subbi from Suq ash Shuyukh; Nos. 4452 and 4454, Subba; and No. 4455, a Turkoman(?) from An Najaf.

Demography.-No. 4441 was a sister of No. 4440 and No. 4451 was a daughter of No. 4452 .

Skin.-No. 4447 had a light freckled skin.

Hair.-Seven individuals had dark brown and four black hair. No. 4451 had brown, No. 4447 red-brown, and No. 4455 brown-gray hair. There were four individuals in each of the medium and coarse eategories of hair texture. Five individuals had fine hair. The majority had low wavy hair, four very low wavy, and one deep wavy hair. No. 4453 had cut her hair in mourning.

Eyes.-The majority had dark brown eyes. Nos. 4451 and 4454 had gray-brown eyes and No. 4455 light brown with dark specks. Nos. 4445 and 4455 had bloodshot, No. 4452 yellow, and the remainder clear sclera. No. 4447 had rayed irides. Only one individual had gray-ringed eyes. No. 4441 had her right eye turned inward.

Nose.-Three individuals had a straight profile, two a concavoconvex, one a convex, and the remainder concave profiles. Nos. 4453 and $\mathbf{4 4 5 4}$ had compressed wings. Five individuals had flaring and the remainder medium wings. Tip thickness was average plus in No. 4453. Nos. 4437, 4447, and 4455 had elevated nasal tips while Nos. 4446,4453 , and 4454 had depressed tips. No. 4418 had a very small nose. Nos. 4445 and 4418 had low nasal bridges.

While No. 4437 had a straight septum with an upward inclination, No. 4453 had a straight septum with a downward inclination. Nos. 4446, 4447, 4454, and 4455 had convex septa with upward inclinations.

\begin{tabular}{|c|c|c|c|c|}
\hline \multirow{5}{*}{$\begin{array}{c}\text { No. } \\
4418 \\
4437 \\
4441\end{array}$} & \multicolumn{4}{|c|}{ DENTITION } \\
\hline & Bite & Loss & Wear & Description \\
\hline & marked over & … & $\ldots \ldots \ldots$ & slight stain near gums \\
\hline & marked over & $\cdots$ & $\ldots \ldots \ldots$ & $\cdots \cdots \cdots \cdots \cdots \cdots$ \\
\hline & marked over & $\cdots$ & $\ldots \ldots$ & $\begin{array}{l}\text { crooked; rather yellow; } \\
\text { brass cap on } 2\end{array}$ \\
\hline $\begin{array}{l}4445 \\
4446\end{array}$ & $\begin{array}{l}\text { edge-to-edge } \\
\text { slight over }\end{array}$ & $\begin{array}{l}1-4 \\
\text { none }\end{array}$ & slight & stained \\
\hline $\begin{array}{l}4447 \\
4448\end{array}$ & $\begin{array}{l}\text { slight over } \\
\text { edge-to-edge }\end{array}$ & $\begin{array}{l}1-4 \\
1-4\end{array}$ & average+ & stained yellow \\
\hline 4449 & slight over & $\cdots$ & $\ldots \ldots \ldots$ & $\begin{array}{l}\text { gold plated upper lateral } \\
\text { incisors }\end{array}$ \\
\hline 4450 & marked over & & & $\begin{array}{l}\text { slightly stained; one gold } \\
\text { tooth }\end{array}$ \\
\hline $\begin{array}{l}4451 \\
4452\end{array}$ & $\begin{array}{l}\text { slight over } \\
\text { slight over }\end{array}$ & $\begin{array}{l}1-4 \\
9-16\end{array}$ & average + & $\begin{array}{l}\text { stained } \\
\text { stained }\end{array}$ \\
\hline $\begin{array}{l}4453 \\
4454\end{array}$ & slight over & & $=0$ & several molars broken \\
\hline 4455 & & $17+$ & average & \\
\hline
\end{tabular}


Teeth.-Five individuals had marked-over occlusion, six slightover and two edge-to-edge. No. 4418 had good, No. 4449 excellent, and Nos. 4445 and 4451 bad teeth. The eruption was incomplete in Nos. 4418, 4437, 4441, 4448-4451, and 4453.

Henna.-No. 4418 had applied some and No. 4455 much henna to the hair.

Tattooing.-Five individuals (Nos. 4437, 4441, 4445, 4450, and 4455) had some tattooing. Nos. 4418,4448 , and 4449 were extensively tattooed.

Branding.--No branding was recorded. 


\section{ARABS OF THE HOR AL HAWIZA}

BY

E. S. DROWER ${ }^{1}$

Linguistic Notes.-For the sake of convenience and simplicity the following system of transliteration of Arabic words has been used. The system, with few changes, is basically that adopted by the Oriental Institute of the University of Chicago. ${ }^{2}$ Because of difficulties of typesetting, those consonants that are represented by two English letters are not underlined, and instead of $k, q$ has been used.

Other modifications from the classical Arabic result from the fact that the spelling is intended to show the exact dialectal sounds heard among the marsh-dwelling Arabs, who live east of al-'Amāra. All modern dialects of Arabic differ in vowel values from the system set up for the classical language. The diphthong ai becomes $\bar{e}$ (as in fete), and $\bar{o}$ replaces $a u$ and sometimes $\bar{u} ; \bar{a}, \bar{v}$, and $\bar{u}$ remain the same as in classical Arabic, but $\breve{e}$ (as in met) is frequently heard as well as $\breve{a}, \breve{\imath}$, and $\breve{u}$. In certain cases the vowel has disappeared entirely. Consonantal sounds occurring in this dialect in addition to those of the classical language are $g$, a phonetic development from $q$; ch (as in chat), a phonetic development from $k$; and $p$ and $z h$ (as in azure). The final $h$ of feminine nouns has been omitted. The assimilation of $l$ in the article to the following consonant is not indicated. Hamza at the beginning of a word has been disregarded.

The marshes of southern 'Irāq, sometimes called the Great Swamp and known to the 'Irāqi as Al-Hōr, must have existed since very early times, for the country is alluvial, low-lying, and

${ }_{1}^{1}$ Lady Drower accompanied the Expedition to the Hor al Hawiza during April, 1934, in order to record details of the life and customs of the marsh-dwellers. Her special knowledge of Arabic and Mandean served her in good stead during the compilation of these data. Since her philological records are of unusual significance we have decided to include the diacritical marks throughout this chapter rather than to relegate them to the Glossary, as was done in Part I, No. 1. The sections of this chapter have been edited to conform to the general plan adopted for publication of the data from Iraq.

During the war the original notes on this section were destroyed and correction has therefore been hampered.

2 Brux, A. A., "Arabic-English Transliteration for Library Purposes," in American Journal of Semitic Languages and Literatures, vol. 47, No. 1, pt. 2, Oetober, 1930. 
subject to inundation when the Tigris and Euphrates are in flood. The district was inhabited during the Babylonian and, according to some archeologists, during the Sumerian epochs, although this is not verified, as the mounds rising above the expanse of reeds and waters have not yet been excavated. On the slopes of several great mounds, at al-'Aziziya, Wājif, and elsewhere, lie many potsherds, which would seem to indicate former large settlements. The word tell is not used by the marshman to designate these hills, for such a mound, called an ishān, is thought to be protected by the magic of dead civilization. Indeed it is related that a man, digging for buried treasure on the mound known as Abū al-Dhahab ("Father of gold"), was suddenly smitten from behind by a melek, a spirit supposed to haunt graveyards and lonely places, so that he died. No doubt the prosperous Babylonian marsh-dwellers, like the present day marshmen, traded in rice and other grain, fish, straw, reeds, reed mats, and such commodities.

The historian, al-Balādhurī, describes the marshes as covering an area fifty miles broad and two hundred miles long and stretching from al-Kūfa to Bașra. He attributes their origin to the reign of Kubādh IV, a Sasanian king of the fifth century A.D. During this period the Tigris burst its confining banks and dykes, flooding all the low country to the south and southwest. In A.D. 629, the Tigris and Euphrates both rose in a mighty flood, spreading over the reclaimed land. The Sasanian king, Parviz, fought heroically against the encroaching waters, but his task was too much for him. When the Moslems came in hordes from Arabia and the Sasanian monarchs departed, the dykes were not repaired and the marshes were not reclaimed. Even then, however, the remains of some prosperity persisted, and in the earlier years of the Caliphate, attempts were made to repair old earthworks and dykes, and to reclaim the land. The Mongols and Turks, however, completed the ruin.

Thus, after centuries of neglect the vast swamps of today are given over chiefly to waterfowl, wild boar, and otters, and the waste of waters, reeds and rushes is populated only by poor communities living under primitive conditions.

Plant life flourishes. The surface of the swamp water is covered with the liliaceous leaves of the $g a^{\prime} \bar{\imath} b a$, which is often dried and pounded into a powder said to be beneficial when blown into the eyes of cattle. In spring the white blossoms of a water weed (uzhêr al-batt) rise above the surface of the water.

Although land on the islands is cultivated throughout the marshes, areas of intense cultivation such as those near the Chahalā 
(Kahalā), Majar al-Kabir, and other small rivers and their tributaries are found only on the western fringes of the great swamp.

The villages are built of reeds and the roads are chiefly waterways. In a few of the district villages the sheikhs' houses can be reached by automobile. For instance, the old, dismantled railway from al-Bașra to al-'Amāra is used as a road by people of Qal'at Sālih because it is raised above the surrounding country and is therefore immune to floods. Between Halfãya and al-'Amāra there is also a good automobile road. Within the marsh itself, however, waterways are the sole means of communication.

The principal tribes of these marsh districts are the $\bar{A} l$ bu Muhammad, the $\bar{A} l$ Suwā'ad, ${ }^{1}$ the $\bar{A} l$ Sūdān, the Uzairij, and the Bani Lām. The leading sheikhs of the Uzairij are Sheikh Shawwai al-Fahad and Sheikh Mutlaq al-Salmān, who has succeeded Sheikh Salmān al-Minshad.

Qal'at Sālih is the district proper of the $\bar{A} l$ bu Muhammad. It extends from Majar al-Kabir to the Hōr al-Hawiza from west to east, but the tribesmen also follow the banks of the Chahala River, a tributary of the Tigris, from al-'Amāra, and those of the Majar alKabir, the Michiriya, the Shatt, the Kasra, and Hafira, all of which eventually lose themselves in the marsh.

The $\bar{A} l \mathrm{bu}$ Muhammad are farmers, makers of reed mats, and fishermen. They are a large tribe and in times past have been wealthy, although, owing to the poor price obtained for grain during recent years, they have become impoverished. Their principal sheikhs are Fàlih al-Saihūd, ${ }^{2}$ to whom most of the tillage on and about the Chahalā belongs, Muḥammad al-'Araibī, who is a member of the Chamber of Deputies, and Majid al-'Khalifa, who sometimes leased the Government Muqāta $a$ of Majar al-Kabīr and is a wellknown agriculturist, and finally Țāhir al-Ḥātim, who lives near Ezra's Tomb (al-'Uzair).

Of all the marsh sheikhs the one most universally respected, and the one whose word has most weight in any council, is undoubtedly Sheikh Fālị̣ al-Șaihūd, although Sheikh Ghaḍ̆bān of the Bani Lām was formerly a man of power and wealth. (His successor, Sheikh Hiātim, has neither his wealth nor his prestige.) Sheikh Fālih's power is, however, that of personality, for he is a

${ }^{1}$ Lady Drower prefers the use of the "u" in the spelling of Al Sawā 'ad. (H.F.)

since dead. The writer describes conditions as she found them in 1934. Conditions changed radically during and since World War II, both politically and economically. 
remarkable character, and his massive physique is as impressive as his vast hospitality, his generous character, and his great physical strength. An old man, possibly eighty-five years of age, he shoots far better than the younger men. He weighs about three hundred pounds, is tall, tireless, jovial, and dignified. Although he holds many conservative ideas, including a sterner code of honor than some of the more modern of his contemporaries, he has built a school for his tribesmen and encourages the activities of the Government doctor, whose services are much needed.

The Suwã'ad interpenetrate but do not mix with the $\bar{A} l$ bu Muhammad. Some of the Suwā'ad are also found north of the Sūdān tribesmen, who inhabit the district between the Musharra and the Chahalā rivers as far northwest as al-"Amāra and as far south as Bahatha on the southwest and Hōr on the southeast. They are cattle-keepers and farmers. Muḥammad al-Mūsā and Shibl alShiya are the leading sheikhs.

The Sūdān also grow rice and other grains. They are taller and darker than their neighbors, the Suwā'ad.

The Bani Lām, a sheep-owning tribe that formerly possessed great wealth, are still more or less nomadic. In the past a constant feud between them and the $\bar{A} l$ bu Muhammad was ready to erupt at any time, especially under a weak government. They are now on good terms, and the old feud has not manifested itself seriously in recent years.

Since the Banī Lām extend to the northeast of the al-'Amāra district and are found chiefly in the plains between the hills of Iran and the Tigris and in the rich grazing lands east of the Shatt al-Tìb, they are not, strictly speaking, a marsh tribe. In summer, when the plains become parched, they move their flocks in search of herbage into the foothills of Iran, a habit that has sometimes led to disputes with the authorities of Iran. Their northernmost sheikh is Jūwi al-Lāzim, and their paramount sheikhs are Hātim al-Ghaḍbān, Qumandār al-Fahad, and Alwān al-Jandīl, the last a member of the Chamber of Deputies in Baghdad. ${ }^{1}$

\section{AGRICULTURE}

The lands owned by the various sheikhs are divided into estates (maqāți $\bar{\imath}^{6}$ ) and the allotment of the rich, silt-bringing flood water that irrigates the rice crops needs careful adjustment.

${ }^{1}$ Alwān al-JandIl, Muhammad al-'Araibi, and Majid al-'Khalifa more or less took it in turns to be deputies, two at a time. 
Irrigation is chiefly by means of flooding and sometimes by minzaha; water spreading over land is called bāryāu (Pers. bāriyāb). In such places the engine-worked pump is unnecessary. The waterwheel $\left(n \bar{a}^{\natural} \bar{u} r\right)$ and the charid (karid), a contrivance for filling waterskins and lifting and emptying them by a pulley (see Field, 1940, Pl. 48), are little used in low-lying lands and not at all in the marshes themselves. The minzaha is a popular method of irrigating patches in cultivation near the banks of a river, stream, or canal. Two men are required, and a shallow basket daubed with pitch, called the 'arāwì, is swung down into the stream by means of ropes and hauled up to the bank, where it is emptied at the top of the swing into a water channel. The men work with extraordinary rapidity. For larger areas, flooding is all that is required and, as the land is lowlying, this is easily performed. The water is let in from a shallow gutter (mishrab), and fed from a small channel ('ibra), which in turn is supplied by a canal (garma). Drainage water is termed suffa.

The most important product of the whole 'Amāra Liwā is rice, the easily flooded land of the marsh country being especially adapted to its cultivation. The best rice is the variety called 'anbar; other varieties are shitāl, herfī, and hewaizawì. Rice (rizz or timman) or, more commonly, unhusked rice (shilib) is grown in seed beds; when the young shoots have come up they are transplanted into the mud left by the last year's floods. This area is protected by ridges of earth sufficient to keep the water standing at a depth of a few inches above the roots of the young rice. Thus, the shilib is transplanted in early spring and is ready for harvest about June or July, according to the quality of the rice and the local conditions.

In the cultivation of rice a triangular harrow of primitive construction $(\operatorname{mar} \bar{z} z a)$ is used. An isosceles triangle is formed of three strong reeds, two slightly overlapping at the apex of the triangle. To the two angles of the base two ropes are fastened. This light harrow is held, apex upward, by one man, while a second man drags it across the rice field by means of the two ropes (Pl. 218), thus levelling the mud and dragging out the shallow-rooted weeds (daghl), leaving the rice shoots unharmed. The rice is threshed with the help of oxen, the resulting rice straw (būh) being used for fodder, for mixing with clay when making pots or mud walls, or for export into other parts of the country. The rice is stored in a large, round basket-bin (matbuga), which, when full, is covered over with mud. From time to time the mud cap is broken open, the rice sifted, and 
a new cap added. There are often a number of these rice bins in an enclosure fenced about with reeds or with a mud wall (Pl. 64). To prevent buffaloes from breaking down the corners of a reed enclosure, square holes are dug in the ground at each corner (Pl. 57, Fig. 2).

Other crops are wheat (the varieties, guraita and shäfĩya), barley (sha'îr aswad and sha'ì 'Irāqū), yellow maize (udra safrā), sorghum (udra baid̄a), millet (dukhun and māsh khadrāwī), and lentils ('adas). Melons (battīikh) and watermelons (raggī) are also cultivated and, to a small degree, lady's-fingers, onions, and other vegetables. The cultivator of the melon patch is not called a falläh, but a baghwān, or gardener.

Millet, grown in mud that cannot be watered after the floods recede, is reaped by hand during September. The earliest harvests are those of wheat and barley, which are gathered in May. Plowing the ground for the sowing of grain also takes place in this month. It is performed by oxen drawing a simple plow (fiddān) (Pl. 68, Fig. 1), which consists of a straight tree trunk, usually willow, fitted into a curved cross-piece, one end of which is pointed and shod with iron. The yoke $(n \bar{\imath} r)$ for the oxen is fitted into holes in the straight piece. The furrow made by plowing is called a sikka. The spade (mishā), which is used throughout 'Irāq, is shaped to a rounded point and is fitted to a long wooden handle. A wooden cross-piece is inserted just above the iron blade, so that the bare foot can thrust on it when digging.

Agricultural labor is paid in kind. Any money that a marsh tribesman receives is earned by weaving reed mats, building reed huts, and selling dried fish, woollen cloth, or other textiles woven by him or his women. The crafts of boat-building, tool-making, and gold- and silver-working are entirely in the hands of the Subba ${ }^{1}$ or Mandeans.

\section{Domestic Animals}

In the marsh country the water buffalo is the main domestic animal. The water buffaloes of the $\overline{\mathrm{A}} \mathrm{l}$ bu Muhammad are famed for their quality. The marsh tribes also keep a slightly humped, small, yellowish-fawn type of cow, extremely mild of temper. Bullocks draw the plows. Donkeys are found everywhere and usually have sores and broken ears, the result of harsh treatment. Goats belong

${ }^{1}$ Although Lady Drower now prefers the use of "a" in Sabba, the "u" has been retained throughout this manuscript. (H.F.) 
to the common black-and-white variety. Fowl are generally small, but one sometimes sees fowl of small body with powerful legs and feet. This variety is used for cockfighting, a sport of which the Marsh Arabs are fond.

The majority of the wealthier sheikhs have horses of good pedigree. I asked an 'Irāqi friend to give me a list of their breeds. He named: 'Ubāyyat ash-Sherrāf, Șaqlāwat al-Jedrān, Shuwaimat as-Sabbāh, Dahamat al-'Amīr, Mu'nakiyyat al-Hidrij, and Kahalat al-'Ajūz. Legend, he said, attributed each name to some incident attending the first owner or to a nickname given to the first horse acquired by him. The animals, according to story, were trapped and stolen from their owners, a horse-owning tribe, during a raid (ghazū). 'Ubāyyat ash-Sherrāf, for example, was so called because the mare after having thrown him fled from her new owner with his ' $a b \bar{a}$ ' on her back. Saqlāwat al-Jedrān was so named because the Arab who had taken the mare was called Jedrān, and the root sql refers to the mare, "Slender-in-the-flanks-and-glossy." Shuwaimat as-Sabbãh means "Little Mole of Sabbāh"; Kahalat al-"Ajūz is "The Collyrium of the Old Woman," referring to the animal's blackness; and so on. It is possible that the legend depicts times when the superior strength of tribes owning horses induced less fortunate tribesmen to obtain these animals by ruse.

Buffaloes are easily fed, for their favorite diet is rushes and reeds. These are cut with a slightly curved knife (minjal) that has a saw edge and a wooden handle. The knife is used not only for cutting fodder of all kinds, but also for cutting the stout gașab used in making reed huts, beds, bridges, and punt poles. The gașab often replace wood throughout the marsh districts.

A platform (dibin) on which water buffaloes sleep is made by bending gașab reeds in situ, piling rushes (bardi) and mud onto the reeds, and thus building an island. Buffaloes are also kept in a reed pen (sitra).

Rice straw, kept in square mud bins, and chopped straw (tibin) are also used as fodder for cattle.

The milk-giving animals are the large, black, water buffaloes, cows of a light-colored, slightly humped variety, goats, and sheep. The Banī Lām, who seldom keep cows or buffaloes and do not sell their products, obtain milk from the female camel (nāgah). Milking of the buffaloes and cows is performed at the side of the beast, but goats and sheep are milked from behind, between the back legs, while the head of the animal is held by an assistant (Pl. 71). 
It is believed that the buffalo and cow will not let their milk flow freely unless the calf is allowed to suck a little before the milker sets to work. If the calf dies, its skin is stuffed and thus made into a dummy $(b \bar{a} u)$ and the mother is allowed to smell at the skin before being milked. Lambs and kids are separated from their mothers while the latter are at pasturage, but they are reunited at sunset.

The sheep of the Bani Lām are their chief wealth. The breed of their animals is that common to the whole country - a sheep which has a fatty base to its tail, known as the liyya, from which the animal draws nourishment during days of sparse vegetation; in fact, it corresponds to the camel's hump.

Tribal ownership of an animal is usually indicated by a brand, although one tribe of the Banī Lām inserts a ring into the right ear of the camel. The word for brand (wasm) is similar to that used for tattooing (washm $)$ in other Arab countries; in 'Irāq, the word for the latter is daqq.

\section{HunTing AND Fishing}

Here and there in the marshes a waterway (gahn) through the reeds leads to a small space of trampled rushes (chibäsha), the lair of wild boar, who may start up and plunge snorting into the shelter of the high reeds. During the breeding season many of these wild pigs migrate from Hawiza and the low ground below the Jabal Hamrin into this region. The male pig, often the size of a small donkey, has been known to charge upon and upset boats, while it is reported that boars have attacked automobiles on the road between Qal'at Sālih and al-Qurna.

The marshman, who hunts the boar with his light gun ( $j a^{\prime} z a$ or tanbal) or with his antiquated firelock (bandega), is fond of relating encounters with these animals. I here give one such narrative.

"A year and a half ago I was bidden to go and collect a party of men to complete making a canal. Riding a white mare I went across country where there were sarim [thorns] and tahama [a shrub] and ghedām [undergrowth]. I went, and presently I saw a wild sow [bagura] standing in my way. She had a gray body and a red neck and big ears, and long tusks set crosswise, over a foot long, and one eye as big as my hand and the other a little smaller. She had great flapping lips which blew when she wanted to eat, hair on her body, and she stood a little shorter than a man's height. She rose and tracked me, and stopped at about the distance of yonder reed 
hut, and I, as it may be, here. I took a small stone and threw it at her. She rose and began to snort and spit at me, and the mare began to tremble and I too trembled, for I had only a stick in my hand, and no gun, and I fled on my mare, who leapt away. I began to weep, and say, 'Whither can I go?' She came after us, until we reached a place where there were buffaloes, and I rode amongst them. She came, the sow, and gored one of the buffaloes with her tusks and the buffalo's belly was torn and it died. Meanwhile I fled on. Still she came after me. I saw a hole in the ground, and I dropped off the mare's neck into it, whilst she continued to follow the mare, which she caught, and gored so that it died. Then she returned and began to smell and root about on the ground looking for me. She examined the ground minutely and squealed, and I bit on my finger and wept and thought of my father. At last she went away, and I remained in the hole for some time, prisoned because of my fear. Then I returned, but I had not made the canal or collected the men or anything! I said, 'W'Allāh, I will not go,' for I was frightened of her. W'Allāh, this is my tale."

Wild duck, geese, snipe, partridge, and teal are lawful food. Religion demands that their throats must be cut after they have been shot. Although wild boars are plentiful, the Marsh Arab, true to his Mohammadan faith, hunts them only for sport. He refuses to touch them. Birds are sometimes trapped. A duck trap (dossha) and a snare ( $n \overline{o s h} a)$ made like a double sieve (used for catching gazelle or fish) are used.

Pelicans may be shot for sport, although the Marsh Arab rarely wastes precious cartridges on a wily bird, which always flies at a considerable height and when on open water never allows the hunter to approach within range. The stork (Hajji Laqlaq) is considered a sacred bird since it is believed to make an annual pilgrimage to Mecca.

According to local report, the iron fish-spear ( $f a \overline{l i h}$ ) is sometimes used for killing a partridge when the bird is sitting. The hunter moves round and round the bird, closing in gradually, a maneuver that seems to daze it. I have seen Shammar tribesmen of northern Iraq use the same technique when shooting bustard.

Reptiles and amphibians are rare (see Schmidt, 1939), but the many varieties of fish found within the marshes have been the backstay of a Marsh Arab fishing industry for many centuries.

In water channels and rivers the natives usually fish with a net (shabbaka), which varies in size according to the width of the river 
or water channel for which it is intended. Some of these nets stretch nearly across the whole width of the Tigris River. Weighted with lead, they use as floats karabs (the woody base of a palm frond). After being hand-netted, the mesh is toughened by immersion in boiling lime (nūra).

The net is paid out by a man standing in a mashhüf, while his assistant rows or paddles across the stream. After the last catch has been hauled in, the net is hung up to dry.

A second type of net, the selliyya, small and circular, is thrown outward by the fisherman with a dexterous movement of the wrist.

The fish-spear is used in shallow water, where the water weed, both subaqueous and on the surface renders the nets useless. Fishspearing is usually done at night, a moonless night being preferred, although it sometimes takes place by day in clear and shallow water. At night, flares made of burning reeds and rushes lure the fish to the surface. As soon as the dazzled fish has risen high enough, it is speared by the fisherman who, weapon poised in his hand, stands alert on the "neck" ("anaq) of the chalabiyya. The spear is shaped like a long toasting-fork with prongs of varying length, each tipped by a barb (Fig. 11). The three-pronged spear is called $a b \bar{u}$ thalätha or thlüthiyya, the five-pronged, abū khamsa or khumessiyya. In both, the longest prong is the center spear, the heart (lebba). In the fivepronged spear two short prongs are fitted to the shaft between the $l e b b a$ and the side prongs. The torch is held by a man sitting in the middle of the boat, with a supply of fuel beside him. As the flare (mash'al) burns low, he takes another bundle of reeds and lights it from that which is dying down.

In order to bring the fish to the surface in deep water, a drug, digitalis (zahar), or rubyān (marigold seed?), which stupefies but does not injure the fish, is scattered on the surface.

Fishing by line and hook (for the latter the 'Irāqi Arabic word shess is used) takes place only in open water, free from weed. The fish-hook (Fig. 11) resembles exactly those excavated at Jemdet Nasr (cf. Field, 1926).

It is probable that dried fish have been exported from the marshes since the earliest settlements were established there. The so-called "Tigris salmon" (bizz) is so large that a good specimen, when placed on the back of a small horse or donkey, will almost touch the ground on either side. It seldom is found in shallow water, but remains in the Tigris, Chahalā, or larger waterways. Local names of other fish are bunniyya, shabbüt, shilich (shilij), sabra, himriyya, 'aqad 


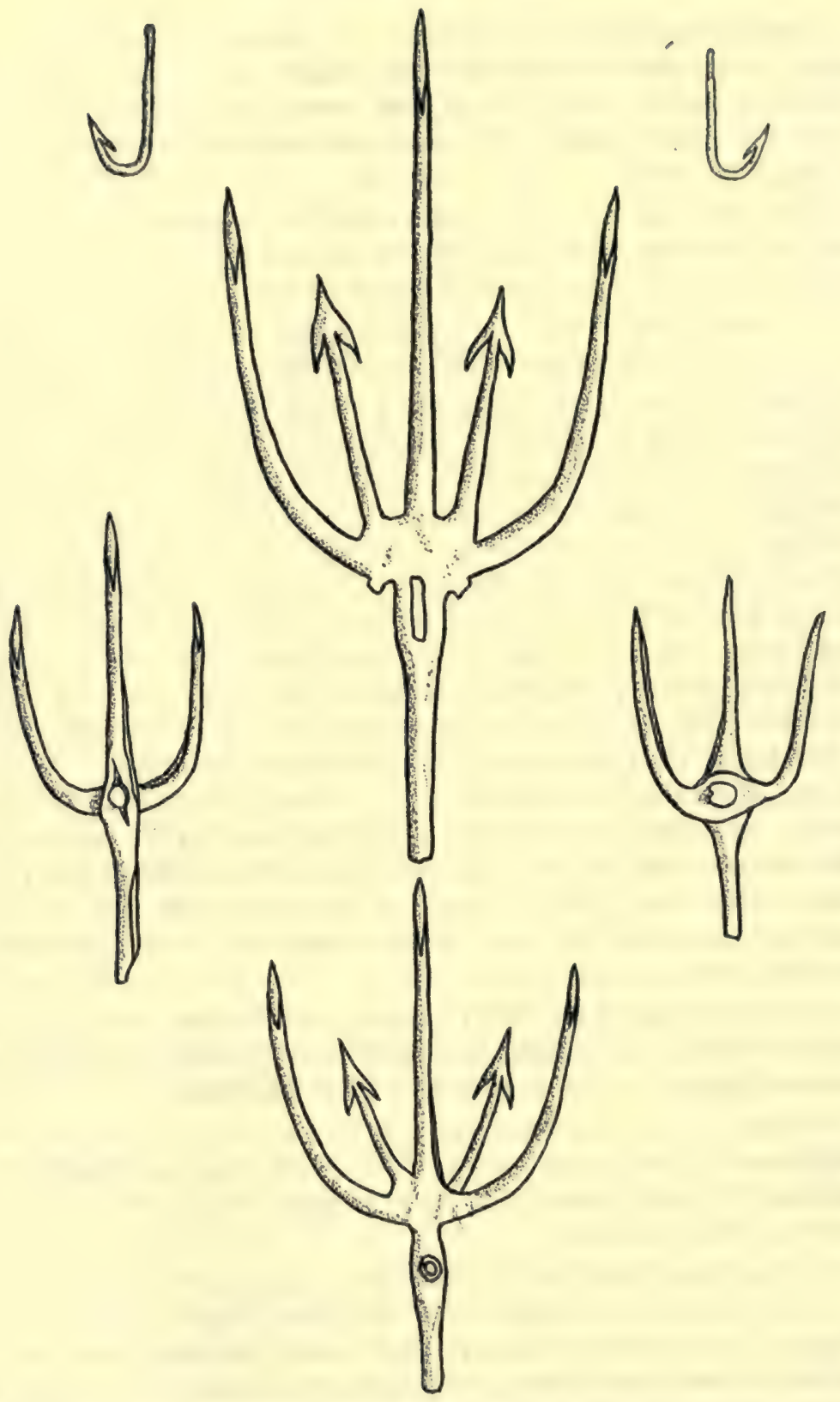

FIG. 11. Iron spear-points and fish-hooks used by $\bar{A} l$ bu Muhammad fishermen. 
('jed; this is also called the gațān or qațān in the marshes but in Bașra barzan and in Baghdād dhikr), jerriyya (pl. jerrī), akțūna, nabbāsh, and $a b \bar{u} a z-z u m m e \bar{e}$. The local name for the bizz mentioned above is 'anza, or jașșana; the latter word is also used in Bașra. The fish called subūr in the marshes is known in Baghdād as Abu suwaif.

\section{TrANSPORTATION}

The sole method of transportation is by means of the waterways. The sailing ship, barge, and raft, which form the principal river craft, seldom penetrate into the marshes.

The largest boat (bargash mirhal) is used mainly for exporting reed mats, but one often sees a whole family with its dismantled reed hut, reed mats, furniture, cooking pots, fowl, animals, rice, and flour mills, being transported to another village on one of these large, shallow-draught boats. A smaller boat of the same type is called bargash. Sometimes two of these boats are lashed together to carry a stack of giant reeds (chäya mäl bardi).

Occasionally there appears in the inarshes another type of boat (dāneq), which differs little from the bargash except that it has sails.

Next in size to these is the tarrāda, which will seat from ten to twelve persons. It is decorated on the interior by a studding of large, round-headed nails nearly an inch in diameter, called girsa. The bottom of the tarrāda is often furnished with a removable flooring upon which mats or mattresses can be spread, while round cushions are placed against the arched crosspieces that span the craft. These crosspieces cannot be used as seats; they are back supports, for the passenger must sit on the floor of the boat if he is not to disturb the equilibrium. Such refinements as mattresses and cushions are, as a rule, only for people of importance or guests; the marshman is content to sit upon strewn rushes.

The generic term for the shallow, wide boat used in the marshes is mashhüf (Pls. 141-144). It is of a simple design, carvel-built, with inner ribs curving up from a center piece or backbone. This center piece ends in a long beak called the 'anaq, which serves to push a way through rushes and reeds in the swamp. The boat is pitched on the exterior and around the edges of the interior, the pitch being applied by hand with a rag and afterwards pressed smooth with a roller (Pl. 143, Fig. 2).

The smallest craft (chalabiyya) can hold two or three persons and is used for fishing. In the Muntafiq area this little boat is called $z \bar{a}$ 'ima chulèka. 
The usual method of progress is by means of a paddle (gharräfa) in the stern, while a man in the prow punts with a pole (mardī), which is usually made from a stout reed although cane (gan $\bar{a})$ imported from India is preferred because of its superior strength. The handle of the pole is finished with a knob of bitumen. The paddlers are not a necessity, for a skilled puntsman wielding the pole with strength and swiftness can propel the boat alone.

Several of the great sheikhs prefer a large boat (balam), built and imported from al-Bașra; Sheikh Fālih has a teak balam, which cost thirty pounds sterling (about $\$ 150$ at par). Two men scull in the prow of the boat; the oars (mijdäf) have pear-shaped or square blades and each oar is tied to the rowlock (shaubak), which consists of a notched piece of wood in a socket of painted wood faced with brass. The passengers sit in the middle of the boat on a mattress with cushions, and four men sit at the stern paddling, first all on one side and then all on the other. The last paddler steers the boat.

There appeared to be little difference between the oar and the paddle. It is interesting to note that the extremely primitive sweeps used on rafts supported by inflated skins (keleks) are called $\operatorname{maj} \bar{a} d \bar{\imath} f$.

The most primitive form of water transport consists of a floating bundle of reeds (Pl. 145, Fig. 1), a means of progress probably used by the earliest and most primitive inhabitants of the marshes. A marshman will propel himself on one of these bundles as easily as in a mashhüf.

When going against the stream, the punter, with one or two others if the craft is heavy, springs to land with a tow rope (shārūfa) and trots along the bank (chiffa) at a steady pace, leaping any small ditch and wading any irrigation canal that comes in his way. I have seen men at Qal'at Sālih towing a sailing ship (mahēla) and taking astonishingly wide leaps, one after the other. They often run naked, and their fine, muscular bodies indicate excellent health.

\section{DWELLINGS}

Villages are scattered throughout the marshes (PI. 57, Fig. 1; Pls. 58, 59). Passing these villages in a mashhüf, one sees the inhabitants at their daily tasks, for they live outside and perform most of the household work, such as cooking and baking and weaving, in the open air. The waterway is the sole link with the outside world; peddlers who make the circuit of the marsh villages bring news as well as bales of cloth and cotton, spices, tea and coffee, and the other wares that come from towns like al-'Amāra, al-Nāșiriya, al-Bașra 
and Qal'at Sālih. The light-colored, shaggy watchdogs bound along the bank for a little distance, barking furiously; children, naked or half-naked, gaze and run to look, while the women occasionally glance up from their milling, winnowing, or baking to shout a friendly greeting to the men who pole the boat.

The larger reed villages, built on dry ground, may consist of several hundred huts. In the heart of the swamp, however, one comes upon groups of reed huts built upon platforms of reeds and rushes, with mud trodden down firmly, and covered over by layers of reeds and reed mats. These islands are called chibā'ish. ${ }^{1}$ To move from house to house, a man must wade, swim, or go in a boat, although here and there huts are grouped on one platform or connected by a bridge of reeds. In flood time, more rushes and reed mats are piled on so as to bring the dwelling above the water.

The general term for a reed hut is sarifa, but there are many varieties. In the marshes proper the most popular type of living-and guest-hut is the $k \bar{u} k h$, a hut with a rounded roof. It is only in recent years that the wealthier marsh sheikhs have replaced the big reed reception house (madīf, invariably pronounced mudīf; see Pls. 52,53 ) by a brick-built diwanniyya (Pl. 50, Fig. 1 ), and even now the madif serves as a guest room for town visitors and is used for the daily friendly gatherings. In summer the reed hut is infinitely cooler than a mud or brick construction, for the latticework of the lower wall admits the evening breeze and the fresh night air, whereas bricks and mud retain the heat of the sun even at night.

In the madi $\bar{f}$, huge ribs formed of great bundles of reeds (shebāb) rise symmetrically to form the perfect arch of the roof (PI. 53). These giant reeds (gasab) are hollow, jointed, and extremely strong. Before they are inserted into the ground at regular intervals, like a colonnade, facing each other, they are bound into firm bundles as much as two feet thick, by means of ropes of twisted rushes (PI. 54). The plumy heads are then bent over and cut off and the ends of the opposite bundle interwoven with these so deftly that the joint is hardly visible. The two bundles thus united now form an arch. Occasionally the arch receives further support from vertical bundles placed on and not in the earth and down the middle of the hut. These, curved or straight, are called $b \bar{a} q \bar{a} t$. Reeds bound together in a pointed bundle may be called shäsha (Fig. 13).

1 There is a village of some size called Chiba'ish, built entirely on these platforms. The root $k b s h$ is found in several Semitic languages ( $k b s$ in Akkadian and Arabic, $k b s h$ in Hebrew and Aramaic) with the meaning "to tread down" or "stamp under foot," and is extremely common in Mandean magical documents where devils and enemies are "trodden down" or "subdued." 
The next step in the erection of the hut is to bind transverse bundles of reeds to the arches, the lowest being about two feet from the ground ( $\mathrm{Pl} .54)$. Each bundle (hatar) is formed of reeds thinner than the shebāb. Next, a light latticework of reeds, covered in winter, is inserted between the lowest hatar (pl. ahțär) and the ground to admit air and coolness in summer. The framework is then overlaid with reed mats (bawāri $)$, one overlapping the next. There are often two layers of these mats or a thatching of reeds above the mats. One madīf which we visited (Pl. 52) was covered over entirely by a single bāriya woven in one piece, above which were a hundred and fifty overlapping reed mats of smaller size. Reed mats are placed along the sides of the hut and the two end walls are constructed of erect bundles of reeds covered with mats and strengthened by $a h t \bar{a} r$. There is often an entrance at both ends consisting usually of a square opening without a door or other covering.

Most living-huts are of the kūkh pattern described above, but they are not so carefully and elaborately built. The end walls are often bundles of reeds with their feathery tops still uncut, propped against the structure or bound together by reed ropes or by ahțär, while the entrance may be merely an aperture in these reeds. The entrance is supposed to face Mecca; actually, entrances face all directions.

A second type of hut is rarer in the marshes, except on the Jabal Hamrin side and approaching Bașra. As it is the usual type in Khuzistān and not uncommonly develops into a mud-wall hut with a reed or thatched roof, this type, the jemāli, may be regarded as an embryo house - a reed hut in transition. The smaller dwellings are easily uprooted, and one sees mats and shebāb and ahtār all piled up on a bargash ready to be re-erected elsewhere.

The framework of the jemāli consists of two strong sheaves of stout reeds, bound so that they can be divided into a fork at the top. These are placed apart at the distance of the planned length of the hut. The feathered ends of the reeds may be cut off or not. Into the forks, the trunk of a palm tree, or a pole, or sometimes even

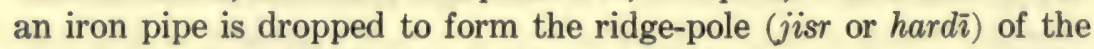
structure. Occasionally the builder uses forked poles to support the ridge-pole instead of the two bundles of reeds. The ridge-pole projects at either end of the building when it is complete. Matting placed over this ridge-pole is stretched to meet two side walls of reed mats strengthened by upright bundles of reeds, these side walls being much lower than the end walls. Sometimes the structure is 


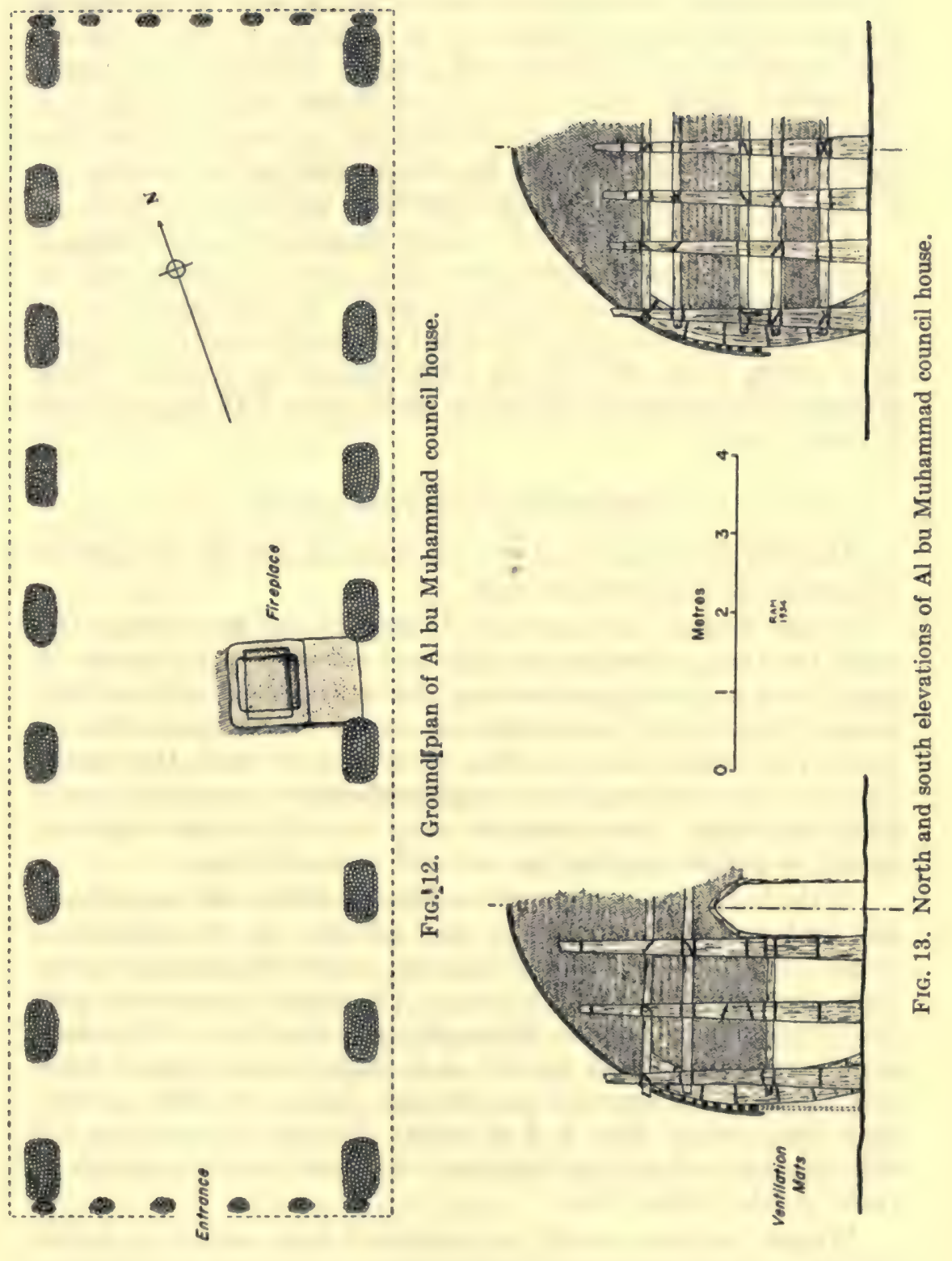


daubed over with mud; sometimes the side walls are replaced by libin (mud mixed with chopped reeds or straw) and the matting on the roof is further strengthened by a thatching of reeds. In this case, the result is not unlike the cob cottages of Devon and Cornwall in England, except that the walls are thinner and the thatching lighter in character. The jemāli, however, is rare in the marshes except as a shelter for cattle; its sharply sloping roof suggests an origin in a higher country, where snowfalls might be expected.

A third type of hut, kishik, usually situated on a river bank, is square and often of extreme grace, with interior dividing walls of latticework and small arches, all of reeds. It often has a portico (sōbāt) of reeds. No other type of hut has interior walls. It is used as a sitting room and for the entertainment of friends. These pleasure huts are built for sheikhs or other people with leisure enough to enjoy them.

\section{DOMESTIC WoRK AND APPLIANCES}

The living huts of the Āl bu Muhammad and the $\bar{A} l$ Suwā'ad are nearly all of the kūkh pattern.

Poorer families have not the luxury of two reed huts. One small reed hut, sometimes so light and temporary that it can be taken down and re-erected in a day, shelters man and wife and their furêkh ("little brood"), as children are termed in affectionate diminutive. The smaller animals often share the hut with the family. The hen sits on her eggs in a round earthenware receptacle (mögif) filled with ashes. Sometimes the mōgif has a lip in which grain is placed, so that a brooding hen can feed without rising.

In the hut of one young sheikh whom I visited, a calf was tethered and fowl strolled in and out as they wished. At the farther end (yōsar) of the hut stood a reed platform (sarīr) with trusses of stout reeds about three feet high for legs. This couch was covered with brightly colored mattresses. Although her husband was an important sheikh, my hostess used this hut as a sitting room, dressing room, and kitchen; her servants and women slaves (for most sheikhs keep black slaves) slept in it at night. She shared a sleeping hut with her husband and children and such fowl or other animals as cared to take shelter there.

Women and men usually are separated from each other during the day. No woman is veiled and there is no formal objection to a man who sits or talks with women. Whenever their work lies together, there is friendly intercourse between the two sexes. 
Women, however, are not allowed to eat with the men, nor do they sit with them in the madif.

Piles of mattresses and pillows, often covered with silk, are the pride of a prosperous sheikh's wife, or wives. Round, silk-covered bolsters, protected about the center by a cotton wrapping and edged with Manchester lace, serve as pillows by night and reclining cushions in the hut by day. Such cotton covers or even tablecloths - the latter used only when town guests are present-do not receive very frequent washings.

In places where it is difficult to get soap, which is imported from towns, or where the housewife is very poor, a dried and powdered saponaceous herb (shnän) is used for washing. Often soap is not used. The woman thumps the wet garments on a stone, rinsing them several times over in the muddy water at the river brim and drying them in the sun.

Around the sides of a well-furnished reed hut stand tall clay jars, ranging in height from about one to six feet, for the storing of grain. These tall clay bins, received by the owner in lieu of wages, are called sudüd; the smaller sizes are sudayyid. The largest șadd is termed the minkhal. The mouth of the salt jar $(w \bar{a} w \bar{\imath})$ is stopped with clay, but there is a hole in the sloping shoulder so that the housewife's hand can slip in and grasp some of the contents. A wide-mouthed jar $(k \bar{o} z)$ of porous clay with a rounded bottom contains the drinking water and is usually set in a high wooden stand at the door of the reed hut so that air may circulate around the wet surface and cool the water. A pan, also porous, is set below to catch the water which percolates through the $k \bar{o} z$. The shurba, a pitcher with a handle, is placed near the receiving pan on the ground.

Water is brought from the river by a woman or girl; I have never seen a man condescend to this task. The miskhana, a tall, graceful copper jug with a long neck and a handle, is used for dipping up the river water. The water carrier stoops to fill her miskhana, sometimes wading in to get unmuddied water, and sets her pot on her shoulder or head for the return journey. In summer, surface water becomes hot, and pots are let down into deep, cool water, called mai al-'arūs, "bride's water." Although bilharzia is a common disease, water for drinking is not boiled.

A large covered basket (sebt) is also used for storing objects, and for general household purposes there are the tabga and the guffa, bowl-shaped baskets of shallow and deep make respectively. Some of these baskets are homemade, but many of the colored baskets are 
brought from Karbalā and al-Najaf when some member of the family goes there on pilgrimage, or they are bought from peddlers who travel by boat from village to village (see Fulanain). Clothes are hung on a teltela, a rail of bound reeds secured to two of the strong reed bundles that support the roof.

Even a sheikh's wife has little leisure, for she with the help of her maids must perform all the household tasks. These include milling, bread-making, cooking, butter-making, the preparation of curds (rōba) and dung cakes (mutttal), milking, obtaining water, laundry, collecting pot herbs or simples, and finally, sewing, spinning (with a distaff), weaving, dyeing, and basket-making.

The housewife cooks her meat in tinned copper cooking pots. These are obtained in the copper bazaars of the towns and are not a local product. The cooking hearth ( $\mathrm{Pl} .66)$ is usually on the outside of the hut ${ }^{1}$ and consists of three fire-blackened bricks (manassib) upon which she sets her pot, building up the dung cakes and reed fuel between them. The dung cakes are made from buffalo dung (sarjīn) mixed with chopped straw and worked into flat cakes (muttal) about the size of small pancakes but thicker. They are dried by propping them one against the other in pairs on the ground in the sun or by placing them along the ledge afforded by the ahtär, the horizontal bundles of reeds on the houses. When dried, these dung cakes are stacked together and the top of the heap protected from rain by a clay cap (gubba māl muttal). Dung for fuel is also formed into balls (jella), but these are little used in the marshes. The common Baghdādī word for the flat dung cakes is bartōkh. Another form of fuel for domestic purposes is made by the Subba, who have a process of wetting reeds with water and baking them in a kiln into a hard cake $(r u b b \bar{a} k h)$ that burns without smoke.

The diet of the Marsh Arab is simple. The staple foods are rice and bread made of rice or wheaten flour. Sour butter, curds, and a rough cheese also form part of the daily food.

Chicken or any other kind of meat may be cooked with boiled rice and mutton fat or melted butter. Mutton, kid, or beef is, however, a luxury rather than a necessity. Chickens can be procured for the equivalent of ten cents. Fish, fresh or dried, and eggs are used as substitutes by the poorer people. For festal occasions a lamb or sheep is killed, and a guest is offered many delicacies, such as hamud-helu, a stew in which raisins and dried apricots have been cooked with the meat; pilau, rice, cooked in butter or mutton

${ }^{1}$ Rice bread, however, is often made indoors (see p. 388). 
fat, with meat or chicken, raisins, almonds, and fried onions; and muhallabi , a dish of rice flour boiled slowly in sweetened milk, flavored with rose water and served cold.

Fresh fish are cooked in fat with onions and herbs, or are split open, propped up by reeds near a hot fire of reeds to grill in their own fat, and finally laid in the hot ashes for a final browning. Fish thus prepared are said to be mashgüf. Dried fish generally taste somewhat tainted, since the curing is crudely done. The process consists of splitting open the fish immediately after they are caught, sprinkling them with salt, and finally tieing them to a rope to dry in the sun and wind.

Wild herbs are utilized, both raw and cooked. The white heart of a thick rush ('agèl) is eaten raw and considered a delicacy. A plant called halba is used as a vegetable. A pink flowering marsh plant $(g a t \bar{a})$ is put into a pan with a little salt and water and eaten as a relish with bread. The yellow fluff from the flower of the bulrush (bardī) is made into a sweetmeat (khurrẹt) in the following manner. Water is boiled in a pot, anc a cloth, upon which the yellow fluff and sugar are placed, is laid above the boiling water. The cover of the pot is then clayed in so as to prevent steam from escaping. When the khurrêt and sugar, or date syrup (dibis), have been steamed for an hour or two, they harden into a solid, brittle cake about the consistency of sulphur and not unlike it in appearance. This is eaten as bread and is made only in the marshes, though it is sent to the markets of all big 'Irāqi towns, where it is greatly appreciated.

"Thorn-grapes" ("inab $m \bar{a} l$ shōk) are eaten and the leaves of the arjējil, like many other plants, such as cress (rishäd), serve as salad. The women never have far to go in search of some edible herb, plant, or root wherewith to flavor their dish or add to their menu.

Rice flour is milled by the women. The rice is husked and then pounded in a tall, wooden receptacle (jāwan) hollowed out for only half its length, the solid part acting as base. While it is pounded, one woman, or more often two, perform the task to a rhythmic cry of "Hai hèya! Hèya Hūu!" (Pl. 66). The instrument (mijenna) that is used is not unlike a croquet mallet but longer, the hammer end being uppermost. When the rice has been winnowed by tossing it in a shallow basket, the wind carrying off the light husks, it is ground in a hand mill (mijrisha) made by the women. The round grinder ( $\mathrm{tag})$ is formed of clay on a wooden core (Pl. 65, Fig. 1). First sun-dried, it is subsequently baked to the requisite hardness by being covered with a heap of red-hot buffalo-dung cakes. Both 
upper and lower țāg are corrugated, the instrument used for making the corrugations being often the household mess, a flat copper spoon with seven holes. The upper $t \bar{a} g$ is faced with roughened pitch. Each $t \bar{a} g$ has a round hole in the center fitted with an iron socket, called the eye ('ain), through which passes the connecting axle $($ gatab). The handle is simply a short piece of wood stuck into the upper țāg.

Rice bread is often baked in the house over a round, earthen fire pan (mangala) or over a fire hearth in pancake-like loaves. It is of two kinds: the sịna (literally, "bread of pilgrimage") and the rīṣa", the former being somewhat thicker than the latter. When a woman makes $r \bar{i} s \bar{a}$ ' she takes a copper, tin-plated basin (țāsa), and makes a paste of rice flour, salt, and water, just thin enough to pour. Upon the hot surface of an iron pan (tâwa) inverted over the fire embers, she pours the dough, flattening the loaf with her hand until it is round and of equal thickness. Then she covers it with a copper tray, also tinned. In a moment or two the bread is ready. Sìha, which is prepared in the same fashion, is crisper.

Wheaten bread is prepared in a different manner (Pl. 67). Flour, salt, and water are worked into a dough, which is tossed from palm to palm until it is flat and round. The thin flap of bread is then wet with a little water and slapped with a dexterous movement against the smooth interior of the tannūr, a large earthenware oven shaped like an Iranian water cooler $(h u b b)$, its base sunk into the ground and set in rough mud mixed with straw. The round, flat loaves adhere to the sides of the oven, which is heated by a fire of reeds. Bread is not called khubz as elsewhere in 'Irāq, but 'aish (=Life) as in Egypt.

Although coffee is the favorite beverage of the Marsh Arab, tea is often served in small, waisted glasses (istikān) half filled with sugar. Loaf sugar made from sugar cane is preferred. Coffee, on the other hand, is bitter and black, and aromatic with cardamom. Milk is never added to either tea or coffee; according to the Arabs this is a barbarism practiced only by Europeans.

One of the principal features of the interior of the hut is the coffee hearth, given the Turkish appellation, $\bar{o} j \overline{a g h}$; in a private hut it is called a moggif. It is a square on the ground of the hut, enclosed by a low, raised, rounded, mud ledge, not entirely surrounding the square but leaving an aperture of about six inches (Fig. 14 and Pl. 63, Fig. 2). On this hearth, fire is kindled, usually of dung cakes, started by burning reeds or thorn. Firetongs (mingäsh) are used to arrange 
the fuel. By this hearth sits the coffee-maker, for no amateur hand is allowed to meddle with the solemn business of coffee-brewing. The beans, which should be of a jade color, are first roasted on the mughlä, a flat pan with a long handle often decorated with brass knobs. When the beans are roasted brown, not black, they are placed in a brass mortar (häwan). The chiming of the pestle is a signal for passers-by to stroll in and squat against the reed ribs of the hut. The coffee beans must be pounded coarse.

Ready on the hearth is the big, long-beaked pot ${ }^{1}$ (gumgum) containing hot water. The coffee-maker does not use fresh hot water for his brew, but shurba, that is to say, colored coffee water from

FIREPLACE

PLATFORM

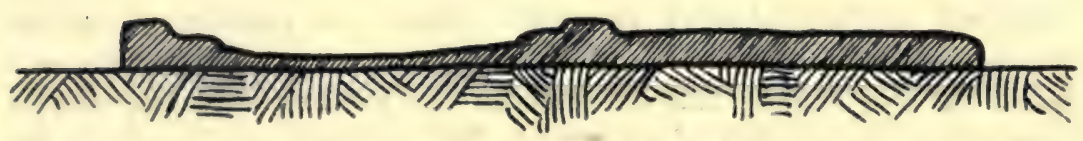

FIG. 14. Cross section of fireplace in Al bu Muhammad council house.

previous brewings contained in a smaller pot of the same shape, the telgâma. This is poured on the coffee from a still smaller pot, the della. There are generally more than one of these smaller pots in the hot ashes, but only one gumgum and only one telgāma. While it is boiling the coffee should foam up three times, and three times be set aside to simmer. A little cooler water is sometimes added to settle the grounds, and a little cardamom seed to give the coffee an aromatic flavor. Palm fiber stuffed into the spout of the della filters the liquid as it comes out. A cloth (beez) is used to hold the hot metal. The coffee-maker rises to go the round of the hut, beginning with the sheikh, holding the handleless cups, three and four at a time, in one hand and the della in the other. He pours a spoonful of coffee into the topmost cup and offers it to the sheikh, who swirls the coffee slowly round the cup several times before drinking. When he has swallowed the first minute draught, he receives a second quantity with the same procedure, and sometimes a third. To indicate that he needs no more, the sheikh shakes the cup slightly before handing it back. The principal guest is then offered the same cup, and the coffee-maker goes the round of the company collecting cups as they are empty and refilling but not washing them.

${ }^{1}$ For drawings of coffee-making utensils, see Field, 1935, Text-Fig. 36. 
Every sheikh of standing has his own coffee-maker, who accompanies him if he goes away for any length of time. Coffee is the symbol of hospitality and to omit a man when coffee is being served is an insult that is only to be wiped out by blood. It is a common way of indicating to a man that his sister or near female relative is unchaste, and it is expected that the man to whom this silent hint is given will immediately go and cut the throat of the woman who has sullied his family honor.

\section{ARTS AND HANDICRAFTS}

Weaving of both cloth and reeds is one of the chief occupations in the marshes. Reed mats (bawāri ) made in the marsh district are used extensively throughout 'Irāq and are even exported to Iran. They are simply made, with a technique that apparently has remained unchanged since very early times. A number of strong, pliable reeds (bardī) (see Pl. 69, Fig. 1), softened by immersion and split, are laid closely side by side on the ground, and the weaver interlaces a second set of split reeds laid at right angles across the first, starting in the middle and working first up and then down. The ends of the second set are then plaited into a third set, the weaver sitting on the part of the mat already completed. While he is working he keeps his hands and the reeds wet by means of water kept beside him in a bowl. When the mat has reached the size required he cuts off the ends, folds over the edges, rolls up the mat, and ties it with a rope (banda). The rough edges can be sewn with string or reeds by the women when the mat is purchased or used.

Cloth weaving, called häyicha, is performed by men as well as women, the former being accounted the more skillful. The loom, which is primitive in type, may be erected either in the house or outside. The weaver stands before it in a hole in the ground, known as the juma. The main framework of the loom, often of wood, in one case was of reed bundles $(s h e b \bar{a} b)$ stuck into the ground and bound together in the customary way with reeds (Pl. 60 and Pl. 61, Fig. 1). Four horizontal bundles of reeds, thinner than the shebāb, were called mushharat. Extending for some yards, the warp threads were fastened to a thick wooden peg (bakra). The names of the various parts of the loom were: the shuttle (minhüch); the batten ( $g a f l$ ); the comb (misht), the teeth of which are set between two reeds called the fechch; the wired frame $\left(\operatorname{def}^{\prime} a\right)$, which pressed the threads into the material; and the cloth beam (noil). A reed wheel for winding thread was called the $d \bar{u} \bar{a} b$, and a reed bobbin, a nāzüga. 
A simple device for skeining wool consisted of a stick bent until its ends overlapped, secured by thread so as to form a loop (Pl. 62, Fig. 2). This was called a mațwā.

For their own use, the marsh tribes weave rugs of poor quality, saddle bags, and tenting from goats' or sheep's wool. While I did not see any woollen ' $a b \bar{a}$ cloth woven in the marshes, in al-'Amāra and Qal'at Sālih the tribesmen place stakes in the ground at intervals for the required length of cloth and the man walks from end to end unwinding the wool from his tray of bobbins.

All silk comes from the markets of the big towns, and foreign artificial silks are rapidly supplanting the hand-woven silks that were formerly used for the ' $a b \vec{a}$ 's of the wealthier women or for the bride's zibun. Artificial silk has become the principal stock of the silk merchants in the towns, for it is cheap, shiny, and brightly colored, all popular qualities.

The embroidery adorning the ' $a b \bar{a}$ 's, which are loose-sleeved coats worn by men and women alike, is done by the men and is called kalabdūn. The thick wooller winter ' $a b \bar{a}$ ' is called khäkhiyya because of its brown earthy color (cf. Hind. khāk $\bar{\imath}=$ dusty; dustcolored from Pers. $k h \bar{a} k=$ dust); the middleweight ' $a b \bar{a}$ ' is a jisriyya; the transparent woven summer ' $a b \bar{a}$ ' is a bisht. The metal thread tie-ups ornamented with "bobbles" of gold or silver thread are gettãn, the metal thread edging is chasbi, and the metal oversewing of the seams is maksur. Women have metal embroidery on the sleeve of the ' $a b \bar{a}$ ' called bakhkhiyyah. The ' $a b \bar{a}$ 's are tailored by men, and they usually make the zibūn, a gown worn, in the case of men, over the ankle-long shirt (dishdäsha).

The use of cheap aniline dyes has now largely replaced vegetable, mineral, and animal dyes. Nevertheless some natural dyes are still used. Since these tribesmen are often color-blind, for red they use zarga $\bar{a}$, which is obtained from copper sulphate. Curiously enough, for blue in varying shades they employ indigo, blue tattooing powder and tamarind (tamr hindī). For green, an infusion of willow leaves (gharb) is made. For orange and red, pomegranate juice (dbāgh māl rummān) mixed with powder of vitriol $(z \bar{a} g h)$ and indigo (chuwìt) is used. For yellow and brown, particularly for dyeing the light summer ' $a b \bar{a}$ ', they employ an infusion of kubbān, a curious waterweed with flesh-colored, transparent tubers that grow like fingers, five in a group. This weed has a bright yellow blossom and flowers freely in the months of April and May. For purple, tahama leaves are boiled down. 


\section{Clothing and ORNamentation}

No women are veiled, not even those in the sheikh's household, unless they happen to go to a town, where they comply with town usages. When local townsmen or foreigners are present, women of the sheikh's family withdraw into some seclusion, but tribesmen, if they are of lower degree, can converse with them.

The usual form of hairdressing is a straight fringe over the forehead (jidhdha), with the rest of the hair plaited. Sometimes the plaits are looped up and fastened on the head; sometimes they hang down, their length increased by black threads plaited with the hair.

I had the privilege of helping with the morning toilet of a sheikh's wife who, although she had seven children, was still in her twenties and had a skin of which any European woman might be proud. Her complexion was fair and she scorned the use of powder or cosmetics. A black-skinned slave girl brought a long-spouted ewer $(i b r i \bar{q})$ and a basin with a perforated cover (lagan) upon which the soap was placed and set them before her mistress, who sat on the floor of the reed hut. The lady, having removed her headdresses and upper garment so that neck and arms were bare, washed herself with the water that the slave girl poured over her hands and dried herself with a towel brought by another Negro handmaiden. All the while a mirror was propped against a wooden box so that the lady might see herself. This wooden box was highly important, for it contained her wardrobe. Another box of the same kind, with a large lock, held her jewels and talismans. A fine comb of sandalwood was brought and she unplaited her black hair, which she wore parted, without the usual fringe. It was slightly reddened with hinnā. ${ }^{1}$

Her hair rebraided, with two side locks combed forward so that they would appear beneath her headdress, the sheikh's wife took her black wimple (füta), usually called shèla in the marshes, and, putting it well to the back of her head so that the top remained uncovered, she held it together with her teeth while covering her

1 The green leaf (Lawsonia sp.) is dried, powdered, mixed with water, and applied to the hair as a paste. Hinnā, or henna, is usually mixed with țin khäwa, a saponaceous earth called gil by the Iranis. This earth, if placed with the pink petals of the jūri rose (a rose used for making rose water) takes the perfume of the rose. The tinn khäwa imparts a gloss to the hair and lessens the dyeing quality of the henna, which is astringent and often stops the falling of hair. This refers to the real henna, not the so-called "Persian henna," which, mixed with a compound of indigo or some other dye, darkens the hair. See Hooper and Field, pp. 134-135, 192-193. 
forehead with a black headband ('așāba). A long black turban (kësh), which had previously been extended and smoothed out by her maids, was then folded round her head in a boat-shape. This done, she brought the ends of her shèla, wimple-wise, under her chin.

The lady's dress, which she had put on before completing her hairdressing, consisted of a slightly waisted zibūn and above that a transparent, wide-sleeved, black garment called a häshimi. This had no fastening and could be slipped over the head. Above that again was the ' $a b \bar{a}$.

When the headdress was arranged to her liking, ornaments (Pl. 73) were produced from the unlocked treasure box. Around her turban the lady draped a long, narrow, triangular slip of black silk about a meter in length, to each end of which were hooked two bands of jewelry called agäl. This slip is called the habar. The two bands of jewelry can be unhooked, fastened together, and used as a stiff collar $(t \bar{o} q)$ or used separately and worn on the wrists as bracelets (manâtish, named from the pins that fasten the bracelets together). Next, she looped upon her turban a gold gurdāla, a twostrand and four-strand filigree chain with pendent "hands of "Abbās," and filigree stars or flowers with ruby centers. The gurdāla is a favorite ornament, varied and rich in design and is, like the rest of the jewelry, the work of Subba goldsmiths. The headdress was now further ornamented by two pieces of red silk braid (nejūm) about a yard in length, fastened so as to fall on either side of the face. To these were attached a little blue zuwijiyya to ward off the Evil Eye, three heavy, round, gold buttons $(g u b \bar{a} b)$, and twenty-seven gold $l u^{\prime} b a$, ornaments resembling Byzantine coins, but formed on a mold and pressed together in two halves. There was also cheff al batt, an ornament in the shape of a webbed foot, of gold, crystal, and rubies surmounted by a gold crescent. The final touch was another protective blue button (khdrāma) and a silken tassel of red and green.

About her neck the lady clasped several necklaces, including a wide collar of large turquoises. In addition to these she wore a long gold chain to which rows of gold coins were attached, called the maksara.

Marsh beauties do not wear the pearl and turquoise nose-stud (warda) so popular in the rest of 'Irāq, but they have the swinging nose ring (khazzäma) worn through one nostril by tribal and poorer women throughout the country. When rings are worn through each nostril, the left ring is called the $s h a^{\prime} a$ and the right one the 
zummām. My friend did not wear any of these, but she wore enormous earrings (tarāchi ) of gold filigree set with pearls and rubies, and another pendent gold hook (matreg) in the helix. Around her ankles she fastened heavy gold anklets (hijil). Poorer women wear silver anklets.

At the end of her toilet the lady took up her small collyrium flask, into the top of which is screwed a pointed rod used to apply the black pigment to the eyelids. The proper way to apply kohl $(k u h l)$ is to roll the eyelid and apply the pigment with the point of the rod to the inner side of the lid. This should be done at night, and the eyes washed in the morning. Enough of the pigment remains to give the desired effect; an extra touch is sometimes added. Kuhl is supposed to benefit the sight, but, as the phial is freely handed about from woman to woman, trachoma may often be transmitted by this means.

Kuhl is bought in lumps. Soaked in water for three months, it is then ground very fine and mixed with "clean" butter. A small brass mortar with a brass pestle (sadd) is used, one such being kept in the hut for pounding herbs, medicines, and henna. The best $k u h l$, called ithmid, comes from Mecca.

The young woman, like many others, had covered her two upper, second incisor teeth with a gold casing, a practice that usually results in the decay of the teeth.

Rings are worn on the fingers and sometimes on the toes. Fetkha is the word used for a toe ring, but it is also applied to a ring worn on the forefinger. A woman of standing has her own name or that of her husband engraved on a gold or silver ring (muhr=seal). A flat broad bracelet $(k h \bar{s} s a)$, usually set with imitation or real turquoises and rubies, is worn on each wrist by most women.

Other types of jewelry worn by the women consist of glass bangles, called by one woman ma'a dad and by two others, majadiyya; earrings of the type called shadr, with a complicated pattern of gold beads set on a solid gold background; a silver ring with inset turquoise, connected by a silver chain inset with turquoise to a bead bangle (itmãm); a long pendant at the side of the head made of large amber and gold beads, a flat gold bead set with a turquoise (khadrāma), a large red bead (zuwijiyya), and a gold coin $(g h \bar{a} z \bar{\imath})$; a finger ring usually called mahbes, worn by all except the poor women, who substitute silver, copper, and glass for the gold and precious stones. A brightly colored fringed kerchief (cherghad) is occasionally wound above the black headband covering the forehead. 
Except for an occasional ring, signet, or watch chain, men wear no jewelry. Boys, however, often have a thick silver ring (tōq) about their necks, decorated by a turquoise set into the clasp or into the center.

\section{Social ORganization}

The marsh tribes, like the other tribes of 'Irāq, acknowledge the leadership of a sheikh, whose authority is subdivided among lesser sheikhs. These are, in fact, feudal communities. The tribesmen work for their sheikh and are paid in kind and not in money; they are also entitled to the protection, advice, and hospitality of the sheikh, who is their "father." Upon the arrival of a sheikh in a village, the inhabitants immediately come forward to kiss his hand and place it against their foreheads in token of respect and fealty. They must fight for him to death if there is need and take up his quarrels as he must take up their quarrels, if they have suffered serious wrong at the hands of a man of another tribe.

Intertribal disputes may lead to exceedingly vindictive and cruel treatment of one tribe by another. I was told that one hostile marsh tribe captured a boy, buried him up to his neck, put his eyes out and left him to die. He was rescued by a British political officer, but died soon after.

If murder has been committed, a tribe raided, a blood feud or a desperate quarrel begun, during which injury has been done by one tribe to another, the matter may be settled by handing over money, cattle, women, or a combination of all three. Compensation is agreed upon in conclave, usually through the offices of a mediating tribe.

The custom ( $\left.f a s l_{l}\right)$ of handing over women to settle intertribal disputes is more common with the marsh tribes than elsewhere in 'Irāq. The fașl-woman, often a child who has just reached puberty, is sent among the enemies of her tribe to bear children to a stranger and swallow the taunts of those who still cherish bitterness against her people. If she bears no child she may be sent back to her tribe to be exchanged for another girl. It is said that sometimes a faslwoman is returned to her people even after she has given birth to a son. In practice, however, the fasl-woman is often the means of effecting a genuine reconciliation between two hostile tribes or sub-tribes. If the father of her children becomes fond of her, she may be allowed to see her people or they may be allowed to visit her. Thus, by degrees, relations of a friendly character become established between erstwhile enemies. The marsh tribesmen, 
once honor (sharaf) has been satisfied, are able to forget a bitter quarrel and to attribute its cause to destiny (nașīb).

In times of peace the tribesman often goes unarmed but for his chumāgh, a stick with a knotted or crooked end, useful for driving cattle or, if need be, for self-defense. He may sometimes carry a short mace with a round bitumen head called a magwār or, more rarely, a mace with a stone head, called a șakhriyya. More effective is the curved dagger (khanjar), sometimes kept in a decorated sheath which is stuck into the belt (see Field, 1935a, Fig. 37).

The sheikhs themselves are changing, inevitably, under conditions that bring them into constant relationship with towns, government officials, motion pictures, and modern inventions. Government schools flourish at al-Amāra, Qal'at Sālih, Garmat 'Alī, and many other towns of the district. Until recently it was thought unmanly for a sheikh to be able to read or write; such unwarlike accomplishments were left to the mullā. Each sheikh had his mullā, who combined a number of offices in one person. He kept the sheikh's accounts, read and answered his letters, acted as his agent, dealt with visitors and politics, and enjoyed a good deal of power. The sheikh today, however, realizes that it is wise to send his sons to school, even if they leave him and go to Baghdād and run the risk of being converted into effendiyya, the generic term for all soft, clerkly, office-hunting townsmen.

The social life of the men centers around the guest hut (madiff). This hut seems to fulfill all the functions of a club, a coffeehouse, and a chapel. Within it, men assemble for coffee and conversation, for council, for mourning, and for prayer. The sheikh, or chief man of the village, sits in the place of honor. If a guest is present, he may sit at the sheikh's right hand or he may be given the place of importance. For such a person of substance or honor, mattresses or carpets and bolsters supplement reed mats placed along the sides of the interior. The common folk sit on the matting. The madif is generally spoken of as "the sheikh's guest house."

The tribesmen consider themselves responsible for the welfare of a guest and his belongings. They become, however, expert thieves if a person unprotected by their laws of hospitality comes within their midst.

Since conversation is one of the main forms of mental recreation, scandal, often groundless, spreads rapidly in the villages. This may be the basis for the reputed low standard of sexual morality among the Marsh Arabs. Homosexuality apparently occurs to a certain 
extent, but stringent tribal laws discourage such vice. Most of the scandal is directed against the women.

The natural avenger of family honor is the brother. If he overhears a slighting remark about his sister or a taunt in the madiff about her light behavior, or if the coffee-maker pointedly omits to hand him a cup when the coffee goes the rounds of the gossips in the guest hut, it is his duty to rise without a word, take his knife, go home, and cut his sister's throat, without inquiring as to the truth of the accusation. If the brother does not murder the girl, her father or some other male relative must do so. In a few cases, the husband of a slandered woman has applied to the local authorities to protect a wife in whose innocence he believes; but the protection is seldom of avail and the knife sooner or later finds its mark. Often the girl so brutally murdered is a mere child, and such a barbarous privilegefor the "Irāqi courts pass nominal sentences in the case of tribal crimes of this type-becomes notoriously abused when property is involved. Moreover, as it is difficult to draw an exact line between townsmen and tribesmen, tribal law has invaded the towns as regards this form of crime. Owing to tribal analogies brutal murderers often escape with nominal sentences if they can but manufacture a plea, true or false, that morality was the cause of their deed.

The marriage customs are similar to those of other parts of 'Irāq. It is taken for granted that a girl shall be regarded as the betrothed of her paternal uncle's son. If her cousin already has his complement of wives or does not want her, she must still have his permission before marrying any other man. The penalty imposed by tribal custom for defiance of this rule, or for unchastity, is death. A man may keep a girl cousin waiting for years, neither marrying her himself nor suffering another suitor to take her, and a girl may remain single all her life because of the caprice of her cousin. Many are the tales of lovers who have braved this rule and met death in consequence. Where there is no paternal cousin, a girl may be given to her maternal cousin, to some more distant male relative, or even to a man of another family or tribe. Those of sheikh's blood take their chief wife from within their group, and race is esteemed more highly than wealth. Owing to these rules, one finds the families of the sheikhs inbred; yet on the whole they seem to possess health and good physique.

A dowry is paid by the bridegroom to a girl's father, who expends most of it on her clothing and jewelry. The townsman pays a certain sum down and promises a further sum should he divorce 
his wife; but in the marshes the second sum is rarely stipulated. The jewelry is looked upon as insurance against divorce, and a divorced wife takes her jewelry with her. Hence the extreme richness and variety of the ornament which these marsh women wear; it is their protection against a dark future which may see them deserted, old, or supplanted by a rival.

When a woman is to be married she places upon herself as much of her jewelry as she can wear. First she is bathed and perfumed. A mixture of seeds, sandalwood, orris root, and tīn khāwa made into a scented paste (mahlab or halabi) is applied to her hair. Her body must then be depilated by a woman called a nattäfa, who sets to work to jerk out hairs one by one by means of a loop of thread and her teeth. Eyebrows are becomingly shaped by the same means. A powder (zurēgh) and pumice stone (șakhara majliyya) are also used, for no hair must remain on her body. The feet and hands are stained with henna. The bride, who is thought to be peculiarly susceptible to the Evil Eye and the Breath, is protected by a number of amulets, and great care is taken that the friend who adorns her shall be a fortunate person, a happy mother of children being preferred.

Rituals in connection with births were depicted for me by a young mother, who showed me how, in her pangs, she crouched and grasped the great reed rib of the hut, and pressed her forehead against the cool reeds, presenting her buttocks to the midwife (jidda), the reed hut crowded meanwhile by the women who had come to support her during the ordeal. With the mother in this crouching position the child is born, being taken by the midwife from behind. At the moment of severance the baby's navel is bound with a little sheep's wool. After the birth the mother's waist is bound tightly by the midwife and she is washed well with hot water. She is bathed again on the third, seventh, and tenth days. She is never left alone during or immediately after childbirth lest evil spirits harm her or the child. For a period of forty days the mother carries a knife about with her to ward off these mischievous beings, who fear any sharp or pointed instrument of steel or iron.

An infant is suckled without adherence to any time of feeding, and the child continues to suck long after it can walk. I have seen a marsh woman take the nipple from the mouth of a young baby to offer it to a child of four years, who beat her imperiously with his fist that he might have her breast. No sheikh's wife, however, suckles her child. She gives it as soon as it is born to a wet nurse (dāya), usually one of her own slaves or dependents. The foster 
mother, with the suckling in her charge, remains constantly at her mistress's side, and the nurse's nipple is rarely out of the baby's mouth except when the child is asleep. The children of such a foster mother have a special relationship to the children of the real mother and are not allowed to intermarry with them. To get rid of her milk a woman bathes her breasts constantly with cold water and binds them tightly.

Divorces are lightly made. A man has but to say to his wife, three times before witnesses, "I divorce thee!" and she is no longer his wife. The sheikhs and wealthier men are prodigal in their matrimonial alliances. One sheikh boasted that he had married thirty-three women and said that his brother had married a hundred. However, modern times and restricted incomes are reducing the number of marriages. Moslem law permits a man only four wives at a time, but the system of divorce allows a man to marry for a short period and then send the girl back to her people. If she has borne him a child, she must leave it with him, for a child is paternal property.

There is, however, one permanent wife. She is generally a cousin who, kept on for reasons of property, family feeling, and possibly genuine affection, has weathered the storms and remained lady paramount. One such proud and elderly dame, of good birth and with the remains of considerable beauty, laughed without a trace of bitterness as she recounted her tactics with rivals. She was always polite to new arrivals, although they did not last long. To get rid of them she employed witcheraft (sihr) and spells, which, sooner or later, were effective.

\section{RELIGION}

The emotional extremes of the $S h \bar{i}^{i} a$ doctrines are far more congenial to the Marsh Arab than the severer rationalism of the Sunni faith. Religion sits lightly upon him, and his spiritual needs are satisfied as a rule by the visit of a divine $(\mathrm{mu}$ ' $\mathrm{min}$ ) for the two sacred months of Muharram and Ramadän. For this he is willing to pay, and if he has made a pilgrimage (ziyãra) to the holy cities of al-Najaf, Karbalā, al-Kādhimain, and Sāmarrā once during his lifetime he has a fair claim to being accounted a religious man.

It is not often that a marshman goes on pilgrimage to Mecca and becomes a hajji. The ziyâra costs less and is a shorter journey than the hajj and the Shi ${ }^{*} a$ Imäms lie nearer to the heart.

The burial customs and mourning rites are complex. In various parts of the marshes a long tumulus rises above the reeds of cultivated 
areas. This is a reed vault (biniyya) covered with mud, which forms a temporary tomb. All who can pay the fees of transport and reburial, except very young children, are interred in such tombs for about a year and then, when a caravan of bodies happens to be setting out for al-Najaf, they are uncovered and carried to the holy city to be buried as close to the shrine as means allow. The higher the fee, the greater the proximity to the tomb of 'Ali. Rich men are transported to al-Najaf without this temporary burial (amāna), which is only a matter of expediency.

The belief is that only those worthy of interment in so holy a place are permitted by the Imām to reach their graves. Hence stories arise that on the way to al-Najaf a corpse has been known to change into a pig or a dog and run off into the desert. These legends are extremely useful to the corpse-caravan leaders who, if they find their convoy of corpses inconveniently large, dispose of them on the way, explaining shortages, if they are discovered, in the traditional manner.

The dead are washed with an infusion of the leaves of Christ'sthorn (Zizyphus spina-christi Willd.), called in the marshes sidr and in the rest of 'Irāq nabqa or nabaq. The body is then sprinkled with camphor $(k \bar{a} f \bar{u} r)$, wrapped in white muslin, and encased with reeds. Before the corpse is interred it must be placed on the ground three times, and it must be buried, if possible, before the sun sets. The instant that breath has left the body, the women begin to wail, beat their breasts, throw dust on their heads, and tear their garments so wildly that often their breasts are exposed. The men carry the body to the grave, the bearers often changing, as they go along, with fresh volunteers, for it is considered a pious and meritorious act to assist the dead man to his resting place.

Organized lamentation and breast-beating take place on the third and seventh days after death, but they are limited to women. The men gather together in the village guest hut or in another large hut, listen to the reading of a portion of holy writ by a mu'min, and say some Fätihas, but they sit in a quiet and orderly fashion. On the other hand, the female relatives, friends, and neighbors of the deceased person gather in and around the hut of the bereaved family, sitting closely together, sobbing and wailing in concert. At intervals, led by a professional mourner ('addāda), who excites them to hysterical grief by repeating praises of the deceased and poignant reflections upon the bereaved state of the mourners, they rise to their feet and jerk their bodies in a kind of dance, flinging 
their unbound and unplaited locks from side to side with the movement of their heads (Pl. 76, Fig. 2). The more passionate mourners tear open their clothing and display their bodies, and all beat their breasts in unison to the 'addāda's chant, punctuating the latter with the regular thud of their palms on their persons, their cries of woe, and the stamp of their feet. The kind of lamenting employed, ejaculatory verse, is simple:

\section{Here is thy fishing spear idle! \\ Thy clothes lie piled together! \\ Thy children are fatherless!}

Very often the community, village, or sheikh may have a local poet. The poets are highly respected and their compositions are usually sung. Ordinarily, they are expert impromptu versifiers. In Baghdād, however, I noticed that two female professional mourners, who functioned alternately, used verses scribbled in a notebook as their inspiration.

The death of the sons of 'Alī, Hasan and Husain, is recognized annually by organized mourning ceremonies. This is fixed for the 'Ashūrā, or first ten days of Muha ram. It happened that in 1934 these ten days fell during our visit to the marshes. We had, therefore, been implored by the Mutasarrif of al-'Amāra to use the utmost caution, for, during these ten days, religious fervor, mounting day by day like a fever, reaches its climax on the tenth day of the month, when all is mourning and displays of grief, such as processions, breast beating, and flagellations; these and the pageantry of passion plays move the entire $S h \bar{\imath}^{6} \alpha$ population of 'Irāq to a frenzy of sorrow and religious fervor.

When we arrived at az-Zubair, black flags flew from the majority of the madīfs and şarā'if. Sounds of prayer and chanting, or loud sobbing as the days wore on, issued from riverside huts. Eventually it became impossible to ignore what was occupying the minds of our friendly hosts, and the marsh people would not shut us out from their griefs any more than they would have excluded us from their joys. Passing by Sheikh Khazal's madīf while the mu'min was leading the devotions, I was invited inside, although men and women ordinarily pray and weep separately. If women wish to listen to the quir $\bar{a}^{\prime} a$, as the reading and devotions are called, they crouch outsidé.

The next day I was invited to visit the large council chamber. The hour of prayer was at hand. Casting a questioning glance upon me the tribesmen asked me if I would like to "see how we weep for Hușain." This ceremony is conducted by the mu'min, who also 
goes to neighboring villages. He called for the pulpit (minbar). An inverted wooden mortar (häwan) was brought in and a cushion placed upon it. On this the divine seated himself, while his congregation, all men, sat on the ground against the sides of the reed hut and about the coffee hearth, where the coffee-maker had suspended his operations. The men loosened their black and white head-kerchiefs (cheffiyya), and brought the cloth crosswise over their mouths, concealing the lower portions of their faces. The ends of the cloth were thrown over their heads.

The mu'min began to recite in a chanting voice and whenever the name of the prophet or of "Ali occurred the men joined in with a muttered, "Pray for him!" or "Pray for Allāh and for Muhammad and for "Ali," or a similar pious ejaculation. Soon the divine was reading from the Hadith the tragic story of the battle of Karbalā. The chant was mostly on three notes, and in the more poignant passages he rose to the highest note. All present, their veiled heads bent low and their hands shading their eyes, lifted up their voices and wept aloud, "eh-ha, eh-ha, eh-ha!" while the women, clustered outside the door, joined in the sobbing.

Then the divine assumed his natural voice and began his simple sermon, the narrative of a thief who, caught in the act, had his right hand cut off and was then brought before the mild "Ali, sonin-law of the Prophet. "What!" said 'Alī, "you are a Muslim and the son of a Muslim?" The thief admitted it. "How can a man be a believer and yet a thief?" The story ended with the repentance of the thief and the cure of his mutilated arm by 'Ali. Sentence by sentence as he proceeded, the mu'min interrupted himself to translate the literary Arabic into the colloquial Arabic of the marshes and to add his own moralizing comments. He ended his picture of 'Alī's clemency by chanting one of those mourning Muharram poems so dear to the $S h \bar{\imath}^{\prime}$ as, his left hand placed at his left cheek. The men within and the women without wept copiously, and the mu'min's own voice became choked with emotion. Then, in a quieter monotone, he recited the F'ätiha, the first short chapter of the Qur'ān, all the men joining in, hands placed palms upward, and the proceedings were at an end.

The same evening there was another service, which resembled that of the morning except that the company was bigger. The divine was eloquent as he read the story of the martyrdom of Husain and his women and children, debarred from water to allay their thirst, transfixed by arrows, and cut off ruthlessly one by one. 
Weeping is infectious, and our own eyes filled. This, the next day, inspired the mu'min, as we sat in an airy kishik by the river, to tell me a story. He said he was always ready to talk about matters of the faith. "Once upon a time, a man who was not a $S h \bar{\imath}^{\circ} a$, a stranger like yourself, chanced one day to be passing by when they were making wailing for Husain. He came, he looked, he was moved, he shed a tear. When he died he went to Jehannam, for he had many faults, and there paid the penalty of his sins and uncleanness. But Allāh, seeing him, brought a basket of seed and, calling the prophet Mūsā [Moses], asked him, 'Seed for seed, what is this worth?' Mūsā could not answer the question; so He called another prophet and another, but none could answer Him. Then he asked Husain, who replied: 'The man's sins were as countless as these seeds, but he wept one tear, and for that tear his sins shall be forgiven him.' Then the man was removed from hell and taken straightway into Paradise."

The mu'mins, who perform temporary duty during this period of mourning, receive a fee for their ministrations.

On the eve of the tenth day, Dr. Smeaton and I accompanied a sheikh's wife in a mashhüf to a Sayyid's house. He and his wife were townsfolk from Karbalā. She, feeling herself an exile in the reed country, had made a garden, with an arbor of vines. In this arbor carpets and cushions were spread and tea was served in small glasses as well as a brew from the leaves of the lemon tree (see Tolkowsky, 1938). The moon was rising, and presently we heard girls' voices by the river, and their laughter.

"They have come!" said our hostess and, going into a little courtyard formed by a fence of reeds, we met a company of girls as they streamed in, irresponsibly gay and not at all, it appeared to us, in Muharram mood, although they were preparing a "mourning" for us. The proper dress for the girls who took part, our hostess said, should have been a white skirt above a black undergarment, but these marsh maids, who were between the ages of ten and fourteen, wore colors for the most part, and here and there one saw the glint of the gold or silver of their ornaments in the moonlight, or marked the swing of a nose-ring or the flash of an anklet. They formed a circle, and broke into a chant, slapping their breasts, dancing on their bare feet, and throwing their heads from side to side. They did not weep; indeed the whole performance seemed like a bursting forth of youthful high spirits. I asked the meaning of the shrill chant to the rhythm of which their bodies swayed, arms swung, and feet moved. It was: 


\author{
Close round Husain \\ And turn back his steed. \\ $O$ that night had passed! \\ Weep noisily!
}

Presently they went out, to go laughing along the river bank and repeat their performance elsewhere.

The tenth morning no coffee was brewed, no bread baked. At dawn prayers and chanting, which had been continuing throughout the night, were still heard. It is considered pious to fast entirely but, as a concession, wheaten porridge (harisa) mixed with sheep's butter (dihn hurr) is cooked overnight so that the hearth stones may remain cold until noon of the tenth day. Into this cereal a little meat, usually mutton, is shredded and a flavoring of sugar and cinnamon (darsin $)$ is added. Harisa, like the hot cross bun of Christendom, has a semi-religious character and when, during Ramadān or times of pilgrimage, companies of pilgrims travel to the shrines of al-Najaf, Karbalā, al-Kādhimain, and Sāmarrā, they forswear all food but this.

We joined in the early devotions in the guest hut. The coffee hearth was cold, and a plate for offerings was put on the square ridge surrounding it. We duly cast in our contribution.

Later, we accompanied the sheikh a little farther upstream to see the "breast beating" there. As the tarräda was poled along, past hamlet after hamlet, we heard sounds of sobbing and wailing from the huts. We banked by a wide, grassy place, where the village madif was surrounded by a dense crowd. Here the sheikh landed, and the tribesmen immediately came to kiss his hand and raise it to their brows. A quirā'a was going on within the hut, but mattresses and cushions were spread for us in the shade of some willows, from where we could view the madif and the multitude about it. Behind the willows and the reed fence, women thronged, and their weeping and breast-thumping mingled with those of the crowd.

A rush of the crowd and the approach of large flags or banners swaying above it told us that a procession was on its way. The flags, torn and soiled, had evidently done duty many times, but they added to the color of the scene. One banner was white with a red border, a green crescent sewn to the center; another was red with a white border; another was all green. Above the heads of the crowd was the tâbūt, the bier, upon which lay the supposed dead body of Husain, covered by a magenta cloth. A wooden bench did 
duty as the bier. Before it walked a group of breast-beaters, naked to the waist, led by a rozakhun, as they term the man who starts the chants and incites the breast-beaters to vigor. When the procession was opposite us it halted; the leader turned to face the breastbeaters and began his chant, to which the men, in perfect time and rhythm, lifted their arms high and brought them down on their chests with great force, like human drums. Spectators thumped or patted their breasts as piety or decorum suggested. Then the procession passed on.

Behind the bier walked men in women's garments, impersonating the women of the martyrs. They addressed appeals, cries for mercy, and lamentations to the crowd. They wore black cloaks (' $a b \bar{a} ' s)$, but their outer robes (zibūns) were of brilliant artificial silks, orange, green, purple, magenta, and red. Two pairs of small boys, in turbans, buttoned jackets, and full trousers, each pair led by a man who had tied a white cloth representing a halter round their necks, addressed the crowd in shrill emotionless voices: " 'Atash! 'Atash!" (Thirst!) They were generously rouged with the red pigment that bazaar doctors smear on sore eyes.

Thirst, thirst!

O Husain, slave of God!

O Faţuma the Flower!

they cried from time to time.

The crowd, fresh from the reading, conjured up the scene of the martyred family, shut off from the river and dying of thirst, of the child pierced with an arrow, lying on his father's breast, and the bloody shroud that the martyrs donned before going into the unequal fight. All wept with loud sobs, tears flowing unrestrainedly.

We followed the procession and crowd to a grassy field. Here a large ring was formed so as to give the passion players a stage in the middle. The "corpse" on its bier was set down in the center of the circle and actors clustered about it, pressing their heads to the bier in grief. The flags were planted in the arena. The breastbeaters once more faced their leader and a mighty breast-beating took place in answer to his inciting chant. Sweat poured over their brown torsos and their breasts were reddened by the force of the heavy blows. One man was led away half fainting, and later I heard that another had "purified himself" (tatahhar) by succumbing to his injuries. It is considered highly meritorious if a man dies as a result of his austerities, and he is assured of reward in Paradise. Indeed, if a pious man dies during Muharram without neglecting 
his mourning, he passes straightway into Paradise without a preliminary expiation of his sins.

The "women" of the holy family, the two pairs of boys, and a man with a kettle of water, who gave the performers a drink from time to time, perhaps acting the part of the distributor of the last few drops of water, paraded around the arena, addressing the crowd as before, while the boys kept up their mechanical cries. Finally, the "women" went among the crowd of women who stood apart from the men, sobbing and wailing, and their advent, recitations, and appeals provoked a crescendo of lamentations. The face coverings worn by the "women" to conceal their manly beards were of diverse colors, and their brilliant dresses and gold-braided ' $a b \bar{a}$ 's trailed in the dusty turf. The procession re-formed and returned to the praying-place (mașallā), for the hut had lost for the time its hospitable character and had become a mosque.

At this point we accompanied the sheikh back to the tarräda and were poled upstream on the homeward way. At noon, fires were lighted, the coffee-maker resumed his post, the weeping stopped, and normal life was resumed. At sunset the young sheikh sat in the madīf relaxed and smiling, while his Negro slaves and some of the tribesmen facing him began to sing love songs of the most carefree and cheerful type, snapping their fingers (daqqa) and beating one heel on the ground as they squatted opposite him (Pl. 76, Fig. 1). To this primitive form of castanets and drum, their male voices sang many attractive songs. 


\section{APPENDIX: NOTES ON THE DATE PALM IN IRAQ}

BY

\section{H. W. Dowson ${ }^{1}$}

Description.-The date, or date palm, called Nakl in Iraq, is Phoenix dactylifera Linn. It is one of several somewhat similar species belonging to the genus Phoenix, which is characterized by the possession of a dense crown of generally hard and bristly, irregularly pinnate leaves, the lower pinnae usually reduced to spines, by small dioecious flowers in branched clusters, and by a terete one-seeded berry fruit with a hard and horny, oblong seed, terete and deeply grooved. The species dactylifera is distinguished from the other species of the genus by its usually large, edible fruit, erect, tall trunk of medium girth, robust and stout glaucous leaves with stiff pinnae in groups, a moderate number of spines, and dead leaf bases that are more vertical than horizontal. Of moderate hardiness, it flourishes in a hot, dry climate, with much water at its roots. It is not known wild (see Pls. 220-224).

Distribution.-The date palm grows south of a line joining Ana, Abu Kemal, Tikrit, Kirkuk, and Khanaqin. This corresponds roughly to $35^{\circ} \mathrm{N}$. Lat. Date palms thrive chiefly on the banks of the Tigris and Euphrates, their tributaries and effluents, and in the oases of Sitata, Ar Rahhaliya, Mandali, Badra, Jassan, and Az Zubair. Shatt al Arab, the river formed by the junction of the Tigris and Euphrates, is lined for the hundred miles of its length with date gardens, extending inland on either hand for an average distance of half a mile. Here, and near the junction of the three rivers, there are probably six million bearing palms. As many more probably surround most towns and villages in the remainder of the country.

Most gardens are privately owned, although some belong to the State and some are held by trustees of pious bequests.

Irrigation.-Date gardens are irrigated either by natural or artificial flow or by lift.

${ }^{1}$ Specialist on Phoenix dactylifera on the Kut-as-Sayyid Estate Limited, Basra, Iraq. These notes were sent from London on July 17, 1939. Since Mr, Dowson in 1939 published a provisional list of the varieties of dates of Iraq together with Arabic names, synonyms, and meanings, we have followed the simplified spellings. These notes were read by Dr. B. E. Dahlgren, Chief Curator Emeritus of Botany at Field Museum of Natural History. 
Natural flow may be either one-way from a river or a spring, or it may be tidal. In the Shatt al Arab district, the tides bank up the fresh river water twice daily and drive it into the multitude of tiny channels that form a network throughout the gardens. It is an exception when the water floods the surface of the land; generally, at high tide the channels are only partially filled. At low tide, the channels act as drains.

Artificial channels are led off from a river at a high level and then are brought to lower levels, from which the water is led out on to the surface of the land. The water may or may not be dammed below the mouth of the channel. This type of irrigation is found chiefly in the Baquba and Middle Euphrates districts.

Lift irrigation is of three kinds: man, beast, or machine. The simplest method is by bucket or kerosene tin. Bucket irrigation is used in Basra for newly planted shoots. The kerosene tin differs from the bucket only in its long broomstick-like handle, which eliminates stooping.

A balanced water-joist (dalw) is used to irrigate small date gardens. It consists of a scoop of leather or a beaten-out kerosene tin fastened to a vertical pole. This, in turn, is attached to one end of a swinging beam, which is weighted at the other end and tied, between the center and the weighted end, to a cross pole supported on two adobe or palm-log pillars.

Donkeys, horses, mules, cattle, or camels are used in two ways: in the karid (or tawi), which is a water-hoist with a sloped ramp down which the animals walk, raising and lowering a bucket from and into a well; and in the noria (naura), which consists of buckets fixed to an endless chain. The chain hangs over a wheel, and reaches down into the well. As the wheel is turned, the buckets bring up water, turn over at the top, empty the water into a trough, and go back into the well. In a circle, about thirty feet in diameter, in the center of which is the noria, an animal draws behind it one end of a pole, the other end of which is attached to the gearing propelling the wheel (see Laufer, 1934).

Water can be raised about three feet with one tray, and twice that distance with four workers using two trays, one at the low level and one at the high. The dalw raises water about six feet, the noria up to about twenty feet, and the karid up to fifty or more.

In the past thirty years the owners of most date gardens which are under flow, and in which the summer lift is considerable (Baghdad district), have put in kerosene or Diesel oil engines and centrifugal 
pumps. A few garden-owners in the Basra district have also installed pumps and engines to reinforce the tides.

Pollination.-The date palm is the only crop which is normally pollinated by hand. In April, the male inflorescences (tal) are cut from the male palms (fahl or dakar) just before the pollen (liqah) is ready to be shed. They are divided into about twenty small sprigs $(i l b)$, one of which is inserted into each of the female inflorescences $(i a q)$ on the female palms.

Propagation.- Since the seed of a palm, the result of crosspollination, inherits characteristics not only from the female parent, but also from the male parent, a seedling date palm (daqal) is far more likely to differ from its mother than to resemble it. Thus, although date palms can be grown from seed (fasm, nawwa, or fasa), they are as a rule reproduced by offshoots, offsets, or suckers (fark, fasl, or jabbar). These sprout at ground level in the axils of the fronds (saaf) of young palms. Old palms only rarely produce offshoots. When the shoots are from five to ten years old, they are removed from their parents. Thəy mature in succession and are removed one by one from the parent tree at intervals of several years.

Maturation.-The date palm begins to bear at from four to six years old, reaches maturity at from ten to twenty, and begins to decline at from thirty to forty years; it may live to be a hundred. It has a tendency to bear during alternate years.

The female flower consists of three carpels. After pollination, when the young fruit is known as hababauk, two carpels fall, and one remains and grows. From the time the green fruit reaches the size of a small marble until it changes color it is known in Iraq as kimri and in Morocco as balah. In June, July, or August, it turns yellow in some varieties and red in others, and, though still hard, is now edible. In this stage, it is known as kalal in Iraq, busr in Arabia, saffar in Morocco, and maksar or akdar in Egypt. When the fruit softens it is then known as rutab in Iraq or naqqar in Morocco. In this stage, the date is considered the most edible. When dried or cured, the fruit, known as tamr in Iraq and Morocco and balah in Egypt, keeps indefinitely.

Production.-The average annual yield of fruit harvested from a date palm in September and October is probably about fifty pounds. The total production is somewhat more than 250,000 long tons.

Uses.- The living palm provides shade for other crops. Beneath the shade of the date palms where drainage is good, especially at 
Baquba, citrus trees are commonly planted. In the Baghdad and Karbala districts, plum, apricot, peach, and apple trees grow beneath the palms, while in the Basra district vines and pomegranates flourish. Vegetables and alfalfa are planted in palm gardens, but usually only in clearings where the palms are young and do not shade the ground.

The root (irq) serves as fodder. The trunk (jid) may be cut up for fuel or hollowed out and used for water pipes and drains. Revetments, bridges, ladders, and steps are also made from the base of the trunk.

A gum, which is occasionally exuded from the palm trunk, is used medicinally in the Punjab.

The heart or growing-point (jummar) is edible when fresh or cooked.

The sap yields a sweet liquor, like coconut milk, which ferments rapidly. It is drunk, both fresh and fermented, in North Africa, to some extent in India, and not at all in Iraq. The sap of an allied species of palm, Phoenix sylvestris Roxb., is used on a large scale in India for sugar making.

Fronds (saaf) provide fuel, thatch, fencing, and bridging materials.

Frond bases (karab) are used for fuel, for packing boats, as floats for fishing nets or for boys learning to swim, and (in Egypt), when split, for brooms.

Frond midribs (jarid) are used as walking sticks, as imitation spears in horseback games, as fish trays, and as roofing rafters. When they are fastened tightly together, they form a sort of paneling, which is used for floors, walls, and roofs of houses. They are also made into bird-cages, chicken coops, bedsteads, cradles, crates, boats, and fans.

From the fiber (lif), rope and matting are made; and with it pack saddles and couches are stuffed. It is used as a coffee strainer and as plugs for irrigation pipes.

Spines (sauk or sulla) are used occasionally as pins, as needles for extracting thorns, and as forks for eating dates.

The leaflets (kus) are woven into matting, from which baskets, mats, fans, and belting are made.

From the spathes (dik or tal) a perfume called "tara water" (malaqah) is distilled.

The fruit bunches, from which the dates have been picked, are used as brooms and as fuel, or are made into twine and rope. 
The fruit is a staple food for man and beast. It can be eaten fresh, cured, or cooked. From it sugar, syrup, spirit, and vinegar are prepared.

The stones are used as cattle food, and as an adulterant for coffee, cocoa, and chocolate. They make good fuel, excellent charcoal, and are used, although not in Iraq, as necklaces.

Export.-Dates exported to Europe and America are packed in wooden cases holding seventy pounds; but those exported to India, Arabia, and East Africa, and those for local consumption are packed in baskets (kisaf) of matting, woven from the dried leaflets of the date palm.

Export fluctuates between 115,000 and 175,000 long tons, with an average of about 150,000 , of which about two-thirds come from the Shatt al Arab district. The remainder, all of the Zahdi variety, come from up country, chiefly from the middle Euphrates and Baghdad areas. 


\section{BIBLIOGRAPHY}

The following compilation of bibliographical references has been almost entirely restricted to publications dealing with the Lower Euphrates-Tigris Region. The exceptions are to references which should be used in conjunction with this publication and such recent standard works on Iraq as those of Foster, Ireland, Longrigg and Main. Copies of the microfilms may be purchased from the American Documentation Institute, 1719 N Street N.W., Washington, D.C.

\section{Blanchard, RAOUL}

1929. La Mésopotamie. Géographie Universelle, vol. 8, pp. 215-232. Paris.

\section{BOESCH, HANS}

1939. El Iraq. Economic Geography, vol. 15, No. 4, pp. 325-361.

China, W. E.

1938. Hemiptera from Iraq, Iran and Arabia. Field Museum of Natural History, Zool. Ser., vol. 20, No. 32, pp. 427-437.

Coon, Carleton S.

1939. The races of Europe. New York.

Corry, C. E.

1937. The blood feud. London.

Dowson, V. H. W.

1921-23. Dates and date cultivation of the Iraq. Pts. 1-3. Printed for the Agricultural Directorate of Iraq. Cambridge, England.

1939. Provisional list of the date palms of the Iraq. Tropical Agriculture, vol. 16, No. 7, pp. 164-168. Trinidad.

Drower, E. S. (Stevens, E. S.)

1931. Folk-tales of Iraq. Oxford.

1937. The Mandaeans of Iraq and Iran. Oxford.

\section{FifL, HENRY}

1932a. The ancient and modern inhabitants of Arabia. Open Court, vol. 46, pp. 847-871. Chicago.

1932b. The cradle of Homo sapiens. American Journal of Archaeology, vol. 36 , pp. 426-430.

1933. The antiquity of man in southwestern Asia. American Anthropologist, vol. 35, pp. 51-62.

1935a. Arabs of central Iraq, their history, ethnology and physical characters. Introduction by Sir Arthur Keith. Field Museum of Natural History, Anthr. Mem., vol. 4.

1935b. The Field Museum Anthropological Expedition to the Near East, 1934. Science, vol. 81 , No. 2093, p. 146.

1935c. Ibid. The Oriental Institute Archaeological Report on the Near East. American Journal of Semitic Languages and Literatures, vol. 51, pp. 207-209.

1936. The Arabs of Iraq. American Journal of Physical Anthropology, vol. 21, pp. 49-56.

1937. See Hooper, David

1939. Contributions to the anthropology of Iran. Field Museum of Natural History, Anthr. Ser., vol. 29, pp. 1-706. 
1940a. The Anthropology of Iraq. Pt. 1, No. 1: The Upper Euphrates. Field Museum of Natural History, Anthr. Ser., vol. 30, pp. 1-224.

1940b. The "Mongoloid Spot" in Turkey and Iraq. American Journal of Physical Anthropology, vol. 27, No. 1, pp. 119-126.

1941. Climatological data from Southwestern Asia. Bulletin of American Meteorological Society, vol. 22, No. 7, pp. 299-300; and Microfilm No. 1591, pp. 1-20, in American Documentation Institute.

1947a. Human remains from Kish, Iraq. Microfilm No. 2345, pp. 1-118, in American Documentation Institute.

1947b. Near East travel bibliography. Microfilm No. 2392, pp. 1-60, in American Documentation Institute.

1947c. Contributions to the Anthropogeography of Southwestern Asia. Microfilm No. 2416, pp. 1-48, in American Documentation Institute.

1947d. Bibliografia. Boletin Bibliografico de Antropologia Americana, vol. 9, pp. 325-333, Mexico City.

1948a. Head deformation in the Near East. Man, vol. 48, No. 154. London.

1948b. Miscellanea Asiatica Occidentalis: I. Microfilm No. 2483, pp. 1-239, in American Documentation Institute.

Foster, Henry A.

1935. The making of modern Iraq. Norman, Oklahoma.

Fulainain, Hajji

1928. The Marsh Arab. Philad.lphia.

Government of IraQ Publications

1929. Maps of Iraq with notes for visitors. Baghdad.

\section{Guest, Evan}

1933. Notes on plants and plant products with their colloquial names in Iraq.

Bull. No. 27, Department of Agriculture, Iraq. Baghdad.

Hooper, David, and Fiet.d, Henry

1937. Useful plants and drugs of Iran and Iraq. Field Museum of Natural

History, Bot. Ser., vol. 9, No. 3, pp. 71-241.

IONIDES, M. G.

1937. The régime of the rivers Euphrates and Tigris. New York.

Ireland, Philip Wrllard

1937. Iraq. London.

Kappers, C. U. ARIENS

1947. Anthropometric data from Southwestern Asia. Microfilm No. 2419, pp. 1-92, in American Documentation Institute.

\section{KEITH, SIR ARTHUR}

1935. Introduction to Arabs of central Iraq, their history, ethnology and physical characters. Field Museum of Natural History, Anthr. Mem., vol. 4, pp. 11-76.

-

1932. The racial characteristies of the southern Arabs (pp. 301-333) in "Arabia

Felix" by Bertram Thomas. New York.

Krogman, W. M. See Keith, Sir Arthur 
LAUFer, Berthold

1919. Sino-Iranica. Field Museum of Natural History, Anthr. Ser., vol. 15, No. 3, pp. 385-391.

1934. The noria or Persian wheel. Oriental Studies in honour of Dasturji

Saheb Cursetji Erachji Pavry, pp. 238-250. Oxford.

LONGRIGG, S. H.

1925. Four centuries of modern Iraq. Oxford.

Main, ERnest

1935. Iraq from mandate to independence. London.

MAXWELL, DONALD

1921. A dweller in Mesopotamia. New York.

SCHLIMMER, J. L.

1874. Terminologie medico-pharmaceutique et anthropologique françaisepersane, pp. 175,460 . Tehran.

SCHMIDT, KARL P.

1939. Reptiles and amphibians from southwestern Asia. Field Museum of Natural History, Zool. Ser., vol. 24, pp. 49-92.

Summerscale, J. P.

1938. Report on economic and commercial conditions in Iraq. Department of Overseas Trade, No. 699. London.

ToLkowskY, S.

1938. Hesperides. A history of the culture and use of citrus fruits. London.

TROTTER, MILDRED

1936. The hair of the Arabs of Central Iraq. American Journal of Physical Anthropology, vol. 21, pp. 423-428.

UVAROV, B. P.

1938. Orthoptera from Iraq and Iran. Field Museum of Natural History, Zool. Ser., vol. 20, pp. 439-451.

WILlCocks, Sir WILLIAM

1911. The irrigation of Mesopotamia. London.

ZaHROON, NAJIM

1946. A Mandean Dictionary on Microfilm No. 2196, pp. 1-63, in American Documentation Institute. 


\section{AL BU MUHAMMAD TRIBESMEN ILLUSTRATED IN PLATES}

764 : Plate 121

765: Plate 140

766: Plate 120

768: Plate 81

769: Plate 112

770: Plate 94

771 : Plate 82

776: Plate 100

777: Plate 122

780 : Plate 125

781 : Plate 85

782: Plate 119

783: Plate 102

784: Plate 99

785: Plate 90

786: Plate 98

787: Plate 98

789: Plate 111

796: Plate 93

797: Plate 137

798: Plate 102

799: Plate 121

800 : Plate 110

801: Plate 131

803: Plate 99

804: Plate 105

806: Plate 108

807: Plate 85

808: Plate 103

809: Plate 138

810 : Plate 110

811: Plate 89

812: Plate 134

815: Plate 97

816: Plate 80

818: Plate 131

819: Plate 83

822: Plate 140

823: Plate 118

824: Plate 104

825: Plate 87
826: Plate 104

828: Plate 139

830: Plate 82

831: Plate 113

832: Plate 129

833: Plate 134

834: Plate 116

835: Plate 84

836: Plate 106

838: Plate 107

839: Plate 113

840 : Plate 140

841: Plate 137

842: Plate 139

843: Plate 135

846: Plate 114

847: Plate 114

848: Plate 112

849: Plate 105

851: Plate 79

853: Plate 133

854: Fiate 116

855: Plate 115

856: Plate 123

858: Plate 128

859: Plate 132

860 : Plate 124

861 : Plate 80

863: Plate 126

866 : Plate 86

867: Plate 109

868: Plate 111

869: Plate 103

871 : Plate 86

873: Plate 100

874: Plate 127

875: Plate 91

876: Plate 101

878: Plate 133

879: Plate 128

880: Plate 106
881: Plate 79

882: Plate 81

885: Plate 130

886: Plate 117

887: Plate 138

888: Plate 101

890: Plate 109

891: Plate 117

892: Plate 132

894 : Plate 135

896: Plate 91

897: Plate 84

898: Plate 97

899: Plate 127

900: Plate 107

901: Plate 136

902: Plate 83

903: Plate 93

904: Plate 88

905: Plate 129

906: Plate 130

911: Plate 92

914: Plate 108

916: Plate 88

917: Plate 89

919: Plate 95

920: Plate 115

922: Plate 119

924: Plate 94

925: Plate 124

926: Plate 96

928: Plate 120

930: Plate 118

931: Plate 122

932: Plate 136

933: Plate 90

935: Plate 87

943: Plate 92

944 : Plate 125

945: Plate 95

951: Plate 126 


\section{AL SAWAAD TRIBESMEN ILLUSTRATED IN PLATES}

954: Plate 156

955: Plate 164

956: Plate 153

957: Plate 159

958: Plate 162

959: Plate 160

960: Plate 158

961: Plate 166

962: Plate 157

963: Plate 162

964: Plate 152

965: Plate 153
966: Plate 155

968: Plate 154

969: Plate 154

972: Plate 161

976: Plate 160

977: Plate 166

979: Plate 157

981: Plate 150

982: Plate 163

983: Plate 149

984: Plate 150

985: Plate 165
986: Plate 156

988: Plate 159

991: Plate 152

992: Plate 151

995: Plate 149

996: Plate 164

997: Plate 163

999: Plate 155

1000: Plate 151

1001: Plate 161

1002: Plate 165

1003: Plate 158

\section{SUBBA MALES ILLUSTRATED IN PLATES}

2888: Plates 174, 175

2890: Plate 179

2891: Plate 179

2892: Plate 200

2893: Plate 185

2894: Plate 197

2896: Plate 185

2897: Plate 206

2898: Plate 203

2899: Plate 208

2900: Plate 194

2901: Plate 199

2903: Plate 192

2904: Plate 201

2905: Plate 200

2907: Plate 207

2908: Plate 199

2909: Plate 178

2910: Plate 184

2911: Plate 196

2912: Plate 206

2913: Plate 197

2914: Plate 196

2915: Plate 205

2917: Plate 176
2918: Plate 203

2919: Plate 171

2920: Plates 188, 189

2921: Plate 187

2922: Plate 180

2923: Plate 194

2924: Plate 169

2925: Plate 193

2926: Plate 170

2929: Plate 177

2930: Plate 186

2931: Plate 173

2933: Plate 198

2934: Plate 169

2935: Plate 201

2936: Plate 204

2937: Plate 171

2939: Plate 170

2940: Plate 202

2942: Plate 183

2943: Plate 191

2944: Plate 191

2945: Plate 193

2946: Plate 198

2947: Plate 183
2948: Plate 176 2951: Plate 202 2952: Plate 173 2954: Plate 172 2955: Plate 181 2957: Plate 172 2959: Plate 204 2960: Plate 178 2961: Plate 180 2962: Plate 181 2963: Plate 182 2965: Plate 182 2966: Plate 208 2967: Plate 177 2968: Plate 205 2969: Plate 184 2970: Plate 186 2971: Plate 195 2972: Plate 207 2973: Plate 187 2974: Plate 190 2975: Plate 195 2976: Plate 190 2978: Plate 192

\section{SUBBA FEMALES ILLUSTRATED IN PLATES}

2981: Plate 210 2982: Plate 209 2983: Plate 212 2984: Plate 212 2985: Plate 210
2986: Plate 214 2987: Plate 213 2988: Plate 209 2998: Plate 213 2999: Plate 211
3001: Plate 215 3002: Plate 211 3007: Plate 214 3012: Plate 215 


\section{INDEX}

Abir, 249

Abu Ajul Lake, 242

Abu al Dhahab, 369

Abu Jidahah, 258

Abu Shahrain (Eridu), 242

Abu Tabr Canal, 241

Abu Zuruq, 332

Abul Khasib, 254

Adil River, 263

Agriculture, 371-373; implements used in, 245-246; products of, 244-245

Ahwaz, 249, 251

Ajman, 253

Akaika Channel, 259

Al Abbud, 263-265

Al Abuda, 252, 259, 332

Al Ajwad, 249, 252

Al Akaika, 332

Al Amara, see Amara

Al Amla, 263-265

Al Azair, $86 e$ Al Uzair

Al Azairij, 249, 250, 260, 290

Al Aziziya, 369

Al Baadwa, 353

Al Badr, 333

Al Baladhuri, 369

Al Balasim, 330

Al Basra, see Basra

Al bu Darraj, 249-250

Al bu Hamza, 331

Al bu Muhammad, 234, 237, 249-250, $260,370-371$

Anthropometric data (221 males measured), 265-289

age of, 265,273

bigonial breadth of, 273

bizygomatic breadth of, 273; groupings, 272

body hair of, 266; compared to Kish Arabs and Dulaimis, 266 cauterization among, 268

cephalic index of, 271,273 ; groupings, 270

demography of, 265, 274-277

disease among, 267. See also Pathology

ears of, measurements and indices of, 273

eye slits of, 267

eyes of, 266-267; groupings, 267

facial measurements and indices of, 271; groupings, 271

fronto-parietal index of, 273

hair of, 266; groupings, 266

head breadth and length of, 270 , 273; groupings, 270,272

health of, 269

henna used by, 269 history of, 263

lips of, 268

location of, 263

minimum frontal diameter of, 270 , 273; groupings, 270,272

Mongoloid element among, 265

morphological characters of, 265 $268,286-289$

musculature of, 268

nasal breadth and height of, 271, 273; groupings, 271-272

nasal index of, 273; groupings, 272

nasal profile of, 267 ; groupings, 268

nasal tip and wings of, 267; groupings, 268

Negroid element among, 265-267

occupations of, 370

prognathism among, 269

raw data: measurements, indices and morphological characters of, 278-288

reed huts built by, 381-384

relative sitting height of, 273

sheikhs of, 370

sitting height of, 273; groupings, 270,272

skin color of, 265; compared to Kish Arabs, 265; to the southern European, 265

statistical analyses of, groupings, 269-272

stature of, 269, 273; groupings, 270, 272

tattooing among, 268

teeth of, 268; groupings, 268

total facial height of, 271,273 ; groupings, 272

total facial index of, 271, 273; groupings, 271

upper facial height of, 271, 273; groupings, 271-272

upper facial index of, 273

vital statisties of, $265,274-277$

zygo-frontal index of, 273

zygo-gonial index of, 273

Al bu Muhammad (three females measured), 289-290

Al bu Sali, 332

Al bu Shairuza, 353

Al bu Shamakhi, 259

Al Budur, 253, 353

Al Buwaish, 249, 250

Al Chaab, 249-251, 260, 329

Al Dabbat, 331-333

Al Daudi (Kurds), 256

Al Diyain (Dijain), 331

Al Dugaimi, 332. See also Al Nawashi

Al Furaijat, 263 
Al Ghanan, 330

Al Ghuzi, 331-332

Al Hachcham, 331, 333

Al Halaf, 329

Al Hamawand (Kurds), 256

Al Hammad, 332

Al Hamra, 330

Al Hassan, 257

Al Hassuna Lake, 242

Al Hathar, 259

Al Hawal, 332

Al Hisan, 331-332

Al Humaidat, 331

Al Husainat, 332-333

Al Husaini, 253

Al Huwair, 247; boat-building at, 247

Al Jaf (Kurds), 256

Al Jazair (Confederation), 251-253

Al Jubur, 353

Al Juhaish, 353

Al Juwaibir, 331-332

Al Khadhimain, 399

Al Khafaja, 332, 333. See also Al Khafaya

Al Khafaya (Khafaja), 330-333

Al Khalil, 333

Al Khamisiya, 247, 255

Al Khazraj, 329

Al Kufa, 369

Al Kumait, 250

Al Kurmashia, 332

Al Kuwait, 247

Al Madina, 247-248; (Nahiya), 253

Al Majid, 333

Al Marshadi, 333

Al Muhaisin, 251, 260

Al Mujarrah, 252

Al Muntafiq, 249-253, 255, 259-260, 330-331; history of, 249-251; population of, in 1920, 254

Al Musakhil, 333

Al Muzaira, 260

Al Najada, 259

Al Najaf, 353, 366, 399, 400

Al Nashwah, 260

Al Nawashi, 332. See also Al Dugaimi

Al Nodah Ali (Iranis), 256

Al Nusairi, 328

Al Qaraghol, 332

Al Qurna, 238, 240-245, 247, 249, 251, $252,258,260,329$; climate of, 243 ; population of, 258 , in 1920 , 254 ; river traffic at, 258; Shiahs at, 258; Sunnis at, 258; weaving at, 247

Al Salman, 332

Al Sarraj, 329

Al Sawaad, 234, 249-250, 260, 263, 370371

Anthropometric data (fifty males measured), 290-301

age of, 301; groupings, 291

bigonial breadth of, 301 bizygomatic breadth of, 301; groupings, 297

body hair of, 292

cauterization among, 293

cephalic index of, 301 ; groupings, 295

disease among, 292-293. See also Pathology

ears of, measurements and indices of, 301

eyes of, 292; groupings, 292

facial measurements and indices of, 295-296; groupings, 296

fronto-parietal index of, 301

hair of, 292; groupings, 292

head breadth of, 301; groupings, 295,297

head length of, 294-295, 301

history of, 290

lips of, 293

minimum frontal diameter of, 301 ; groupings, 295, 297

morphological characters of, groupings, 291-294

musculature of, 294

nasal breadth and height of, 301; groupings, 296, 297

nasal index of, 301; groupings, 296

nasal profile, 293; groupings, 293

nasal tip and wings of, 293 ; groupings, 293

Negroid element among, in nose of, 293

origin of, 290

raw data: measurements, indices, and morphological characters of, 298-300

reed huts built by, 384

relative sitting height of, 301

sheikhs of, 371

sitting height of, 301; groupings, 294

skin color of, 291; compared to the Arab, 291; to the European, 291

statistical analyses of, groupings, 294-296

stature of, 301; groupings, 294, 297

tattooing among, 293

teeth of, 293; groupings, 293

total facial height of, 301; groupings, 296, 297

total facial index of, 301; groupings, 296

upper facial height of, 301; groupings, 296, 297

upper facial index of, 301

zygo-frontal index of, 301

zygo-gonial index of, 301

Al Serai, 332

Al Shadda, 263; buffalo-breeding by, 264 ; reed mats made by, 264 
Al Shadud, 333

Al Shirahna, 331

Al Shuwailat, 332,333

Al Shuwalish, 332

Al Sinajir, 259

Al Sudan, 249-250, 263, 370-371

Al Suwaad, see Al Sawaad

Al Talabani (Kurds), 256

Al Ubaid, 353

Al Uzair (Ezra's Tomb), 240, 263, 370

Al Uzairij, 263, 332, 365, 370

Al Zaiyad, 333

Al Zubaid, 263

Alexander the Great, 242

Alfalfa, 244-245, 410

Ali Gharbi, 243-245, 257

Amara, 237, 240, 241, 243, 244-245, $247,250-251,256-257,263,290$, $330,368,370-371,380,391,401$; agricultural products of, 244-245; Christians in, 255; climate of, 243 ; Jews in, 255; salt from, 247; school at, 396; Shiahs in, 255; Subba in, 255; Sunnis in, 255

An Najaf, see Al Najaf

An Nasiriya, 238, 240, 242, 247, 255, $257-259,331-333,365,380$; 1 rabs in, 258; brick kilns at, 247; Christians in, 258; East Indians in, 258; history of, 258; Iranis in, 258; Jews in, 258; Lurs (Pusht-i-Kuh, Iran), 258; population of, in 1920, 258; Subba in, 258; Subbi woman from, 365-367; Turks in, 258

Anthropometric data (109 males measured), 331-355

age of, 333; groupings, 333

bigonial breadth of, 353

bizygomatic breadth of, 353 ; groupings, 343

cauterization among, 339, 355

cephalic index of, 353; groupings, 341

demography of, 333-334, 343-345 disease among, 335, 339. See also Pathology

ears of, measurements and indices of, 353

eyes of, 335, 353; groupings, 335

facial form of, 334

facial measurements and indices of, 341, 353; groupings, 341-342

fronto-parietal index of, 353

hair of, 335, 353; groupings, 334

head breadth of, 353 ; groupings, 341,342

head form of, 334,353

head length of, 353

health of, 339

henna used by, 354

individuals omitted, 353-355

minimum frontal diameter of, 353 ; groupings, 341,342

morphological characters of, groupings, 334-336

nasal breadth and height of, 336 , 353; groupings, 342, 343

nasal index of, 353 ; groupings, 342

nasal profile, 335-336, 353; groupings, 336

nasal septum of, 336-337

nasal tip and wings of, 336; groupings, 336

Negroid element among, 334

physical appearance of, 334

prognathism of, 334,354

provenance of, $331-333,353$

raw data: measurements, indices, and morphological characters of, 346-352

relative sitting height of, 353

sitting height of, 353 ; groupings, $334,340,342$

skin color of, 334,353

statistical analyses of, groupings, $340-343$

stature of, 353; groupings, 340, 342 supra-orbital ridges of, 334

tattooing among, 340, 354

teeth of, 337-339, 354; groupings, 337

total facial height of, 353 ; groupings, 343

total facial index of, 353

upper facial height of, 353 ; groupings, 343

upper facial index of, 353

vital statistics of, 333-334, 343-345

zygo-frontal index of, 353

zygo-gonial index of, 353

An Nasiriya (twenty-six females measured), 356-367

Anthropometric data, 355-367

age of, 362

bigonial breadth of, 362

bizygomatic breadth of, 362 ; groupings, 361

cephalic index of, 363; groupings, 359

color blindness among, 357

demography of, 364,366

disease among, 366. See also Pathology

ears of, measurements and indices of, 362,363

eyes of, 356, 366; groupings, 357

facial measurements and indices of, groupings, 360

fronto-parietal index of, 363

hair of, 356, 366; groupings, 356

head breadth and length of, 362 ; groupings, 359, 361

head form of, 356

henna used by, 356, 358, 367 
individuals omitted, 365-367

lips of, 358

minimum frontal diameter of, 362 ; groupings, 359,361

nasal breadth and height of, 362 ; groupings, 360,361

nasal index of, 363 ; groupings, 360 nasal profile, 357,366 ; groupings, 357

nasal septum of, 357,366

nasal tip and wings of, 357,366 ; groupings, 357

Negroid element among, 356, 358

prognathism of, 358

provenance of, 365

raw data: measurements, indices, and morphological characters of, 362-364

relative sitting height of, 363

sitting height of, 362; groupings, 359

skin color of, 356,366

statistical analyses of, groupings, 359-361

stature of, 362 ; groupings, 359,361

tattooing among, 358, 367

teeth of, 357-358, 366-367; groupings, 358

total facial height of, 362; groupings, 360,361

total facial index of, 363 ; groupings, 360

upper facial height of, 362; groupings, 360,361

upper facial index of, 363; groupings, 360

vital statisties of, 364,366

zygo-frontal index of, 363

zygo-gonial index of, 363

Anthropometric data, abbreviations, list of, used for, 262

Ants, 246

Apples, 244

Apricots, 244

Ar Rahhaliya, date palms at, 407

Arabia, Central, Bani Qahtan of, 256

Arabistan (Khuzistan), 242

Arabs, 256-258

Armenians, 256

Ashura, 401

Az Zubair, 238, 253, 255, 259, 401; date palms at, 407; population of, in $1920,254,260$; Sunnis at, 260 ; trading center at, 259-260

Az Zubair River, 263

Azair, 244

Bada Channel, 259

Badra, date palms at, 407

Baghdad, 244, 248, 258, 259; boatbuilding in, 248; fruit trees at, 410 ;
Royal College of Medicine in, 262;

Royal Hospital, 331

Bagh-i-Shahi, 238

Bahatha, 371

Bait Abdul Khan, 328

Bait Arar, 328

Bait Chuwaimil, 264

Bait Jandal, 328

Bait Khalifah, 264

Bait Madhkur, 328

Bait Saihud, 264

Bait Wadi, 264

Bait Yasir, 264

Bakhtiaris (Iran), 295

Band-i-Bazugan, 257

Bani Amir, 251

Bani Asad, 248, 249, 252-253

Bani Attab, 332

Bani Hachcham, 332

Bani Himyar, 250, 290

Bani Khaiqan, 252, 257

Bani Lam, 249-251, 256, 260, 263, 370, 371 , 374; history of, $328-330$; sections of, 328-330; territory of, 328

Bani Malich, see Bani Malik

Bani Malik, 249, 252

Bani Mansur, 253

Bani Musharraf, 253, 332

Bani Qahtan, 256

Bani Rabiah, 249, 250, 328, 330

Bani Said, 249, 252, 253, 257, 331-333

Bani Ukhtait, 331

Baquba, citrus trees in, 410

Barley, 244, 246, 373

Basra, 240, 241, 243, 244, 248, 252, $256-258,260,332,353,365,369$, 380 ; boat-building in, 248; climate of, 243; population of, in 1920, 254 ; vines grown in, 410

Basra Liwa, Christians in, 254, 255; Jews in, 254, 255; Shiahs in, 254, 255; Subba in, 255; Sunnis in, 254, 255

Bat-ha, 331, 332

Beans, 244, 245

Beduins, 258, 260

Beetroot, 244, 245

Birds, 369, 376

Boars, 258, 369, 375-376

Boats, building of, 247-248; local names of, 379 ; methods used in propelling, 380 ; types of, $379-380$

Boesch, Hans, 255

Branding (of animals), 330, 375. See also Cauterization (of humans)

Bread, local names for, 388; making of, 388

"Breath," the, 398

Brick-making, 247

Brinjals, 244, 245

British Museum, 234

Brux, A. A., 368 
Buffaloes, 244, 260, 264, 373, 374

Bulrushes, sweetmeat made of, 387

Butaira Canal, 244

Butaniya Lake, 242

Butter, 386

Cabbages, 244, 245

Camels, 243, 244, 374, 408; branding of, 375

Carrots, 244, 245

Cattle, 243, 373-374, 408; eye treatment of, 369

Cauliflower, 244, 245

Cauterization, 339, 355

Chabaish, 331, 332, 381. See also Kabaish

Chahala Canal, 241, 244, 250, 263

Chahala River, 369-371

Chahar Riz, 257

Chaldeans, 255-256

Cheese, 386

Chickens, 384, 386

China, W. E., 237

Christians, 254-258

Citrus trees, 410

Climate, 242-243

Clover, Egyptian, 244

Cockfighting, 374

Coffee, 380; ceremonial drinking of, 389-390; hospitality, symbol of, 390 ; preparation of, 388-389

Color-blindness, 391

Cotton, 380

Cows, 244

Cucumbers, 244, 245

Curds, 386

Curzon, G. N., 301

Dahlgren, B. E., 407

Dair, 253

Darraji, 238, 259

Date palms, 240, 241, 260, 407-411; description of, 407; distribution of, 407 ; irrigation of, $407-409$; local and foreign names for, 409; maturation of, 409; pollination of, 408 ; production of, 409; propagation of, 409; uses of, 409-411

Dates, export of, 411; syrup of, 387

Depilation, 398

Desert, southern, Christians in, 255; Jews in, 255; Shiahs in, 255; Subba in, 255; Sunnis in, 255

Dhafir, 253

Digitalis, fish stupefied by, 377

Diyala River, 240

Dizful (Iran), Subba at, 301

Dogs, 380

Donkeys, 373, 408

Drugs, fish stupefied by, 377

Ducks, 376

Dulaimi, 365
Duwairij, gypsum from, 247

Dwellings, 380-384

Dyes, aniline, 391 ; methods of preparation of, 391 ; natural, 391

East India Company, 251

Education, facilities for, 396

Eridu (Abu Shahrain), 242

Euphrates River, canals adjoining, 238; changing channels of, 241

Evil Eye, 393, 398

Ezra's Tomb (Al Uzair), 263, 370

Failiya, 238, 249

Failiyah Lurs, 256

Fao, 248-249, 251-254

Fauna, 369. See under boars, otters, etc.

Field, Marshall, 233

Field Museum Anthropological Expedition to the Near East, 233, 331

Field Museum-Oxford University Joint Expedition to Iraq, 246

Figs, 244

Fish, 369; local names of, 377, 379; methods of cooking, 387

Fishing, 375, 377; drug (digitalis) used in, 377; flares used at night for, 377 ; iron spear-points used in, 376378; nets used for, 376-377

Flora, 369

Folklore, medical, 339

Fuel, 386

Garmat Ali, school at, 396. See also Qarmat Ali

Geese, 376

Ghamuga Lake, 242

Goats, 373-374

Grapes, 244

Grasses, 244

Grazing, 238, 243, 245, 371

Gufa (Quffah), 248

Gypsies, 365; Persian, 353

Hafira Canal, 263, 370

Hai, 331

Hajji Laqlaq (storks), 376

Hakkam, 257

Halfaya, 234, 290, 330, 353, 370; Al Sawaad near, 263

Hammam Ali, 353

Harta Nahiya, 247, 254, 353

Hassan Kuli Khan (Lurs), 256

Hawiza, 250, 256, 257

-Hawizeh (Iran), Subba at, 301

Hejaz, 329

Henna, preparation of, 392

Herbs, preparation of, 387

Hillah, 353

Homosexuality, 396-397

Hooper, David, 392

Hor, 371 
Hor al Adhaim (Azem), 241

Hor al Hammar, 238, 241, 242, 248, $252,259,331$

Hor al Hawiza, 234, 237, 241, 263, 267, 295 ; agriculture in, $371-373$; ancient sites of, 369 ; Arabs of, 368406; communications to, 370 ; crops cultivated in, 372-373; description of, 368-370; domesticated animals used in, 373; extent of, 369; fiora of, 369 ; folklore of, 369 ; history of, 369; invasion by Moslems from Arabia of, 369; irrigation in, 372; linguistic notes on Arabs of, 368; Mongols in, 369; tribes of, 370; Turks in, 369

Hor Umm Tafra, 241

Hor umr Sauan, 263

Horses, 243, 244, 374, 408; local names of, 374

Houtum-Schindler, A., 301

Hunting, 375, 376

Huts, reed, 381

Ibadah, 253

Indians (East), 258

Industries, 247

Insects, 246

Iranis (Persians), 256, 257, 353

Irrigation, 240, 372 ; methods of, $244-$ 245

Jassan, date palms at, 407

Javrah District, 250

Jebel Hamrin, 382

Jebel Sanam, 238

Jemdet Nasr, 246; fish-hooks from, 377

Jews, 254-259, 366; Arab attitude toward, 255; population of, in 1919, 257

Kabaish, 238, 240, 249, 252, 257, 259. See also Chabaish

Kahala Canal, see Chahala

Karbala, 399, 402, 403; fruit trees near, 410

Karkheh River, 241

Karradi, 247, 257, 258, 331-332; brick kilns at, 247

Karun River, 242

Kasra River, 370

Kassareh, 244

Khas, 247, 257; boat-building at, 247

Khazraj, 250

Khorram Shahr (Muhammera, Iran), $240,242,251,260$

Khuzistan (Árabistan), 242; hut type in, 382

Kirkuk, 256

Kish, 246

Kohl, 394

Kubadh IV, 369
Kurds, 254-257; number of, in 1919, 257. See also Al Daudi, Al Hams- wand, Al Jaf, and Al Talabani

Kut, 353

Kut al Hai, 238, 240, 249, 258

Kut al Imara, 240, 250,257, 260, 329

Kut as Sayyid Estate, 407

Lady's-fingers, 244, 245, 373

Land, distribution of, 260 ; rate of formation of, 242

Laufer, Berthold, 408

Lawsonia, 392

Layard, A. H., 301

Lazar, Yusuf, 233, 262

Lentils, 373

Lettuce, 244, 245

Limes, 244

Lions, 258

Locusts, 246

Lurs, Pusht-i-Kuh (Iran), 256-257, 258

Madan, 253-254

Maize, 244, 373

Majar al Kabir Canal, 241, 244, 370

Majar as Saghir Canal, 241, 250

Mandali, date palms at, 407

Mandeans, see Subba

Manna (Family), 254

Maqil (Magil), river traffic at, 259

Marsh Arabs, agriculture among, 371373 ; arts and handicrafts of, 390 ; birth customs among, 398-399; burial customs among, 399-401; clothing of, 392-395; cockfighting among, 374; color-blindness among, 391 ; dancing of, 406 ; depilation among, 398; diet of, 386-390; divorce among, 399; domestic animals among, 371-375; domestic work among, 385-390; dwellings of, 380-384; dyes used by, 391 ; embroidery among, 391; family honor among, 390, 397; fishing by, 375 , 377; flagellations among, 401 ; food preparation among, 386390; hairdressing among, 392-393; homosexuality among, 396-397; hunting by, 375; jewelry worn by, 393-395; legends of, 400; marriage customs among, 397-398, 399; mourning rites of, 399-401; organized lamentation among, 400; ornamentation of, 392-395; pilgrimages of, 399 ; poets among, 401 ; professional mourners among, 400-401; religion among, 399-406; religious ceremony of, 401-403; silk worn by, 391; singing among, 406 ; social organization of, $395-399$; temporary burial tombs used by, 399-400; transportation among, 
379-380; traps used by, 376; witcheraft among, 399

Mash, 244

Mat-making, 248, 260, 369

Mecca, 399

Melons, 244, 245, 373

Meymourian, Albert, 233, 262

Michiriya Canal, 241, 370

Milking, 374-375

Millet, 244, 373

Minerals, 247

Mirage, 243

Mohammerah (Iran), Subba at, 301. See also Khorram Shahr

Mongols, 369

Mosquitoes, 243

Mosul, 249, 256

Mourning, hair cut for, 366

Muallim, Khedoory, 233, 262

Muhammad, ancestor of Al bu Muhammad tribe, 263

Muhammad Pasha Daghestani, 250, 251

Muhammera, Sheikh of, 249-250

Muharram, 399, 401, 403, 405

Mules, 408

Muntafiq area, Christians in, 255; Jews in, 254, 255; Kurds in, 254; Mandeans in, 254; Persians in, 254; Shiahs in, 254, 255; Subba in, 255; Sunnis in, 255; Turks in, 254

Musharra, salt from, 247

Musharra Canal, 241, 247, 290, 371

Nasir Pasha, 258

Navigation, possibilities of, 240, 241, 259

Nectarines, 244

Negroes, 384, 392, 406

Nejd, 249

Nejdi, 331

Noria (water-wheel), 408

Onions, 244, 245, 373

Oranges, 244

Osetes, North (Caucasus), 233

Otters, 369

Oxen, ploughing with, 373

\section{Partridges, 376}

Parviz (Sasanian King), 369

Pathology, "Baghdad boil," 269, 320, 339

bilharziasis, 385

boils, 306

caries, 322

chicken pox, 269

eyes, 320,335

arcus senilis, $\mathbf{8 5 7}$

blindness, 267, 292, 304

cataract, $267,269,293,304$

color-blindness, 357,391

cross-eyed, 267, 335, 366 favus, 339

fever, 269

headache, 269, 323

pimples, 306

ringworm, 339

scalp infections, 269, 339; scurf, 339. See favus

scars, 268, 306, 323. See Cauterization

skin, 269. See "Baghdad boil"

smallpox, 269, 293, 306, 320, 323, 339

trachoma, 269

ventral disorders, 269, 339

Patriarch of Babylon, 256

Pear Drop Bend, 241

Pears, 244

Peddlers, 380, 386

Pelicans, 376

Persia, see Iran

Persian Gulf, rate of land formation in, 242

Persians (Iranis), 254, 255, 258, 259

Pests, insect, 246

Petis de la Croix, 301

Phoenix dactylifera, see Date palms

Phoenix sylvestris, 410

Plants, 369

Plough, 245, 246

Plums, 244

Pomegranates, 244

Poplar, Euphrates, 246

Population, 256-257; 1919 census figures of, 257

Products, agricultural, 244, 373

Proto-Mediterranean, 256

Pumpkins, 244, 245

Punjab, gum used medicinally in, 410

Pusht-i-Kuh (Iran), 243, 245, 256-258

Qadhat al Hai, 332

Qahtan 256, 329

Qala Salih, 240, 241, 244, 245, 247, 260, 263 ; salt from, 247. See also Qal'at Salih

Qala Sikar, 238, 247, 257-258; brick kilns at, 247; emigration from, 258 ; population of, 258

Qal'at Salih, 370, 380, 391, 396. See also Qala Salih

Qarmat Ali, 240, 241; brick kilns at, 247. See also Garmat Ali

Quraish, 251

Qurna, see Al Qurna

Radishes, 244, 245

Rafts, 248

Ramadan, 399, 404

Reed huts, construction of, $881-384$

Religion, population according to, 255

Rice, 244, 264, 369, 386, 387; cultivation of, 372-373; preparation of, 388 
Rice bread, preparation of, 388

Richardson, F. L. W., 242

Roman Catholics, 256

Royal Geographical Society (London), Permanent Committee on Geographical Names of, 235

Rumaitha, 331

Rustam Agricultural Experimental Farm (Hinaidi), 233, 262

Ruta Creek, 241

Sabians, see Subba (Mandeans)

Sadifa Lake, 242

Sadun, 249, 252, 254, 255, 259

Sadun Pasha, 258

Safwan, 249

Samarra, 353, 365, 399

Samawa, 331, 332

Sand-flies, 243

Sasanians, 369

Sayyid Nur, salt from, 247

Sesame, 244

Shabib ibn Sherif Mani, 249

Shaiba (Shuaiba), 252

Shamiya, 252, 331; Beduins, 254

Shatra, 238, 242, 247, 258, 259, 331, 332; brick kilns at, 247; ghee tinned at, 247; history of, 259; Iranis at, 259; Jews at, 259; population of, 259; Shiahs at, 259 ; Subba at, 259; Sunnis at, 259; weaving at, 247

Shatt al Ahmar, 332

Shatt al Arab, 238, 240, 241, 251-253, 260 ; dates exported from, 411

Shatt al Bada, 238

Shatt al Gharraf, 238, 240, 249, 250, $252,259,331,332$

Shatt al Hai, 240, 331

Shatt al Shatra, 259, 331

Shatt al Tib, 257, 371

Sheep, 243, 374, 375, 386

Sheikh Abbud ibn Muhammad, 263, 264

Sheikh Alwan al Jindil, 371

Sheikh Amla ibn Muhammad, 263

Sheikh Barrak ibn Mufarrij, 250, 329

Sheikh Faisal al Khalisah, 250

Sheikh Falih as Saihud, 233, 370-371, 376,380

Sheikh Ghadhban ibn Bunaiyah, 250, 370

Sheikh Hafidh al Lami, 330

Sheikh Hafidh ibn Barrak, 250

Sheikh Hajii Jabir ibn Khazal, 251

Sheikh Hatim al Ghadhban, 370, 371

Sheikh Juwi al Lazim, 371

Sheikh Khalifah ibn Chuwaimil, 264

Sheikh Khazal, 251

Sheikh Khazal ibn Falih as Saihud, 234, 401

Sheikh Lam, 250

Sheikh Lam ibn Harithah, 329
Sheikh Majid al Khalifa, 370, 371

Sheikh Mizal ibn Hajji Jabir, 251

Sheikh Mubarak (Mulla Barkat), 250, 329

Sheikh Muhammad, 250

Sheikh Muhammad al Araibi, 370, 371

Sheikh Muhammad al Musa, 371

Sheikh Mulla Barkat (Mubarak), 250

Sheikh Mutlaq al Salman, 370

Sheikh of Muhammera, 249-251, 260

Sheikh Qumandar al Fahad, 371

Sheikh Saihud ibn Chuwaimil, 264

Sheikh Salman al Minshad, 370

Sheikh Shabib, 330

Sheikh Shawwai al Fahad, 370

Sheikh Shibl al Shiya, 371

Sheikh Shudaiyid ibn Muhammad, 263, 264

Sheikh Tahir al Hatim, 370

Sheikh Wadi ibn Chuwaimil, 264

Sheikh Yasir ibn Chuwaimil, 264

Sheikh Yuarib, 249

Sherif Mani (Mecca), 249

Shiahs, 254-256, 258-259

Showket, S. Y., 233, 262

Shuaiba (Shaiba), 252

Shushter (Iran), Subba at, 301

Shuwaiyib River, 241

Sikar, 258

Silk, artificial, use of, 391; importation of, 391

Silver-smiths (Subba), 257

Sinderson, J., 233

Sirut, 247; salt from, 247

Sitata, date palms at, 407

Smeaton, Winifred, 233, 262, 331-367

Snipe, 376

Soap, 385

Sorghum, 373

Spear-points, iron, 378

Spices, 380

Spinach, 244, 245

Storks (Hajji Laqlaq), belief concerning, 376

Subba (Mandeans), 237, 247, 254-259

Anthropometric data (ninety males measured), 301-320

age of, 313; groupings, 302

anomalies among, 306

bigonial breadth of, 313

birthplaces of, 301

bizygomatic breadth of, 313, 319 ; groupings, 311

blondism among, 303-304

body hair of, 303; compared to other groups in Iraq, 303

cephalic index of, 313; groupings, 308

demography of, 302, 311-313, 319 disease among, 304, 306, 320. See also Pathology 
ears of, measurements and indices of, 313

eyes of, 304, 320; groupings, 304

facial measurements and indices of, 313; groupings, 308-309

fronto-parietal index of, 313

hair of, 303, 320; groupings, 303

head breadth of, 313 ; groupings, 308,310

head length of, 313

health of, 306,320

henna used by, 306

history of, 257, 301

lips of, 305

minimum frontal diameter of, 313; groupings, 307, 311

morphological characters of, groupings, 303-306

musculature of, 305-306, 320

nasal breadth and height of, 313 ; groupings, 309, 311

nasal index of, 313 ; groupings, 309

nasal profile, 304-305, 320; groupings, 304

nasal tip and wings of, 304 ; groupings, 304

Negroid element among, in nose of, 304

photographic analyses of, 310

racial position of, 310

raw data; measurements, indices, and morphological characters of, 314-319

relative sitting height of, 313

sitting height of, 313; groupings, 307,310

skin color of, 303 ; compared to the Arab, 303; to the European, 303

statistical analyses of, groupings, 307-309

stature of, 313; groupings, 307, 310

tattooing among, 306, 320

teeth of, 305, 320; groupings, 305

total facial height of, 313; groupings, 311

total facial index of, 313 ; groupings, 309

upper facial height of, 313; groupings, 311

upper facial index of, 313

vital statistics of, $302,311-313$

zygo-frontal index of, 313

zygo-gonial index of, 313

Subba (twenty-three females measured), 320-328

Anthropometric data, 320-328

age of, 327; groupings, 321

bigonial breadth of, 327

birthplaces of, 320

bizygomstic breadth of, 327 ; groupings, 326 cephalic index of, 327; groupings, 324

demography of, 321,327

disease among, 323. See also Pathology

ears of, measurements and indices of, 327

eyes of, 322; groupings, 322

facial measurements and indices of, groupings, 324

fronto-parietal index of, 327

hair of, 321; groupings, 322

head breadth of, 327; groupings, 324,326

head length of, 327

health of, 323

minimum frontal diameter of, 327 ; groupings, 324, 326

morphological characters of, groupings, 322-323

musculature of, 323

nasal breadth and height of, 327 ; groupings, 325, 326

nasal index of, 327 ; groupings, 325

nasal profile, groupings, 322

nasal tip and wings of, groupings, 322

raw data: measurements, indices, and morphological characters of, $327-330$

relative sitting height of, 327

sitting height of, 327; groupings, 324,326

statistical analyses of, groupings, 323-325

stature of, 327 ; groupings, 323

tattooing among, 323

teeth of, groupings, 323

total facial height of, 327; groupings, 326

total facial index of, 327 ; groupings, 325

upper facial height of, 327; groupings, 326

upper facial index of, 327

vital statistics of, 321,327

zygo-frontal index of, 327

zygo-gonial index of, 327

Sulaimaniya, 256

Sultan Sulaiman, 249

Sumeria, 252

Sunnis, 254-256, 258-260

Suq ash Shuyukh, 238, 247, 255, 257, 259, 331-333; brick kilns at, 247; history of, 259; population of, 259 ;

Shiahs at, 259; Subba at, 259; Subbi woman from, 366 ; Sunnis at, 259; weaving at, 247

Suwaiq, 247; brick kilns at, 247

Syrians, 255, 256 
Taiah River, 263

Tallya Lake, 242

"Tara water," 410

Tattooing (washm or daqq), 340, 355, 375

Tea, 380

Thulthain District, 250

Tigris Region, Christians in, 255; Jews in, 255; Shiahs in, 255; Subba in, 255; Sunnis in, 255

Tigris River, canals adjoining, 238; river traffic of, 259

"Tigris salmon," size of, 377

Tomatoes, 244,245

Tortoises, 246

Transportation, 379-380

Traps, animal, 376

Trees, 246

Tribal groups, 251-253

Tribal mark (wasm), 330, 375

Tribal system, disintegration of, 260
Turks, 254, 255, 258, 369

Turnips, 244, 245

Uvarov, B. P., 237

Vegetables, 244, 245, 373

Wajif, 369

Watermelons, 373

Water-wheel, 372, 408

Weaving, 247, 390-391

Wheat, 244, 373

Wheaten bread, preparation of, 388

Willow, 246

Witcheraft, 399

Women, status of, 384-385

Wool, method of skeining, 391

Yezidis (Caucasus), 233

Zab River, Great, 240

Zab River, Little, 240 




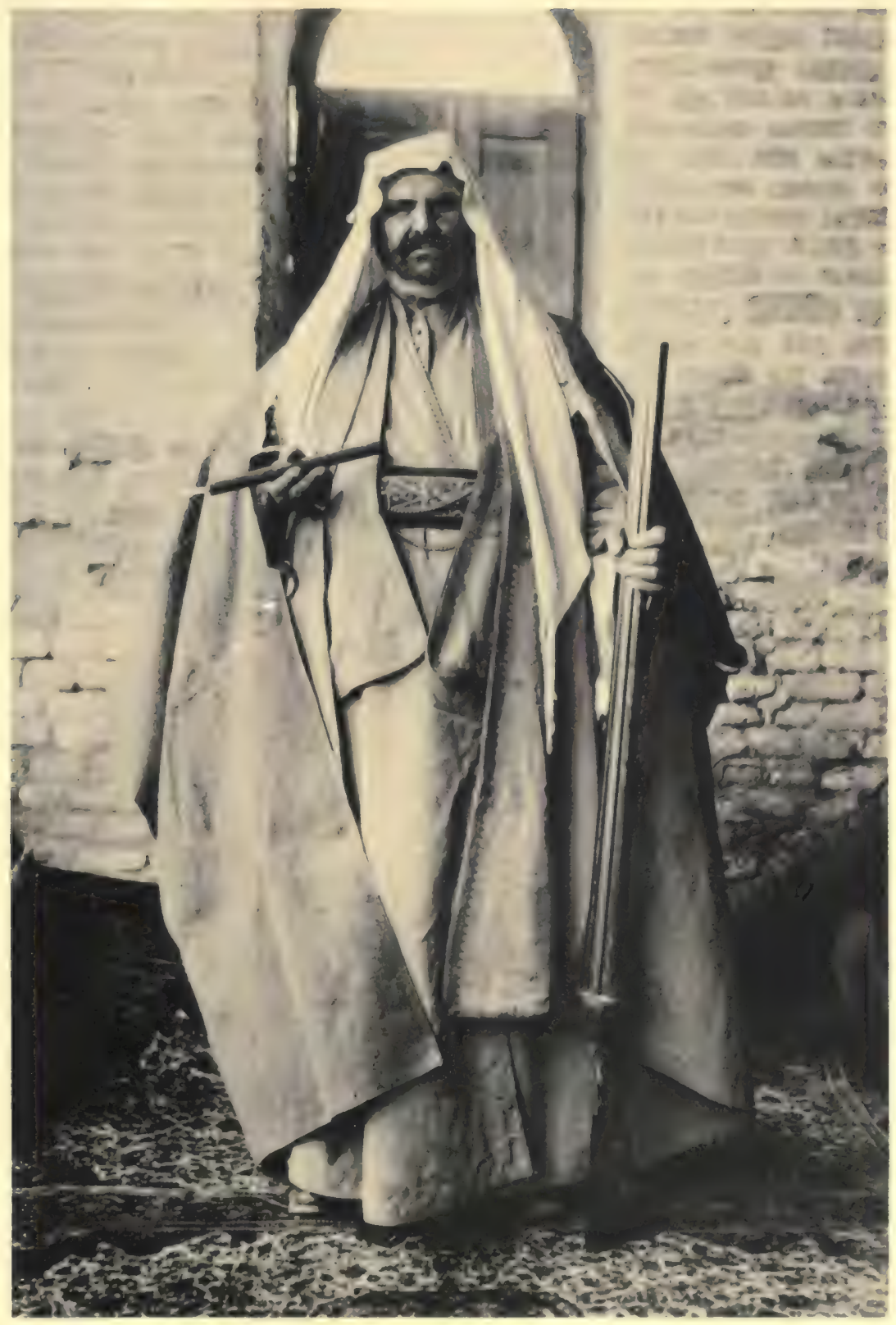

SHEIKH FALIH AS SAIHUD, PARAMOUNT SHEIKH OF THE AL BU MUHAMMAD TRIBE 
Neg. No. 104375 (al)

Field Museum of Natural History Anthropology, Vol. 30, Plate 50

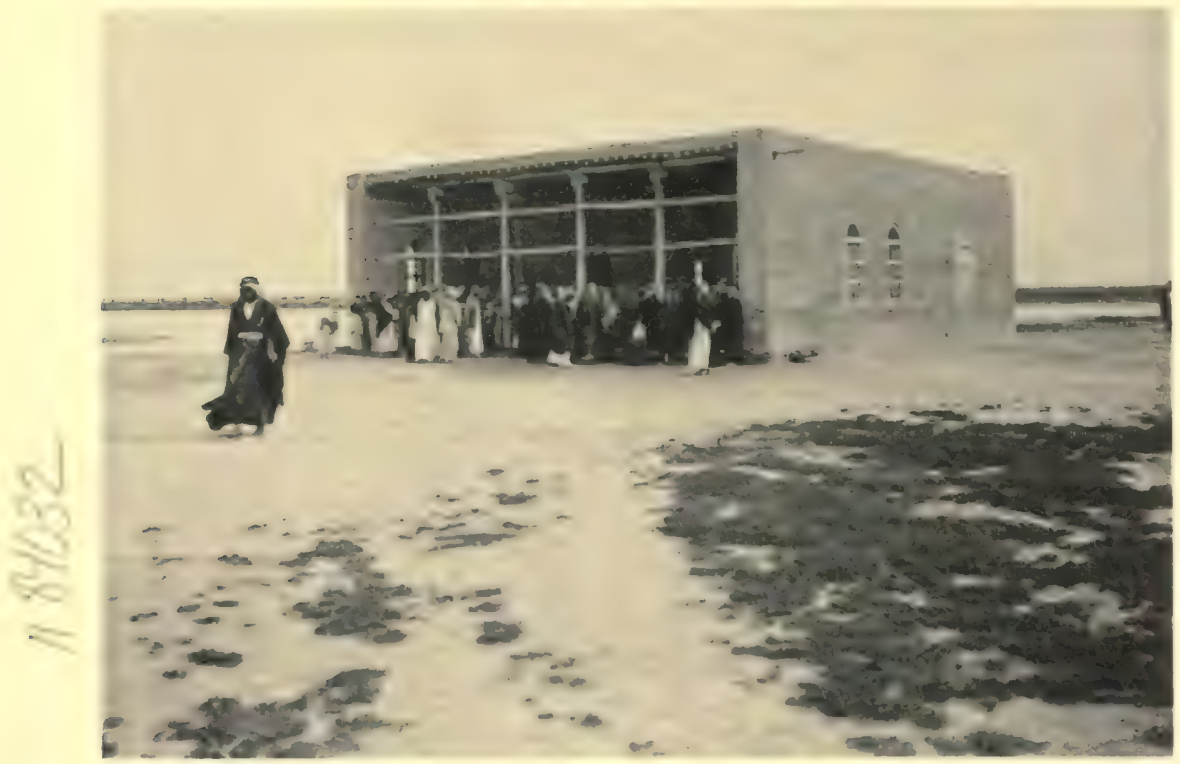

Fig. 1. Brick guest-house

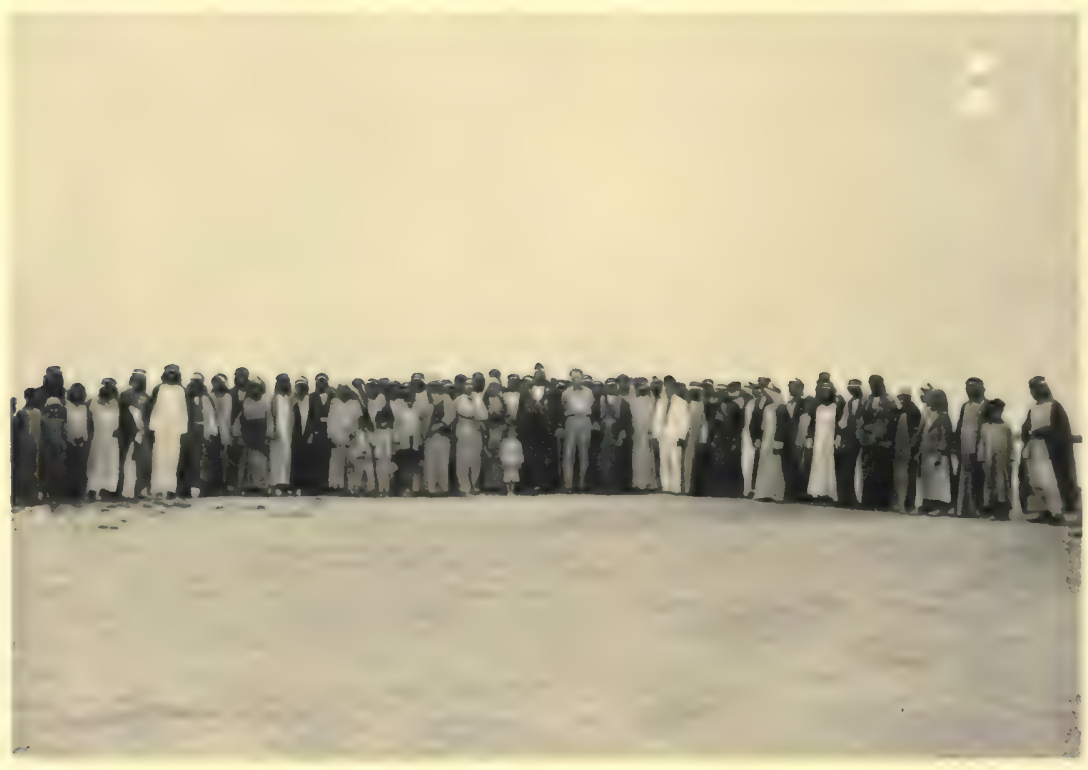

Fig. 2. Sheikh Falih and his tribesmen 


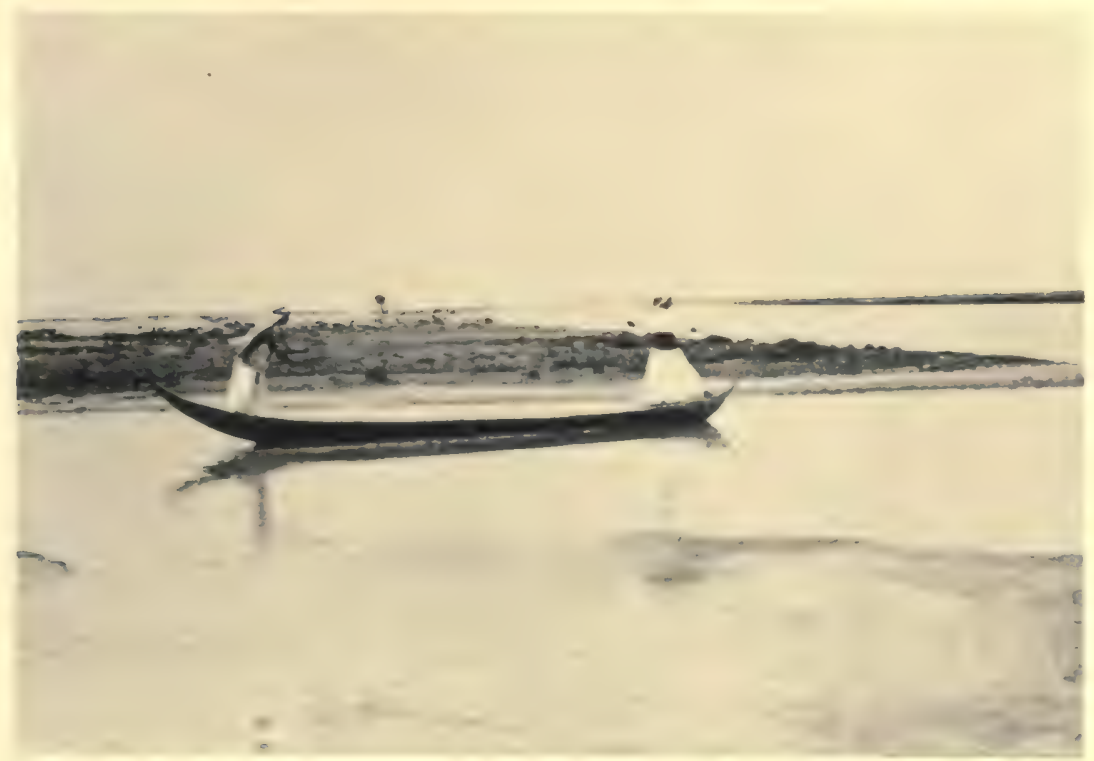

Fig. 1. Spearing fish

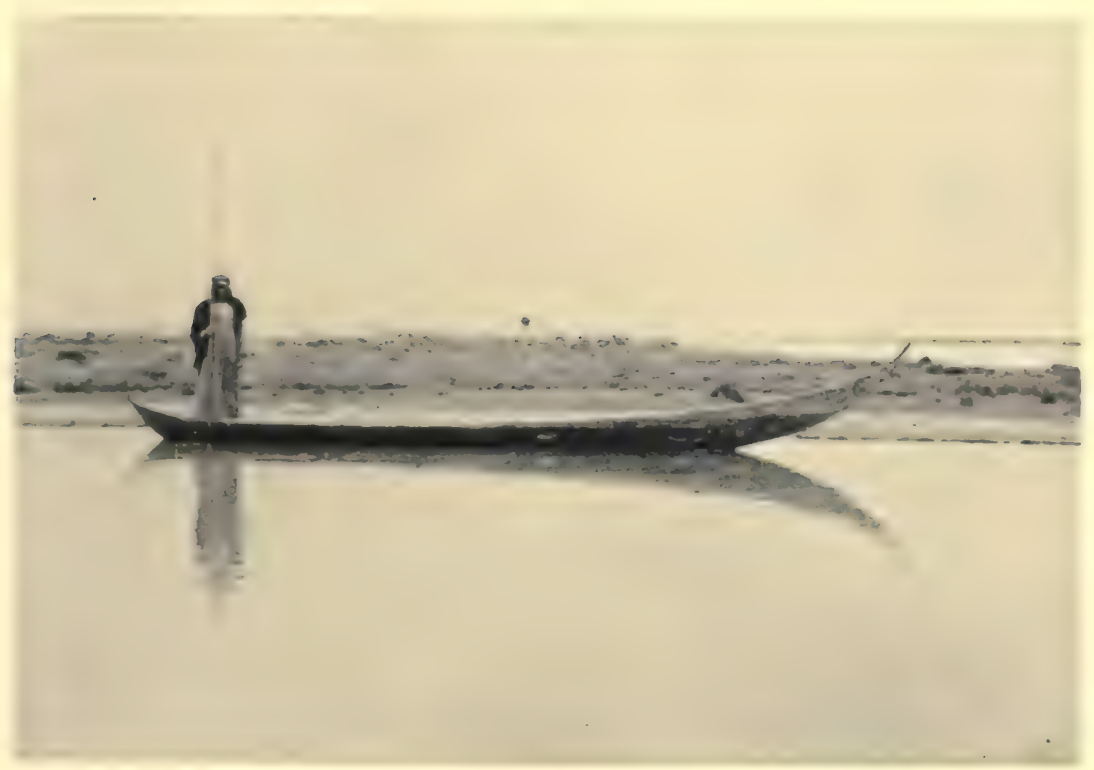

Fig. 2. A large boat 

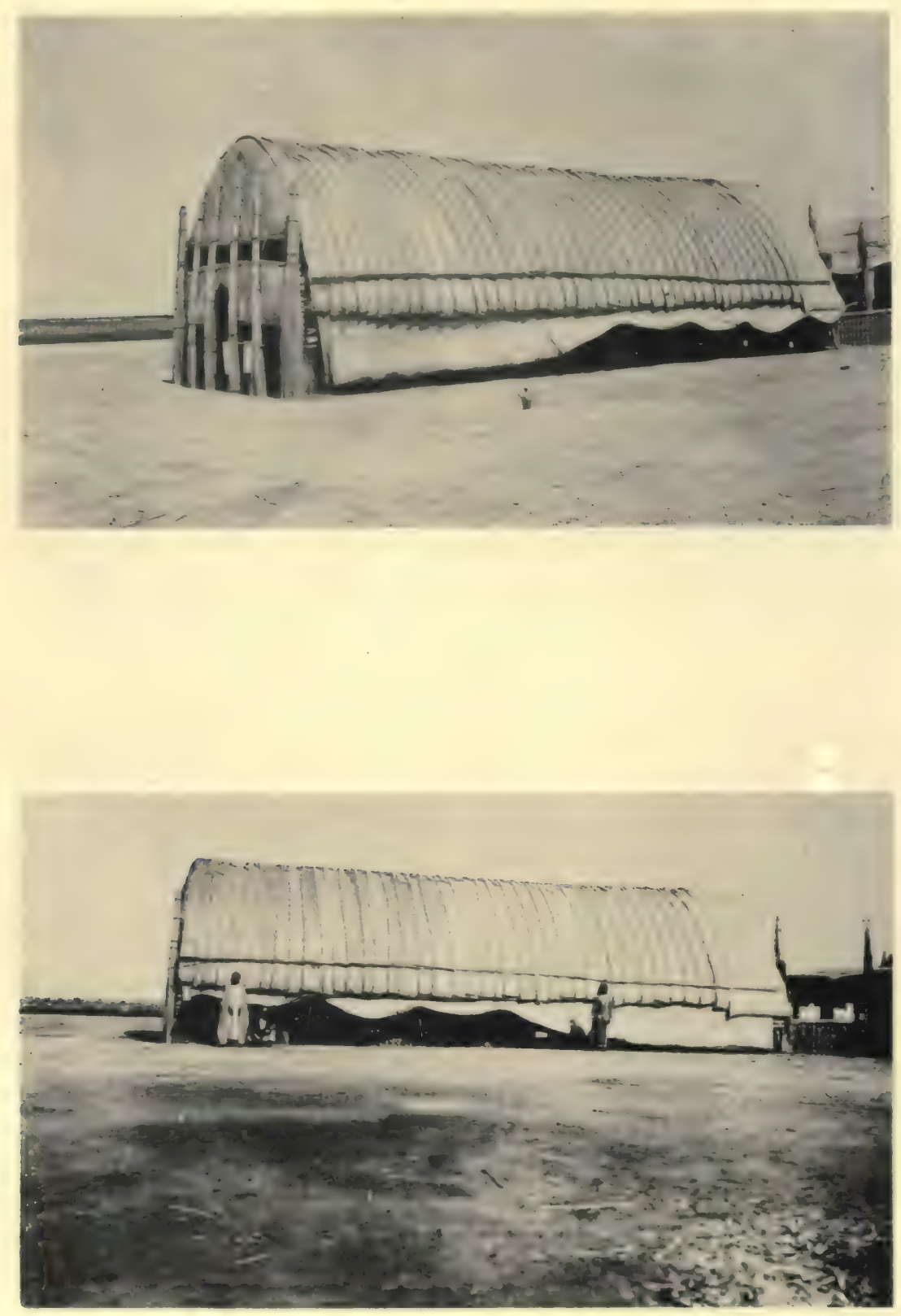

SHEIKH KHAZAL IBN FALIH'S GUEST HUT, CONSTRUCTED OF 150 REED MATS 


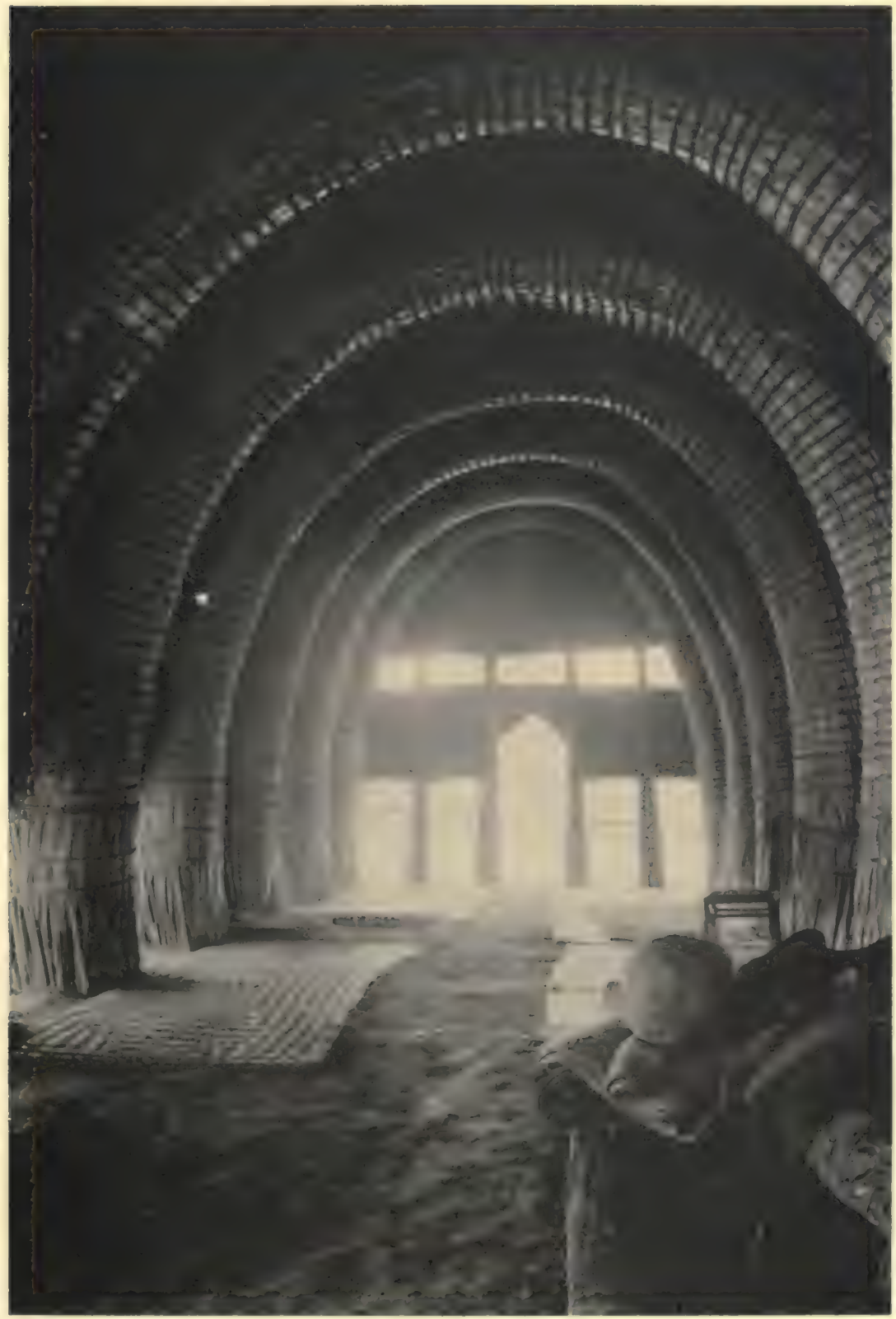

INTERIOR OF SHEIKH KHAZAL IBN FALIH'S GUEST HUT 

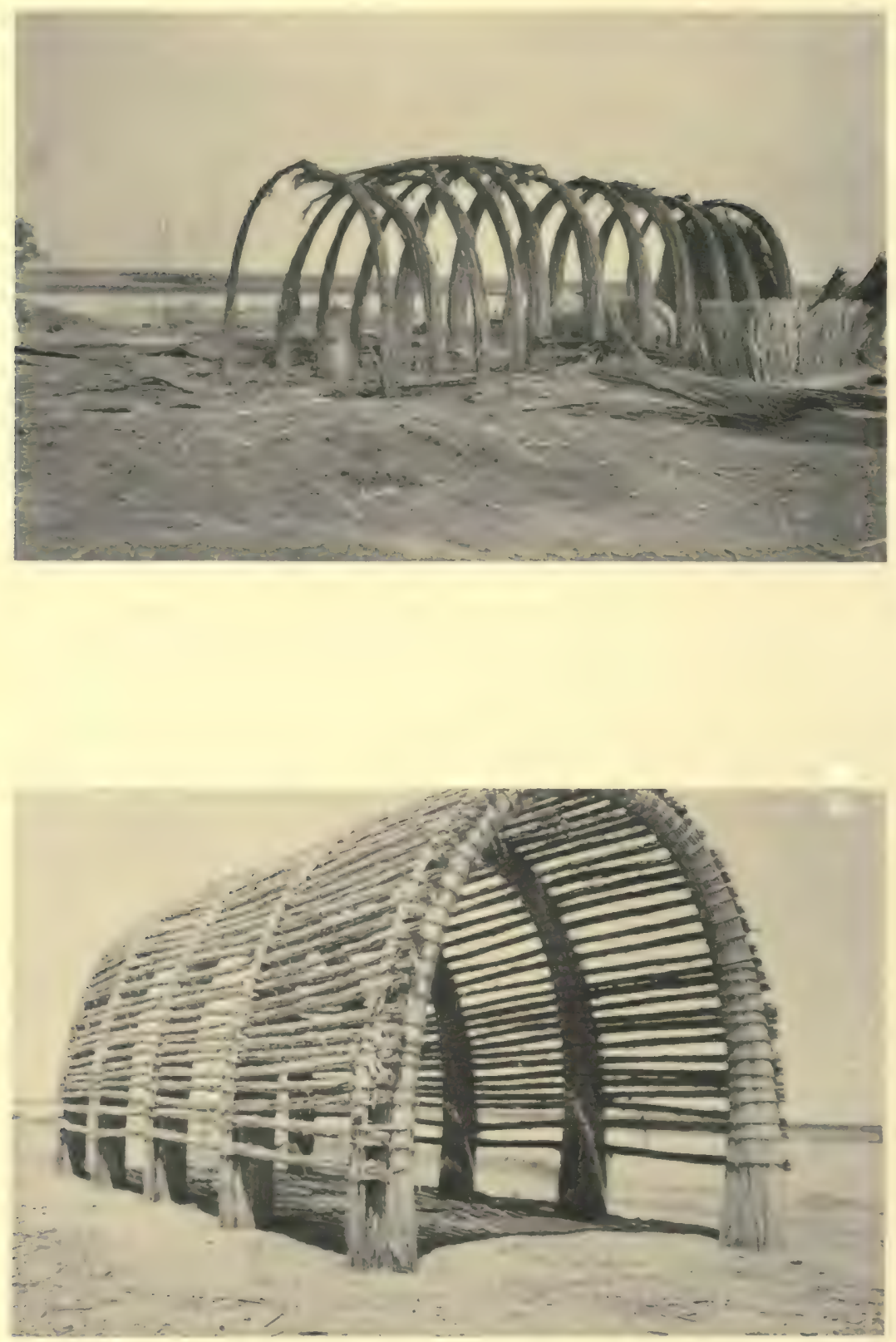

FRAMEWORK OF A REED HUT 


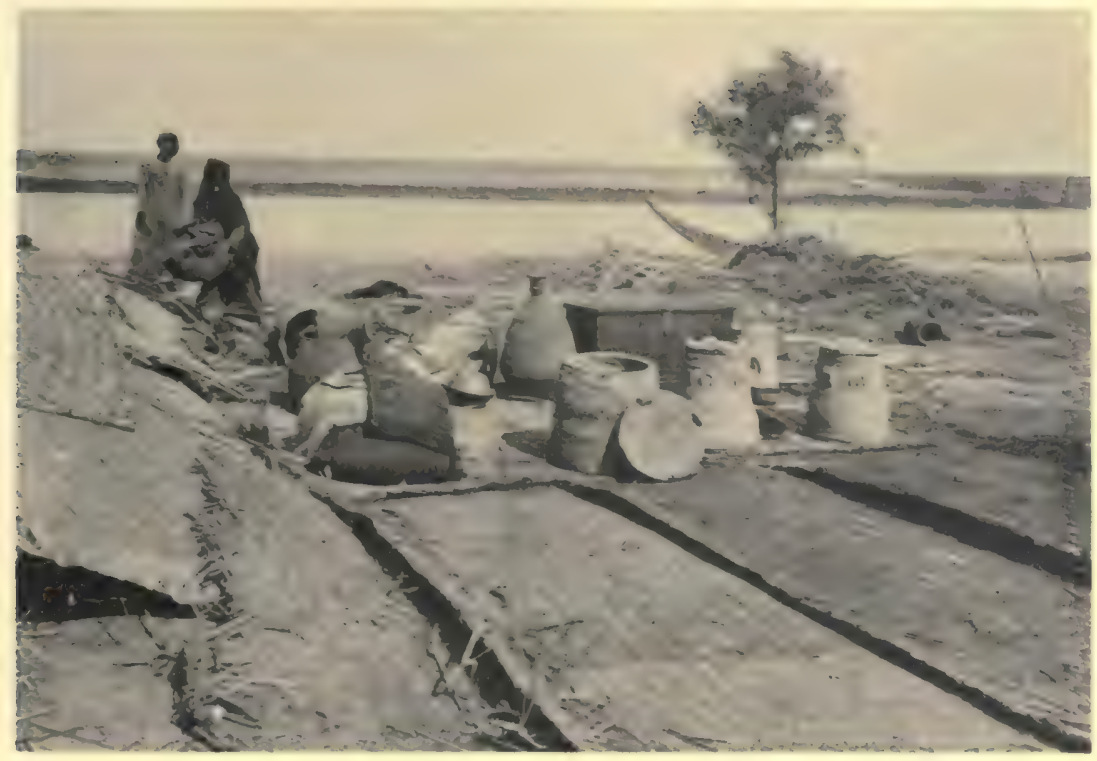

Fig. 1. Household furniture

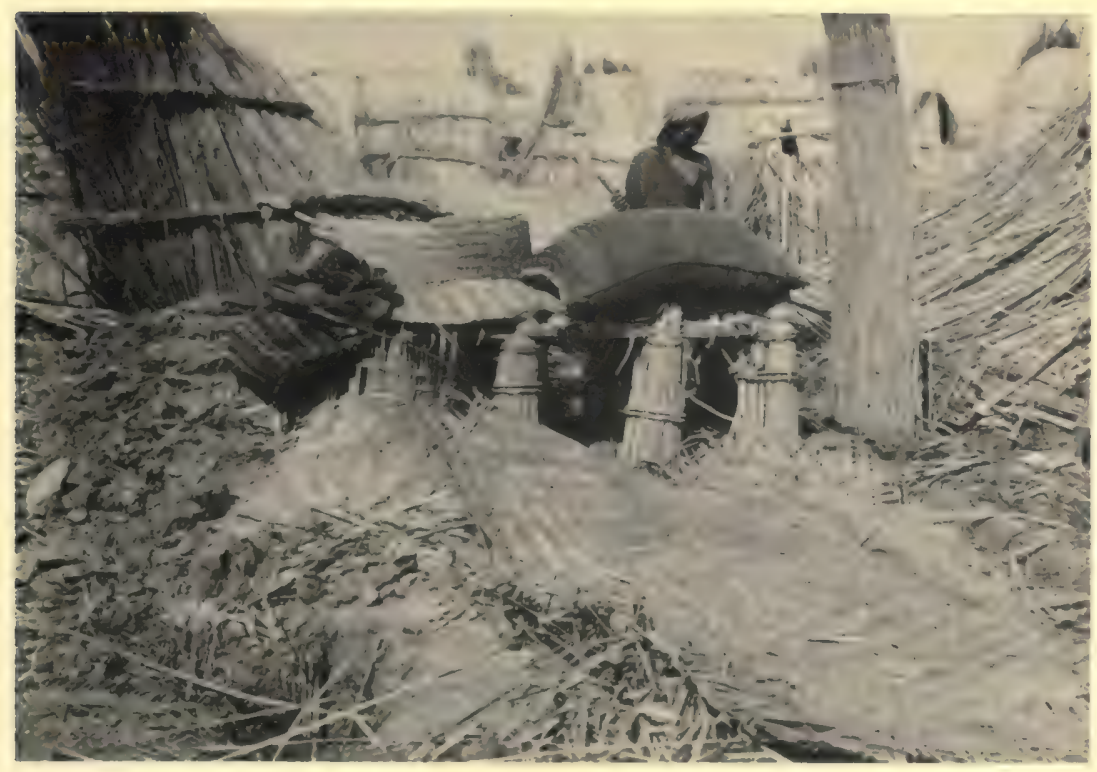

Fig. 2. Raised bed 


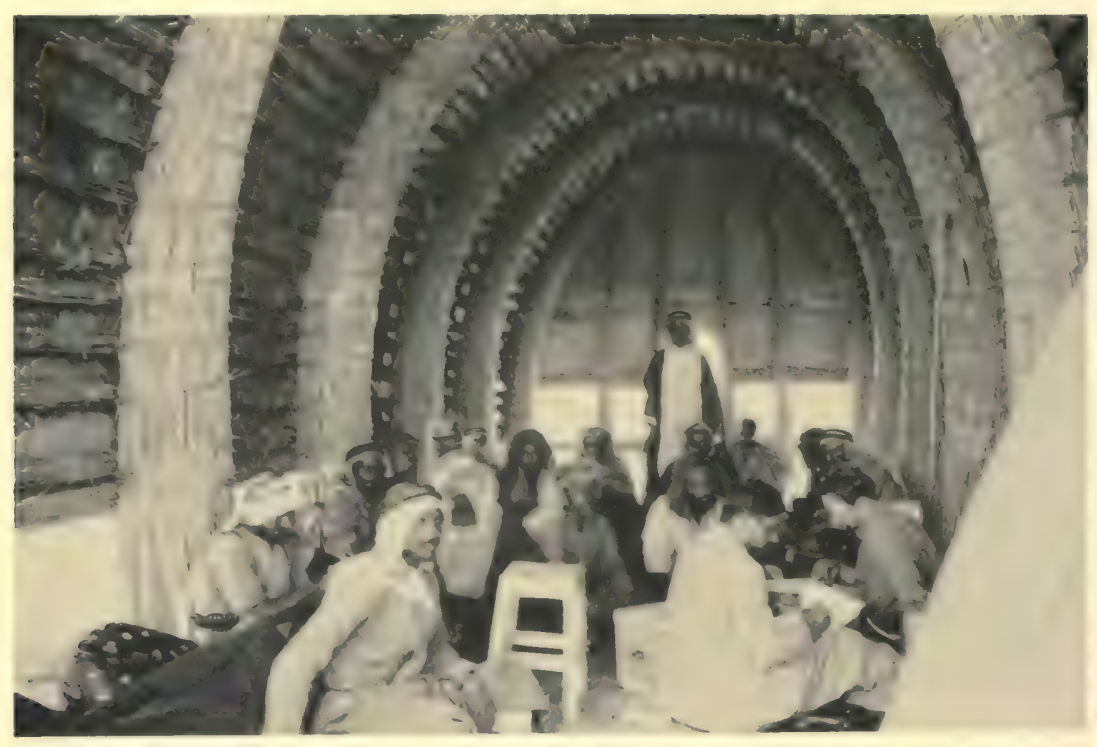

Fig. 1. Interior of council house

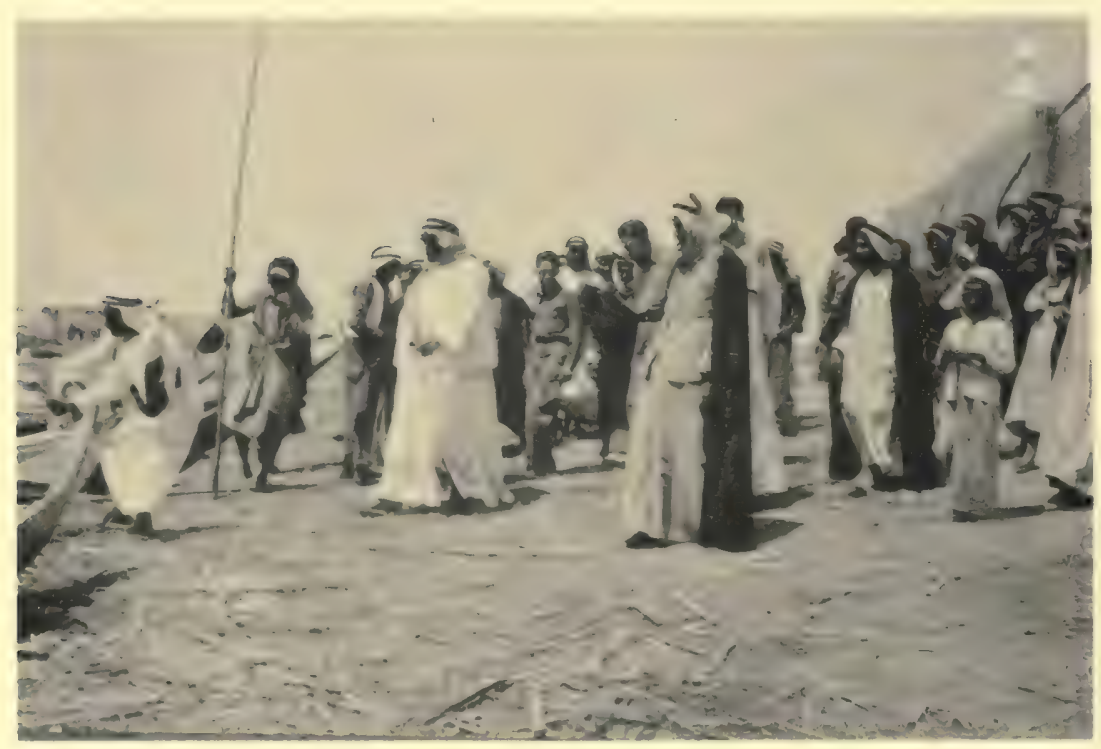

Fig. 2. Sheikh Falih as Saihud entering boat 


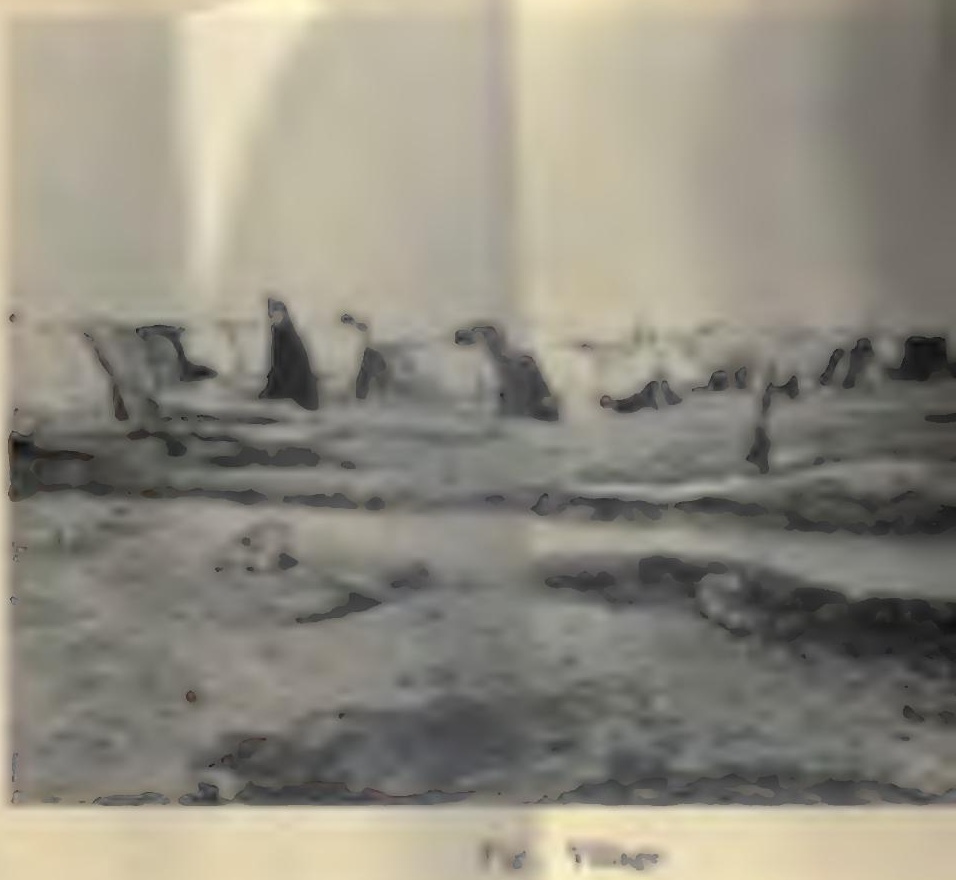

2

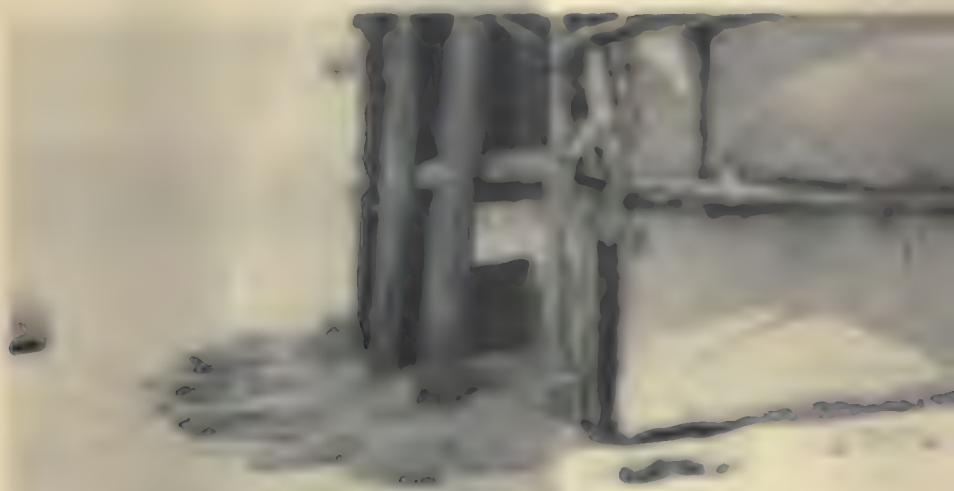

6

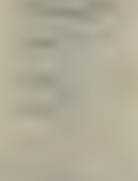

$\therefore \rightarrow$

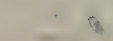

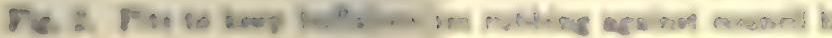



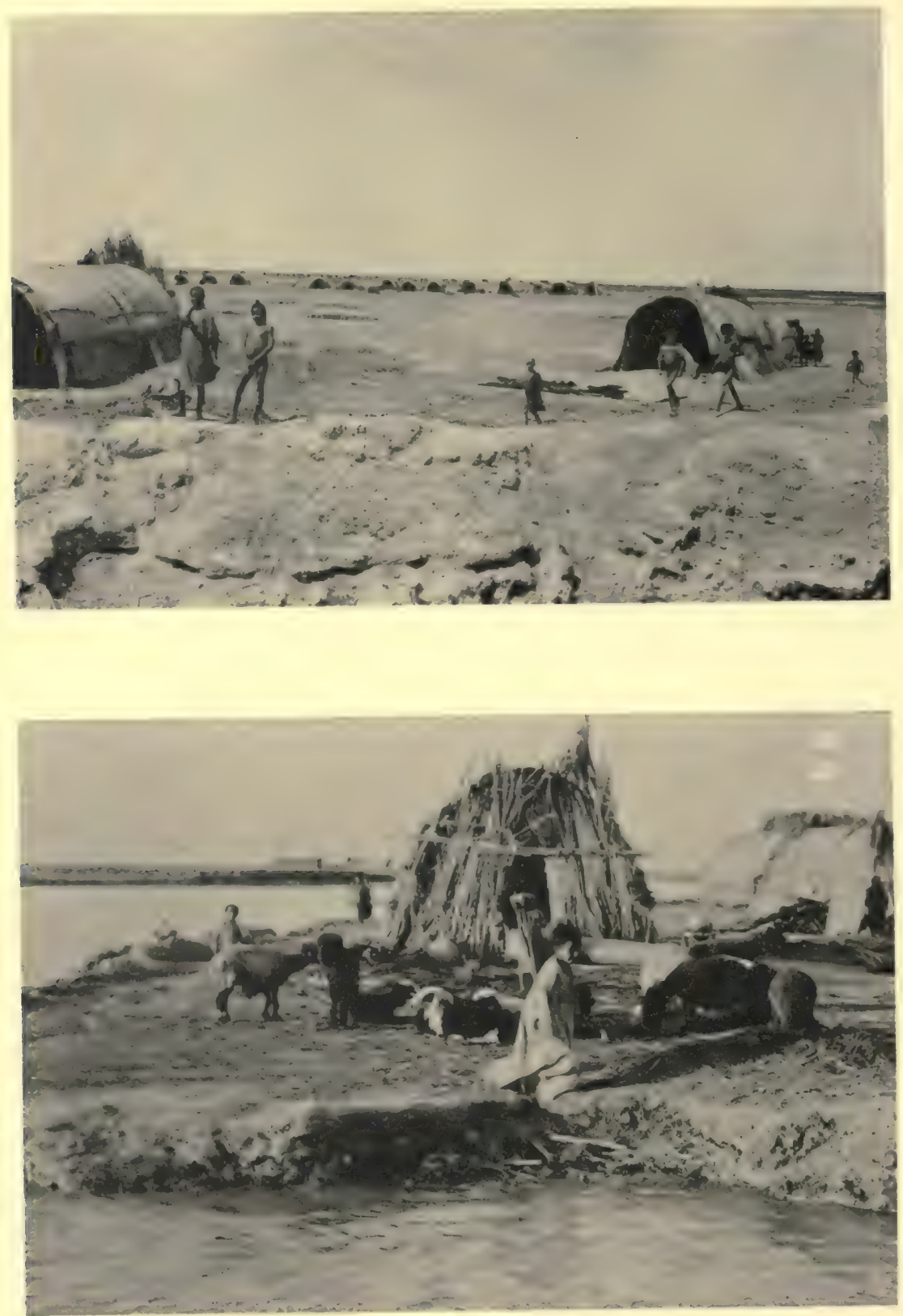

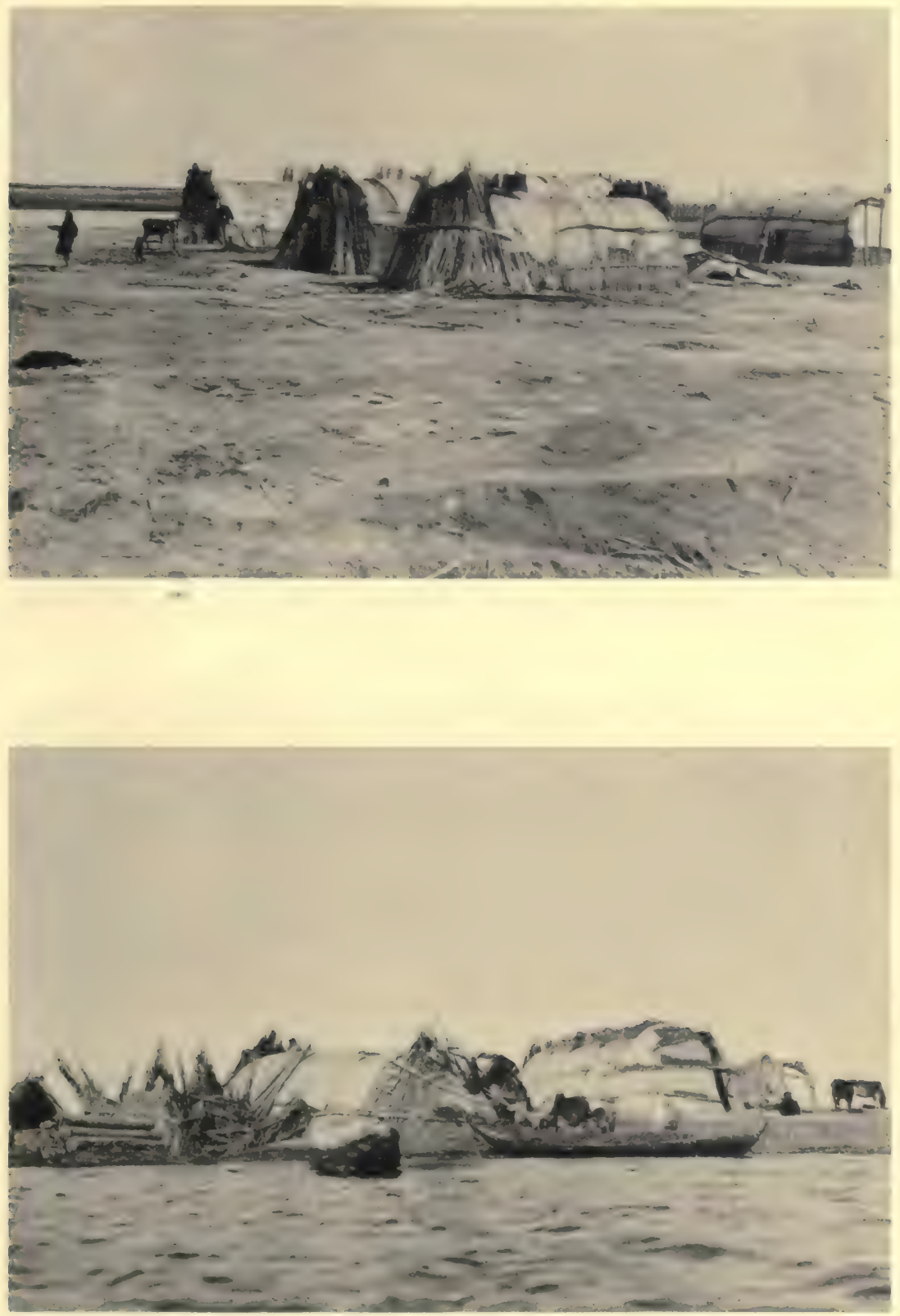

VIEWS OF BEIDHA 


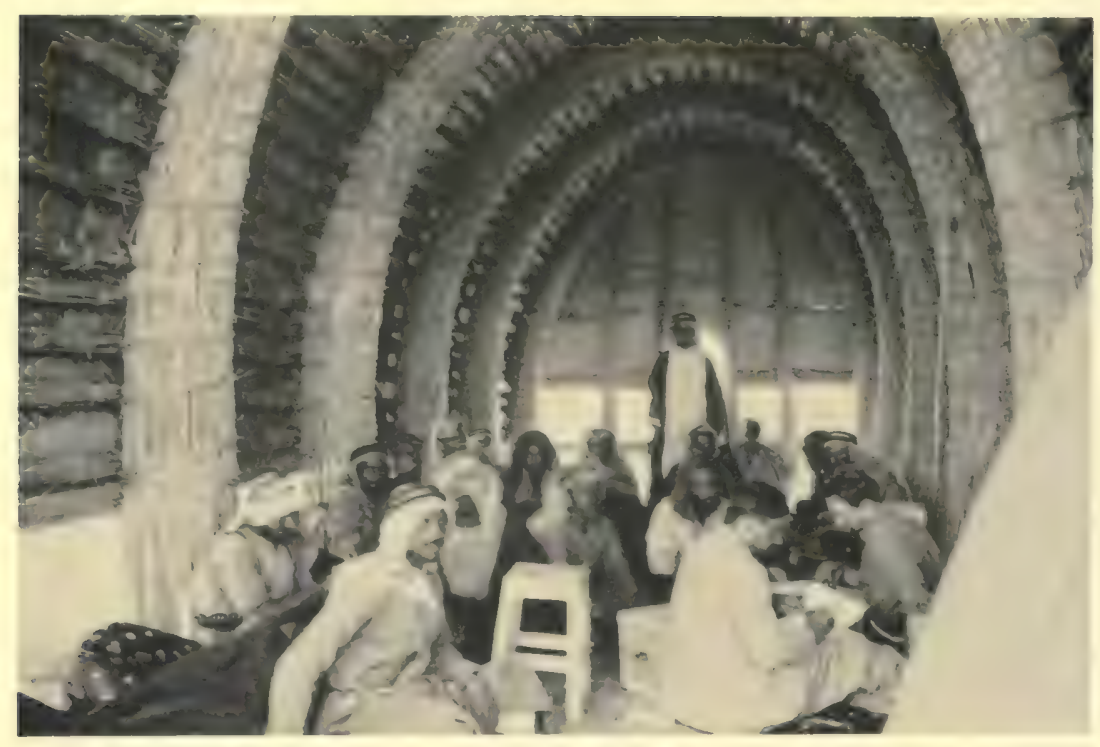

Fig. 1. Interior of council house

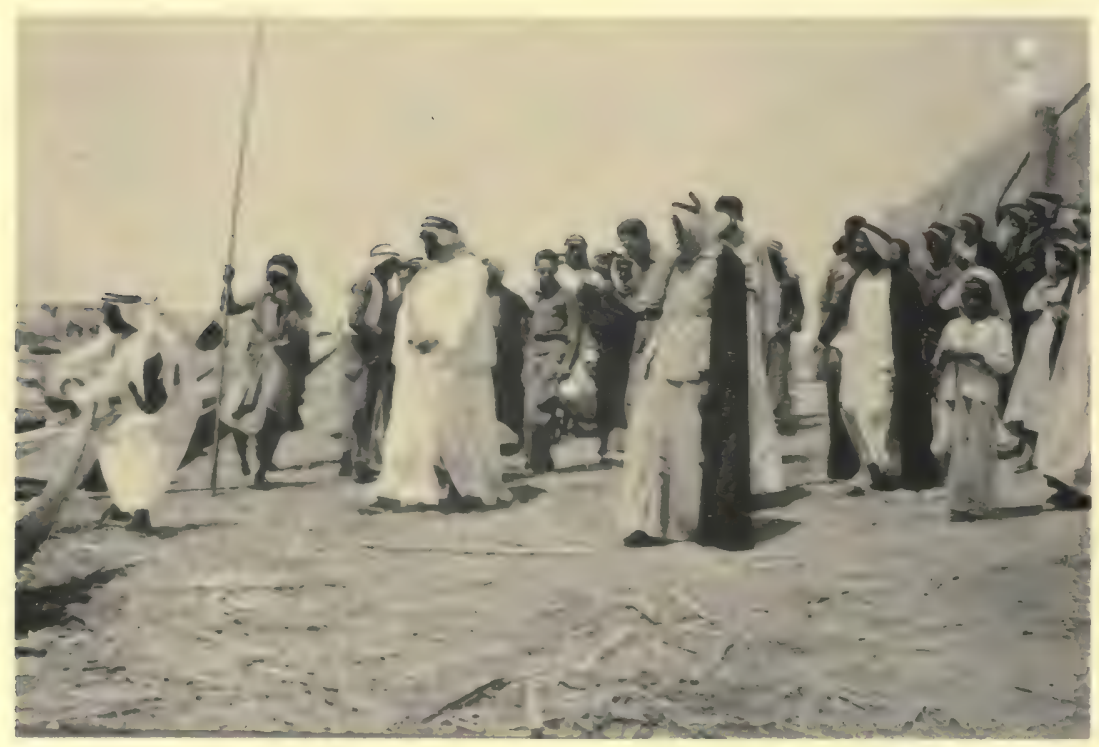

Fig. 2. Sheikh Falih as Saihud entering boat 


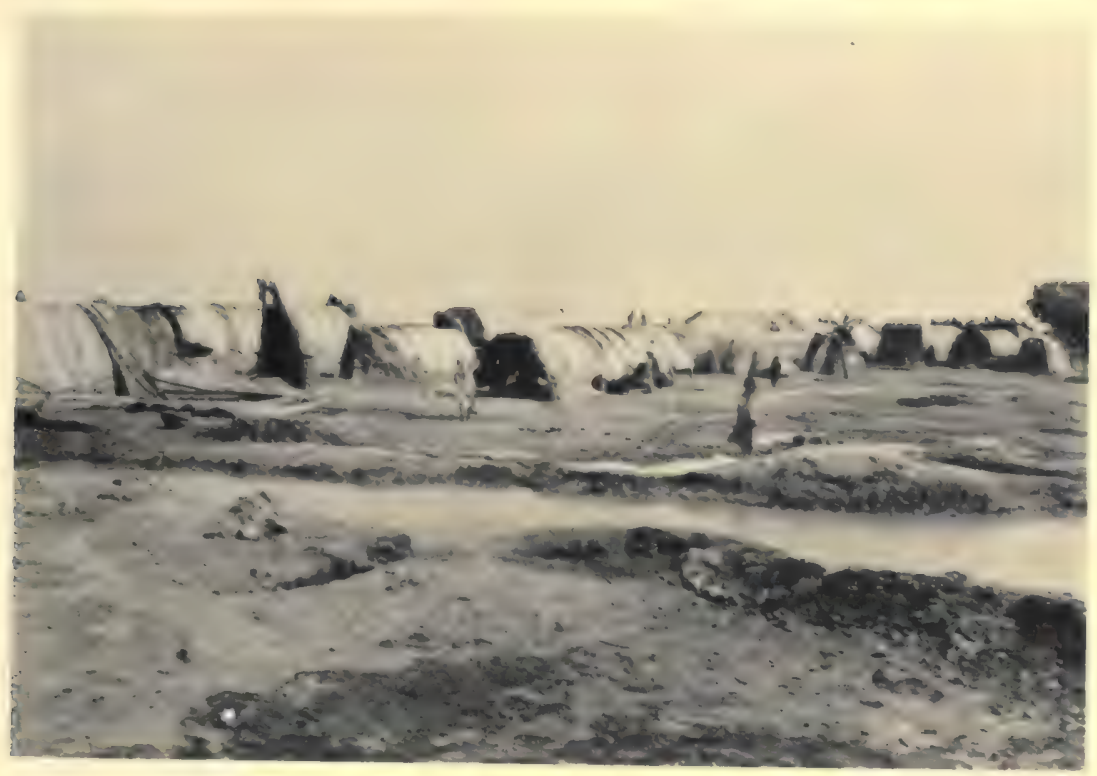

Fig. 1. Village

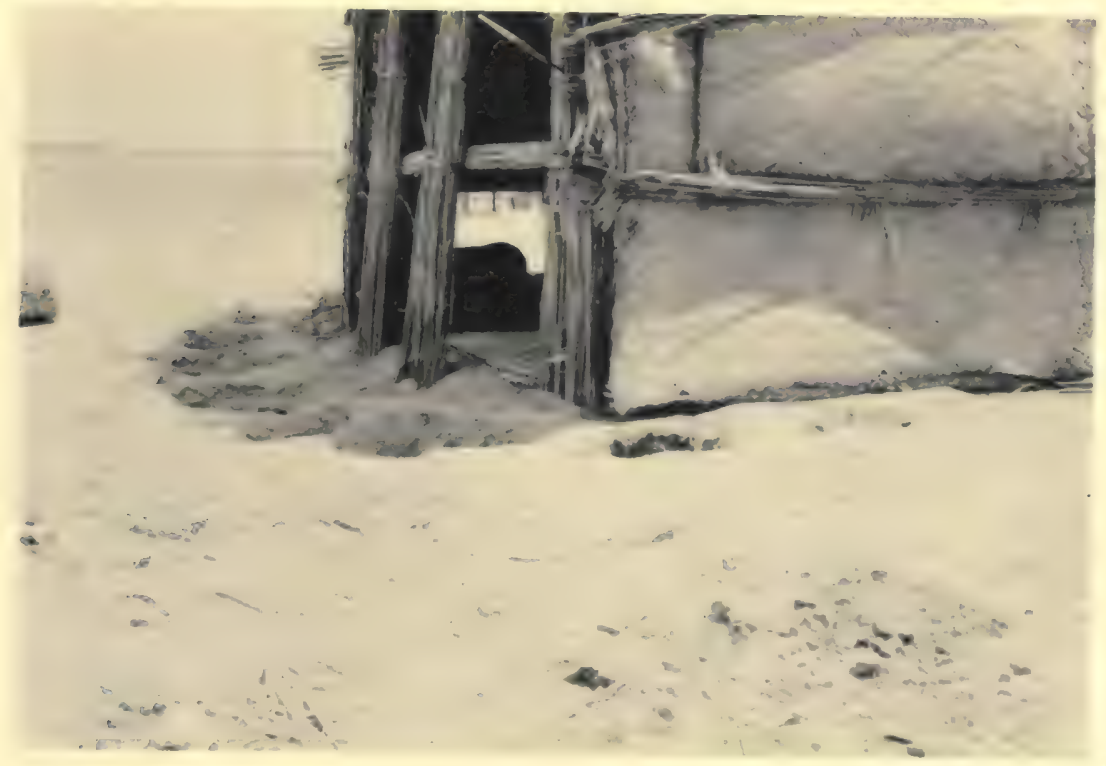

Fig. 2. Pits to keep buffaloes from rubbing against council house 

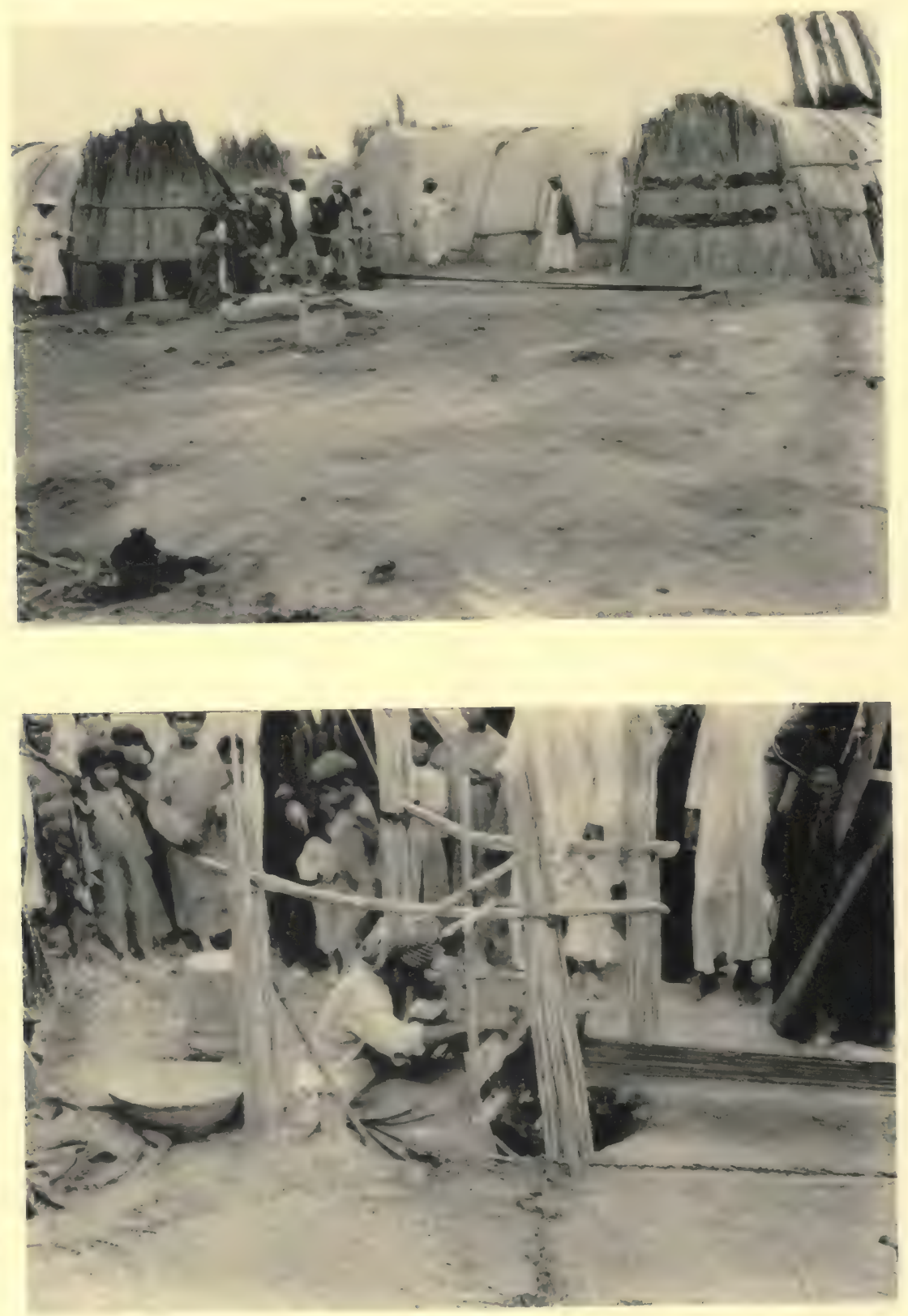

WEAVING AT SHEIKH FALIH AS SAIHUD'S CAMP 


$$
\begin{aligned}
& \text { Album } 135 \\
& \text { Neg. No. } 104376(a 11)
\end{aligned}
$$

Field Museum of Natural History

Anthropology, Vol. 30, Plate 61

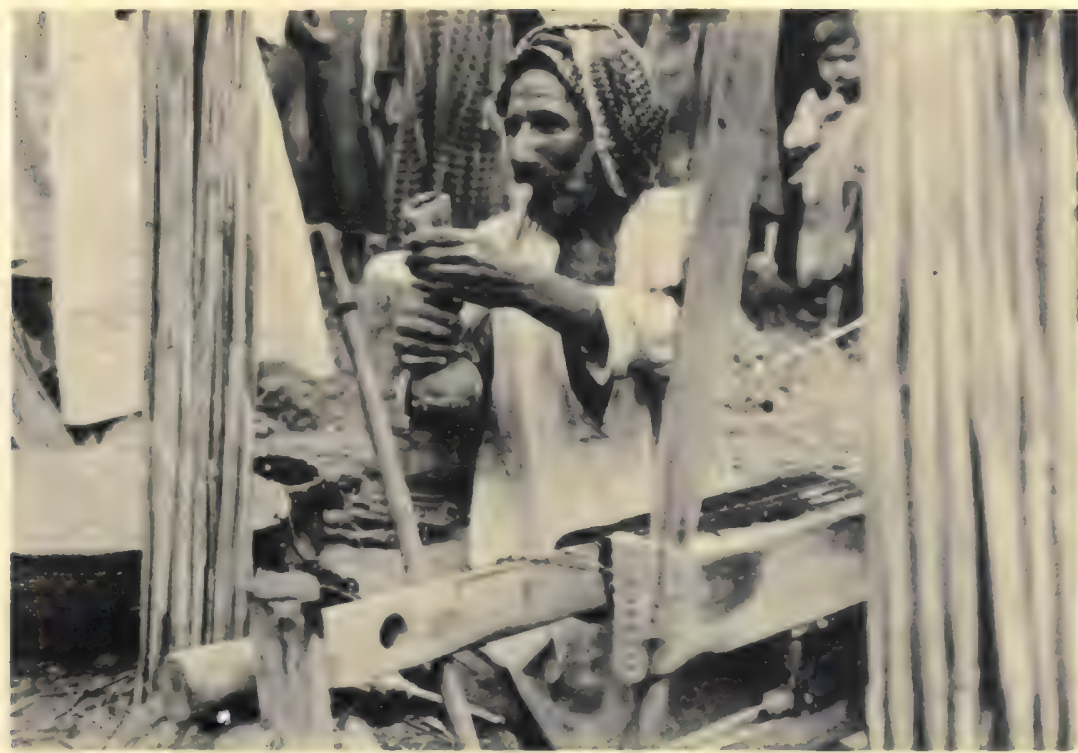

Fig. 1. Weaver smoking pipe

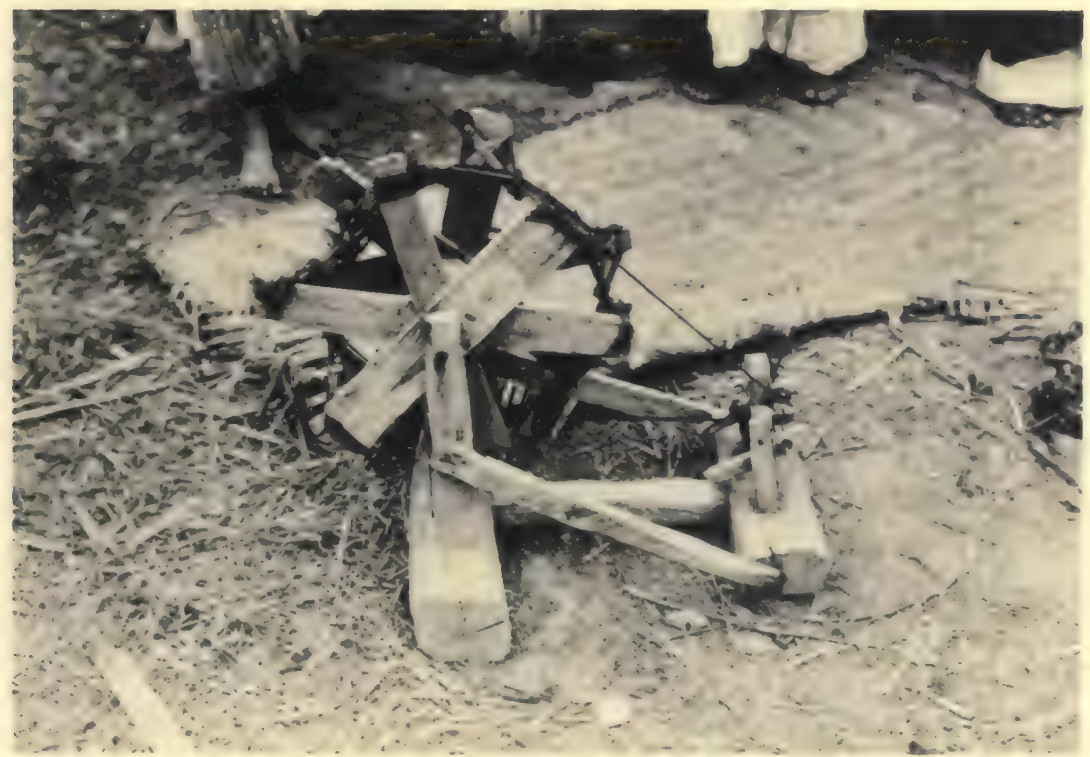

Fig. 2. Spinning wheel 

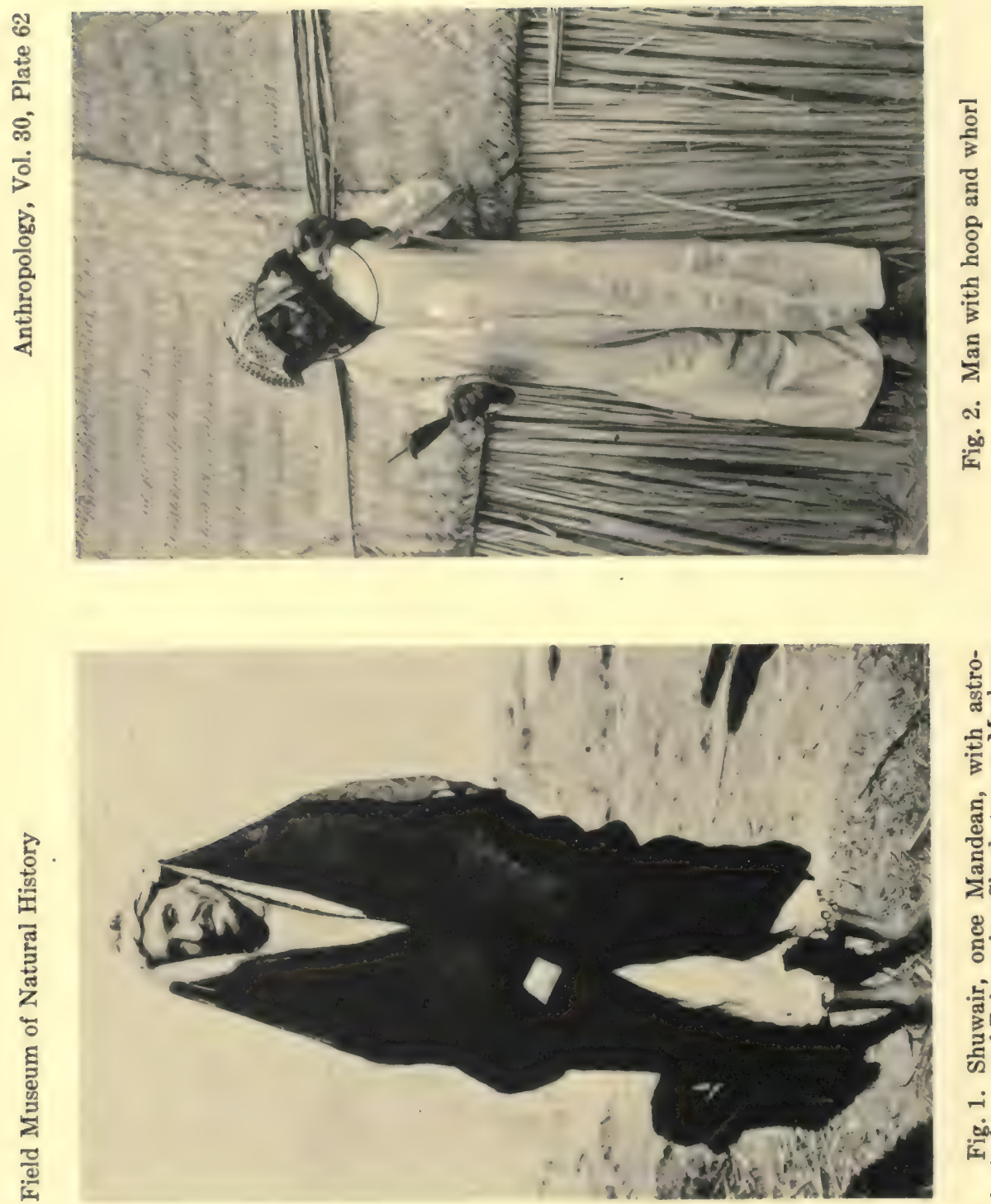

월

证

응 हี้ 踏 \& ธีํ 들 ह 需 วี้ ธี 心 so (당 도웡 


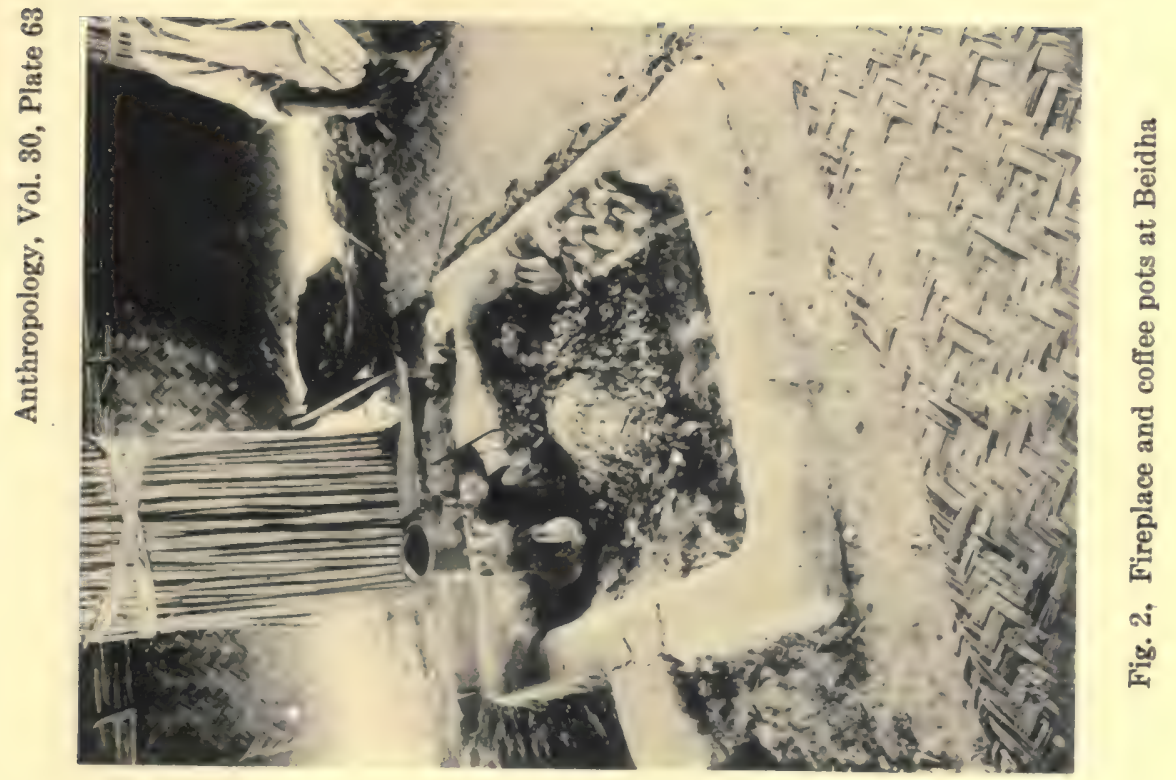

总
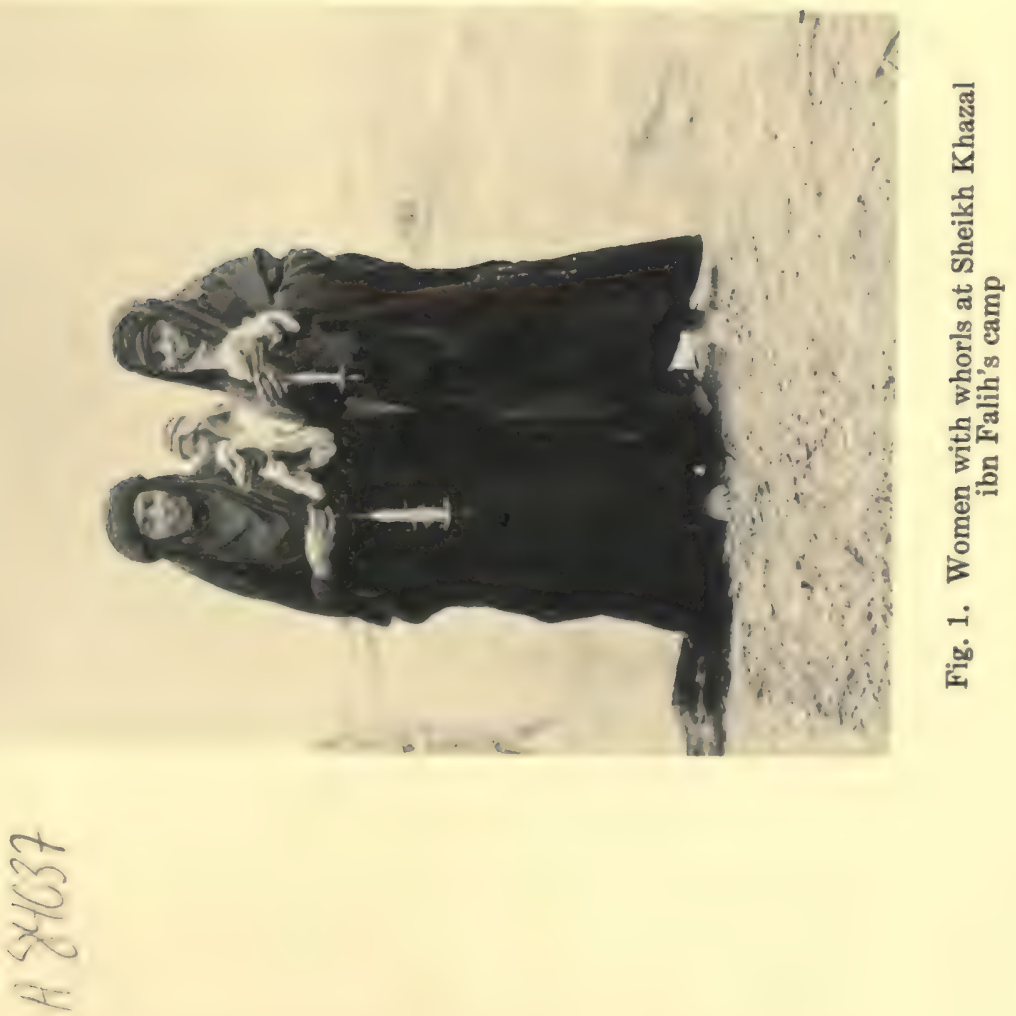

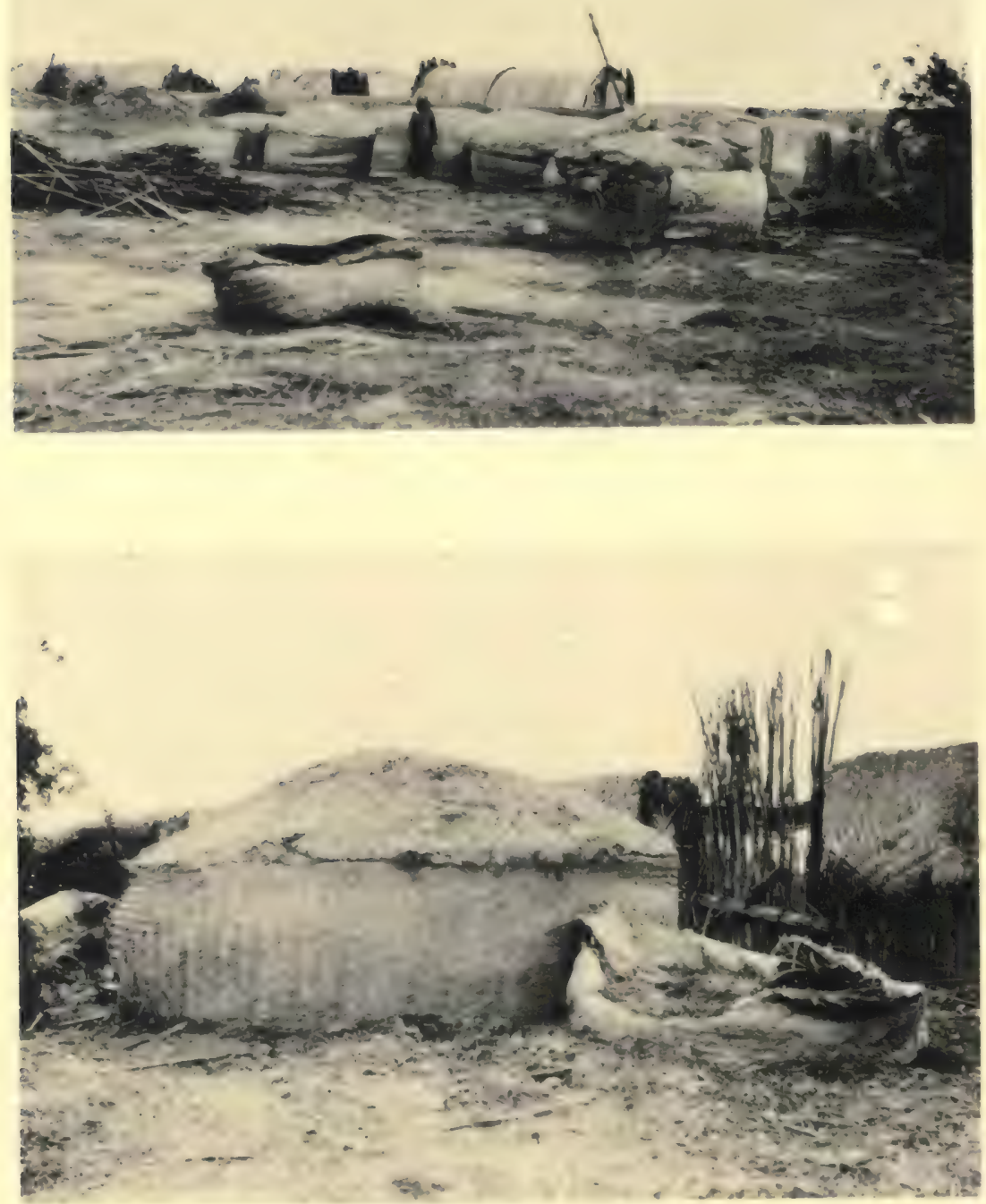

RICE BINS AT SHEIKH KHAZAL IBN FALIH'S CAMP 


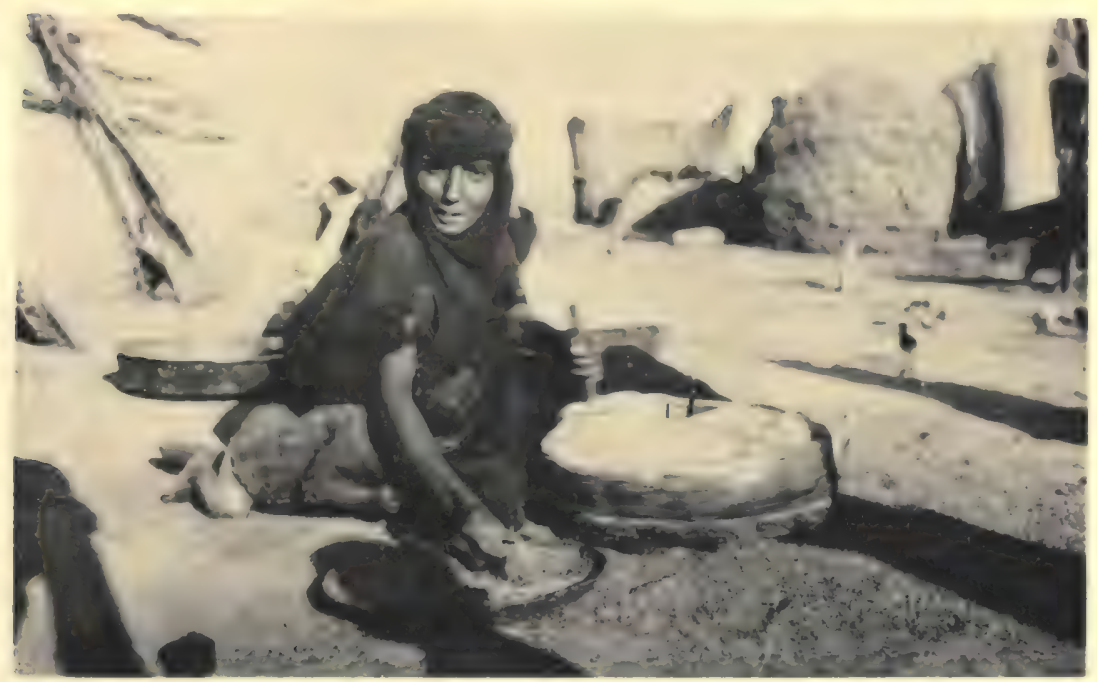

Fig. 1. Milling rice in a quern

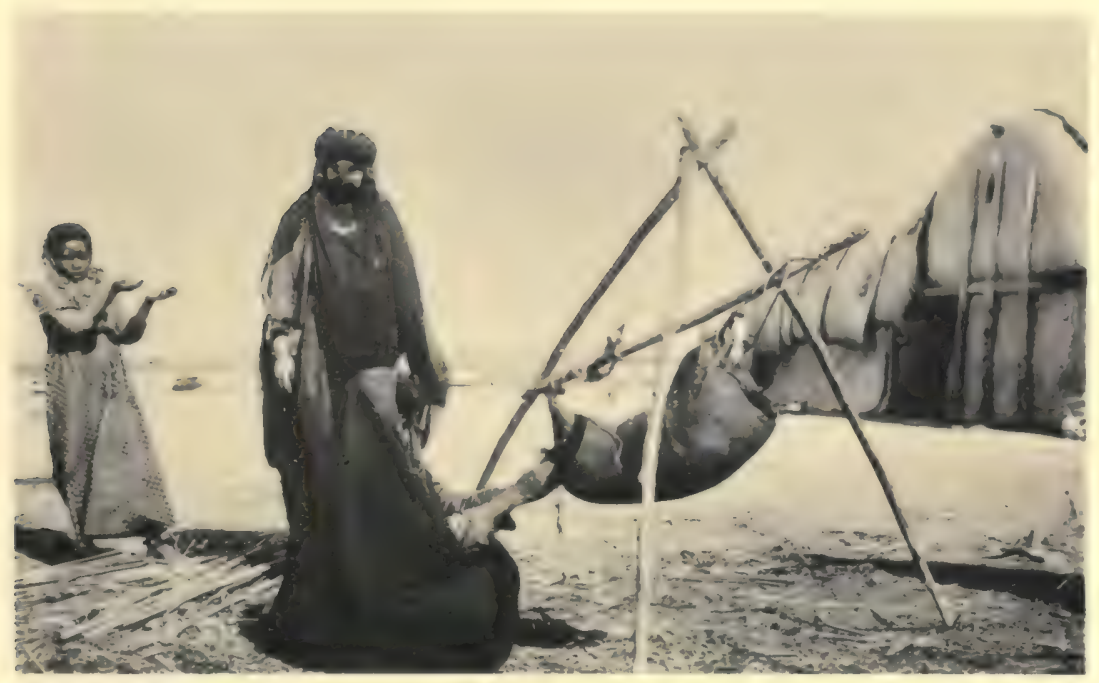

Fig. 2. Making butter in a swinging, goatskin churn

AL BU MUHAMMAD TRIBESWOMEN 

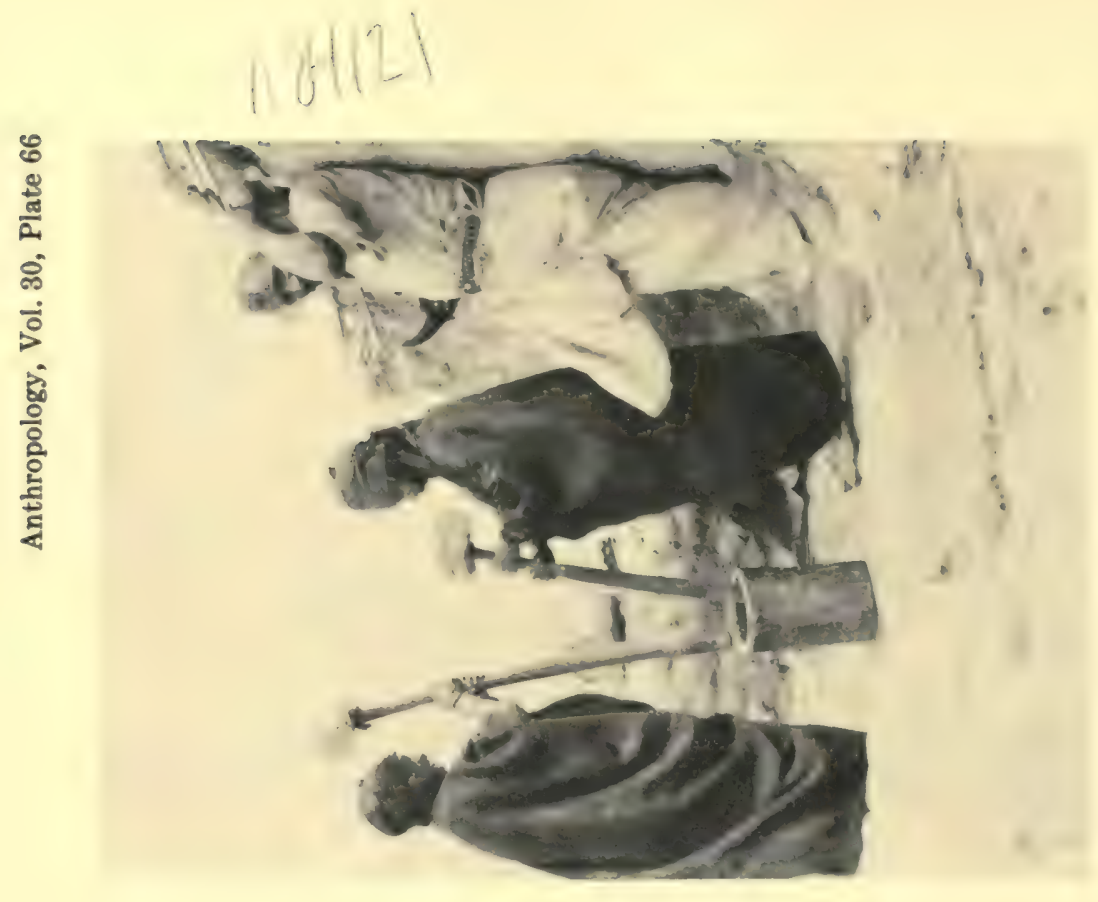

落

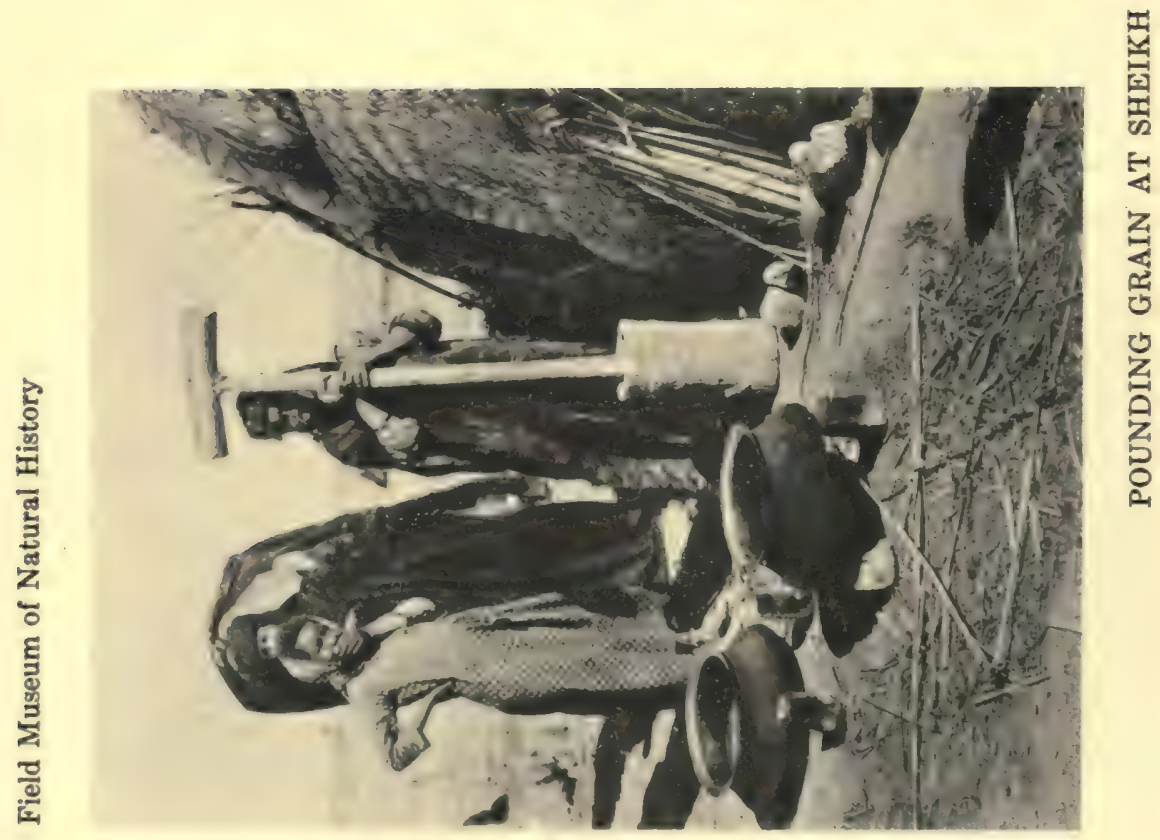

94123 


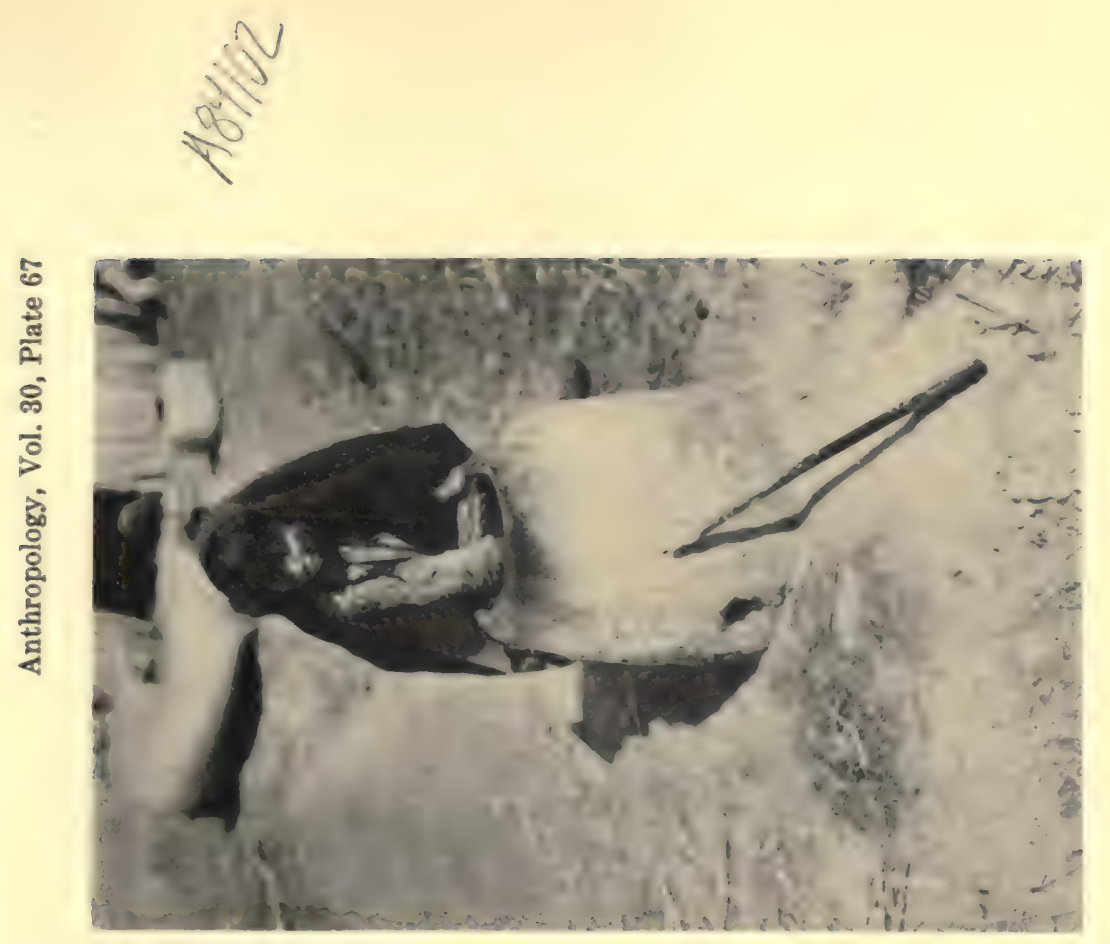

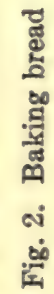

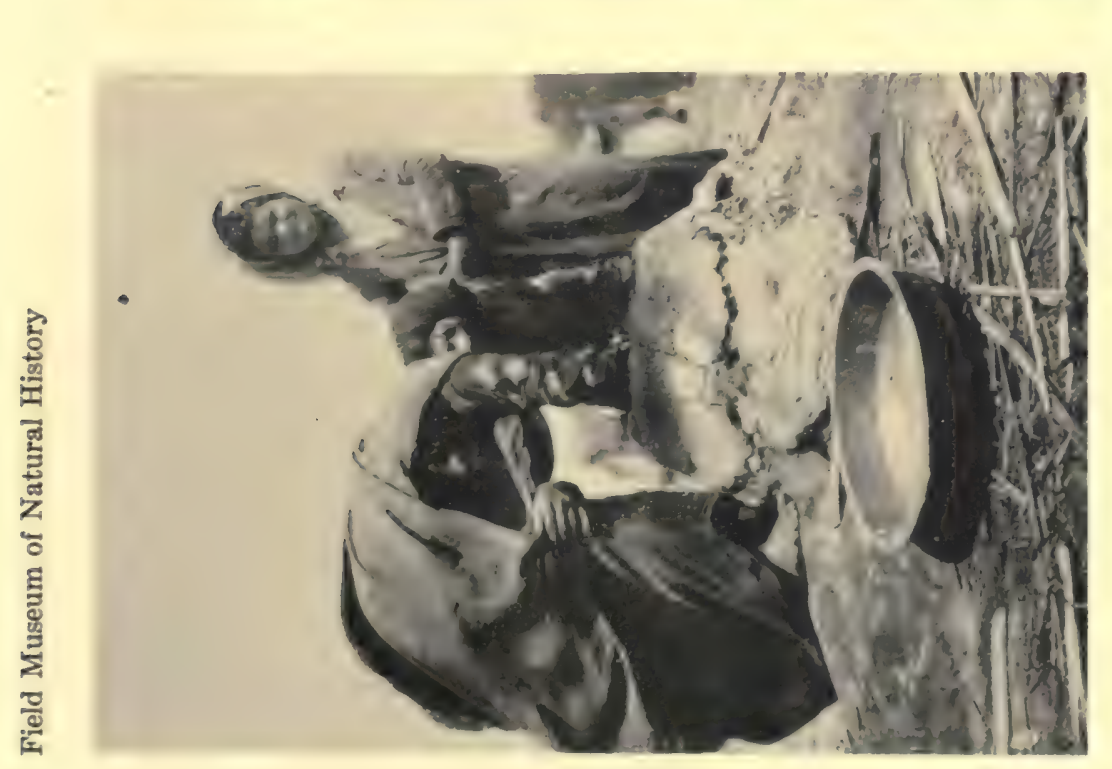

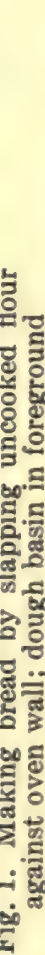

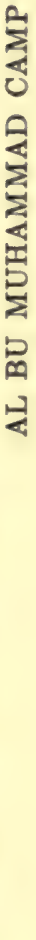




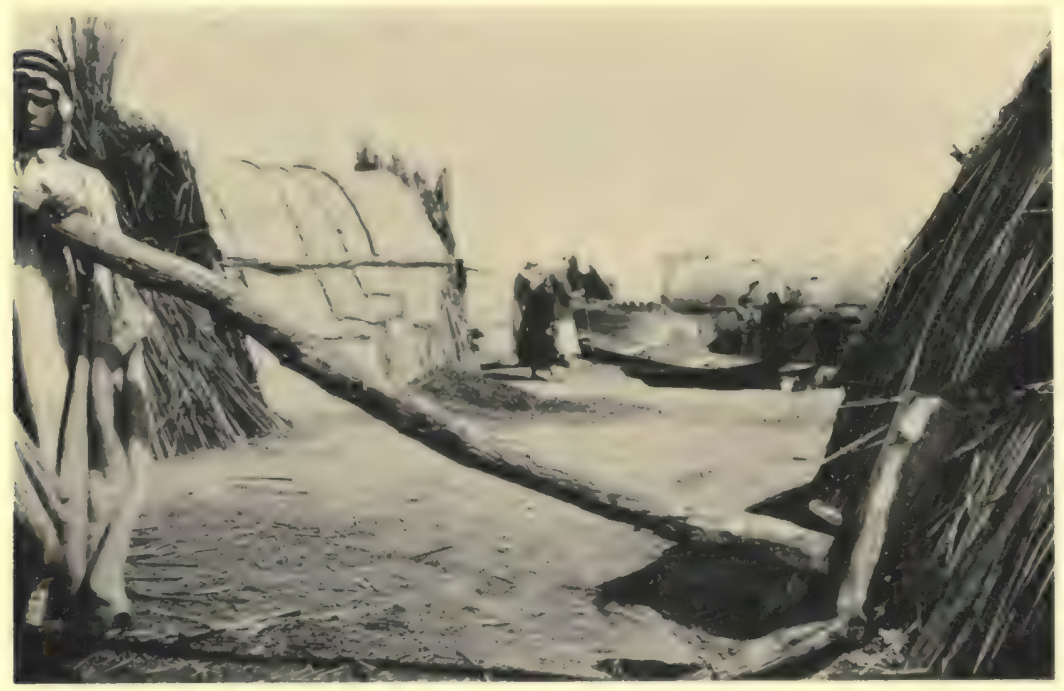

Fig. 1. Plough

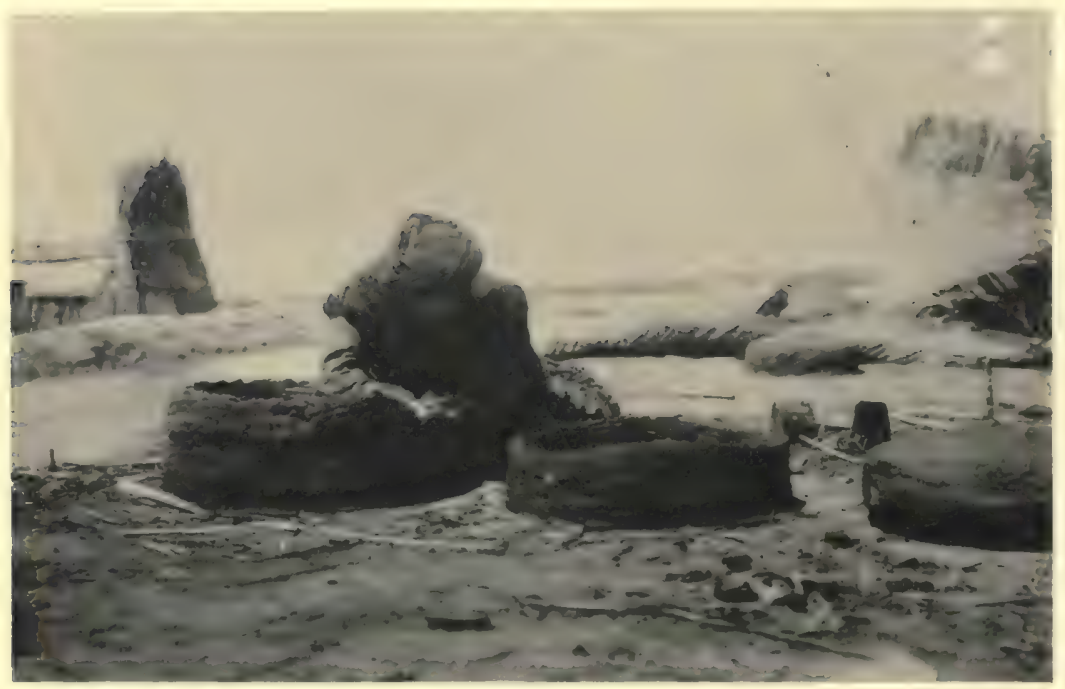

Fig. 2. Woman potter making a clay oven

\section{AL BU MUHAMMAD CAMP}




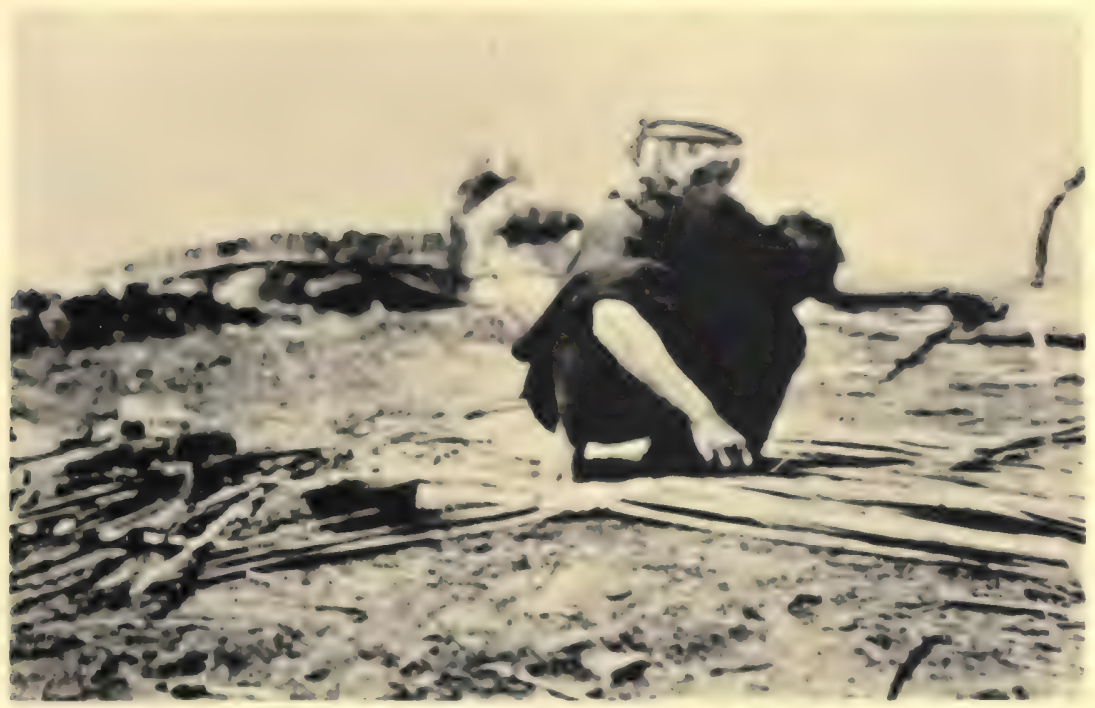

Fig. 1. Man making a reed mat

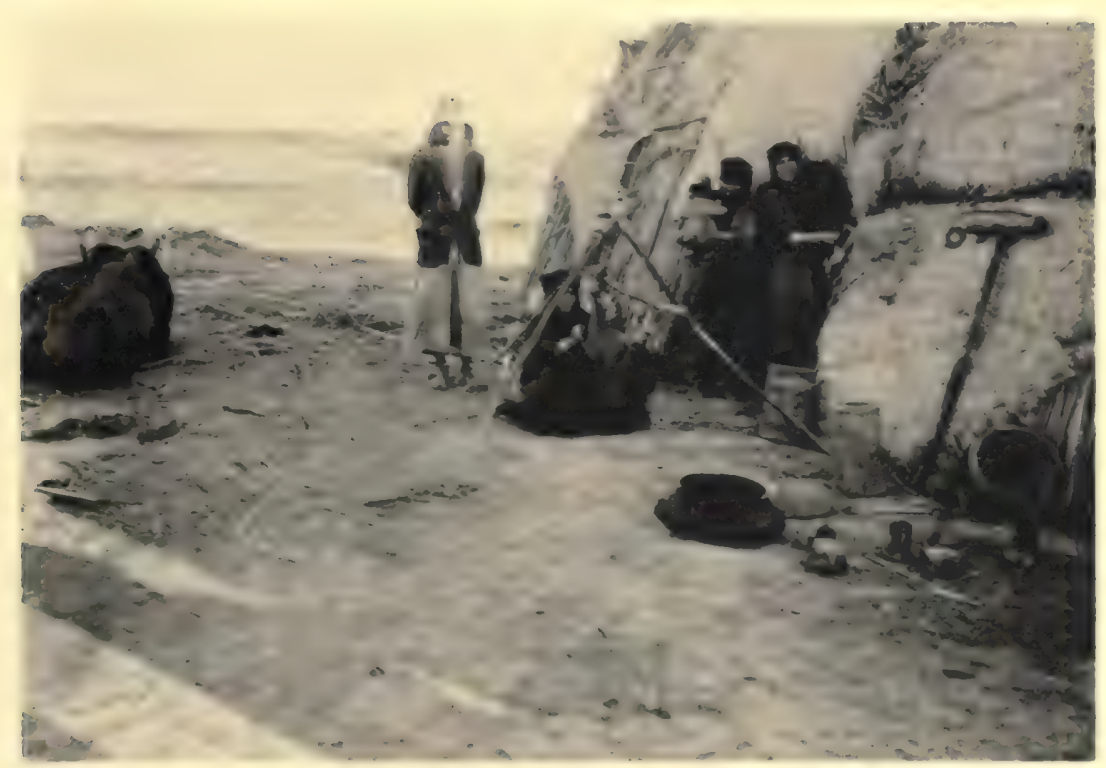

Fig. 2. Woman churning butter

AL BU MUHAMMAD CAMP 


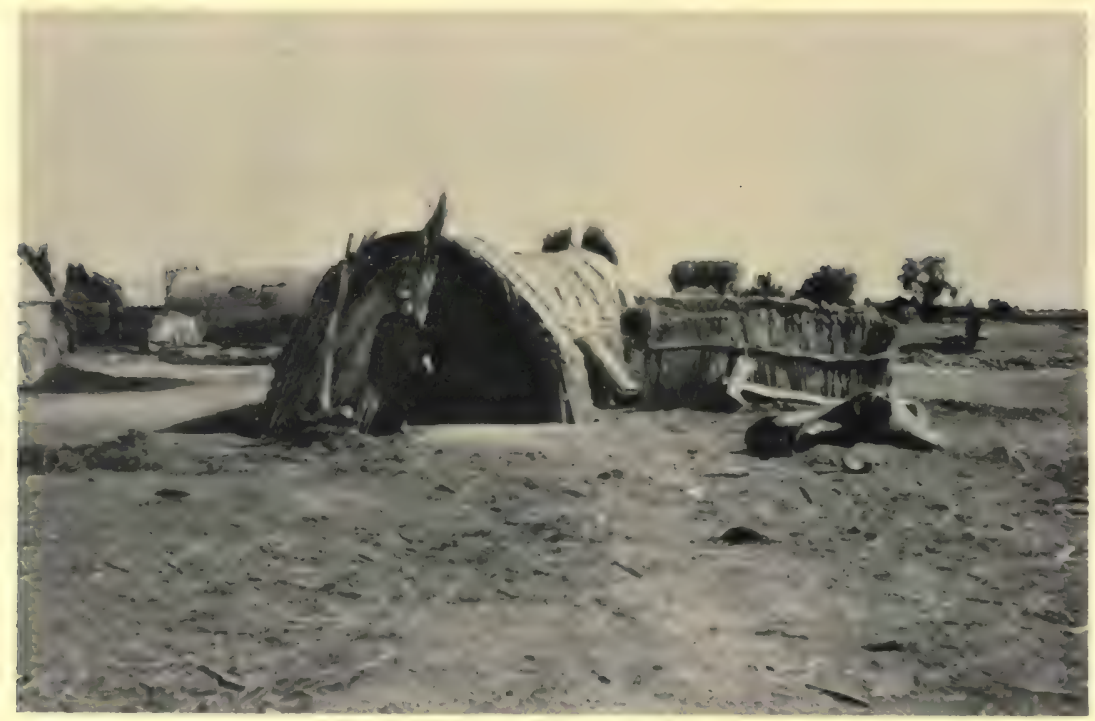

Fig. 1. Cattle pen next to house

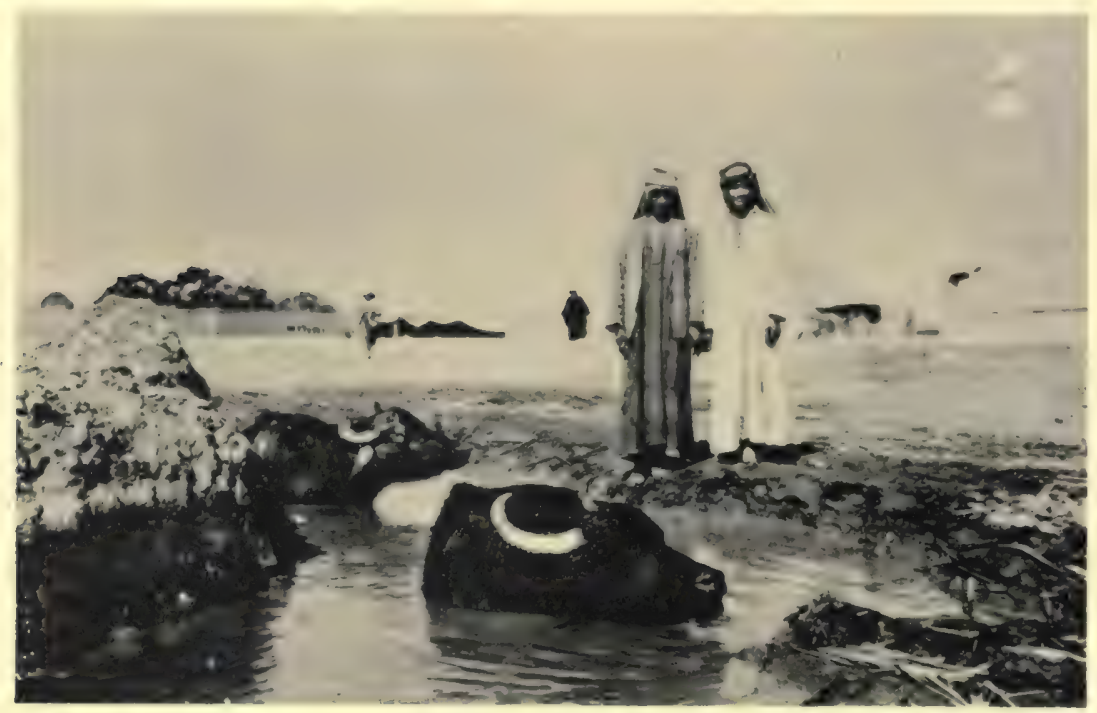

Fig. 2. Buffaloes in a wallow 

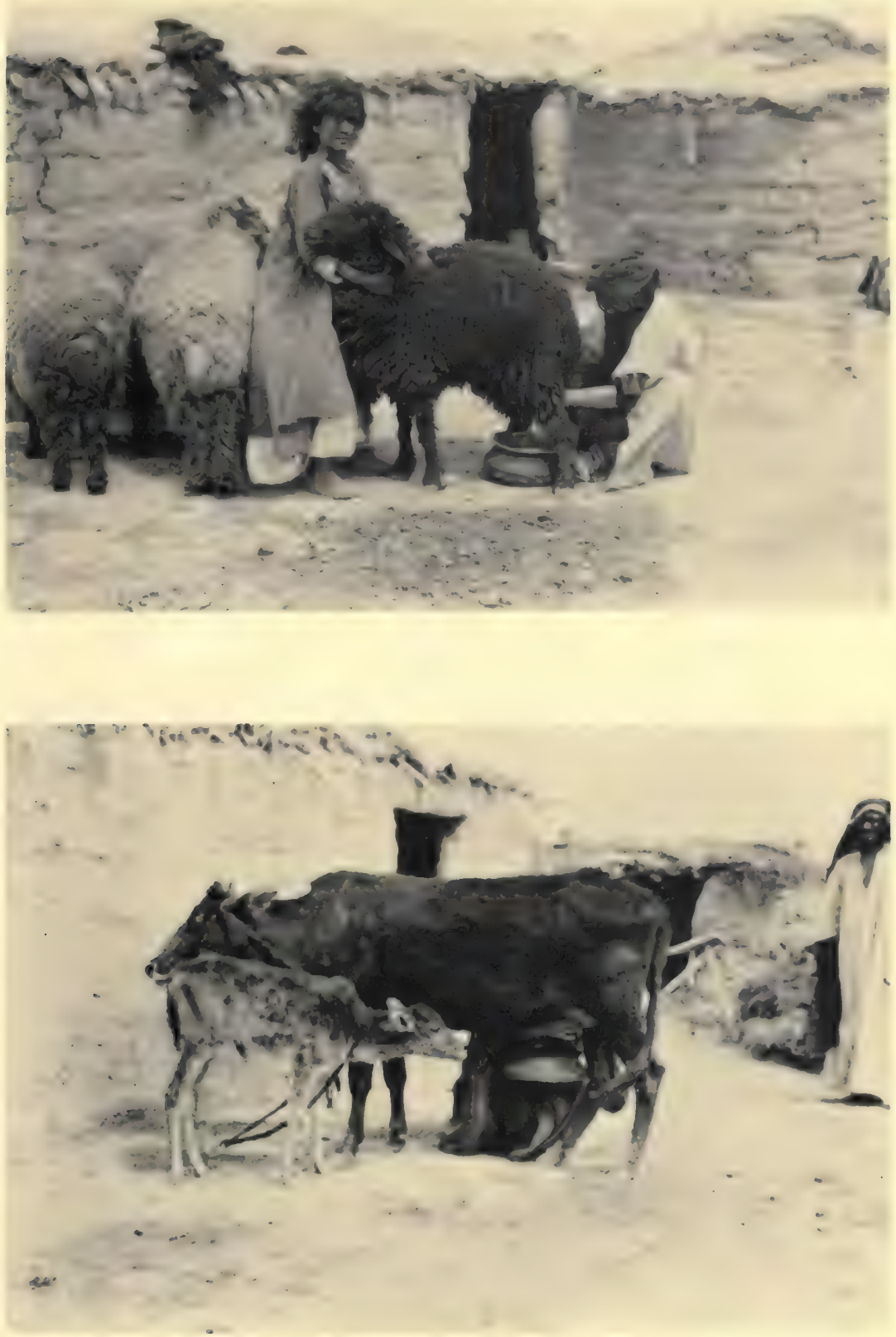

MILKING SHEEP AND CATTLE AT CAMP OF SHEIKH KHAZAL IBN FALIH 


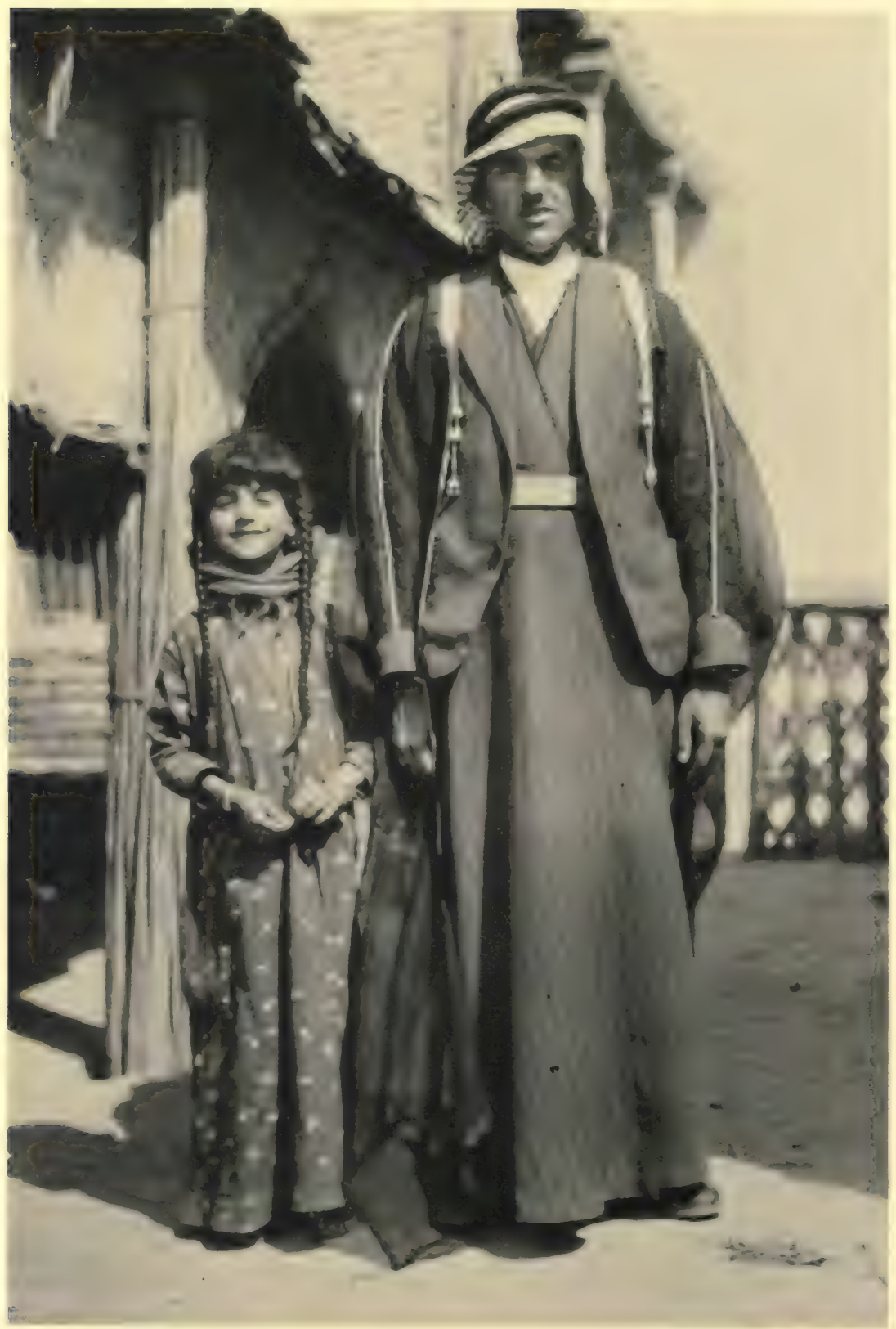

SHEIKH KHAZAL IBN FALIH AND HIS DAUGHTER 

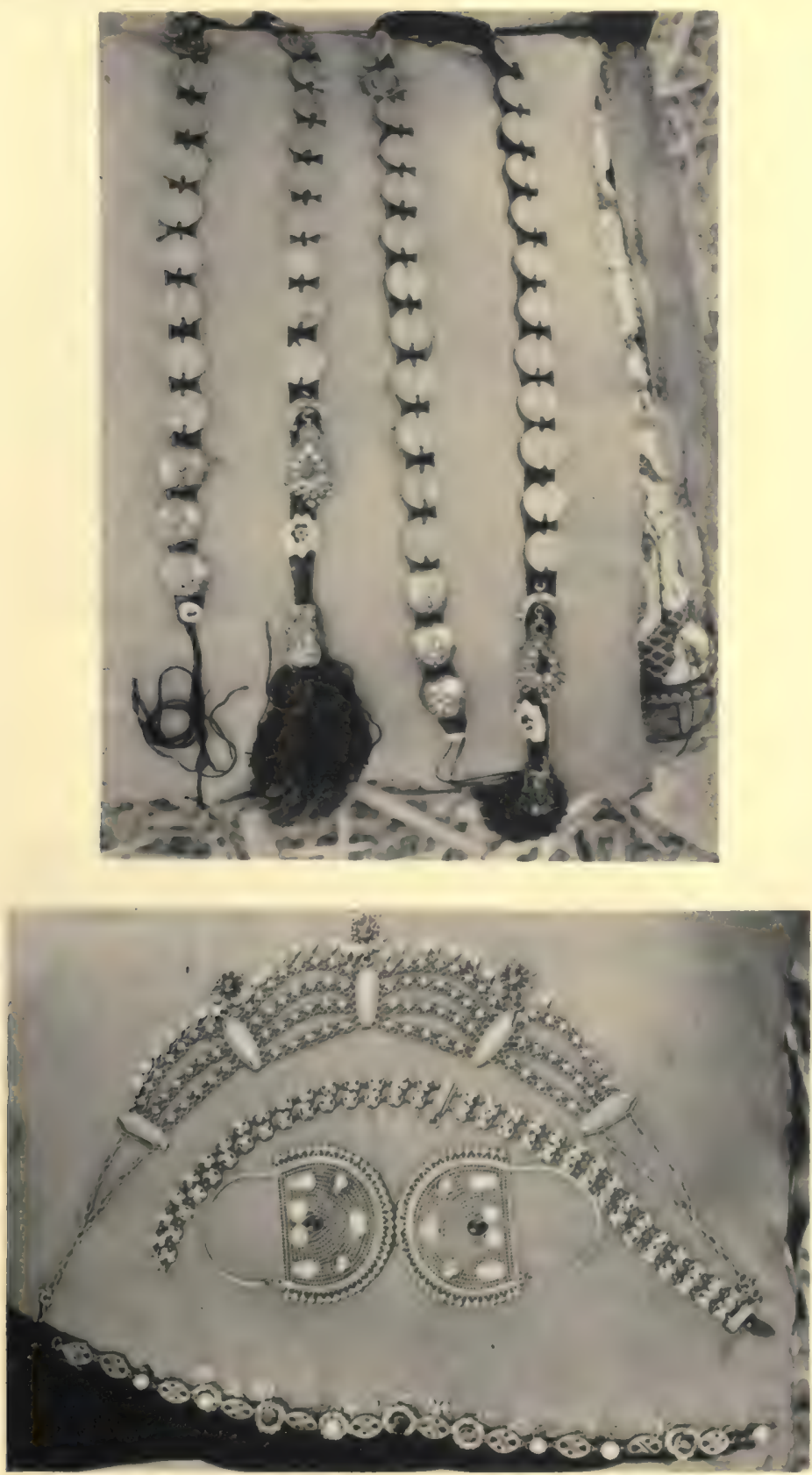

JEWELRY OF AN AL BU MUHAMMAD WOMAN 


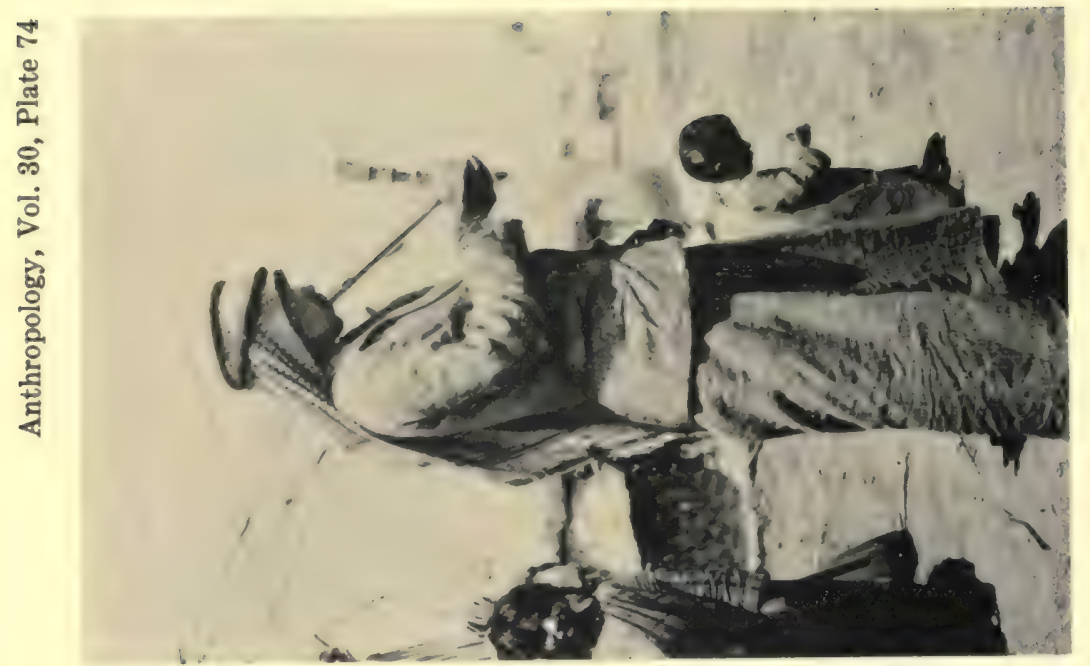

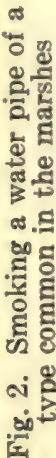

告
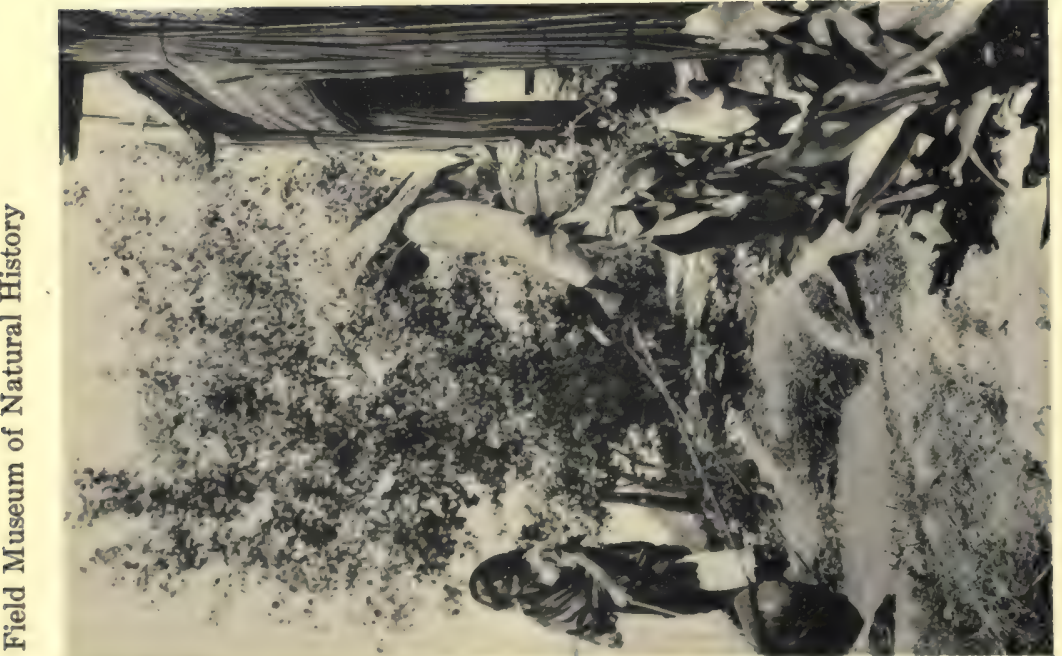

.

$\mp$

ڤે

음

禹

㤩

$-i$

栗 


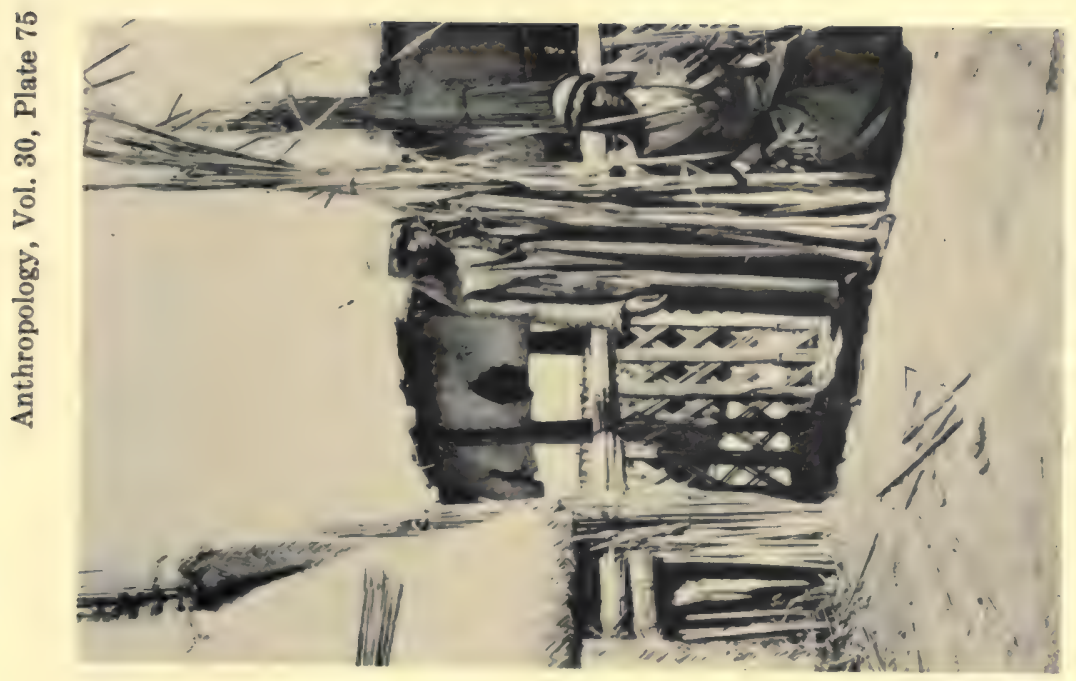

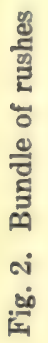

$\sum_{0}^{\circ}$

岕

졸

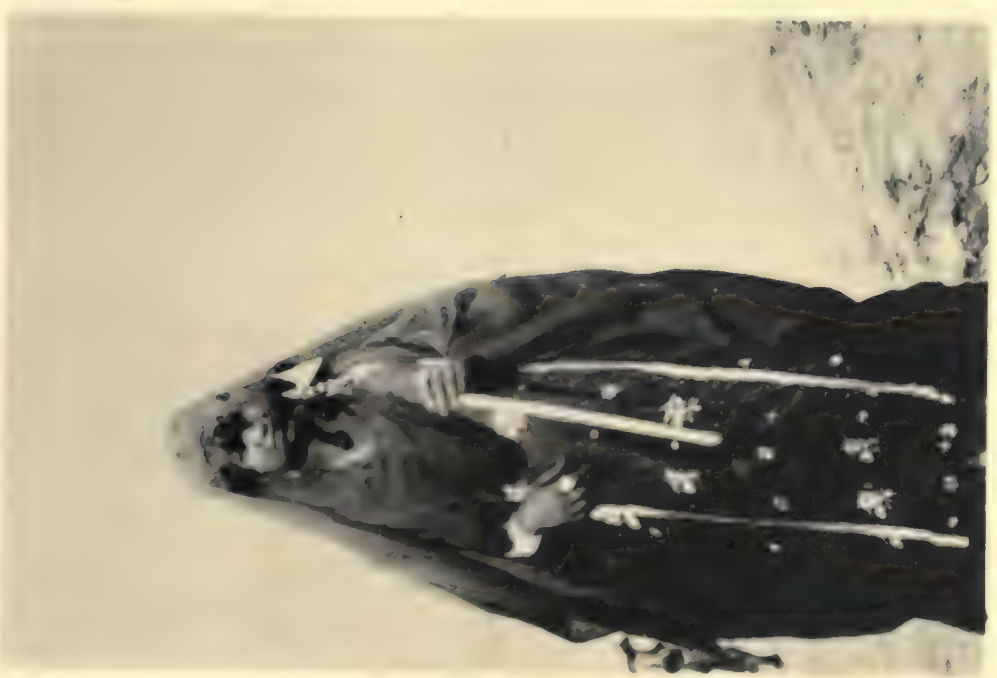

멸 


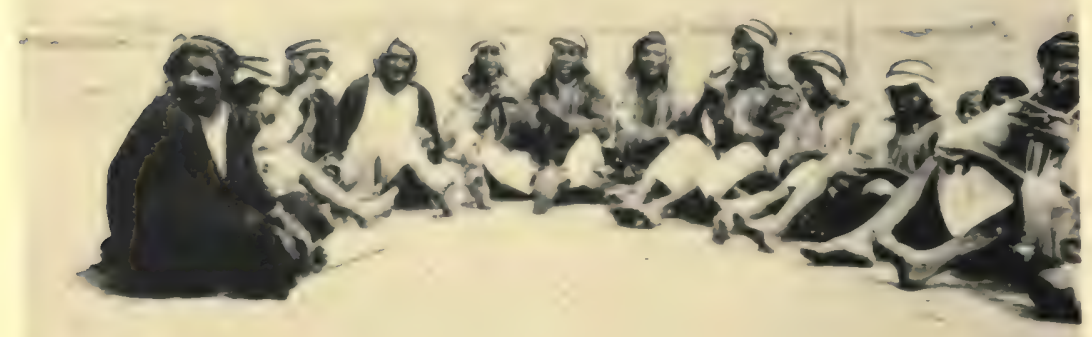

Fig. 1. Relaxation after Ashura. Singing to snapping of fingers and drumming of feet

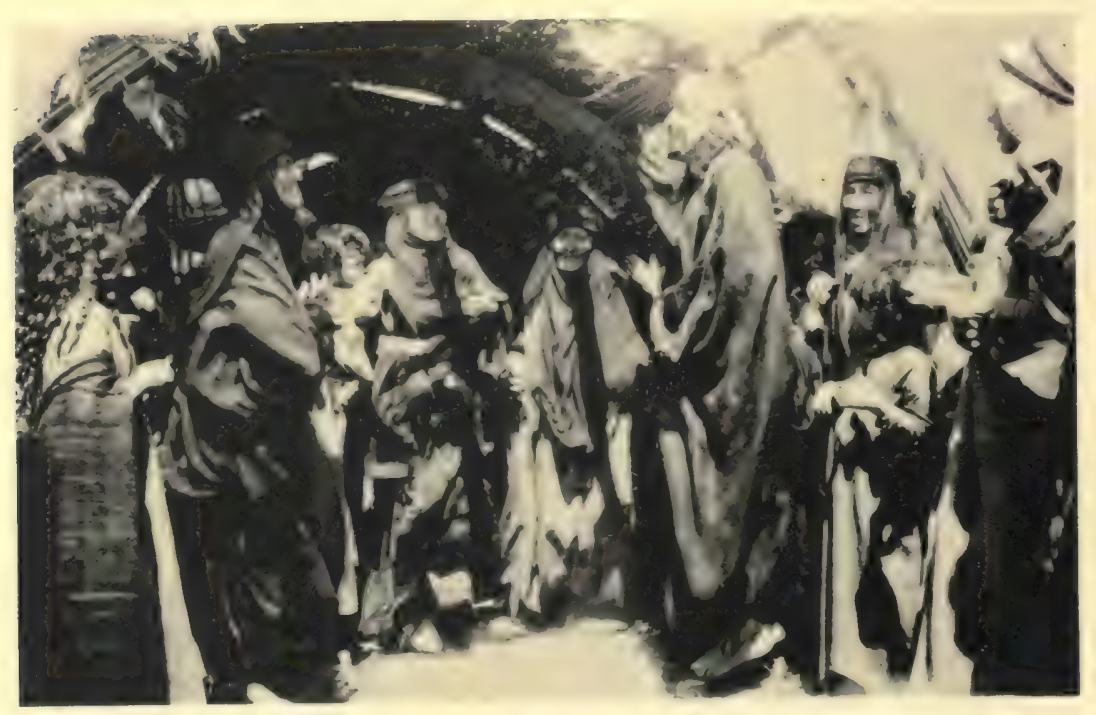

Fig. 2. Breast-beating for the dead. Professional mourner leaping in air

AL BU MUHAMMAD CAMP 


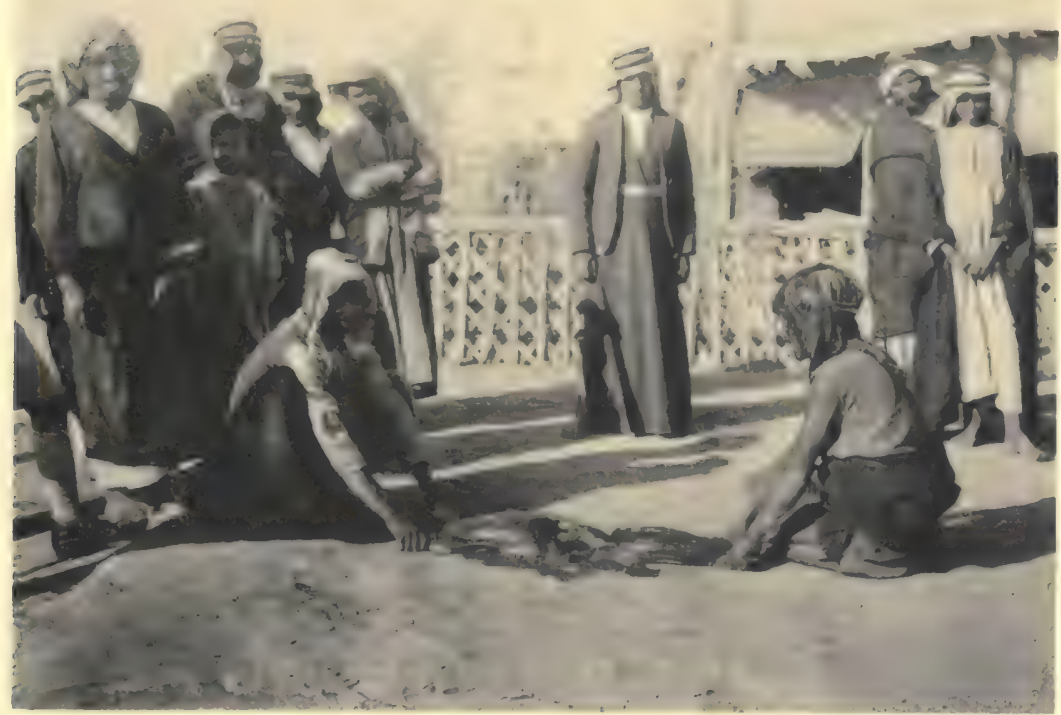

Fig. 1. A tortoise duel

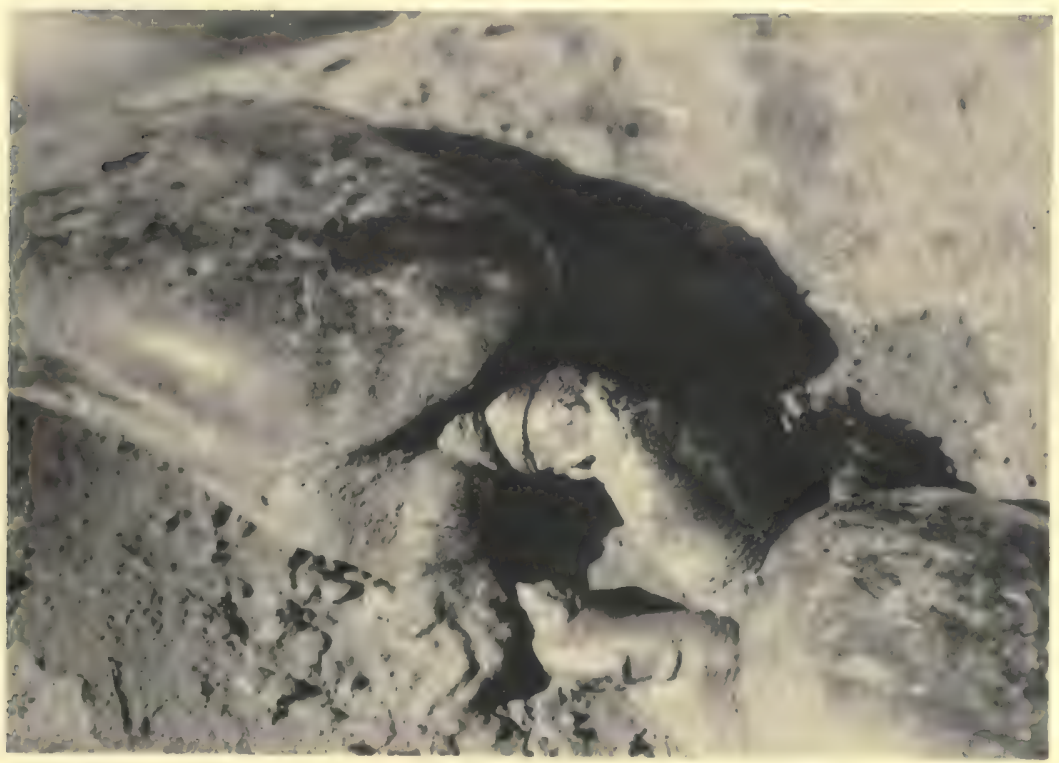

Fig. 2. The death grip 


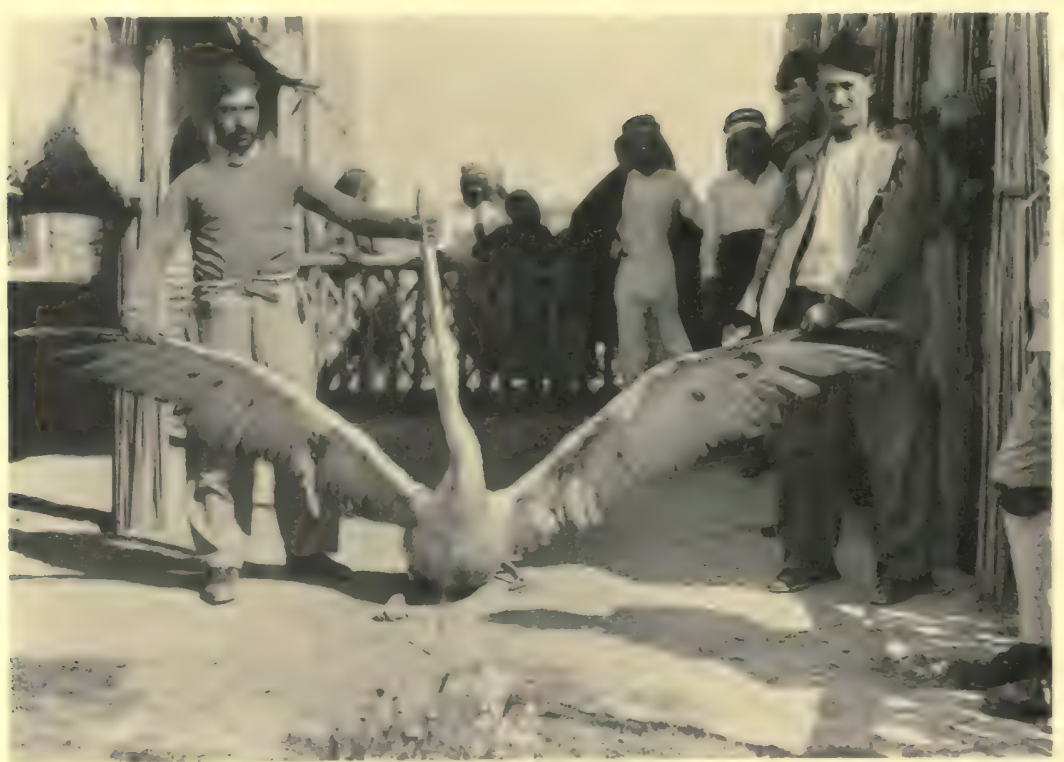

Fig. 1. Large white pelican (Pelecanus crispus)

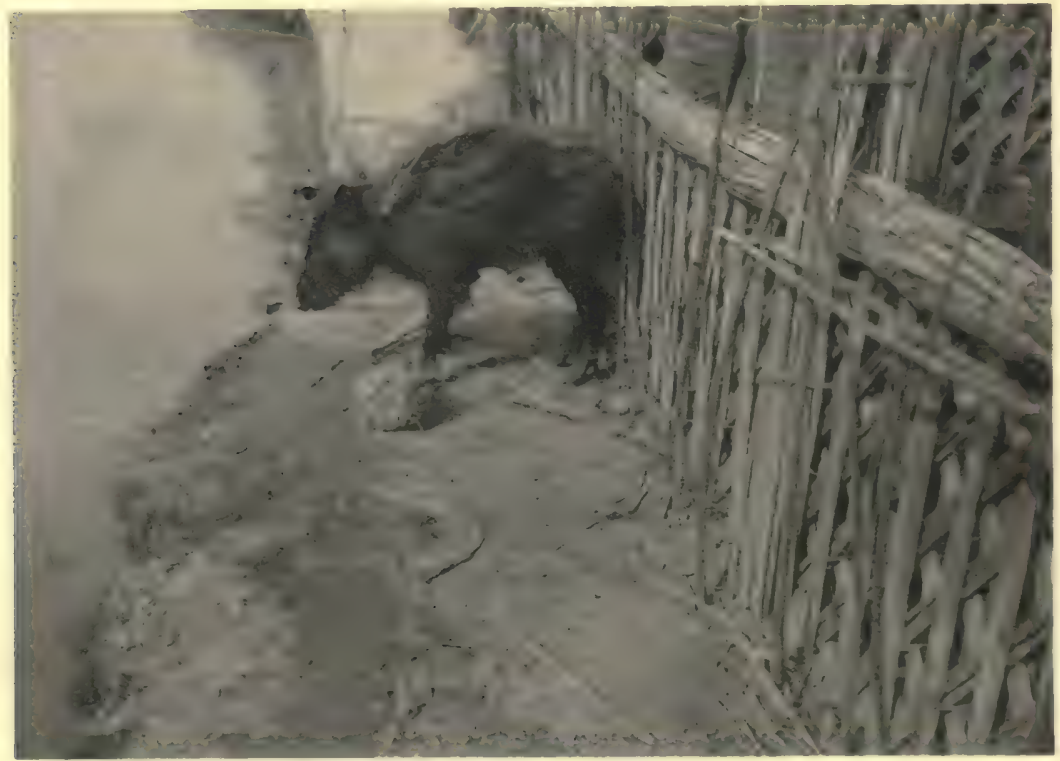

Fig. 2. Young wild boar

AL BU MUHAMMAD CAMP 


\section{al \#139E}

Field Museum of Natural History

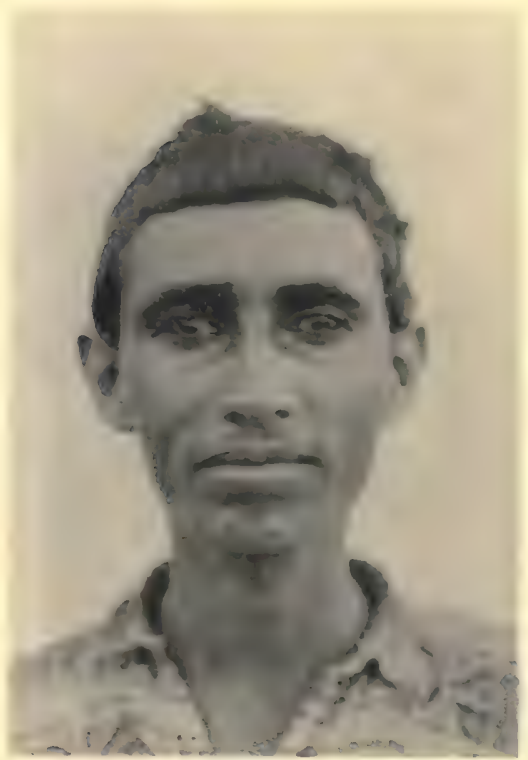

No. 881 (age 20)
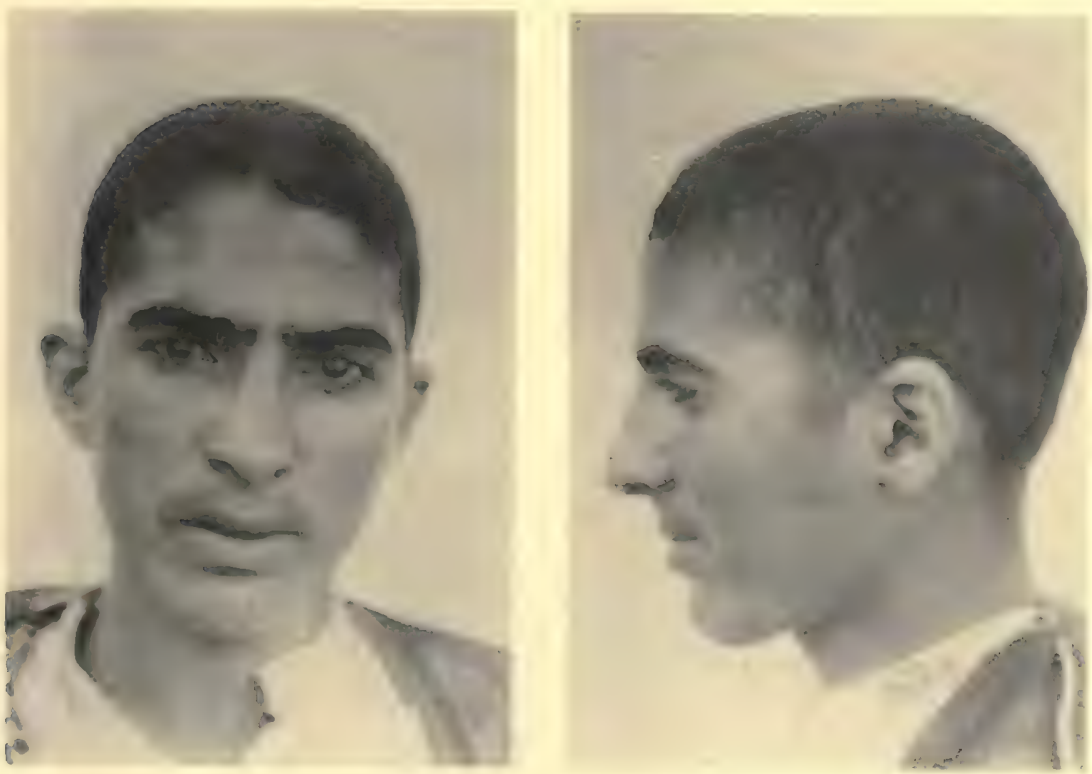

No. 851 (age 20)

AL BU MUHAMMAD CLASSIC MEDITERRANEAN TYPES

$$
\text { aर } 1396
$$

Anthropology, Vol. 30, Plate 79

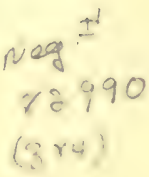

$\forall<x^{-1}$

$<3055$

(3) ve 


\section{$a l \neq 139 \varepsilon$}

Field Museum of Natural History

Anthropology, Vol. 30, Plate 80
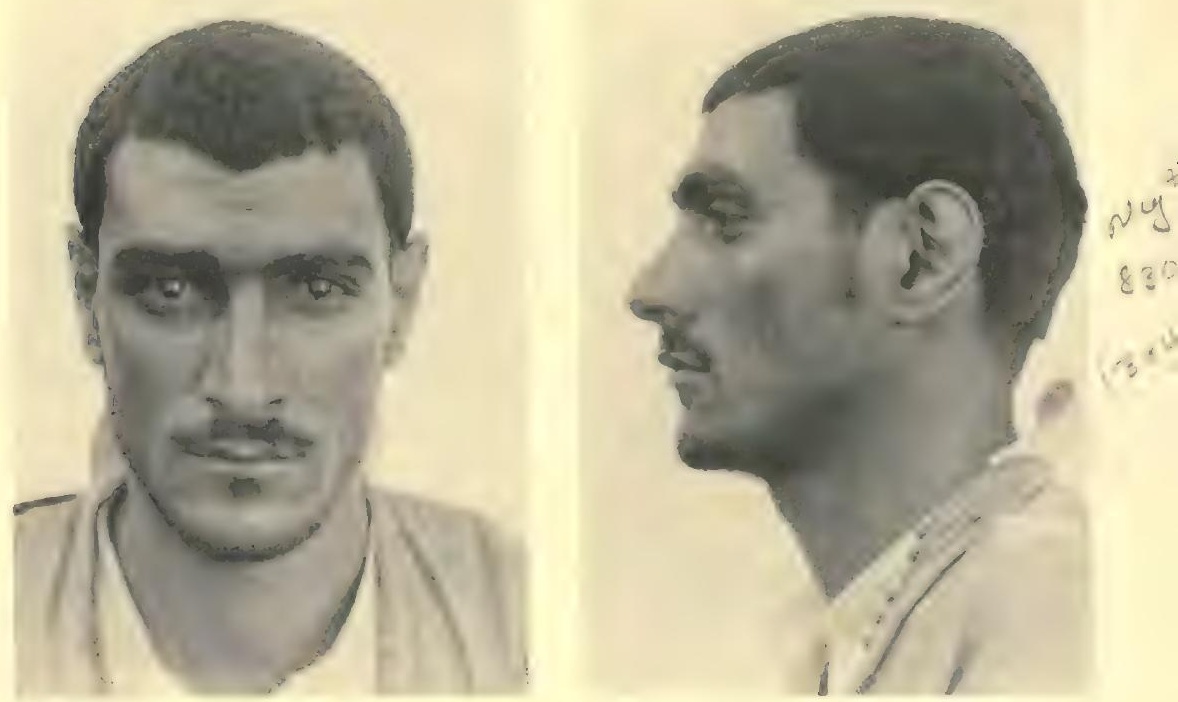

No. 861 (age 25)
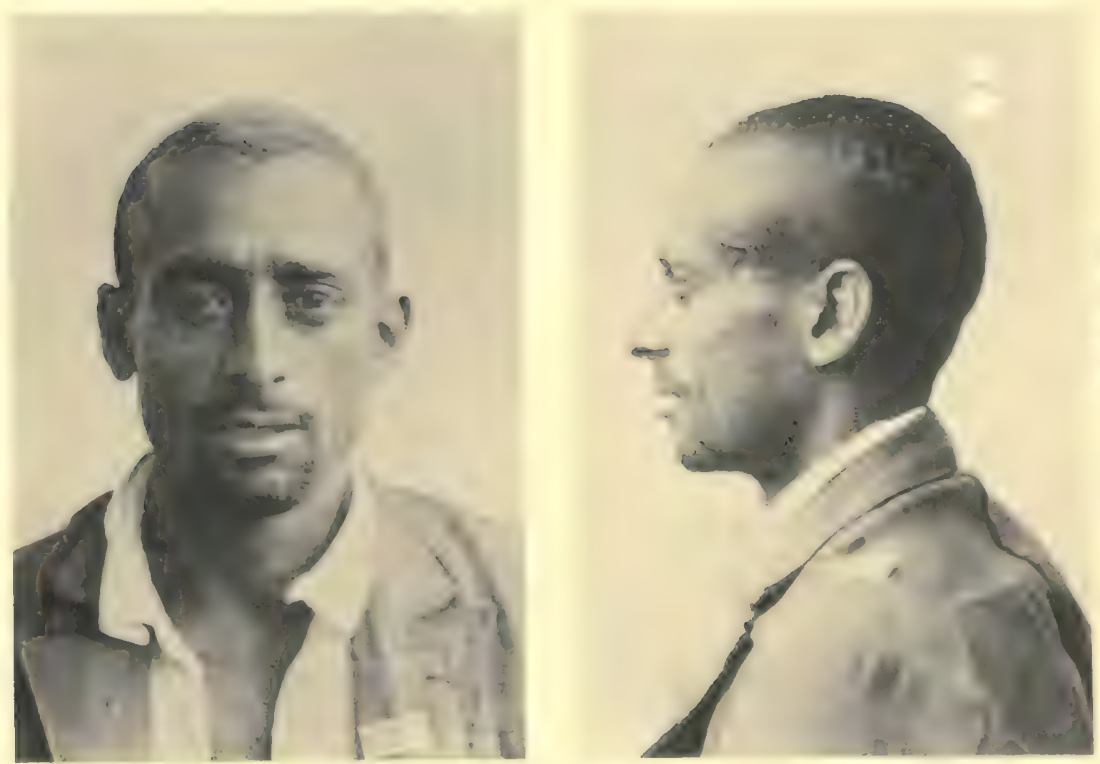

No. 816 (age 25)

AL BU MUHAMMAD CLASSIC MEDITERRANEAN TYPES

$$
\text { act } 296
$$




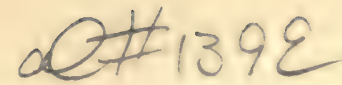

Field Museum of Natural History

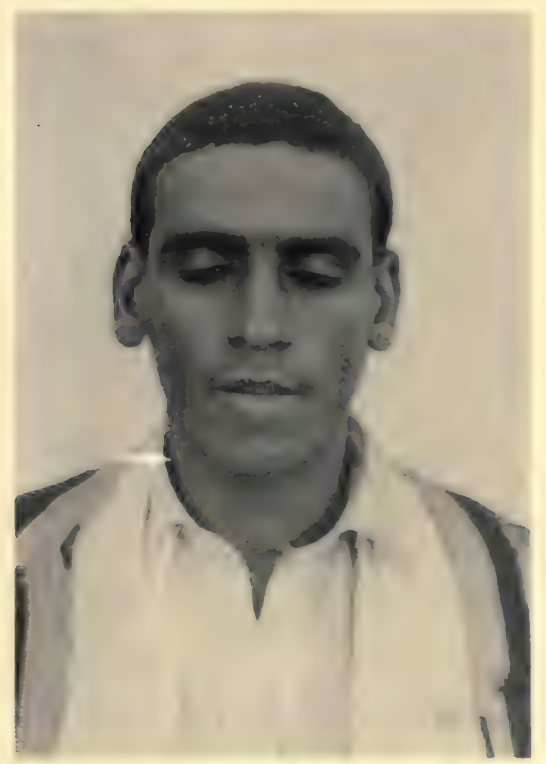

No. 768 (age 25)

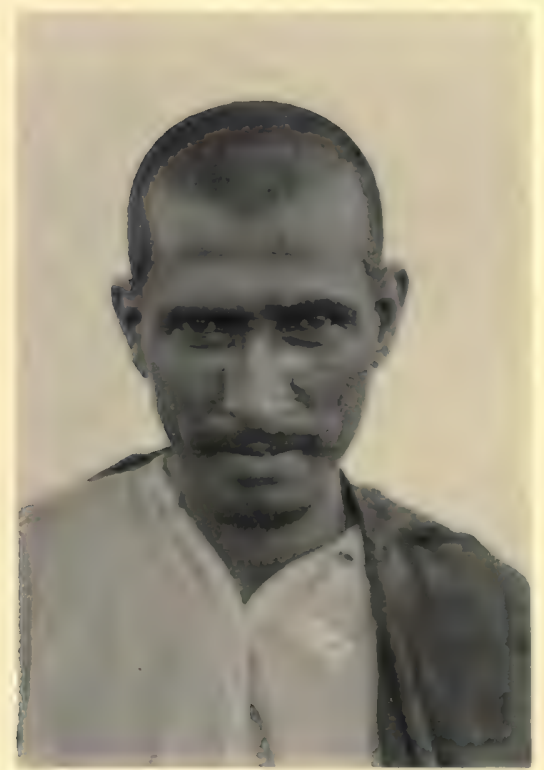

Anthropology, Vol. 30, Plate 81

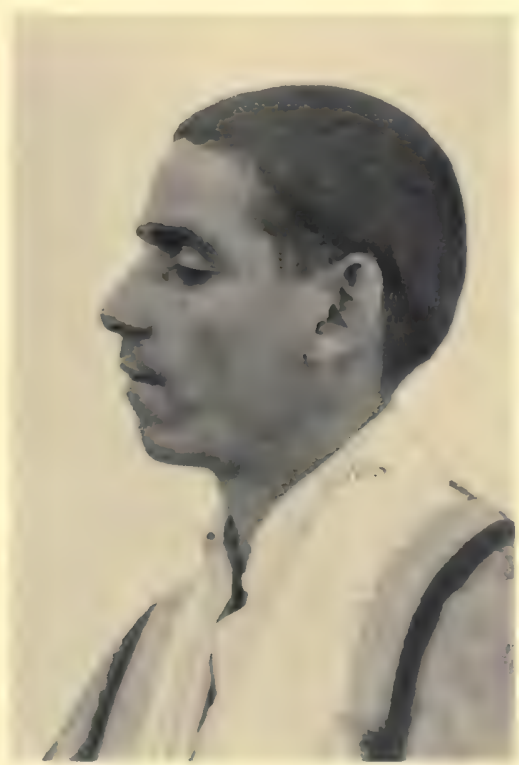

vive 932

$(3 \times 4)$

No. 882 (age 27)

AL BU MUHAMMAD CLASSIC MEDITERRANEAN TYPES

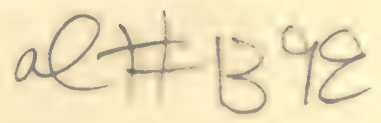




\section{$a b \# 139 \varepsilon$}

Field Museum of Natural History

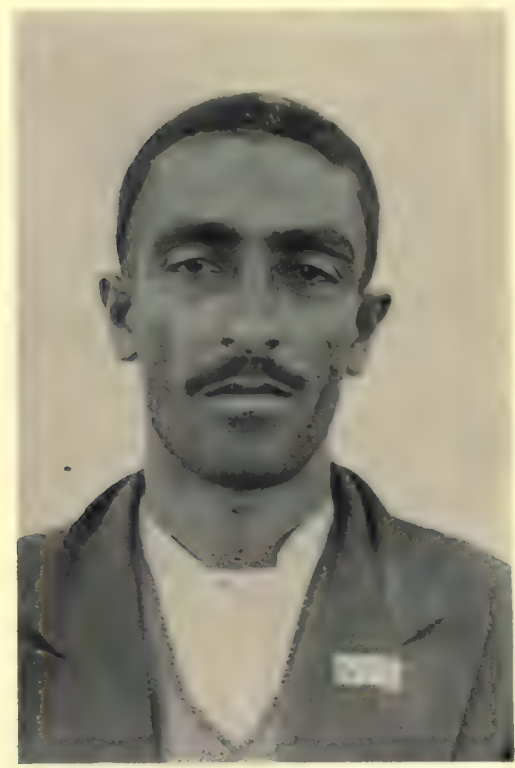

No. 771 (age 30 )
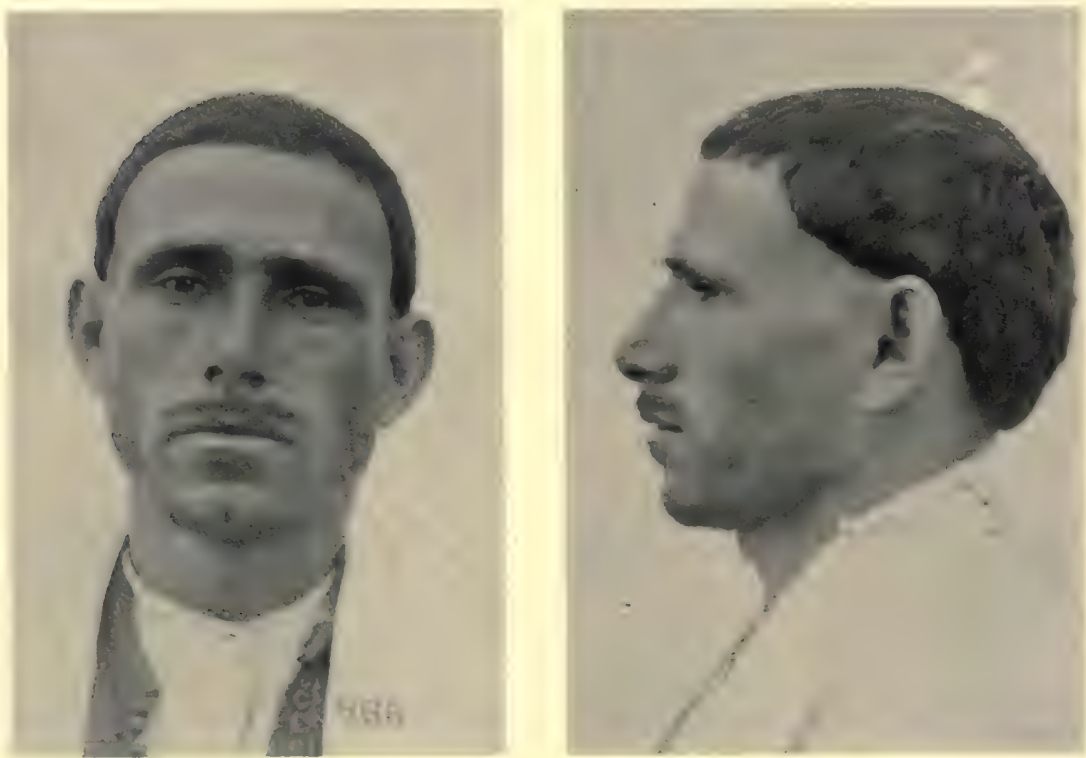

rvg

833

$(3 x)$

No. 830 (age 30 )

AL BU MUHAMMAD CLASSIC MEDITERRANEAN TYPES

$a+\neq 139^{\circ}$ 


\section{alt $1399^{\circ}$}

Field Museum of Natural History

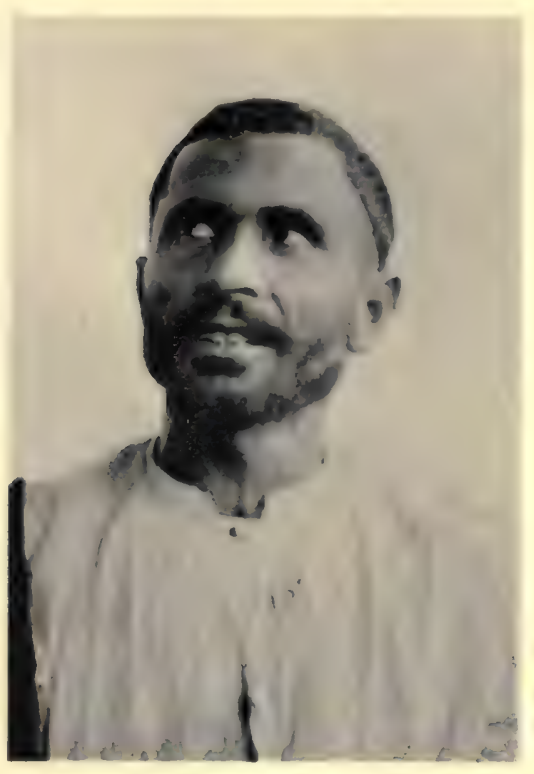

Anthropology, Vol. 30, Plate 83

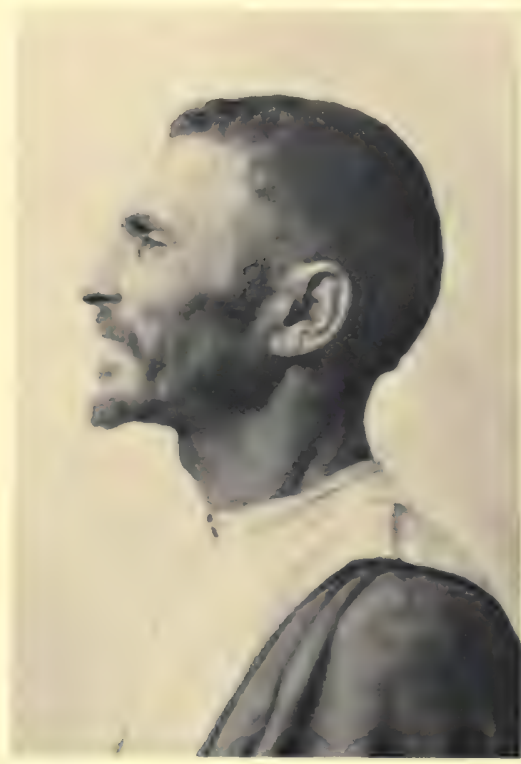

$N g^{T}$ 83106 $(3 Y$

No. 819 (age 32)
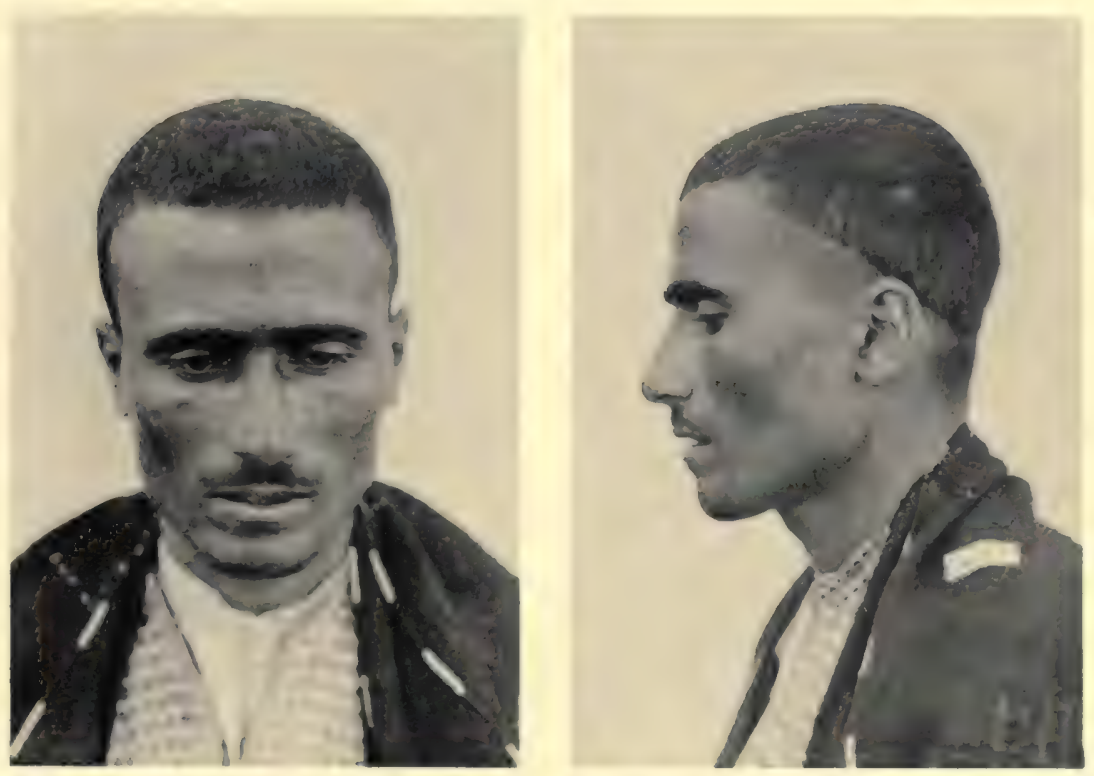

$N g^{4}$

$<+9=$

$(a r y)$

No. 902 (age 33 )

AL BU MUHAMMAD CLASSIC MEDITERRANEAN TYPES

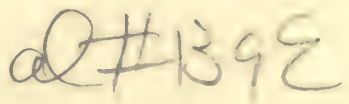




\section{altis9}

Field Museum of Natural History

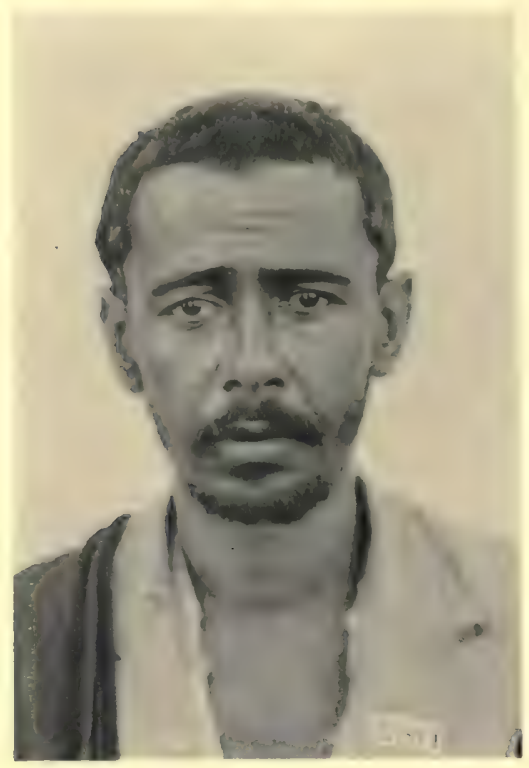

No. 897 (age 33)
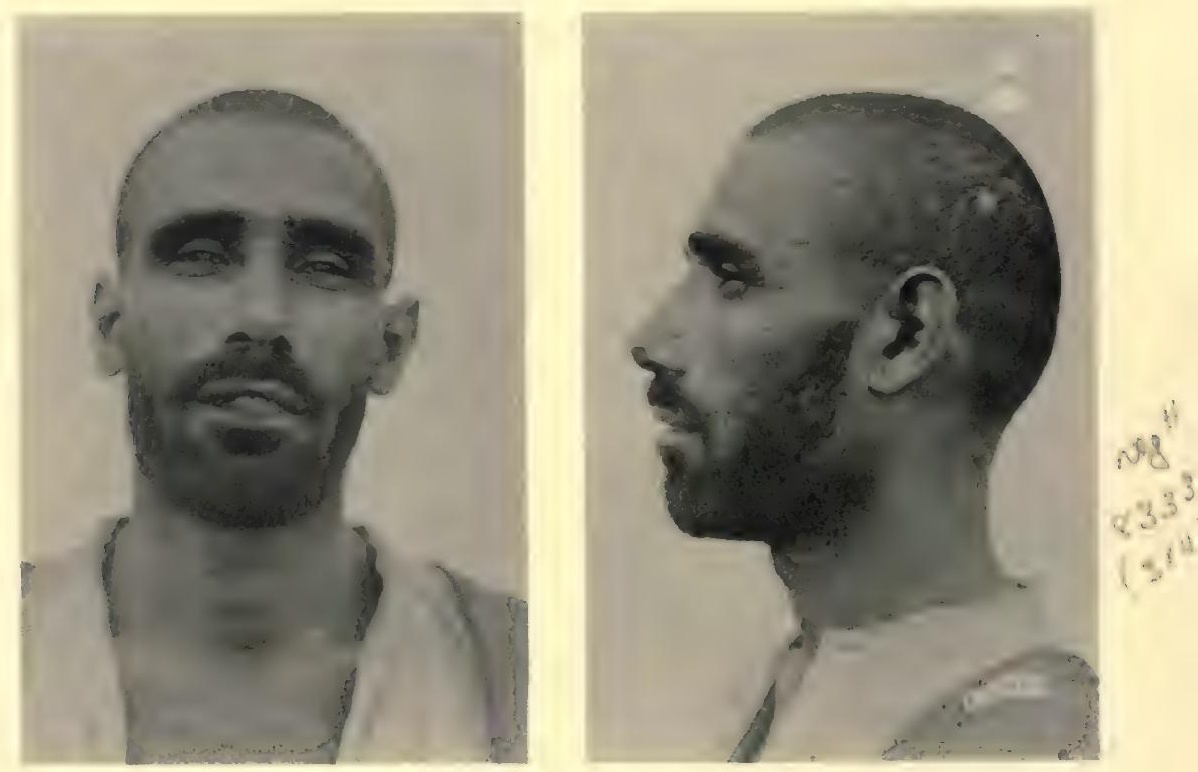

No. 835 (age 35 )

AL BU MUHAMMAD CLASSIC MEDITERRANEAN TYPES

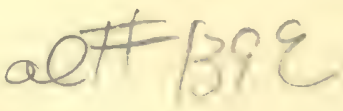




\section{$a 0 \# 1398$}

Field Museum of Natural History

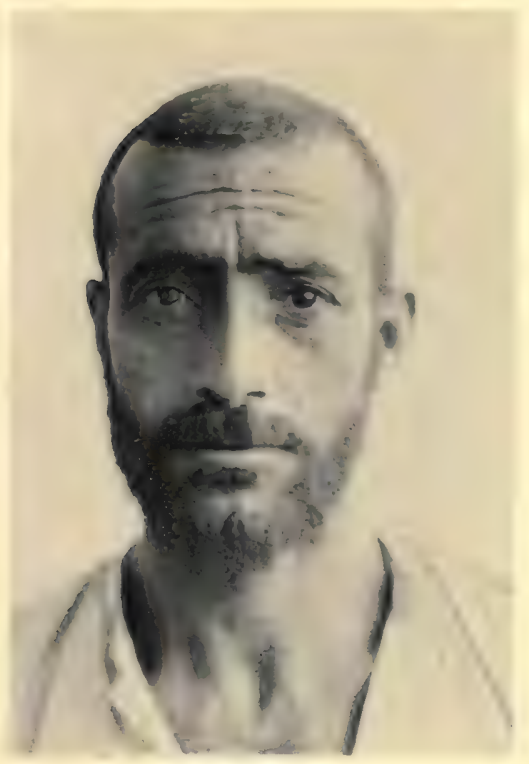

Anthropology, Vol. 30, Plate 85

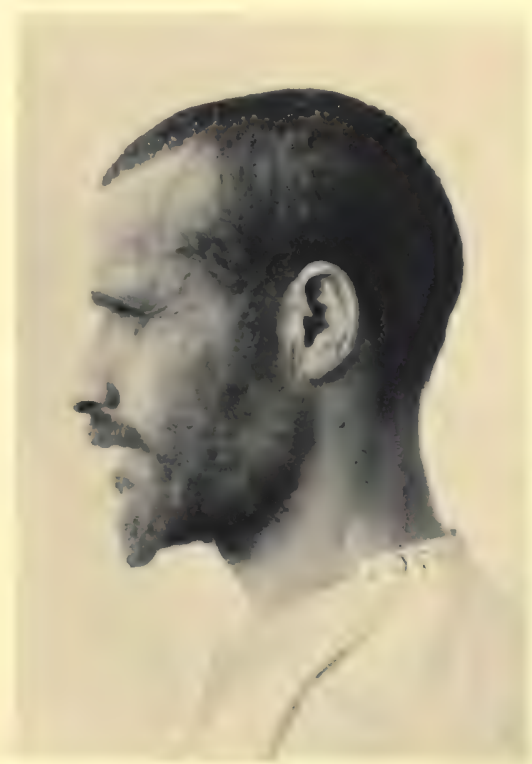

$\sin 1$

Q. 2134

$(3 \times 4)$

No. 807 (age 35)

$p^{20} \sin ^{3} 6^{4}$
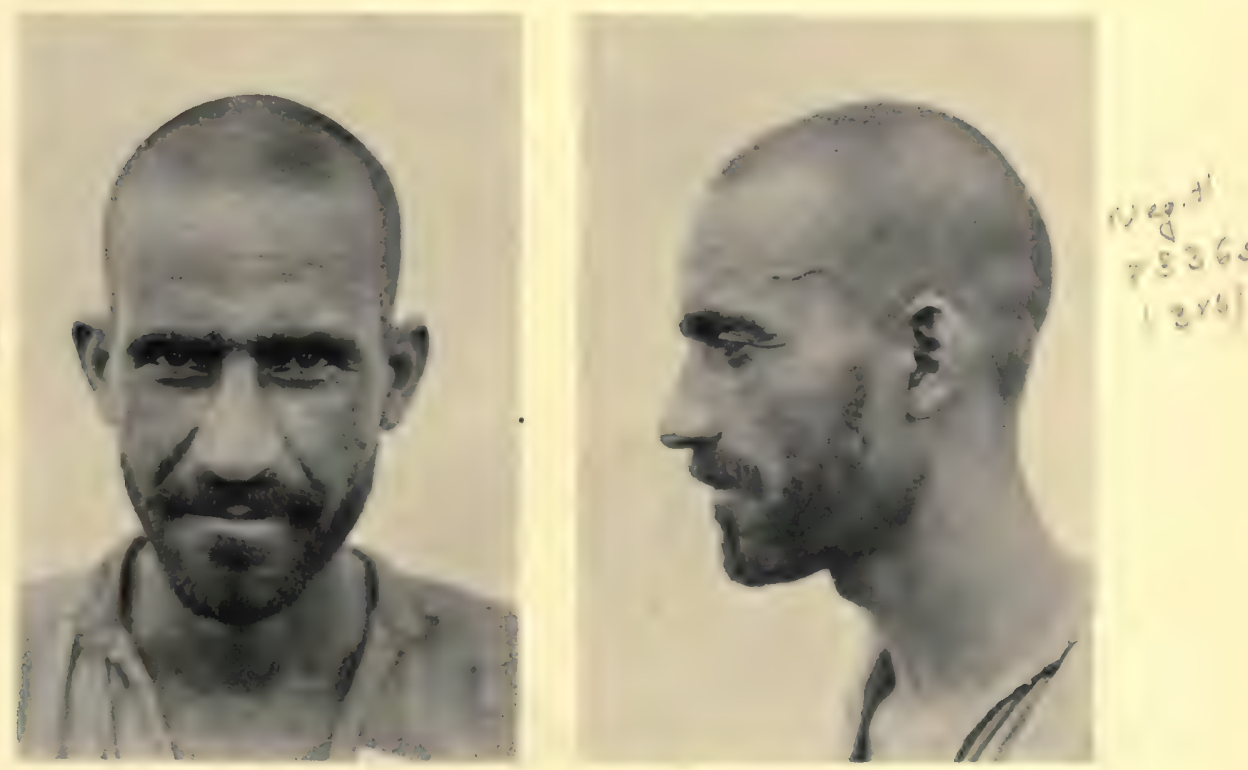

No. 781 (age 35)

AL BU MUHAMMAD CLASSIC MEDITERRANEAN TYPES

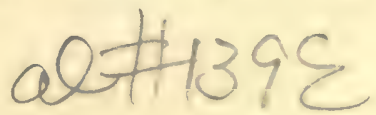




\section{$a b \#_{13} 98$}

Field Museum of Natural History

Anthropology, Vol. 30, Plate 86
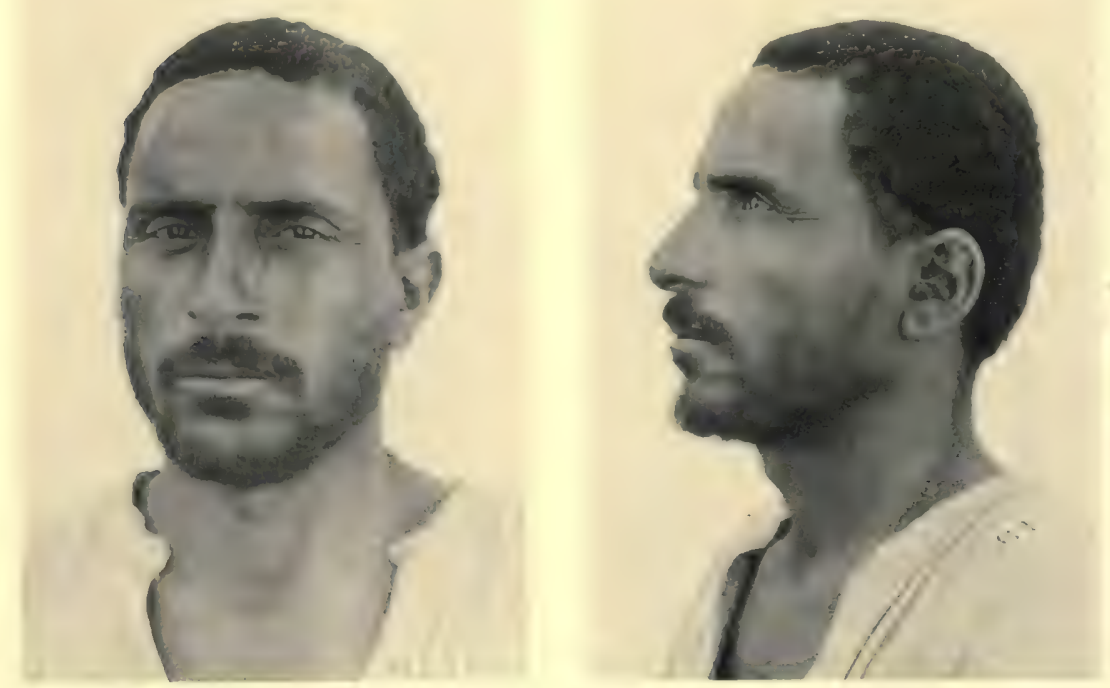

No. 866 (age 35)
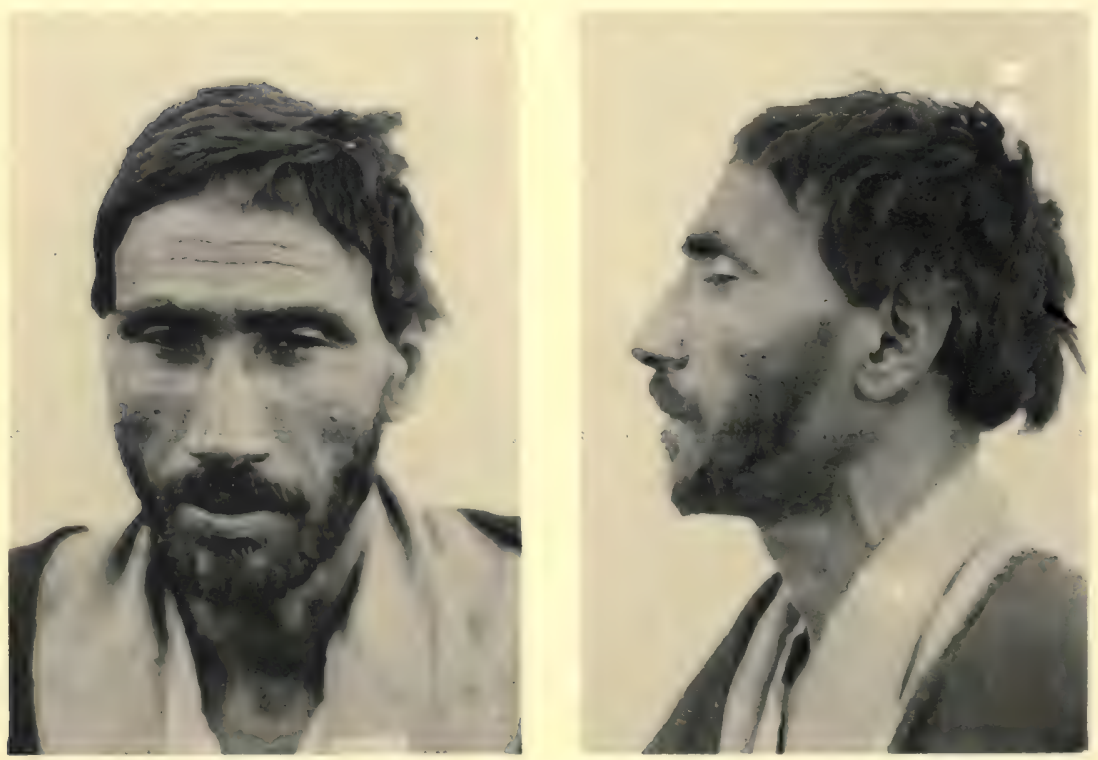

$a^{2}$

$430^{2}$

$13^{4}$

(i)

i)

No. 871 (age 35)

AL BU MUHAMMAD CLASSIC MEDITERRANEAN TYPES

al 139 \& 


\section{$a b+139 \varepsilon$}

Field Museum of Natural History

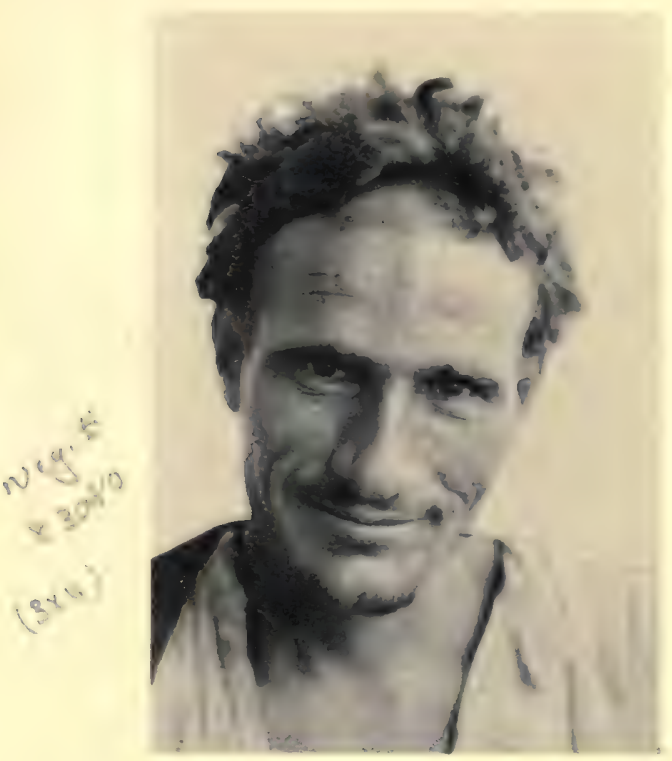

No. 825 (age 35)

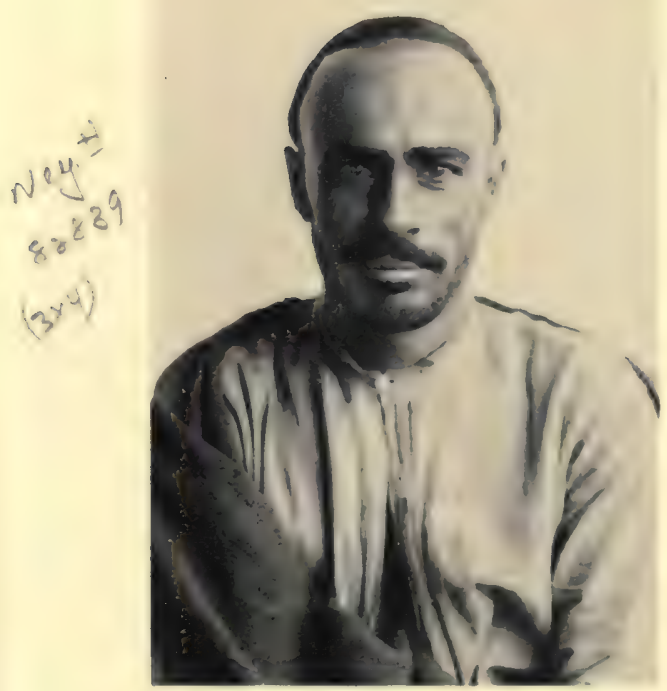

Anthropology, Vol. 30, Plate 87

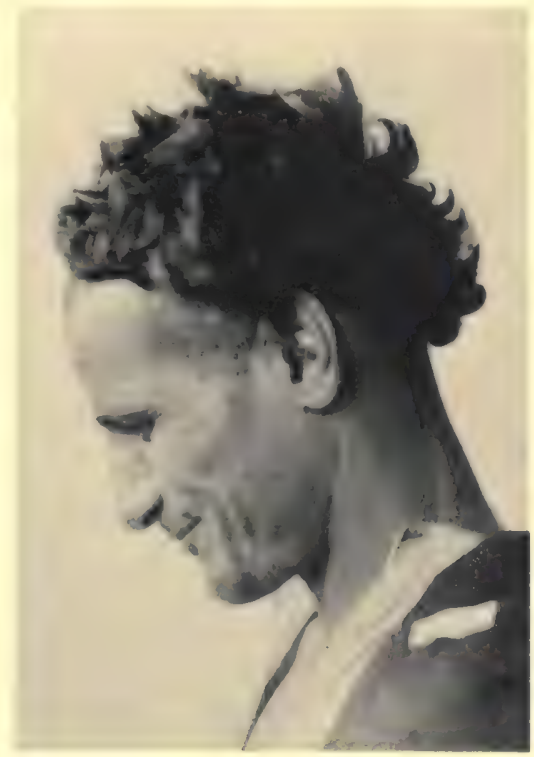

$V=x$

No. 935 (age 35 )

AL BU MUHAMMAD CLASSIC MEDITERRANEAN TYPES

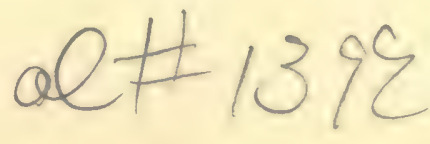



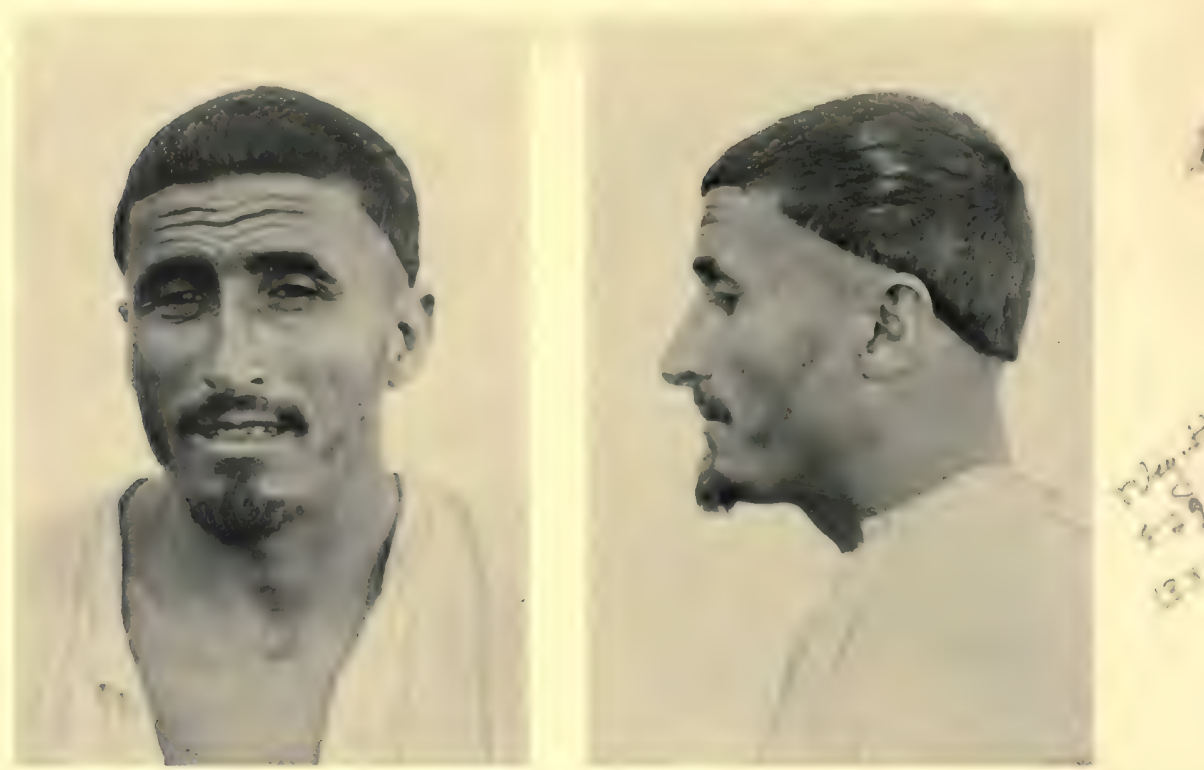

No. 904 (age 35)
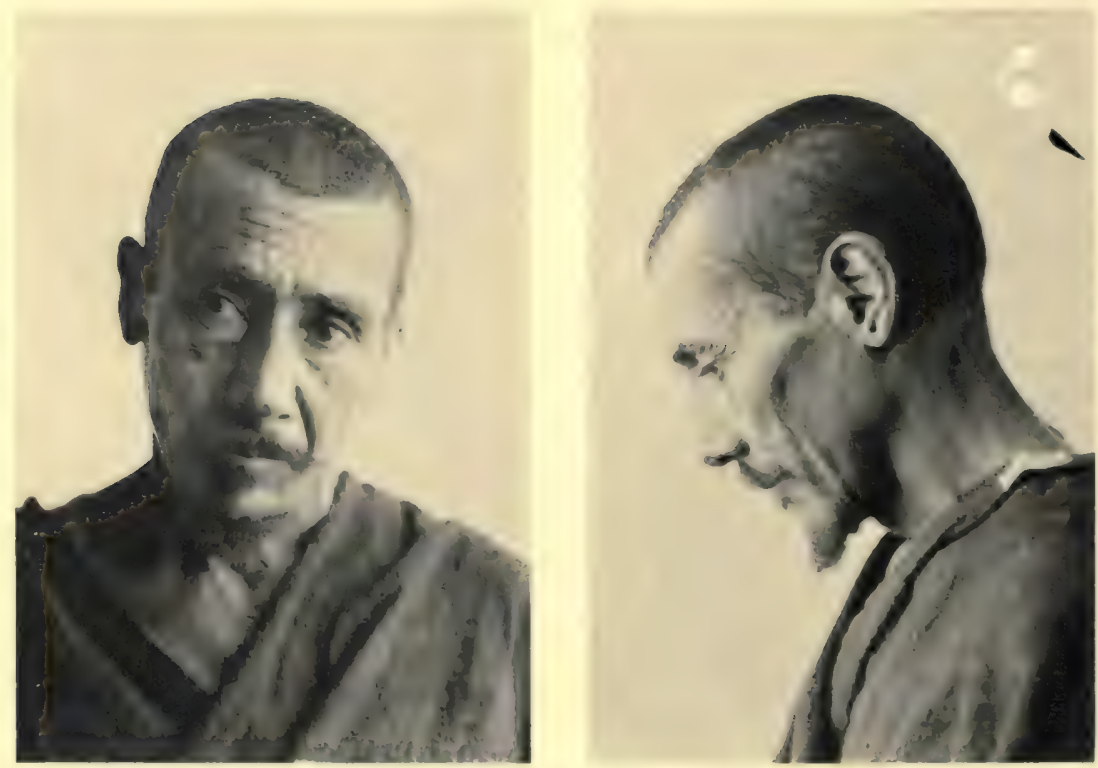

weg
$89^{\circ}$
$\left(3 x^{4}\right)$

No. 916 (age 40)

AL BU MUHAMMAD CLASSIC MEDITERRANEAN TYPES 


\section{al \#1398

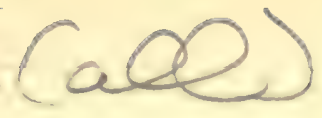

Field Museum of Natural History

Anthropology, Vol. 30, Plate 89
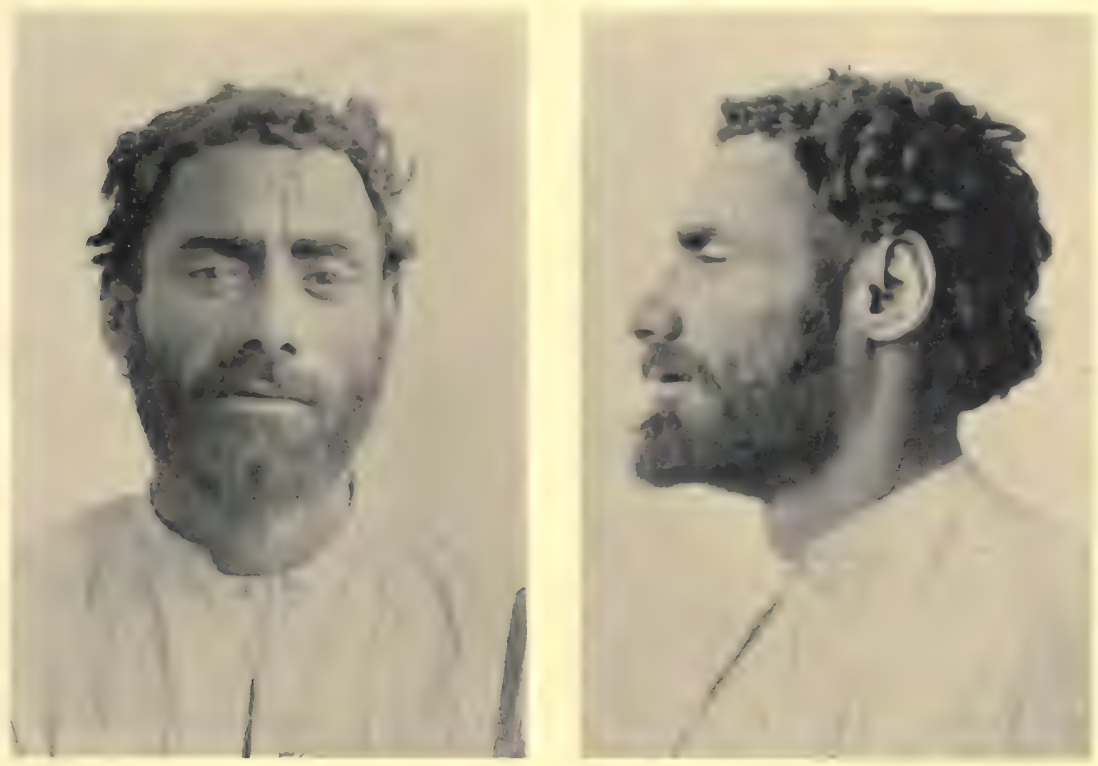

Neg.

231

$(3 r v$

No. 811 (age 40)
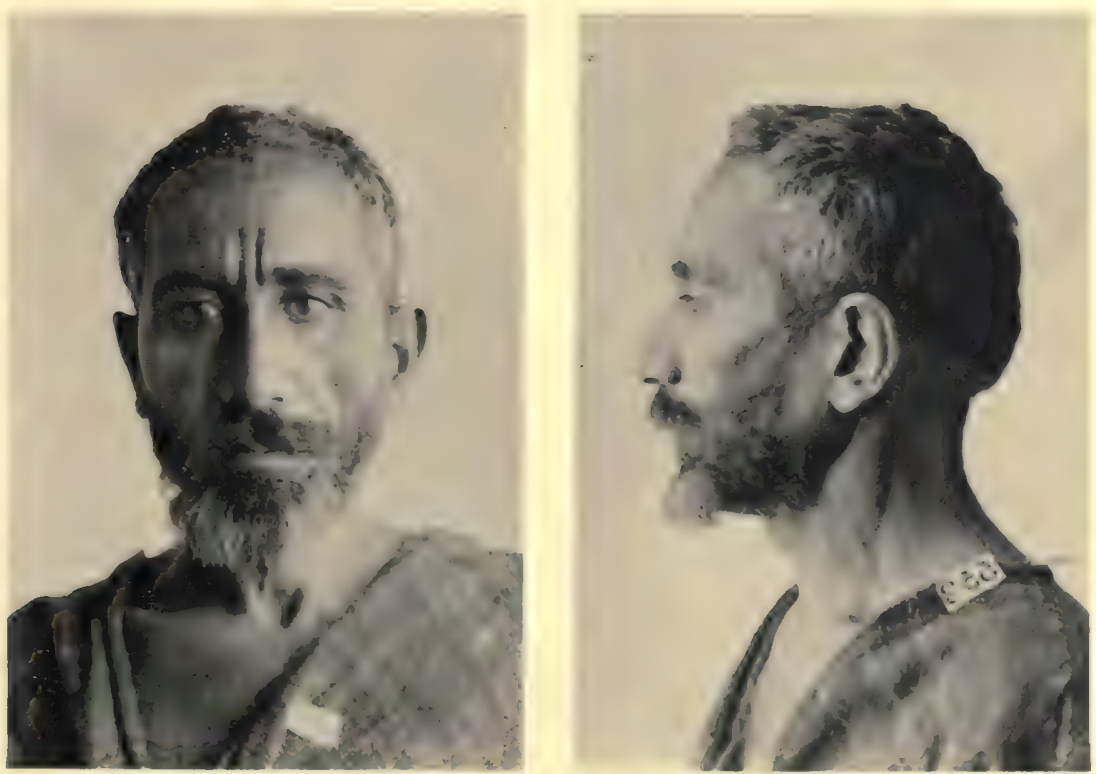

N. $: 4$.

$8: 409$

(3):

No. 917 (age 45)

AL BU MUHAMMAD CLASSIC MEDITERRANEAN TYPES 


\section{$a(39 \varepsilon(a) e)$}

Field Museum of Natural History

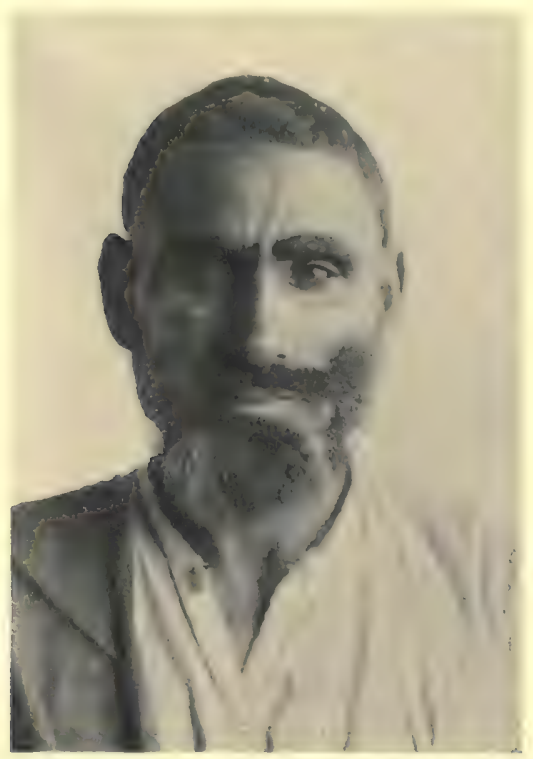

Anthropology, Vol. 30, Plate 90

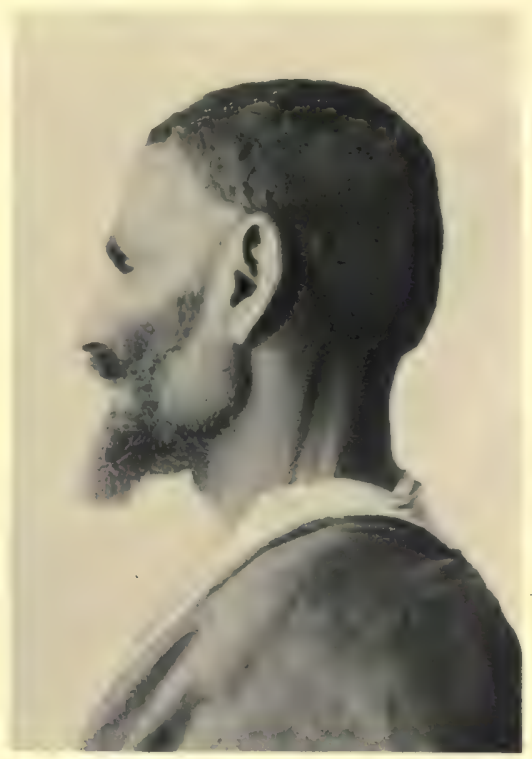

viy'

42

$\left(3^{3}\right)$

No. 933 (age 50)
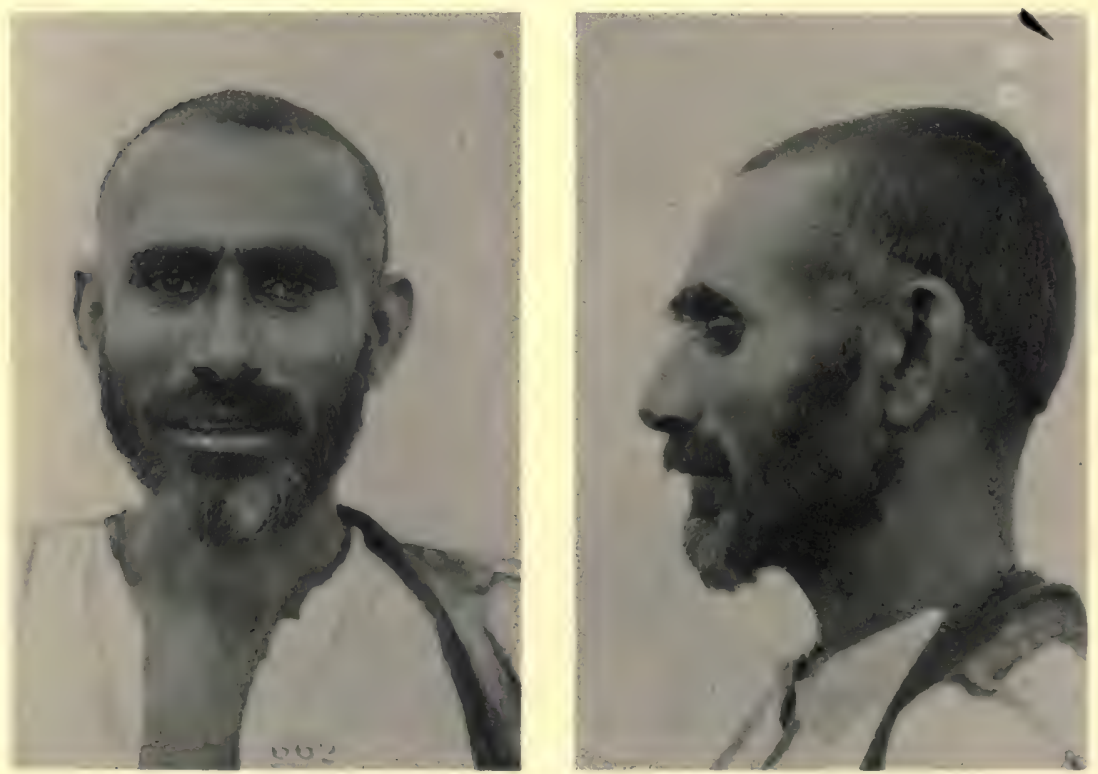

Nige

3,5

$n^{3}$

No. 785 (age 50)

AL BU MUHAMMAD CLASSIC MEDITERRANEAN TYPES 


\section{al 1398 (all)}

Field Museum of Natural History
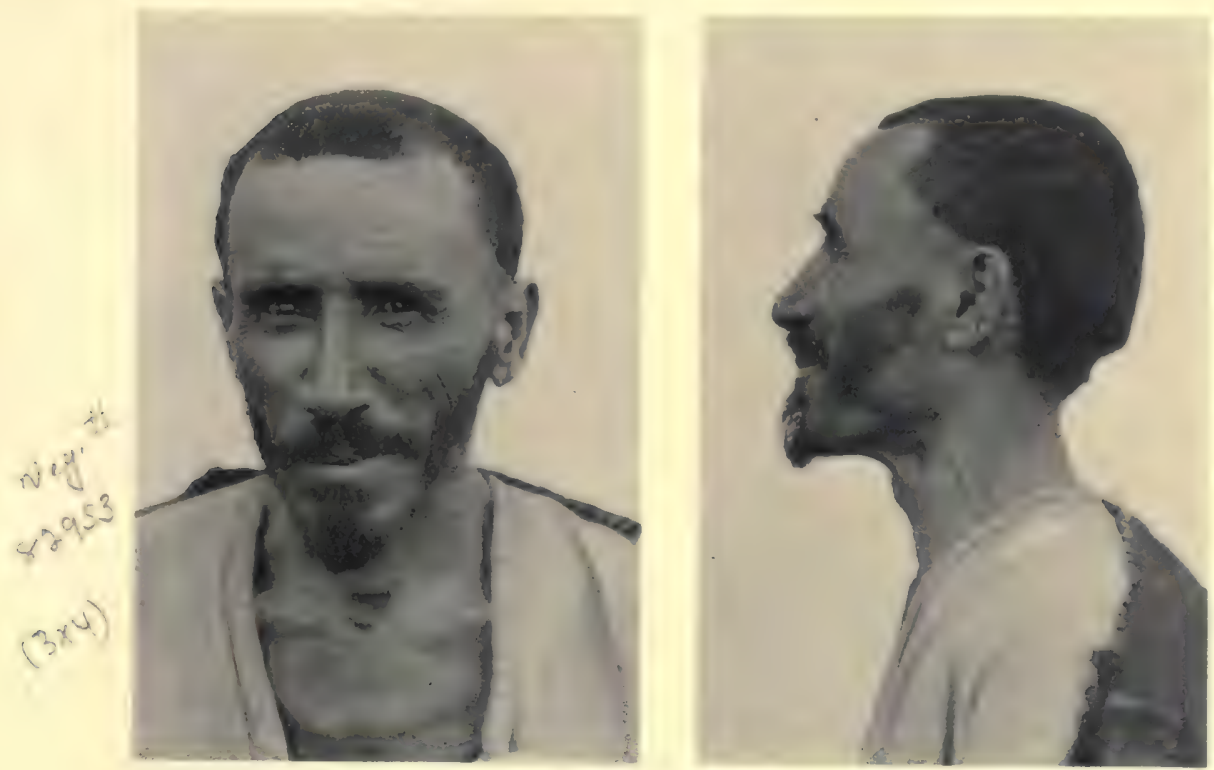

No. 896 (age 50)
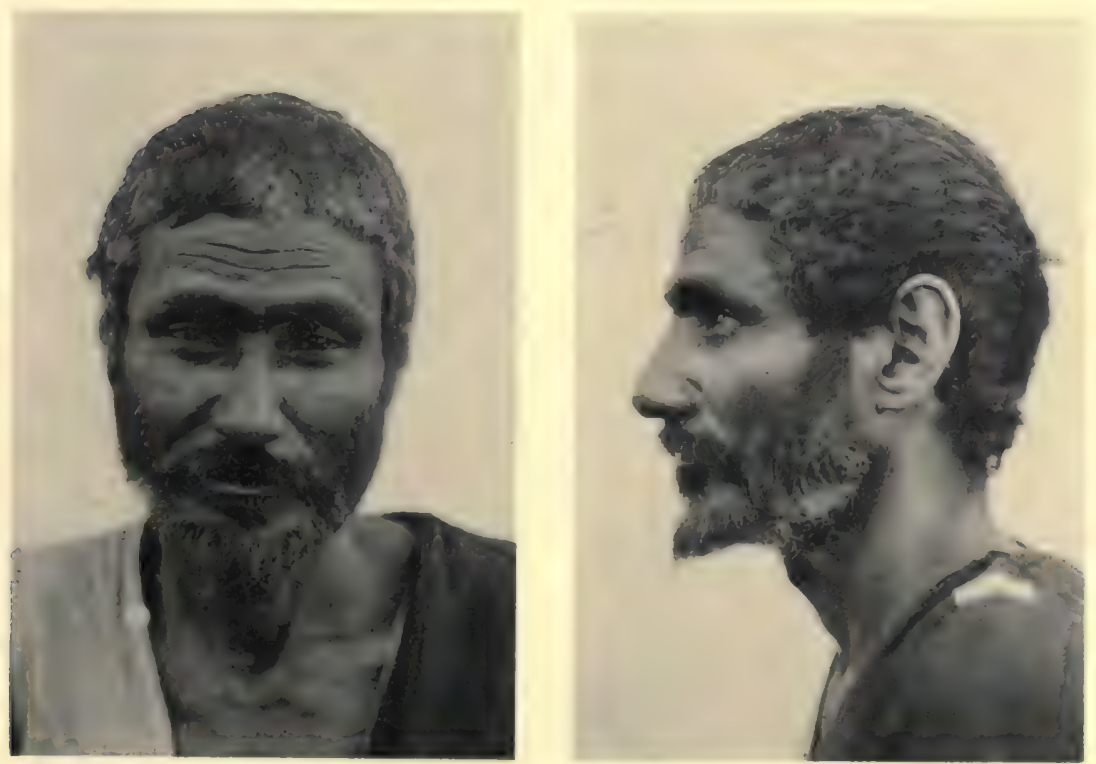

No. 875 (age 55)

\section{인 \\ $r^{\circ}$ \\ ayo}

r) $0 \mathrm{~g}^{2}$

3.854

(3)

AL BU MUHAMMAD CLASSIC MEDITERRANEAN TYPES 


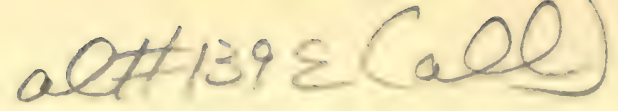

Field Museum of Natural History

Anthropology, Vol. 30, Plate 92
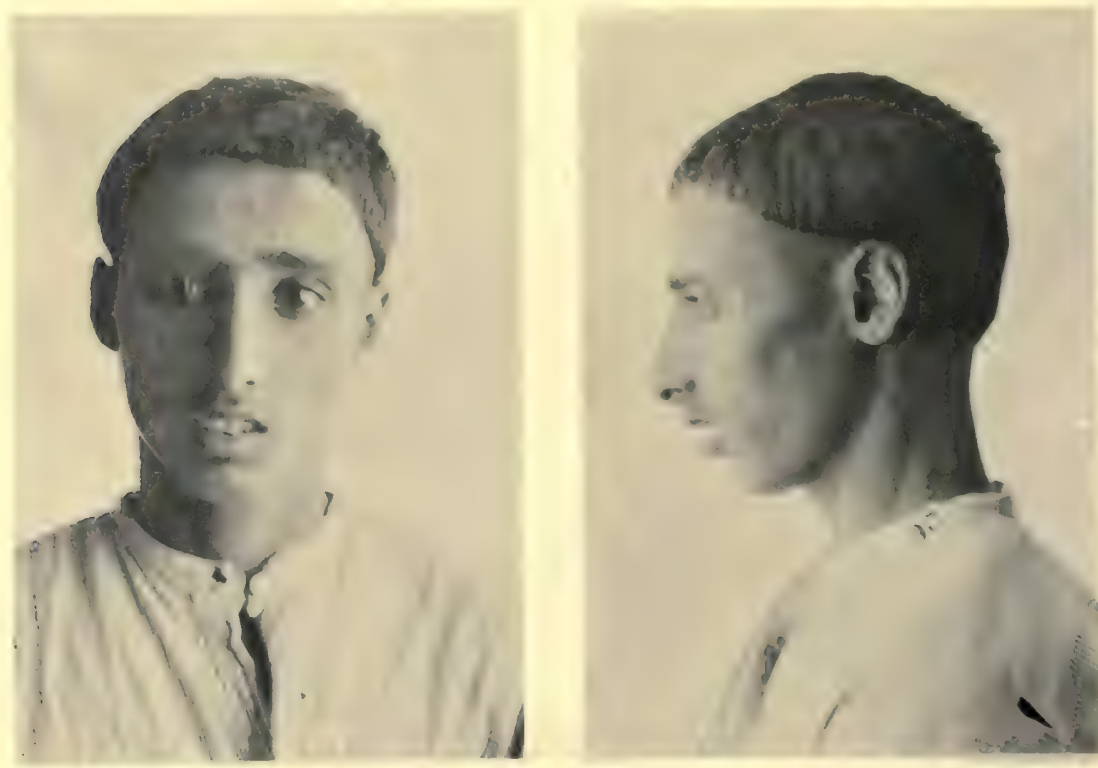

No. 911 (age 18)
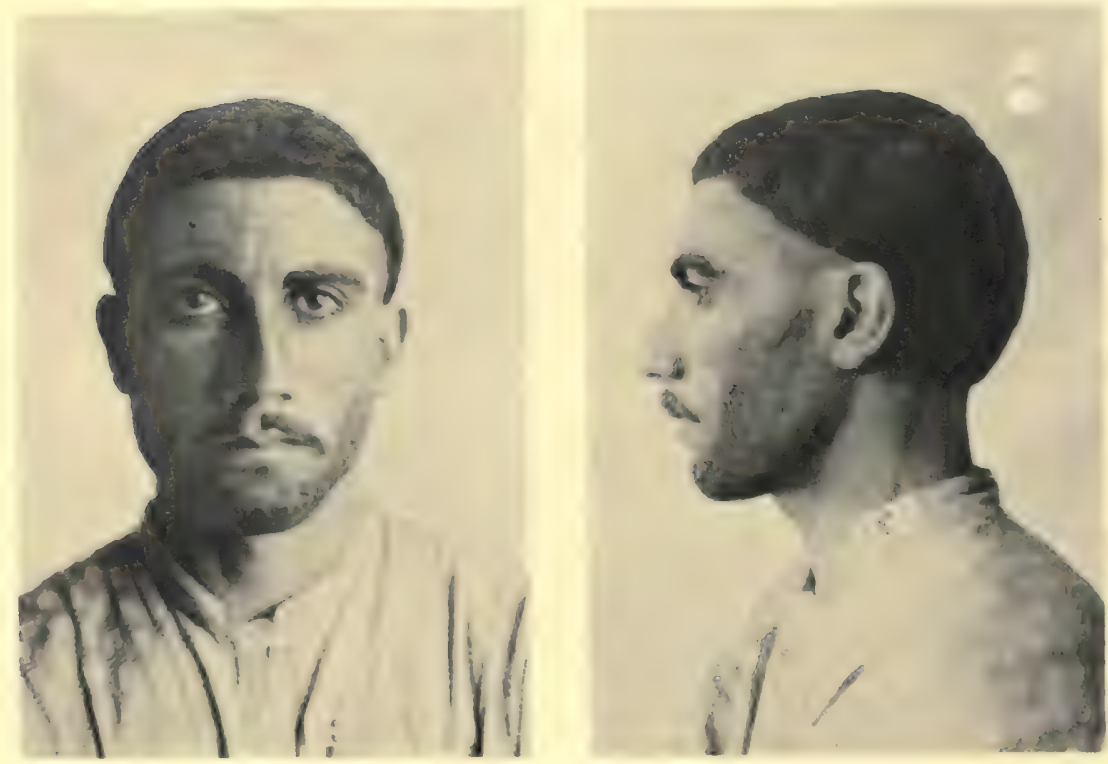

Ney

$g=?$

$\left(3^{4}\right.$ 


\section{$a l=139 \varepsilon(a \infty)$}

Field Museum of Natural History

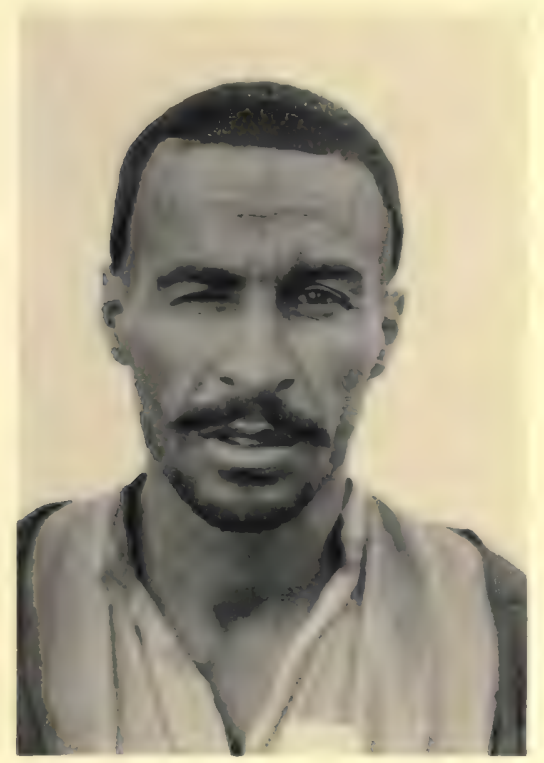

Anthropology, Vol. 30, Plate 93

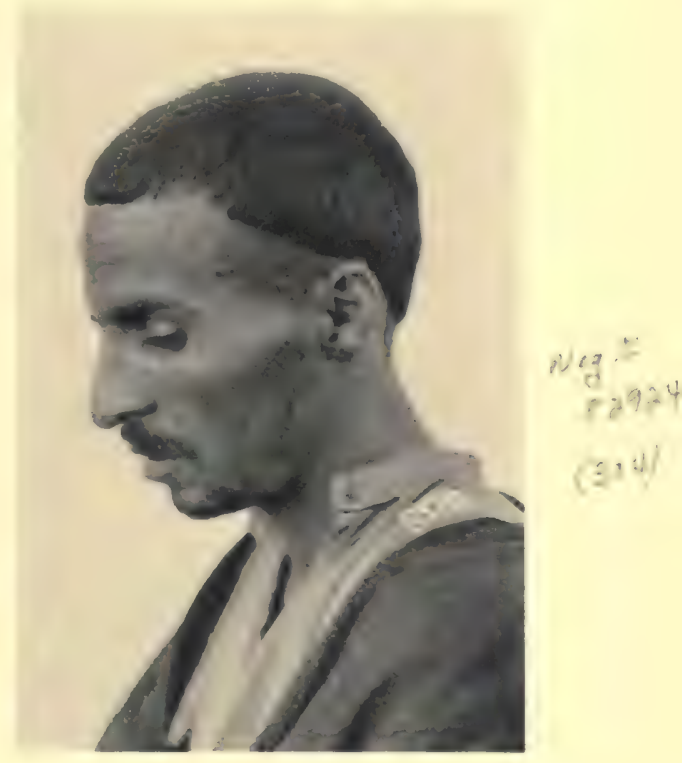

No. 903 (age 35)

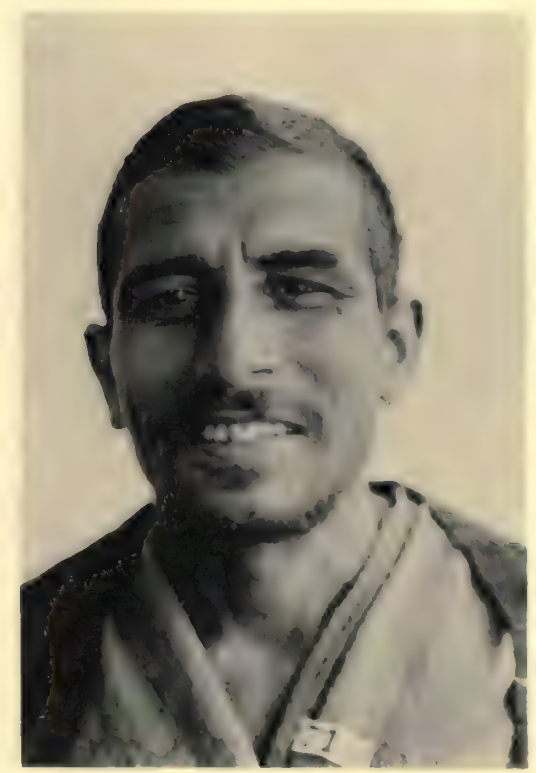

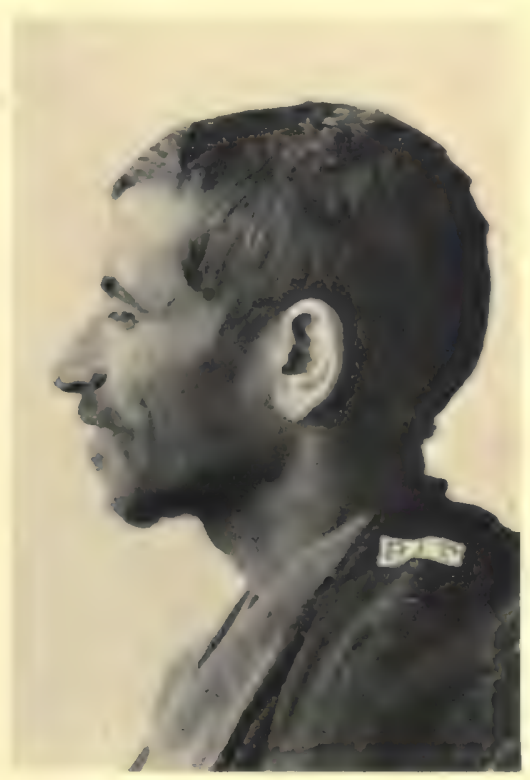

No. 796 (age 35)

AL BU MUHAMMAD CLASSIC MEDITERRANEAN

PLUS CONVEX-NOSED TYPES 


\section{all \#139 (ad)}

Field Museum of Natural History

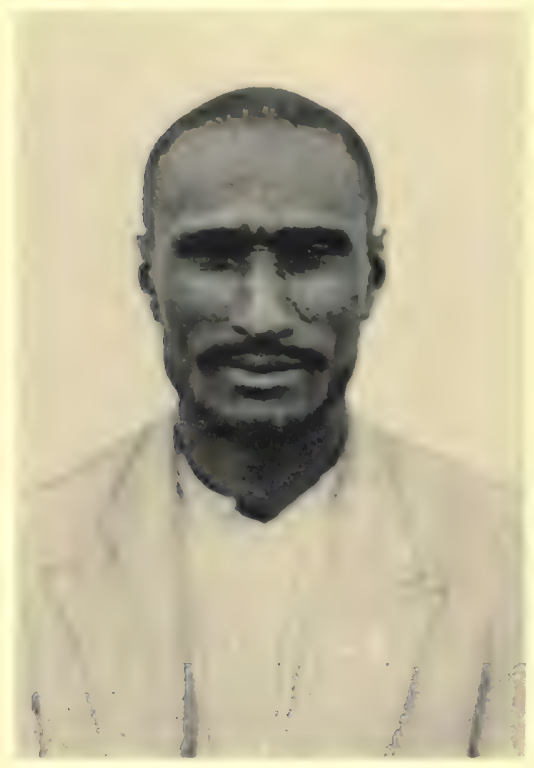

Anthropology, Vol. 30, Plate 94

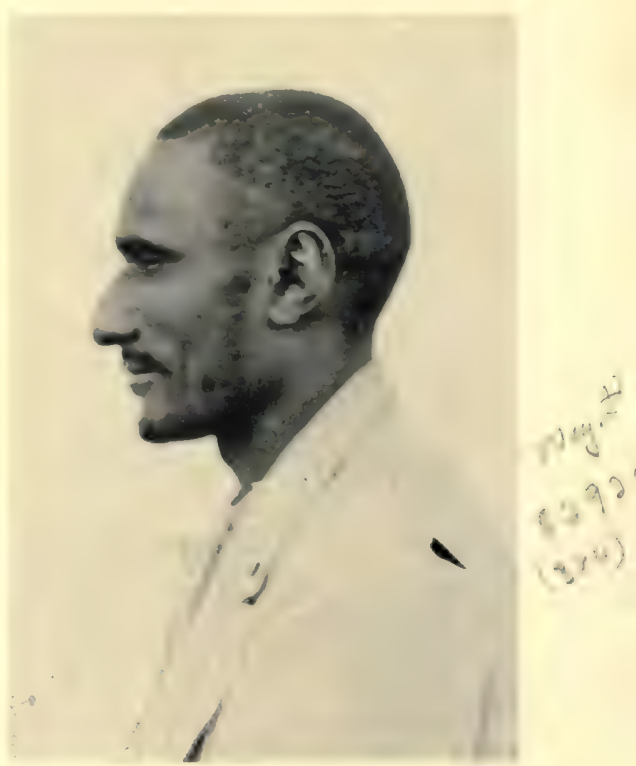

No. 770 (age 35)
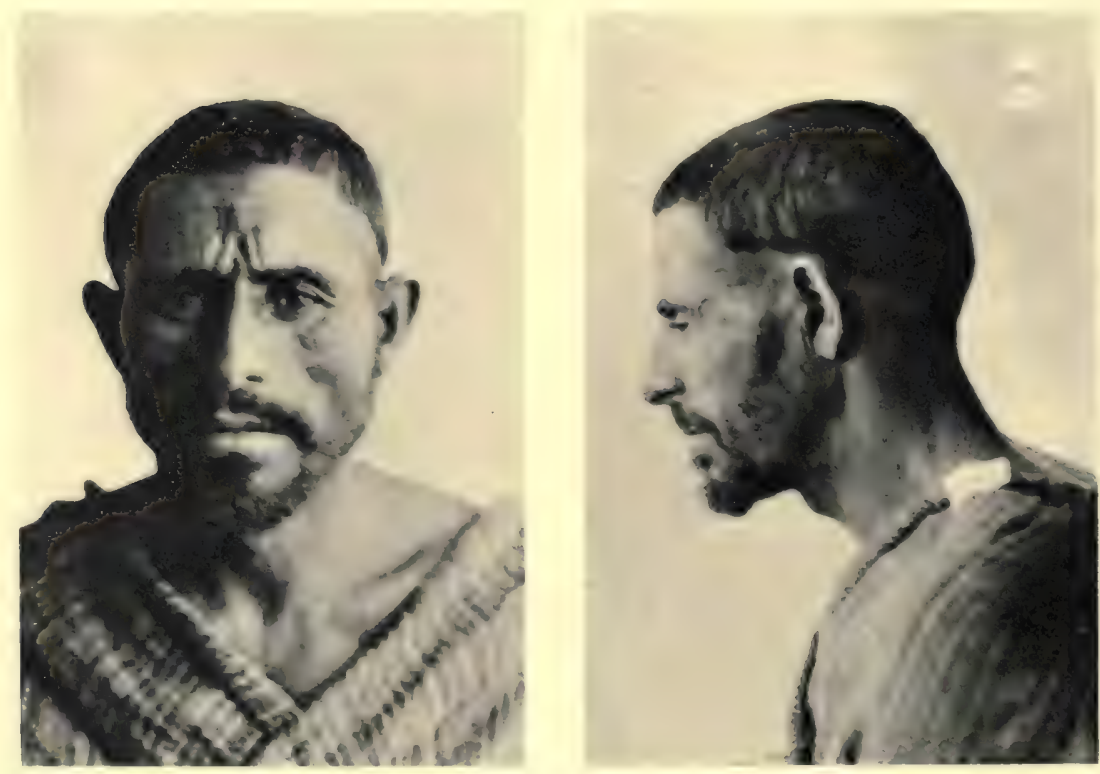

(N) 8

No. 924 (age 40)

AL BU MUHAMMAD CLASSIC MEDITERRANEAN

PLUS CONVEX-NOSED TYPES 


\section{al 1392}

Field Museum of Natural History

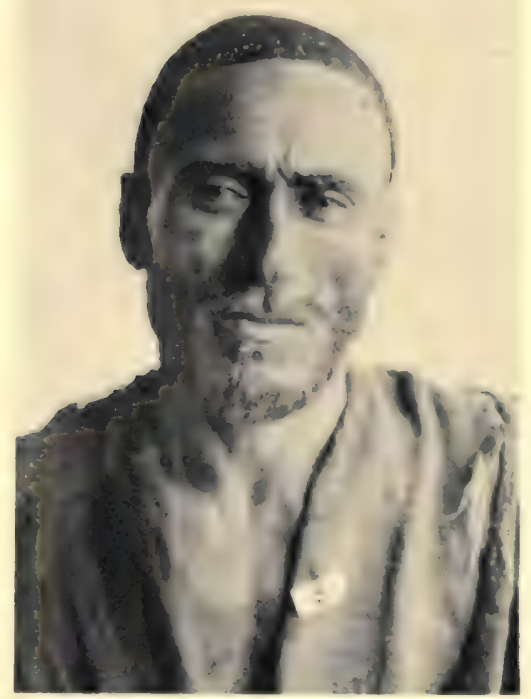

No. 919 (age 40)
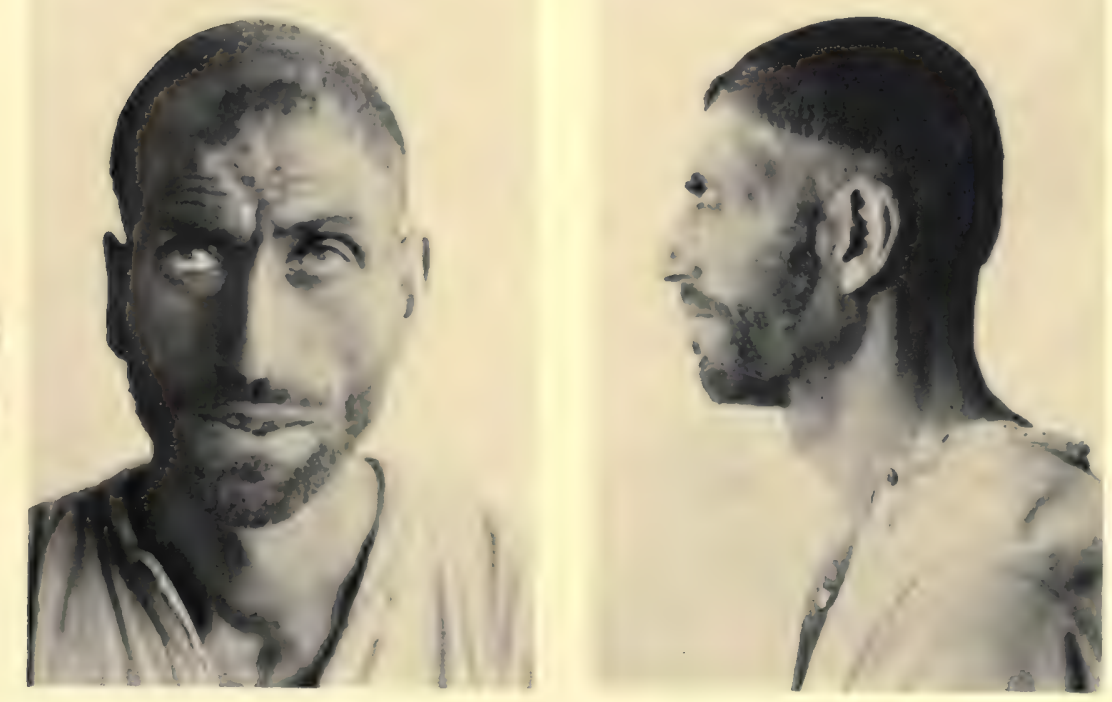

No. 945 (age 40)
Anthropology, Vol. 30, Plate 95

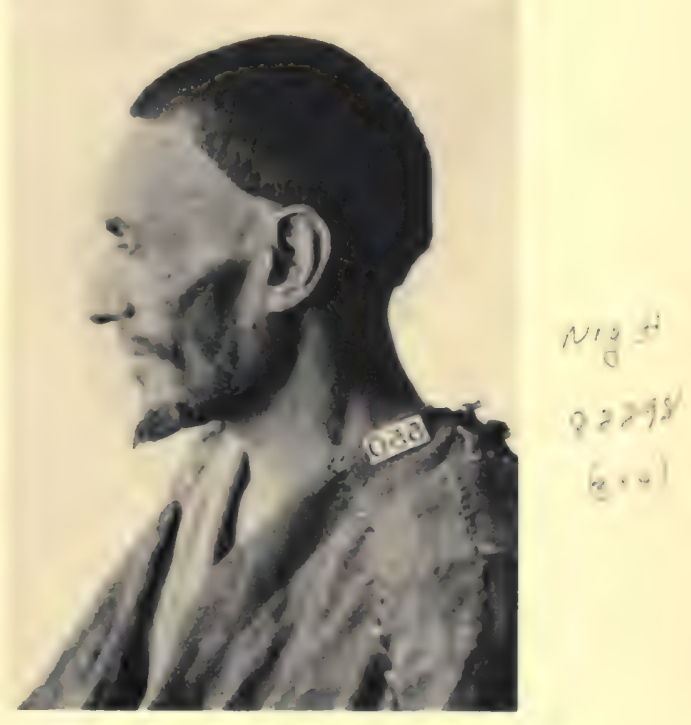

(

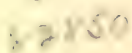

$(3 \times 4)$

AL BU MUHAMMAD CLASSIC MEDITERRANEAN

PLUS CONVEX-NOSED TYPES 


\section{$a(\# 1392(a) 0)$}

Field Museum of Natural History

Anthropology, Vol. 30, Plate 96
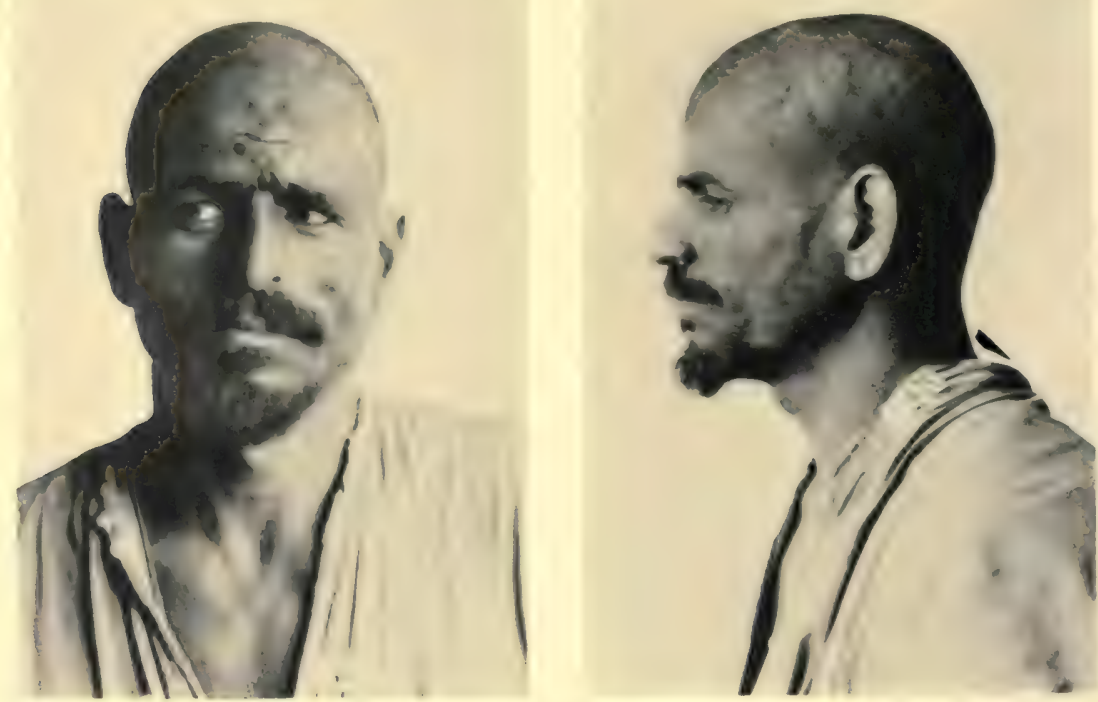

No. 926 (age 40)
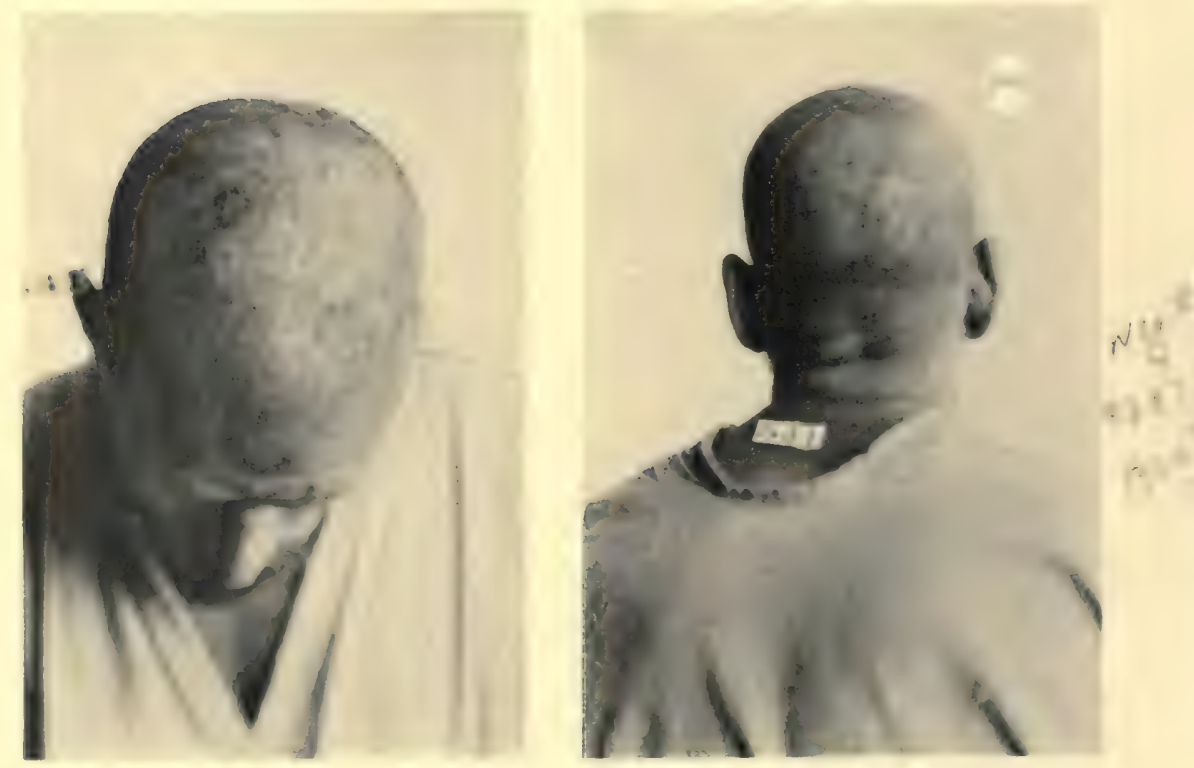

No. 926 (age 40)

AL BU MUHAMMAD CLASSIC MEDITERRANEAN

PLUS CONVEX-NOSED TYPE 


\section{alt 1398}

Field Museum of Natural History

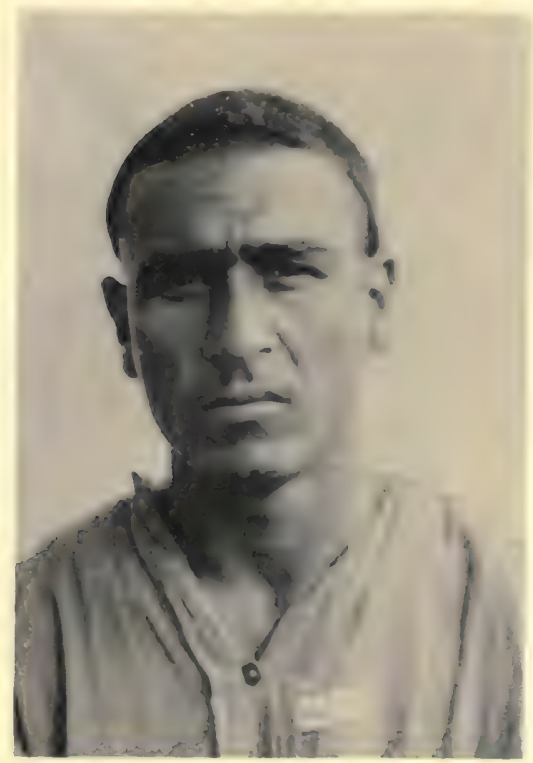

Anthropology, Vol. 30, Plate 97

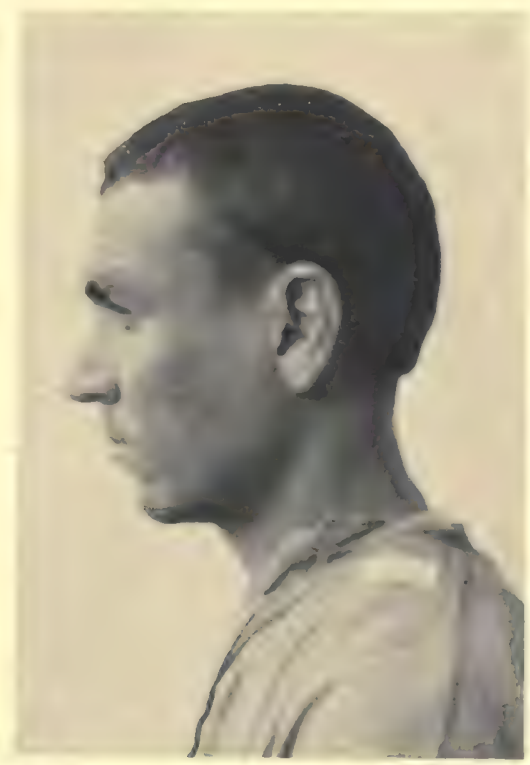

No. 815 (age 22)
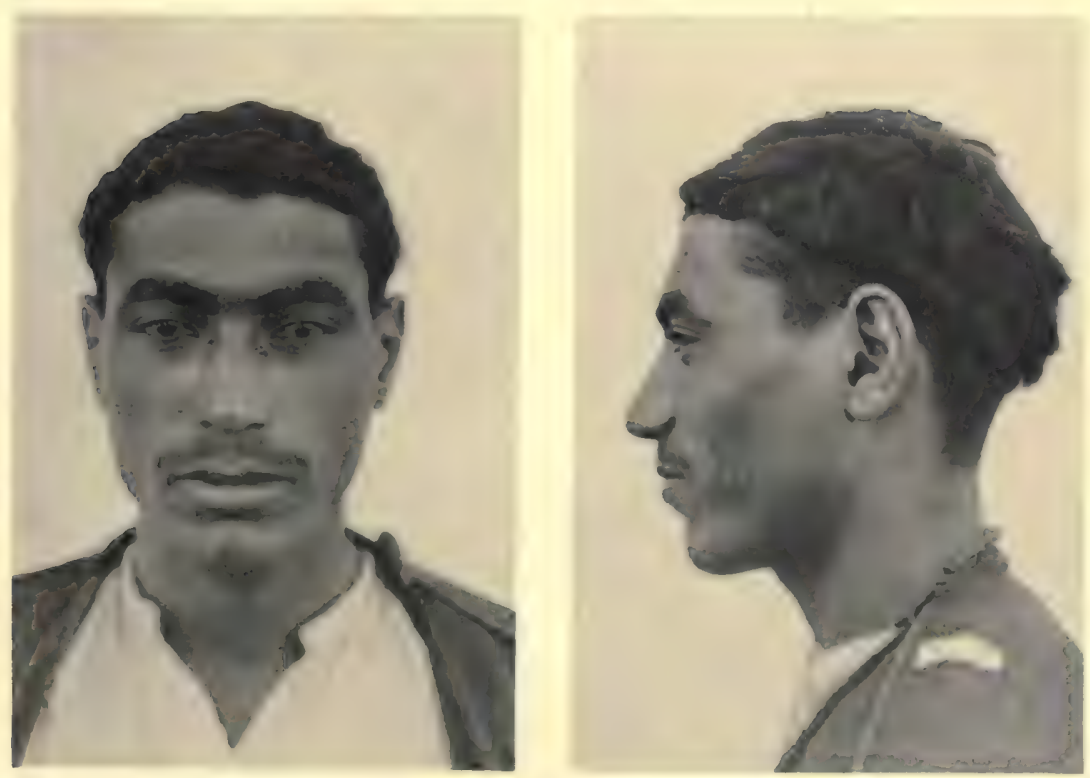

No. 898 (age 23) $\forall \&$

$7^{2}, 0^{4}$ $(5,4)$ nit

1048

$(2,4)$

AL BU MUHAMMAD ATLANTO-MEDITERRANEAN TYPES 


\section{attis?}

Field Museum of Natural History

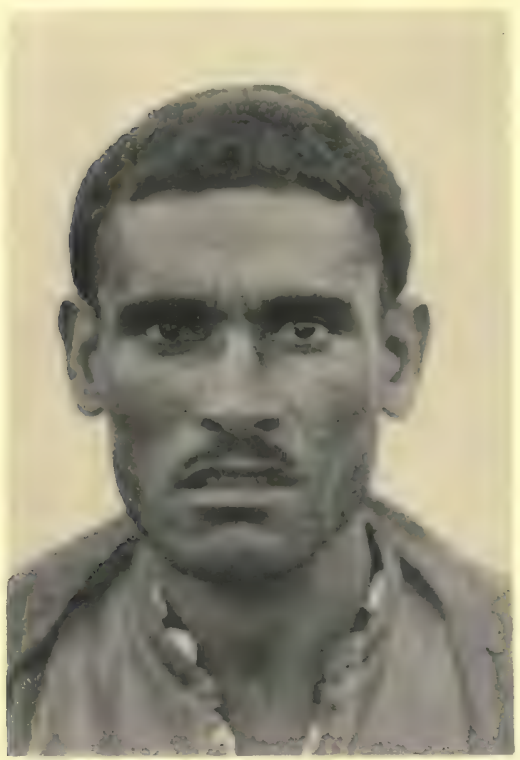

Anthropology, Vol. 30, Plate 98

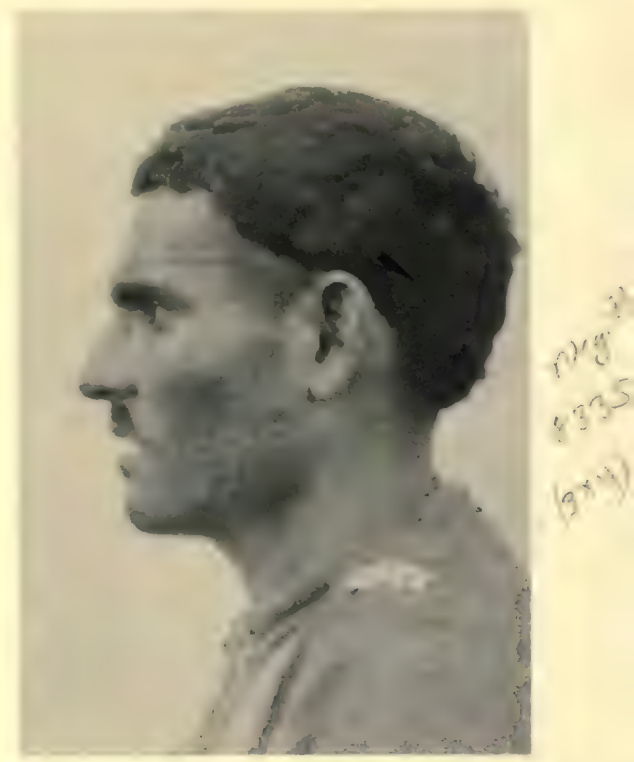

No. 786 (age 25)
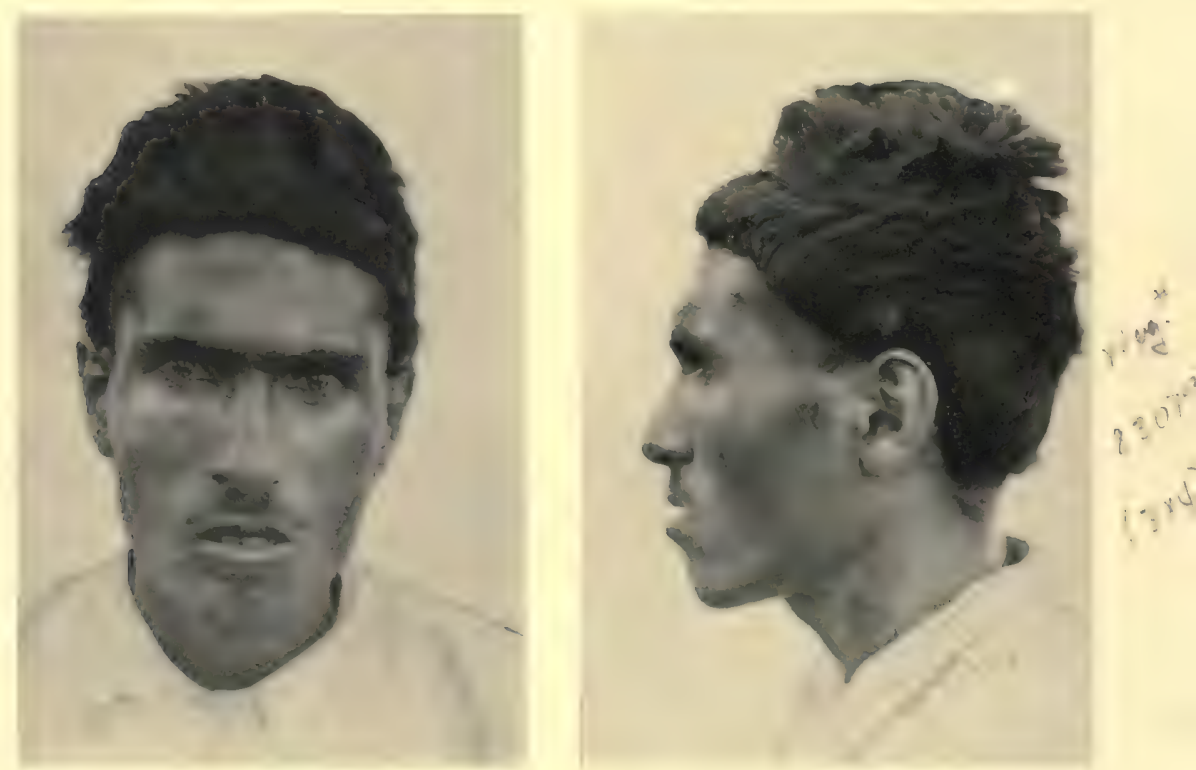

No. 787 (age 25)

AL BU MUHAMMAD ATLANTO-MEDITERRANEAN TYPES 


\section{al $\$ 139 \varepsilon$ (all)}

Field Museum of Natural History

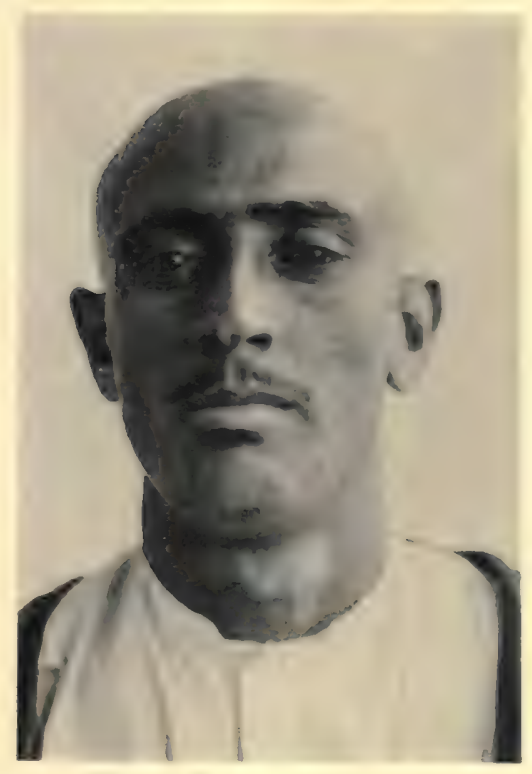

No. 803 (age 25)

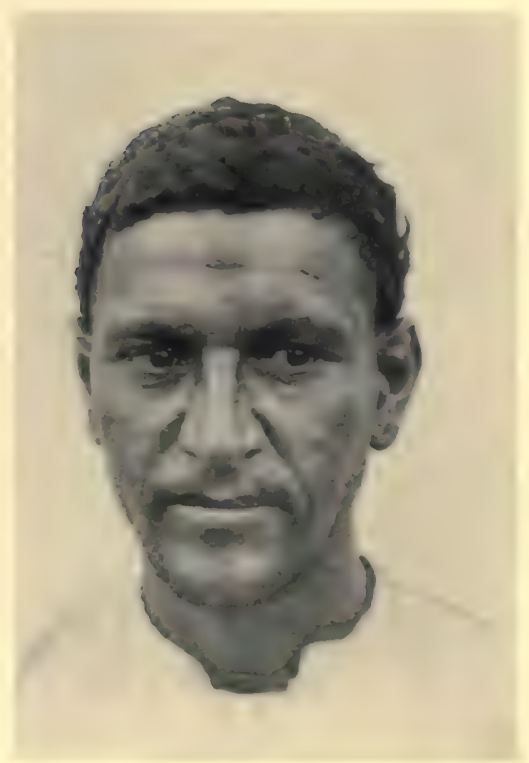

Anthropology, Vol. 30, Plate 99

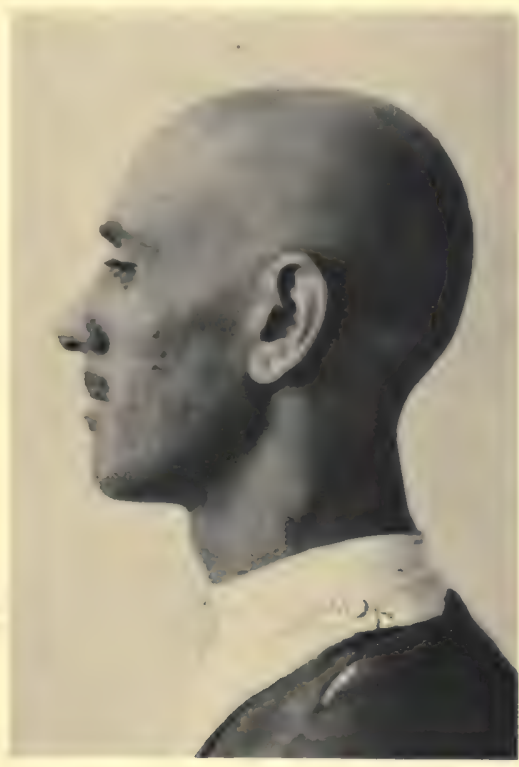

Nhy it

$=8142$

$\left(3 \mathrm{r}^{\mathrm{d}}\right)$

No. 784 (age 30 ) 


\section{$a b \# 139 \varepsilon(a)$}

Field Museum of Natural History

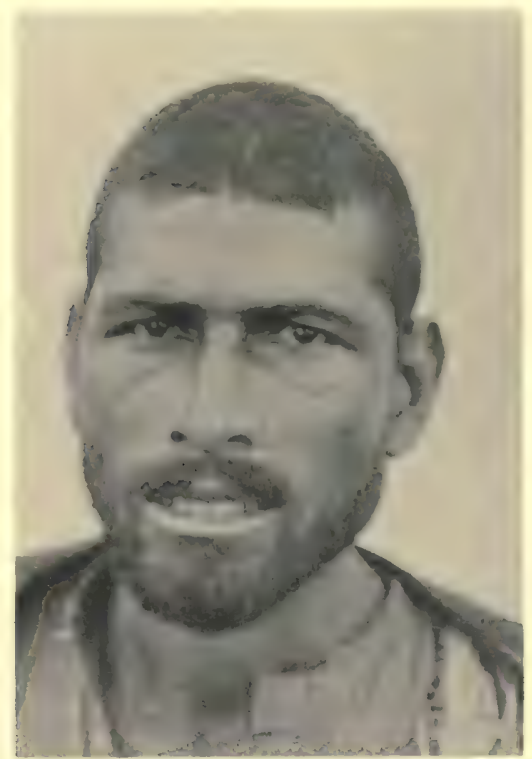

Anthropology, Vol. 30, Plate 100

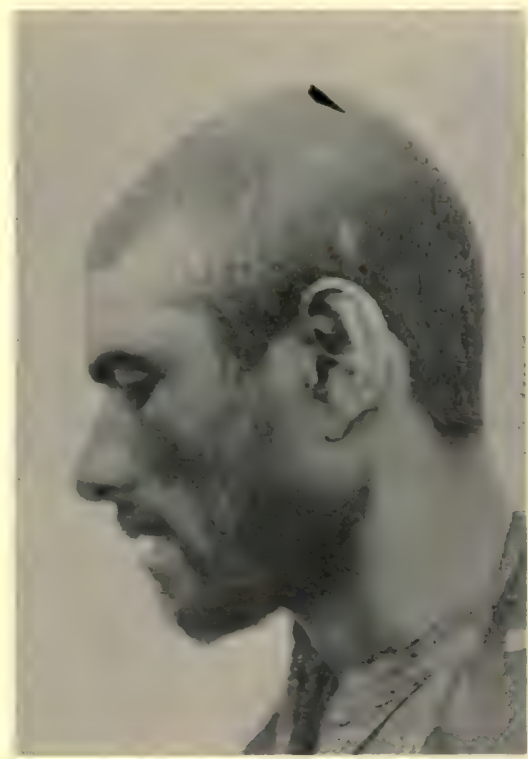

Neg

833

$(3 x)$

No. 776 (age 30)
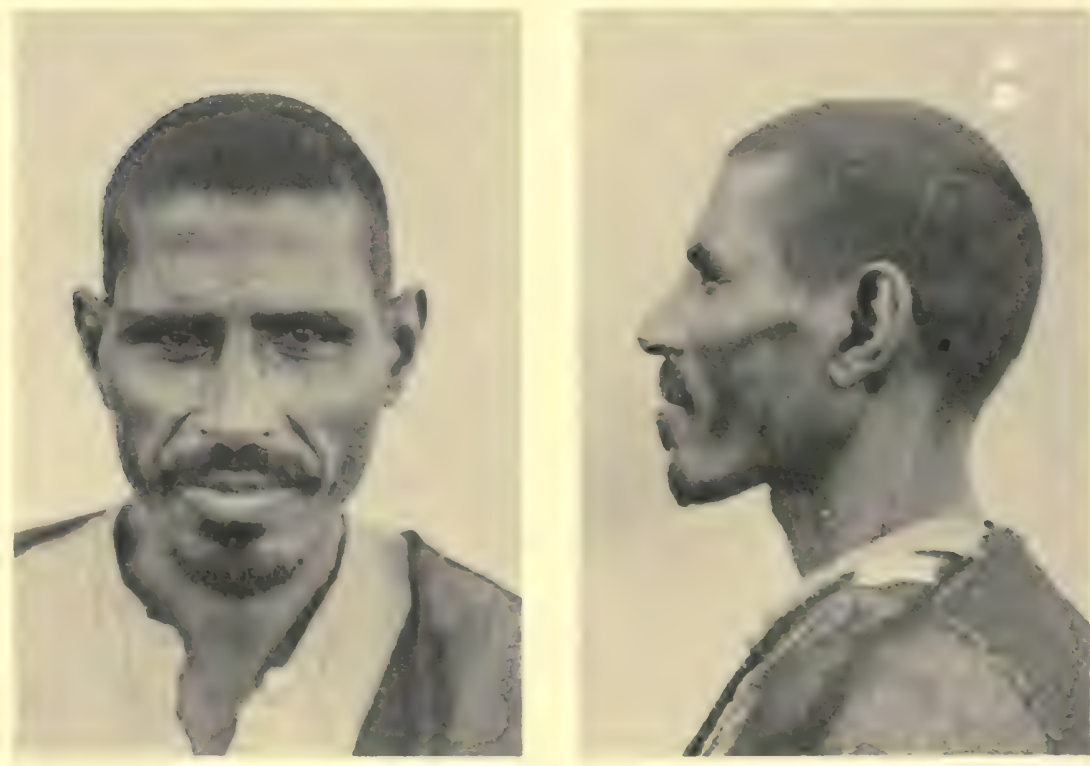

No. 873 (age 35)

AL BU MUHAMMAD ATLANTO-MEDITERRANEAN TYPES 


\section{$a l+39 \varepsilon(a) l)$}

Field Museum of Natural History

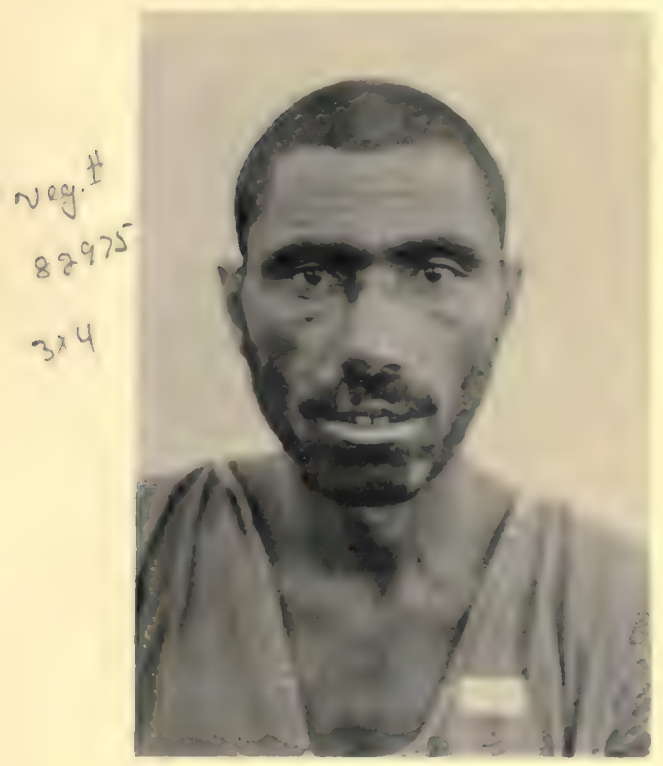

No. 888 (age 35)

$\log 1$

$=19 \dot{7}$

$(3 \times 4)$
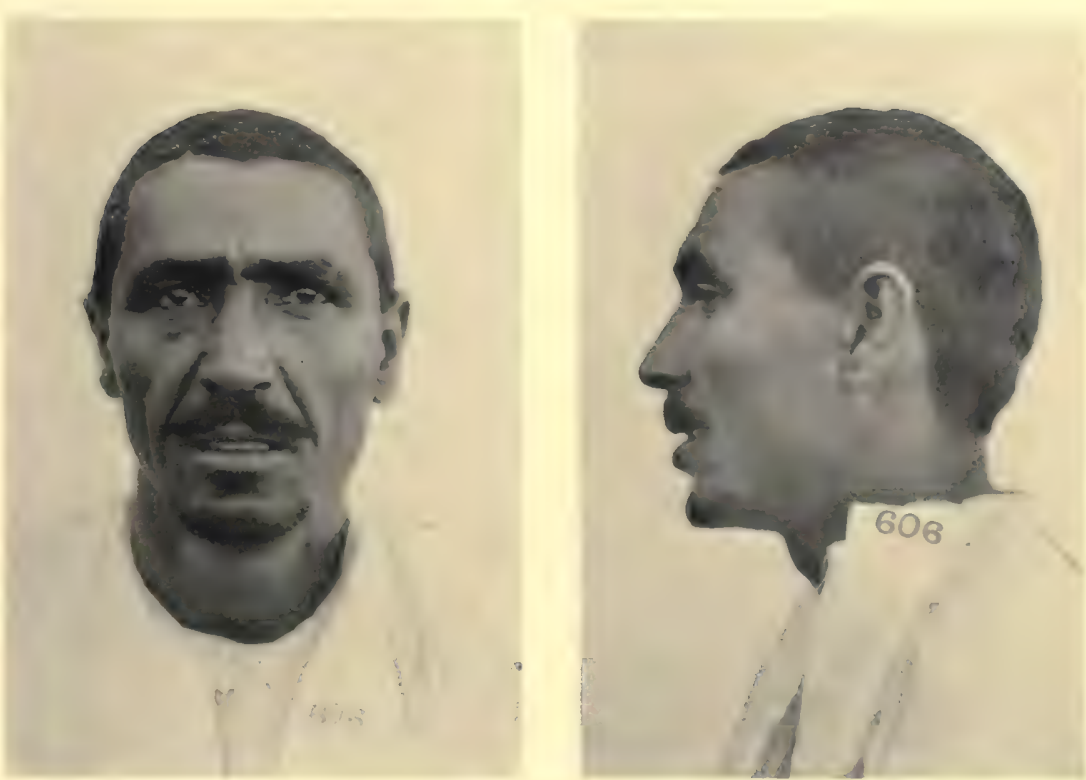

Wey,

$8 \rightarrow=00$

$3+4$

No. 876 (age 35 )

AL BU MUHAMMAD ATLANTO-MEDITERRANEAN TYPES 


\section{all 139 \& (all)}

Field Museum of Natural History

Anthropotogy, Vol. 30, Plate 102
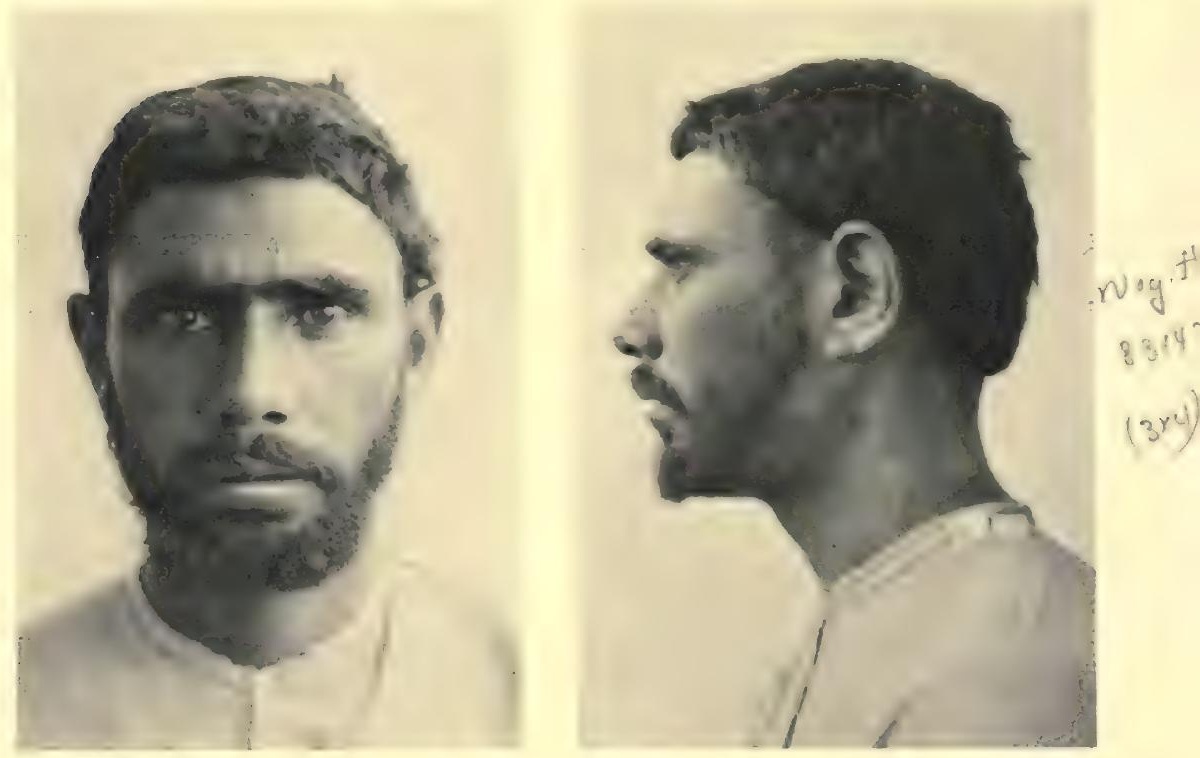

No. 798 (age 35)
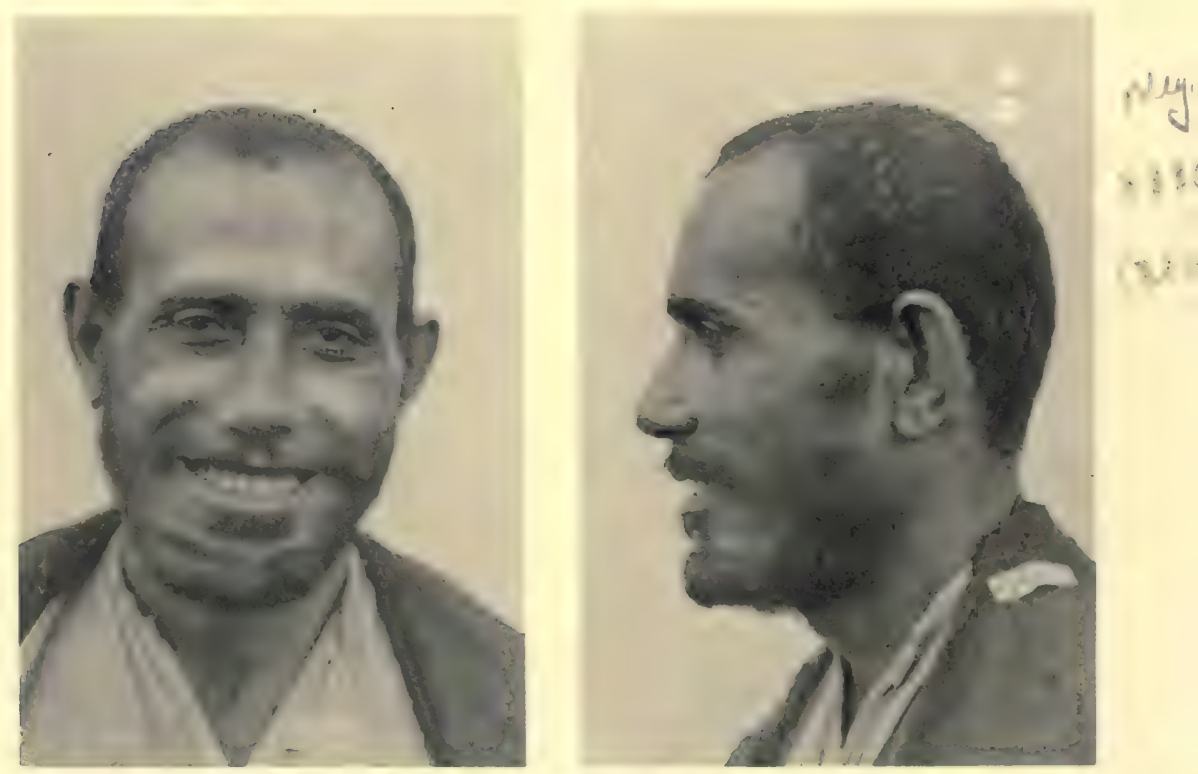

No. 783 (age 35 )

AL BU MUHAMMAD ATLANTO-MEDITERRANEAN TYPES 


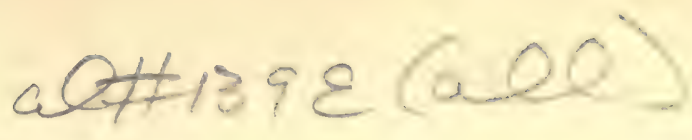

Field Museum of Natural History

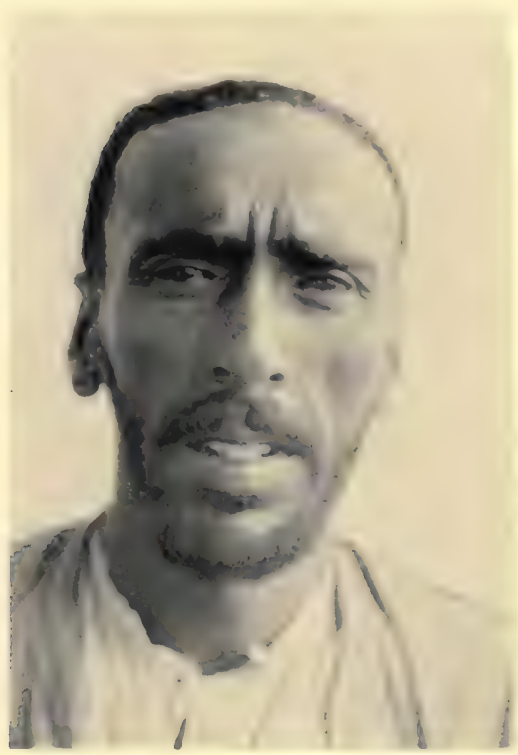

No. 808 (age 35)

83013

$(3 \times 4)$

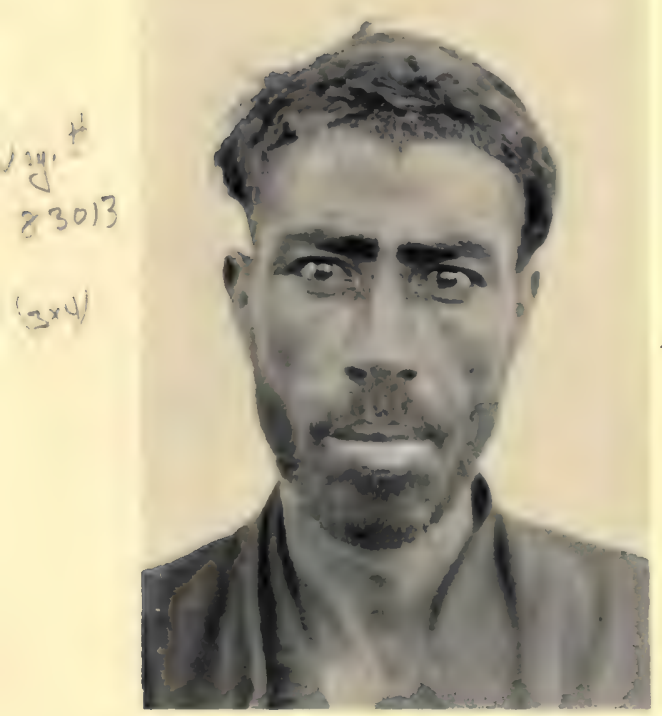

Anthropology, Vol. 30, Plate 103

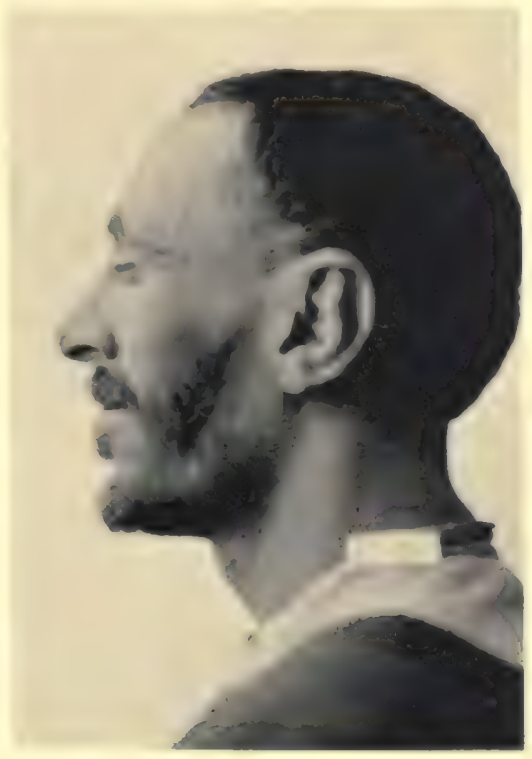

r)e.t

8312

$(3 \times 4)$

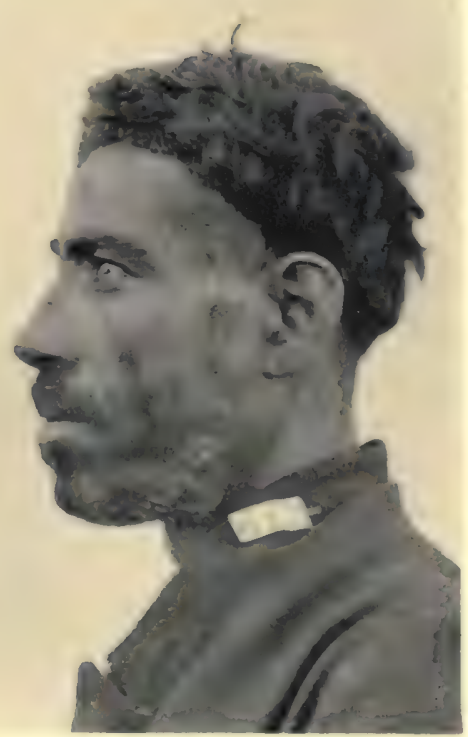

Nigg.

88014

$(3 \times 4)$

No. 869 (age 38)

AL BU MUHAMMAD ATLANTO-MEDITERRANEAN TYPES 


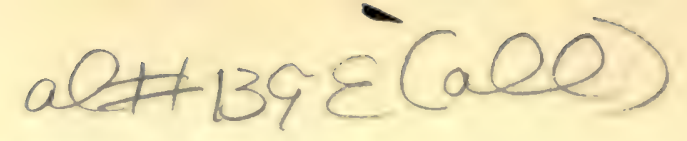

Field Museum of Natural History

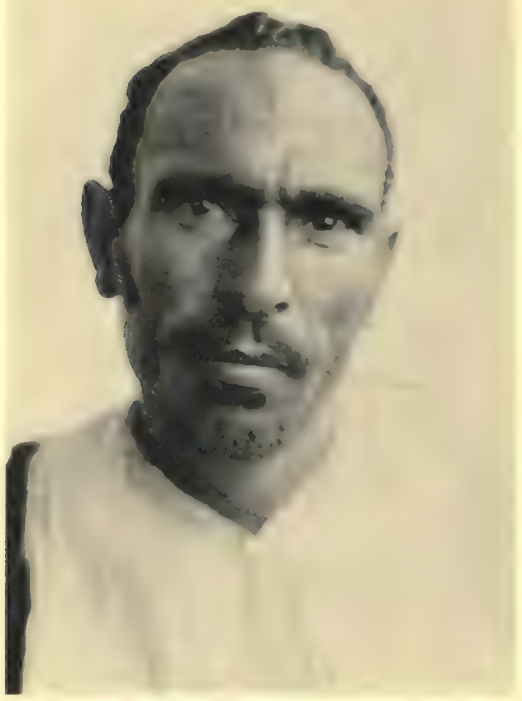

Anthropology, Vol. 30, Plate 104

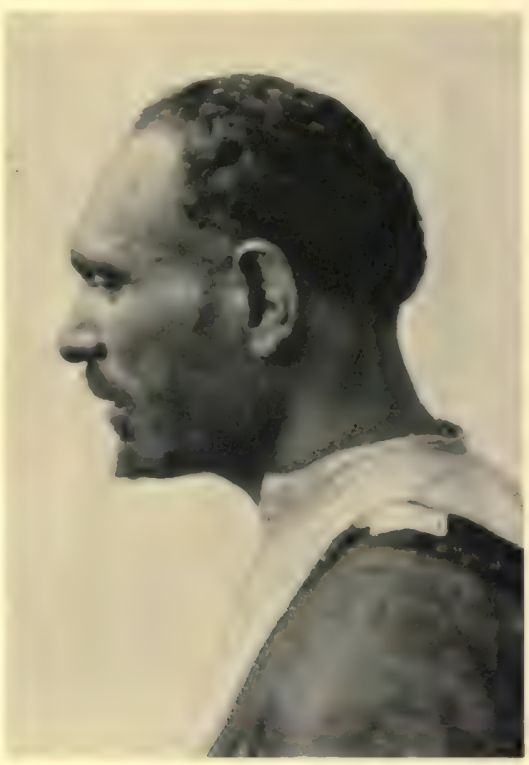

$\pi g^{3}$

0,5

$(-3)^{2}$

No. 824 (age 40)
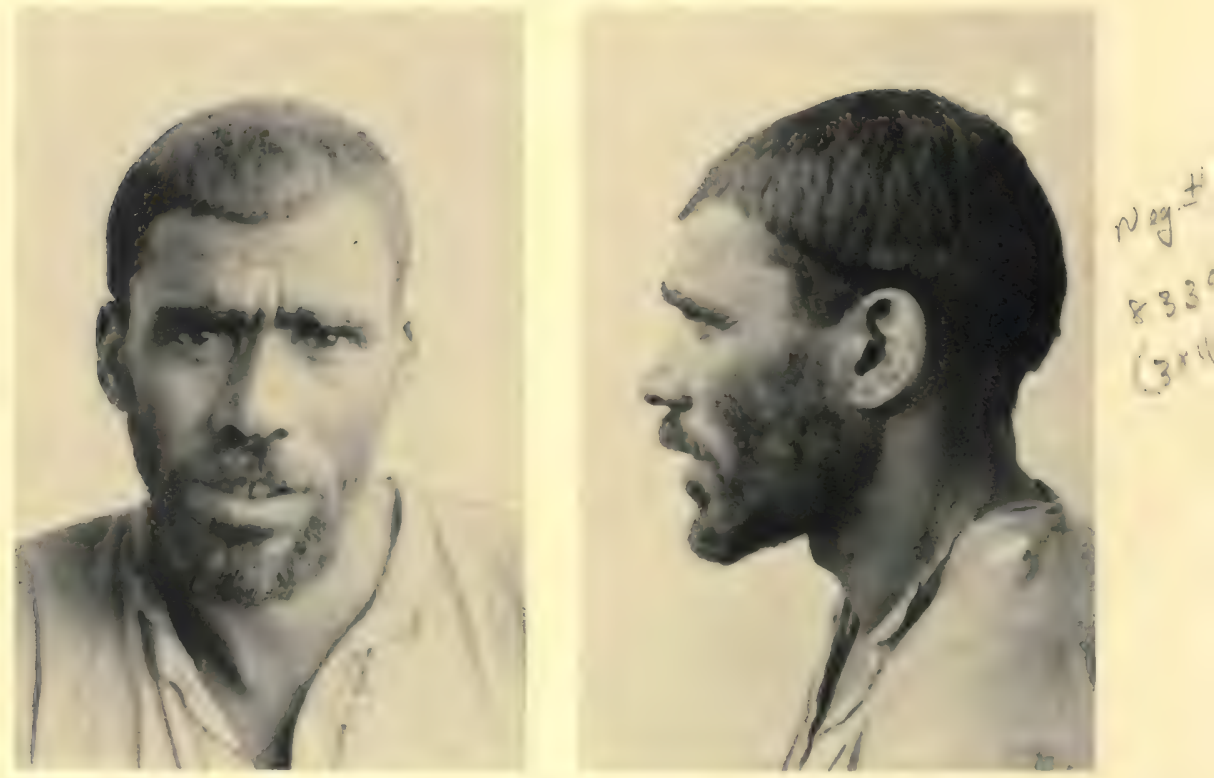

No. 826 (age 40)

AL BU MUHAMMAD ATLANTO-MEDITERRANEAN TYPES 


\section{$a l \# 139 \varepsilon(a Q)$}

Field Museum of Natural History
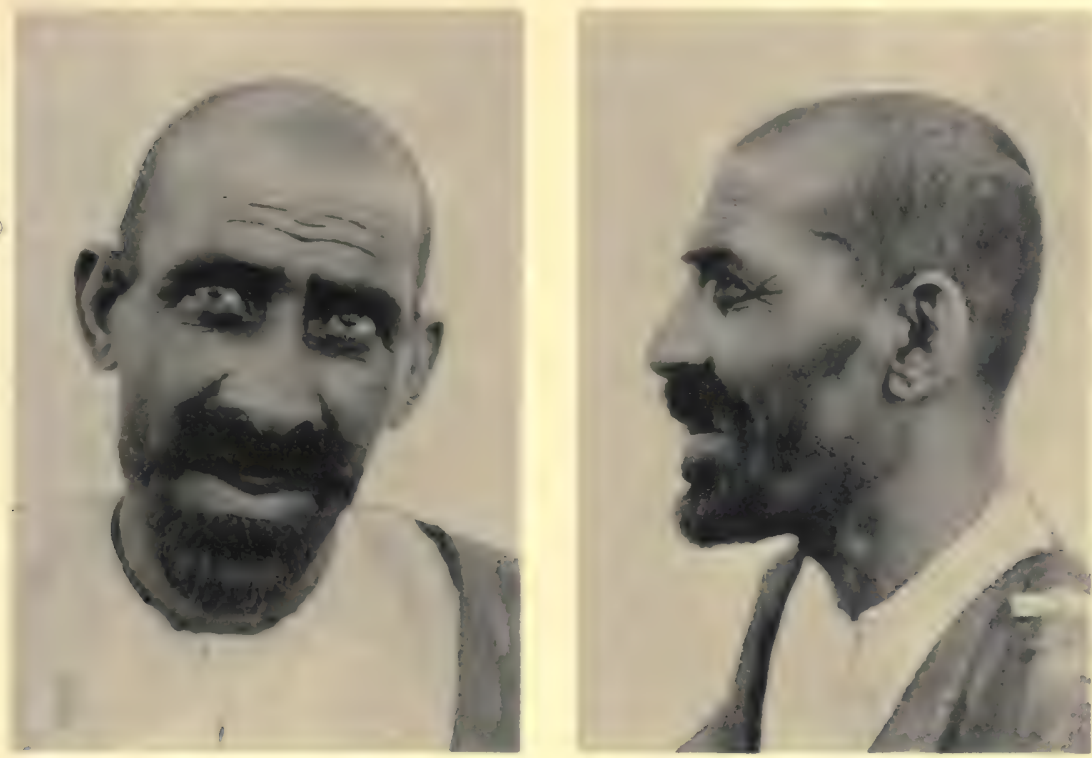

No. 849 (age 40)

$\log _{1}+$

$8: 29$

$\left(3 \times x^{2}\right)$

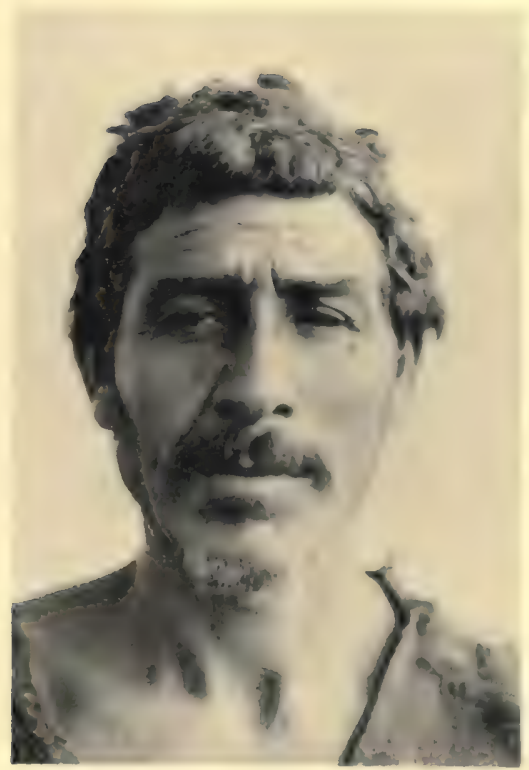

Anthropology, Vol. 30, Plate 105

$$
\begin{aligned}
& \operatorname{Nog} H \\
& 83061 \\
& (3 \times 4)
\end{aligned}
$$

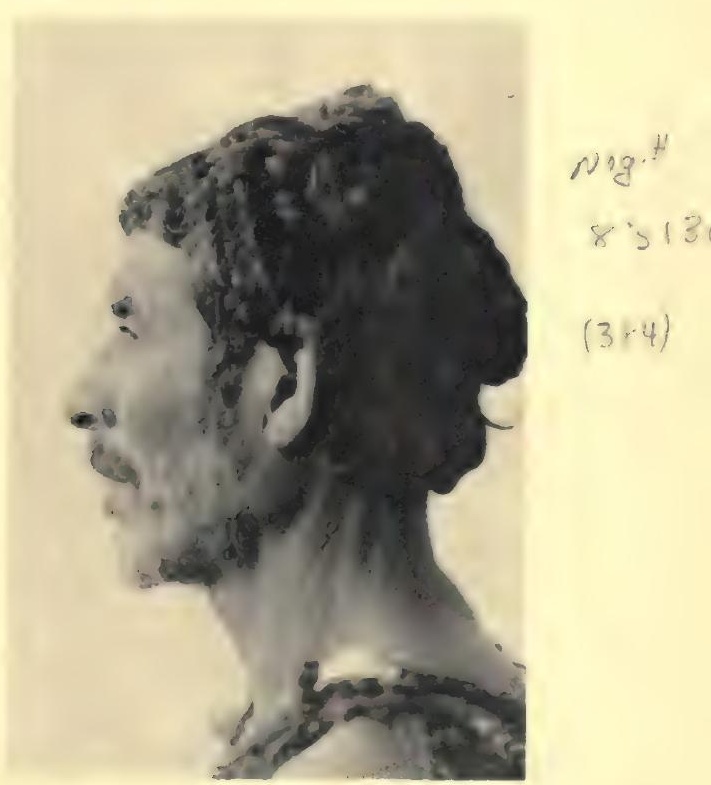

No. 804 (age 50)

AL BU MUHAMMAD ATLANTO-MEDITERRANEAN

PLUS CONVEX-NOSED TYPES 


\section{$a l \# 139 \varepsilon(a)$}

Field Museum of Natural History

$\operatorname{lat} x^{+1}$

$\because 3338$

$3 \times 4)$
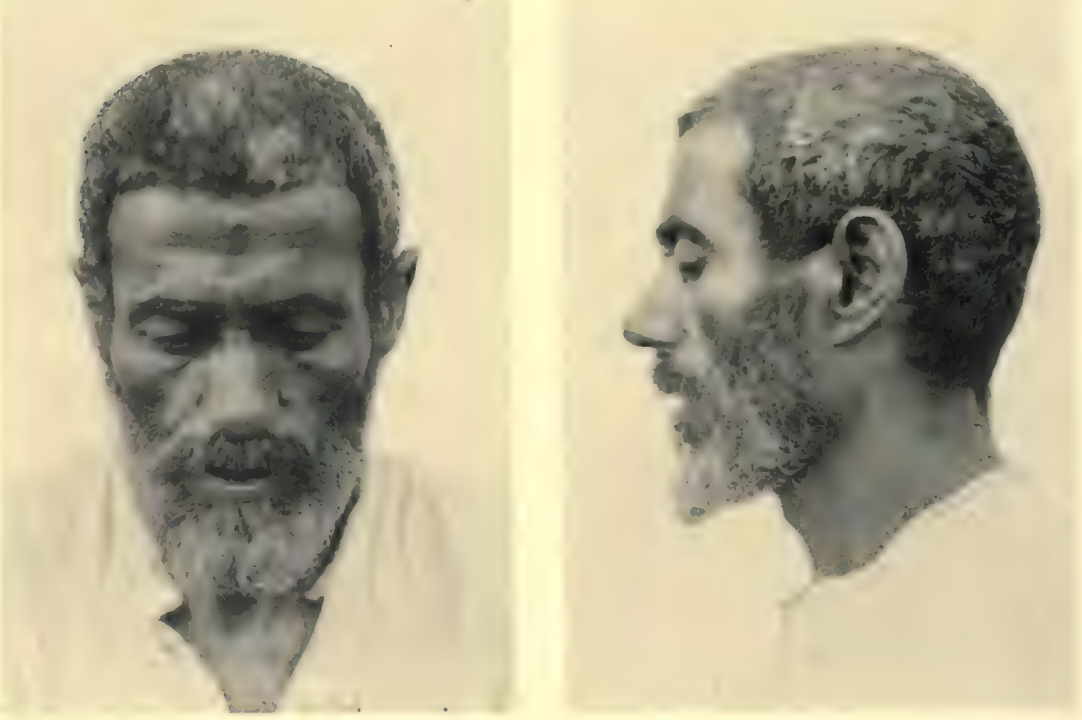

Nig.

883

$3 \times 4$

No. 836 (age 55)

t

2991

$\times 4)$
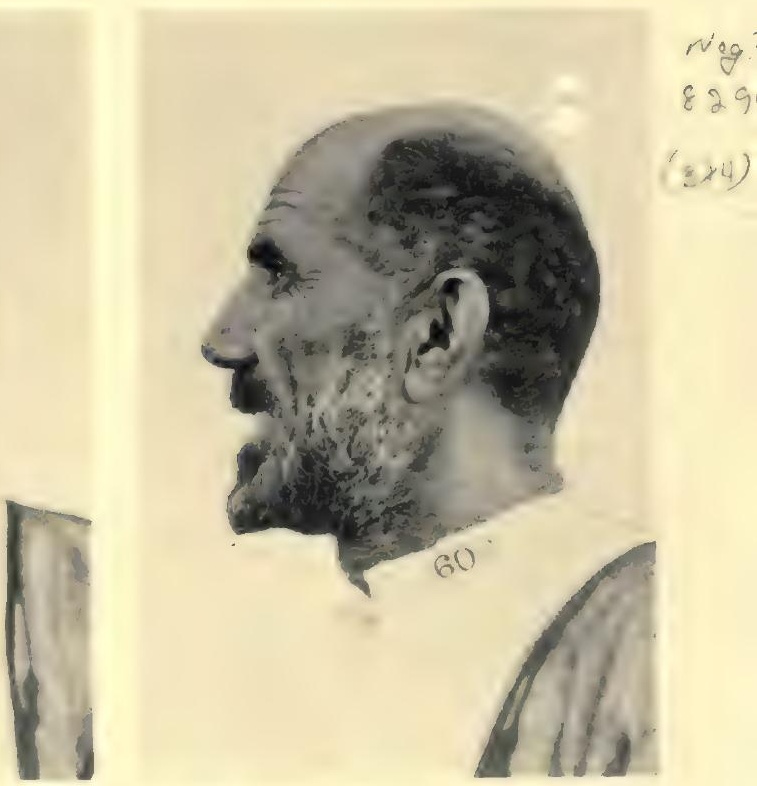

No. 880 (age 56)

AL BU MUHAMMAD ATLANTO-MEDITERRANEAN

PLUS CONVEX-NOSED TYPES 


\section{$a+139 \varepsilon$}

Field Museum of Natural History

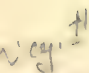

3899 $3 \times 4)$

$3 \times 14$

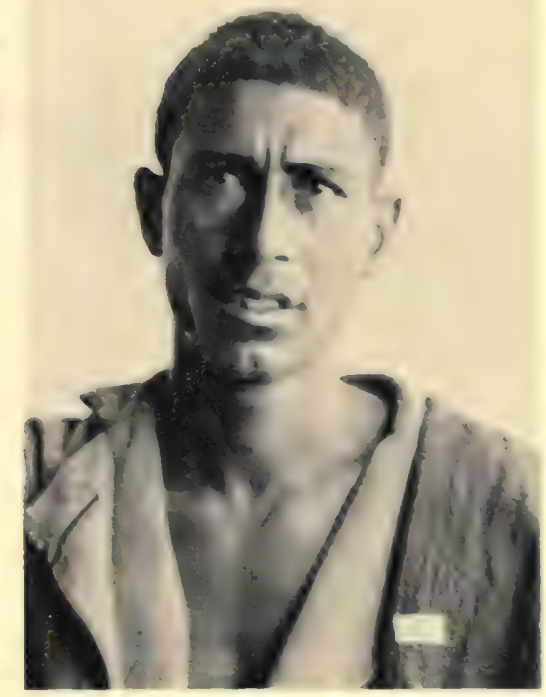

No. 898 (age 23)

918
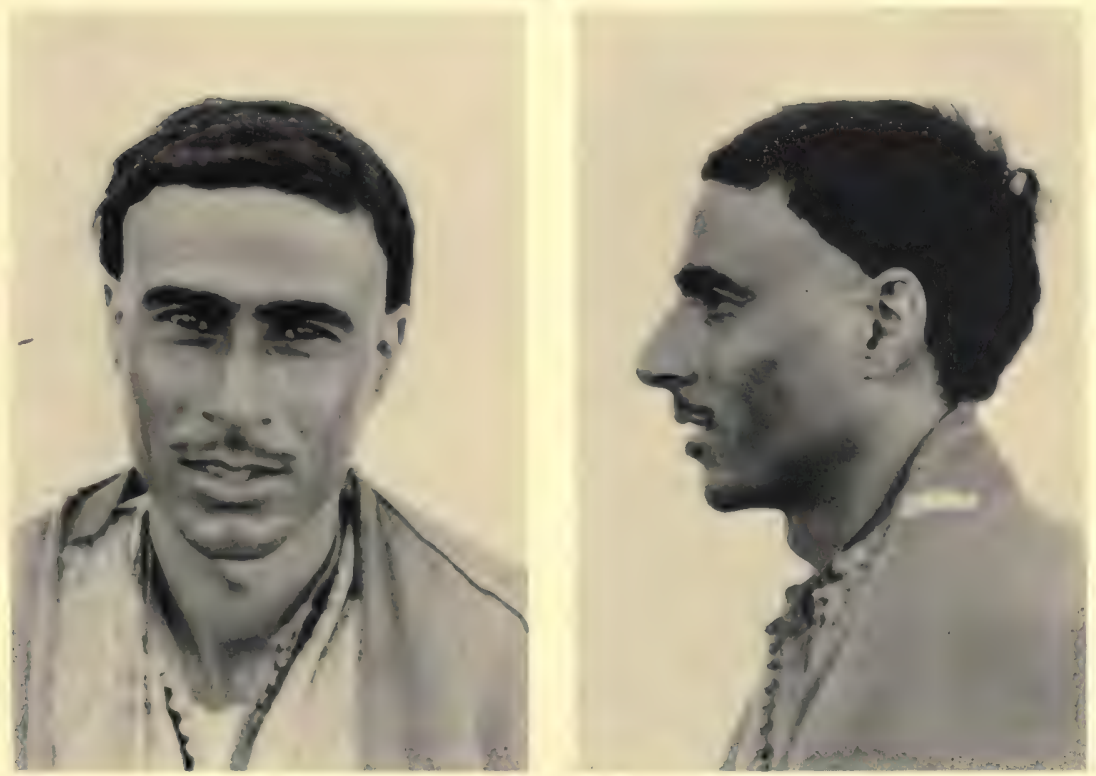

, vey. 는

82940

$(3 \times 4)$

No. 900 (age 25)

AL BU MUHAMMAD ATLANTO-MEDITERRANEAN

PLUS CONVEX-NOSED TYPES 


\section{al \#1392}

Field Museum of Natural History

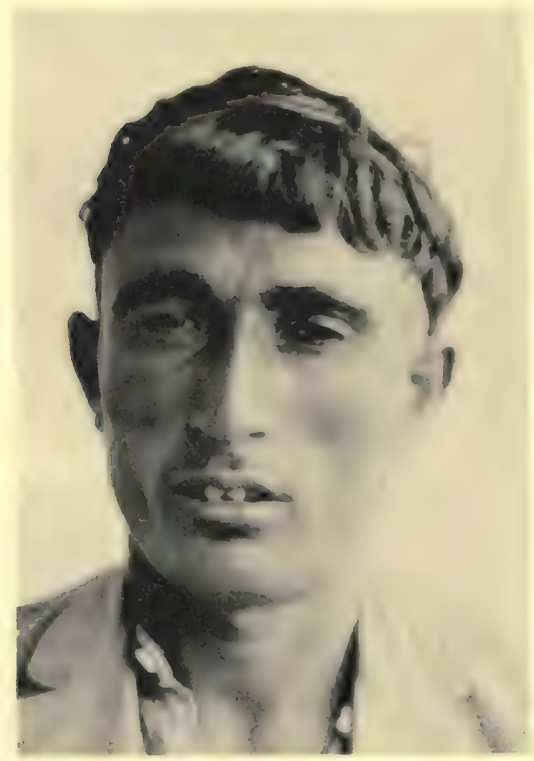

Anthropology, Vol. 30, Plate 108

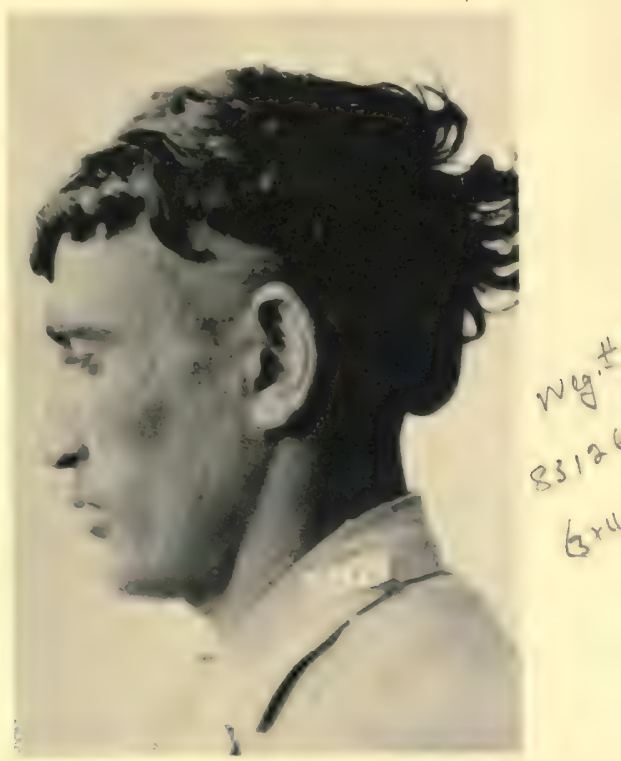

No. 806 (age 25)
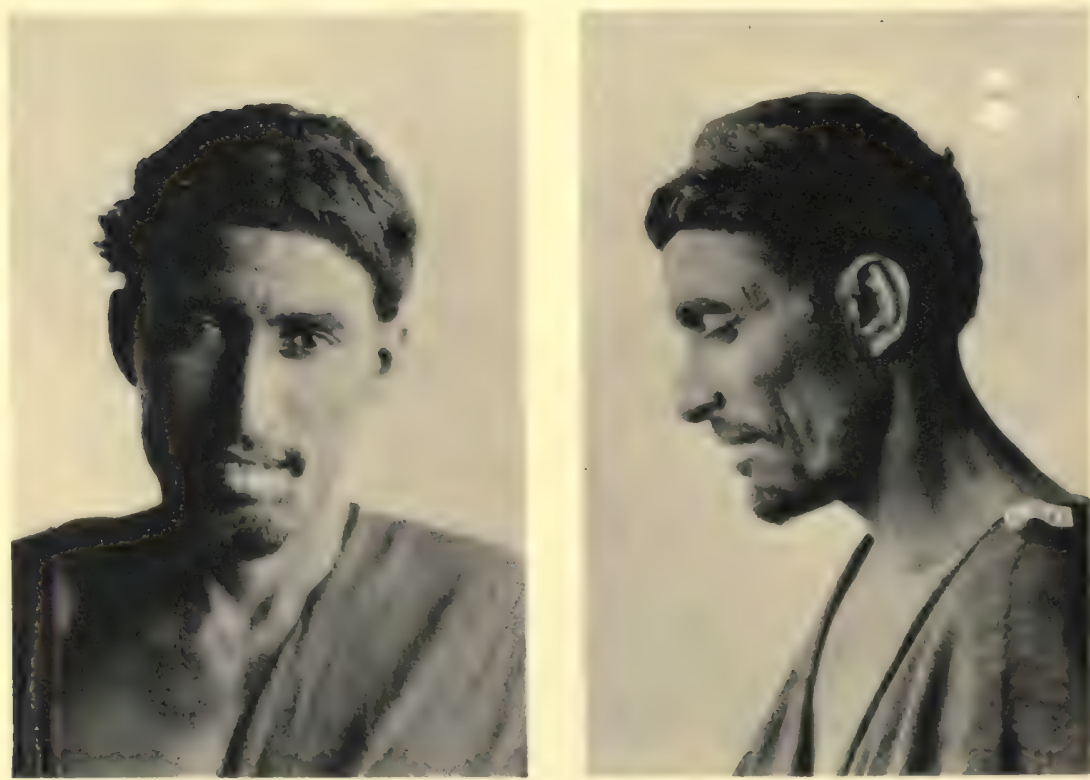

Na9

$x^{9}$

$(3)^{x}$

No. 914 (age 30)

AL BU MUHAMMAD ATLANTO-MEDITERRANEAN

PLUS CONVEX-NOSED TYPES 


\section{$\omega=139 \varepsilon(a \infty)$}

Field Museum of Natural History

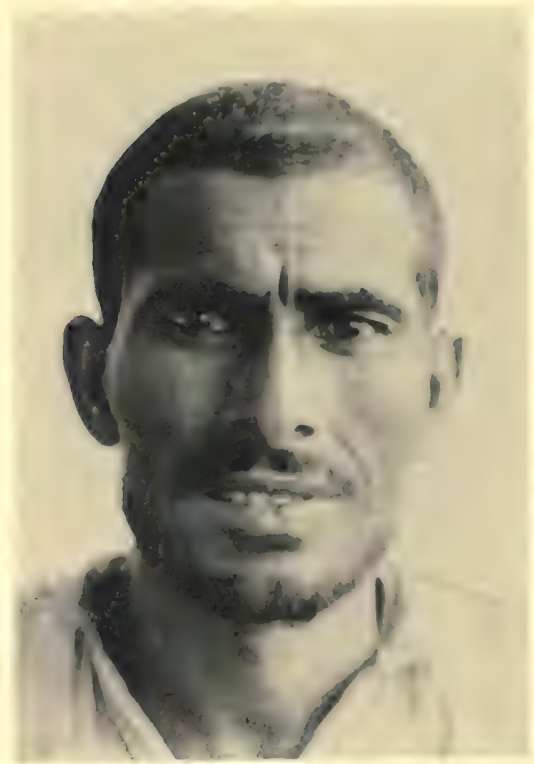

Anthropology, Vol. 30, Plate 110

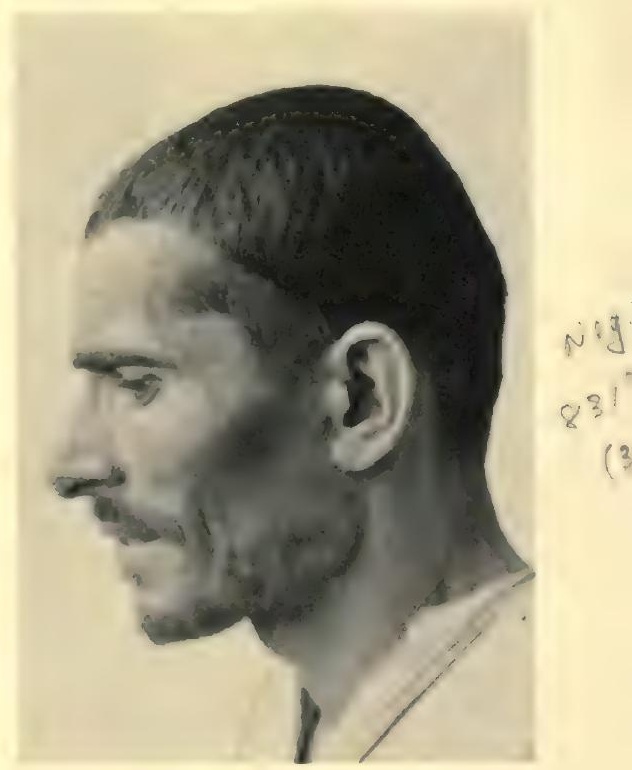

No. 800 (age 30 )
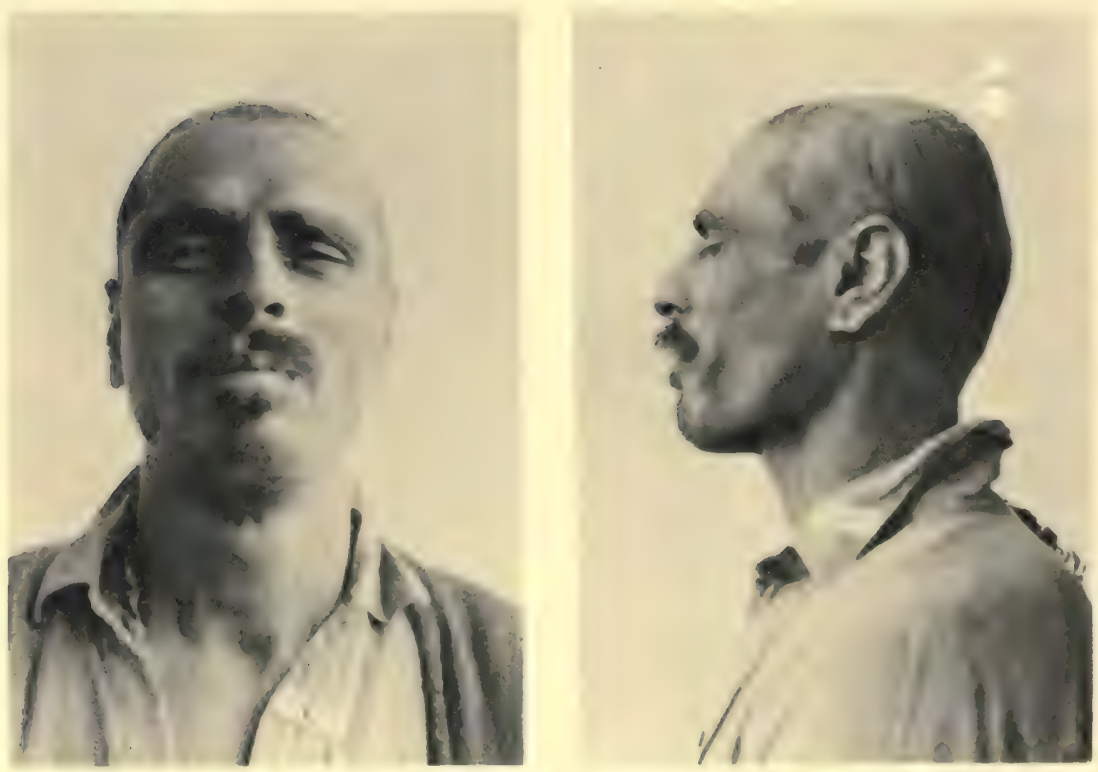

Niy

83

$(3$

No. 810 (age 32 )

AL BU MUHAMMAD ATLANTO-MEDITERRANEAN

PLUS CONVEX-NOSED TYPES 


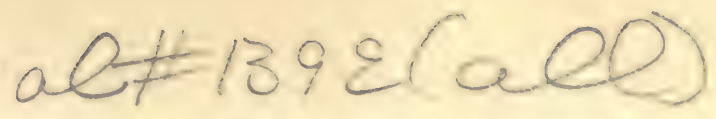

Field Museum of Natural History

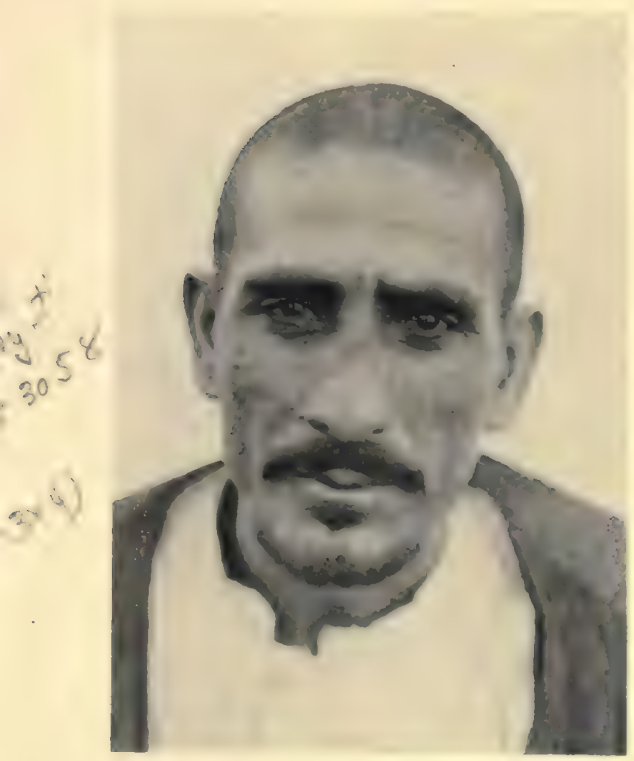

No. 789 (age 33)
Anthropology, Vol. 30, Plate 111

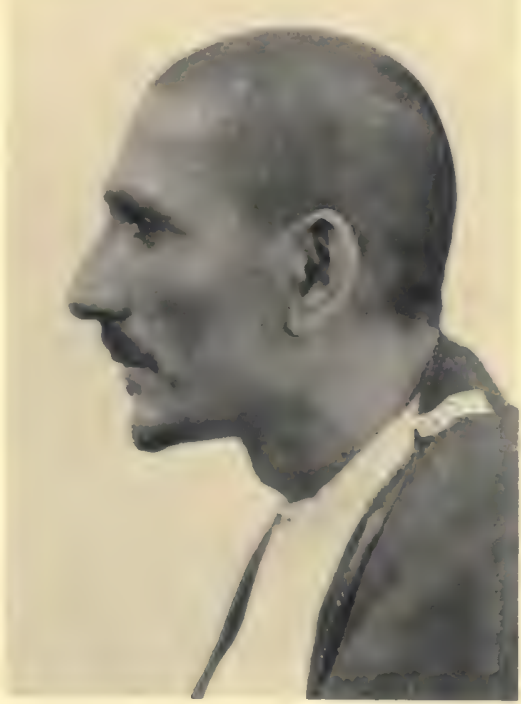

$r \cdot f^{f !}$ 3059

$(3 \times 4)$
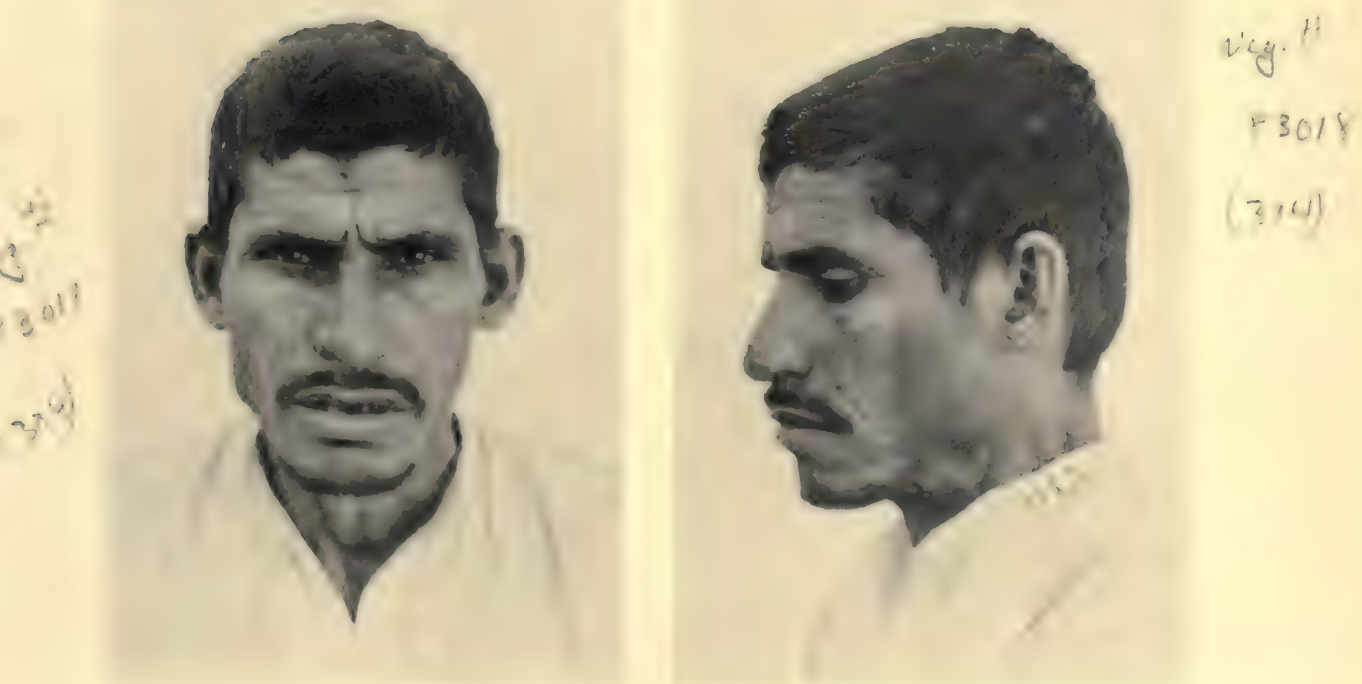

No. 868 (age 35)

AL BU MUHAMMAD ATLANTO-MEDITERRANEAN

PLUS CONVEX-NOSED TYPES 


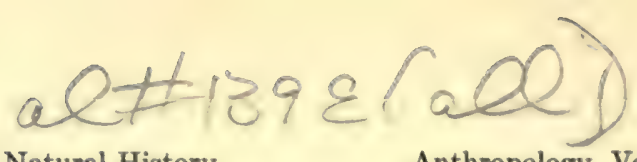

Field Museum of Natural History

Anthropology, Vol. 30, Plate 112
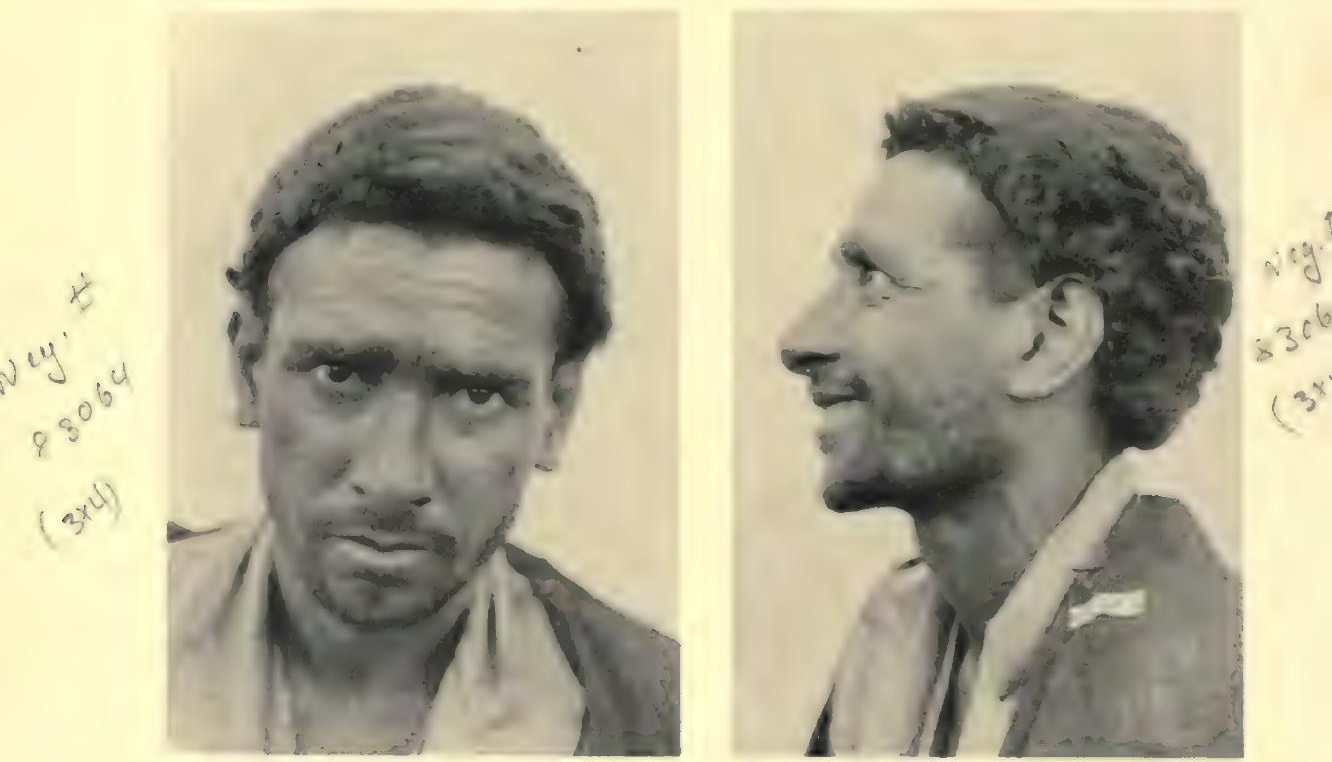

No. 848 (age 35)
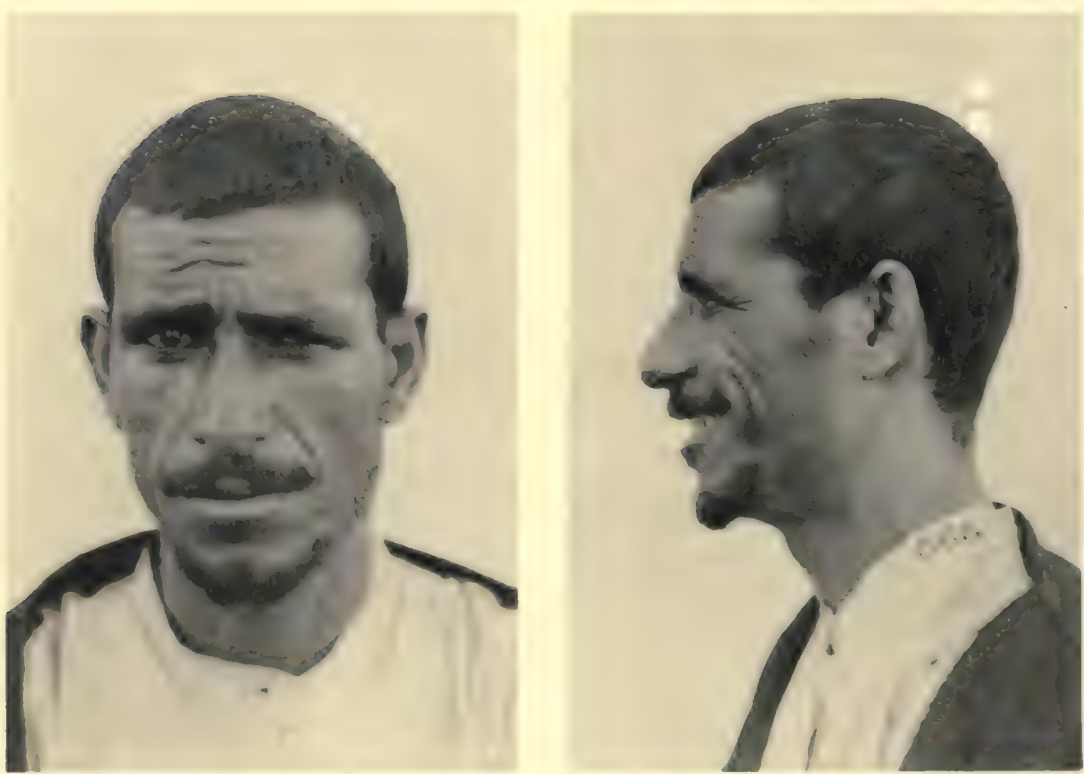

No. 769 (age 35)

AL BU MUHAMMAD ATLANTO-MEDITERRANEAN

PLUS CONVEX-NOSED TYPES 
$a b 139 \varepsilon$

Field Museum of Natural History

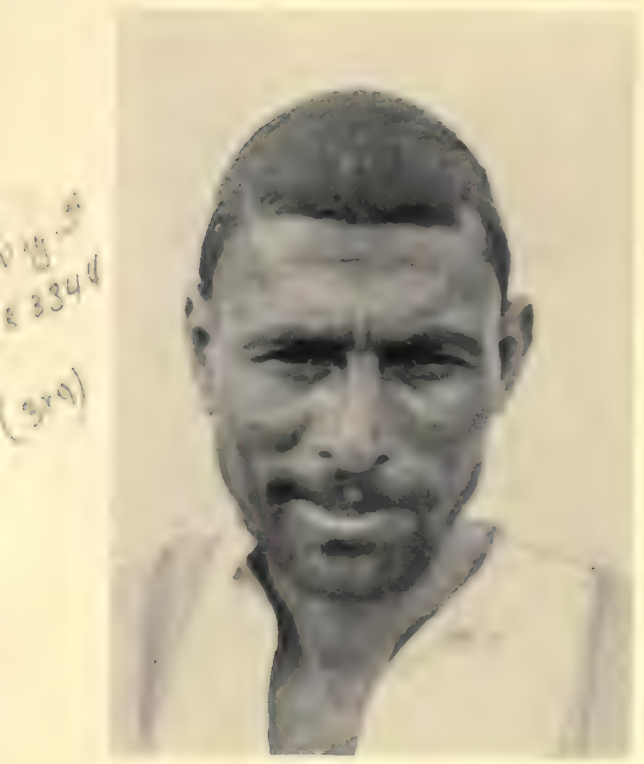

No. 839 (age 40)
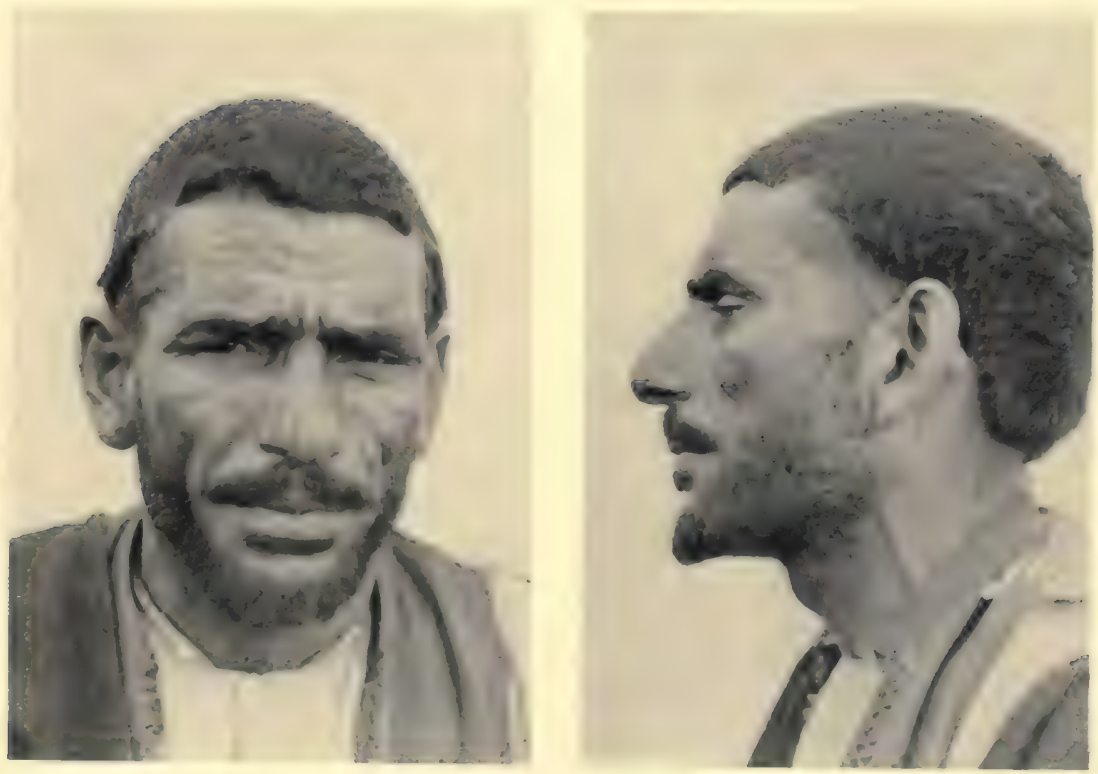

No. 881 (age 40)

AL BU MUHAMMAD ATLANTO-MEDITERRANEAN

PLUS CONVEX-NOSED TYPES 


\section{$a l \# 139 \varepsilon(a \infty)$}

Field Museum of Natural History

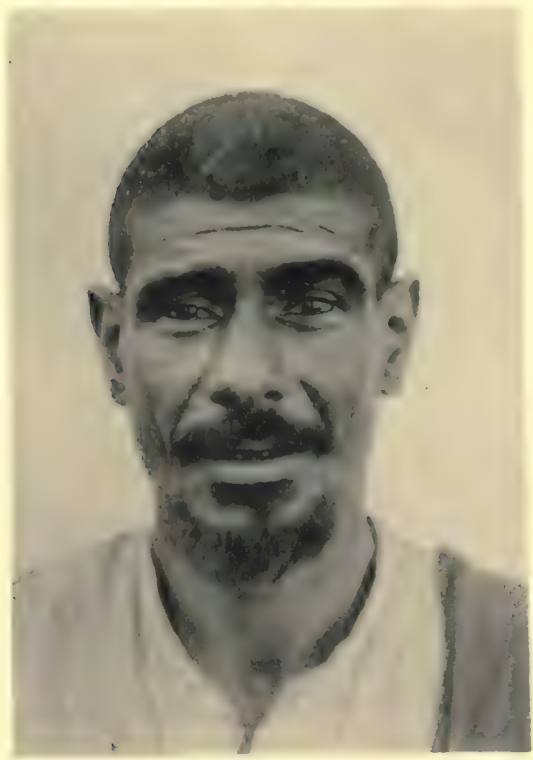

No. 846 (age 40)
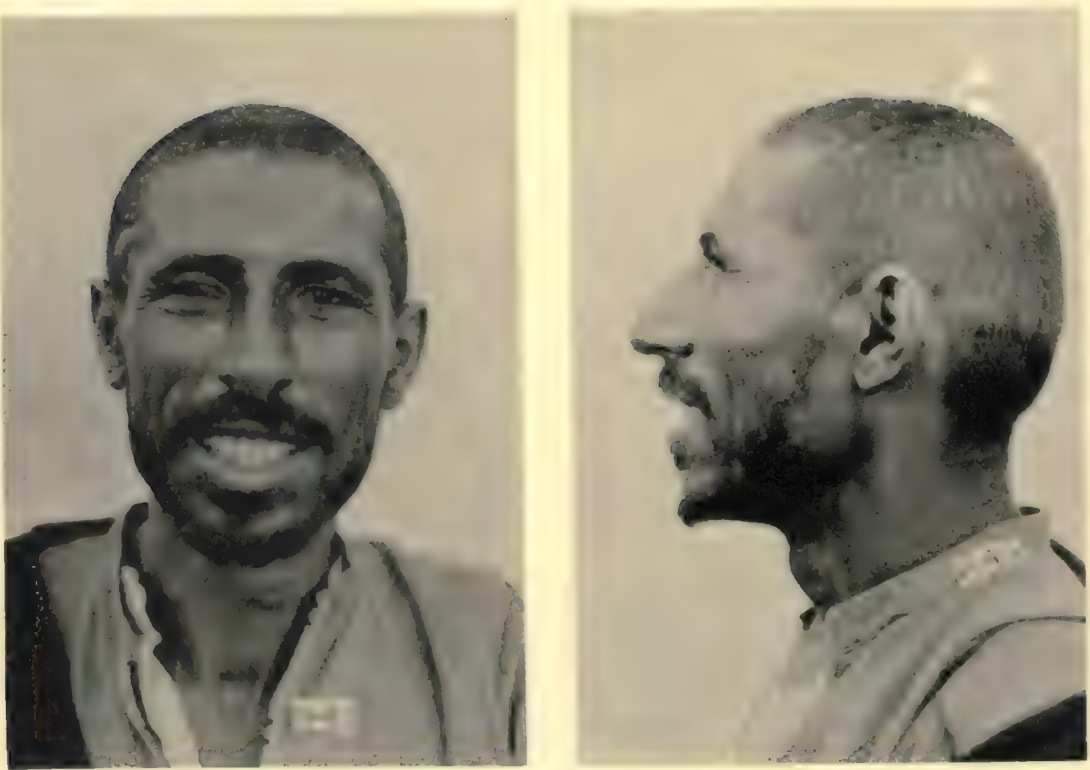

No. 847 (age 45)

AL BU MUHAMMAD ATLANTO-MEDITERRANEAN

PLUS CONVEX-NOSED TYPES 


\section{all\#1398 (ael)}

Field Museum of Natural History

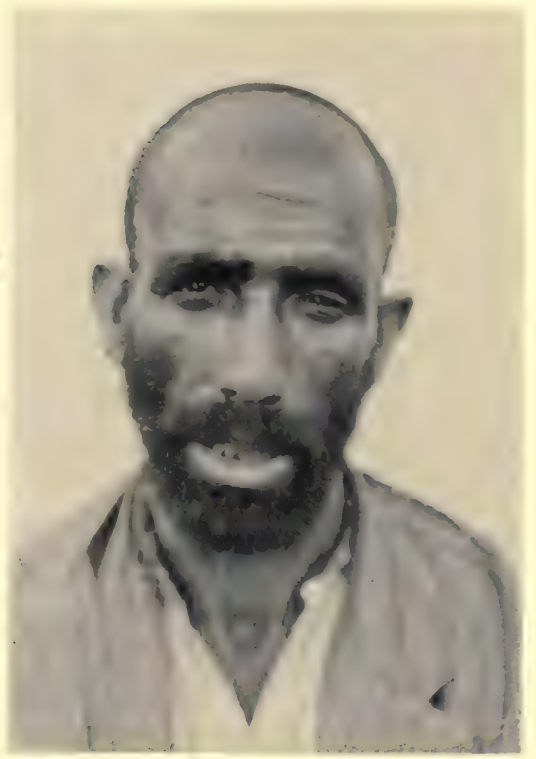

Anthropology, Vol. 30, Plate 115

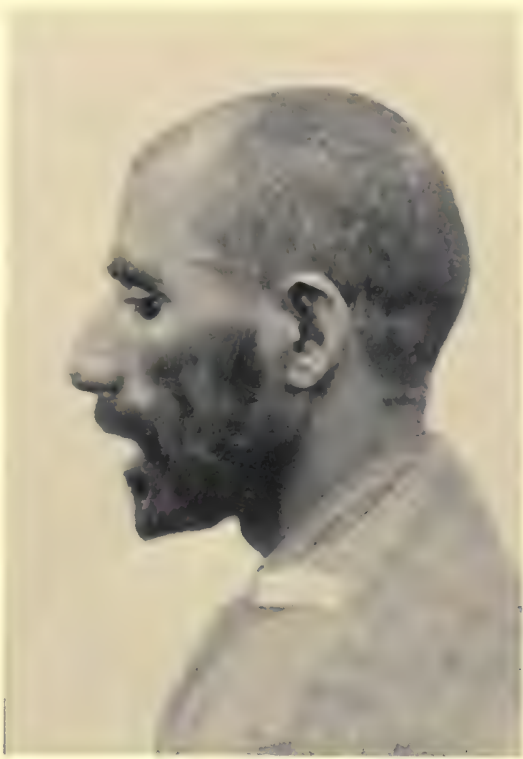

Nig. $\#$

$$
\begin{aligned}
& 83046 \\
& (3 \times 4)
\end{aligned}
$$

No. 855 (age 45)
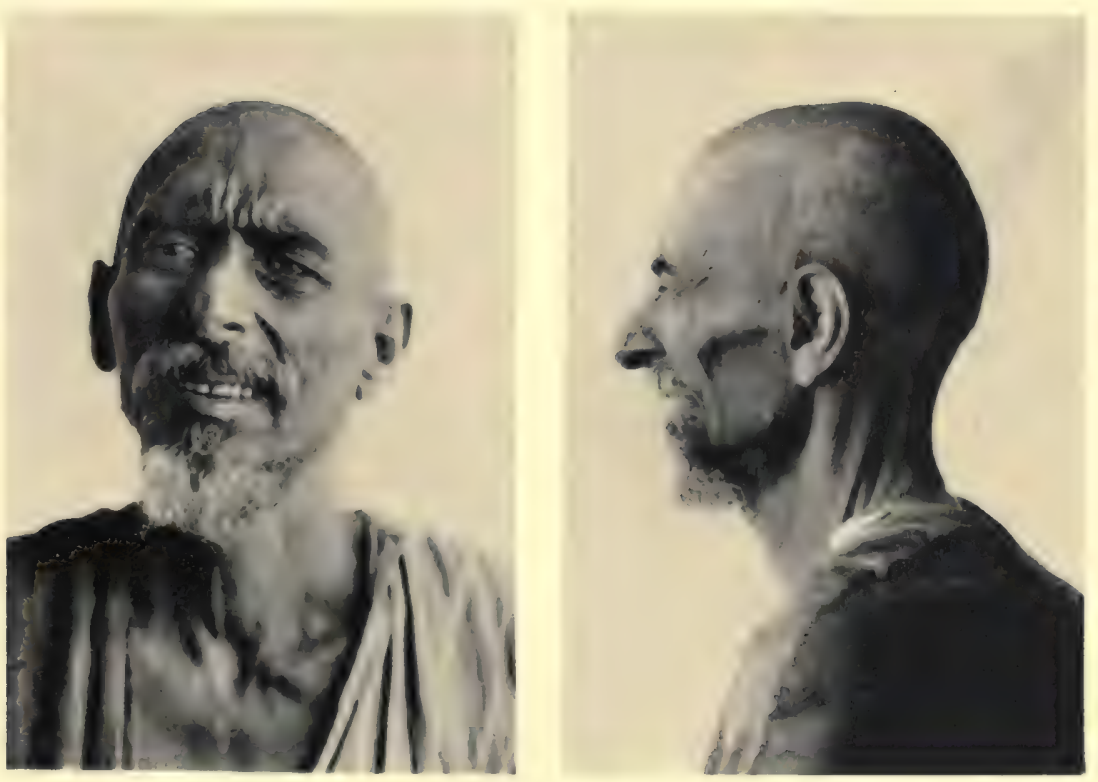

$$
\begin{aligned}
& \text { wegat } \\
& 82 \& 96 \\
& (3 \times 4)
\end{aligned}
$$

No. 920 (age 65)

AL BU MUHAMMAD ATLANTO-MEDITERRANEAN

PLUS CONVEX-NOSED TYPES 


\section{ol\#139ع}

Field Museum of Natural History

Anthropology, Vol. 30, Plate 116
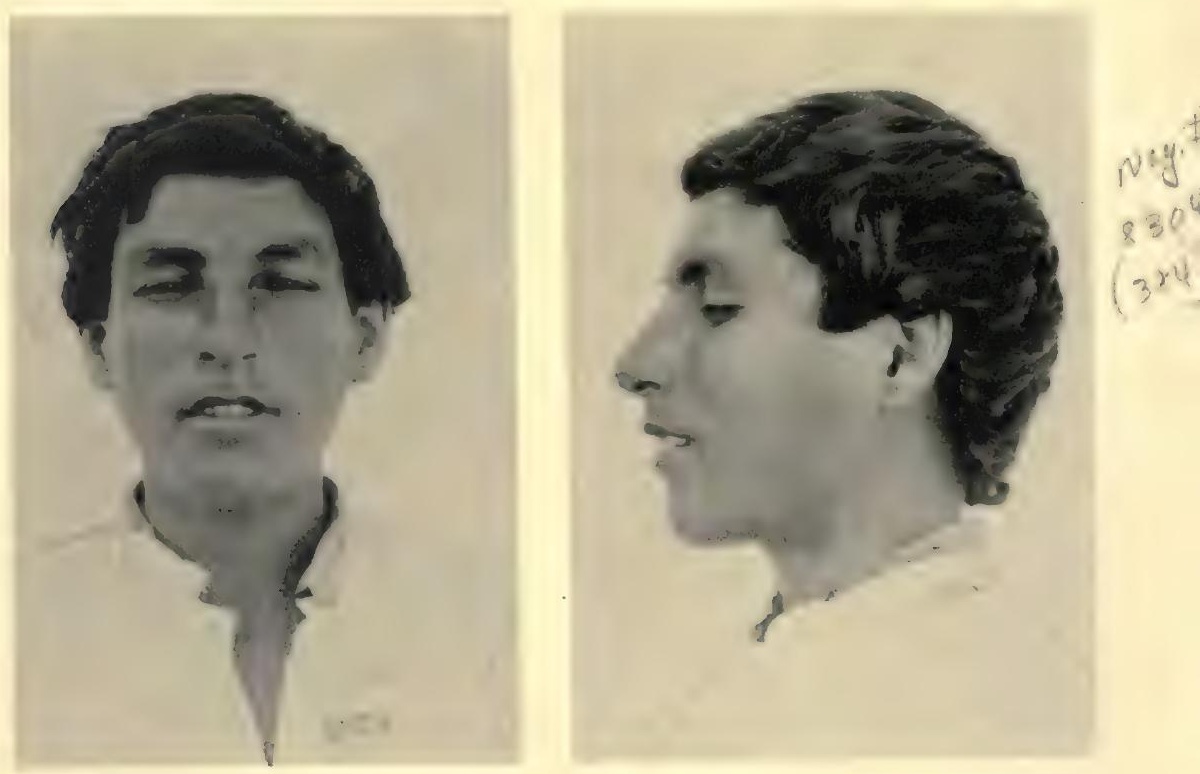

No. 854 (age 20)
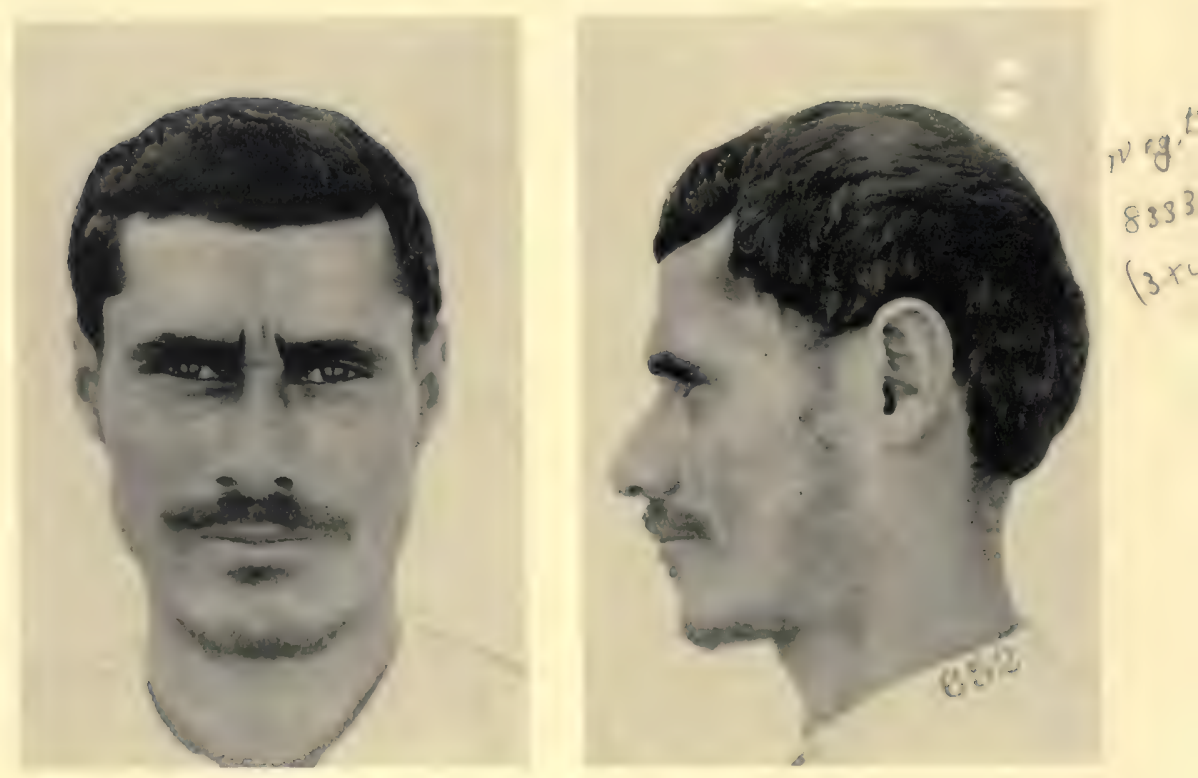

No. 834 (age 35 )

AL BU MUHAMMAD MESOCEPHALS 


\section{$a l \# 139 \varepsilon$ (a)e}

Field Museum of Natural History
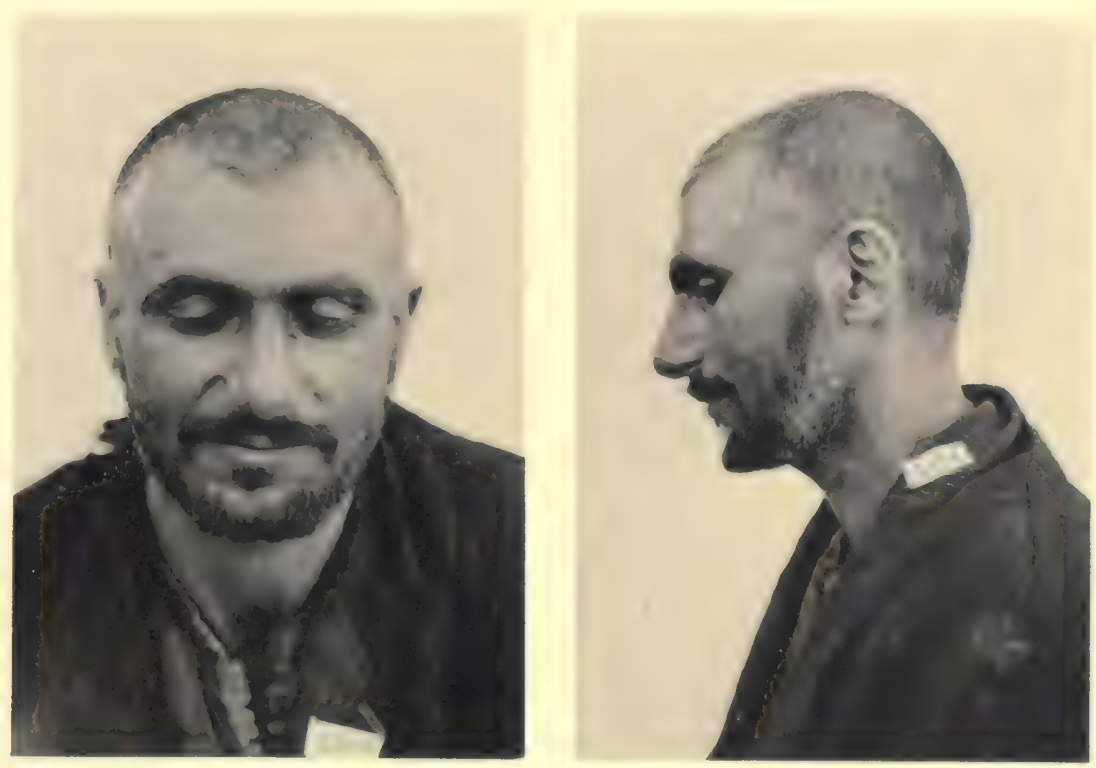

No. 891 (age 40)
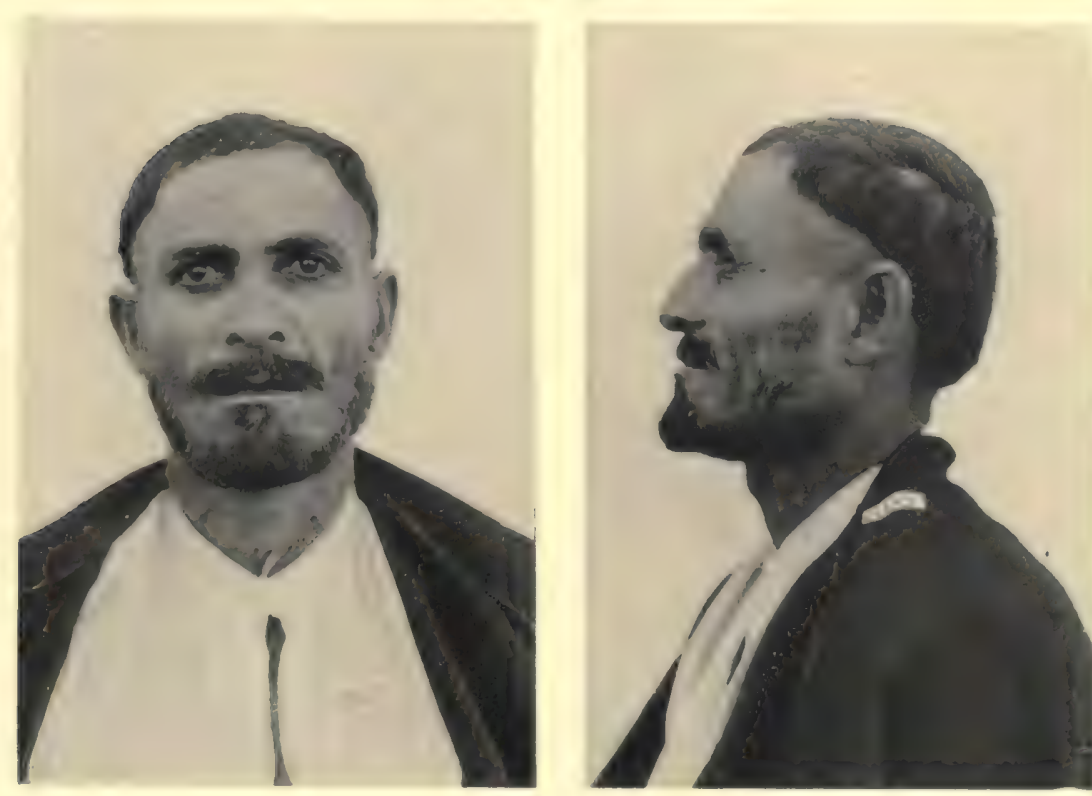

No. 886 (age 40)
Anthropology, Vol. 30, Plate 117

$$
\begin{aligned}
& \text { Niey. } \\
& 809>0 \\
& (3 \times 4)
\end{aligned}
$$

$10 y^{4}$ 60481 $(3 \times)$

$$
\begin{aligned}
& \delta_{82}^{H} \\
& (3+4)
\end{aligned}
$$

AL BU MUHAMMAD MESOCEPHALS 


\section{al\#139ع (ale)}

Field Museum of Natural History

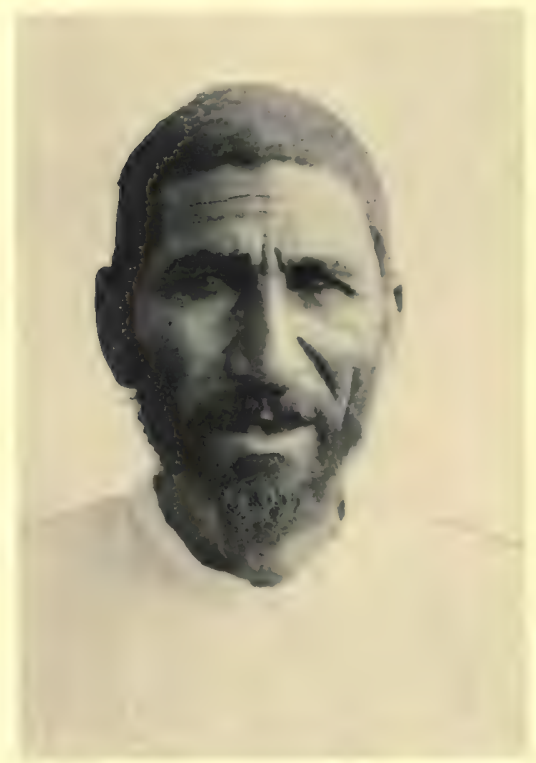

Anthropology, Vol. 30, Plate 118

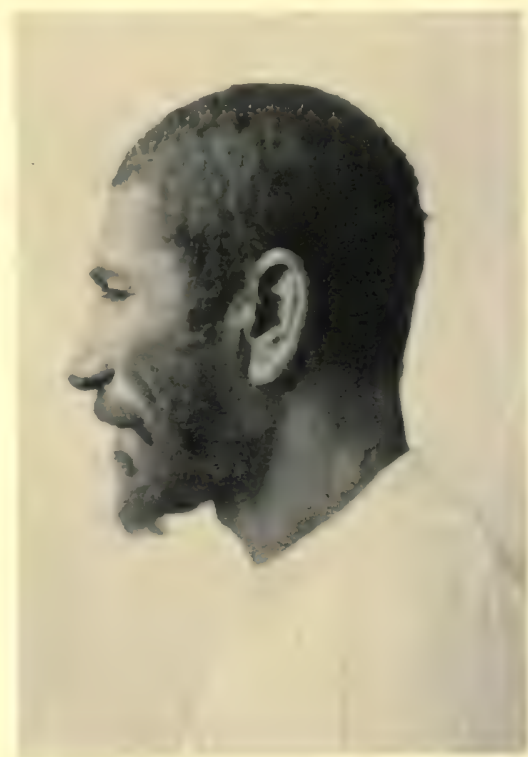

No. 823 (age 46)
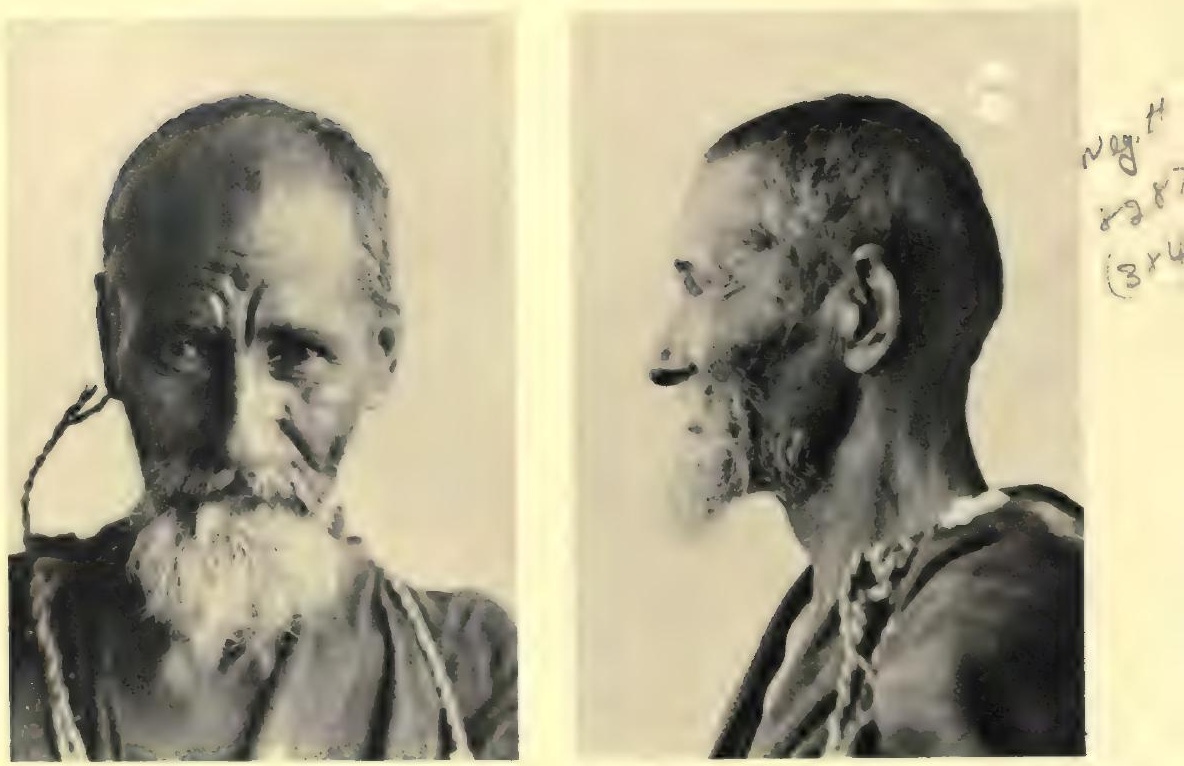

No. 930 (age 60)

AL BU MUHAMMAD MESOCEPHALS 


\section{al\# 139 \& (all)}

Field Museum of Natural History

Anthropology, Vol. 30, Plate 120
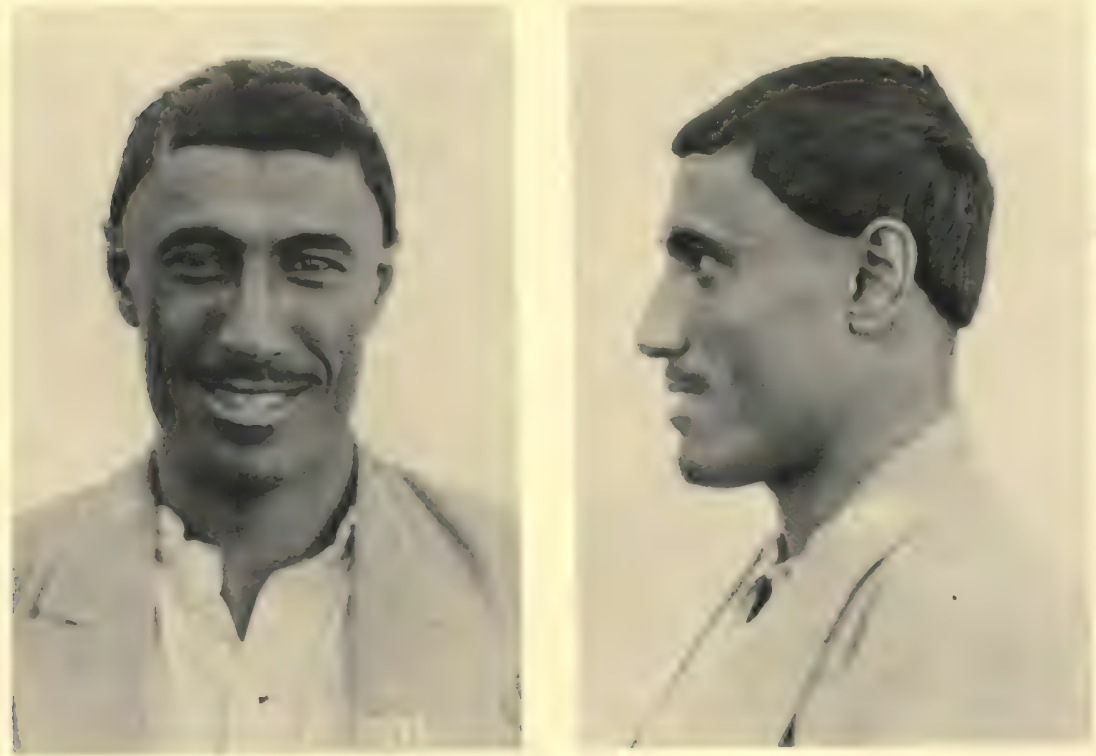

No. 766 (age 30)
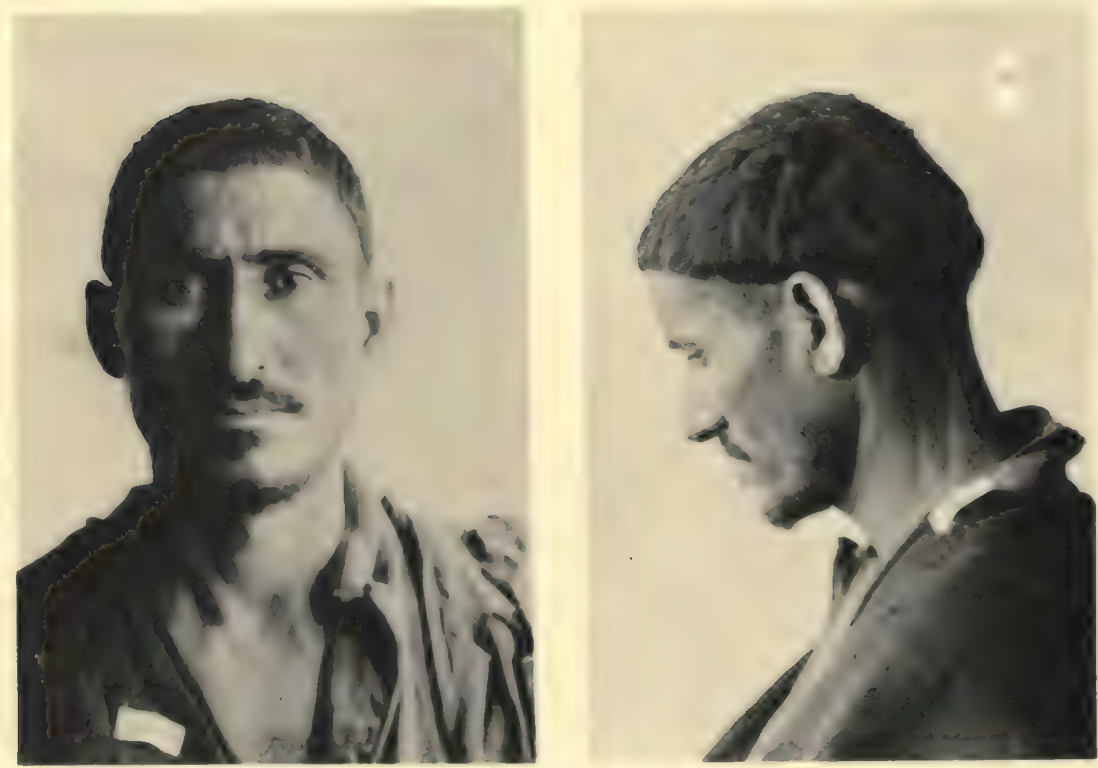

$2 \sqrt{2}$

28

$(3)^{x}$

No. 928 (age 30)

AL BU MUHAMMAD SUB-BRACHYCEPHALIC OR BRACHYCEPHALIC MEDITERRANEAN TYPES 


\section{alt $139 \&$ (ael)}

Field Museum of Natural History

Neg, d 23139 $3 \times 4)$

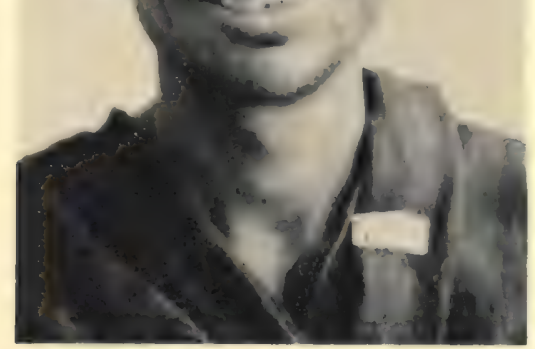

No. 799 (age 33)
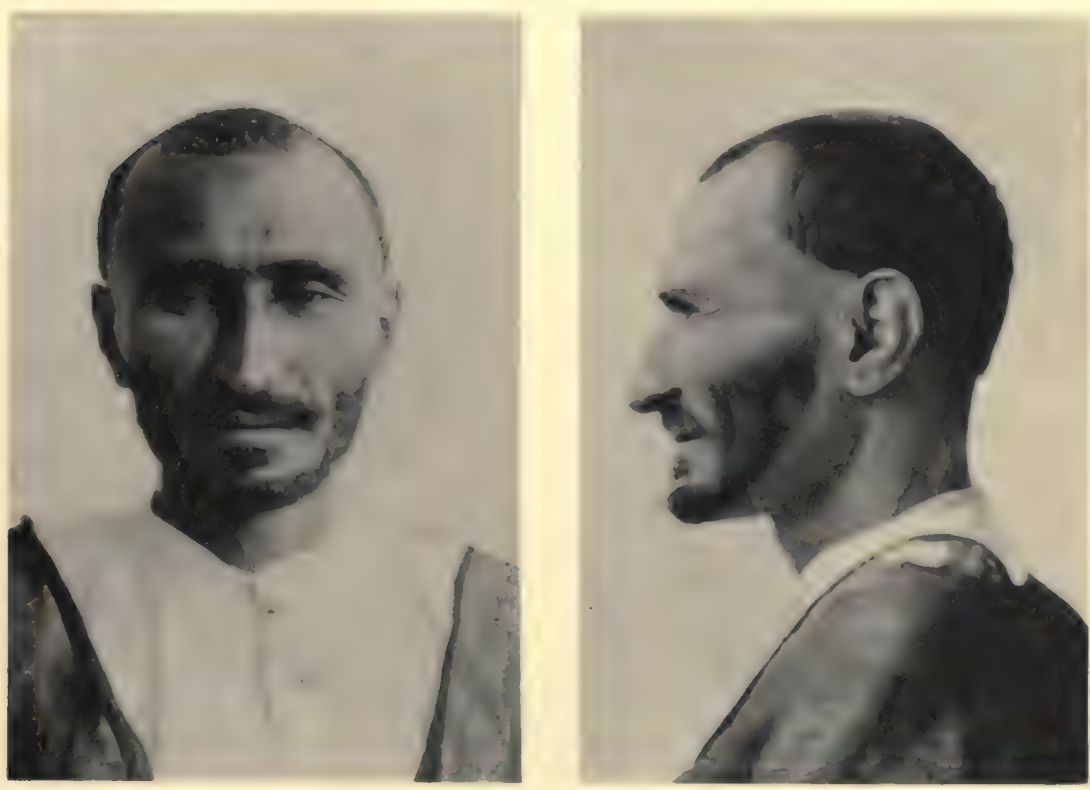

No. 764 (age 40)
Ney, $x^{\prime}$

$83 ! 40$

$(3 \times 4)$
N'y,

8339 :

$(3 \times 4)$ 


\section{al $\# 398$}

Field Museum of Natural History

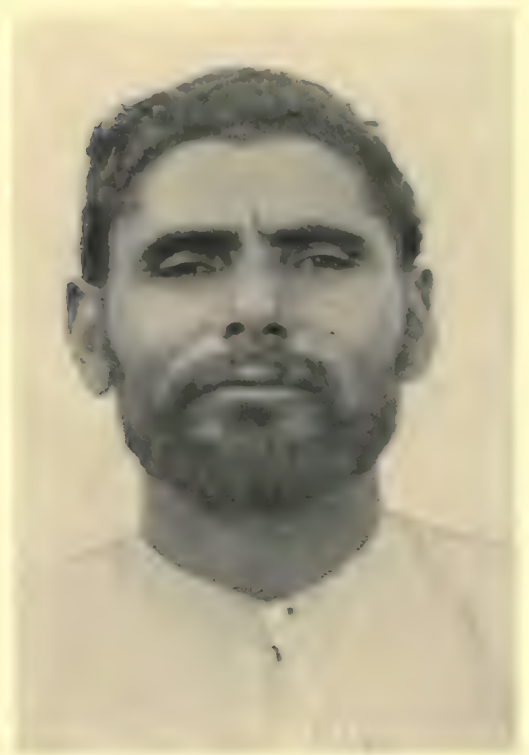

Anthropology, Vol. 30, Plate 122

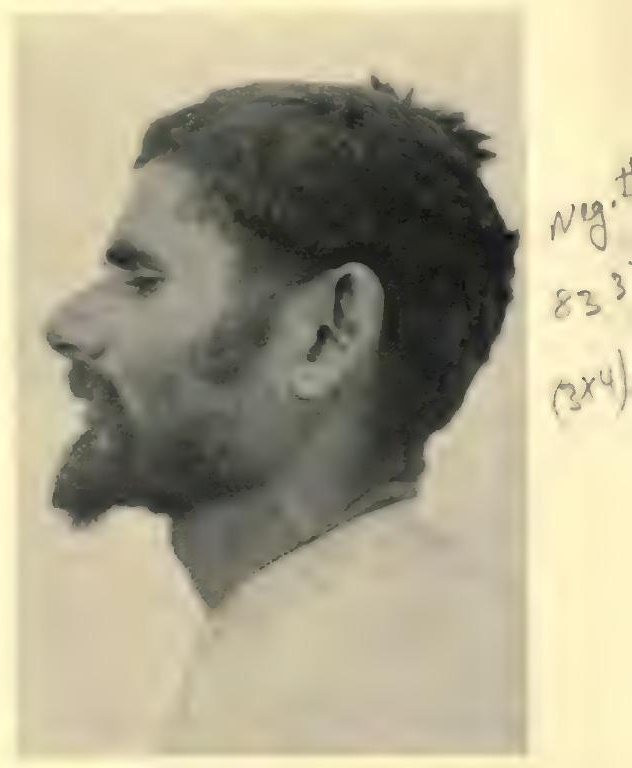

No. 777 (age 40)

$x$

y.

287

$2 x^{(i)}$

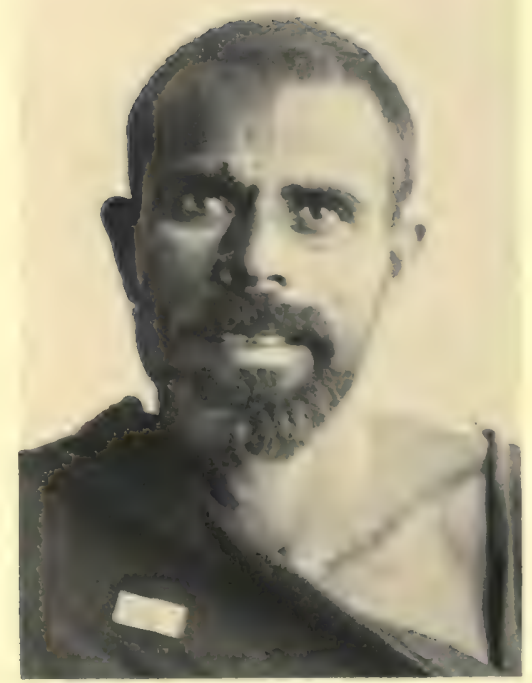

No. 931 (age 40)

AL BU MUHAMMAD SUB-BRACHYCEPHALIC OR
BRACHYCEPHALIC MEDITERRANEAN TYPES 


\section{$a(\# 139 \varepsilon(a) d)$}

Field Museum of Natural History

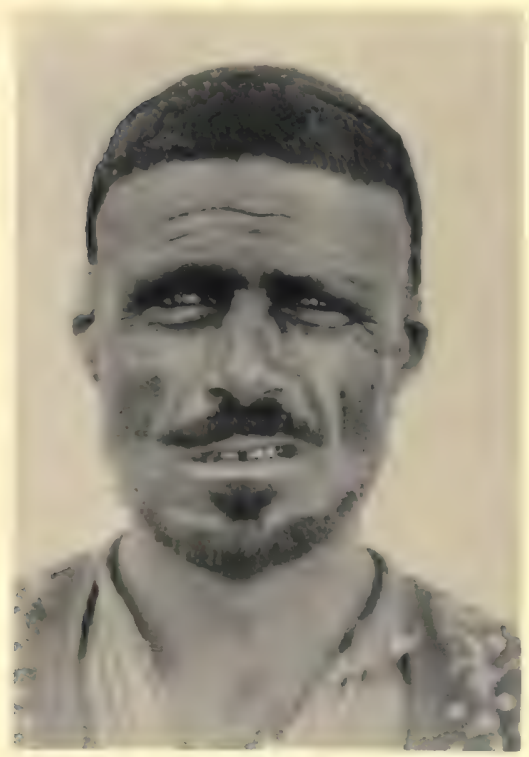

Anthropology, Vol. 30, Plate 123

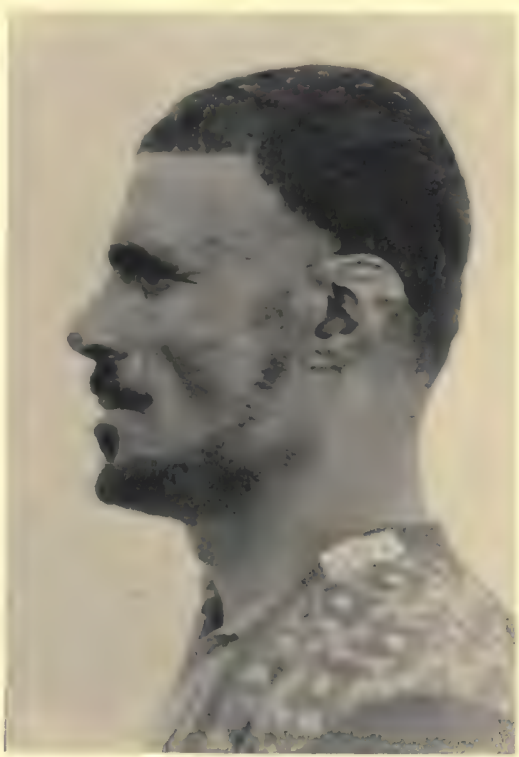

$10 \mathrm{~g} \cdot *$

$\div 304=$ $2 \times 4$

No. 856 (age 50)
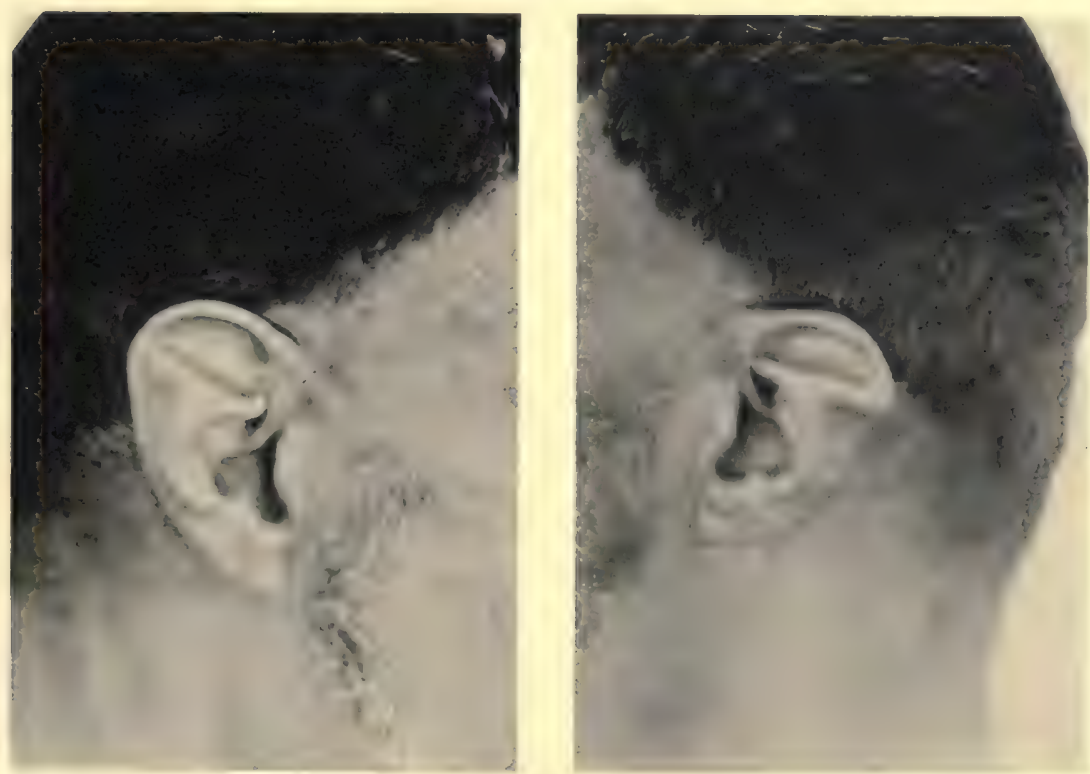

$$
\begin{aligned}
& \text { N.g. } x^{\prime} \\
& 83044 \\
& (3 \times 4)
\end{aligned}
$$

No. 856 (age 50)

AL BU MUHAMMAD SUB-BRACHYCEPHALIC OR BRACHYCEPHALIC MEDITERRANEAN TYPE 


\section{al $39 \varepsilon(a e d)$}

Field Museum of Natural History
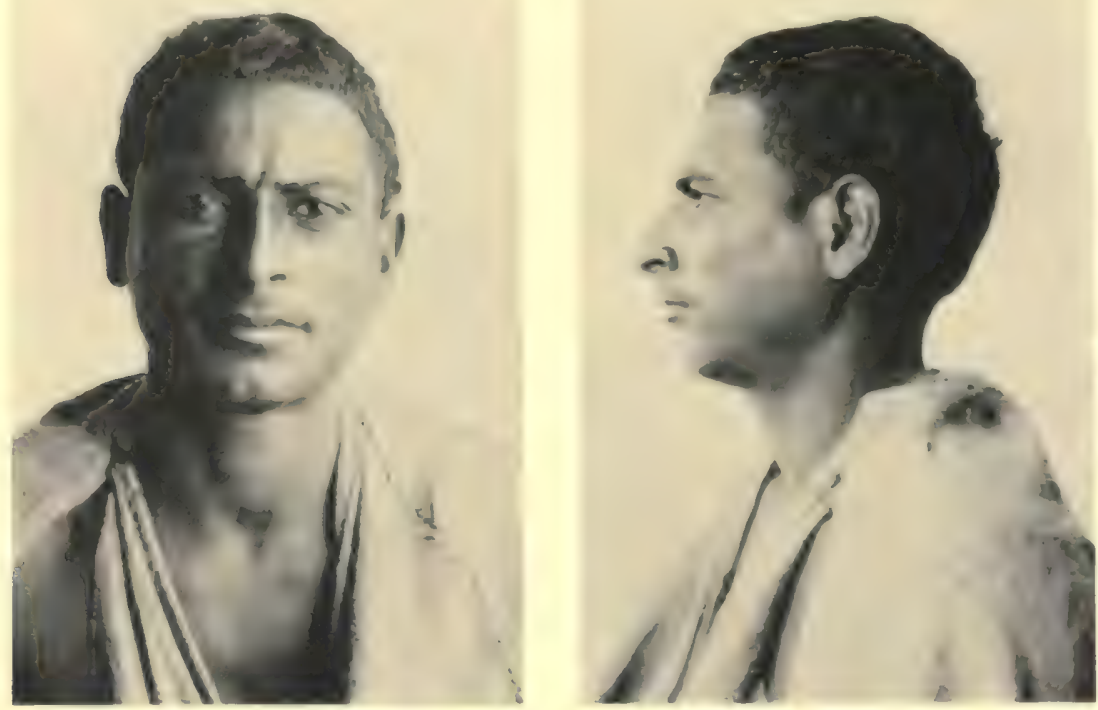

No. 925 (age 20)
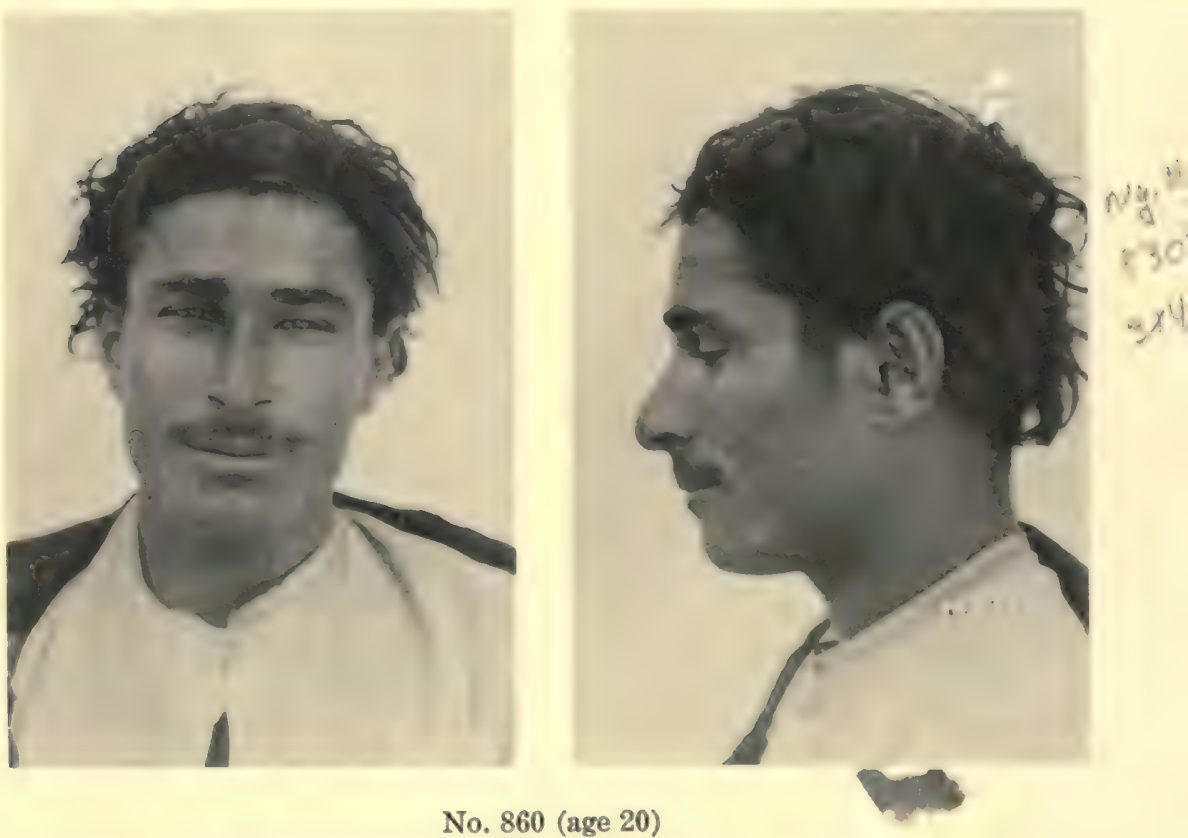

AL BU MUHAMMAD ARMENOID BRACHYCEPHALS 


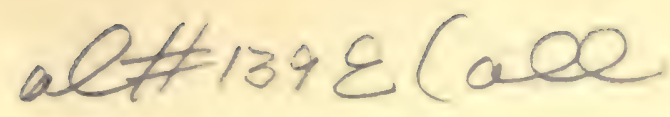

Field Museum of Natural History

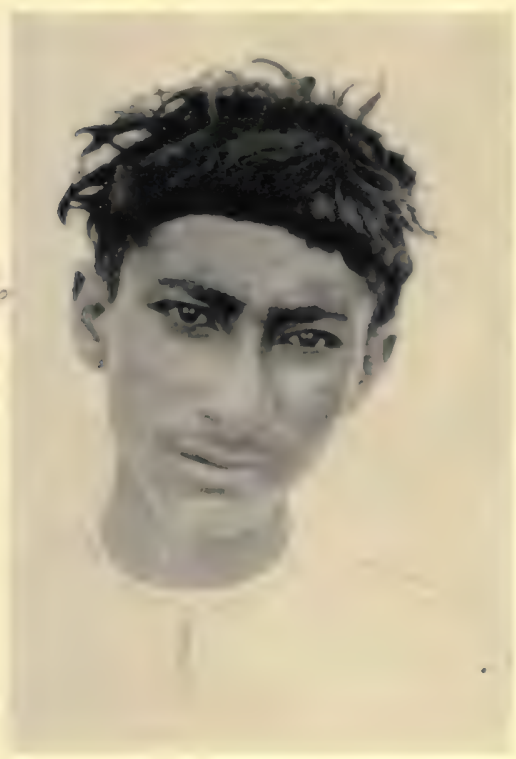

Anthropology, Vol. 30, Plate 125

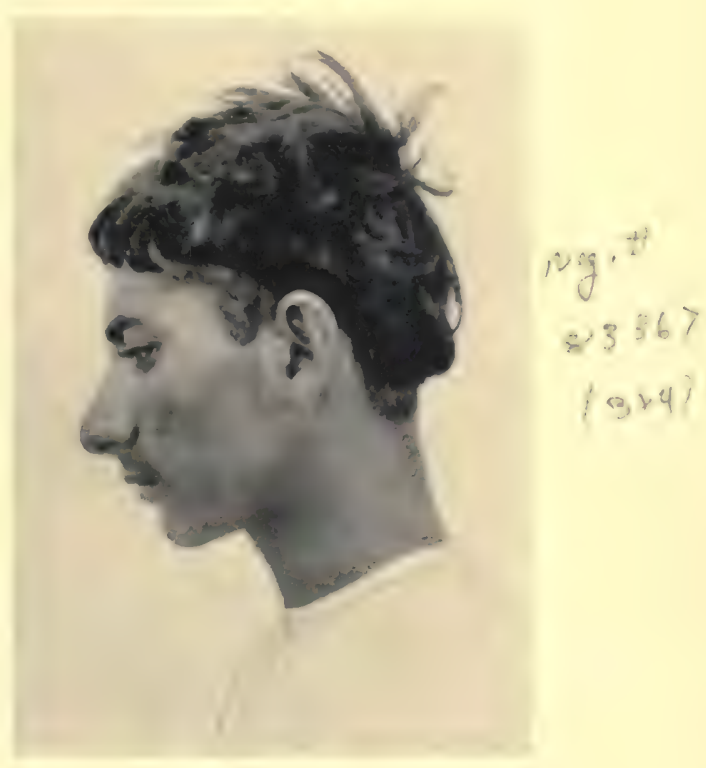

No. 780 (age 20)
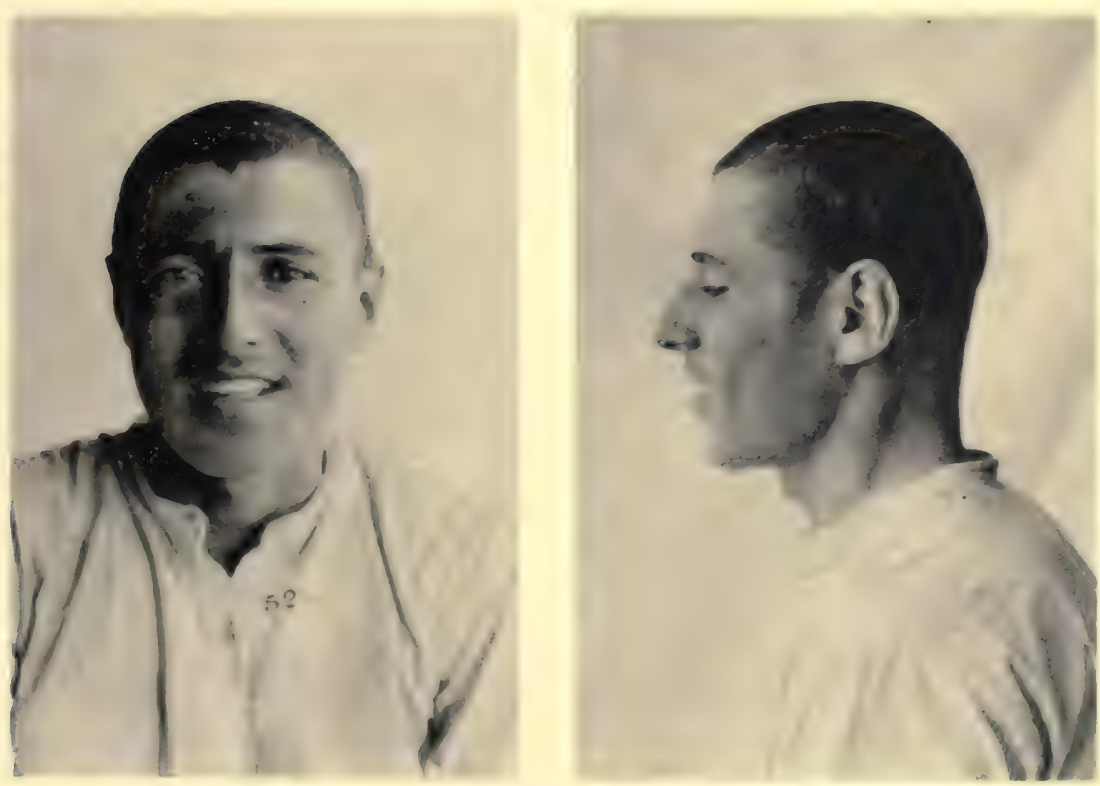

way $x$

82854

$(3 r u)$

No. 944 (age 20)

AL BU MUHAMMAD ARMENOID BRACHYCEPHALS 


\section{alt $139 \&$ (all)}

Field Museum of Natural History

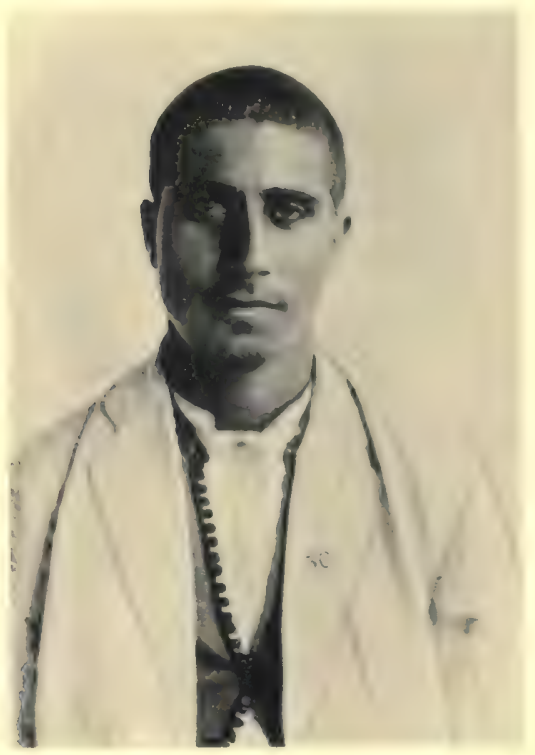

Anthropology, Vol. 30, Plate 126

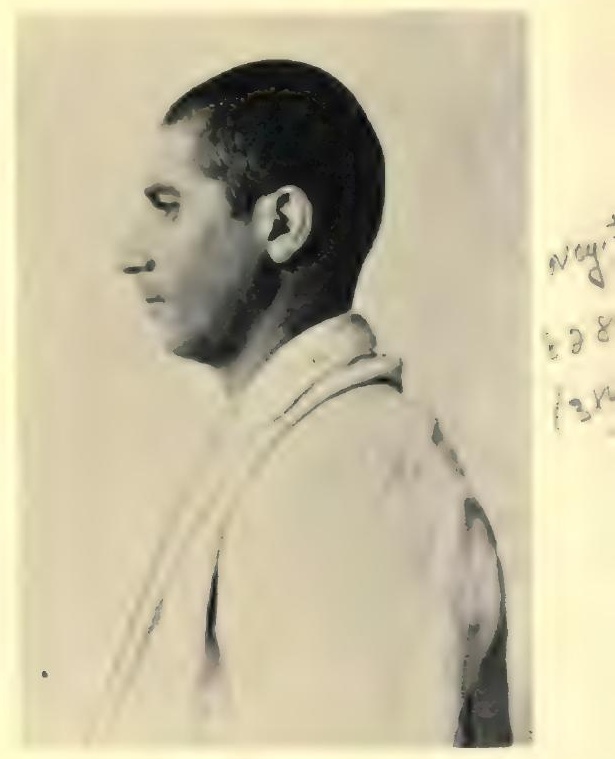

No. 951 (age 20)
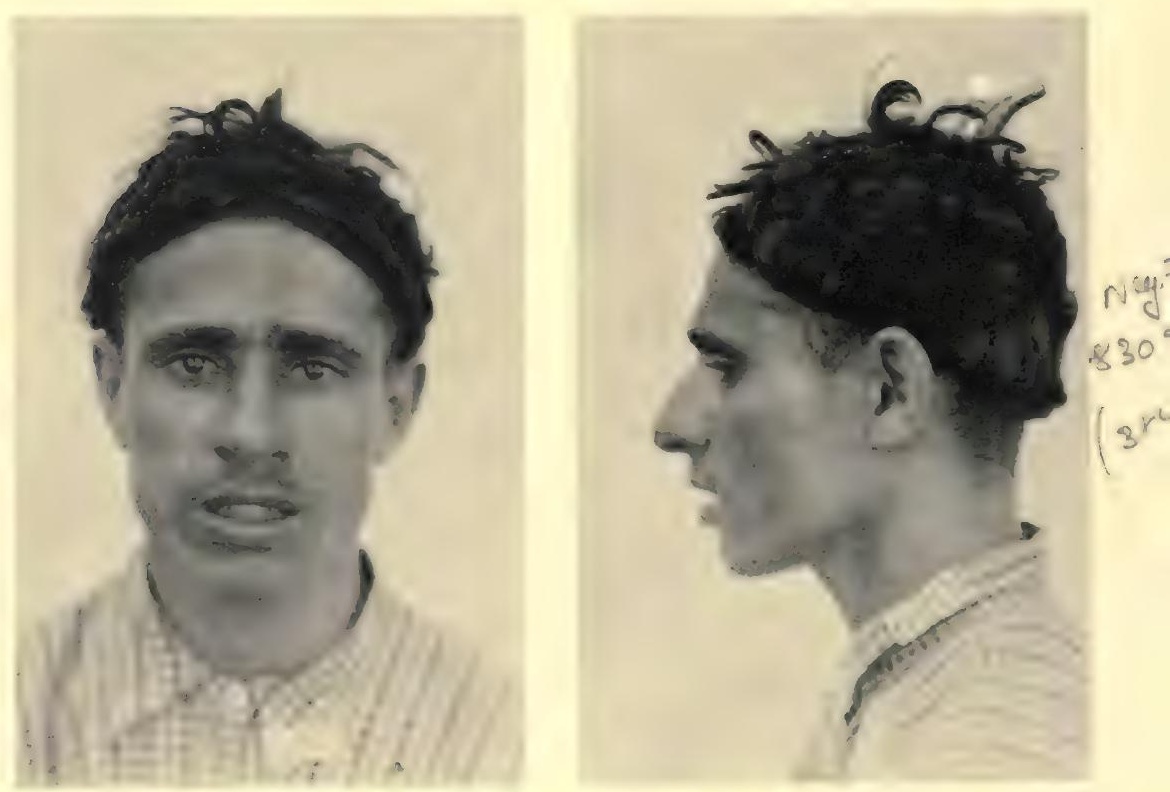

No. 863 (age 22)

AL BU MUHAMMAD ARMENOID BRACHYCEPHALS 


\section{alt $139 \varepsilon$}

Field Museum of Natural History
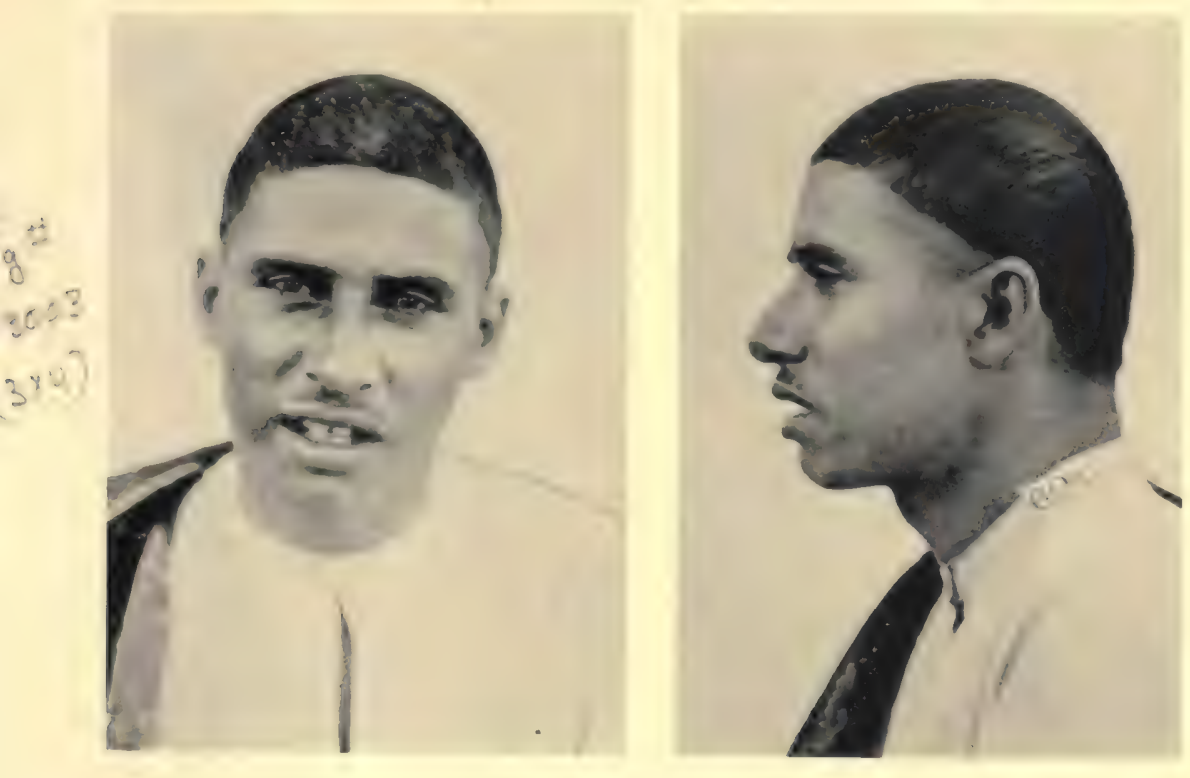

No. 874 (age 25)

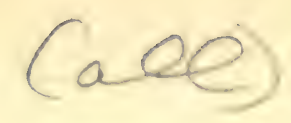

Anthropology, Vol. 30, Plate 127
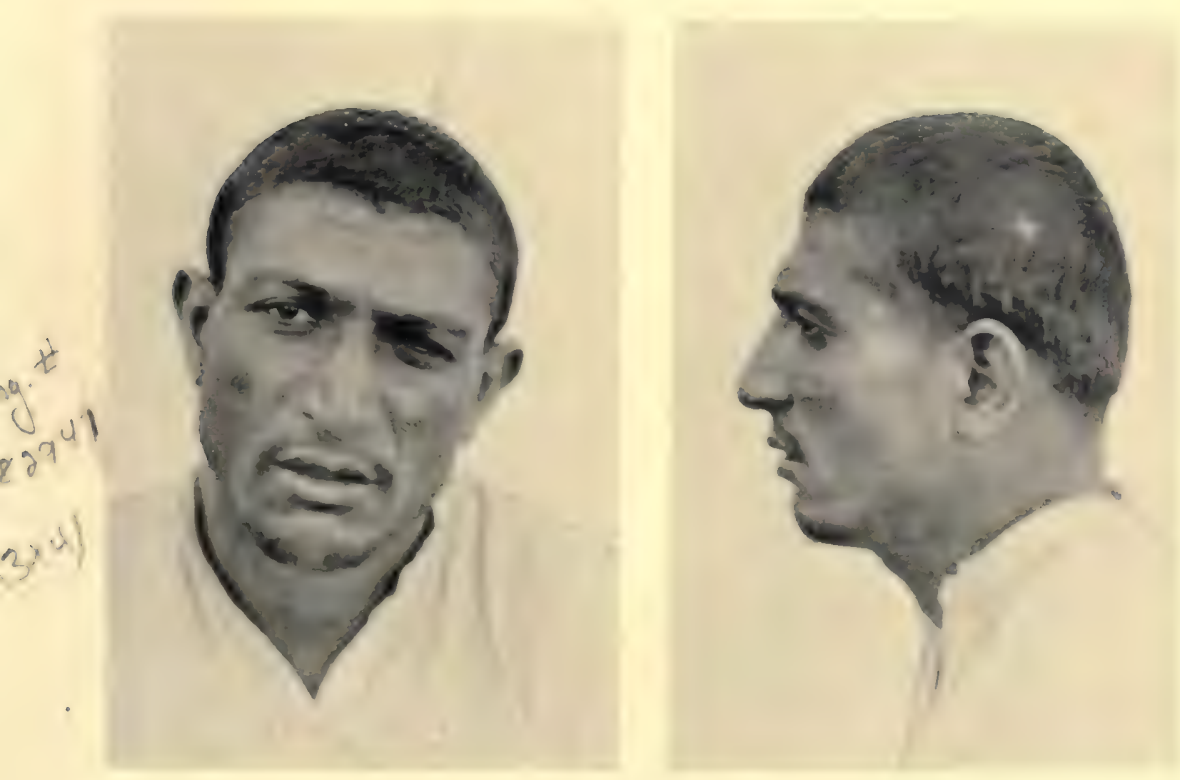

Ny, t $32+4 \%$ $(2 \times 4)=$

No. 899 (age 25) 


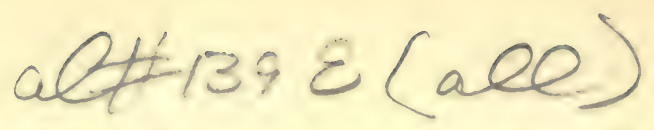

Field Museum of Natural History Anthropology, Vol. 30, Plate 128
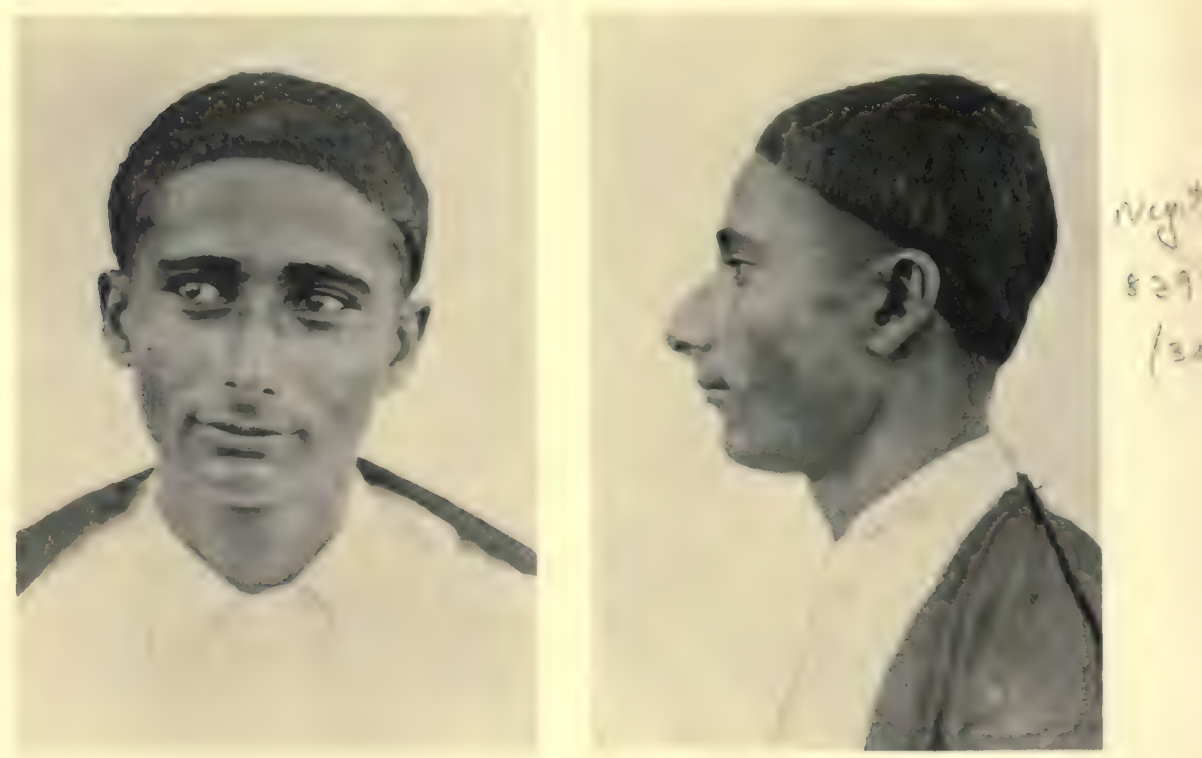

$8 \geqslant 9$

13

No. 879 (age 25)
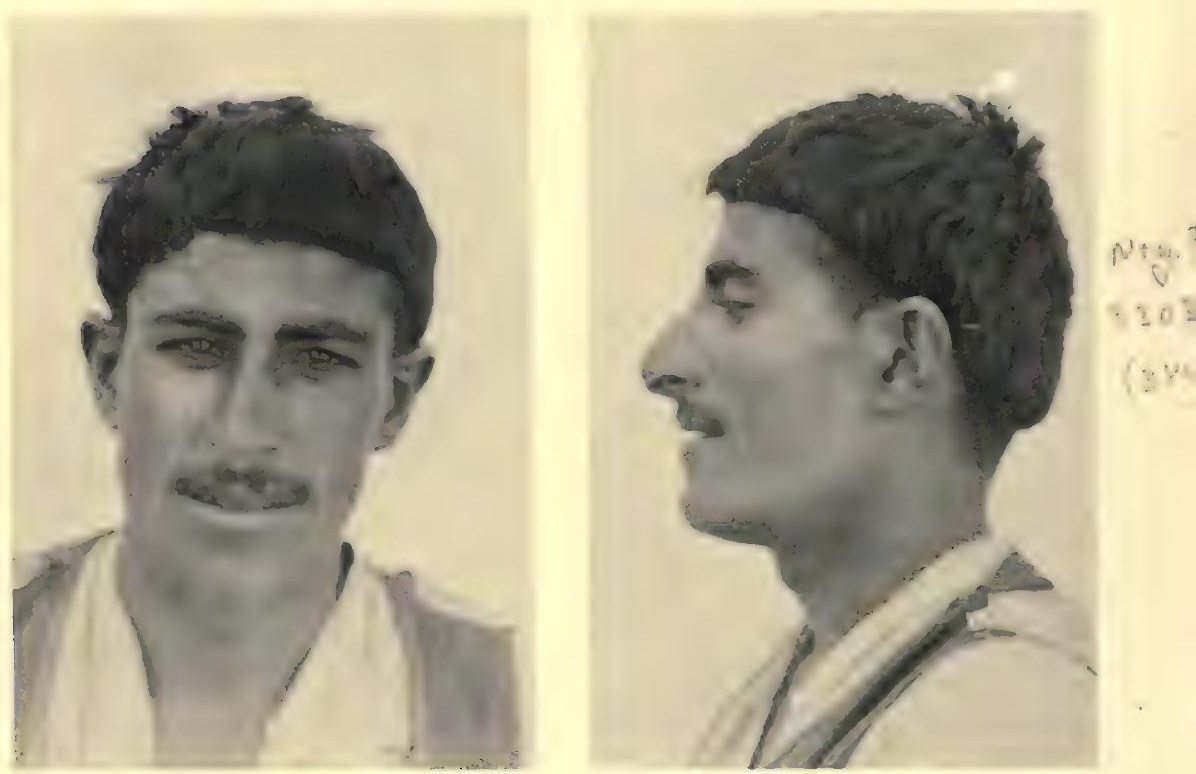

No. 858 (age 30)

AL BU MUHAMMAD ARMENOID BRACHYCEPHALS 


\section{alt $139 \varepsilon$}

Field Museum of Natural History
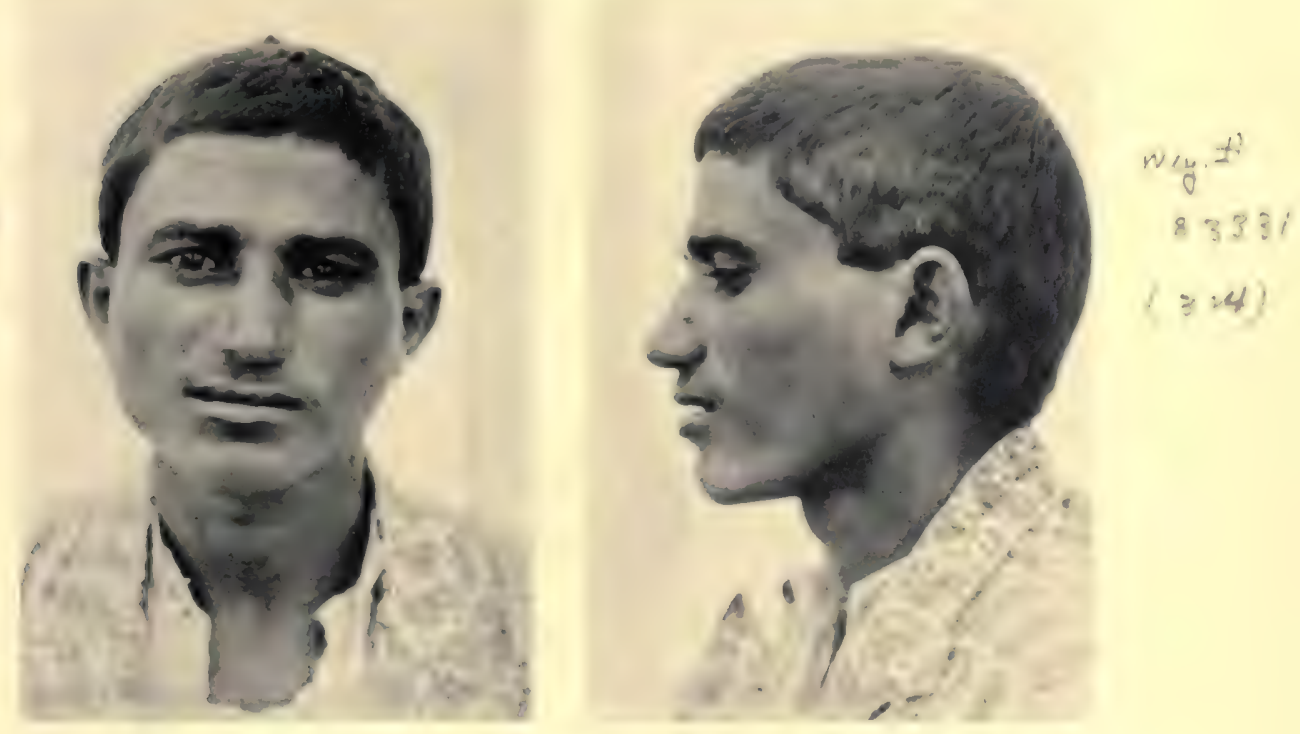

No. 832 (age 20)

$y^{\frac{1}{2}}$
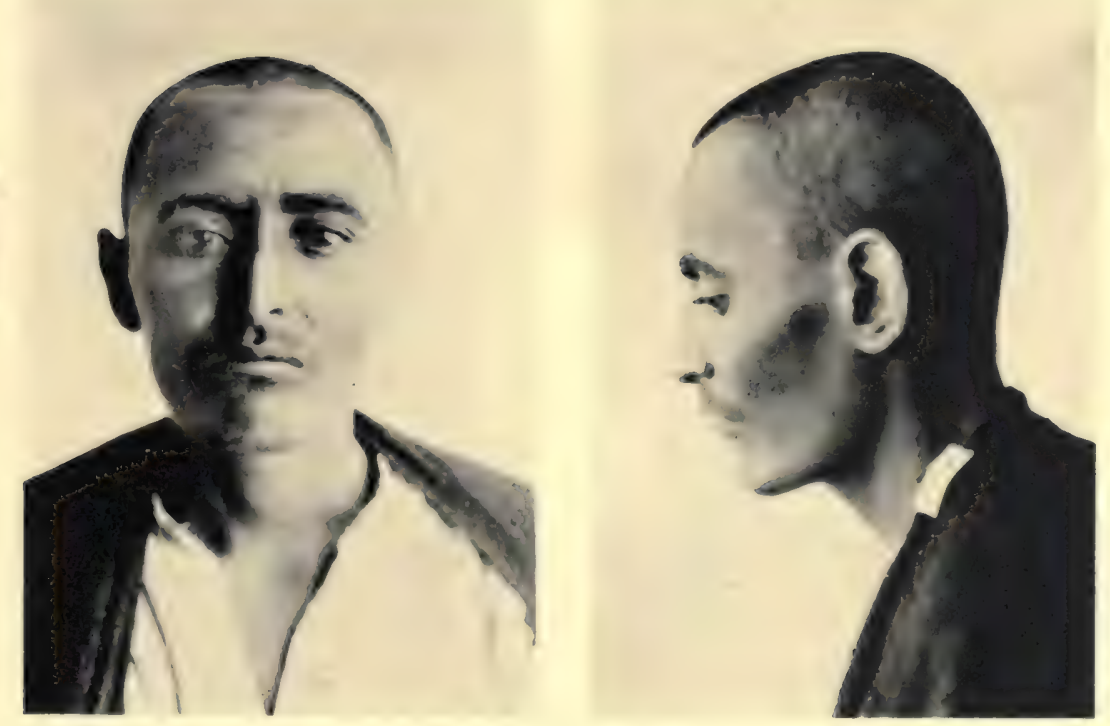

Noy, ti

$z=902$

$(3 \times 4)$

No. 905 (age 20)

AL BU MUHAMMAD MISCELLANEOUS BRACHYCEPHALS 


\section{$a l \$ 139 \varepsilon(a)$}

Field Museum of Natural History

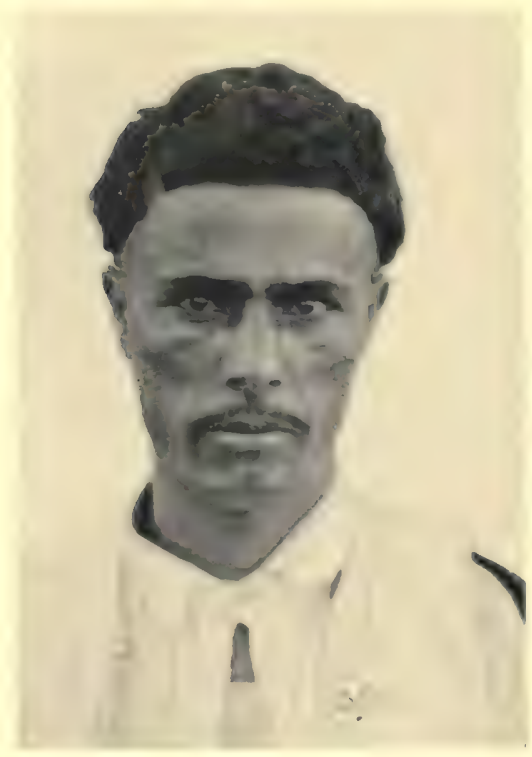

Anthropology, Vol. 30, Plate 130

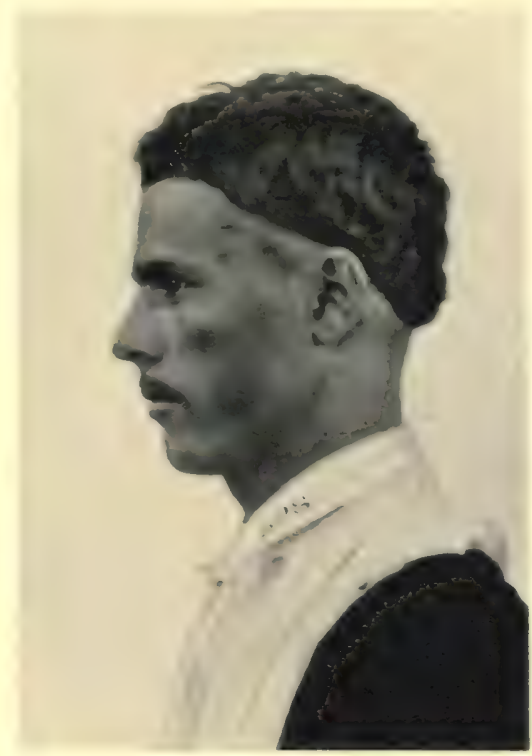

No. 885 (age 20)

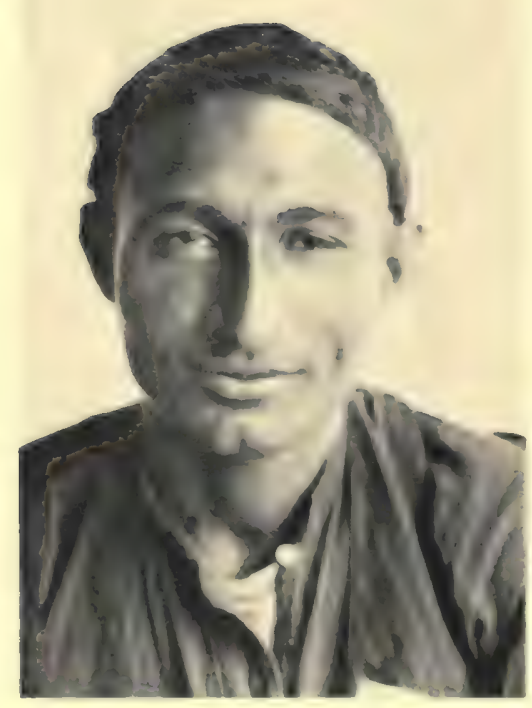

Noy.

824

$(3 x$

$\pm$

हो।

(4).

No. 906 (age 20)
NCy.

ह है

$(3 \times 2$

AL BU MUHAMMAD MISCELLANEOUS BRACHYCEPHALS 


\section{$a l 139 \varepsilon$ (ale)}

Field Museum of Natural History

$y_{10}=$ $-3+2)$

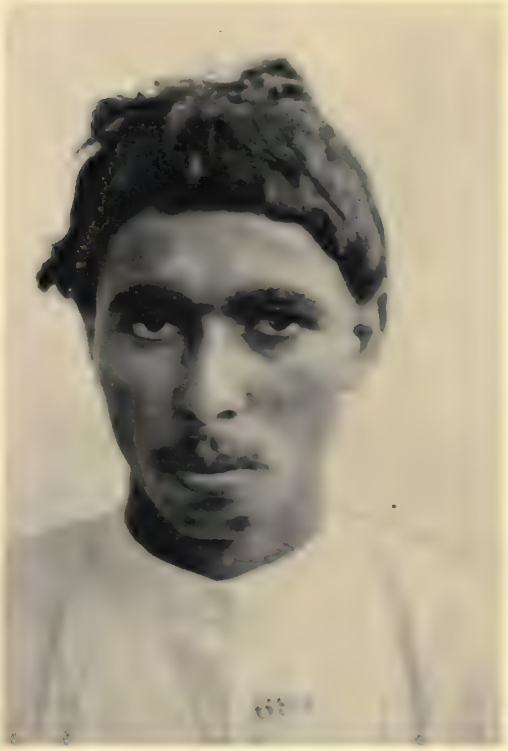

Anthropology, Vol. 30, Plate 131

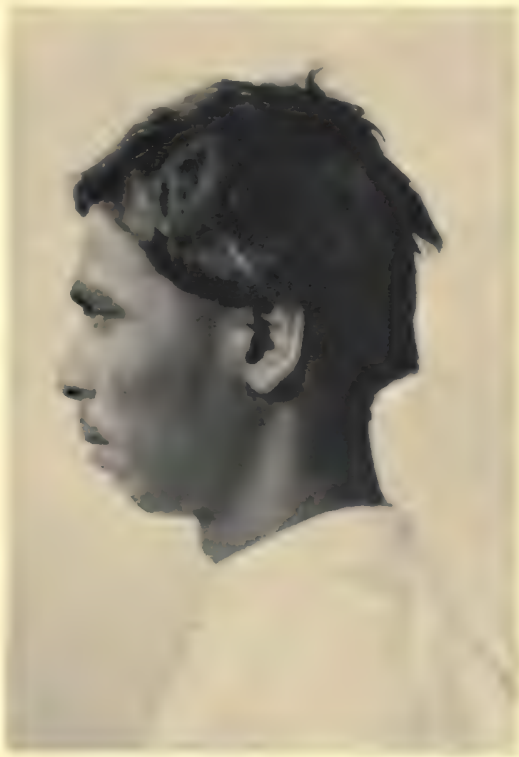

Nig.t

83104

$(3+4)$

No. 818 (age 22)
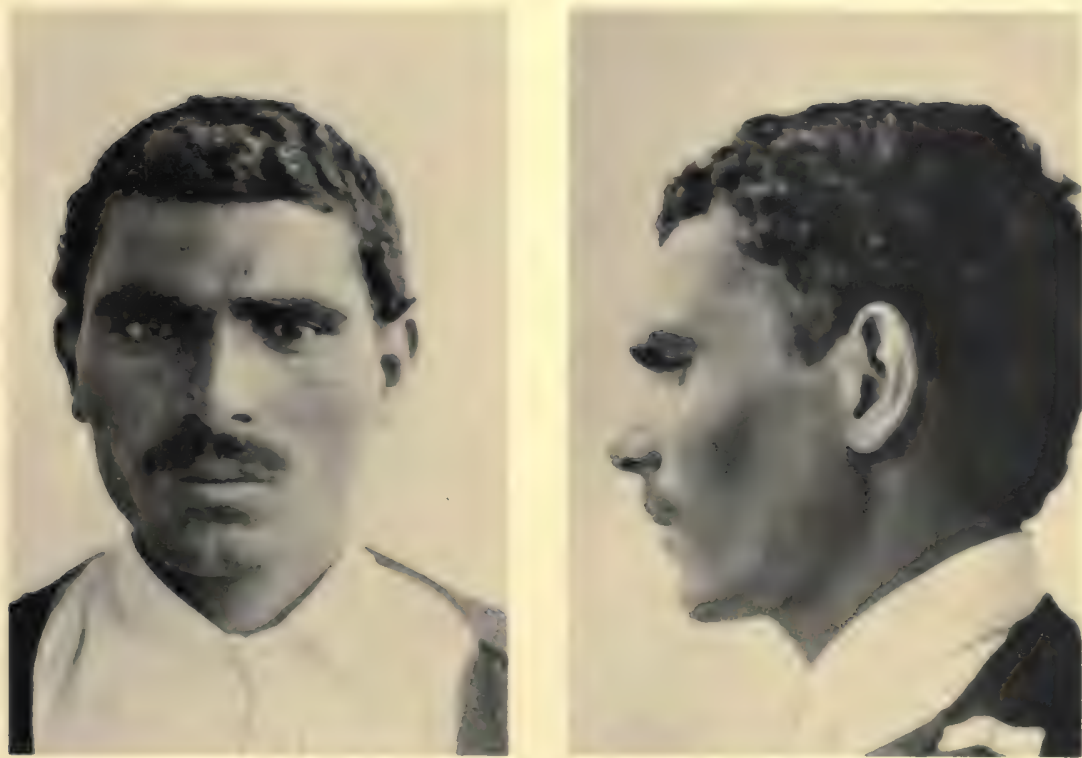

negy. 11

8:136

$(3 \times 4)$

No. 801 (age 23)

AL BU MUHAMMAD MISCELLANEOUS BRACHYCEPHALS 


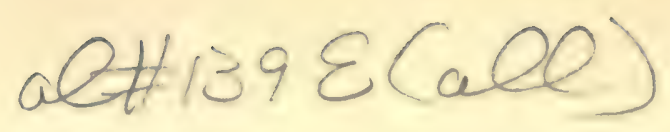

Field Museum of Natural History

$a, x^{4}+x^{2}$

$t^{2}$

$3^{035}$

$3 \times 4)$

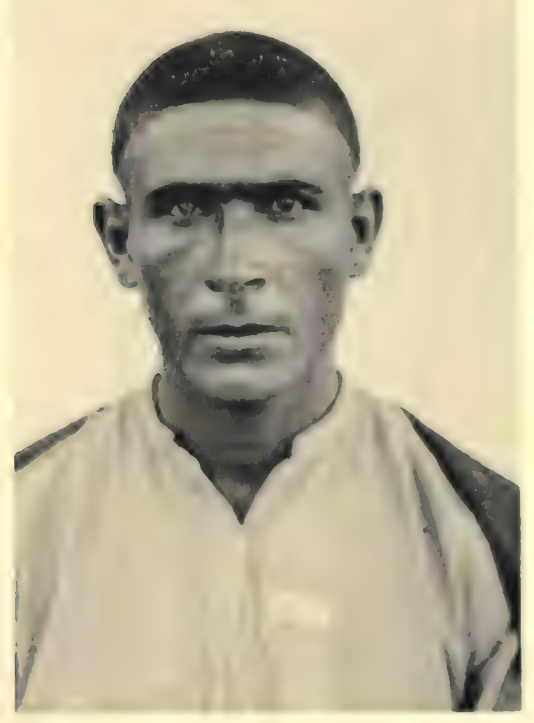

No. 892 (age 25)

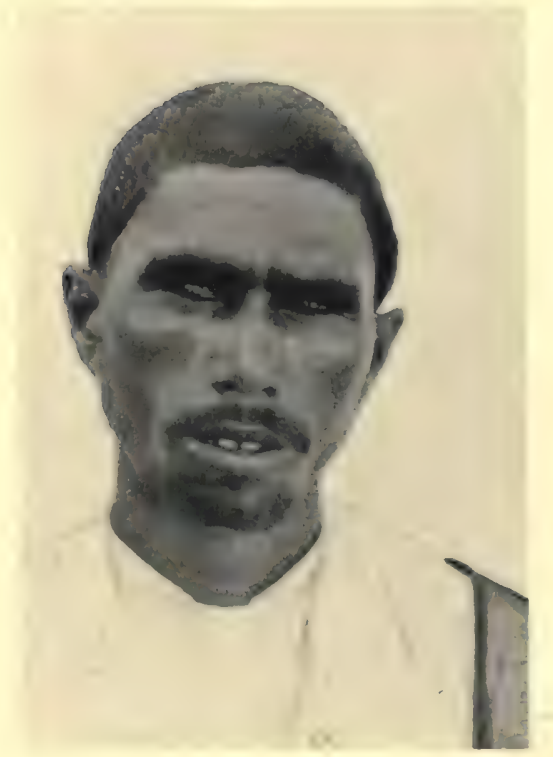

Anthropology, Vol. 30, Plate 132

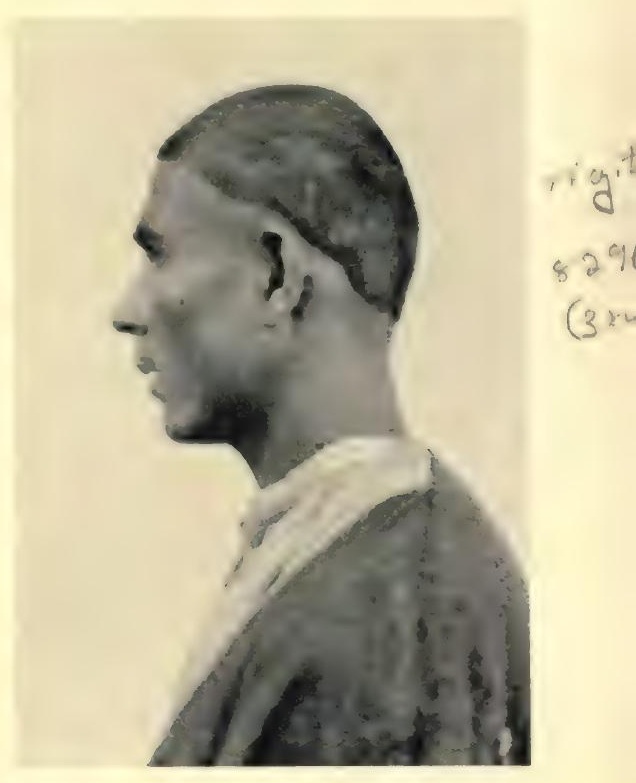

No. 859 (age 28)

AL BU MUHAMMAD MISCELLANEOUS BRACHYCEPHALS 


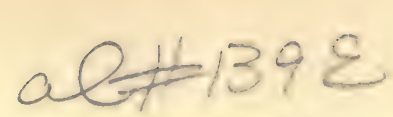

Field Museum of Natural History

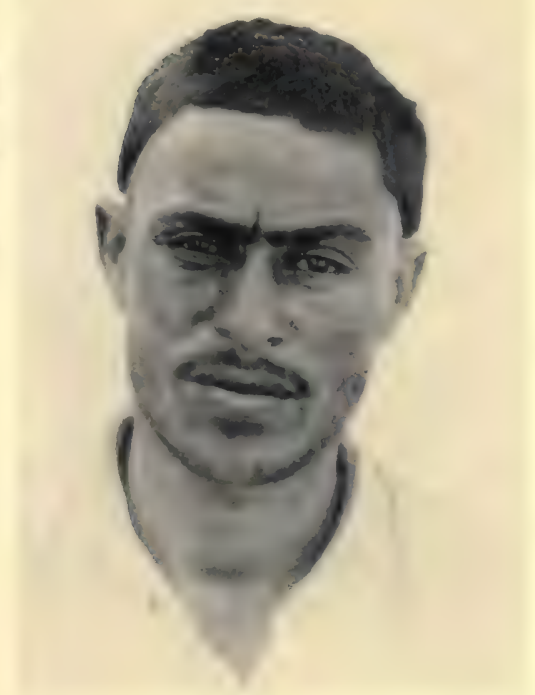

No. 853 (age 28)

$\log ^{2}$

2995

3,4

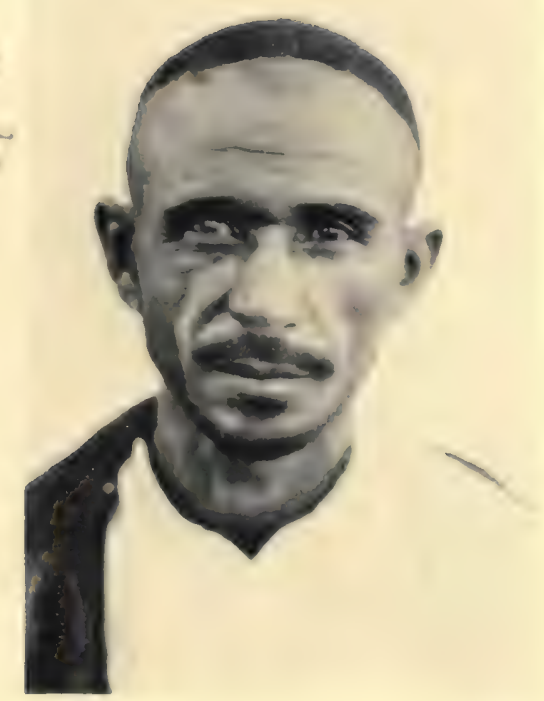

Anthropology, Vol. 30, Plate 133
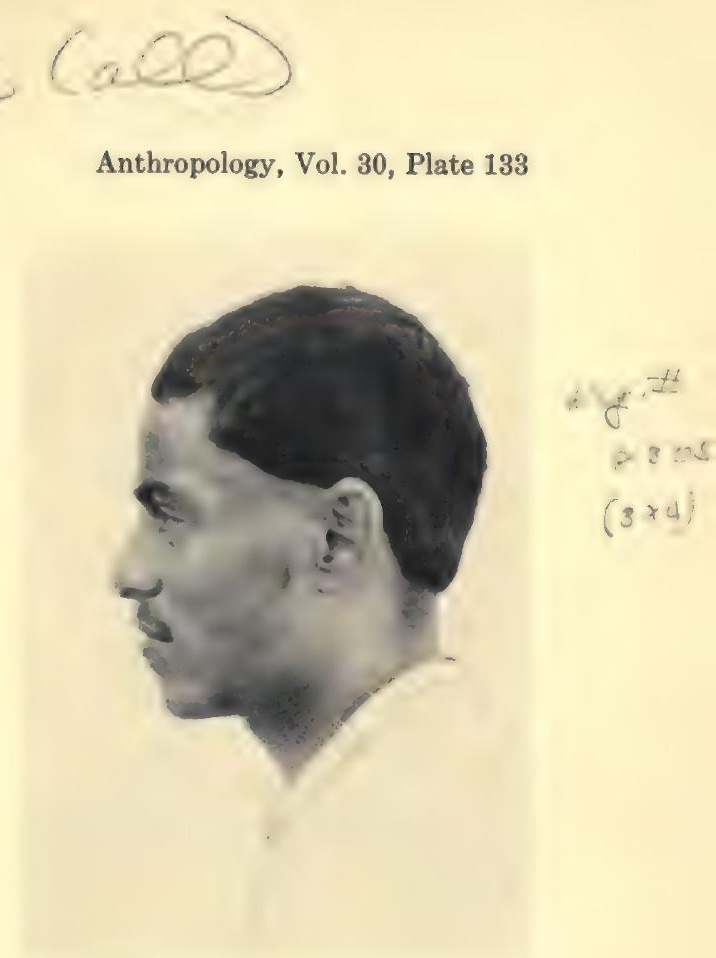

No. 878 (age 30 )

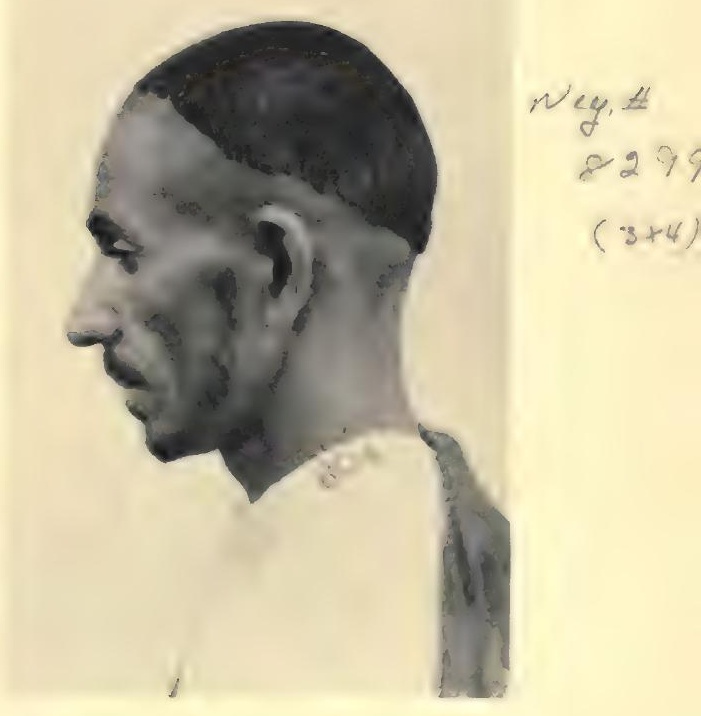
8295 


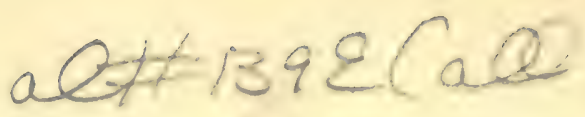

Field Museum of Natural History

Anthropology, Vol. 30, Plate 134
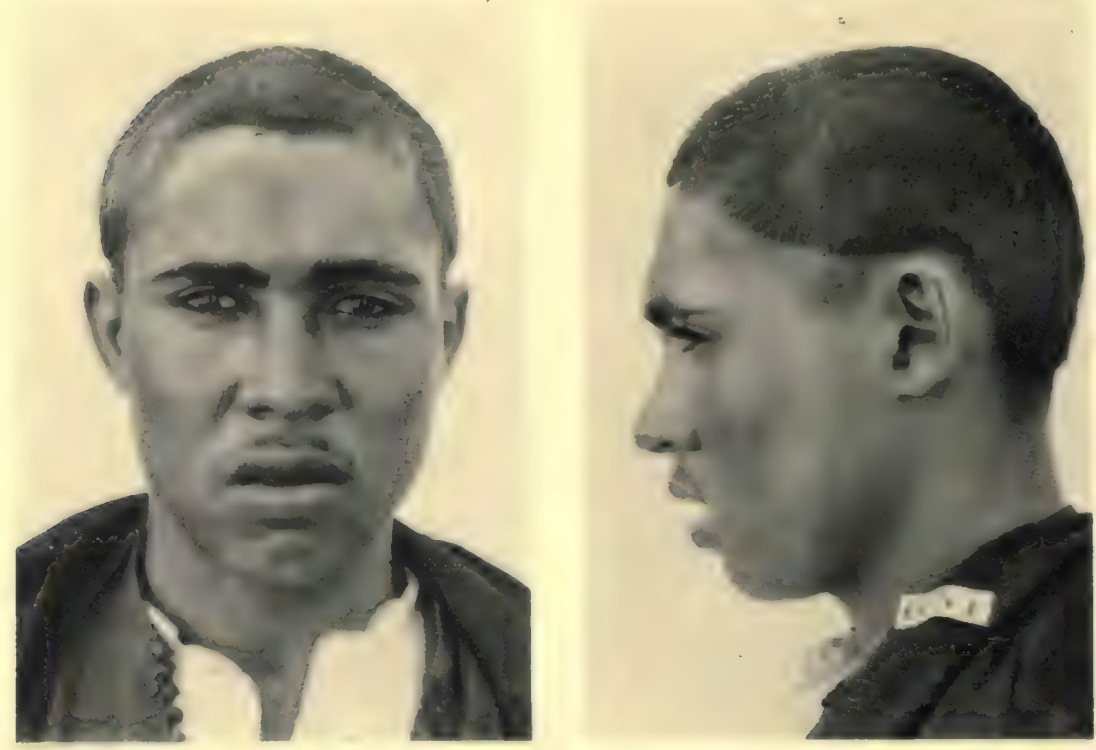

N 2 岁

$\because 28$

$(6 x+1)$

No. 833 (age 20)
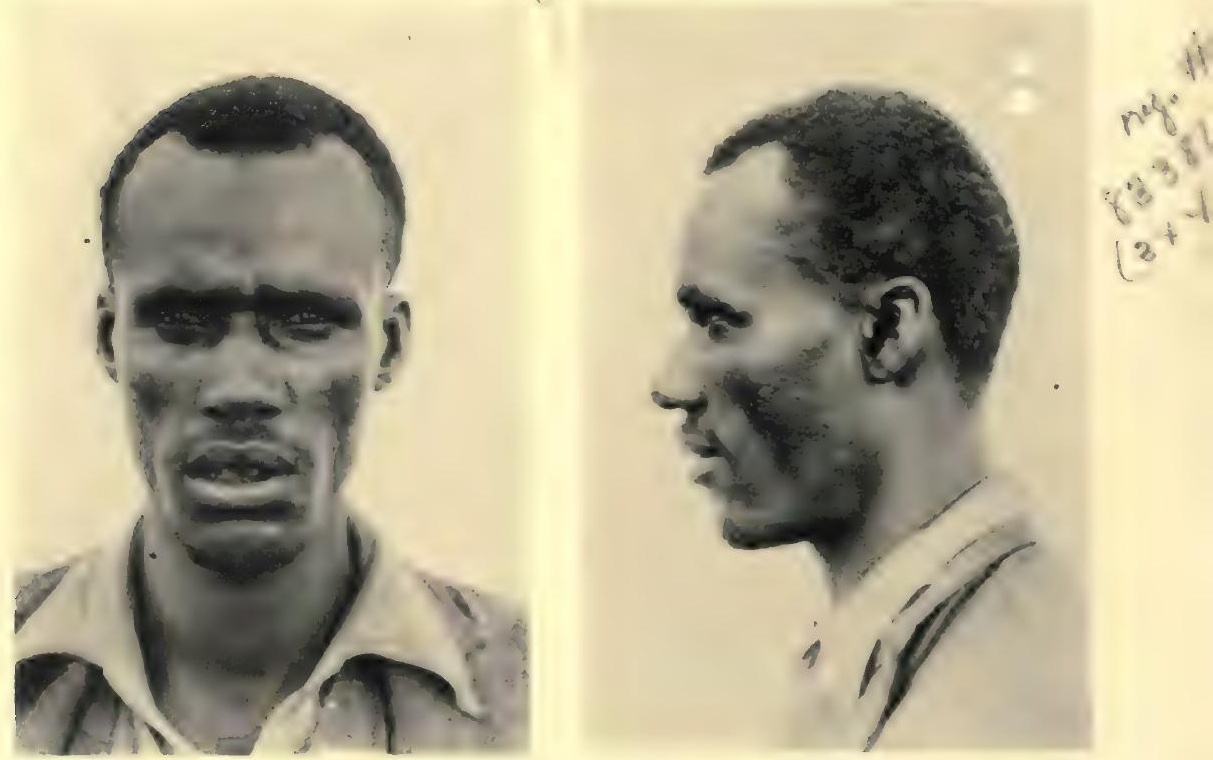

No. 812 (age 35 )

AL BU MUHAMMAD NEGROID TYPES 


\section{$a(1392(a 00)$}

Field Museum of Natural History

Anthropology, Vol. 30, Plate 136

3
3
4
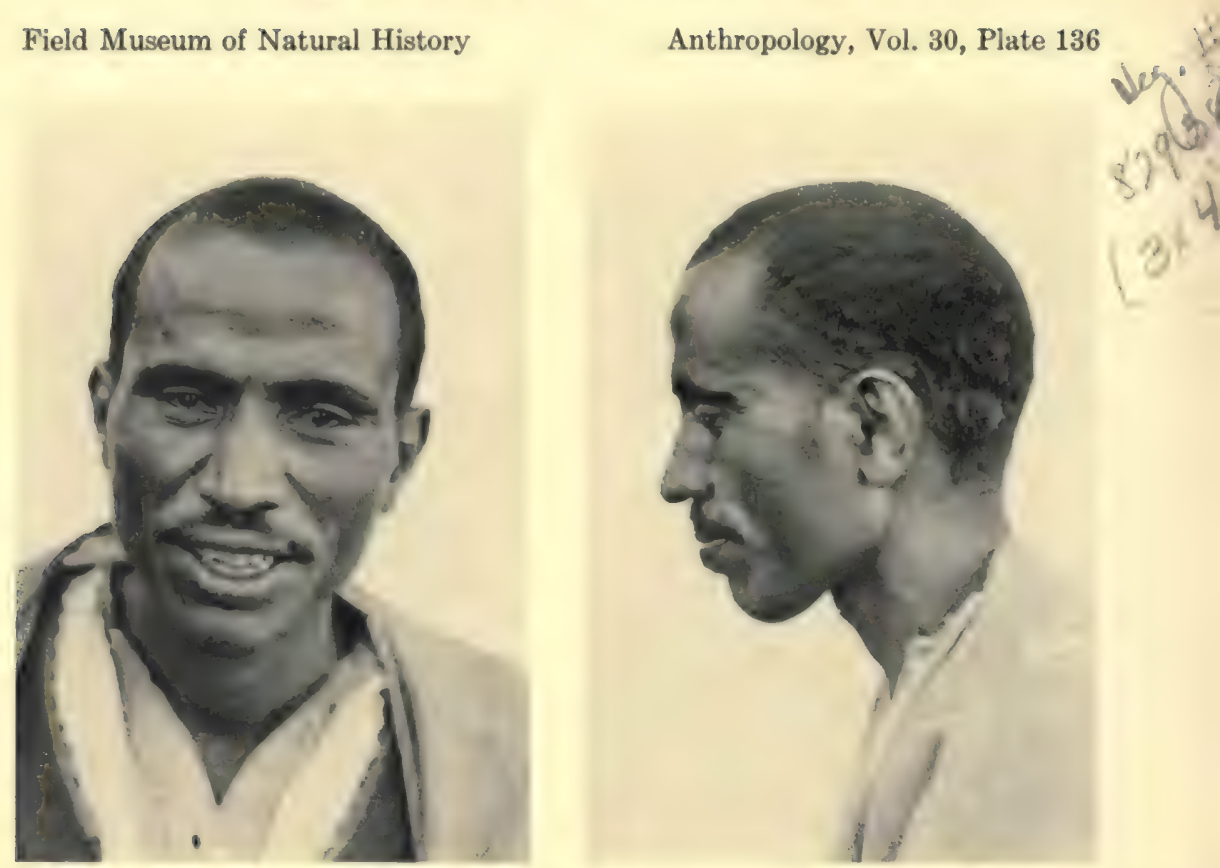

No. 901 (age 35)

if

9

4H)
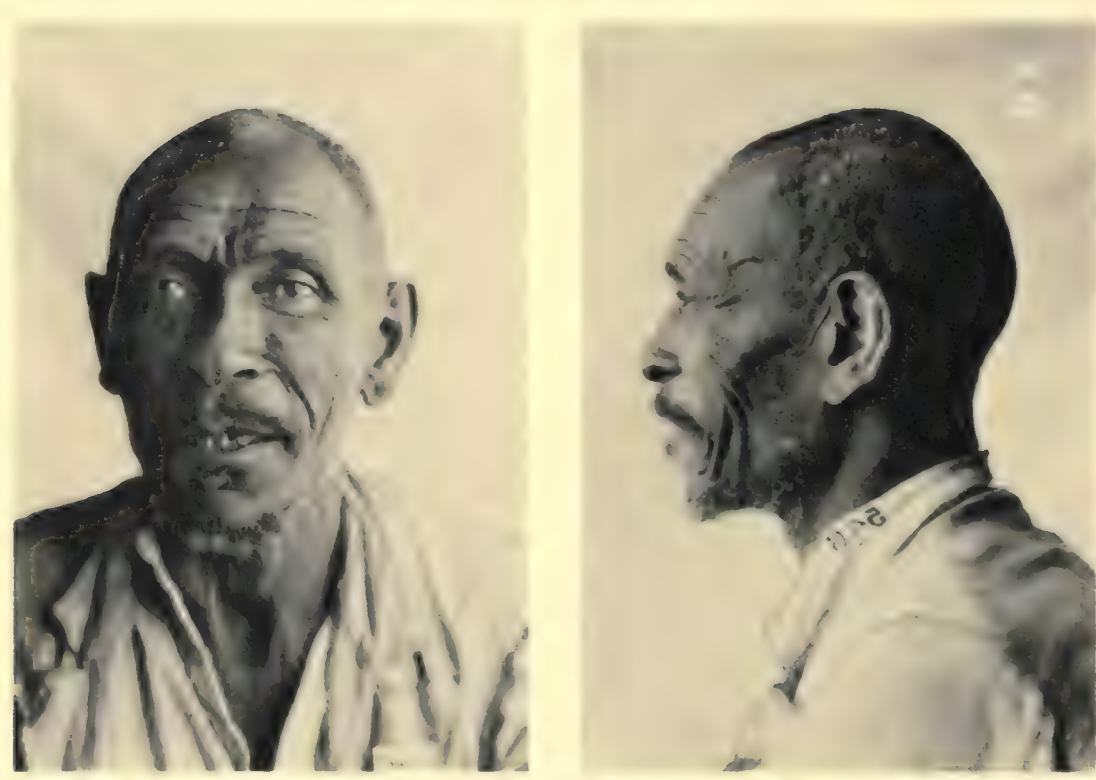

$\mathbb{N}^{2} \mathrm{C}^{\circ}$ 478

$3^{+}$

No. 932 (age 55)

AL BU MUHAMMAD NEGROID TYPES 


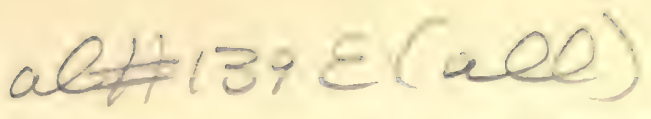

Field Museum of Natural History

Anthropology, Vol. 30, Plate $137 \mathrm{Nec}_{\mathrm{f}}$ th

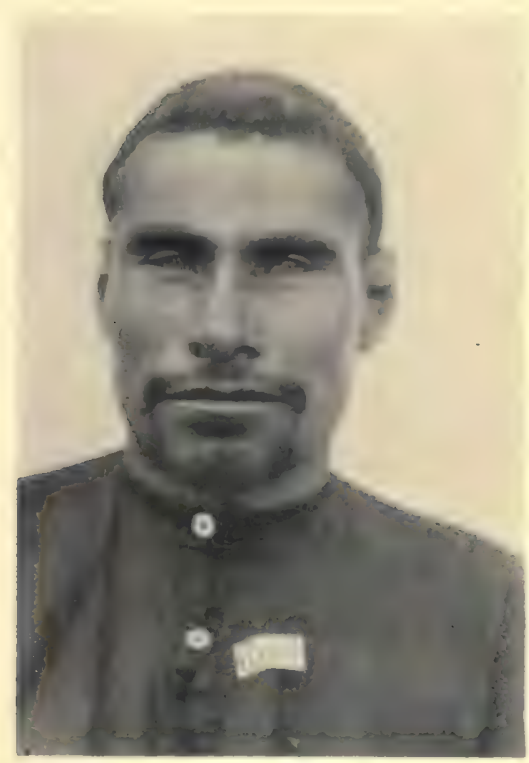

8334

$\lambda^{4}$

b

13

No. 841 (age 30)
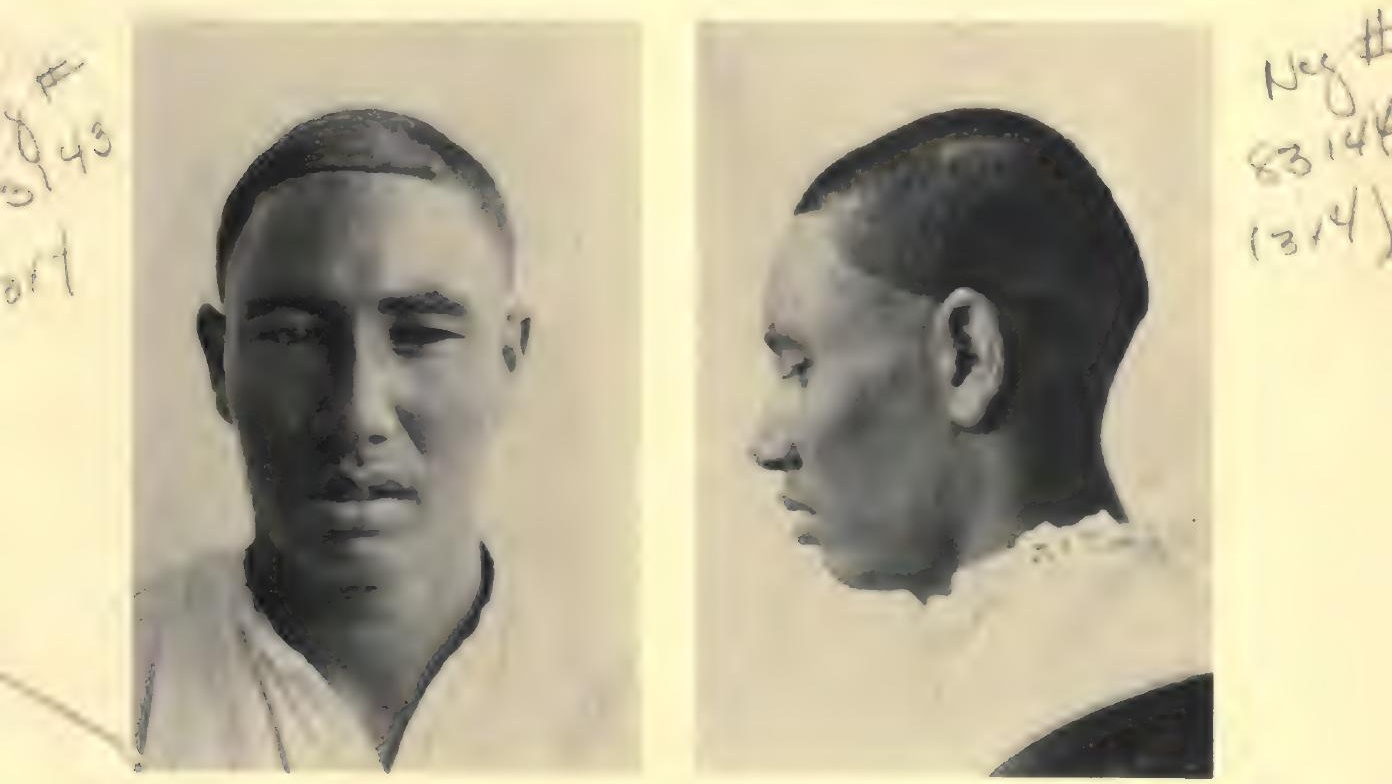

No. 797 (age 22)

AL BU MUHAMMAD MONGOLOID TYPES 


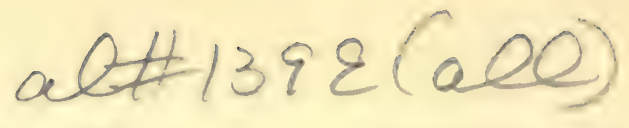

Field Museum of Natural History

?

1)
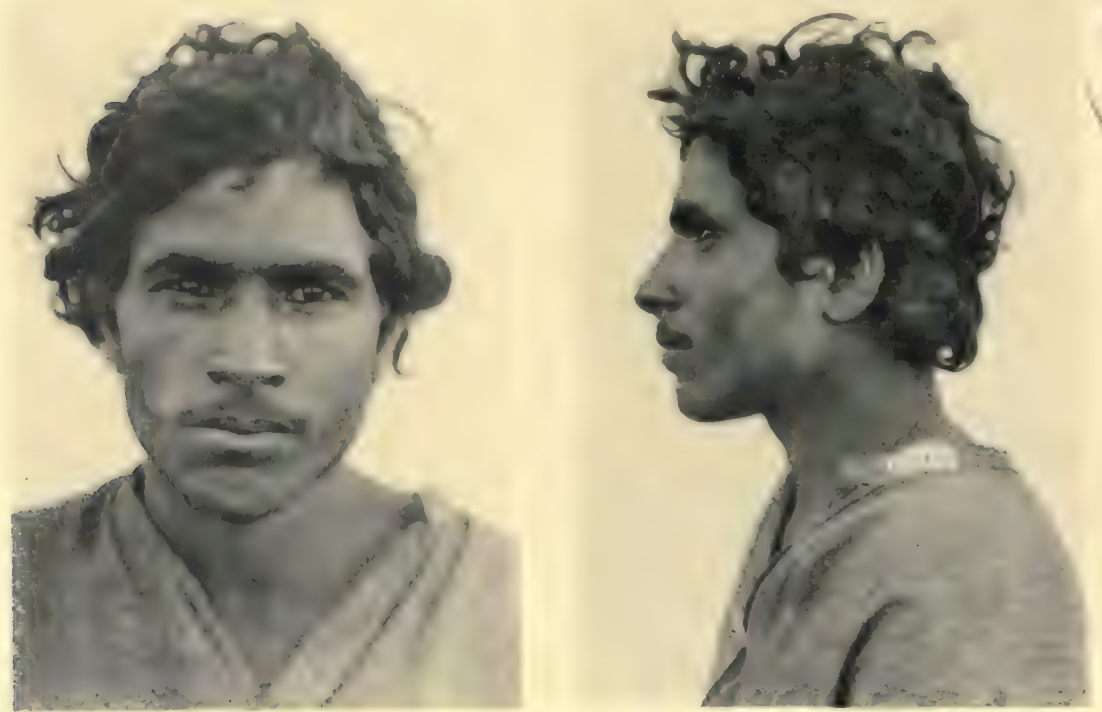

Anthropology, Vol. 30, Plate 138

No. 887 (age 22)
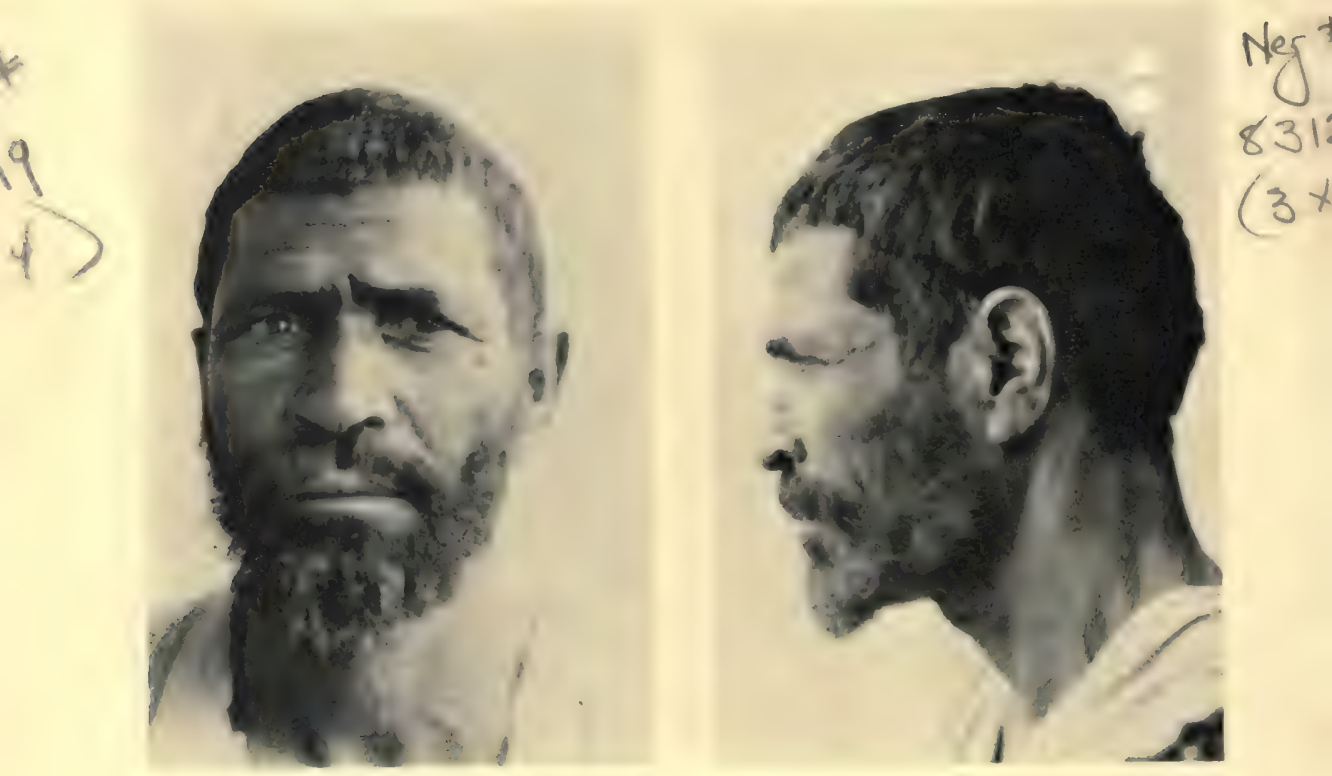

No. 809 (age 40)

AL BU MUHAMMAD AUSTRALOID TYPES 


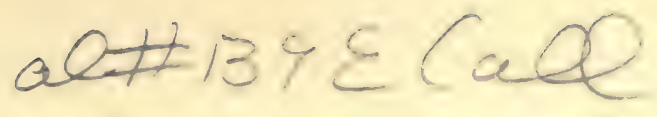

$x$

Field Museum of Natural History

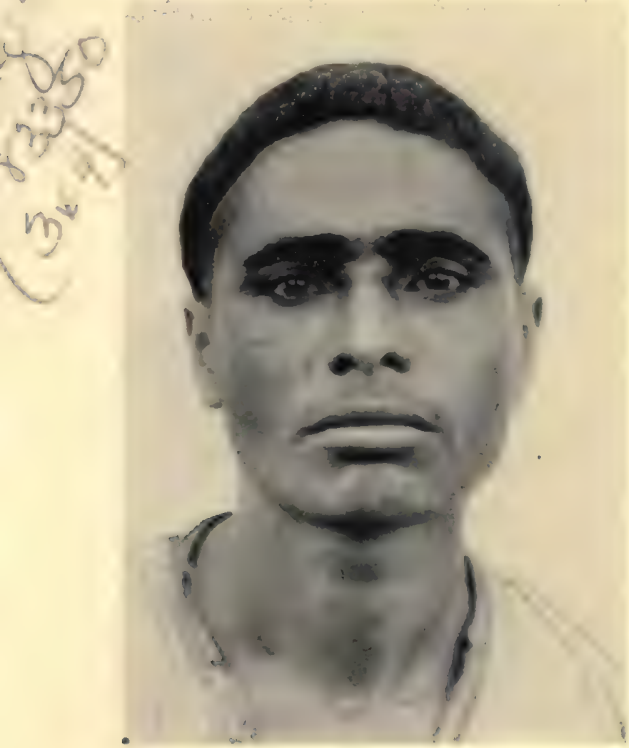

Anthropology, Vol. 30, Plate 139

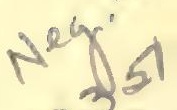

83

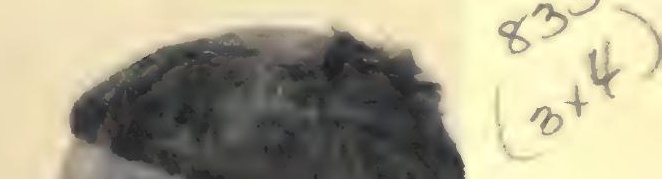

No. 842 (age 20)
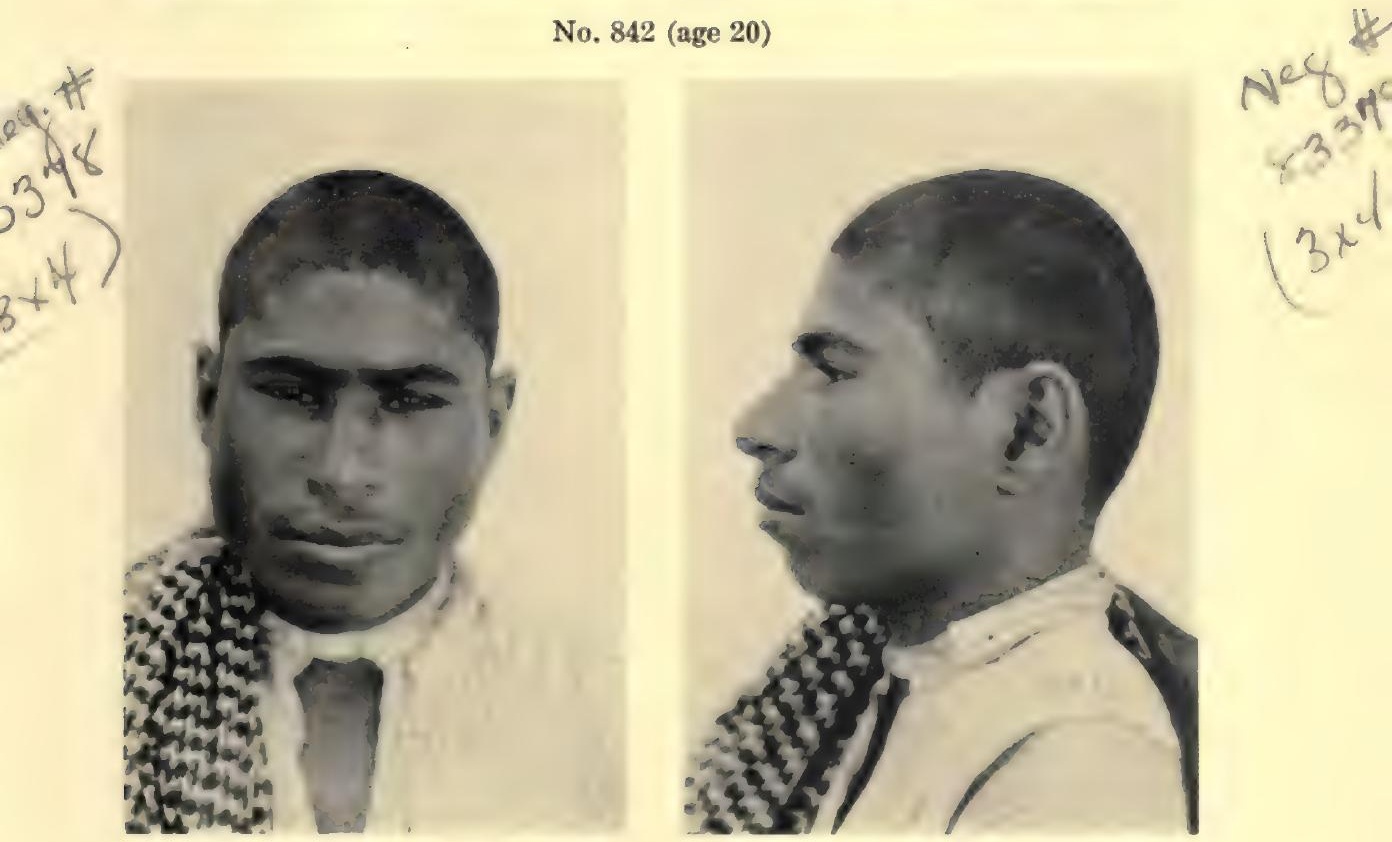

No. 828 (age 20) 


\subsection{9}

Field Museum of Natural History
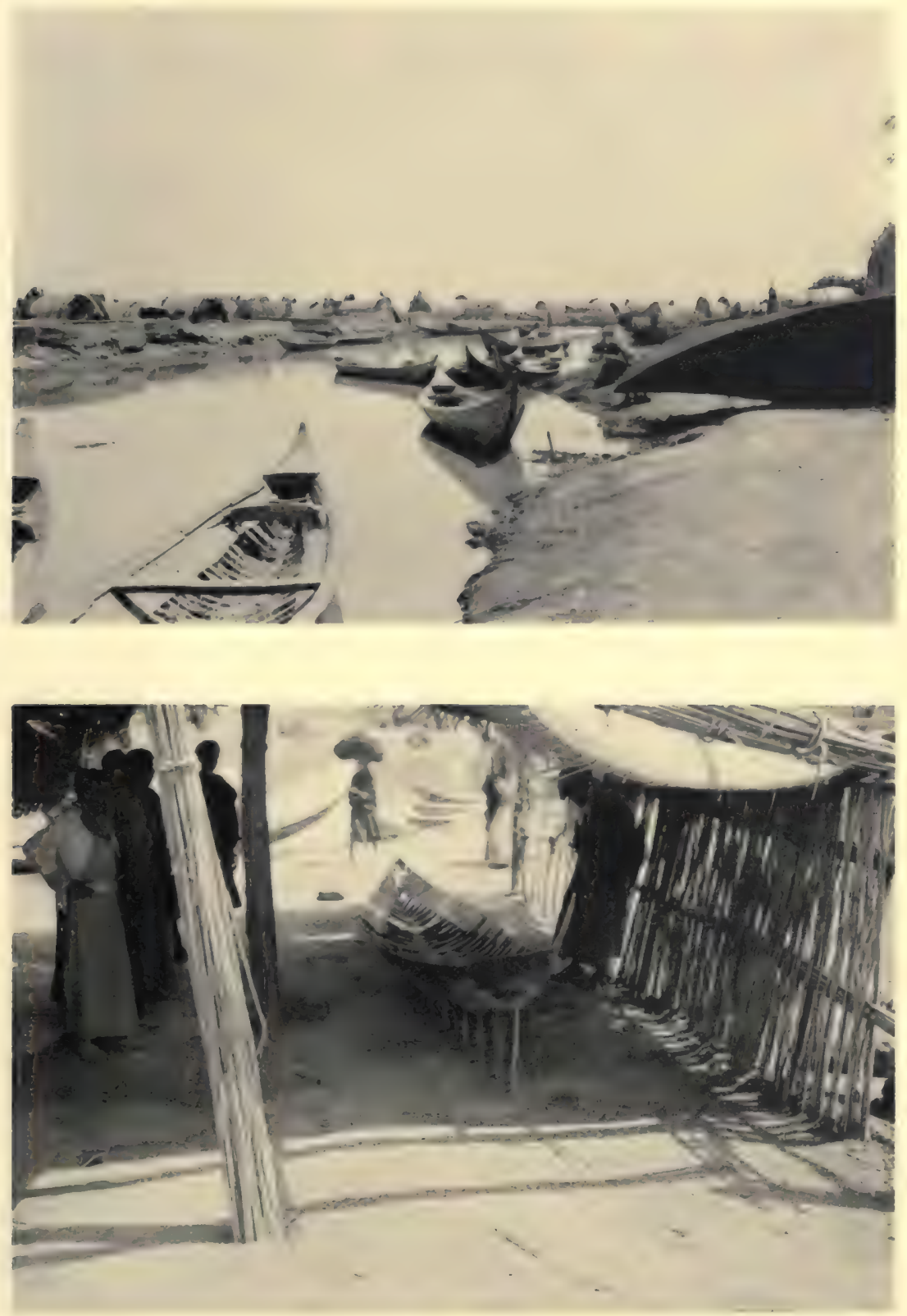

BOATS AT HALFAYA 

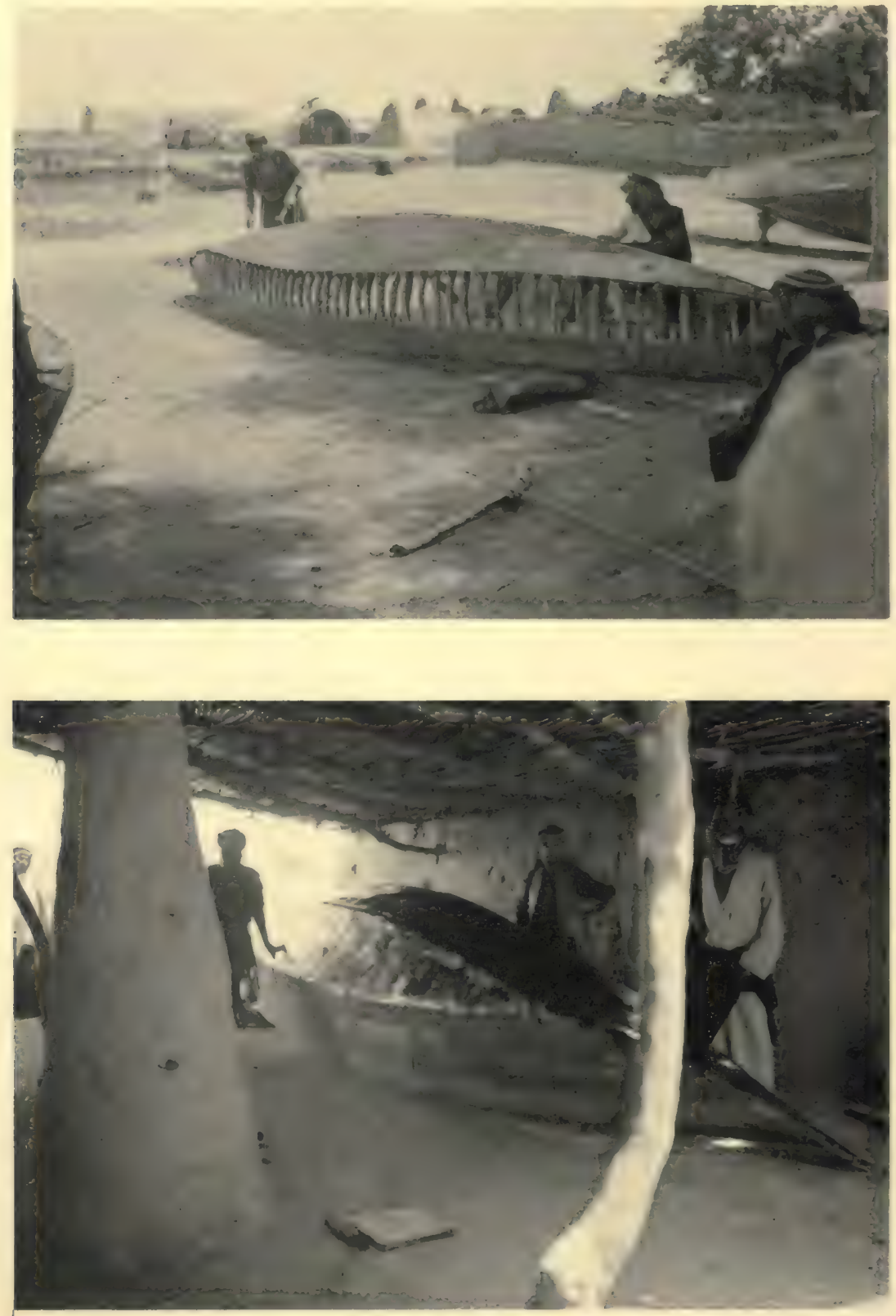

BOAT-BUILDING AT HALFAYA 


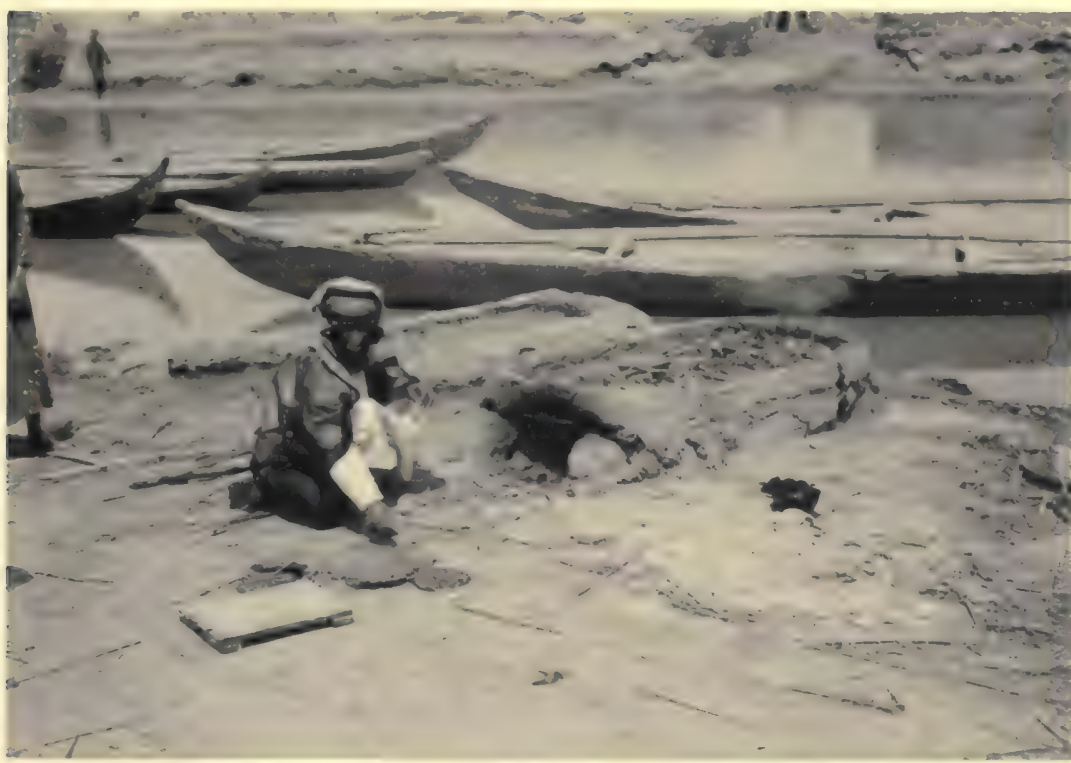

Fig. 1. Heating tar for boats

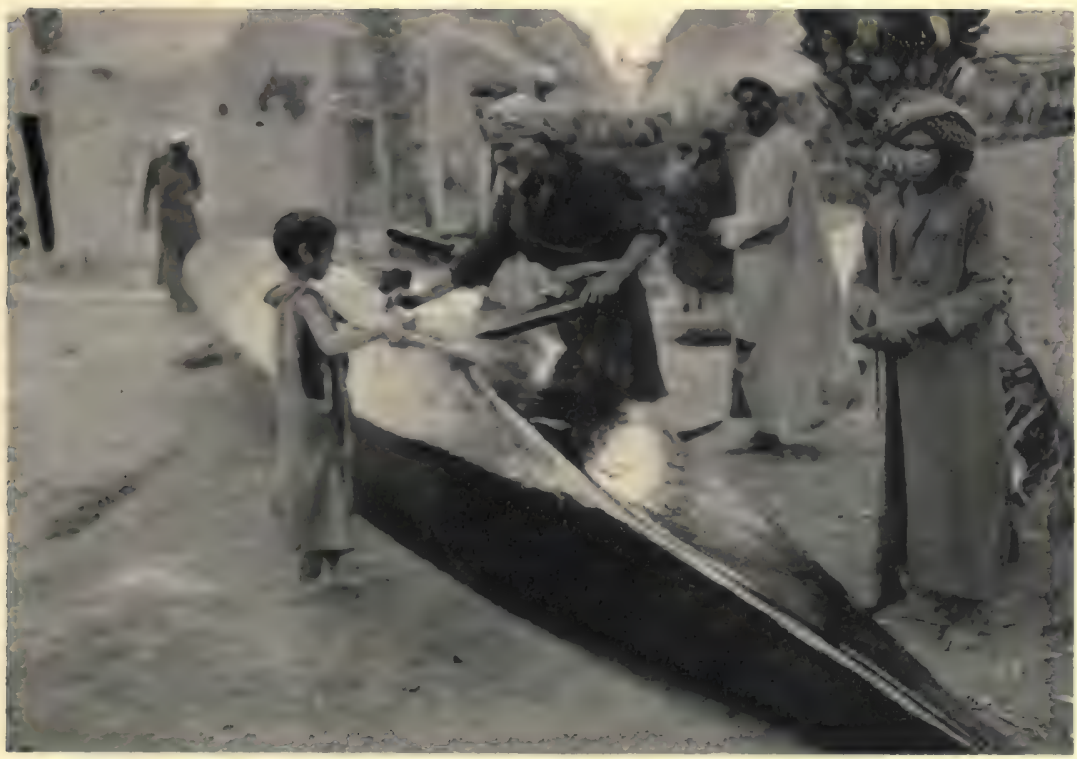

Fig. 2. Tarring the skin used to cover the framework of the boat 
- Field Museum of Natural History

Anthropology, Vol. 30, Plate 144

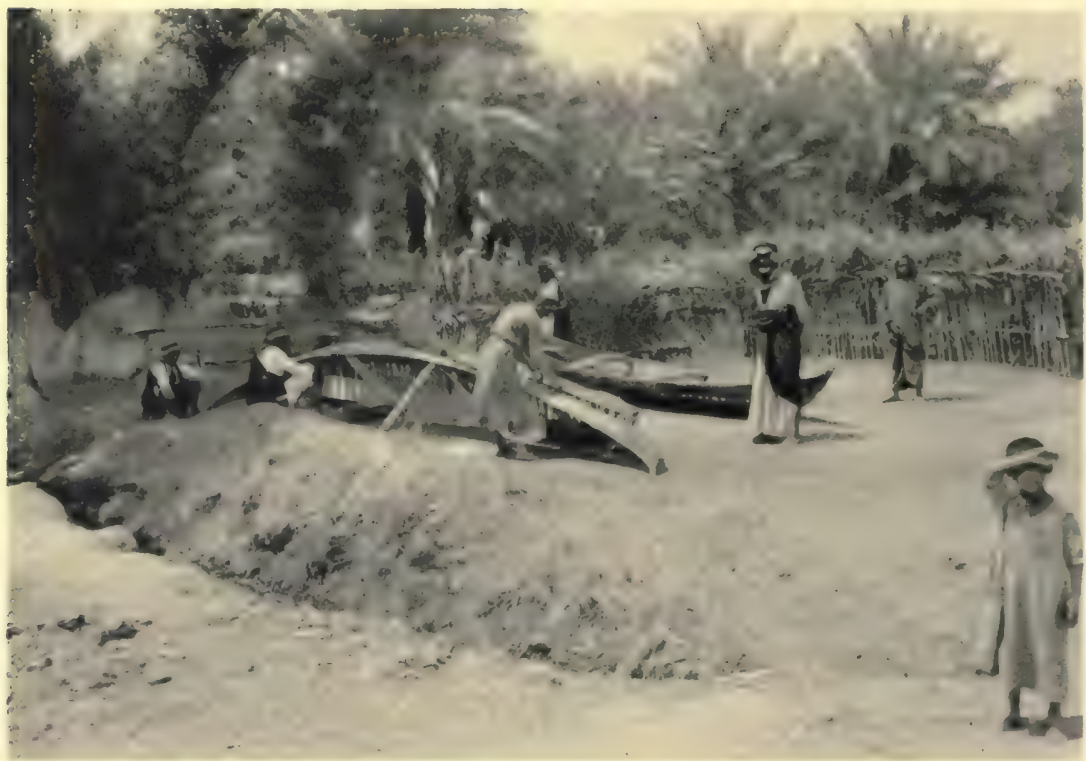

$\frac{\infty}{\infty}$

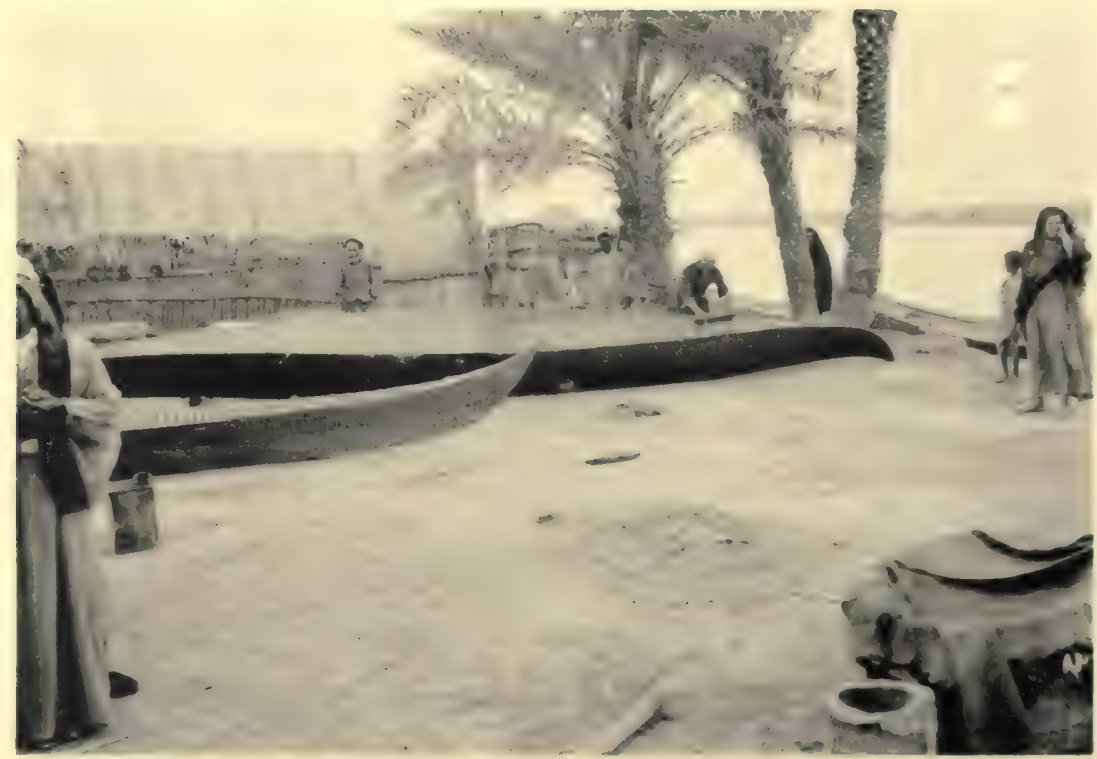

BOAT-BUILDING AT HALFAYA 


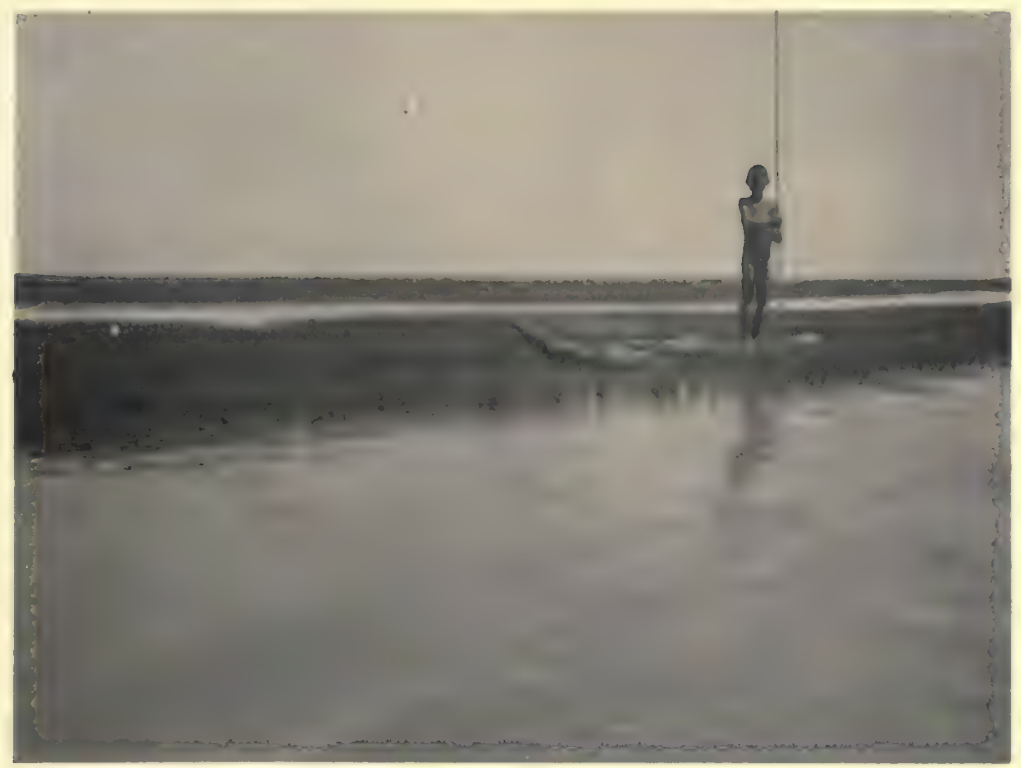

Fig. 1. Primitive type of craft, made of reed bundles

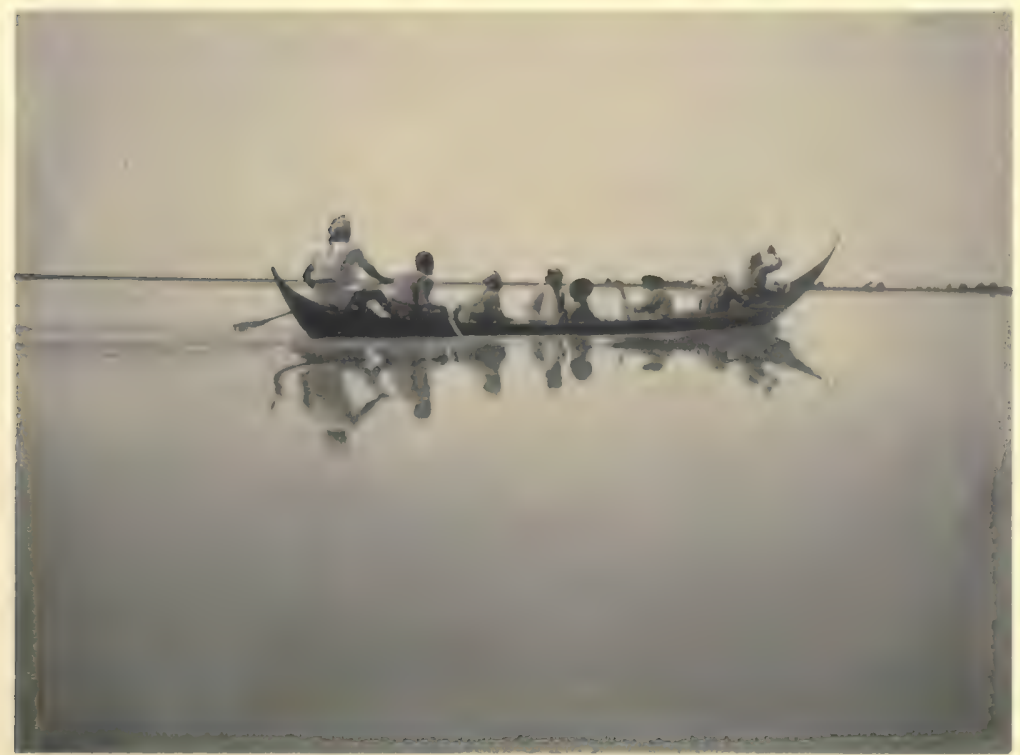

Fig. 2. A hunting expedition 


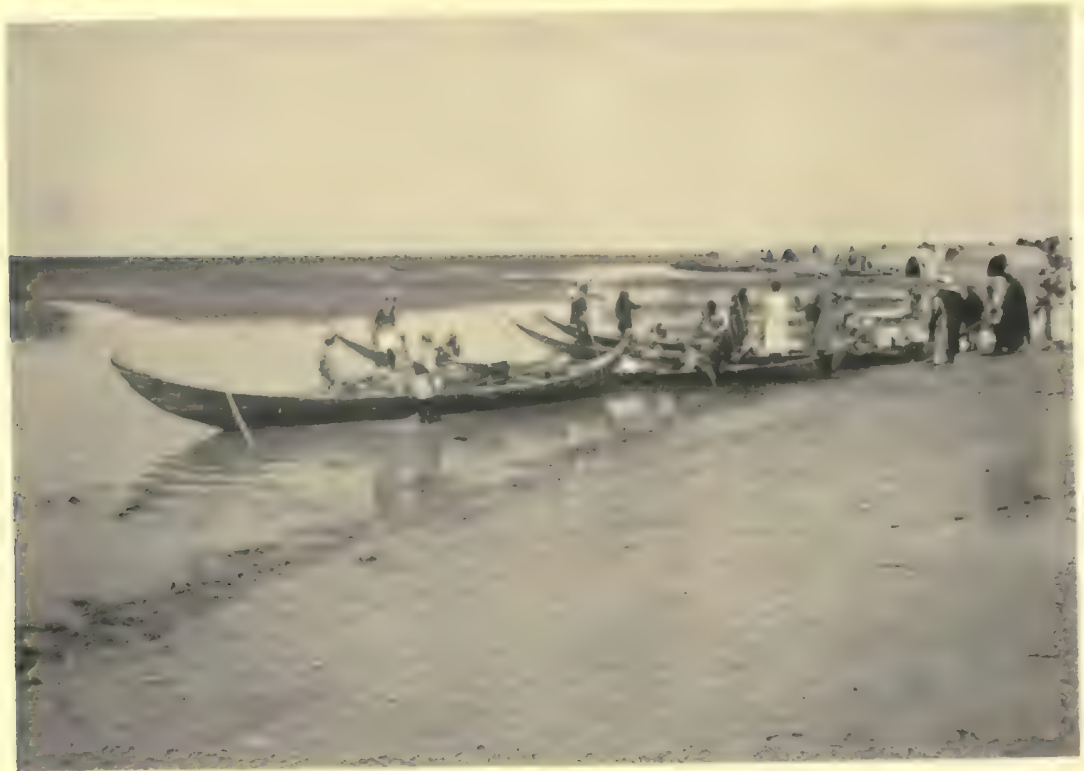

Fig. 1. Boats at Sheikh Khazal's camp

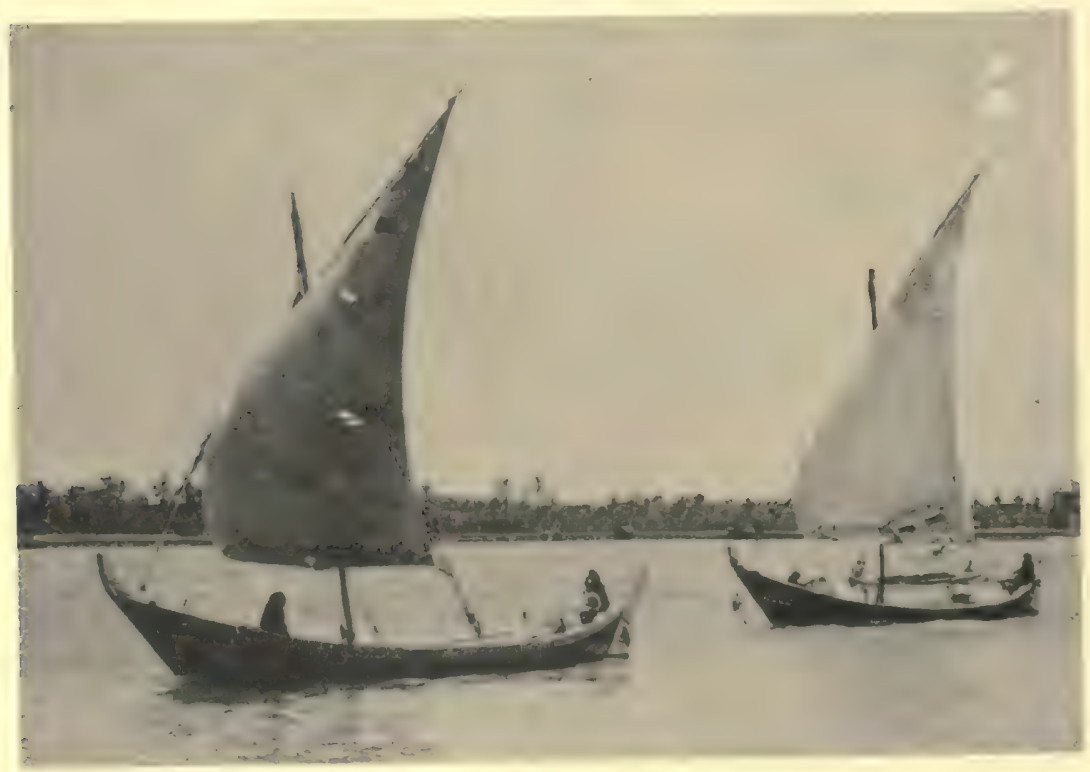

Fig. 2. Lighters on the Shatt al Arab

AL BU MUHAMMAD BOATS 


$$
184159
$$

Field Museum of Natural History Anthropology, Vol. 30, Plate 147

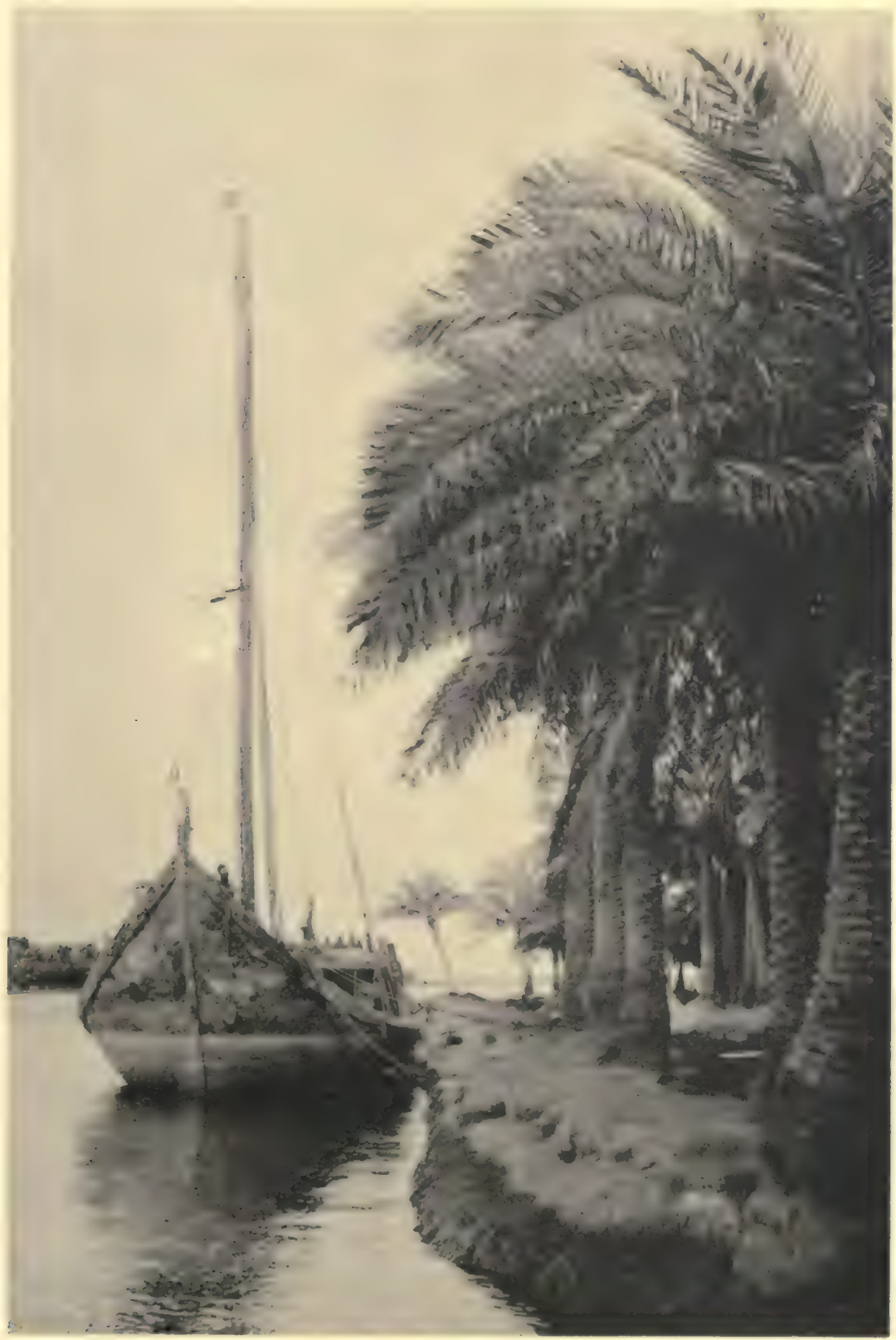

LARGE BOAT AT AL QURNA, JUNCTION OF TIGRIS AND EUPHRATES RIVERS 


\section{A84104}

Field Museum of Natural History Anthropology, Vol. 30, Plate 148

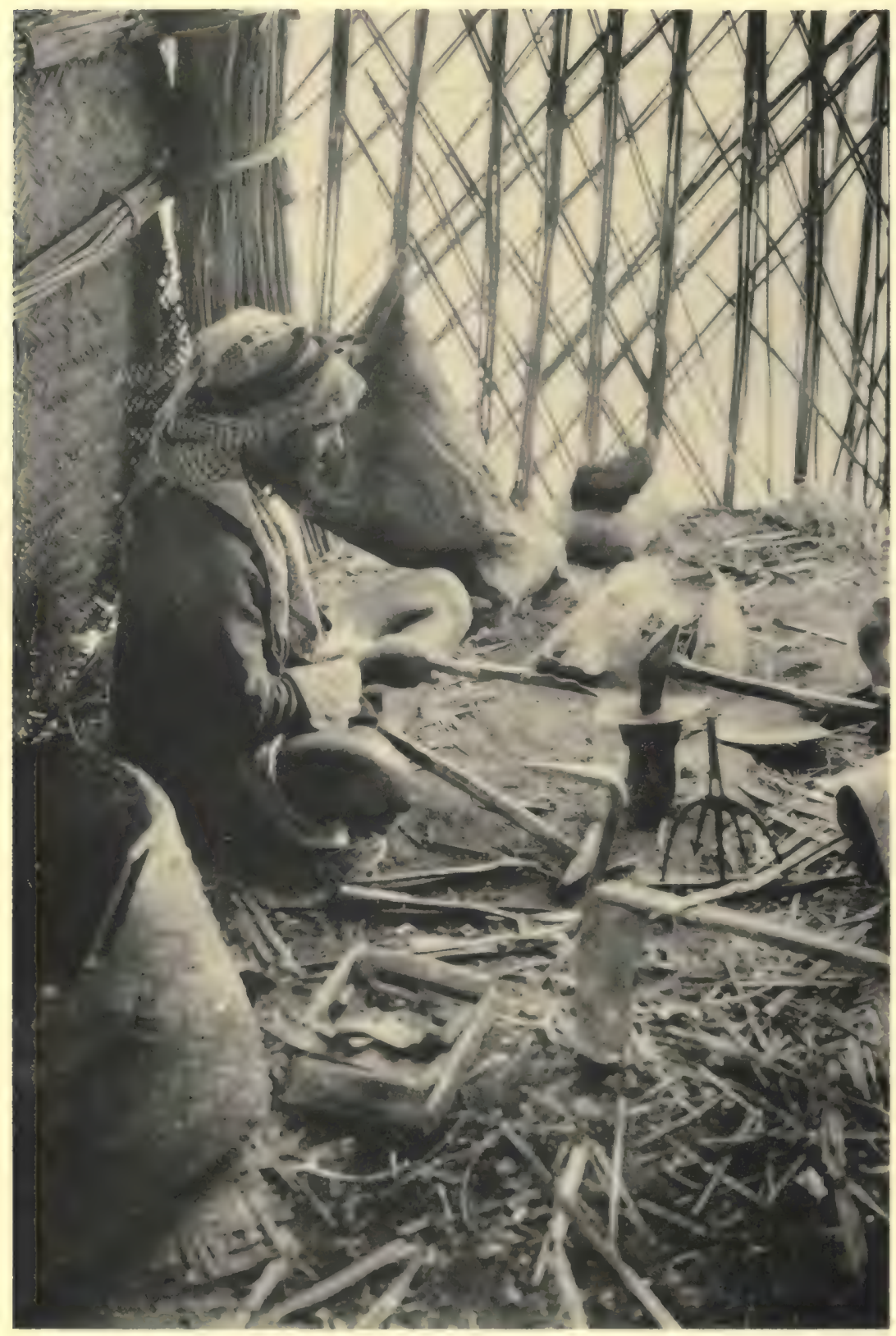

SUBBI IRON-WORKER NEAR SHEIKH KHAZAL IBN FALIH'S CAMP 
$4 e^{3}$

Field Museum of Natural History

4)

\&

$8 \cdot$
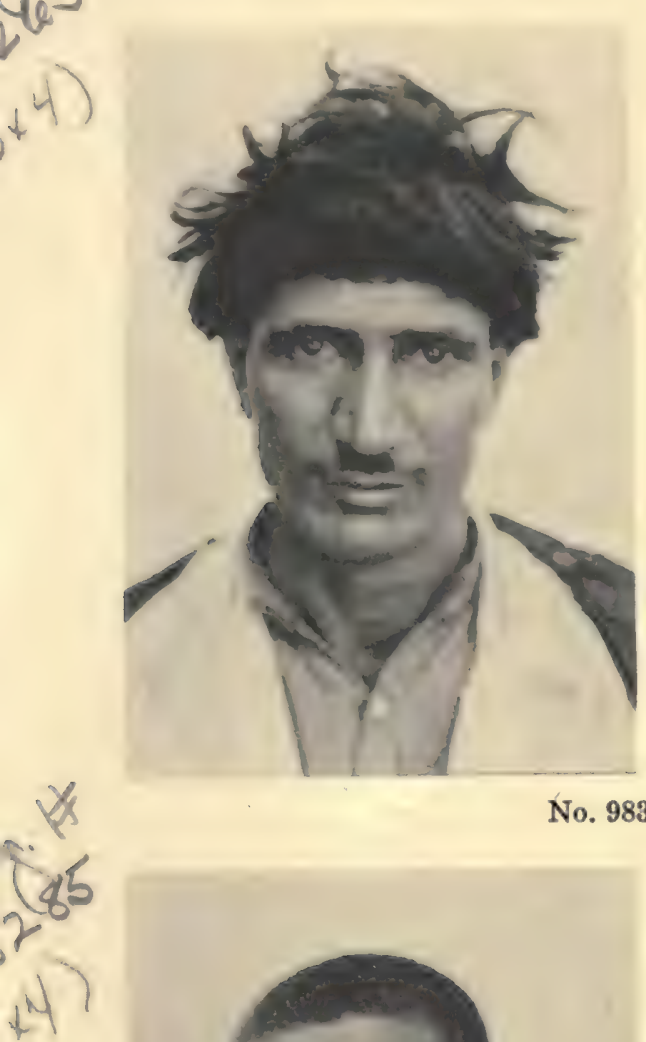

Anthropology, Vol. 30, Plate 149

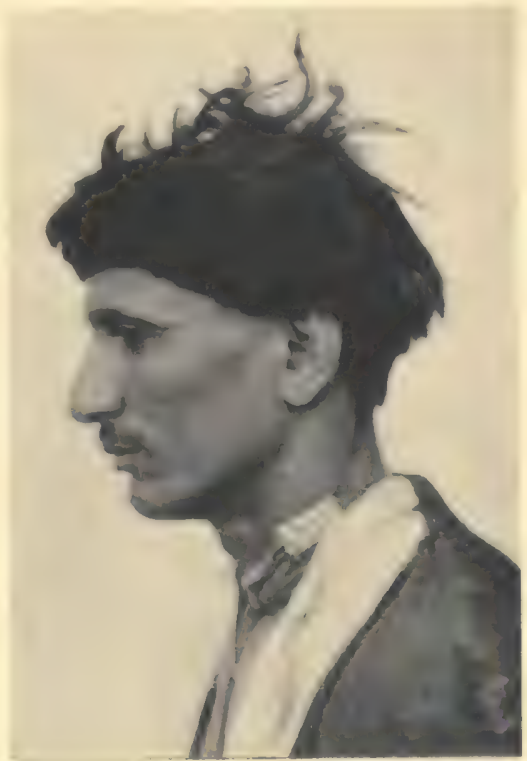

No. 983 (age 20)
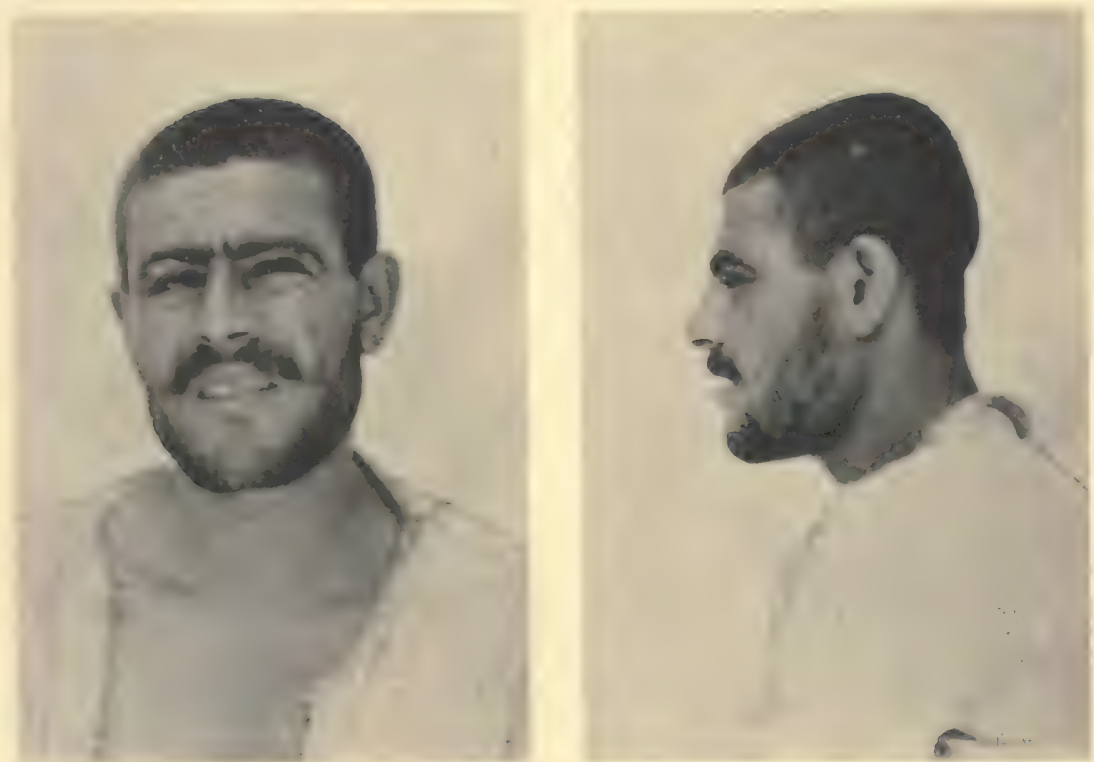

Neg.

83286

$3+4$

No. 995 (age 25)

AL SAWAAD CLASSIC MEDITERRANEANS WITH EITHER STRAIGHT OR CONVEX NOSES 


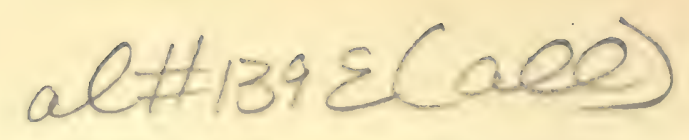

Field Museum of Natural History

Anthropology, Vol. 30, Plate 150

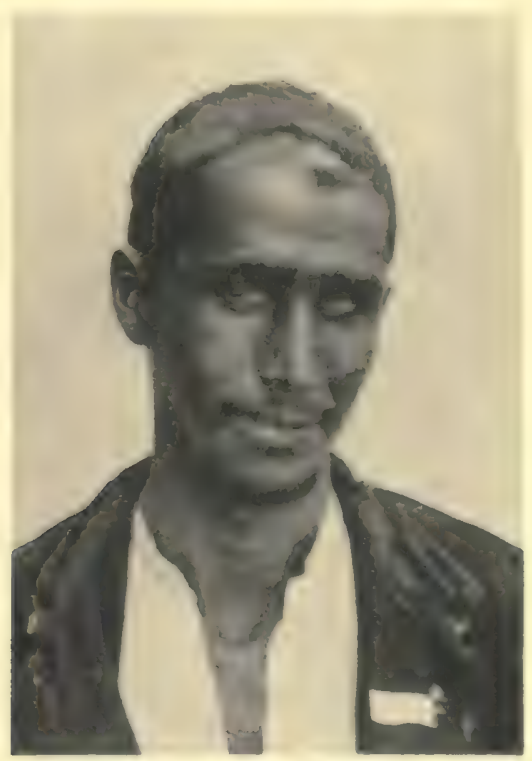

Nex

43

$3^{4}$

1)

No. 984 (age 35)

$\frac{1}{59}$
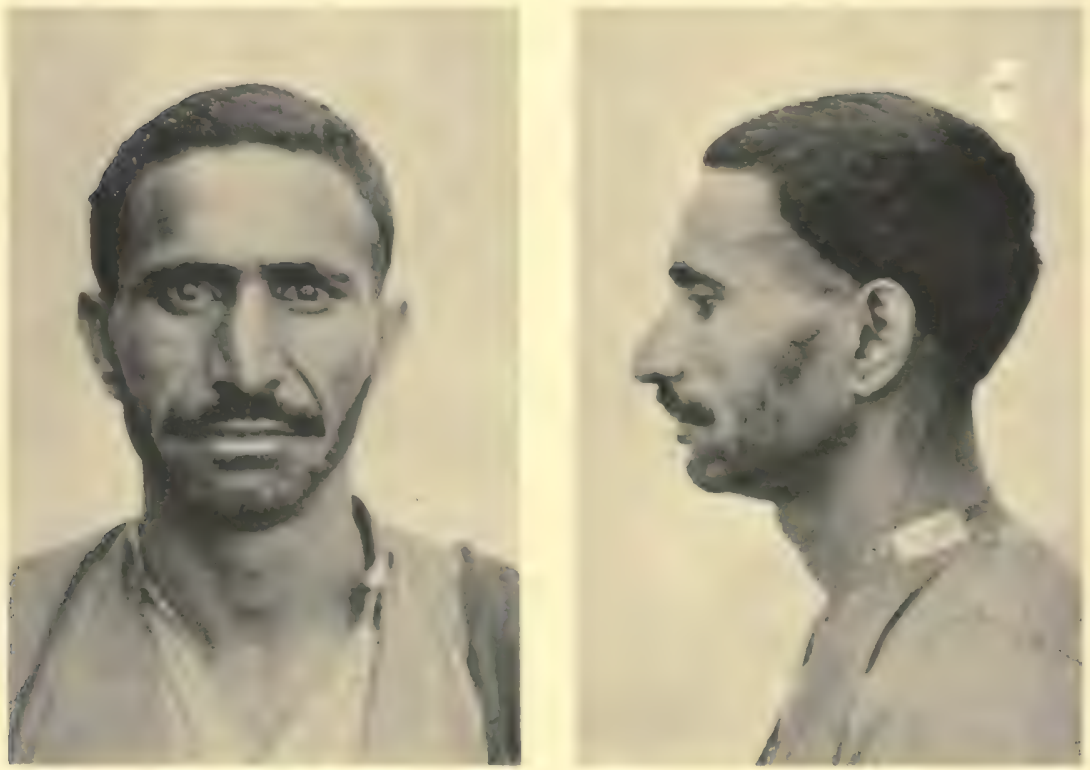

Nec

83

$3 x$

No. 981 (age 35)

AL SAWAAD CLASSIC MEDITERRANEANS WITH EITHER STRAIGHT OR CONVEX NOSES 
Field Museum of Natural History

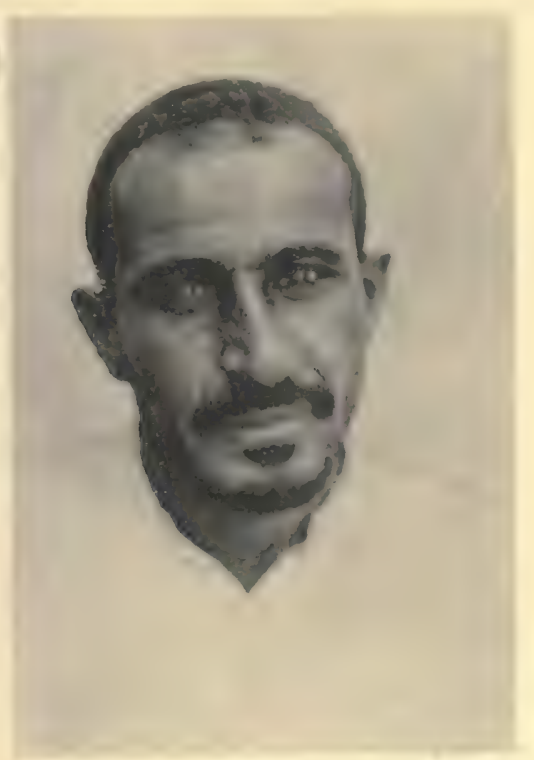

No. 992 (age 35)
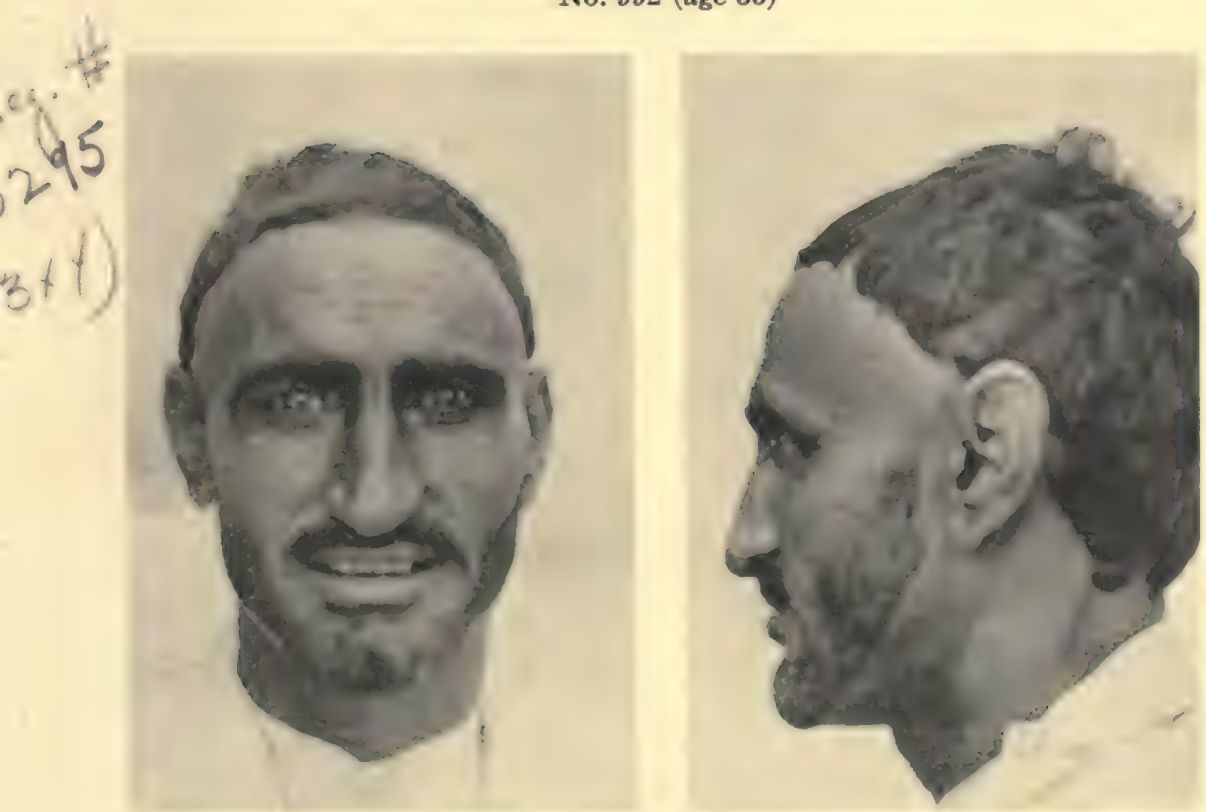

Anthropology, Vol. 30, Plate 151

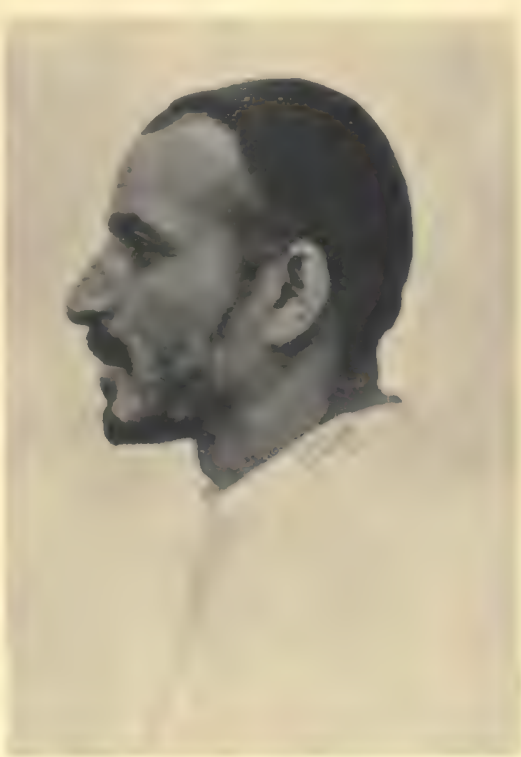

$(3 \times 4)$

Neg $t$

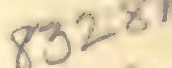

$\log \hbar$

83296

$(3+4$

No. 1000 (age 35)

AL SAWAAD CLASSIC MEDITERRANEANS WITH EITHER STRAIGHT OR CONVEX NOSES 


\section{alt $1398(a) 0)$}

Field Museum of Natural History

40

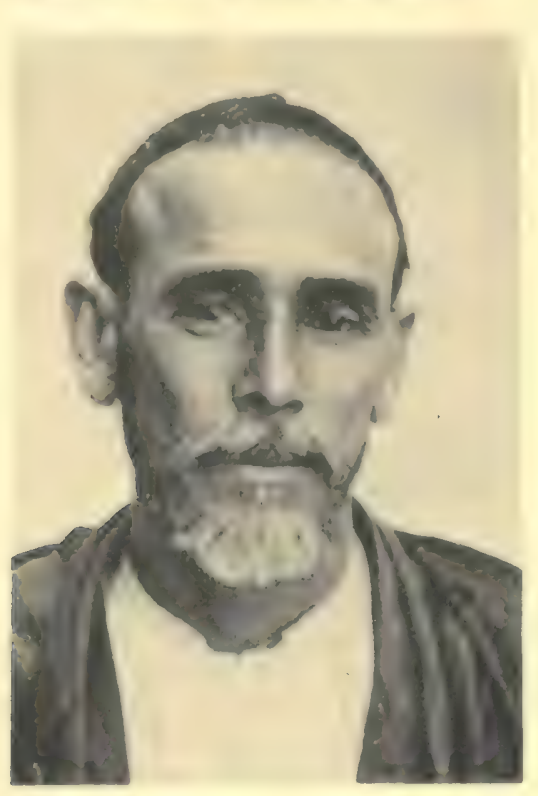

Anthropology, Vol. 30, Plate 154

44)

No. 968 (age 45)
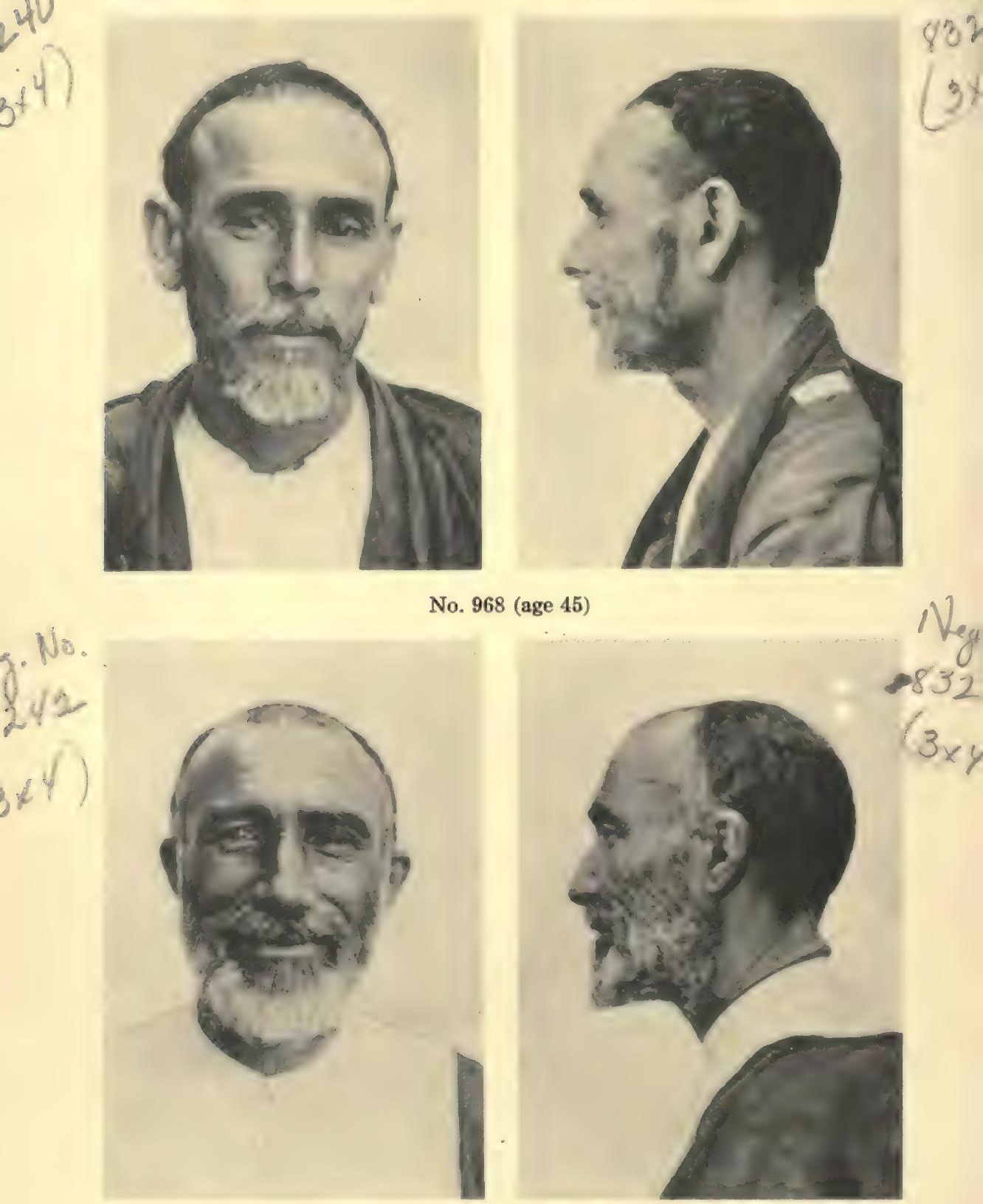

832

$3 x$

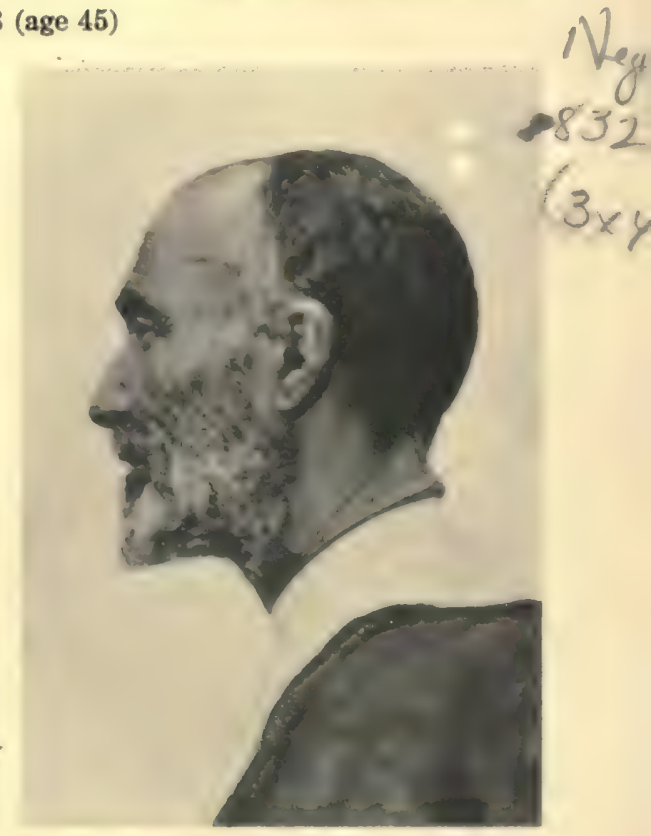

No. 969 (age 45)

AL SAWAAD CLASSIC MEDITERRANEANS WITH EITHER STRAIGHT OR CONVEX NOSES 


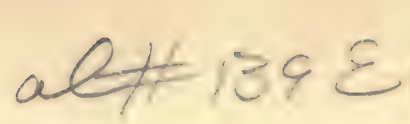

Field Museum of Natural History

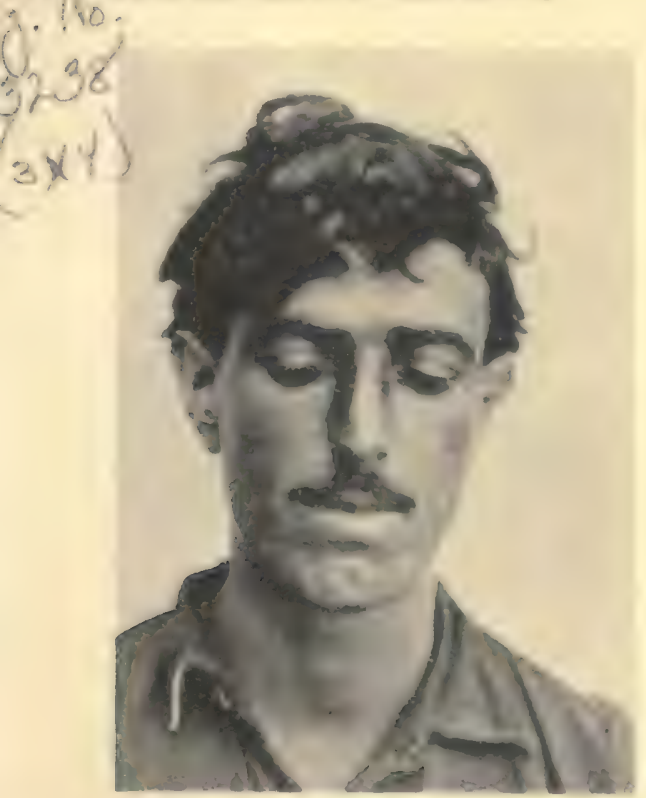

No. 966 (age 20)
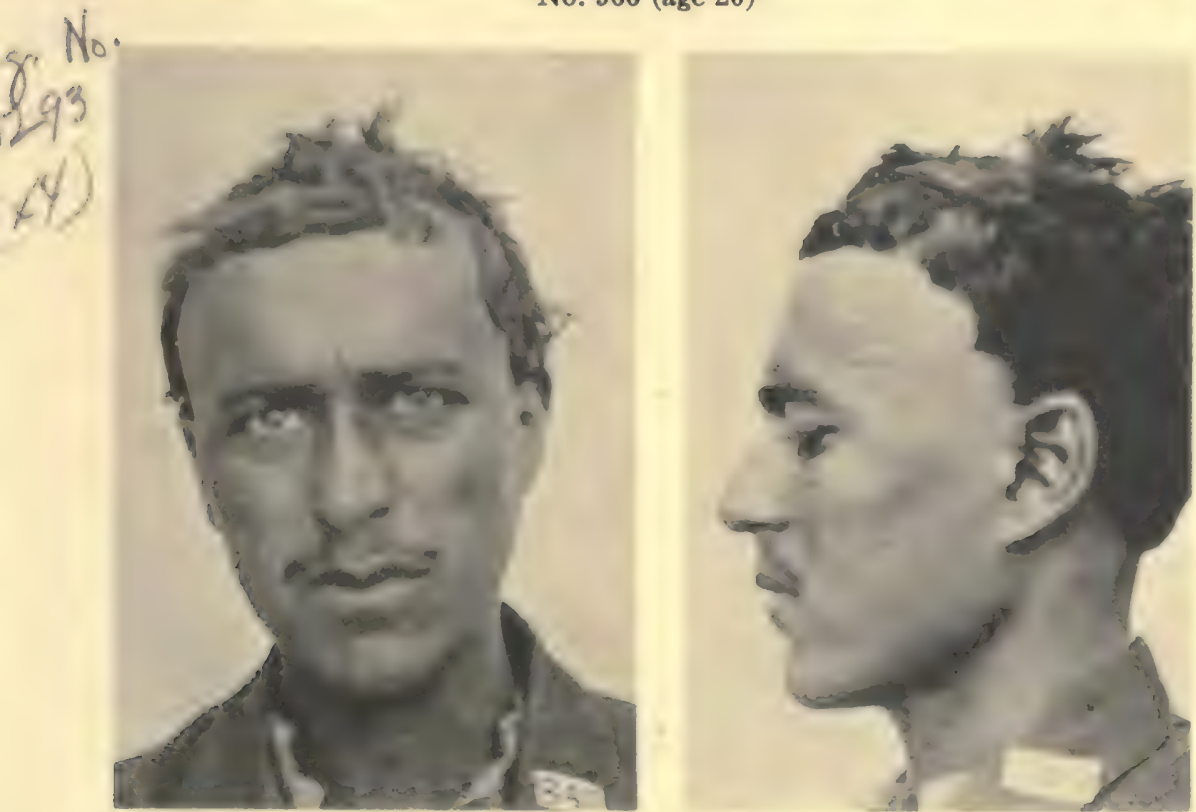

$\mathrm{Neg} \cdot \mathrm{Nic}$ 83294

$(3 \times 4)$

No. 999 (age 20) 
Field Museum of Natural History

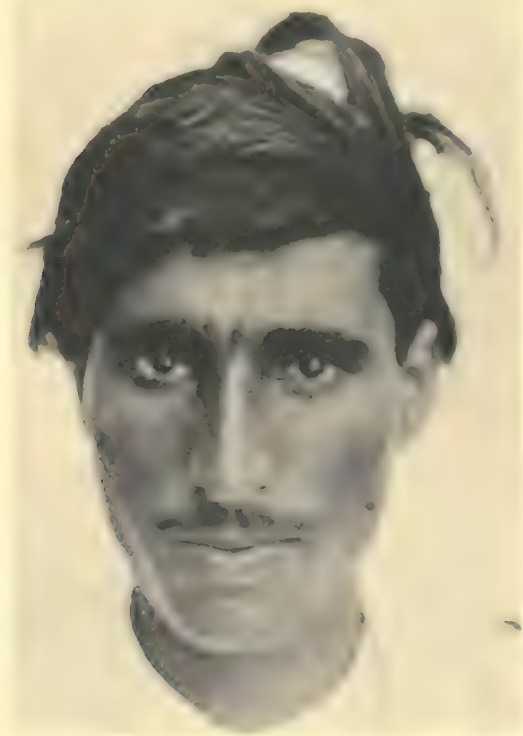

\section{$a l+1398(a b)$}

Anthropology, Vol. 30, Plate 156

Ney 83

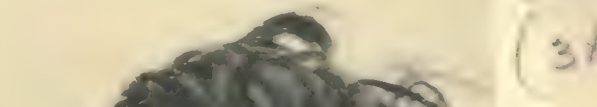
31

No. 954 (age 22)

tit.

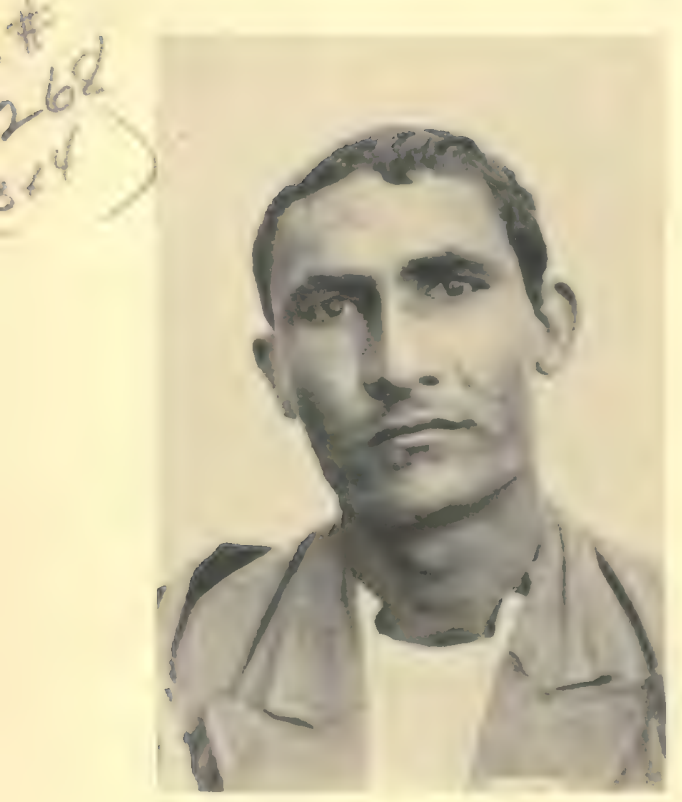

Ner

822

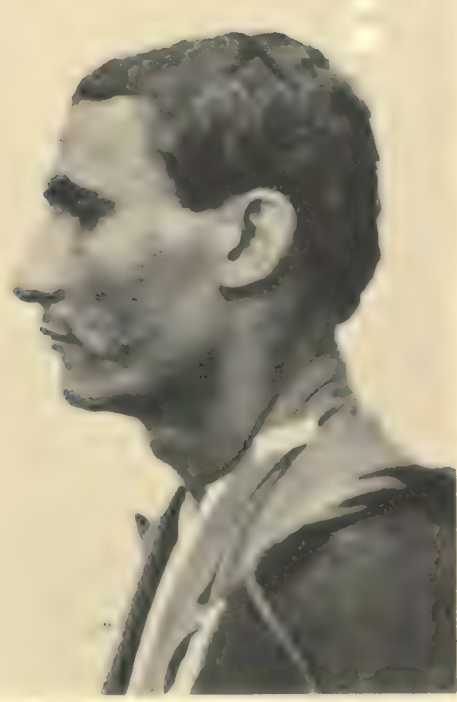

No. 986 (age 23)

AL SAWAAD ATLANTO-MEDITERRANEANS 



\section{alt 1398 (all)}

Field Museum of Natural History

Anthropology, Vol. 30, Plate 158
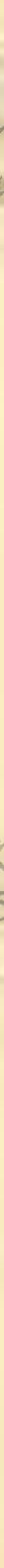

No. 1003 (age 30)

AL SAWAAD ATLANTO-MEDITERRANEANS 


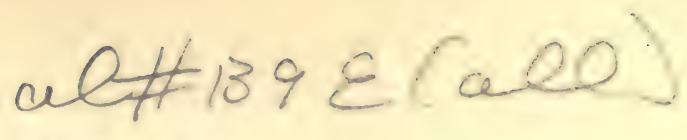

Field Museum of Natural History

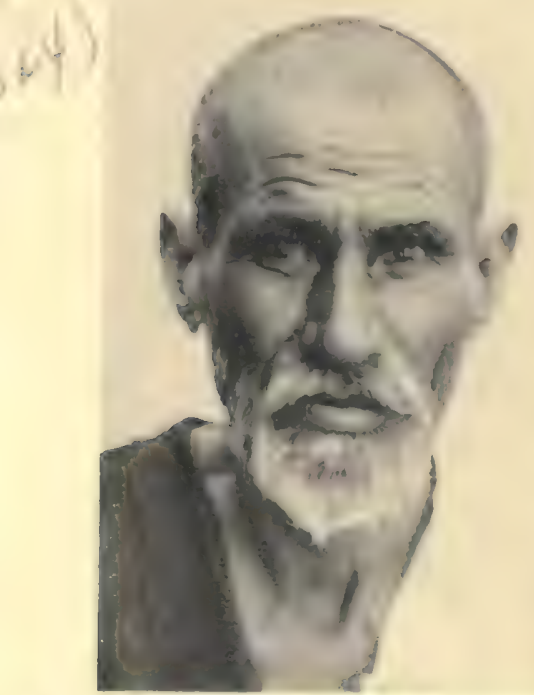

Anthropology, Vol. 30, Plate 159

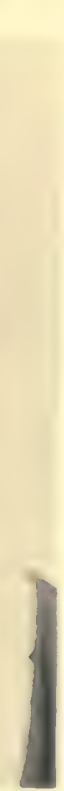

No. 957 (age 55)

$y^{2}{ }^{2}$

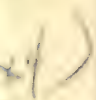

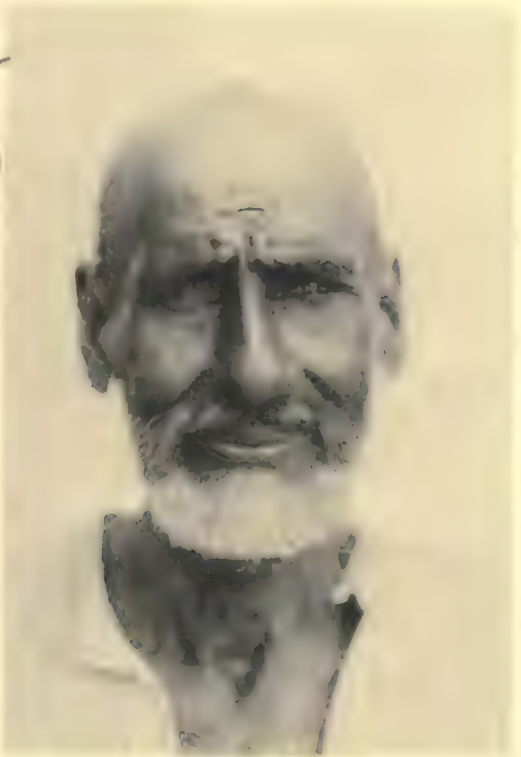

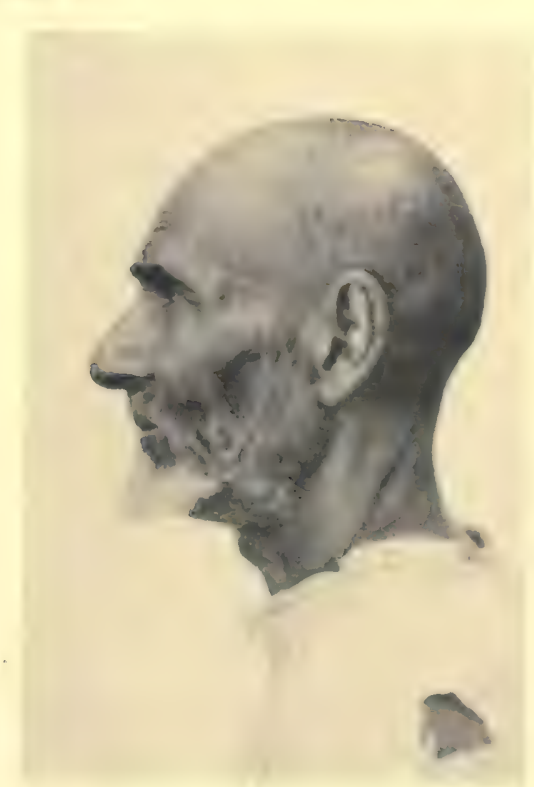

109.7

83021

(3xy)

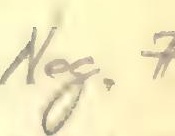

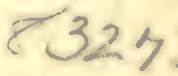

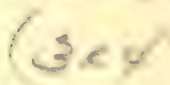

No. 988 (age 60)

AL SAWAAD ATLANTO-MEDITERRANEANS 


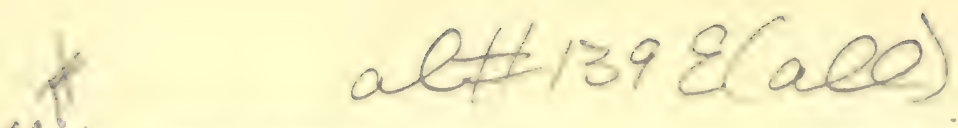

Field Museum of Natural History

Anthropology, Vol. 30, Plate $160 \mathrm{~N} / \mathrm{f}$

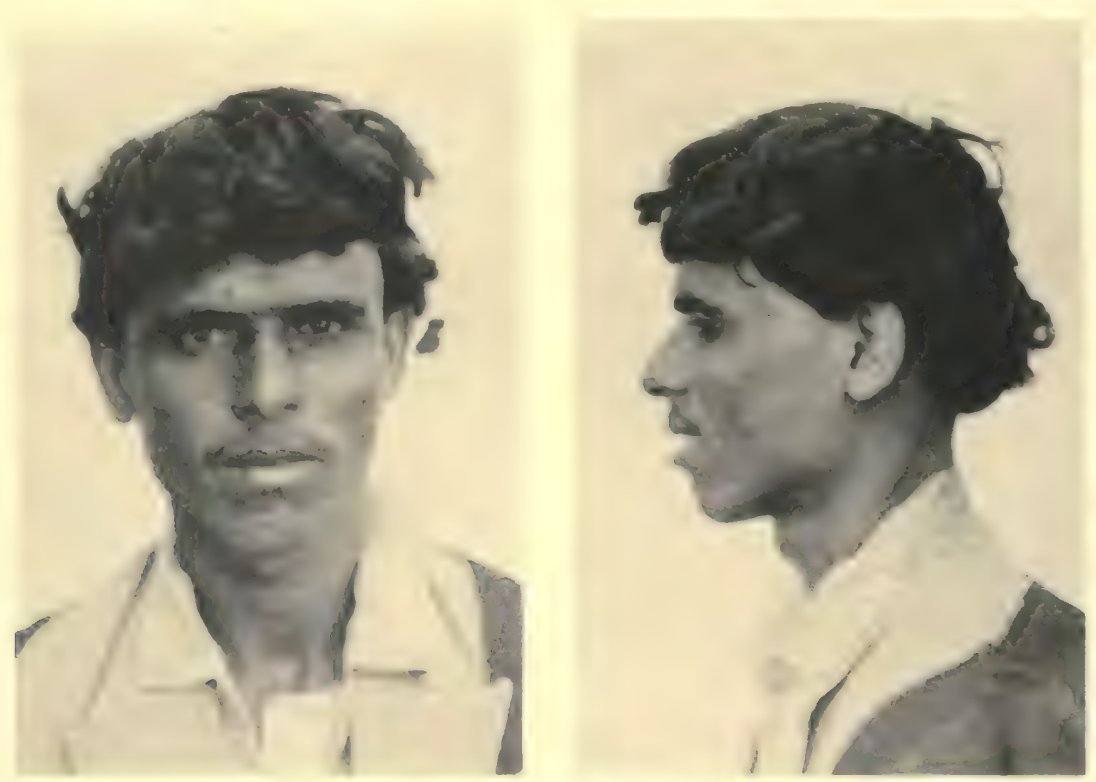

$344)$

No. 959 (age 20)

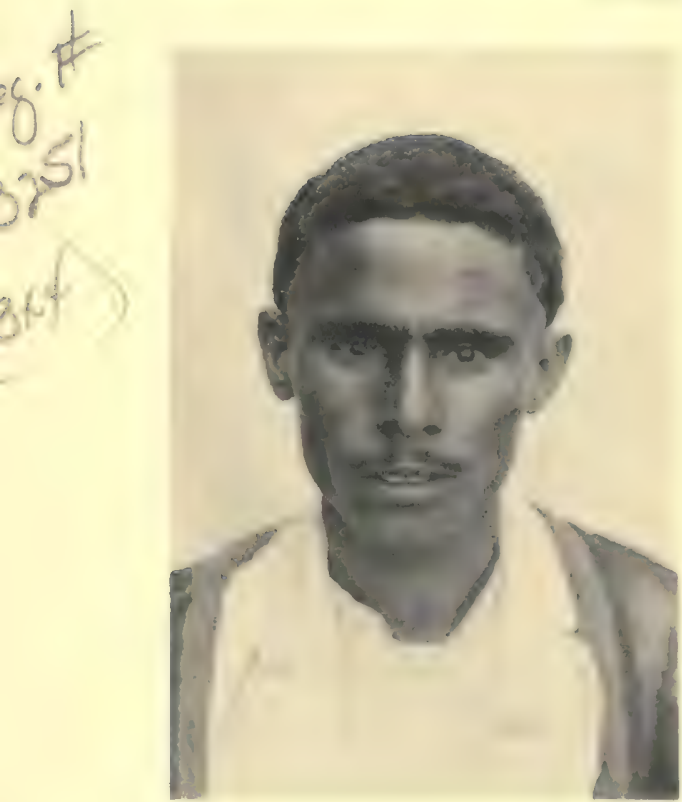

Ne 85

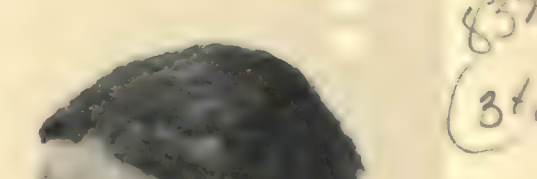

No. 976 (age 20)

AL SAWAAD BRACHYCEPHALS 


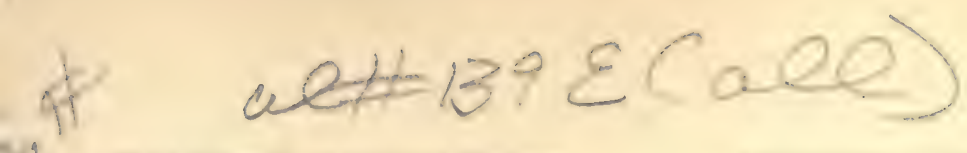

$0^{4} y^{\prime}$ Field Museum of Natural History 11

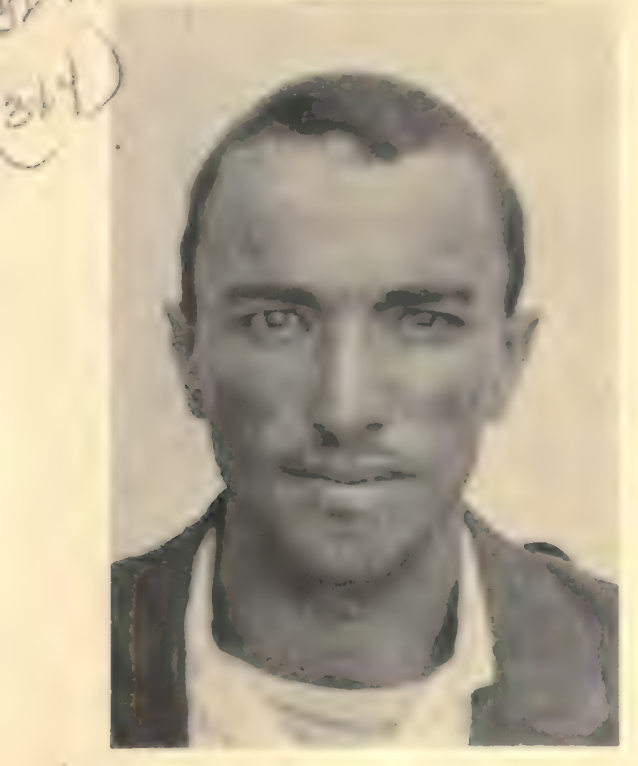

No. 1001 (age 20)

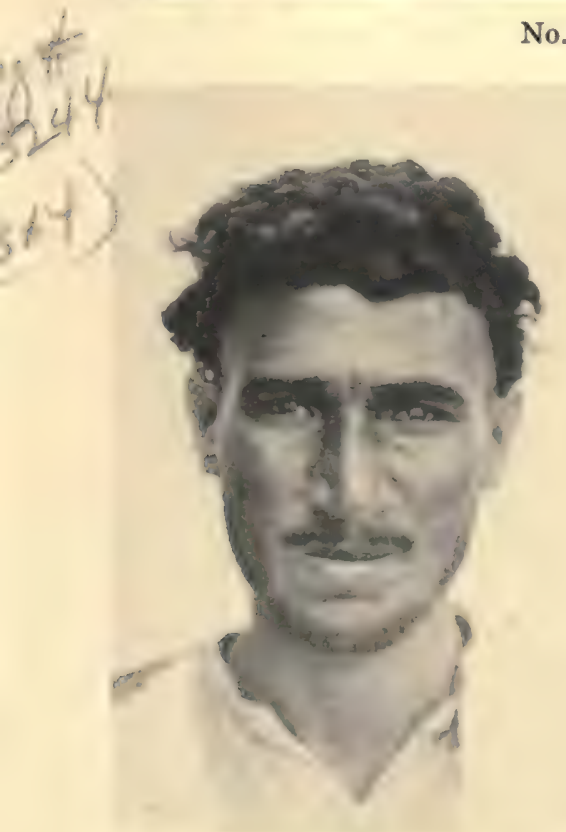

No. 972 (age 22)

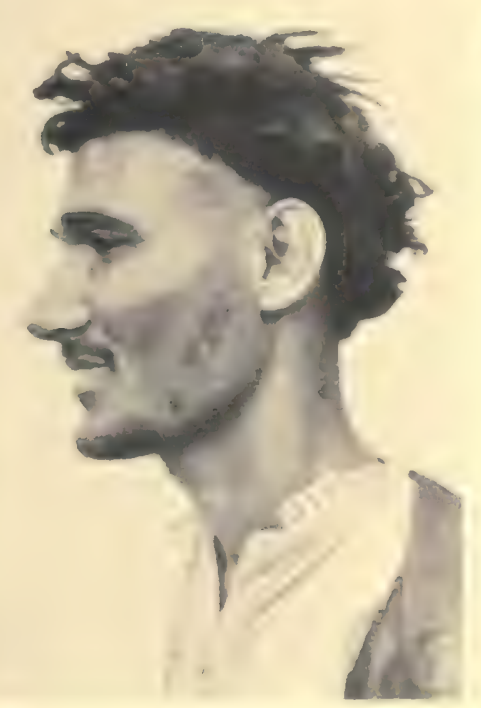

Nes. 832,4 $(3 x)^{2}$ 


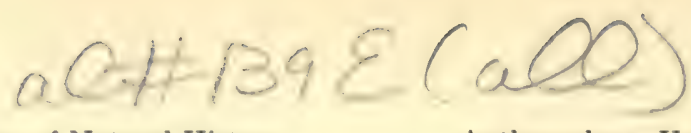

Field Museum of Natural History

Anthropology, Vol. 30, Plate 162

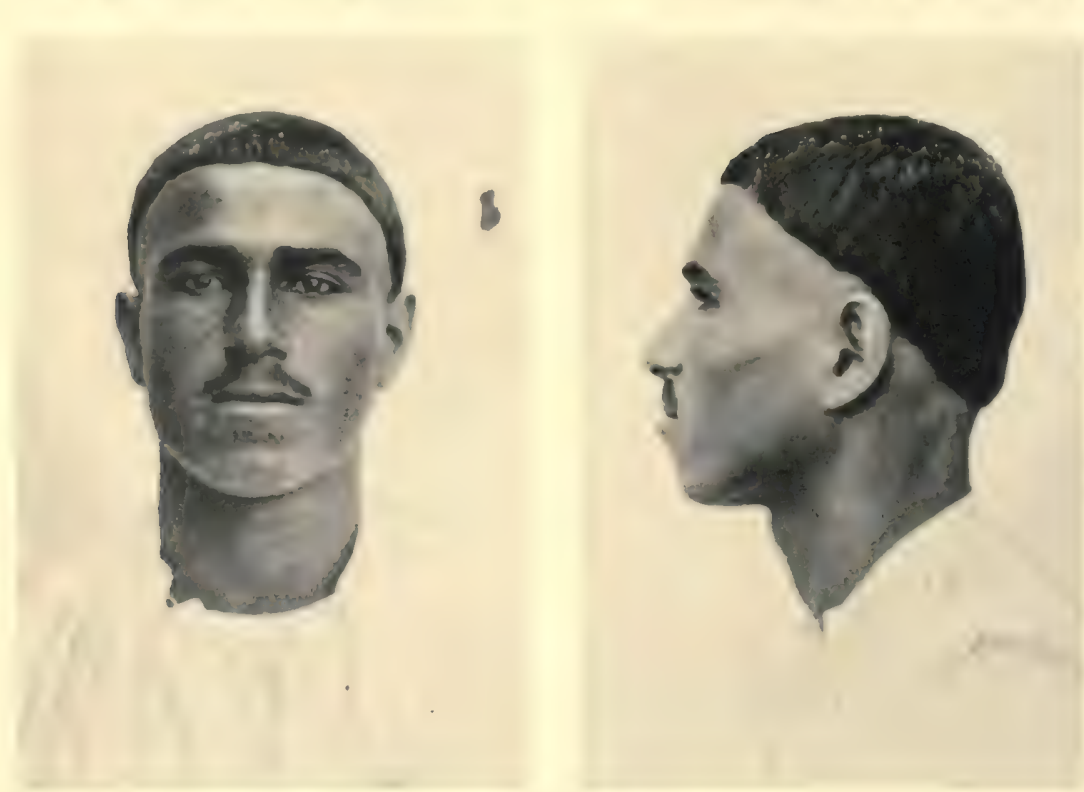

8

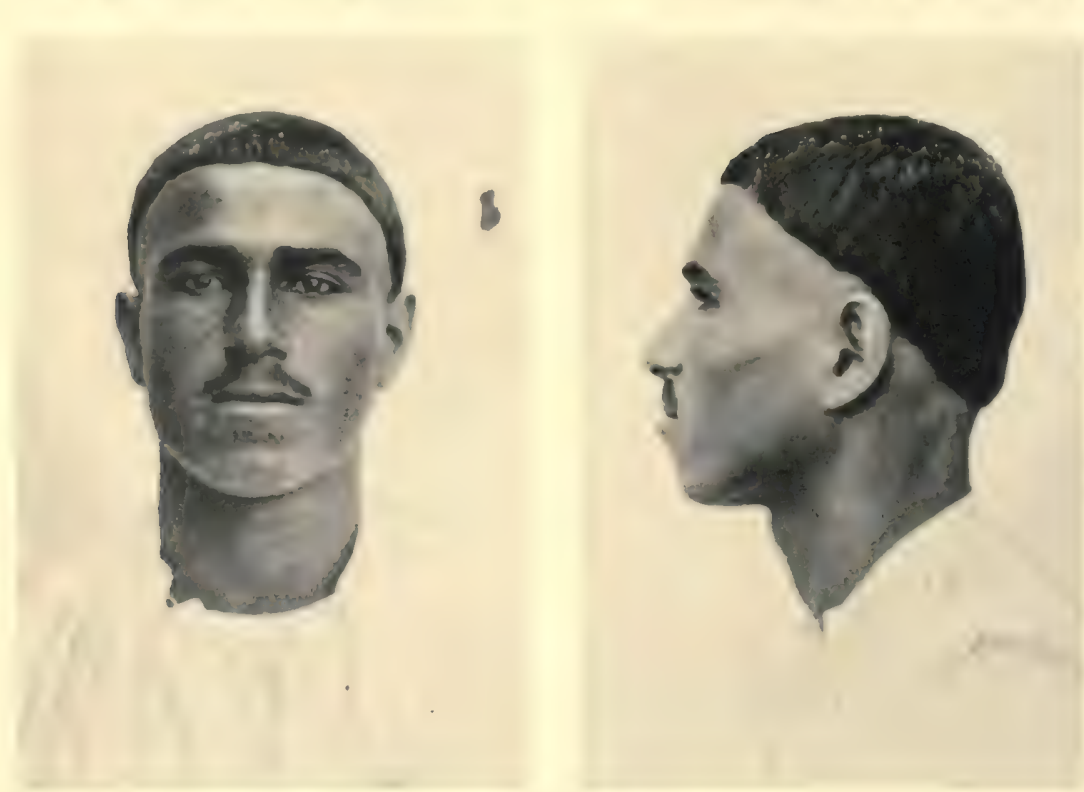

11

No. 963 (age 22)
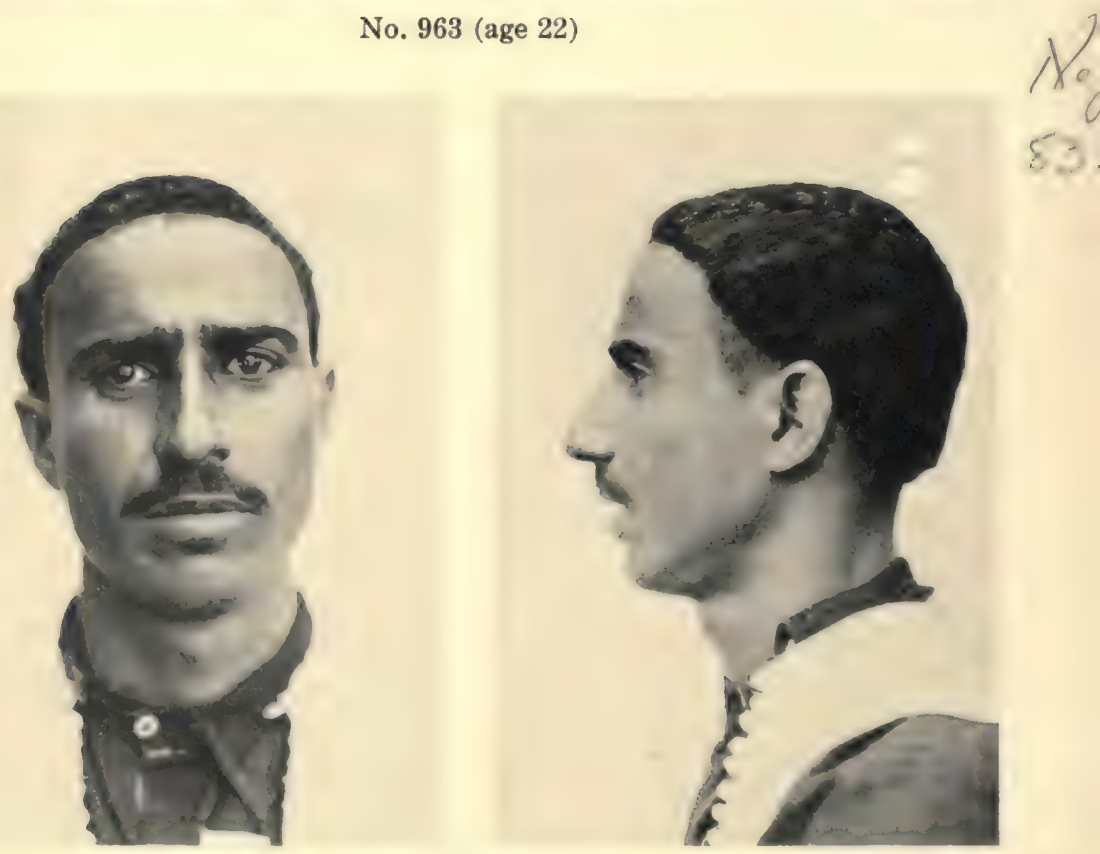

No. 958 (age 25)

AL SAWAAD BRACHYCEPHALS 
86

Field Museum of Natural History

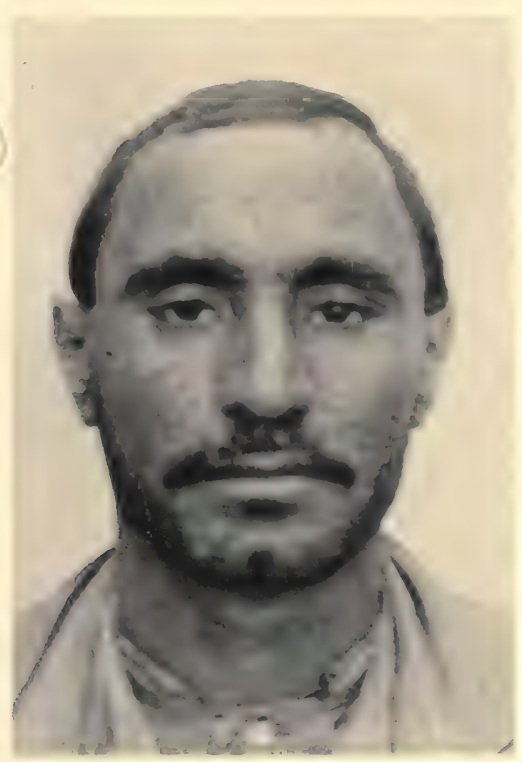

No. 982 (age 30)

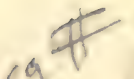

4

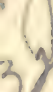

3

\section{$a e^{2}=96$}

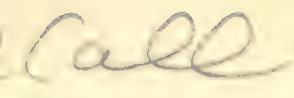

Anthropology, Vol. 30, Plate 163

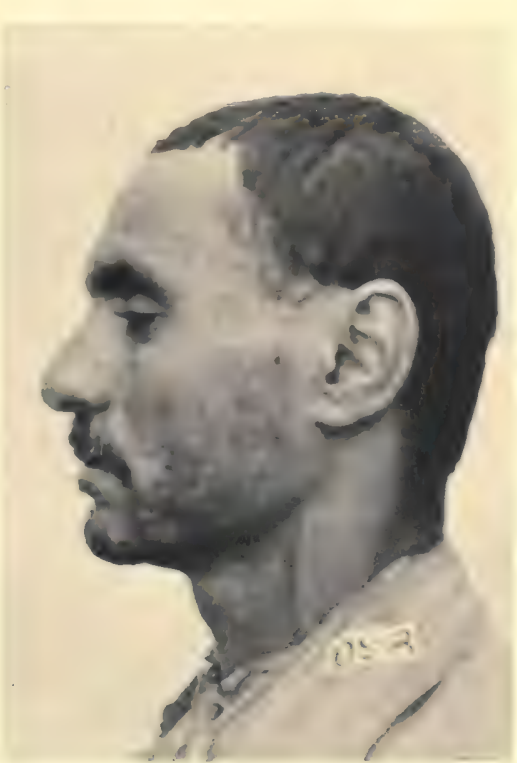

835

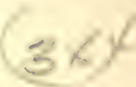

.

Neg.7f

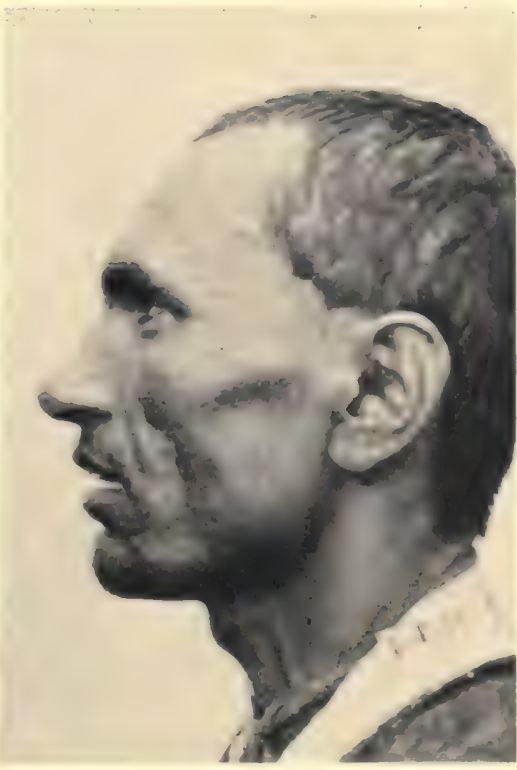

6328

$(5 x y$

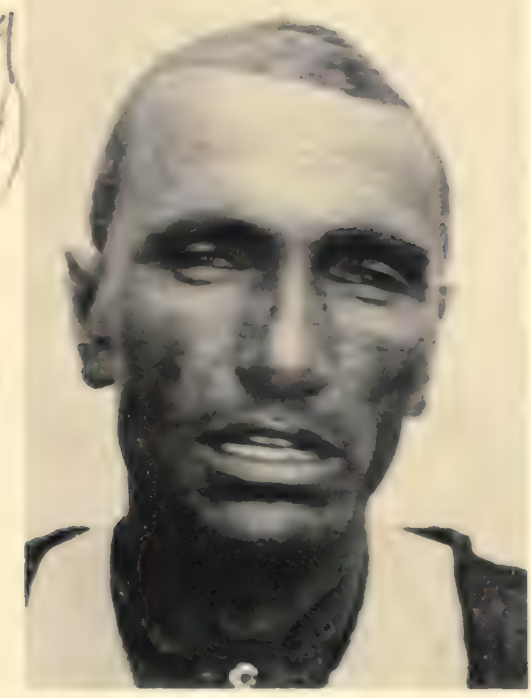

No, 997 (age 35)

AL SAWAAD BRACHYCEPHALS 


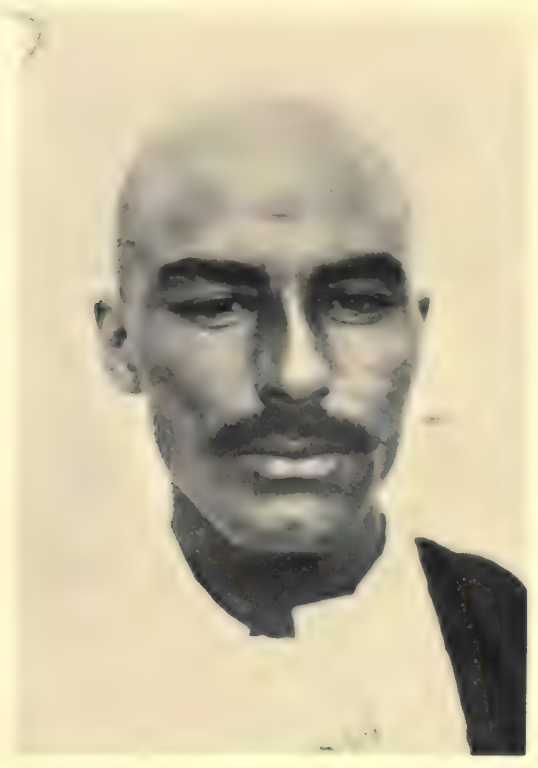

Anthropology, Vol. 30, Plate 165

Nog.
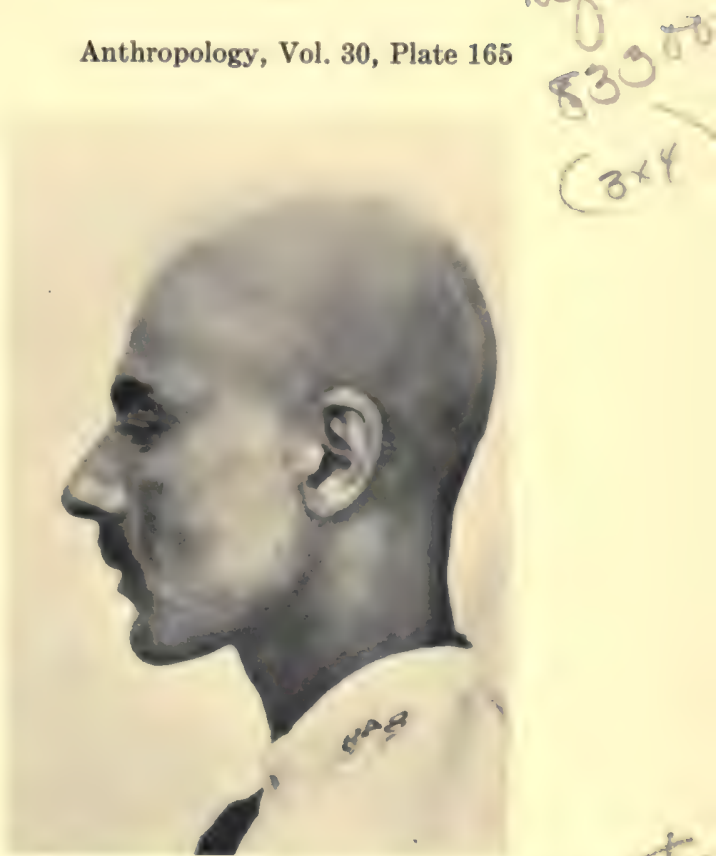

No. 1002 (age 25)
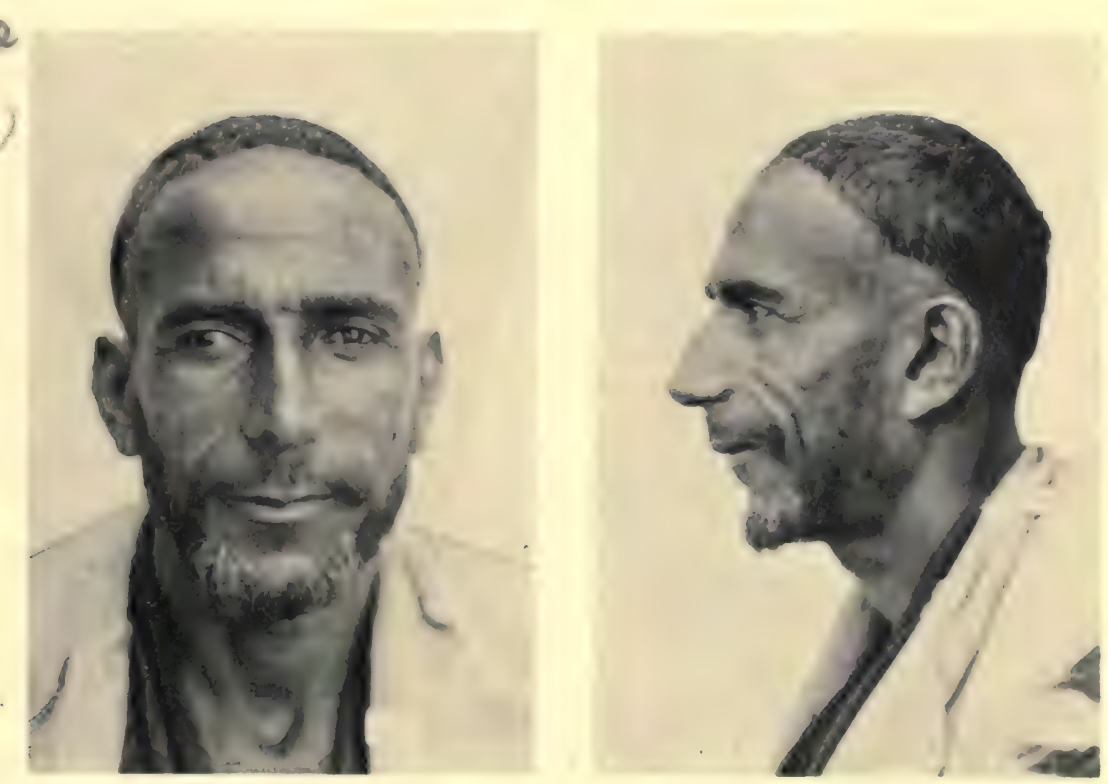

No. 985 (age 45) 


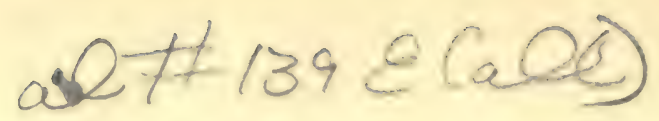

Field Museum of Natural History

Anthropology, Vol. 30, Plate $166 \mathrm{Nec}$

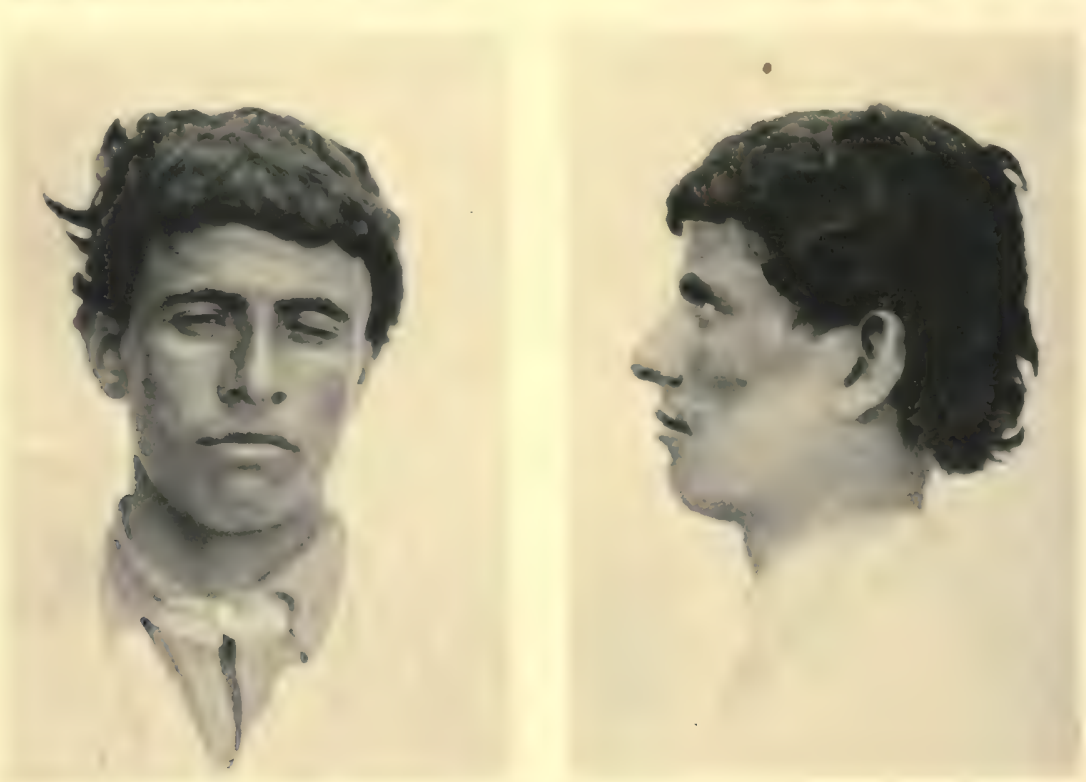

\& 2

3

No. 961 (age 20)
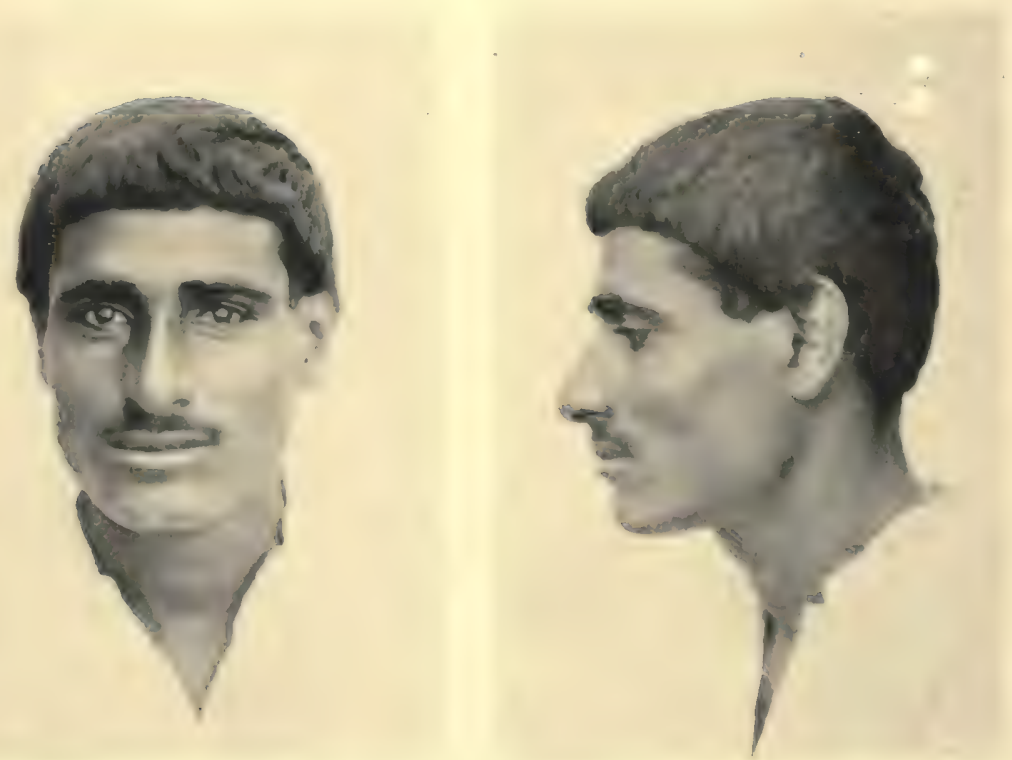

$\mathrm{N}^{2}$

No. 977 (age 25)

AL SAWAAD SUB-BRACHYCEPHALIC ARMENOIDS 


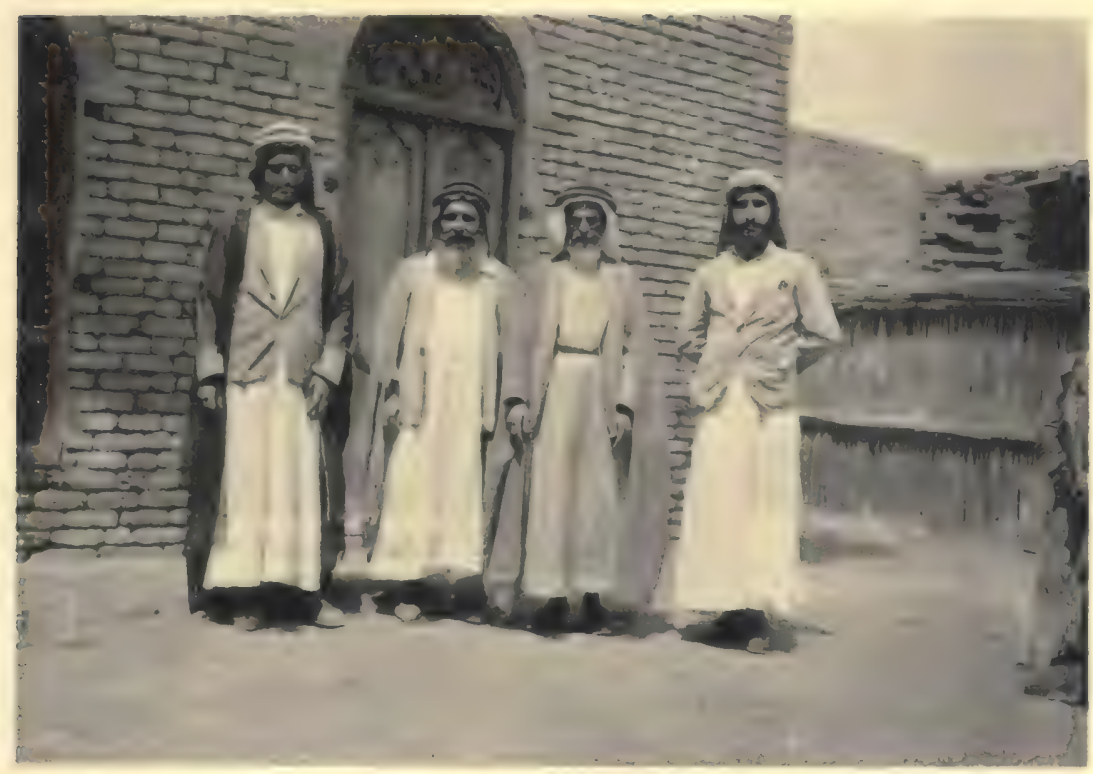

Fig. 1. Subba Sheikhs

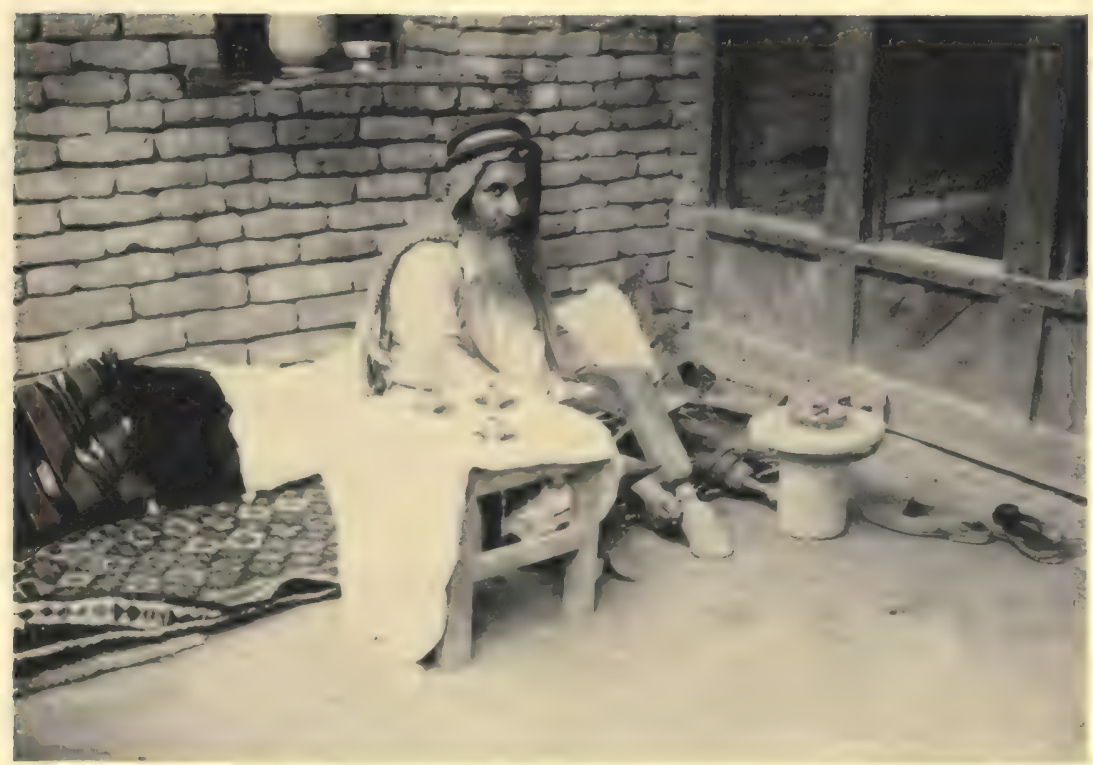

Fig. 2. Subbi smith working on golden coffee set made for King Ghazi's coronation 


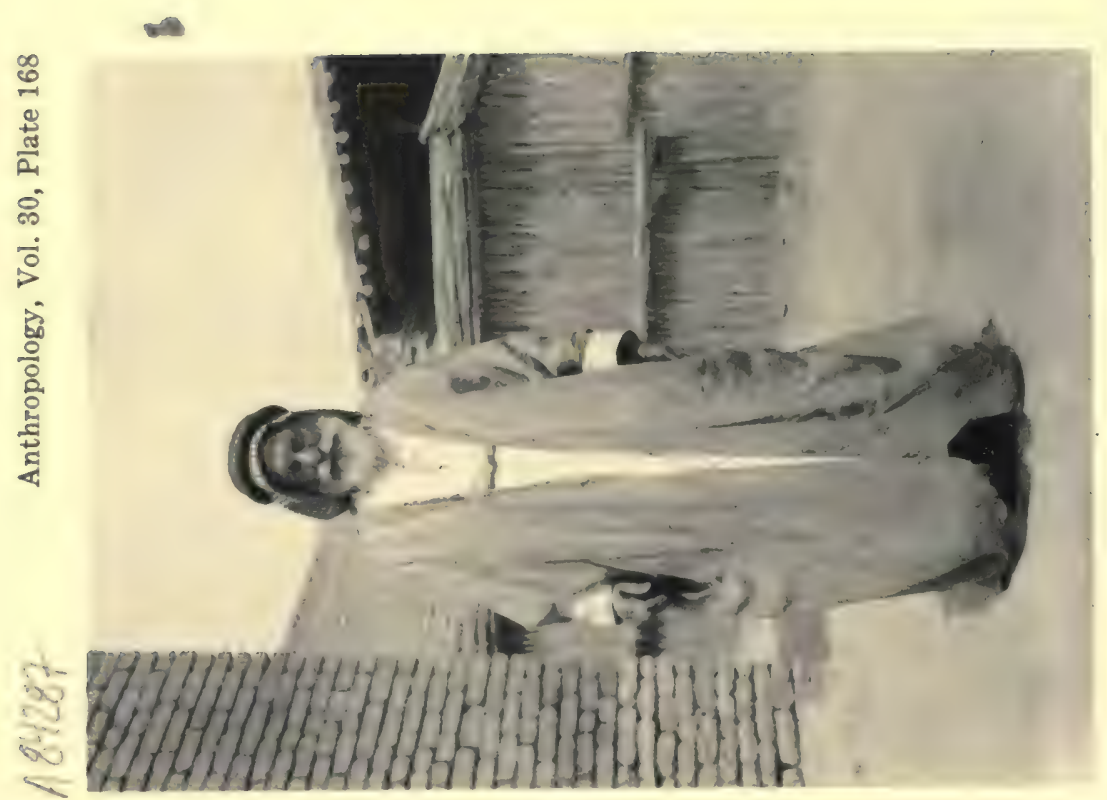

 


\section{$a l \# 1392(a \infty)$}

X. $\left.\right|_{0} ^{N}$ Field Museum of Natural History $1 \int_{3}^{3}$

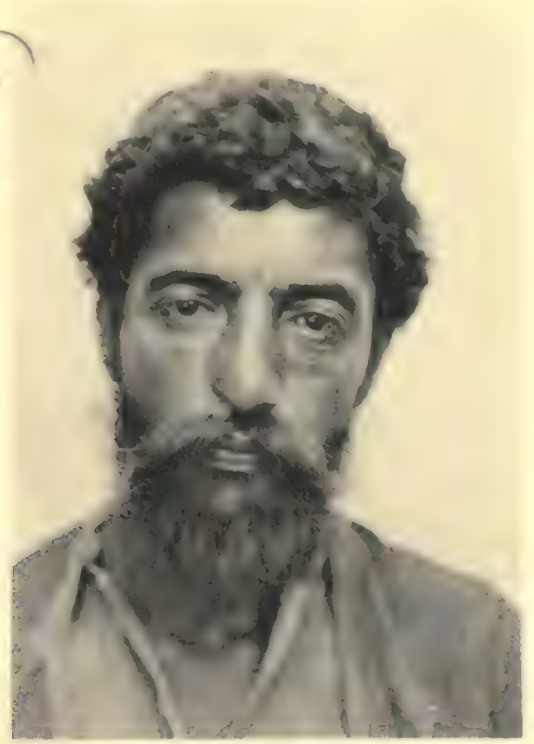

Anthropology, Vol. 30, Plate 170 Ner

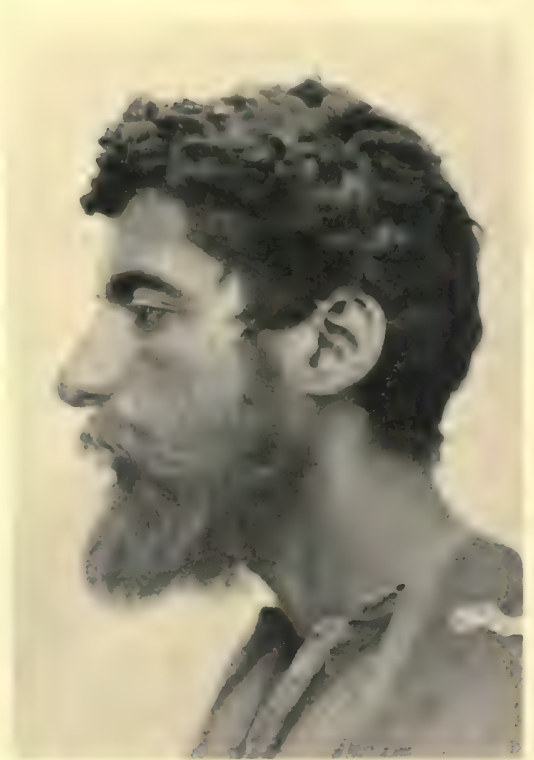

$\hat{\gamma}$

3

No. 2939 (age 30)

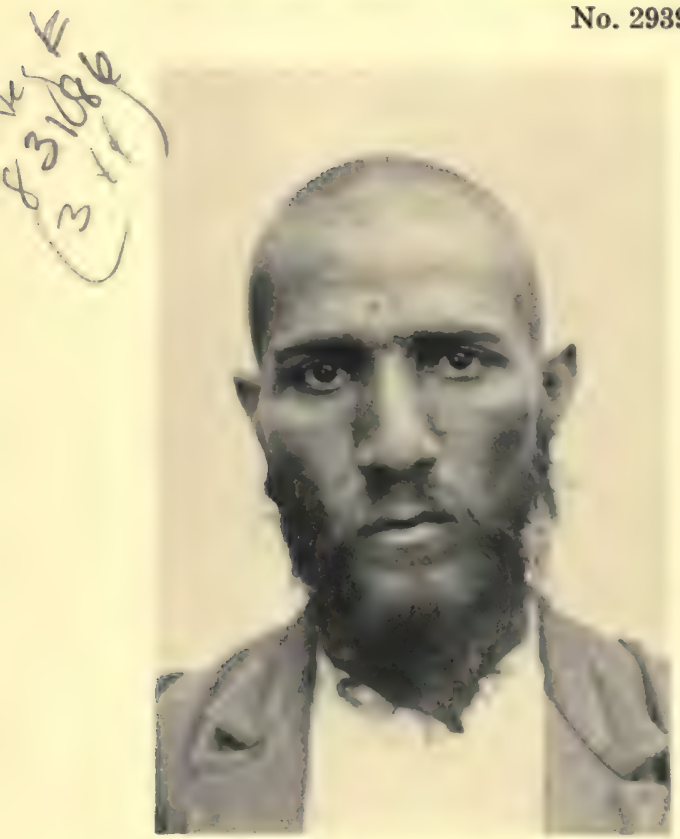

$\$$

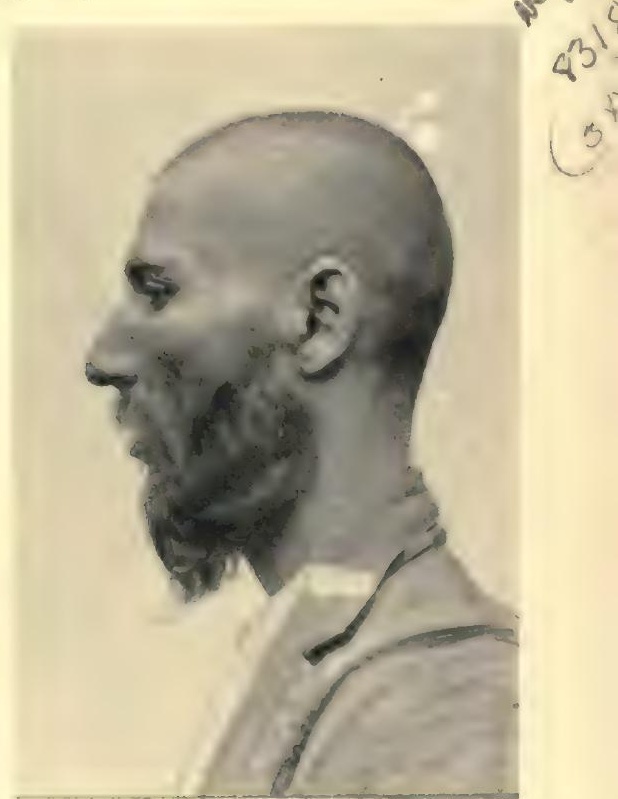

No. 2926 (age 30 )

SUBBA IRANIAN PLATEAU DOLICHOCEPHALS 
Field Museum of Natural History

Anthropology, Vol. 30, Plate 172

125
83
63
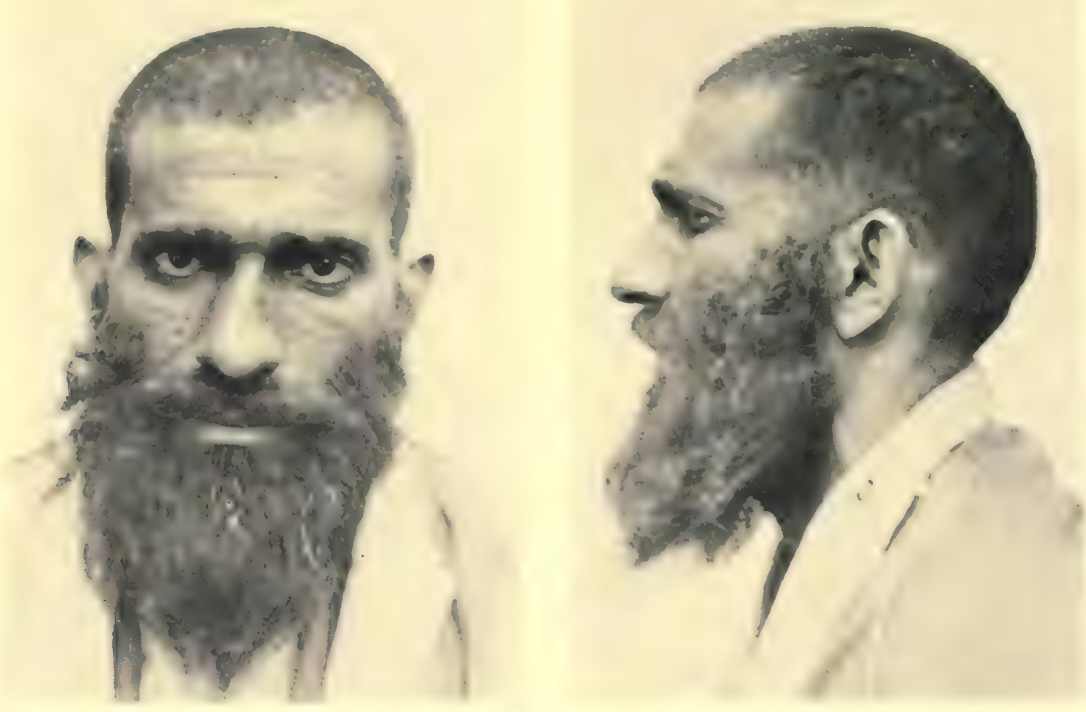

No. 2957 (age 40)

No

83
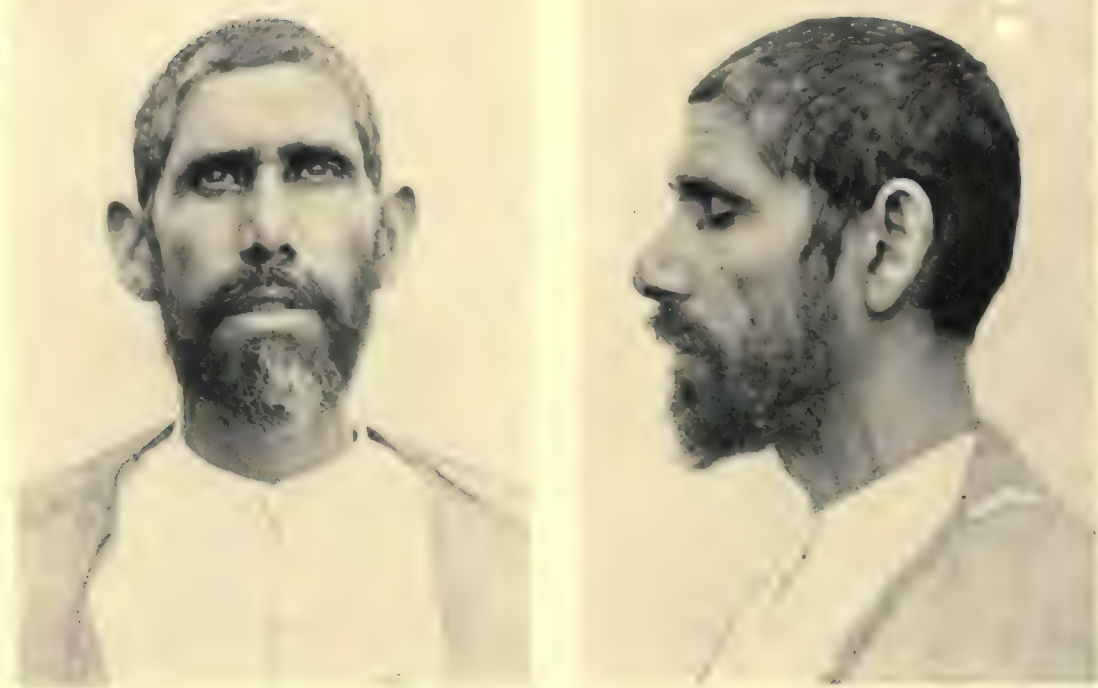

No. 2954 (age 51) 


\section{$a b \neq 139 \varepsilon$}

108 ant

Field Museum of Natural History Co

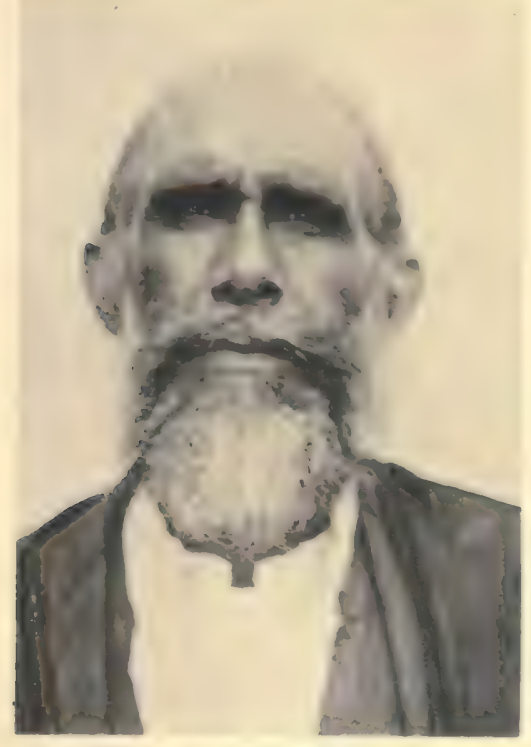

Anthropology, Vol. 30, Plate 173

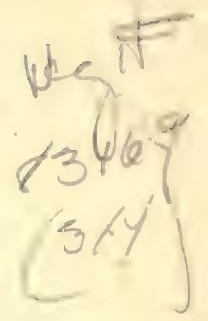

No. 2952 (age 55)
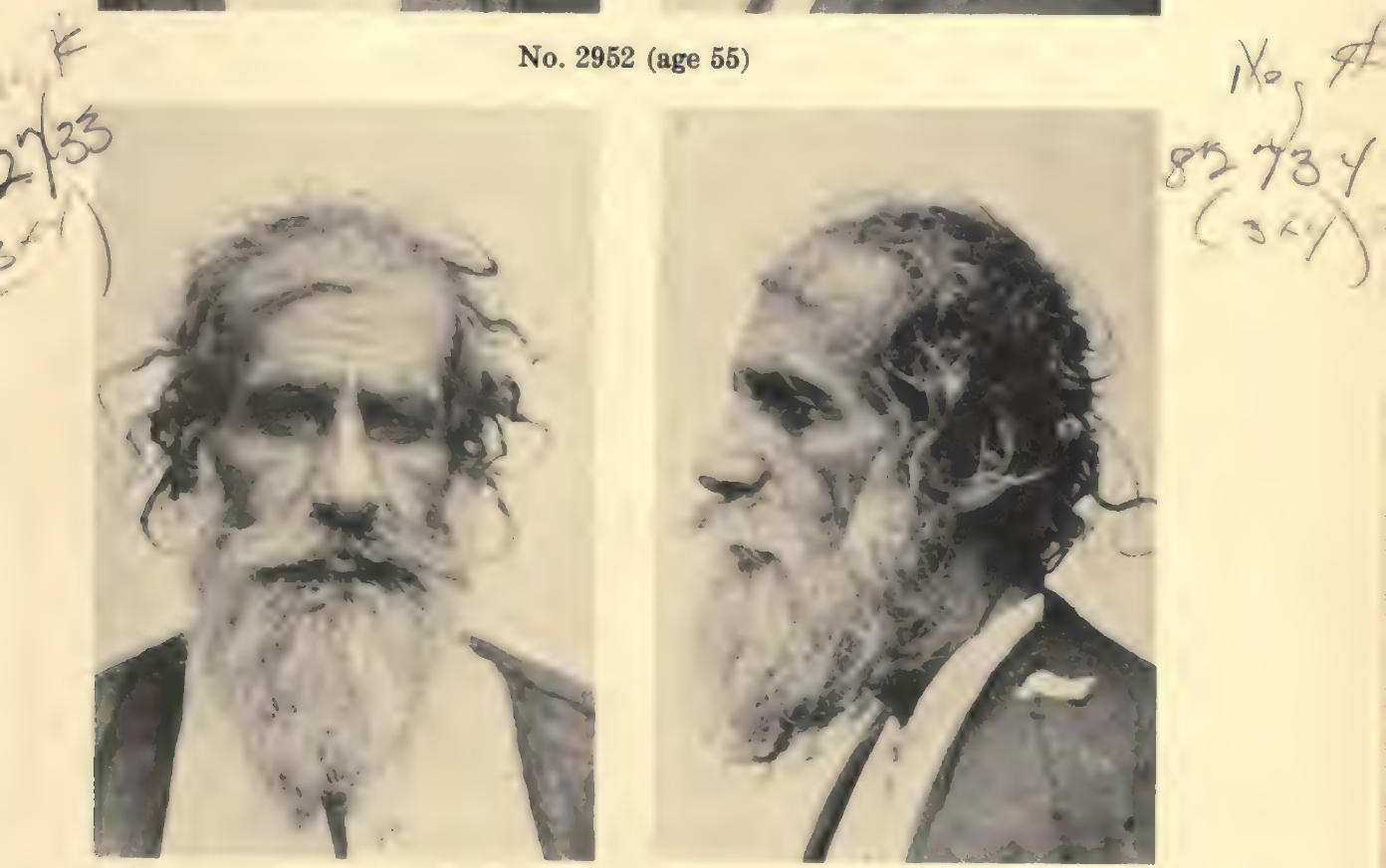

No. 2931 (age 55) 


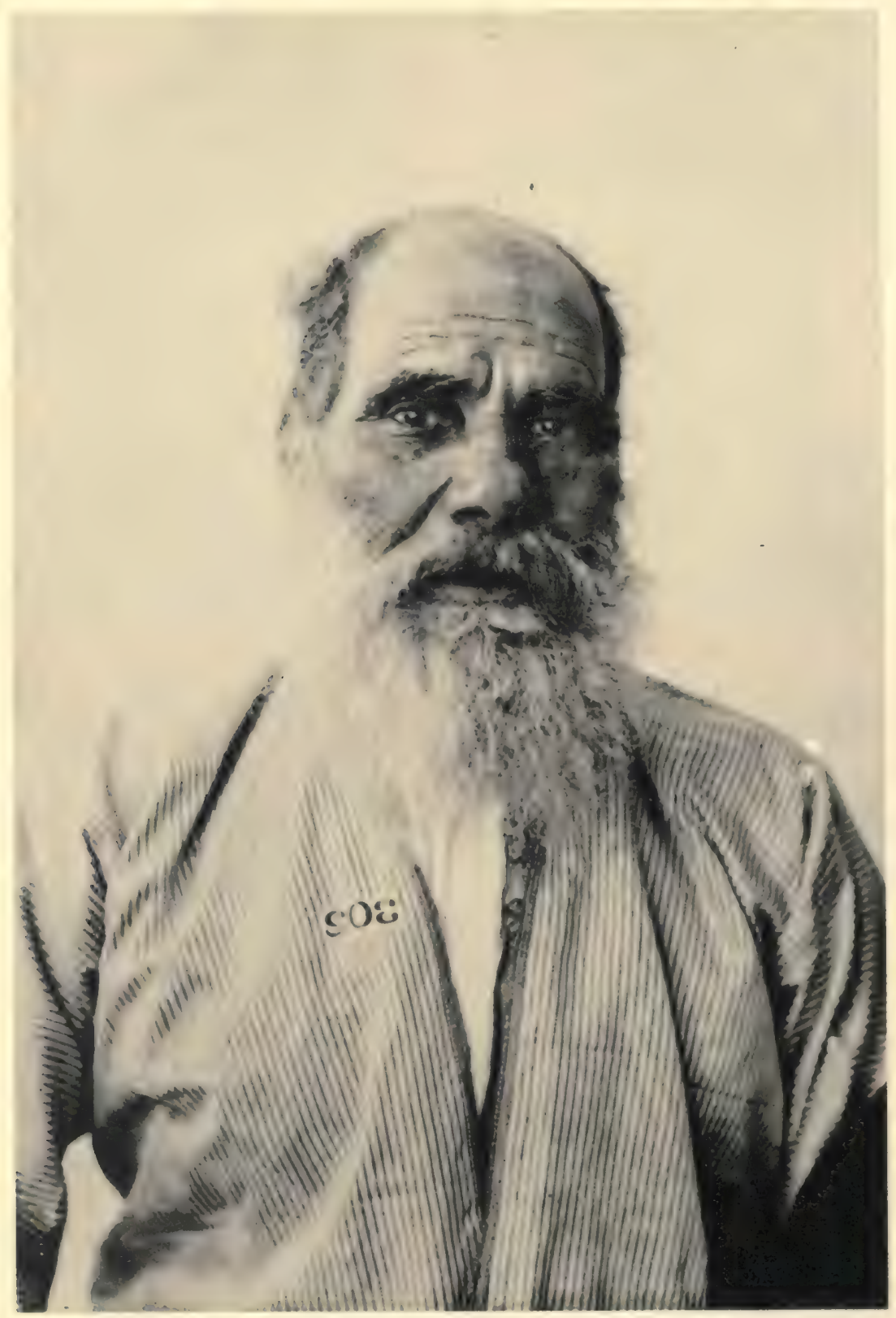

No. 2888 (age 60) 


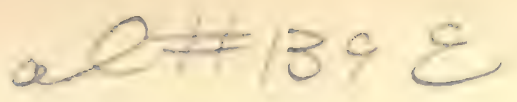

Field Museum of Natural History

Anthropology, Vol. 30, Plate 175

$\operatorname{Neg}_{82}$ \#
385
$36 t$

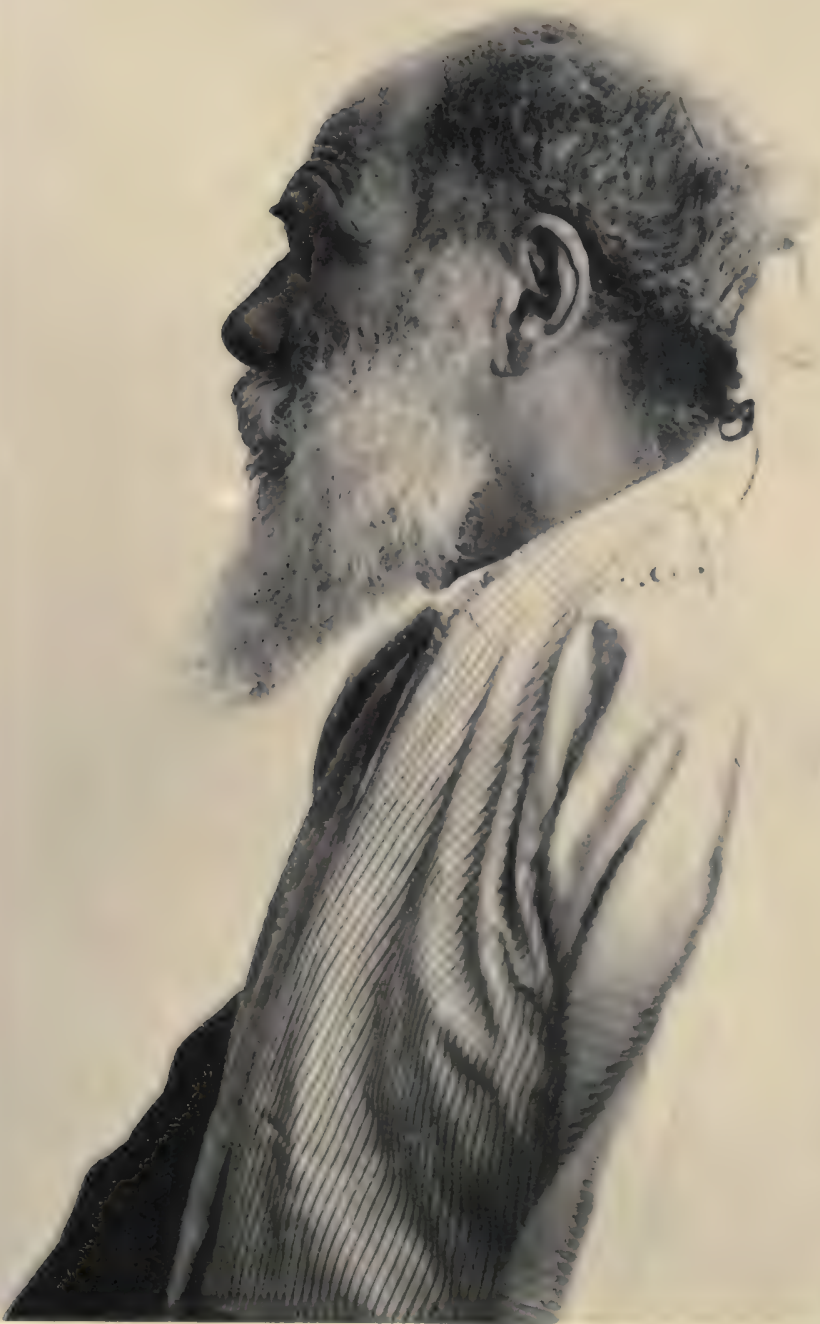

No. 2888 (age 60)

SUBBI AT AMARA 
le Field Museum of Natural History 3 in $3+$
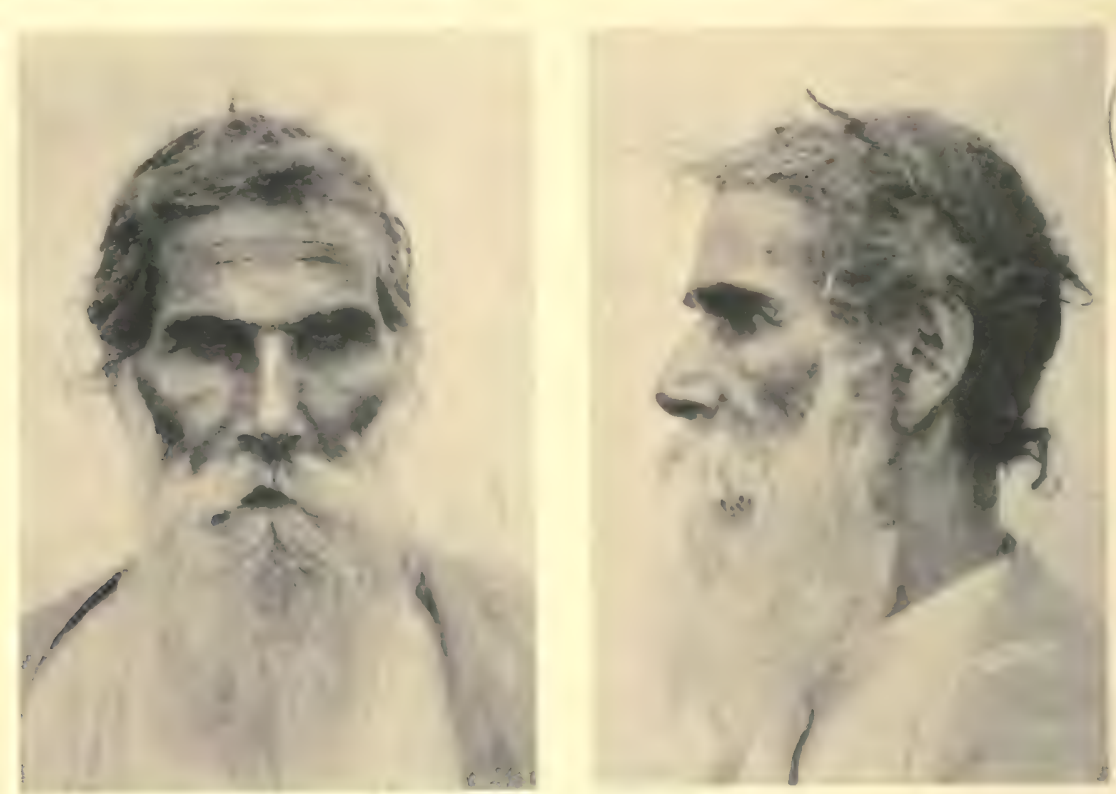

No. 2917 (age 65)

ag
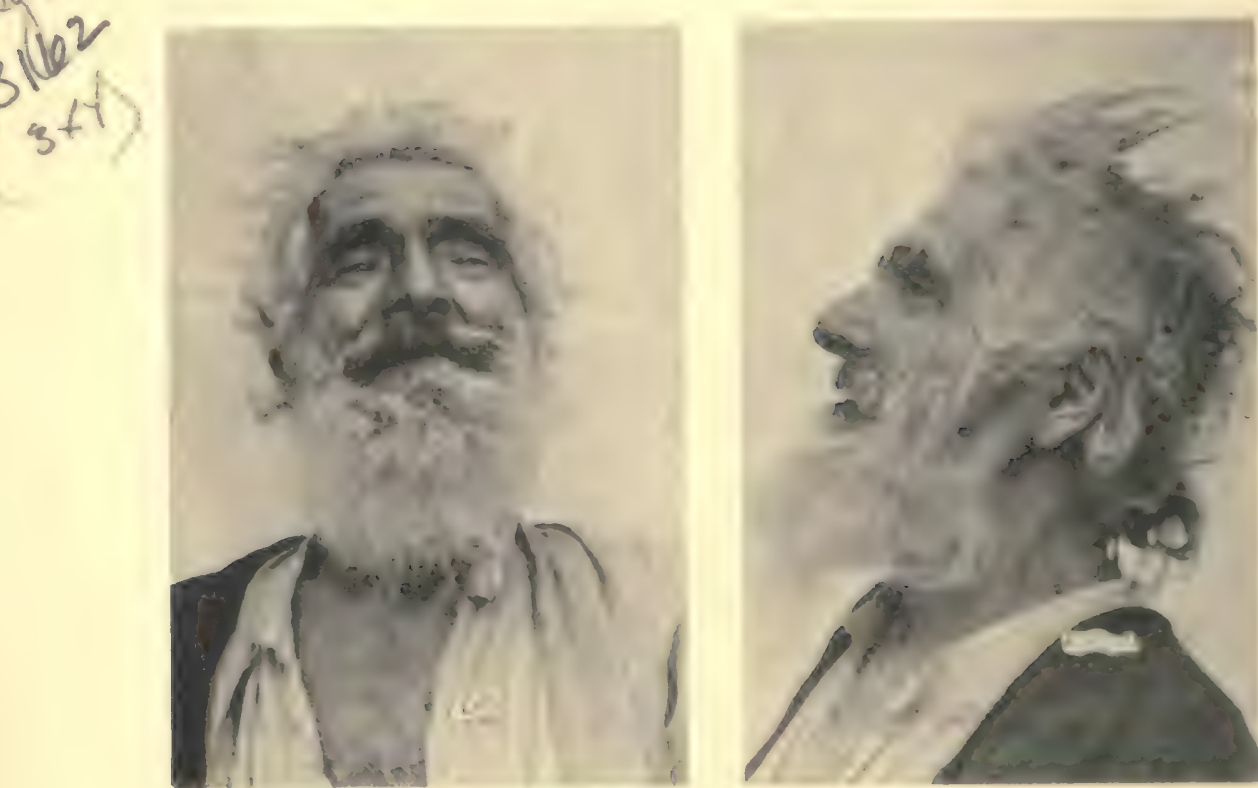

Ne

9

(3)

No. 2948 (age 70)

SUBBA IRANIAN PLATEAU DOLICHOCEPHALS 


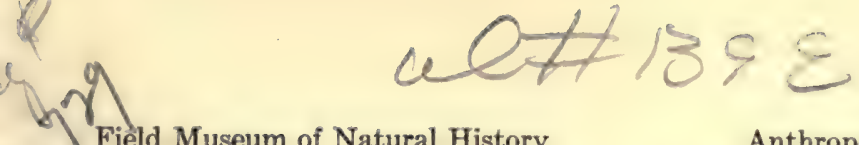
or

Field Museum of Natural History

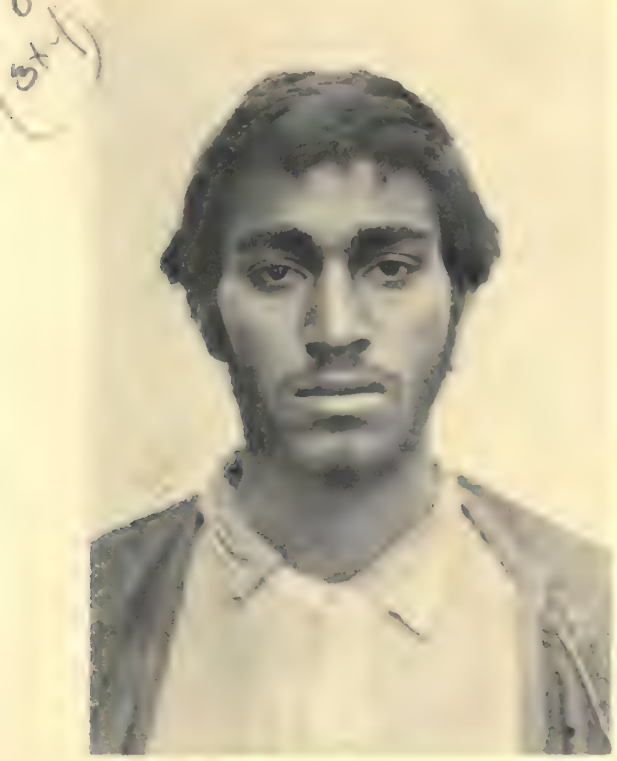

No. 2929 (age 22)

K

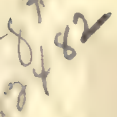

$+$
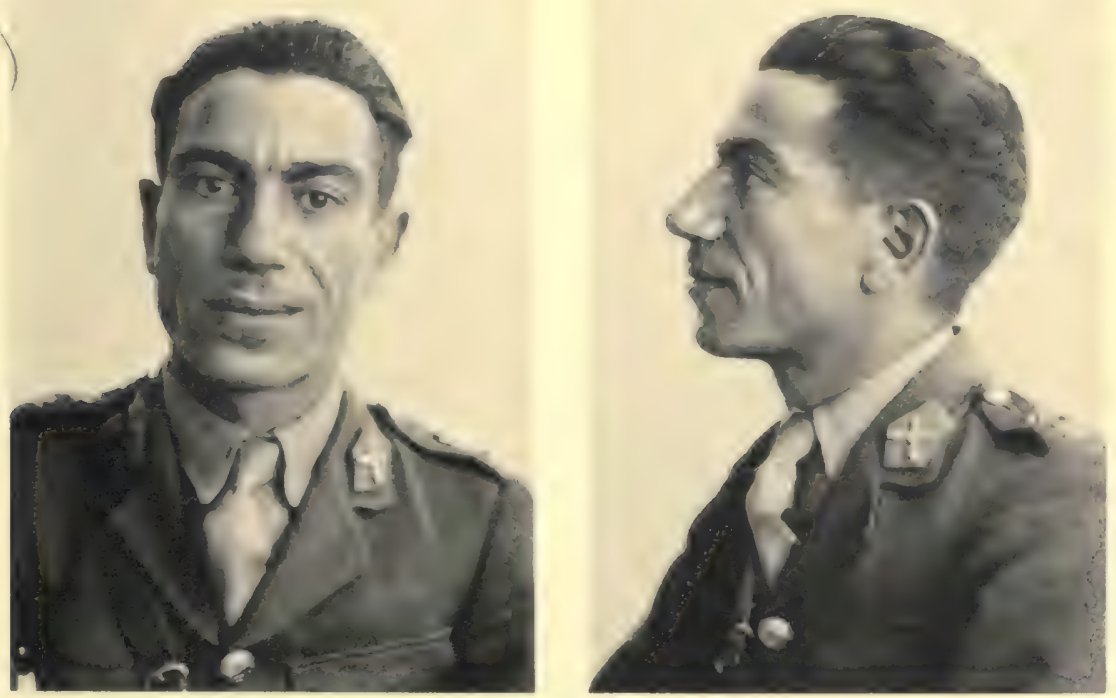

No. 2967 (age 23)
Anthropology, Vol. 30, Plate 177
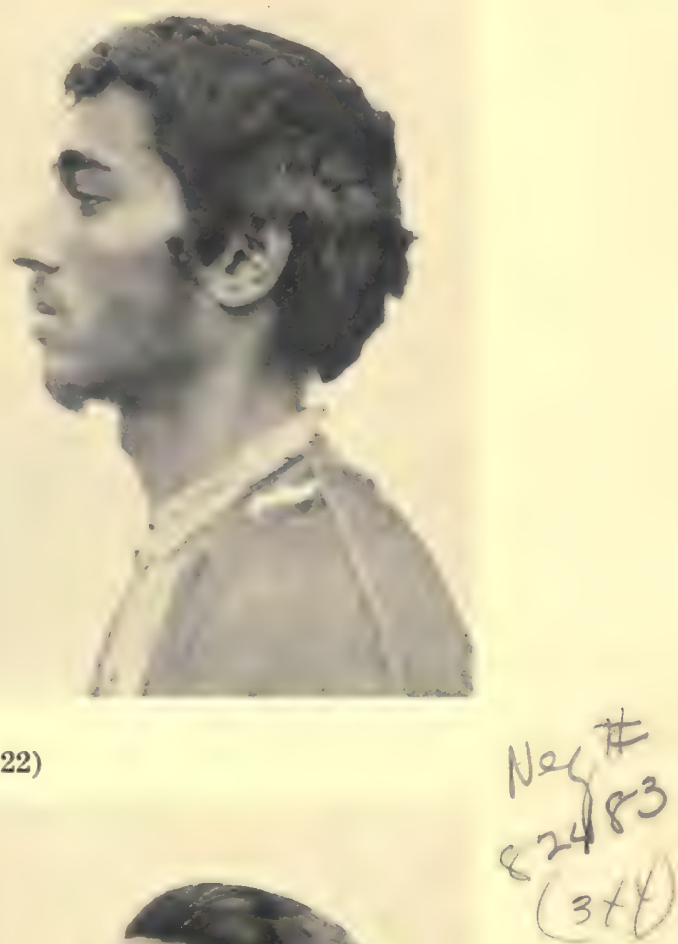
Field Museum of Natural History $\infty$ $7+1$ $b^{4}$

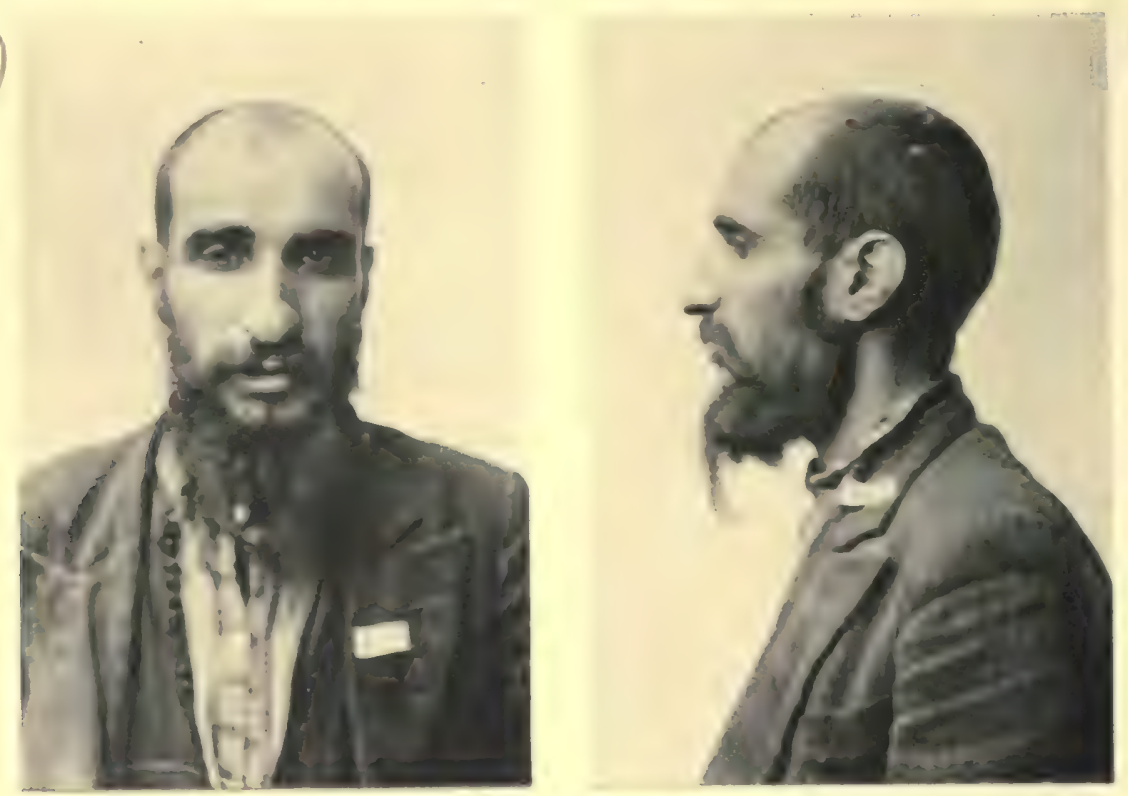

Anthropology, Vol. 30, Plate $178 \mathrm{NC}$

No. 2909 (age 34)
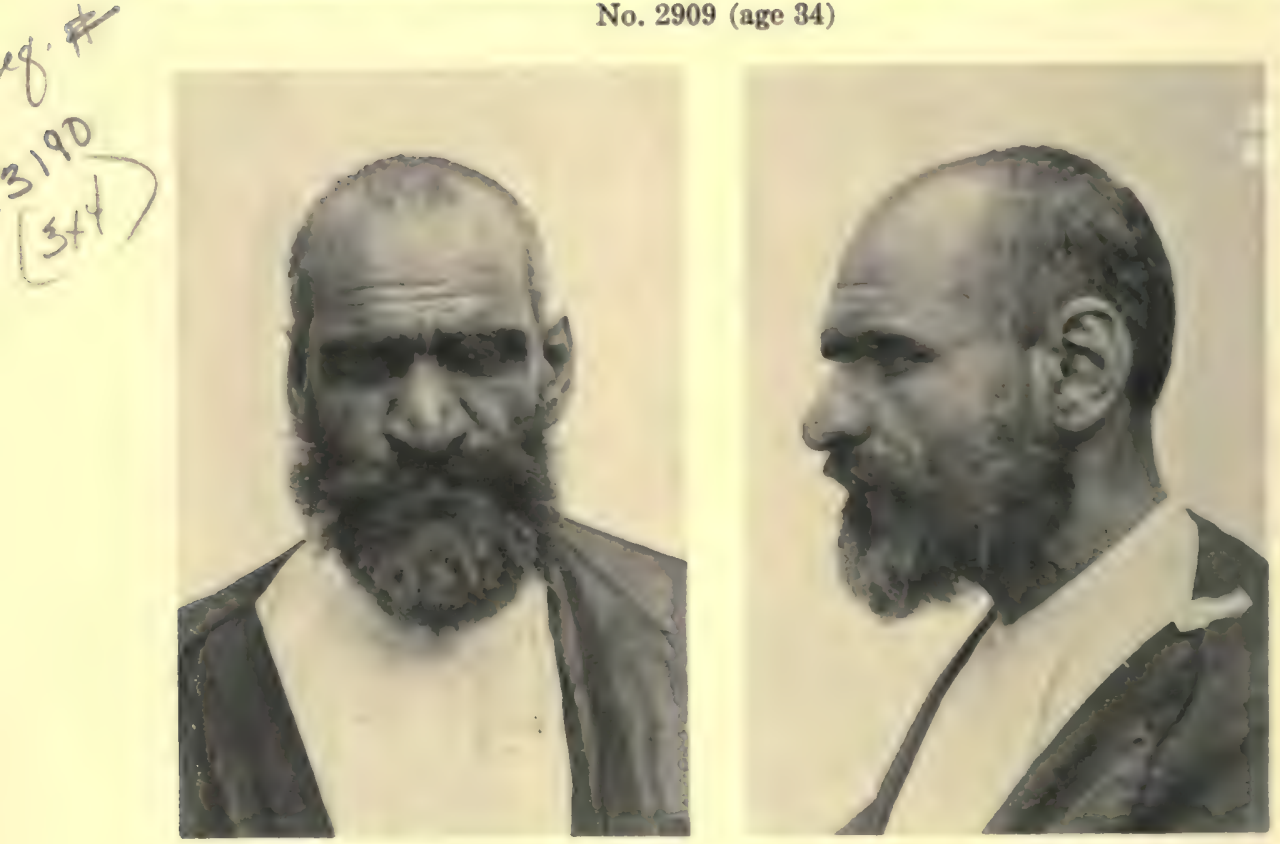

N

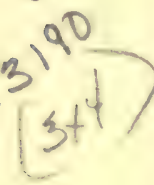

No. 2960 (age 45)

SUBBA IRANIAN PLATEAU LOW MESOCEPHALS 
Gele

Field Museum of Natural History

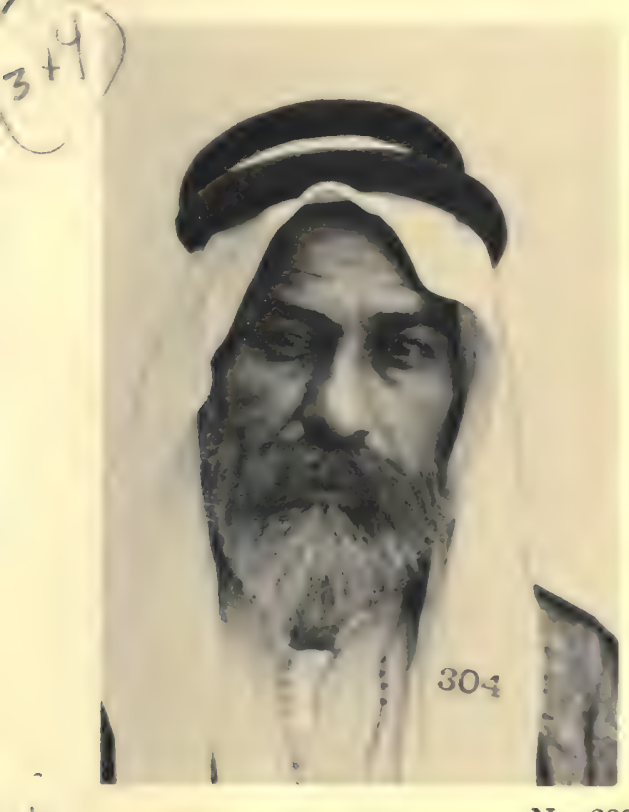

Anthropology, Vol. 30, Plate 179

8

No. 2890 (age 47)

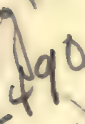

u

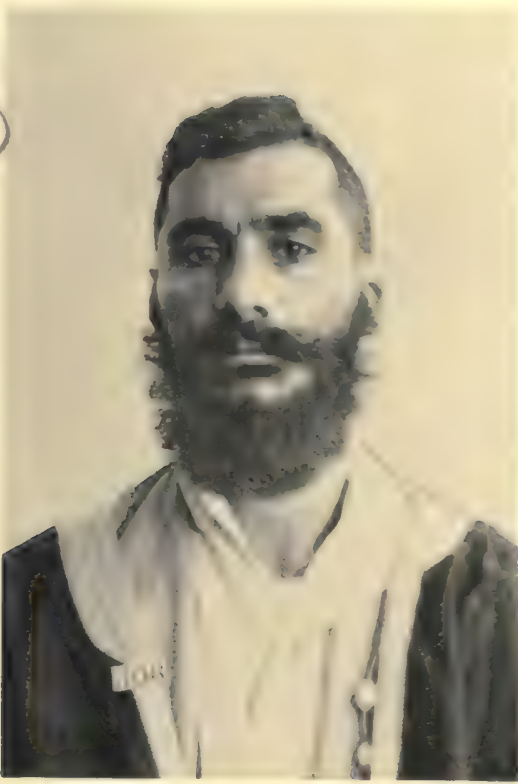

No. 2891 (age 34)

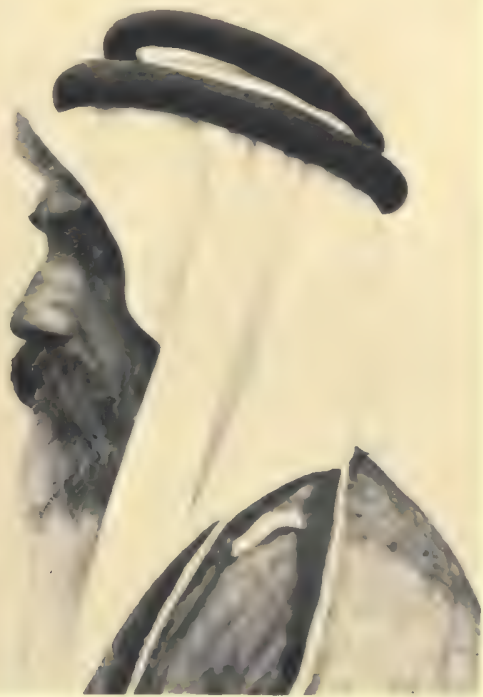

Neq $8+91$ $3+4$ 


\section{$a l \# 139 \varepsilon$}

Field Museum of Natural History

Anthropology, Vol. 30, Plate 180

$\gamma$
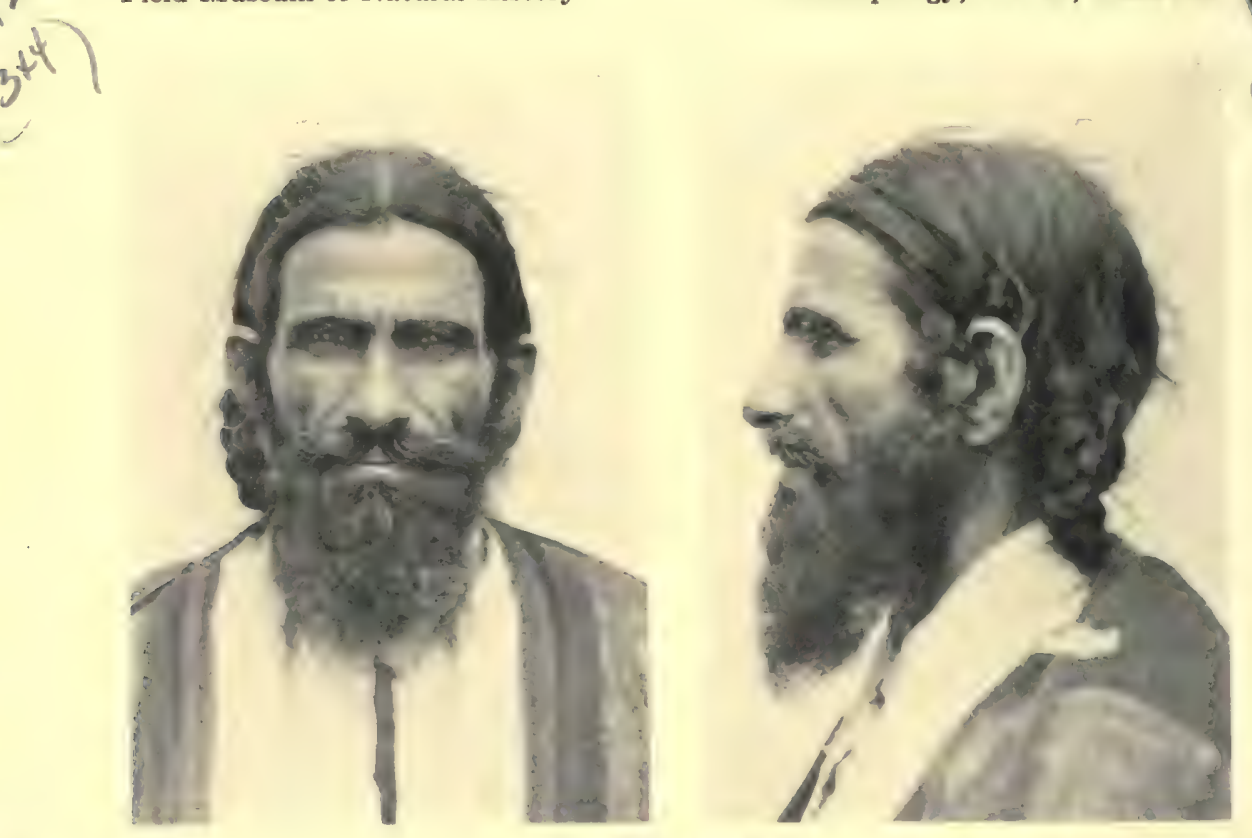

No. 2961 (age 54)
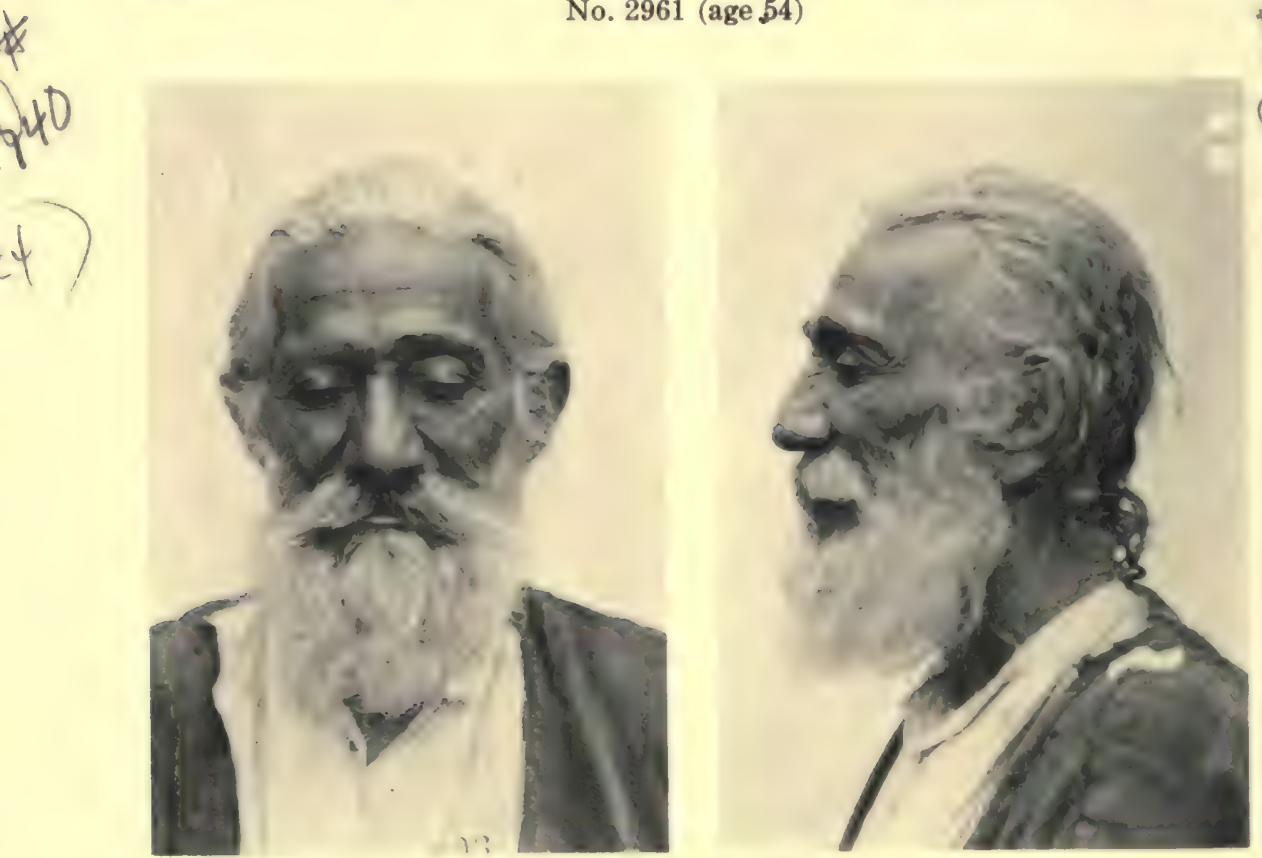

No. 2922 (age 60)

SUBBA IRANIAN PLATEAU LOW MESOCEPHALS 

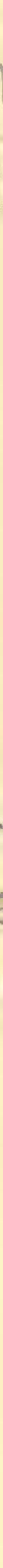

No. 2955 (age 20) 


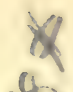

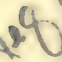

N Field Museum of Natural History $a^{5}$
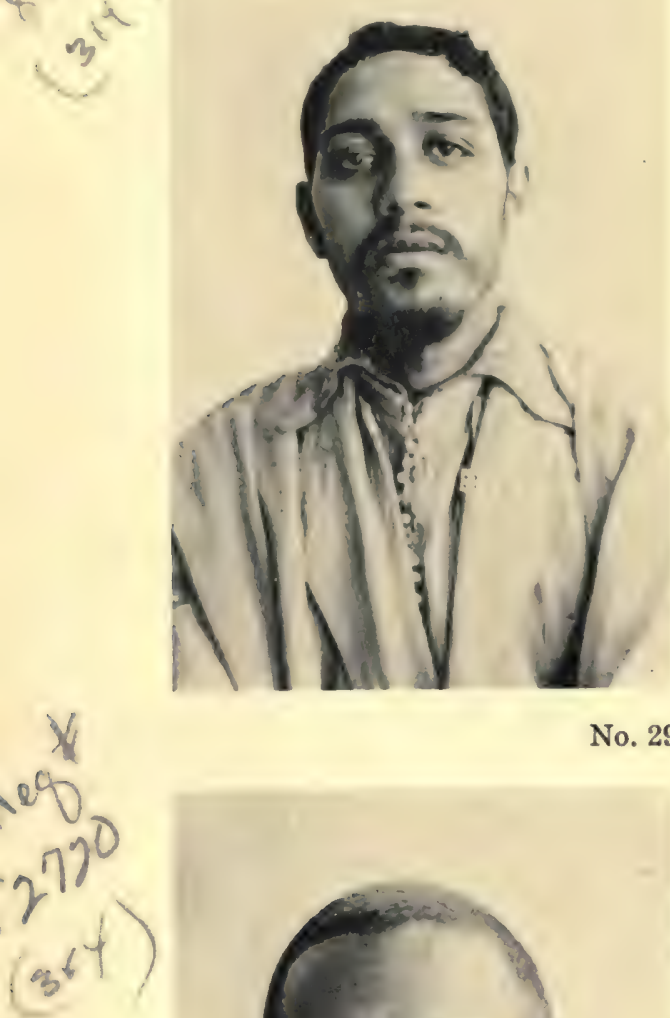

No. 2965 (age 24)

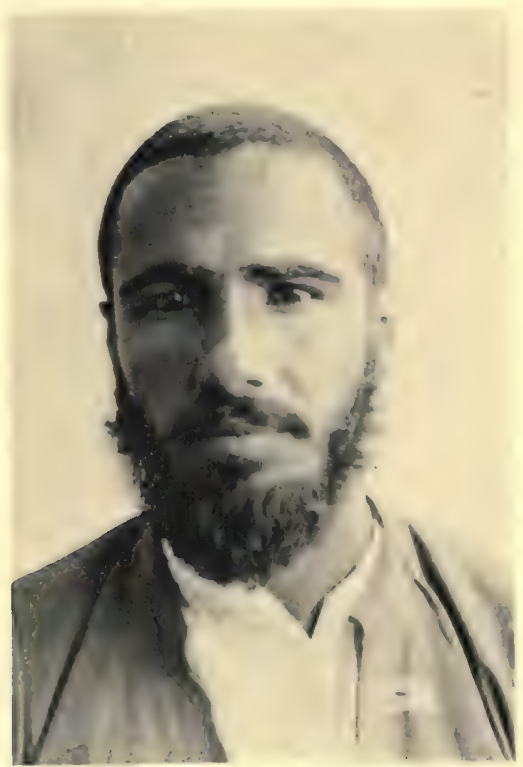

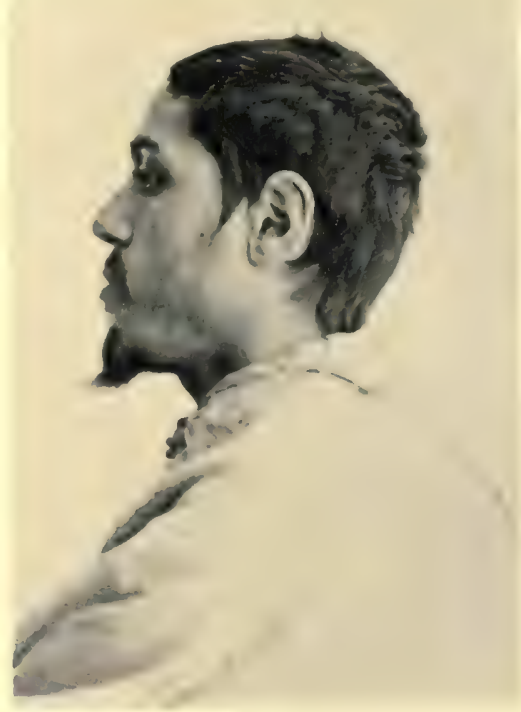

Anthropology, Vol. 30, Plate 182

Ne

$q^{n}$<smiles>[CH]1CCC1</smiles>

$\mathrm{NeS}$

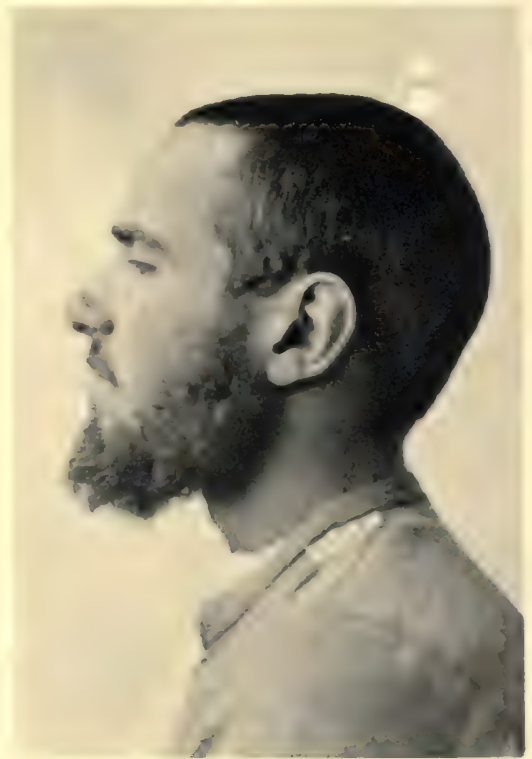

8)

No. 2963 (age 25)

SUBBA IRANIAN PLATEAU HIGH MESOCEPHALS 

Field Museum of Natural History $8^{2}$ $\left(b^{4}\right)$

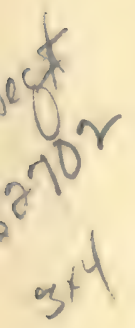

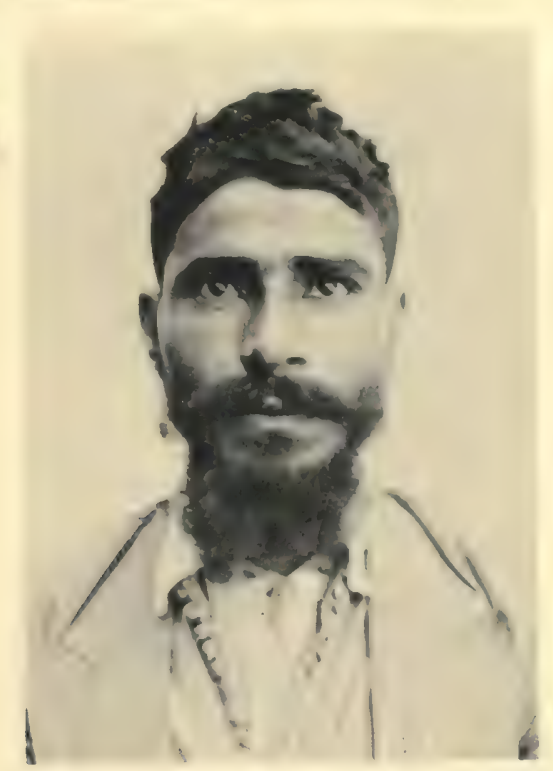

Anthropology, Vol. 30, Plate 184 fes

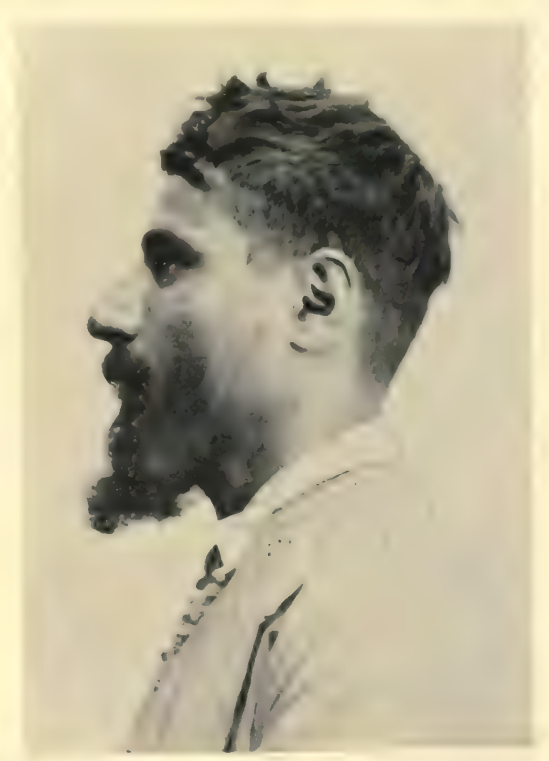

No. 2969 (age 29)

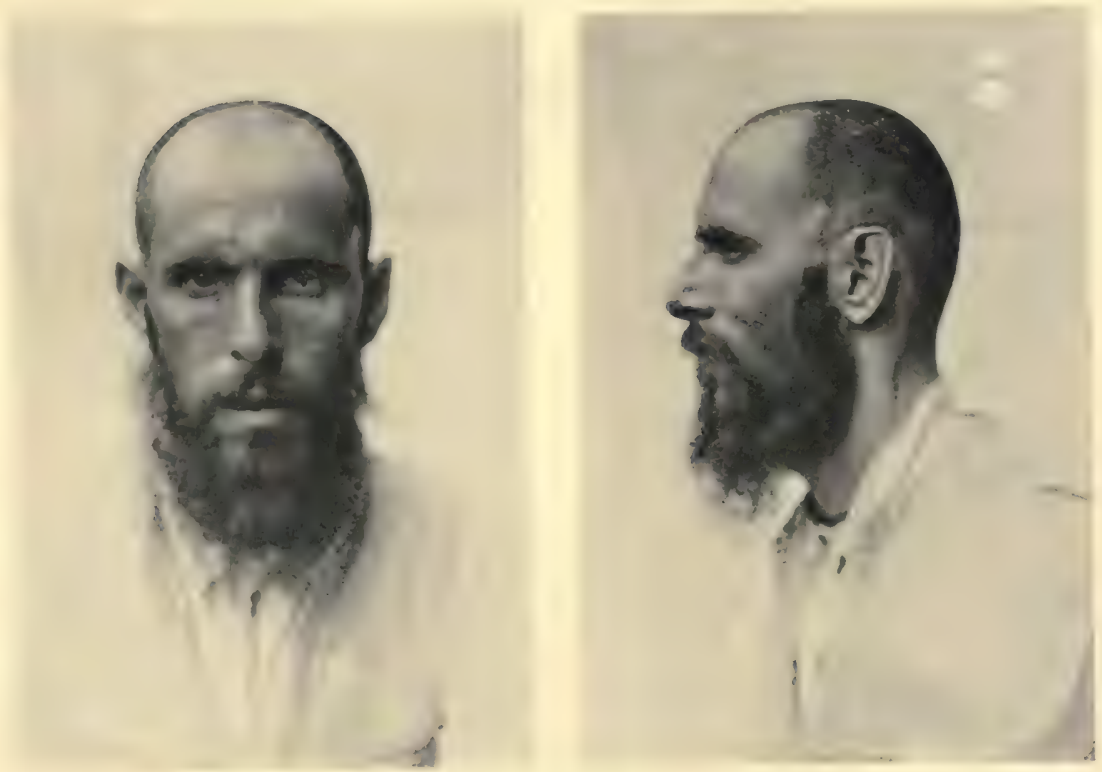

W

$\mathbb{Q}^{2}$

No. 2910 (age 30)

SUBBA IRANIAN PLATEAU HIGH MESOCEPHALS 


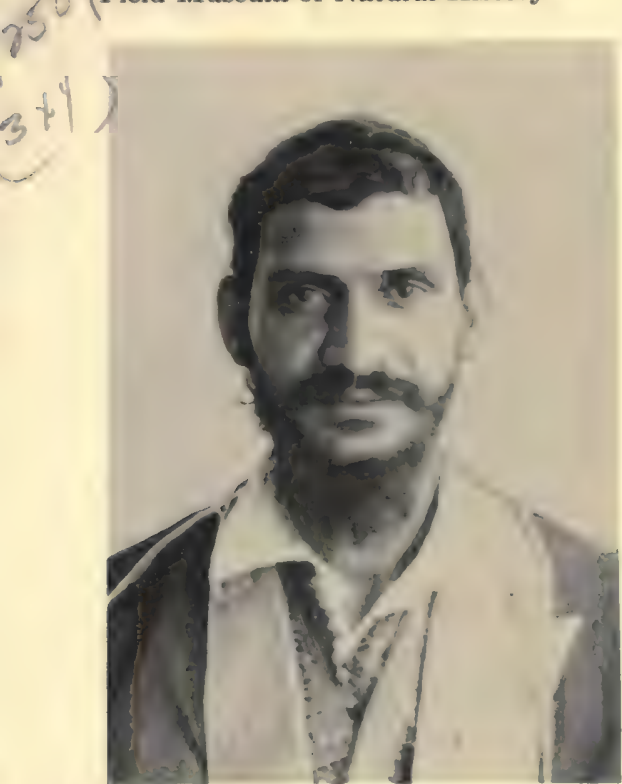

attis?8 


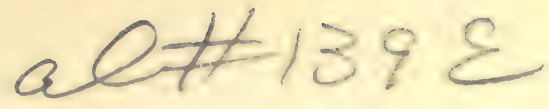

Field Museum of Natural History

Anthropology, Vol. 30, Plate 187
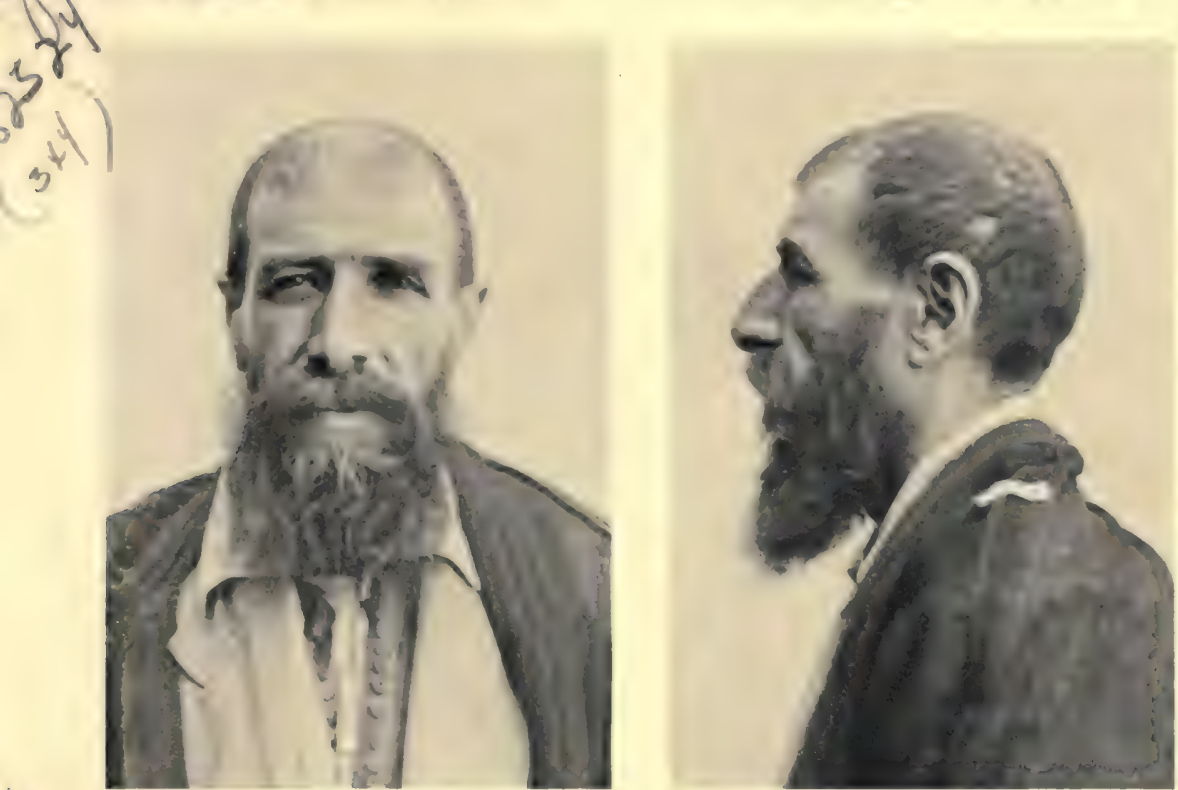

No. 2973 (age 54)
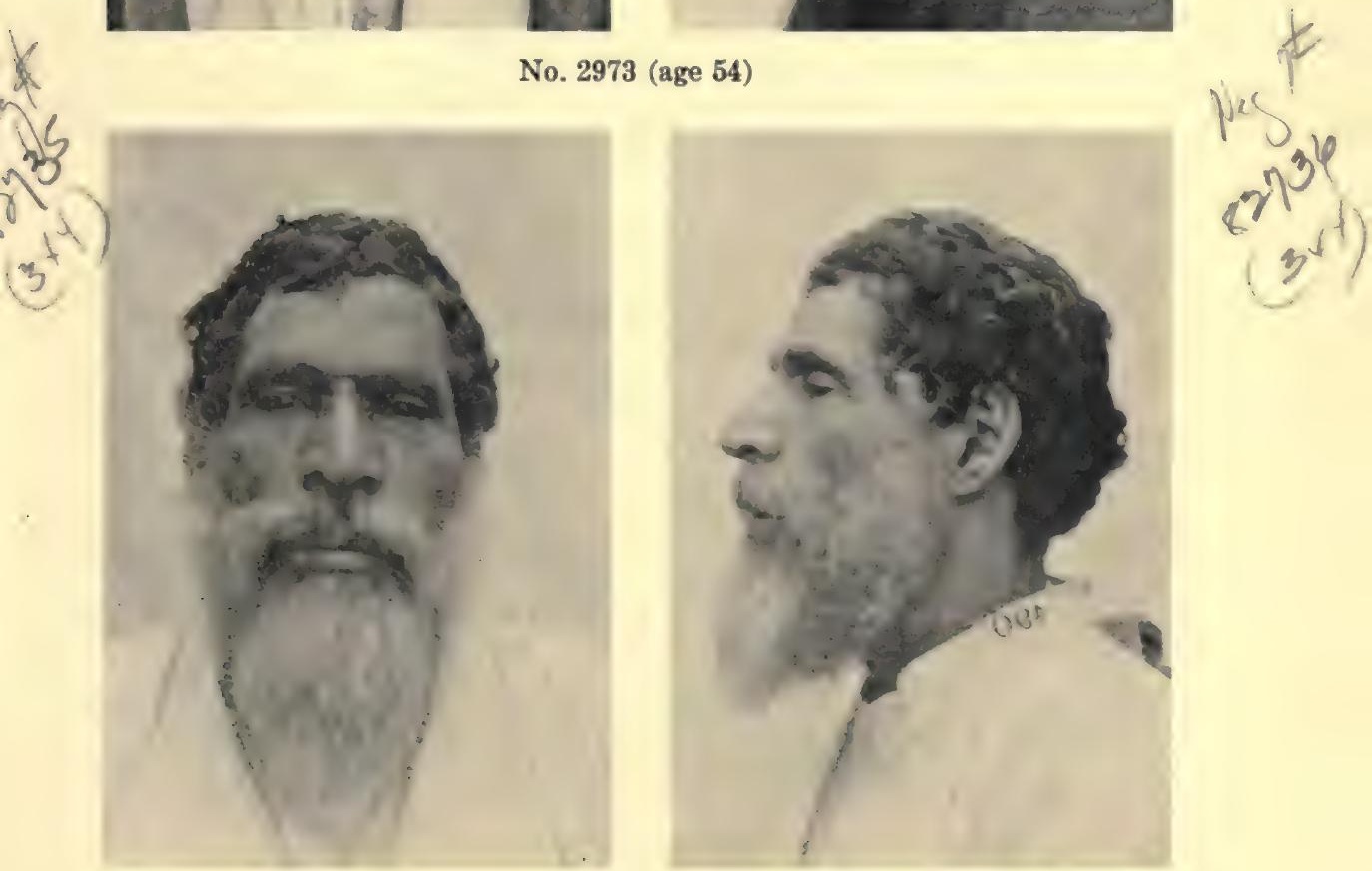

No. 2921 (age 56)

SUBBA IRANIAN PLATEAU HIGH MESOCEPHALS 


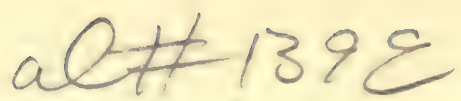

Field Museum of Natural History

Anthropology, Vol. 30, Plate 188

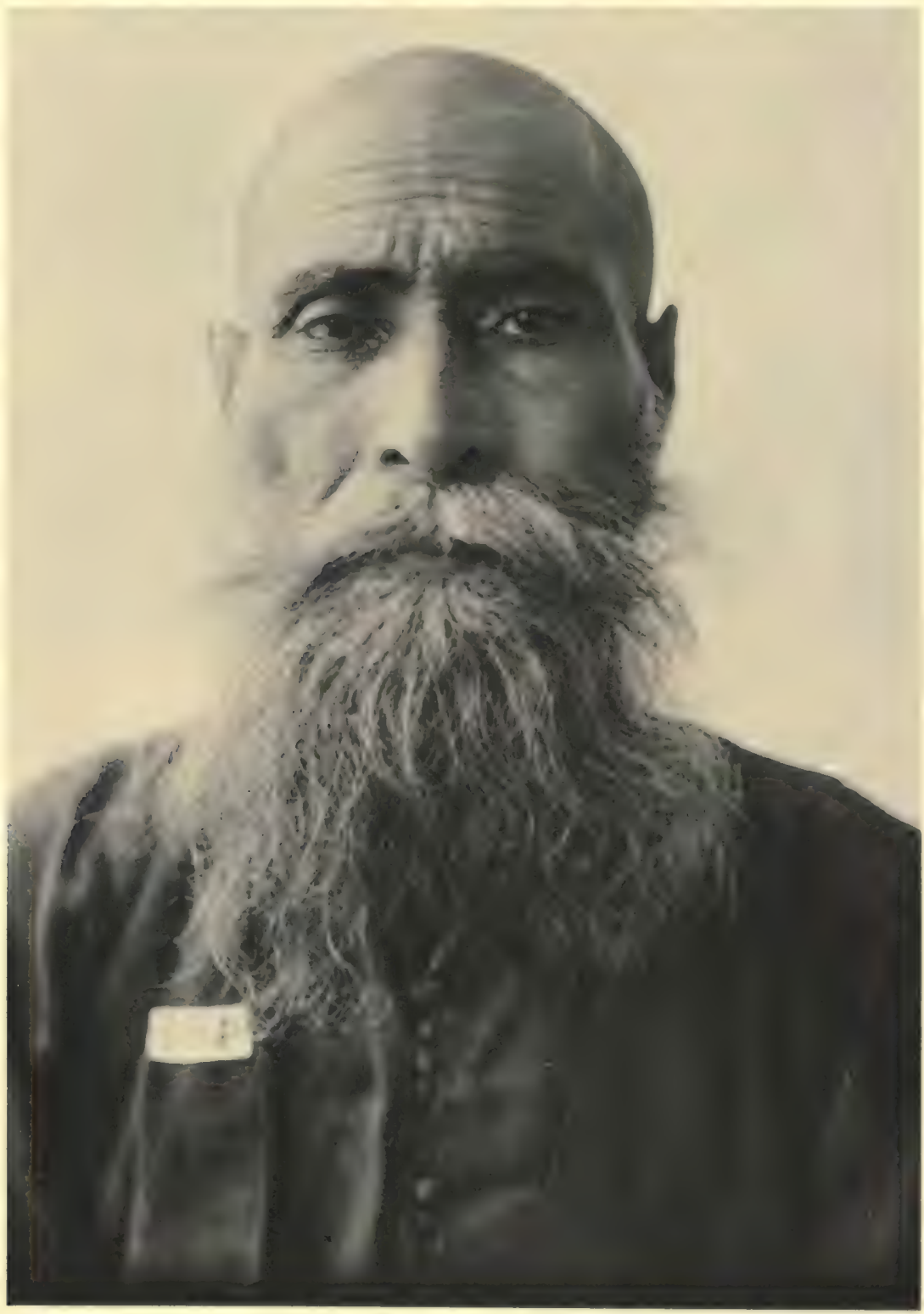

No. 2920 (age 50)

SUBBI IRANIAN PLATEAU HIGH MESOCEPHAL 


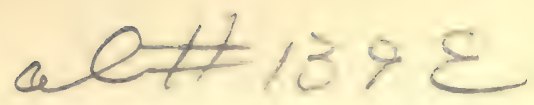

Field Museum of Natural History

Anthropology, Vol. 30, Plate 189

Neglf
82719

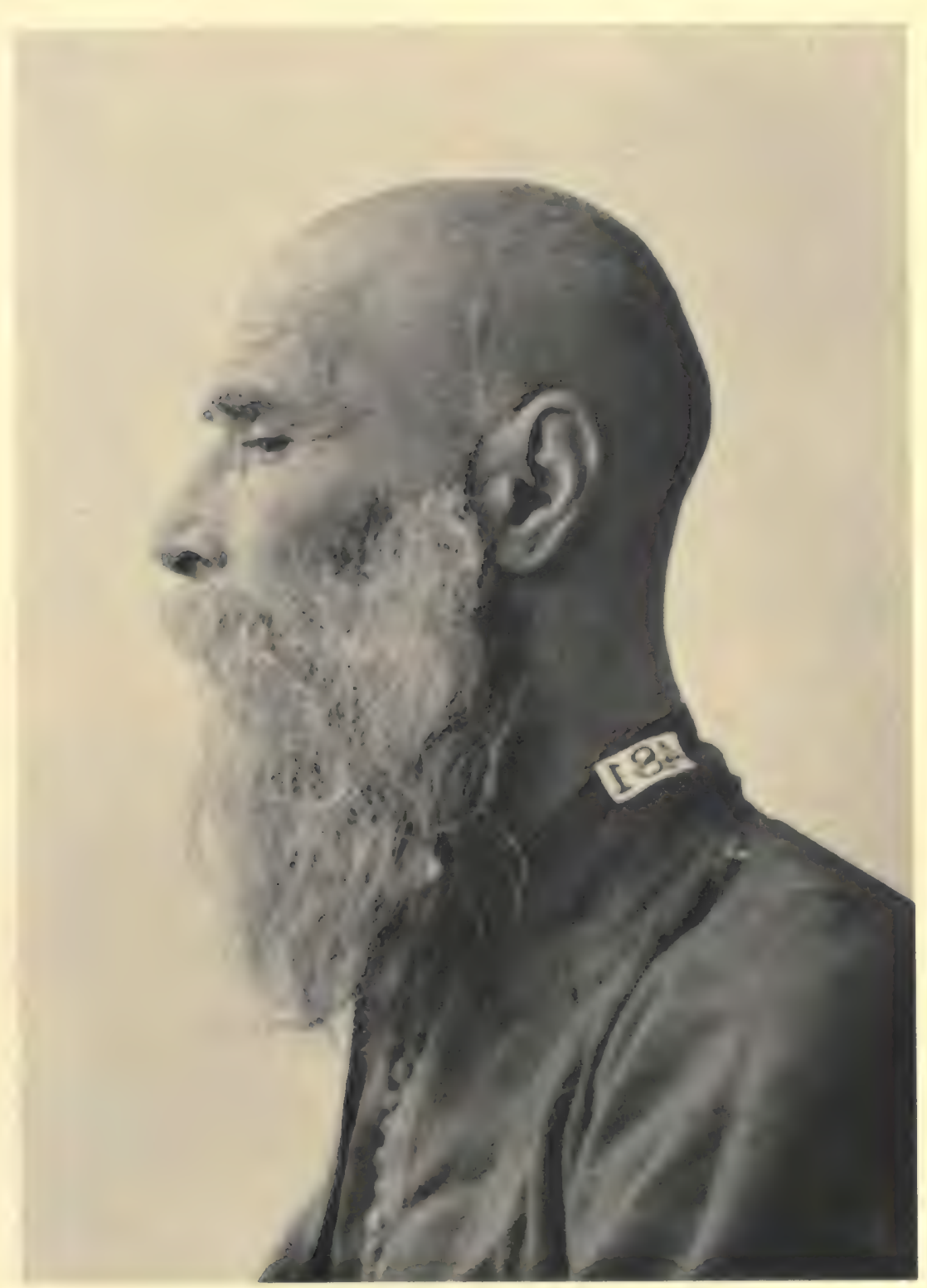

No. 2920 (age 50)

SUBBI IRANIAN PLATEAU HIGH MESOCEPHAL 
No.

$\int^{5} 5^{2}$

alth 392

Field Museum of Natural History

$(3+4)$

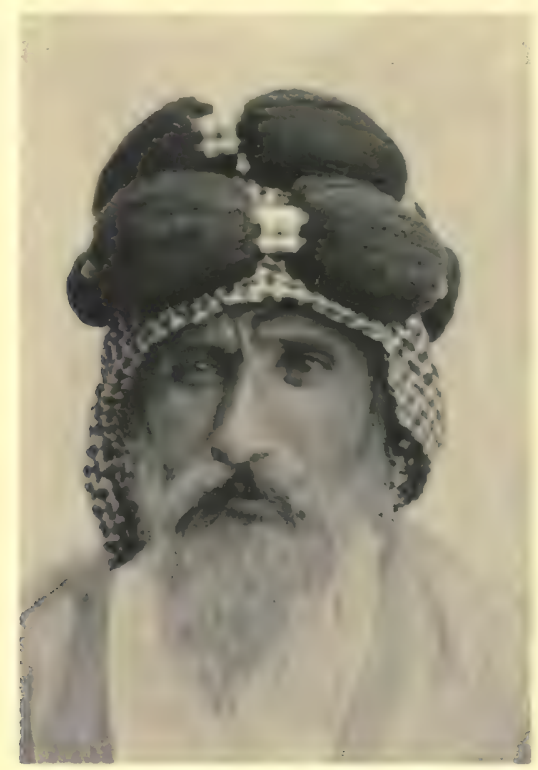

Anthropology, Vol. 30, Plate 190

$8^{\circ}$

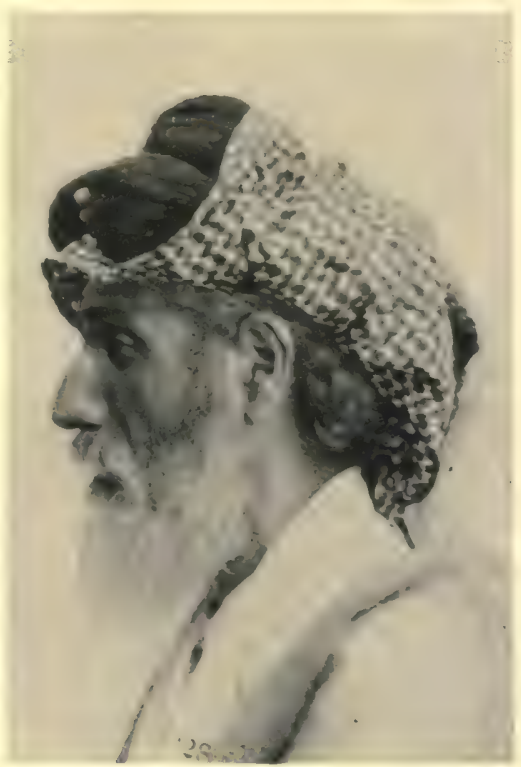

No. 2976 (age 68)
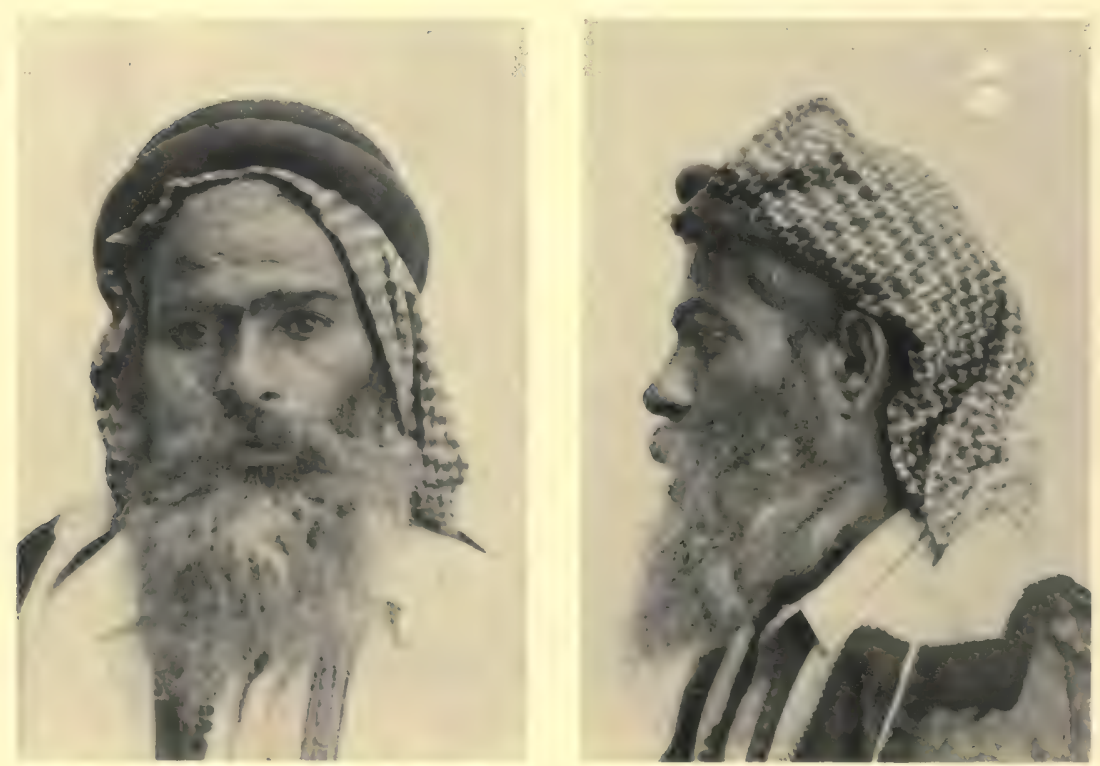

N

82

$(3$

No. 2974 (age 71)

SUBBA IRANIAN PLATEAU HIGH MESOCEPHALS 


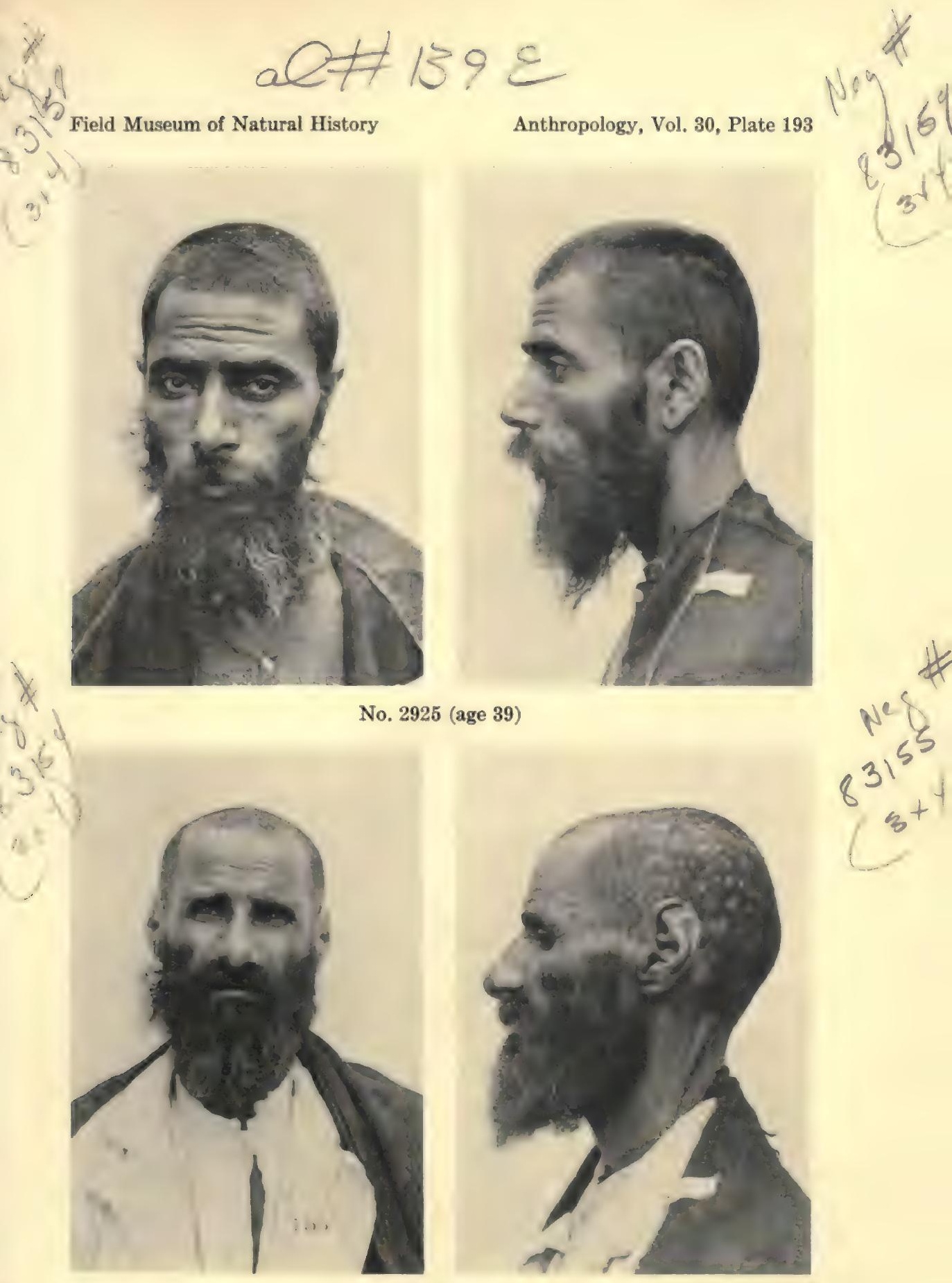

No. 2945 (age 50)

SUBBA IRANIAN PLATEAU SUB-BRACHYCEPHALS 


\section{ab 1398}

Field Museum of Natural History

Anthropology, Vol. 30, Plate 194

Nes

$33^{4}$ Tield Museum of

$(\sqrt{3}+1)$

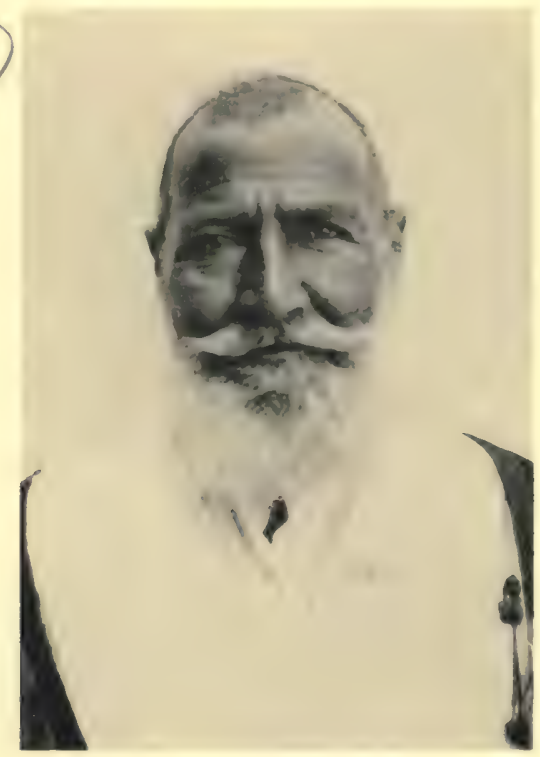

82

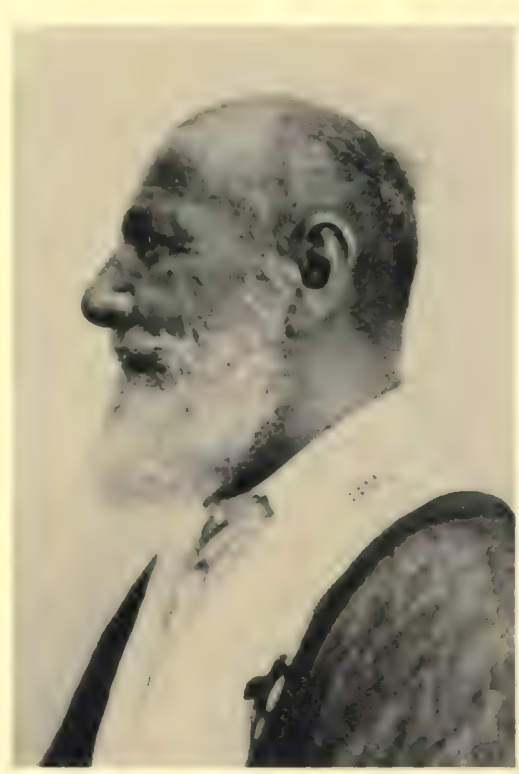

No. 2900 (age 55)

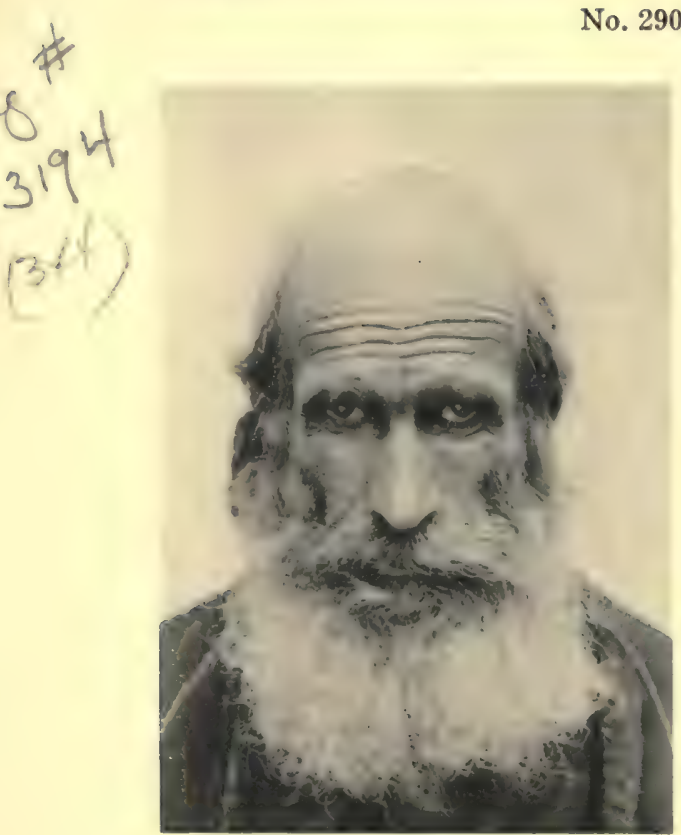

$\operatorname{Ves}$

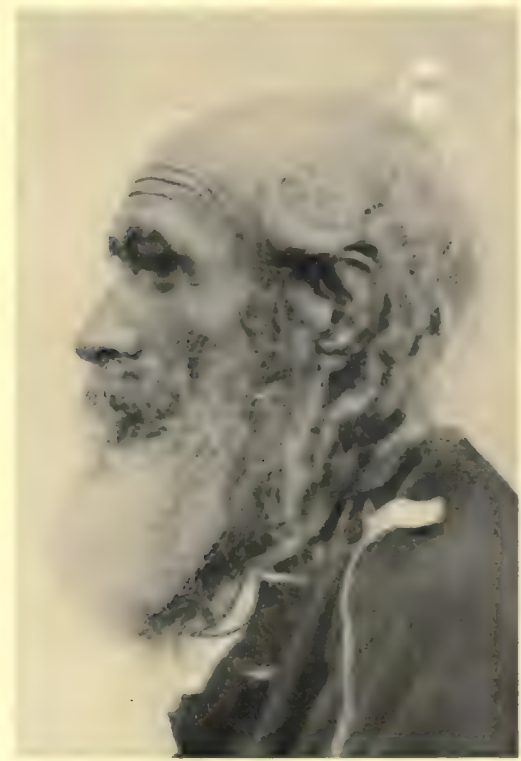

8

3

No. 2923 (age 70)

SUBBA IRANIAN PLATEAU SUB-BRACHYCEPHALS 
$\not x$

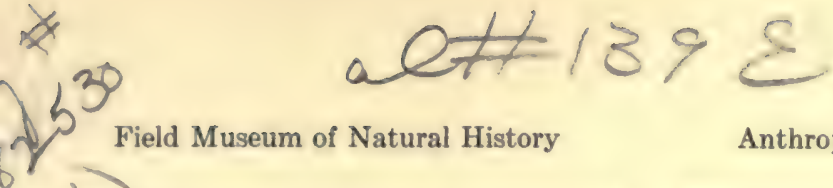

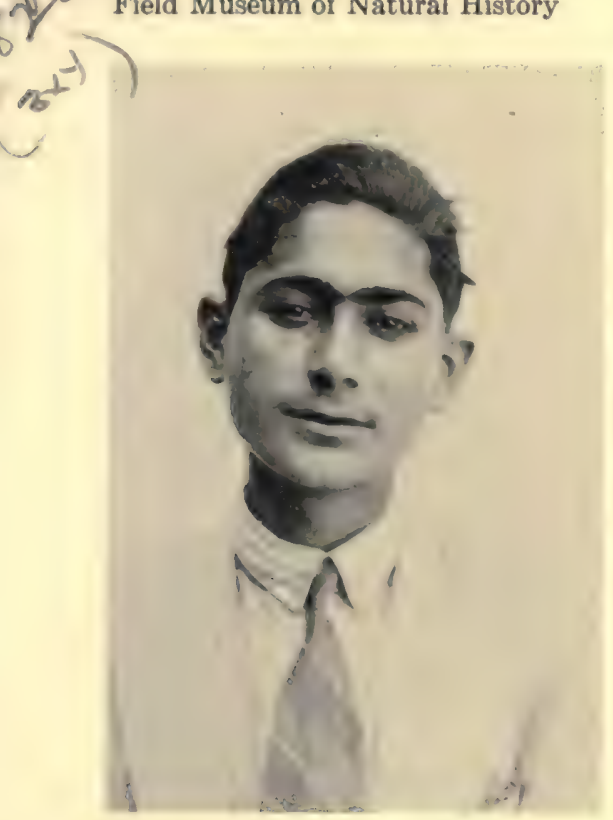

Anthropology, Vol. 30, Plate 195

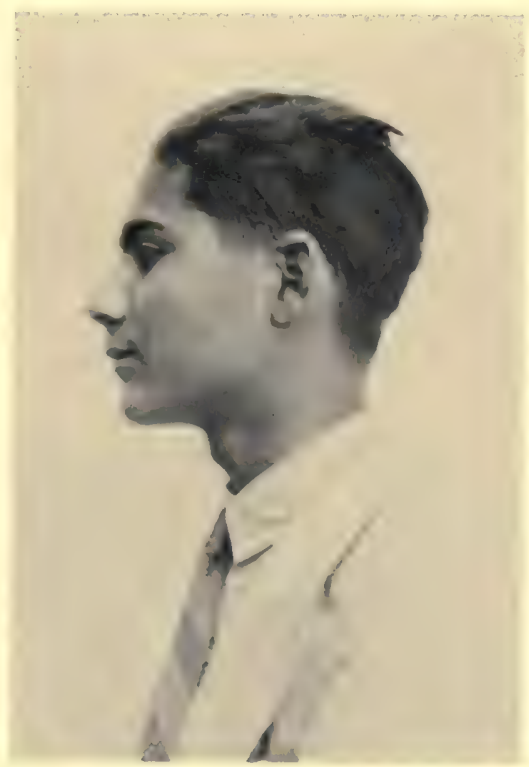

No. 2975 (age 16)

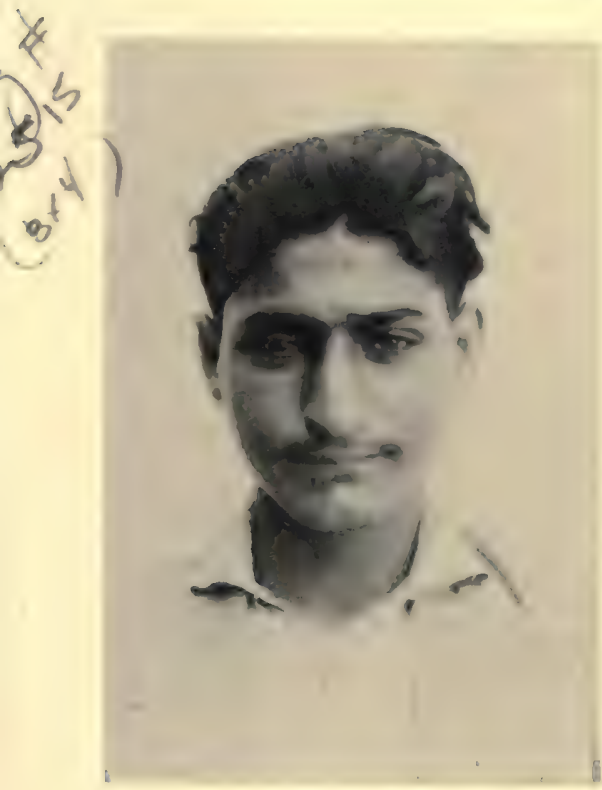

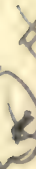

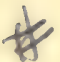

Neg.

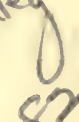

$3^{k}$

-

ot

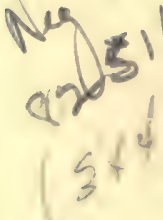

No. 2971 (age 18) 


\section{aett1392} 496 Field Museum of Natural History
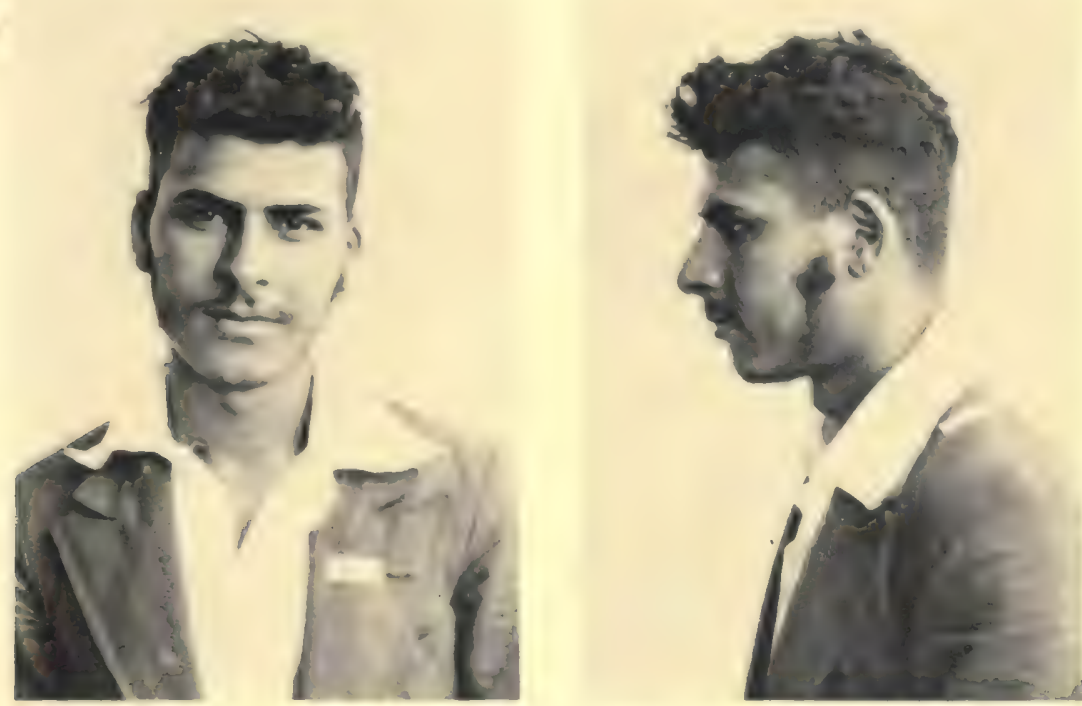

No. 2894 (age 20)

$¥$

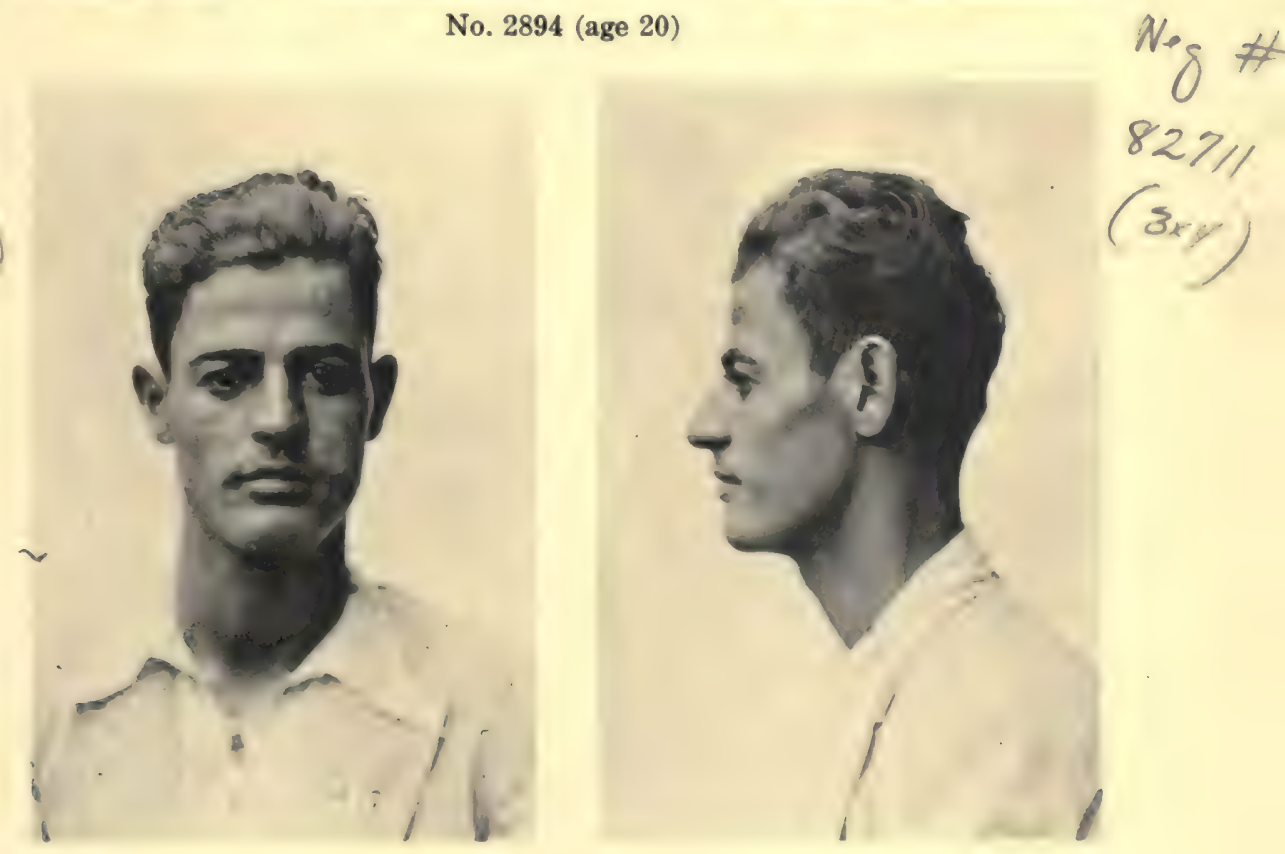

No. 2913 (age 21) 
$+\quad a l+139 \varepsilon$

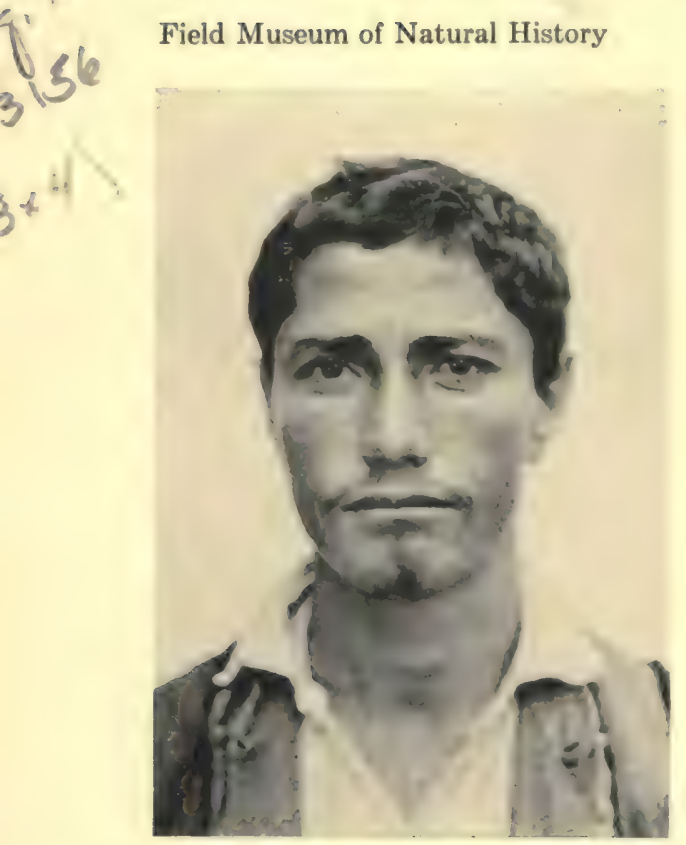

Anthropology, Vol. 30, Plate 198 Neq 83

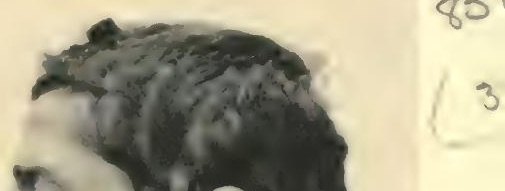

4

No. 2946 (age 22)

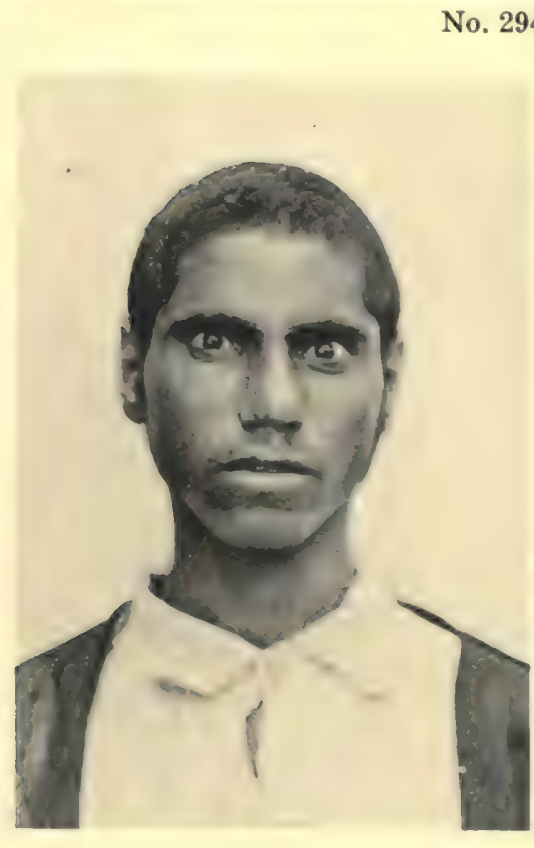

Nea

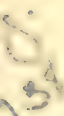

4) $s^{4}$

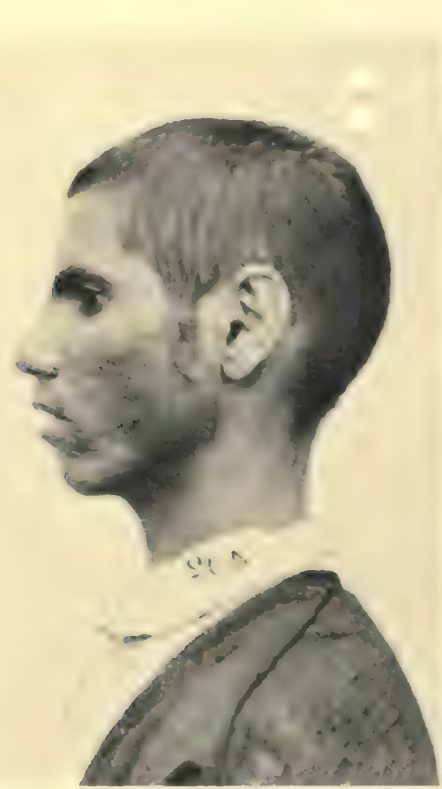

No. 2933 (age 22) 


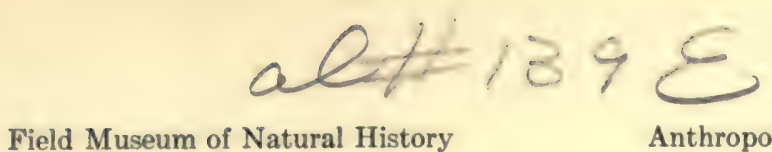

Ho Field Museum of Natural History $\log _{0}$ Anthropology, Vol. 30, Plate 199
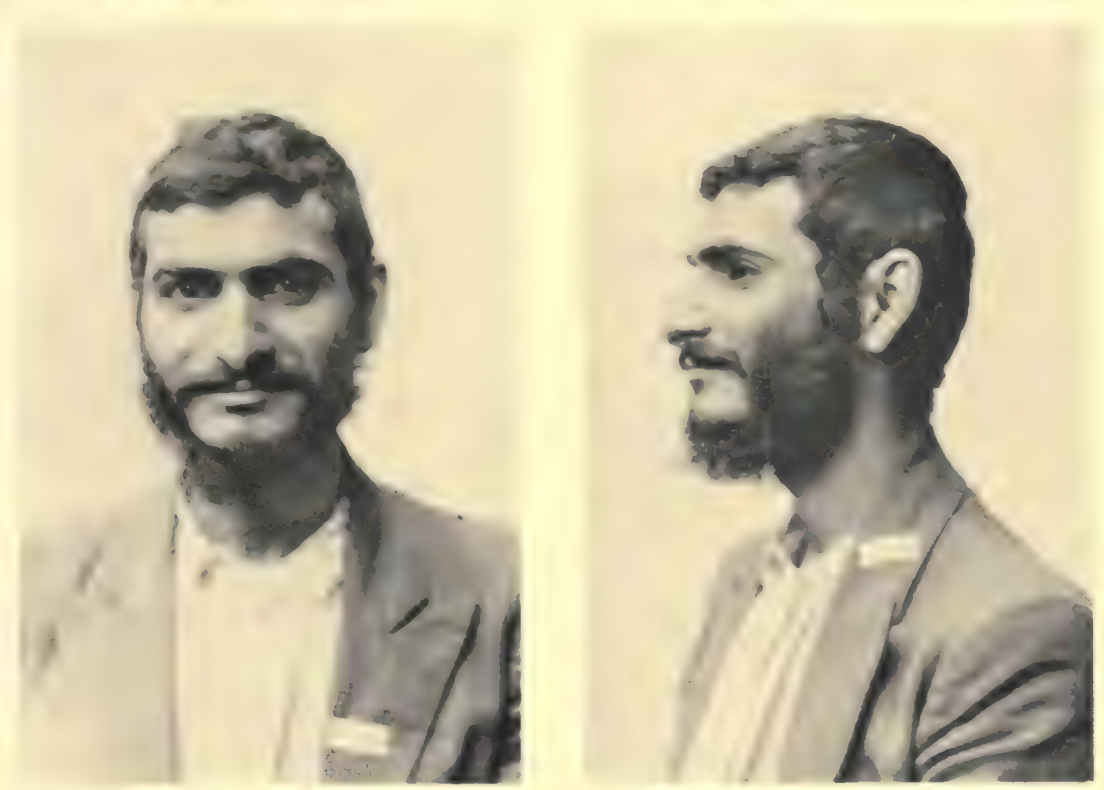

No. 2908 (age 22)

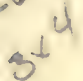




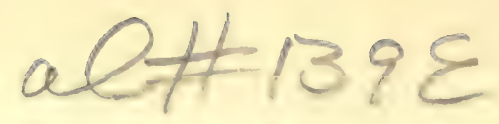

$4 \%$ Field Museum of Natural History 42

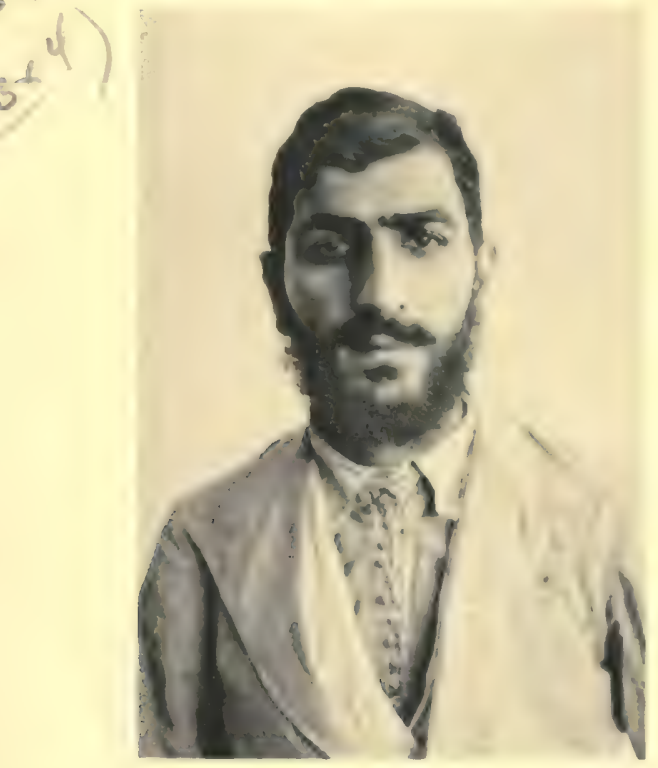

Anthropology, Vol. 30, Plate 200

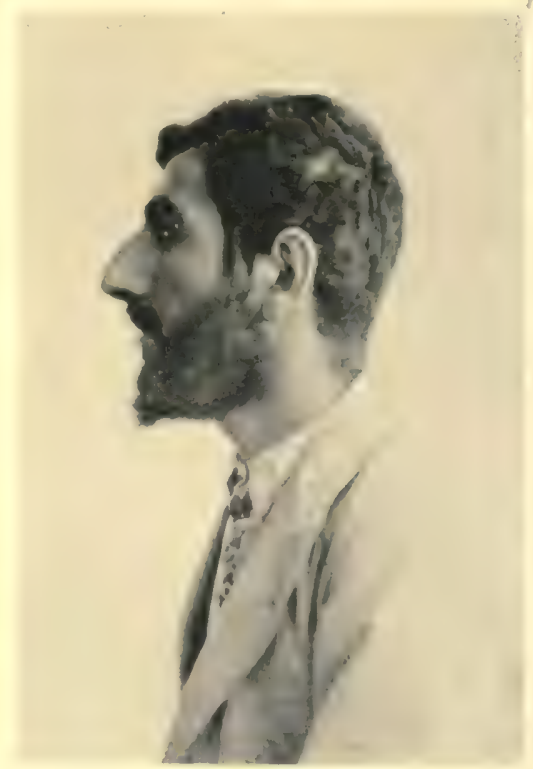
Nu

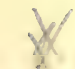

No. 2892 (age 25)

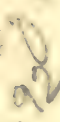

0
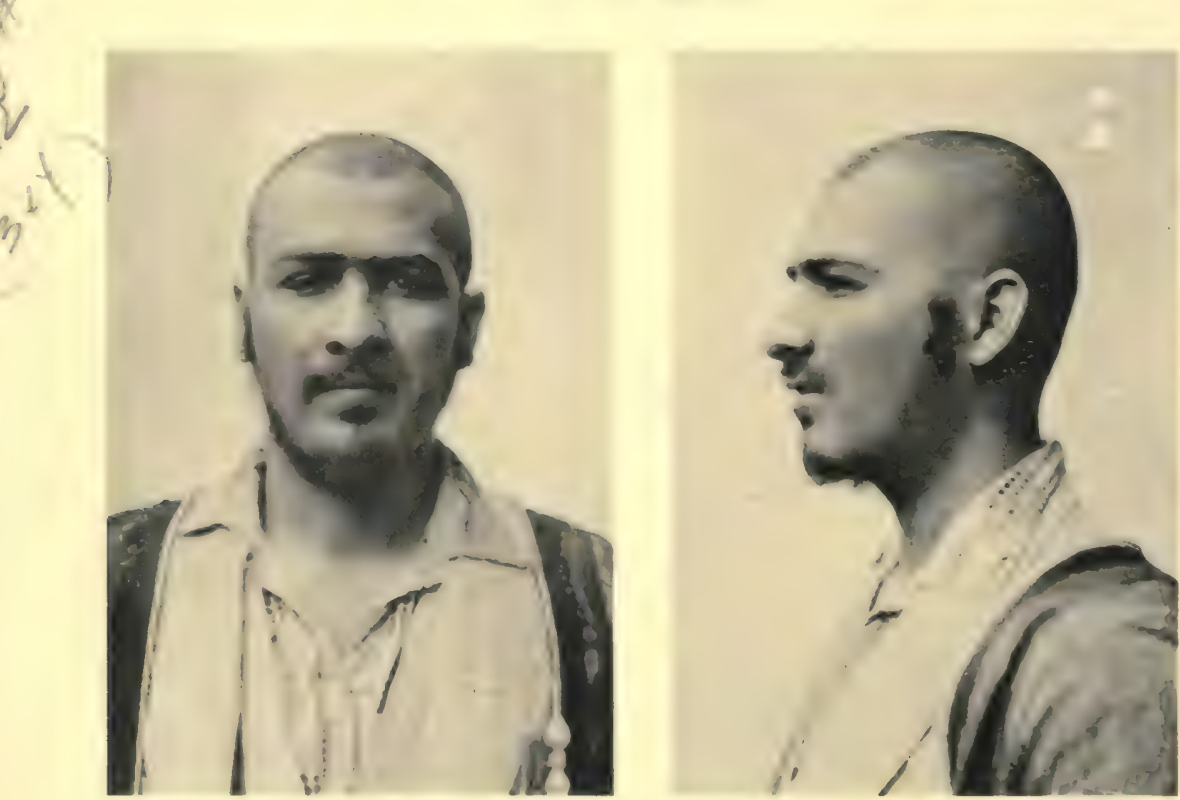

jec

81

3

No. 2905 (age 26)

SUBBA HIGH MESOCEPHALS 


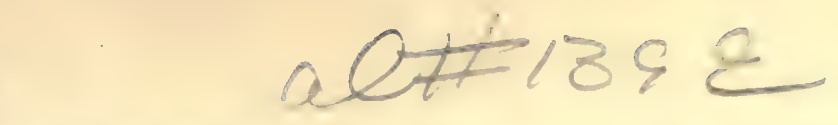

Field Museum of Natural History

Anthropology, Vol. 30, Plate 201

Ner
$8 \gamma 74$
$3+4$
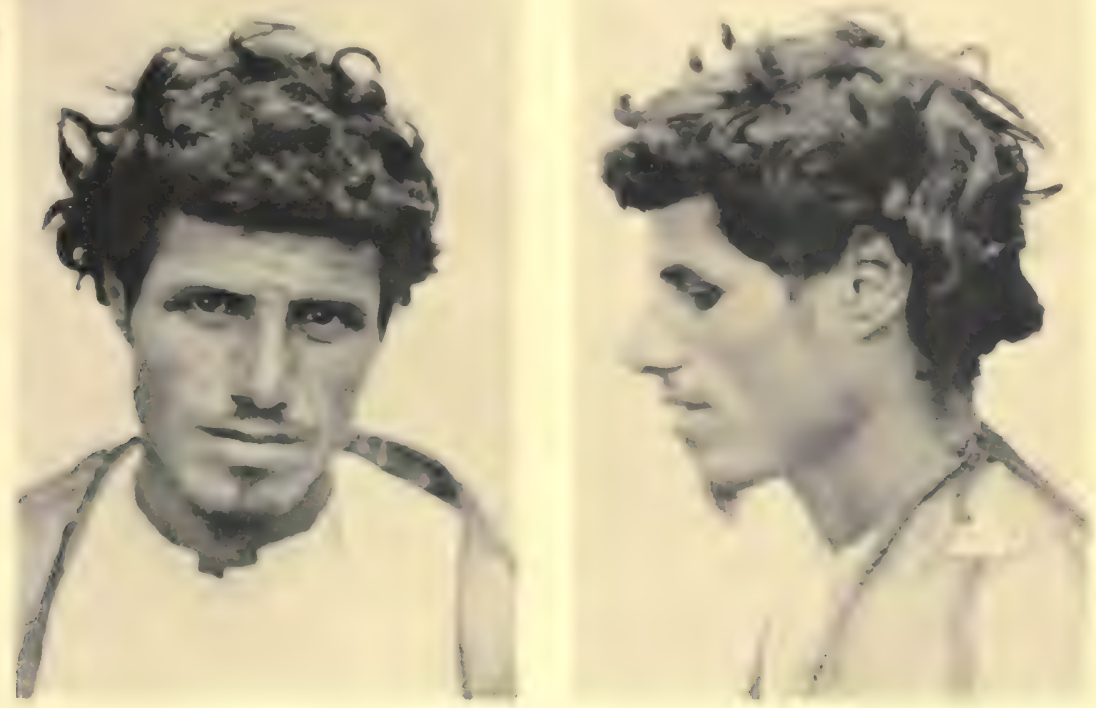

No. 2935 (age 28)
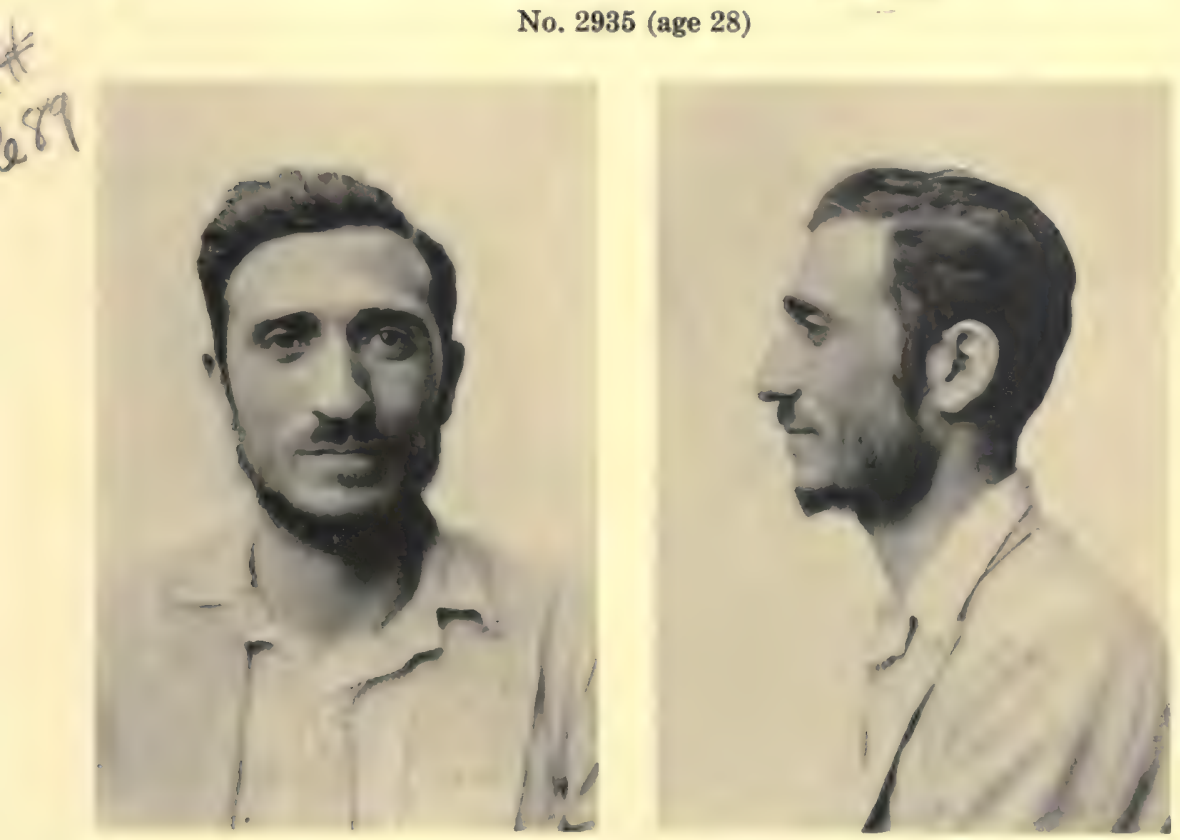

Neg. At $82 e^{9}$ $3 k+$

No. 2904 (age 29) 
Field Museum of Natural History

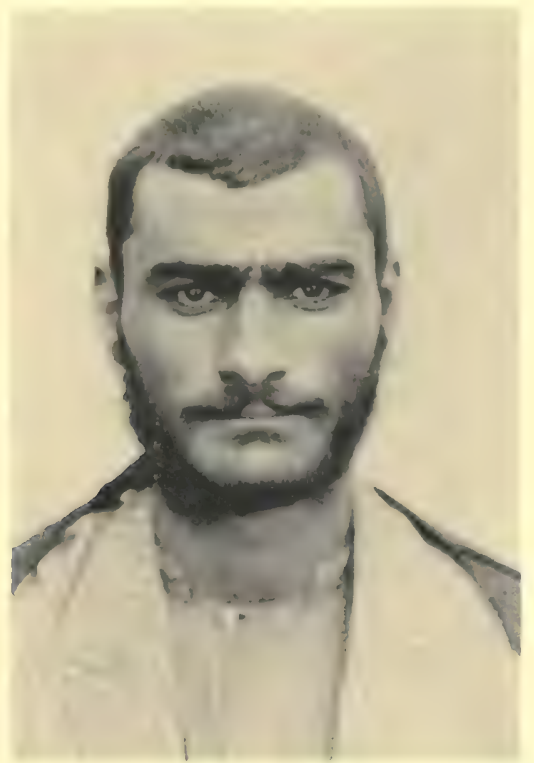

Anthropology, Vol. 30, Plate 202

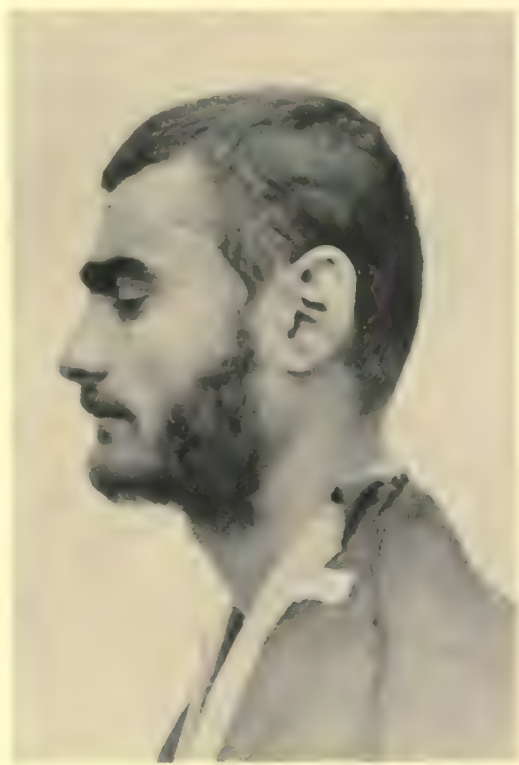

Neg

8

13

No. 2951 (age 20)

N

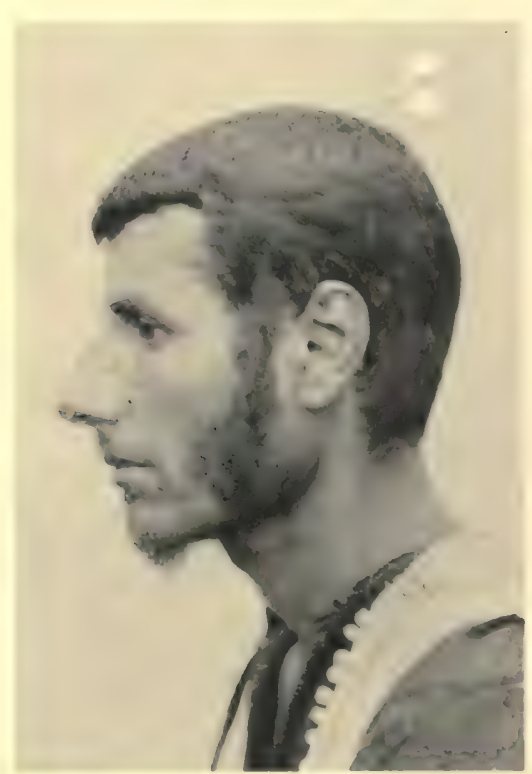

8

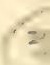

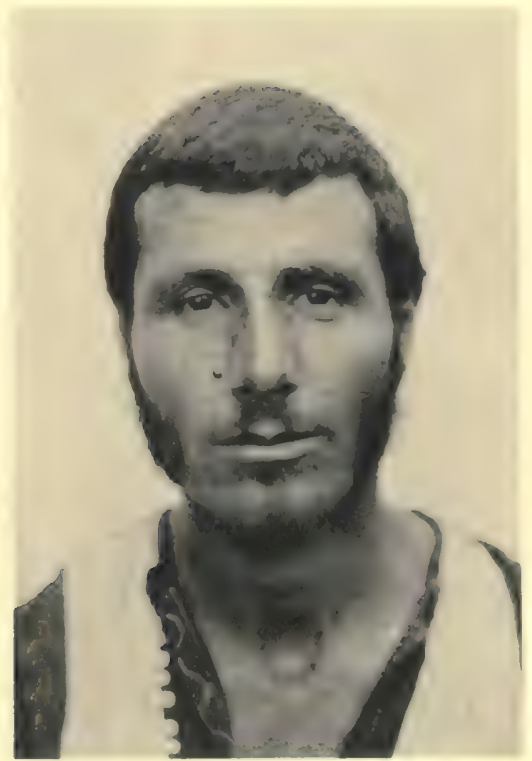

No. 2940 (age 25)

SUBBA BRACHYCEPHALS PLUS IRANIAN PLATEAU TYPE 
Field Museum of Natural History
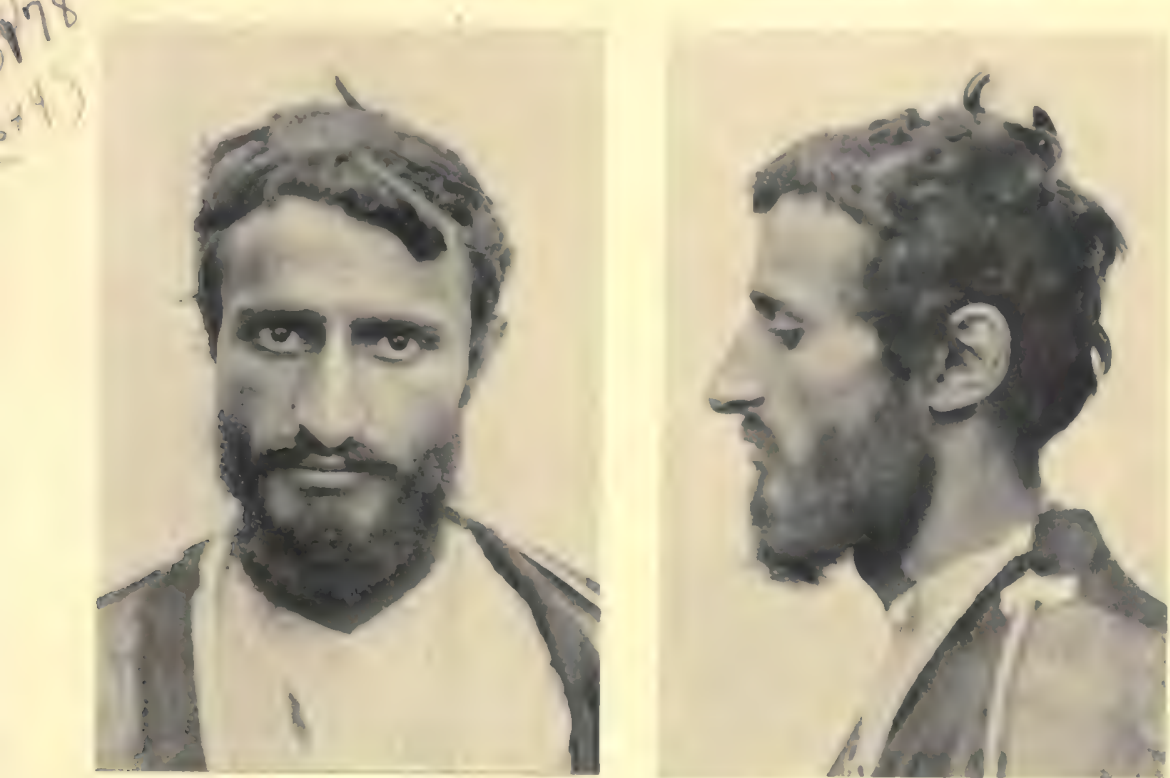

No. 2918 (age 30)

No. 517 $3+4$

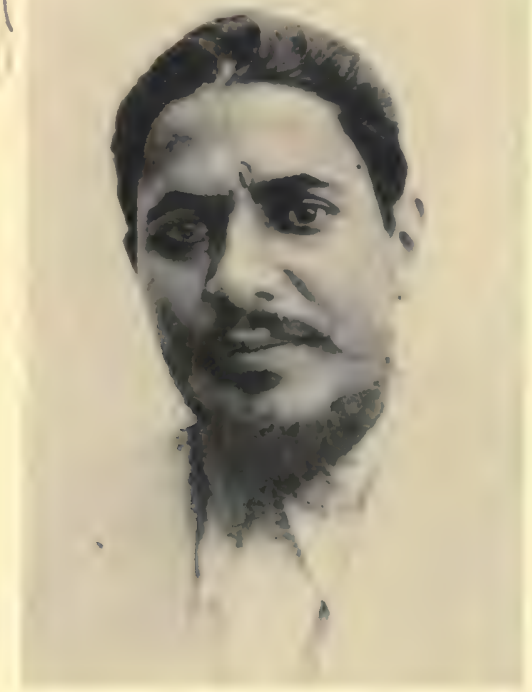

Anthropology, Vol. 30, Plate 203

Nes

8379
$3 \times 4$

Neg

82518

$(3 \times 4)$

No. 2898 (age 32) 
x

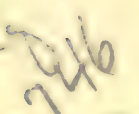

Field Museum of Natural History $\cos _{\mathrm{b}^{+}} \mathrm{k}$

\section{$a l \neq 1398$}

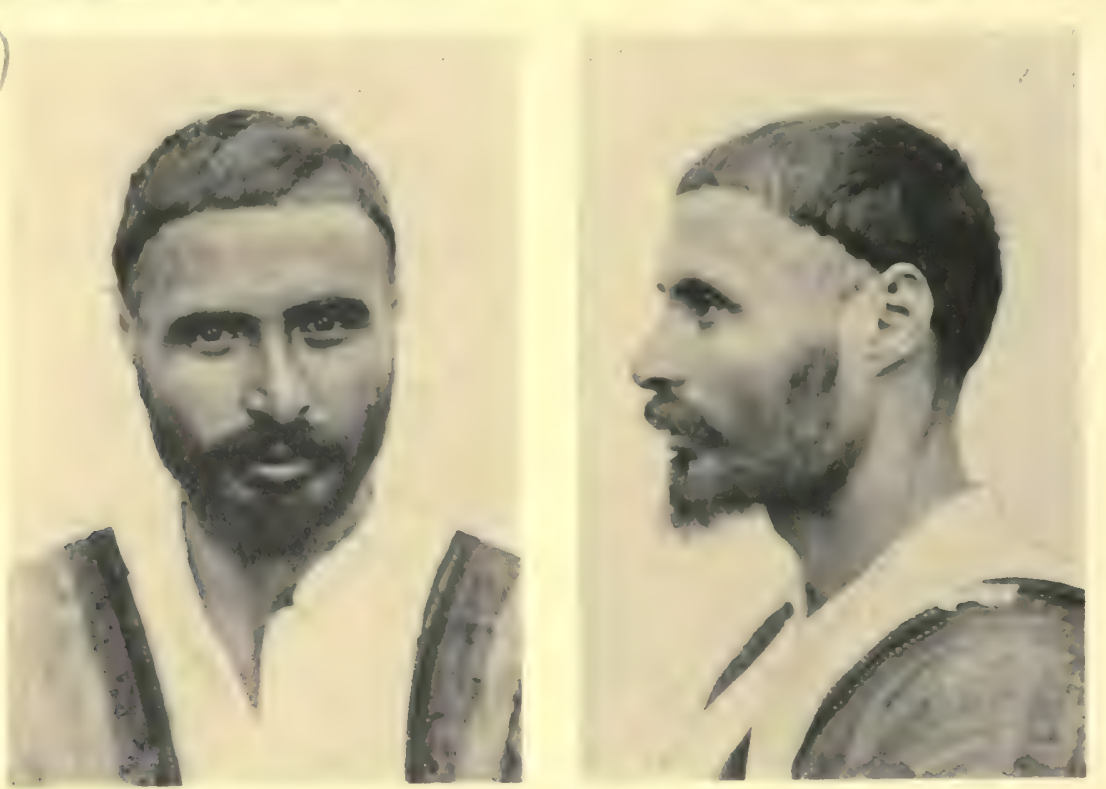

Anthropology, Vol. 30, Plate 204

$\sqrt{e}$

8

13

No. 2936 (age 39)

\&

16

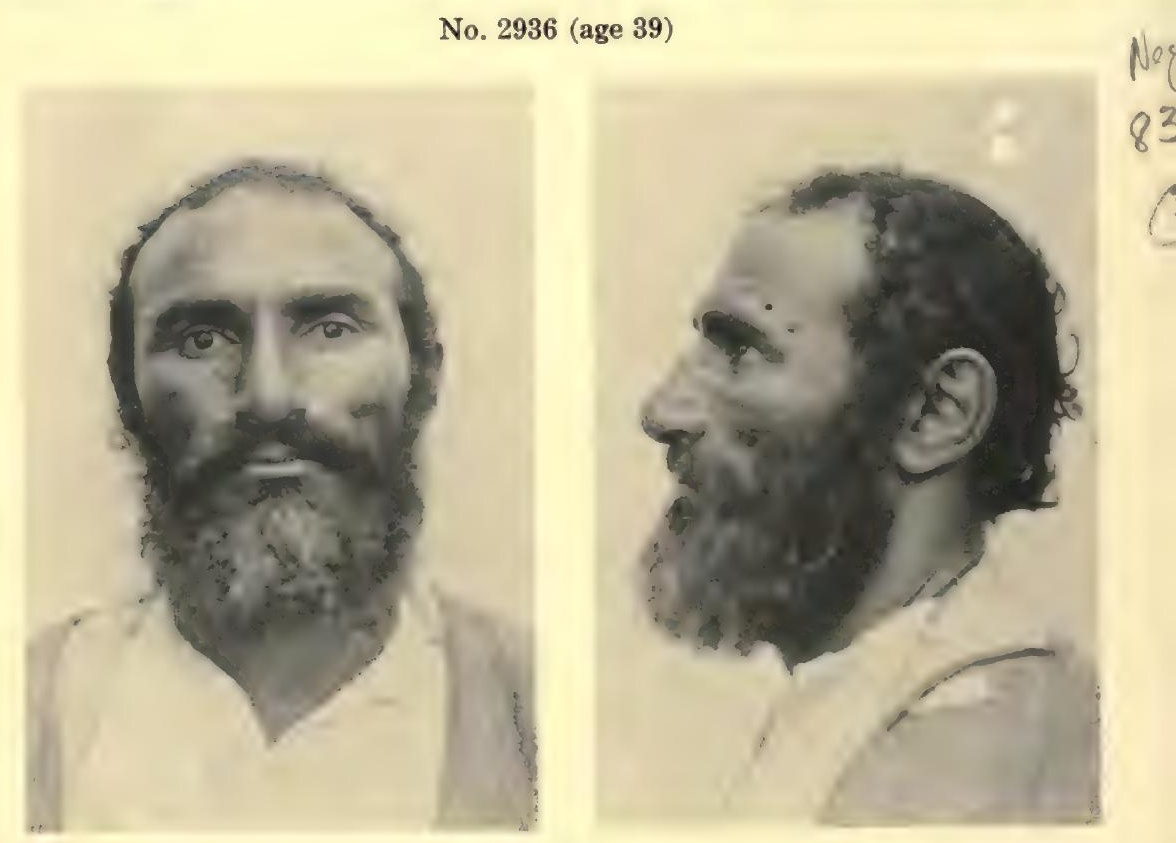

No. 2959 (age 40)

SUBBA BRACHYCEPHALS PLUS IRANIAN PLATEAU TYPE 


\section{altis?}

Field Museum of Natural History $5+4)$

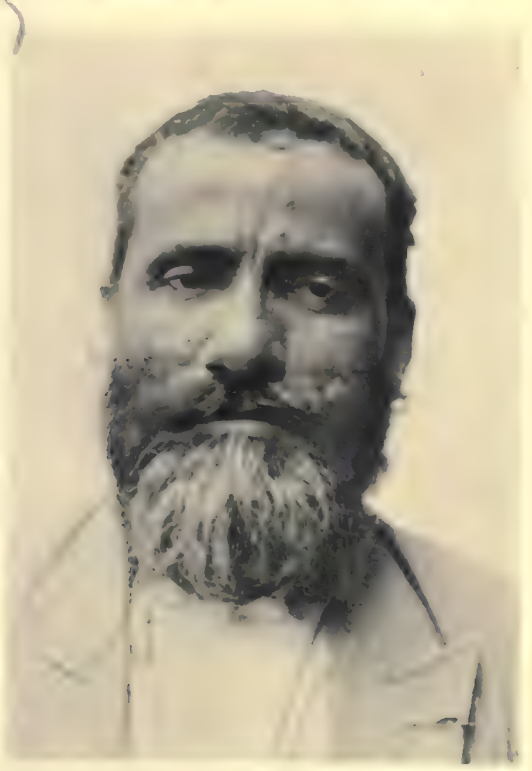

Anthropology, Vol. 30, Plate 205

Neg.
827
347

No. 2915 (age 42)

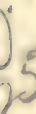

NC

$g^{s}$ $b^{+1}$

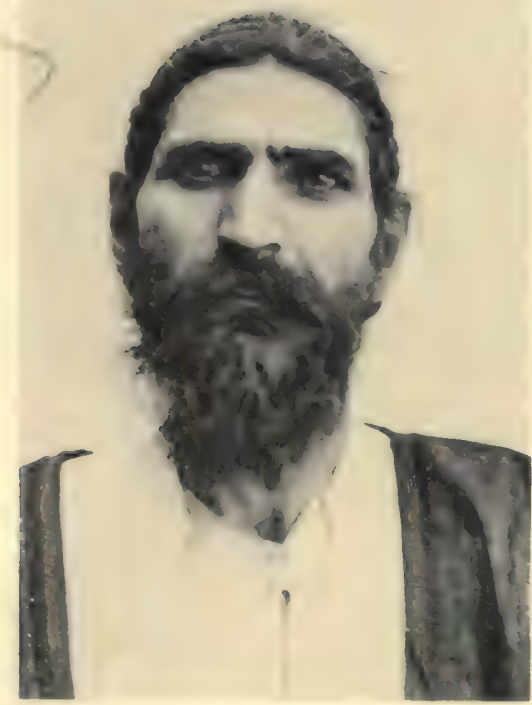

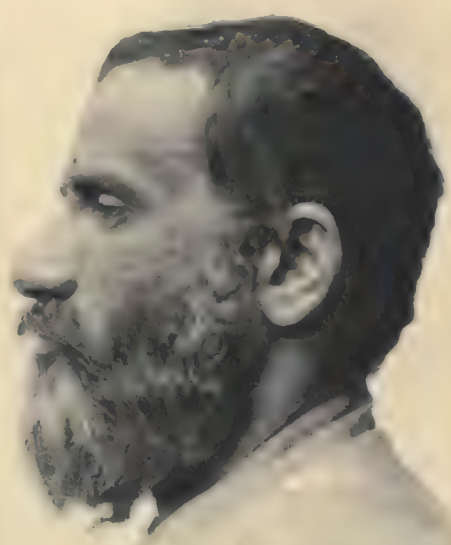

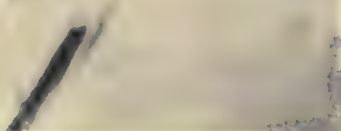

Neg. 4

87509

No. 2968 (age 55)

SUBBA BRACHYCEPHALS PLUS IRANIAN PLATEAU TYPE 
Field Museum of Natural History

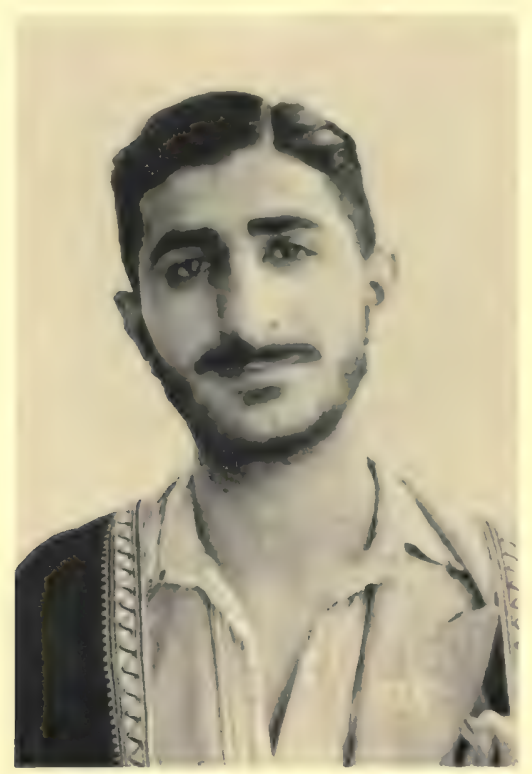

Anthropology, Vol. 30, Plate 206

$N^{4}$

$8^{2}$

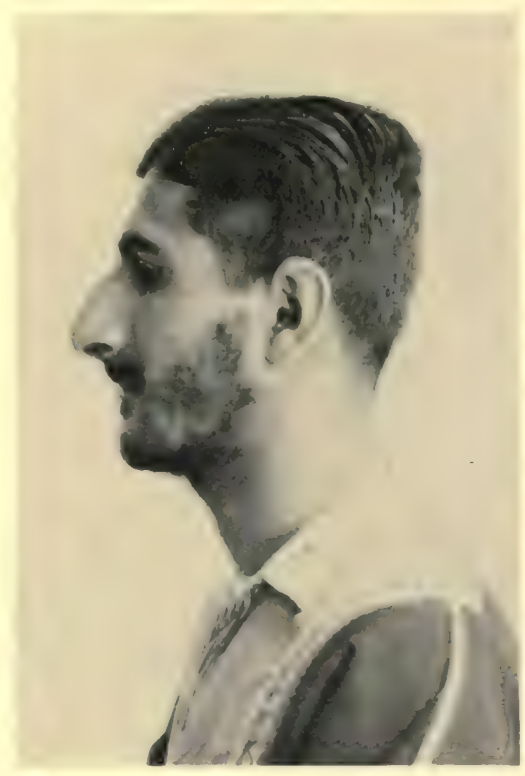

$\sqrt{9}$

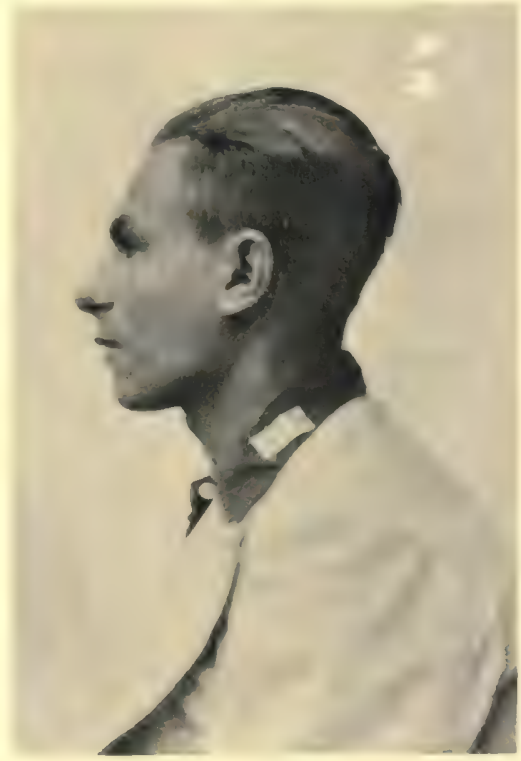

4

age 19)

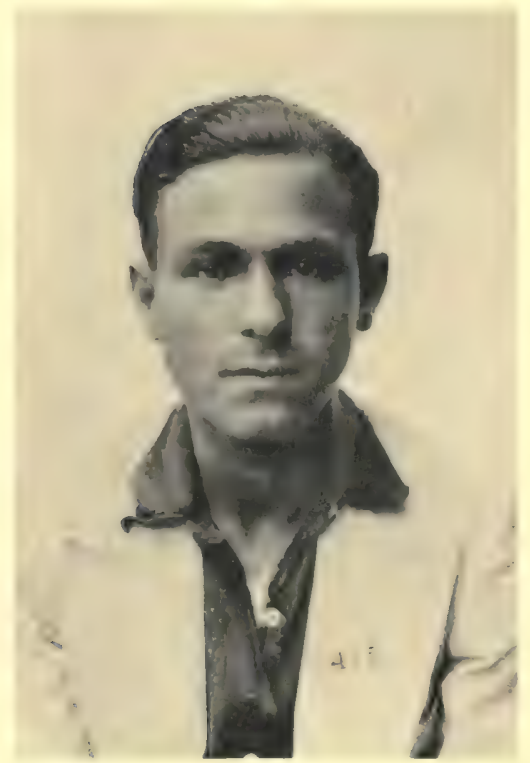

$a^{10}$

No. 2912 (age 20)

SUBBA JEWISH (above) AND NORTH EUROPEAN (below) TYPES 


\section{$a l \neq 1398$}

Field Museum of Natural History

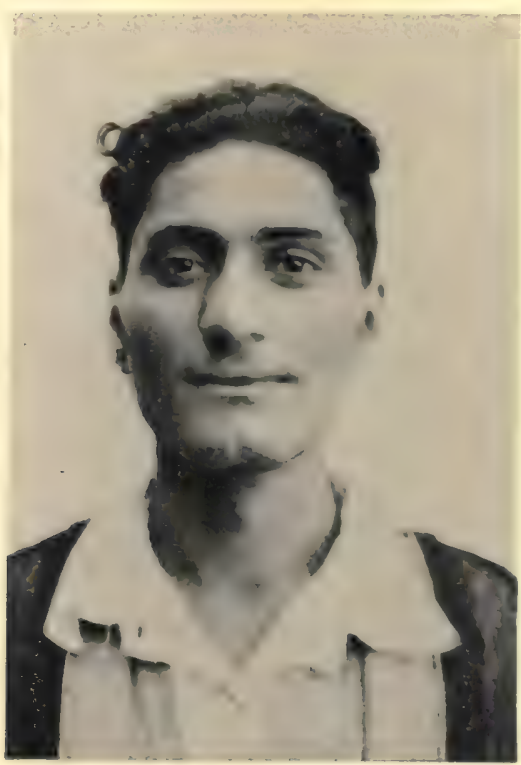

Anthropology, Vol. 30, Plate 207

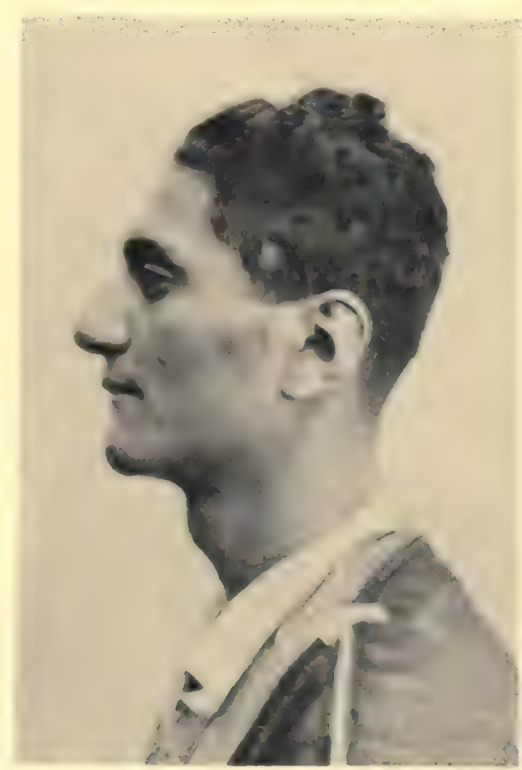

No. 2972 (age 20)

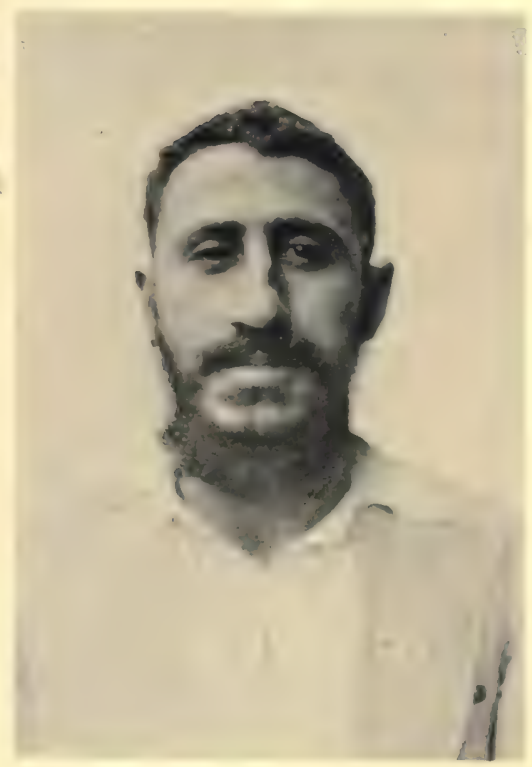
का

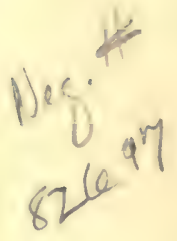

No. 2907 (age 26) 

$\left(\gamma_{6}+1\right)$ Field Museum of Natural History

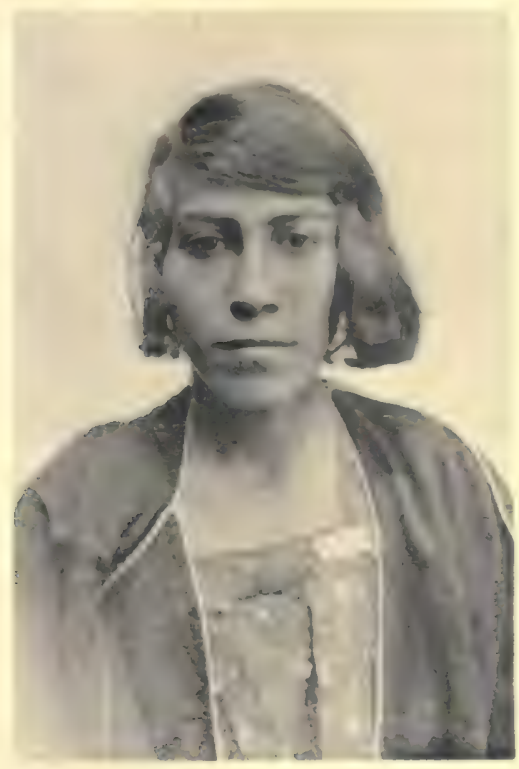

No. 2988 (age 12)

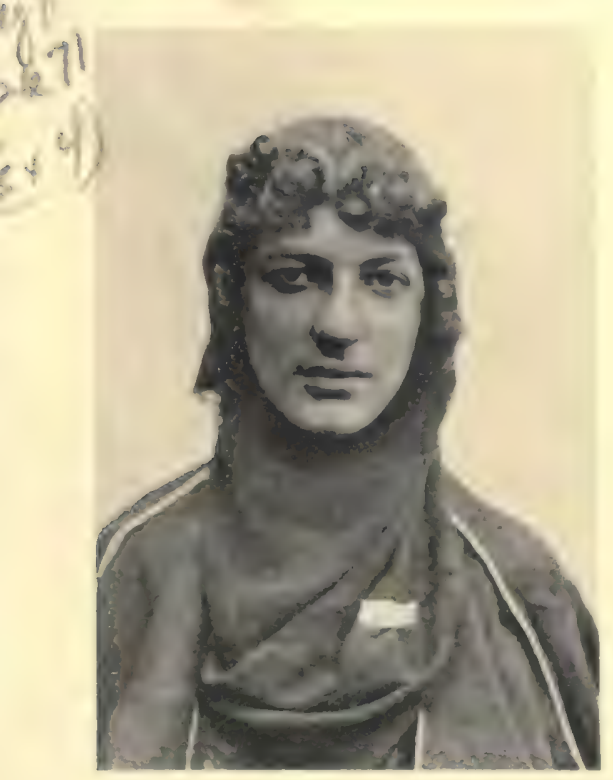

Anthropology, Vol. 30, Plate 209

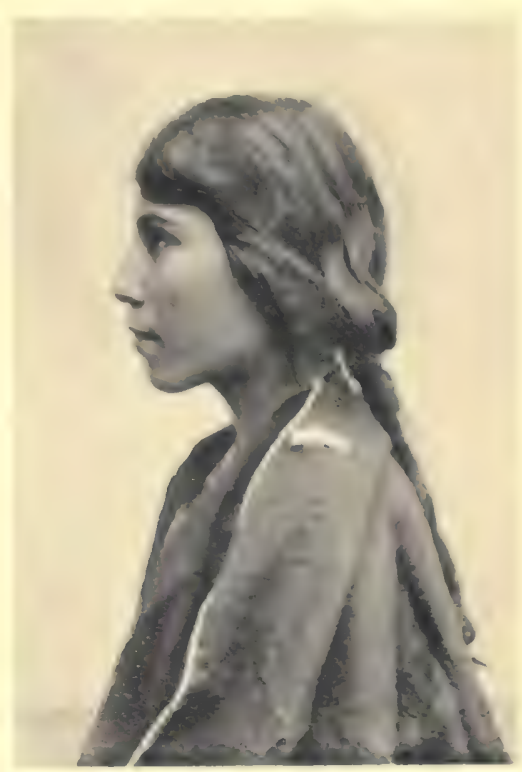

Nee, No

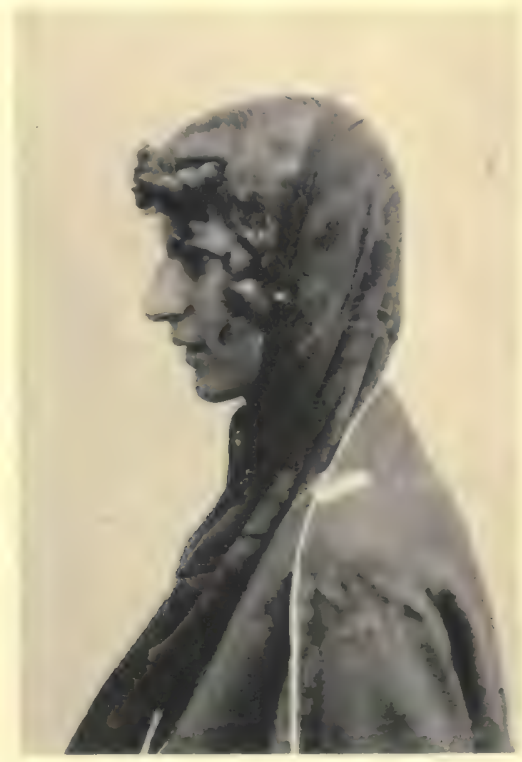

Nee

82672

$5 \times 7$

No. 2982 (age 15)

SUBBA WOMEN 

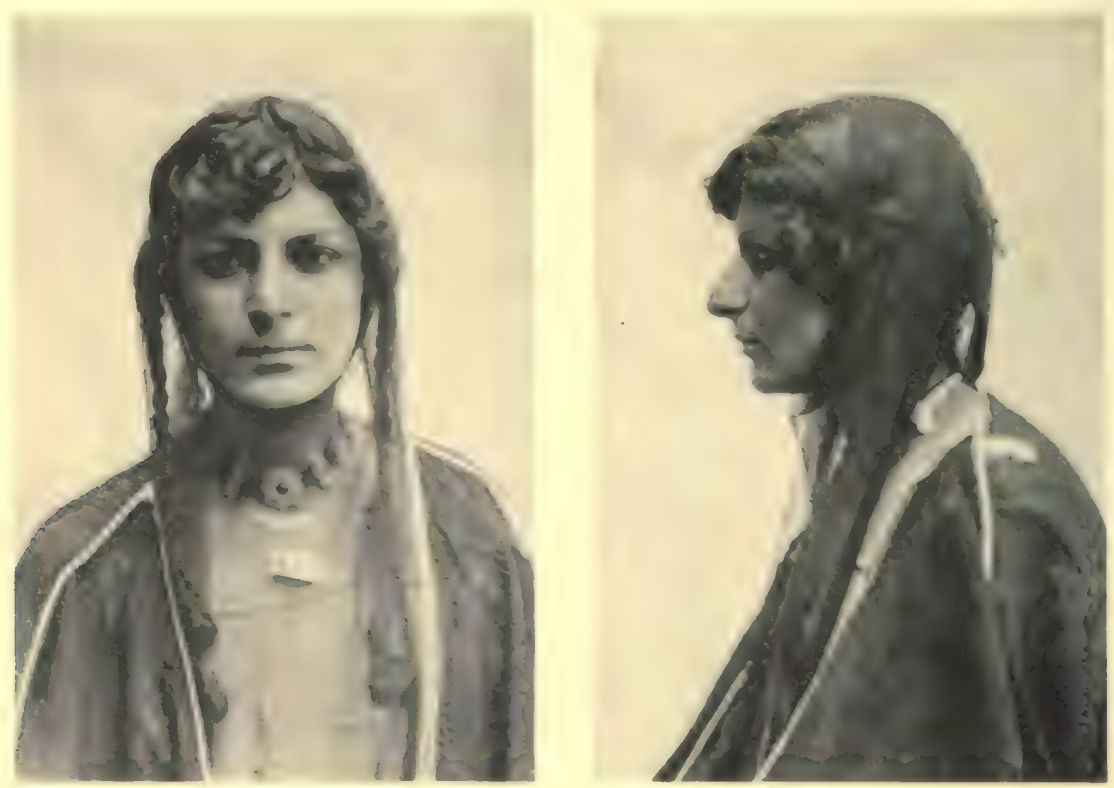

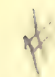

No. 2985 (age 18)
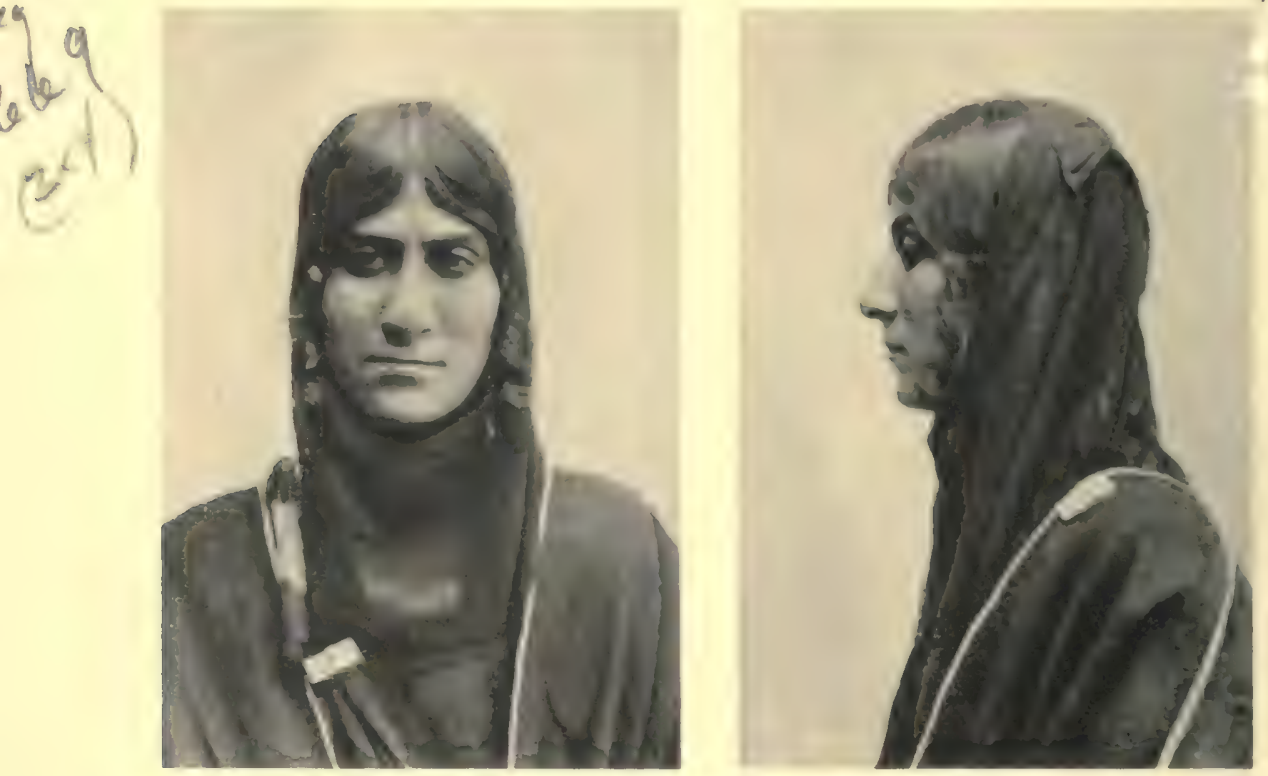

Nec 82

No. 2981 (age 20)

SUBBA WOMEN 


\section{$\operatorname{abt} 139 \varepsilon$}

Field Museum of Natural History

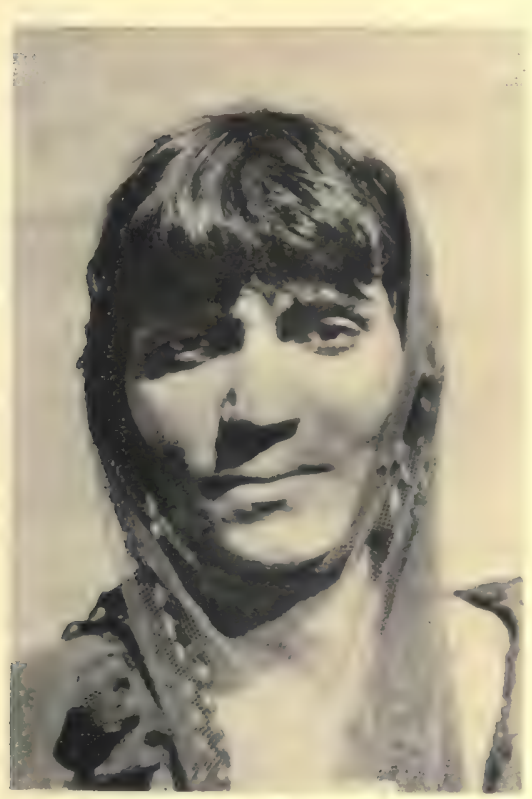

Anthropology, Vol. 30, Plate 211

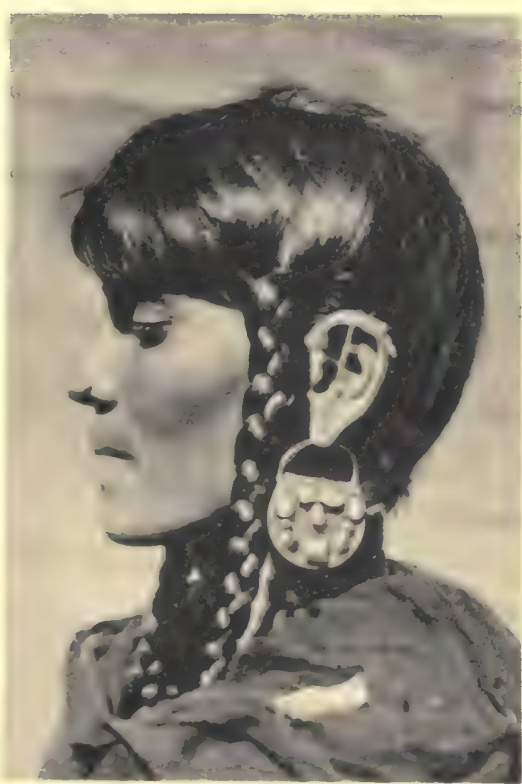

No. 2999 (age 20)

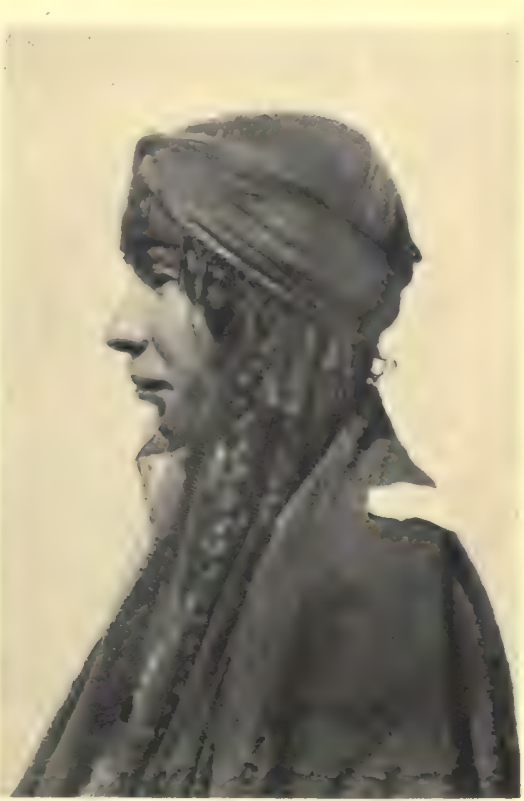

No Nes ${ }^{2} ?^{6}$ $3^{+}$

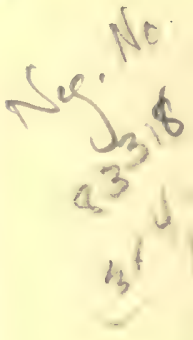

No. 3002 (age 21) 


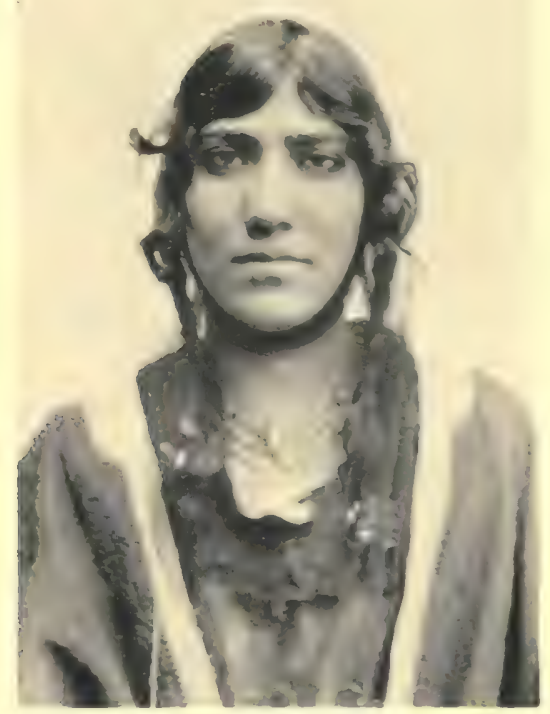

Ne

No. 2984 (age 23)
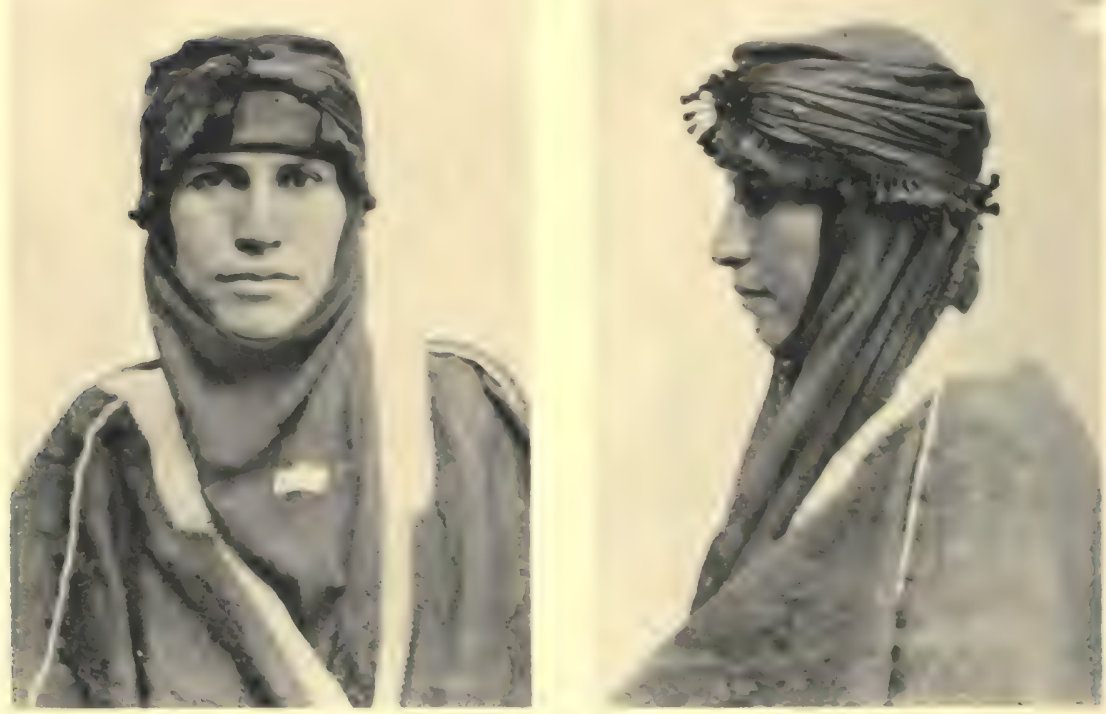

No. 2983 (age 30)

SUBBA WOMEN 


\section{$a l \neq 13 q \varepsilon$}

al

Field Museum of Natural History

Anthropology, Vol. 30, Plate 213

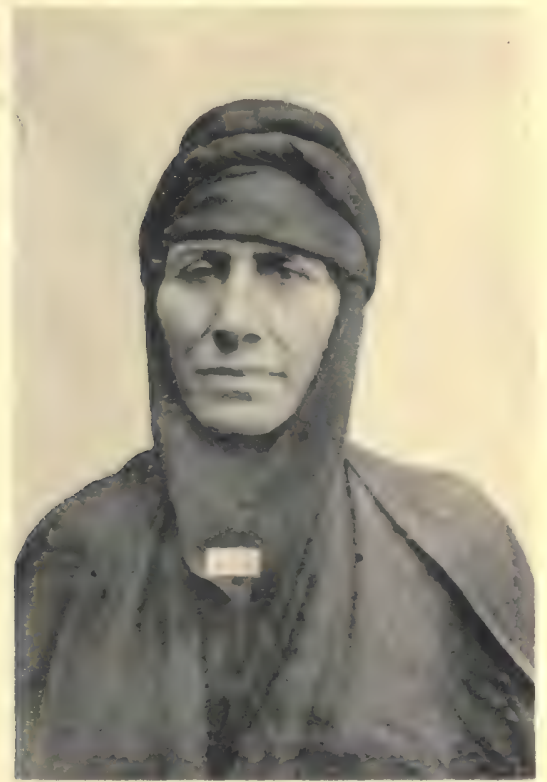

10

1)

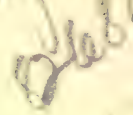

$\lambda$

4

No. 2987 (age 40)

ov
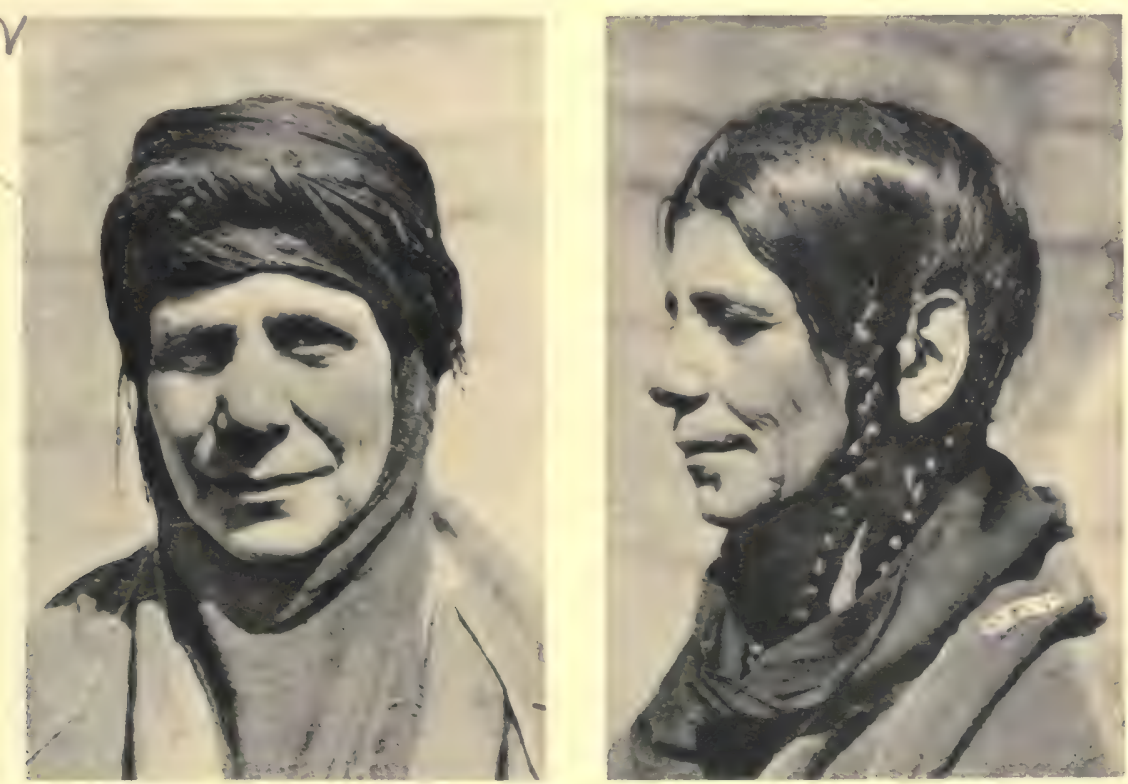

P)

437

$3 x^{4}$

No. 2998 (age 40)

SUBBA WOMEN 
No 6079

Field Museum of Natural History

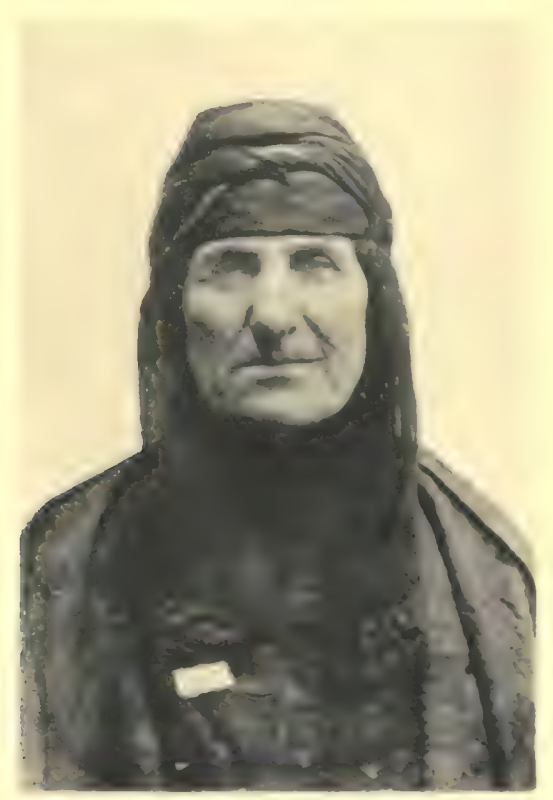

No. 2986 (age 50)

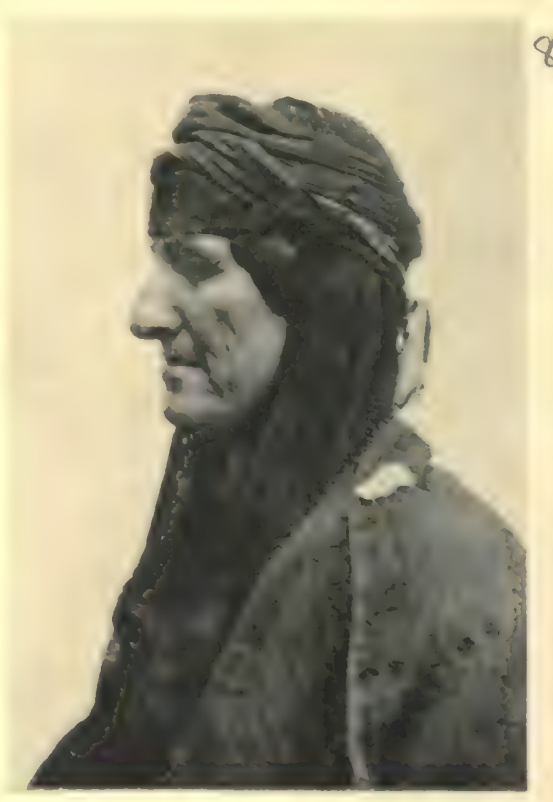

$\not$

$b^{61}$ al $\# 1392$

Anthropology, Vol. 30, Plate 214 82

N.
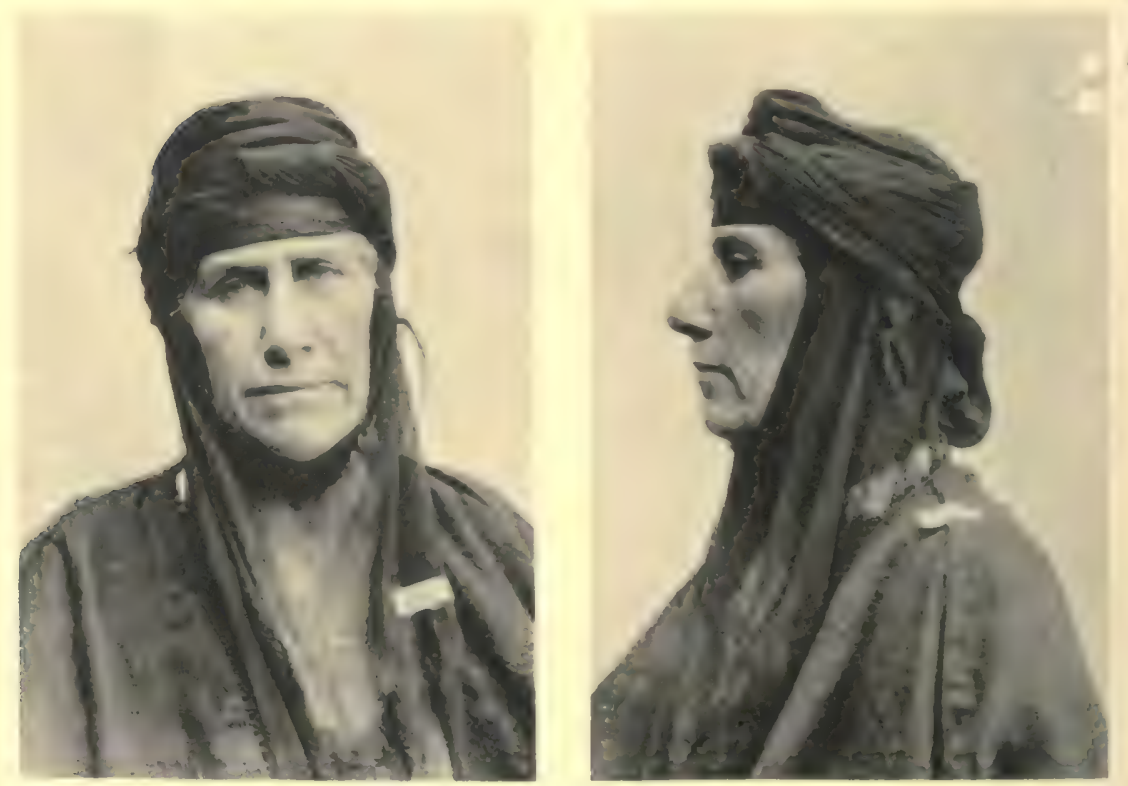

8

No. 3007 (age 50)

SUBBA WOMEN 


$$
\begin{aligned}
& \text { alewan } 139-\varepsilon \\
& \text { Nog. No. } 104417 \text { (all) }
\end{aligned}
$$

Field Museum of Natural History
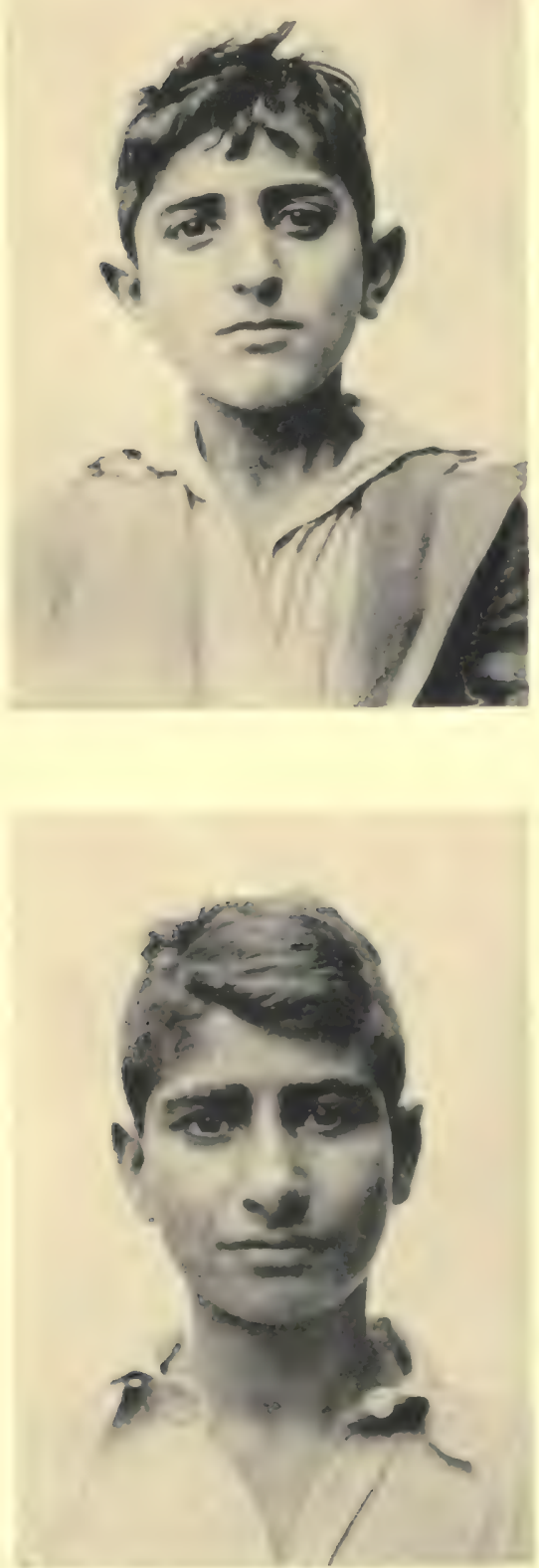

Anthropology, Vol. 30, Plate 216
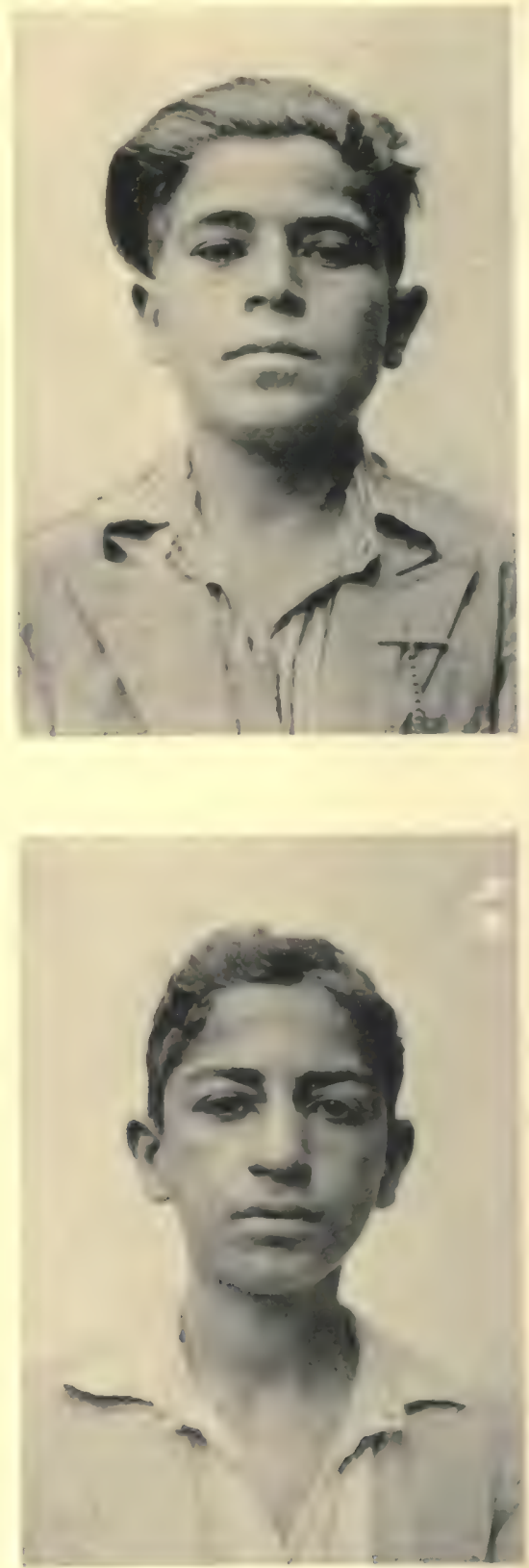

SUBBA CHILDREN 


$$
\begin{aligned}
& \text { Album } 139-\varepsilon \\
& \text { Neg. No. } 104416(a 11)
\end{aligned}
$$

Field Museum of Natural History
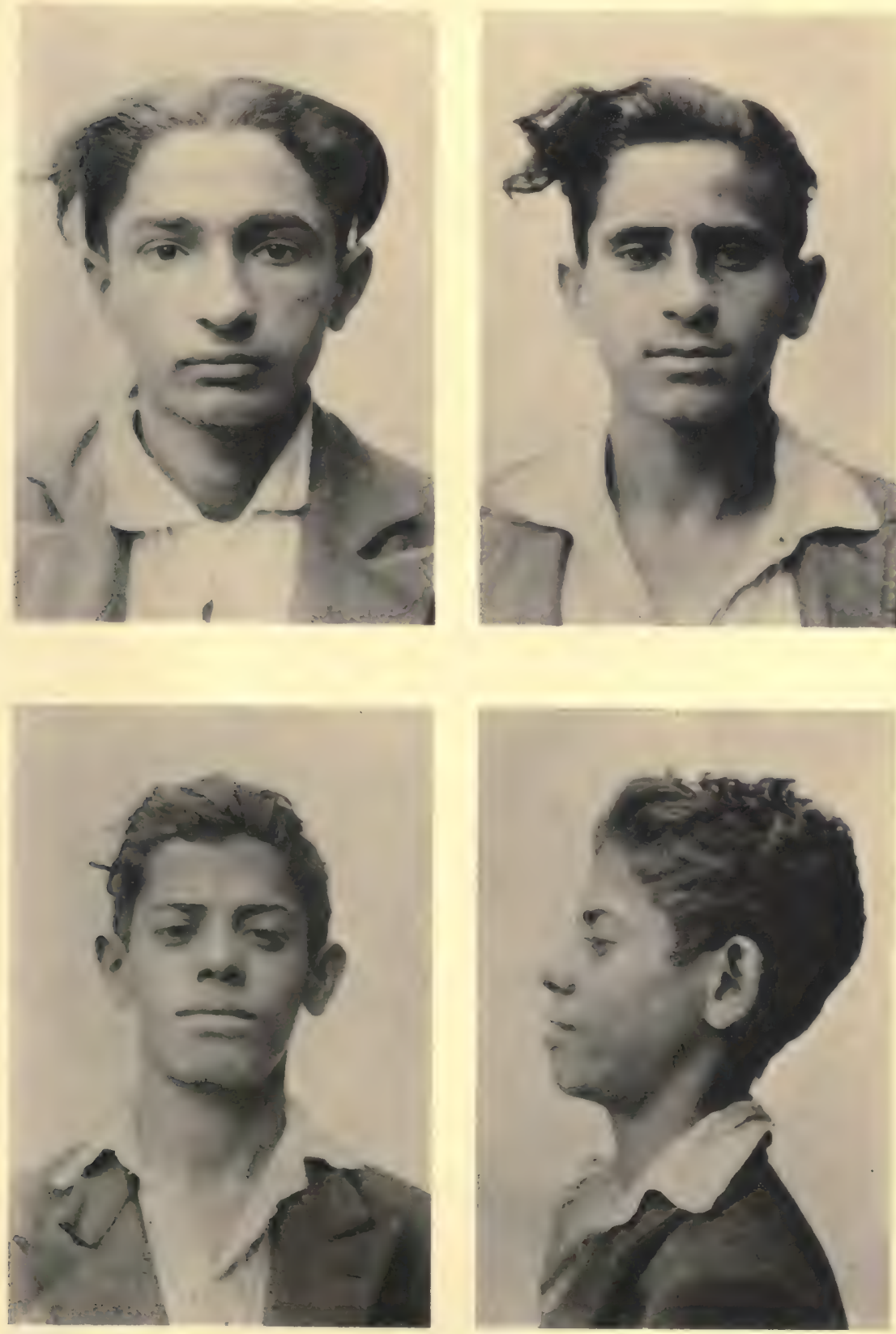


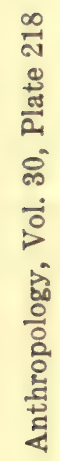
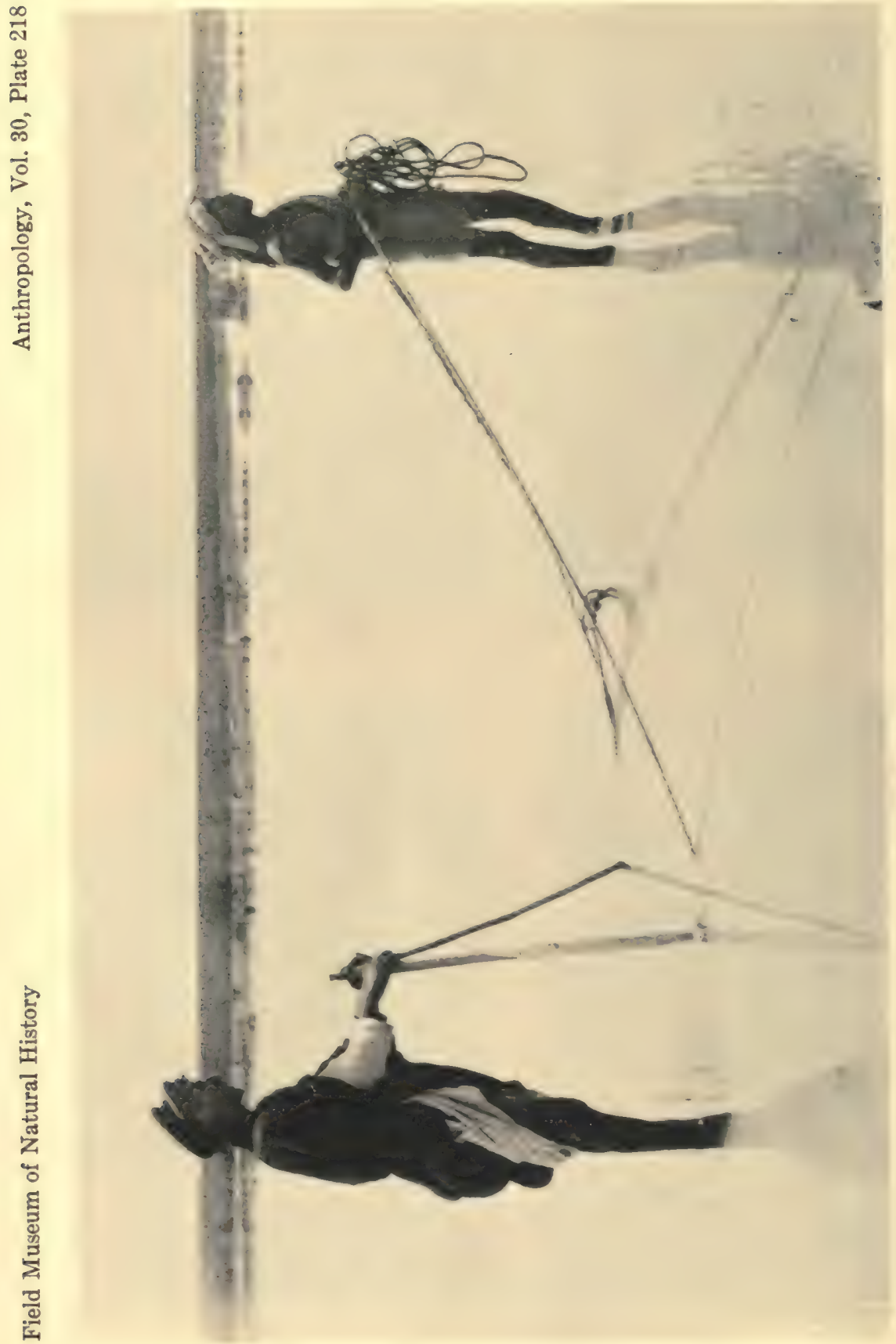

国 


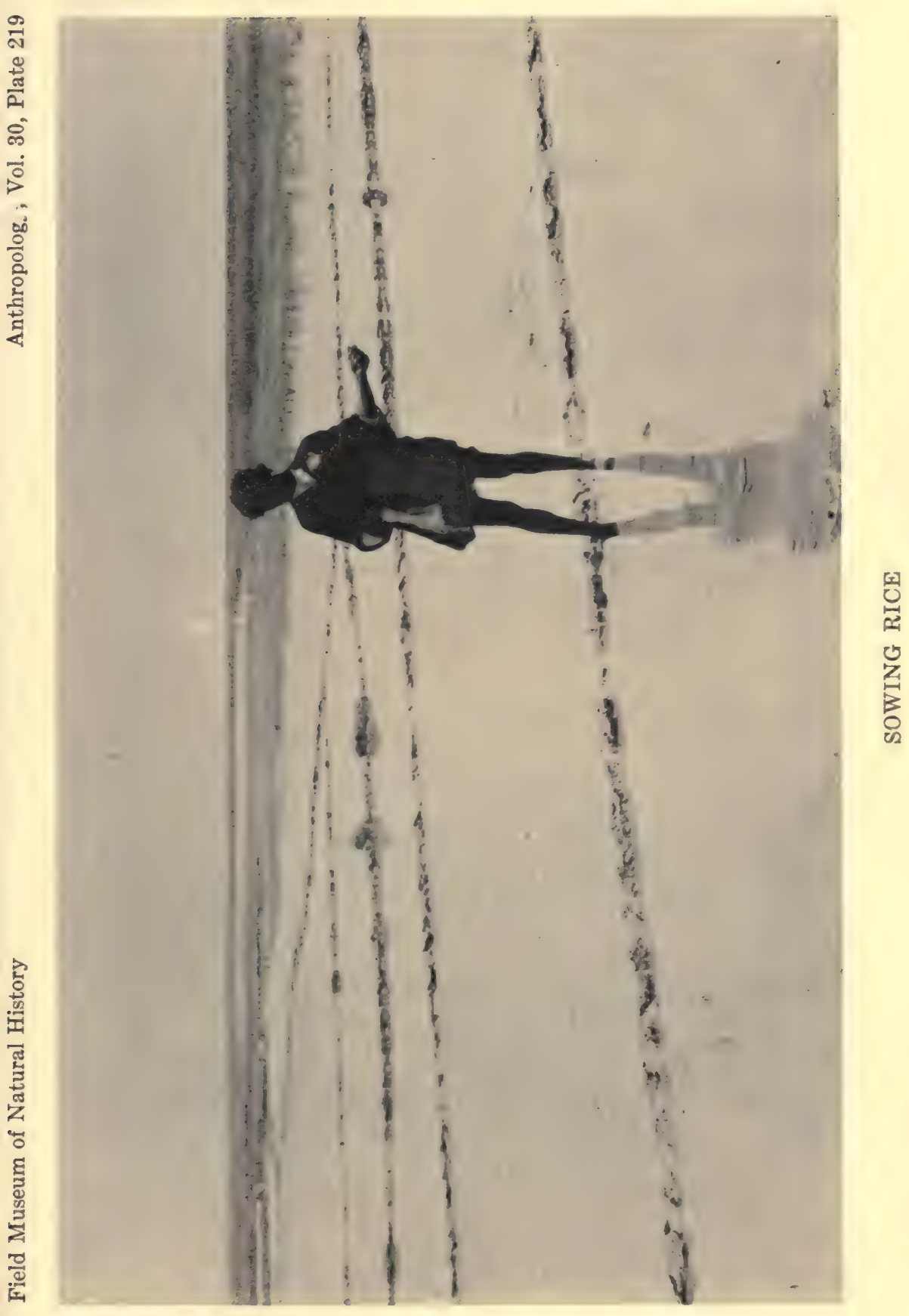


जे

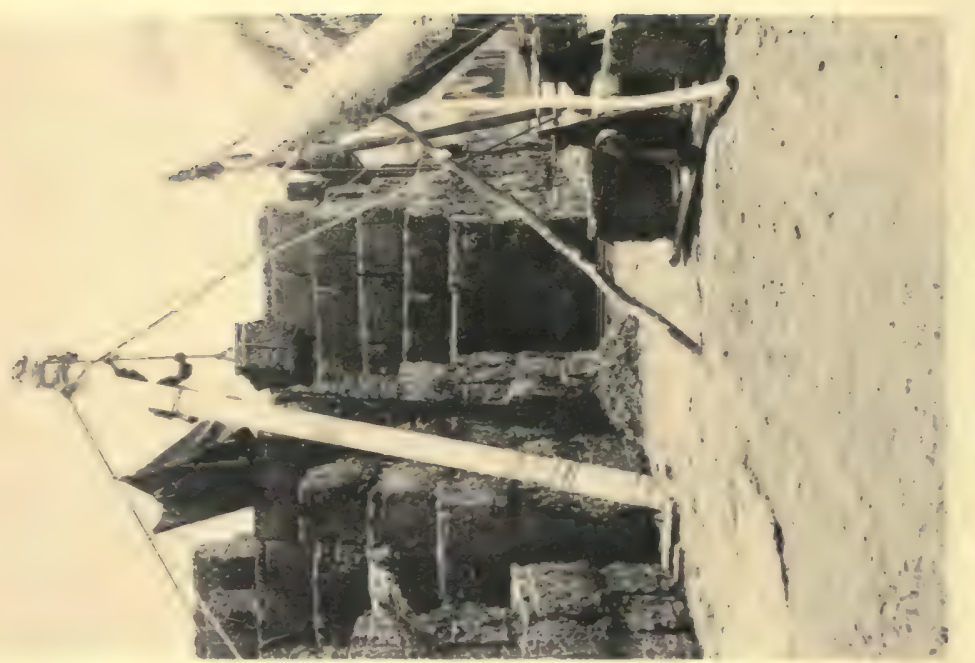

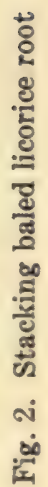

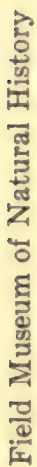

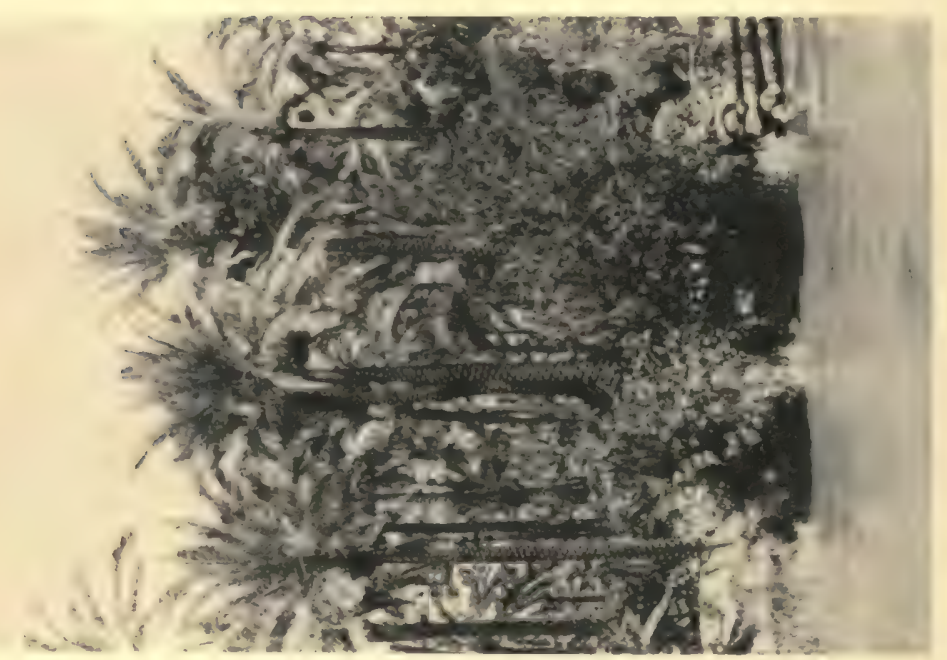

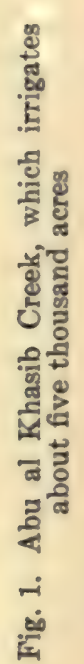

$\sum_{2}^{\infty}$

8

E

丞 


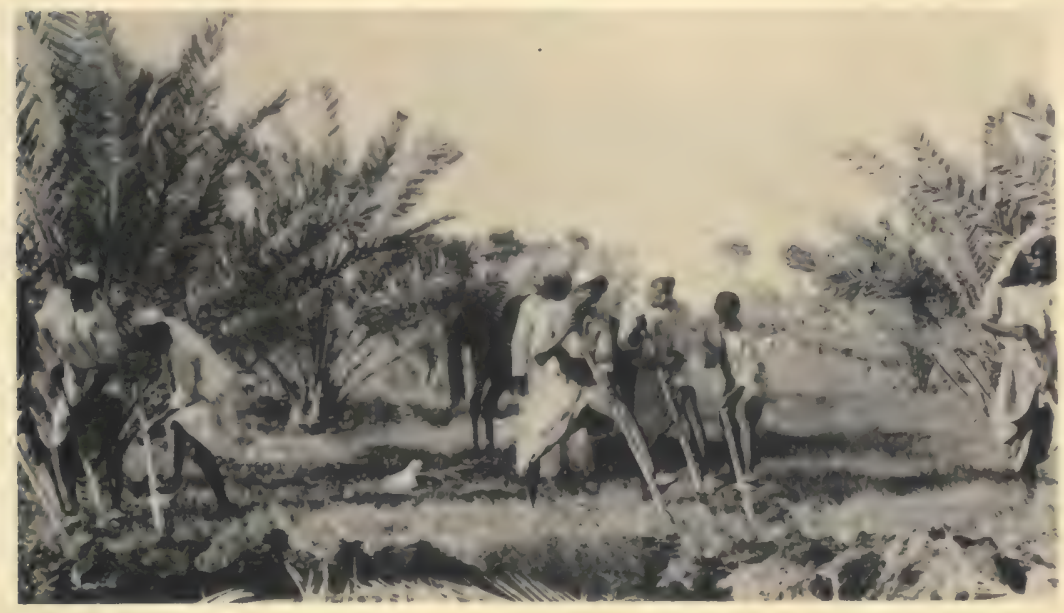

Fig. 1. Digging in alfalfa between rows of palms

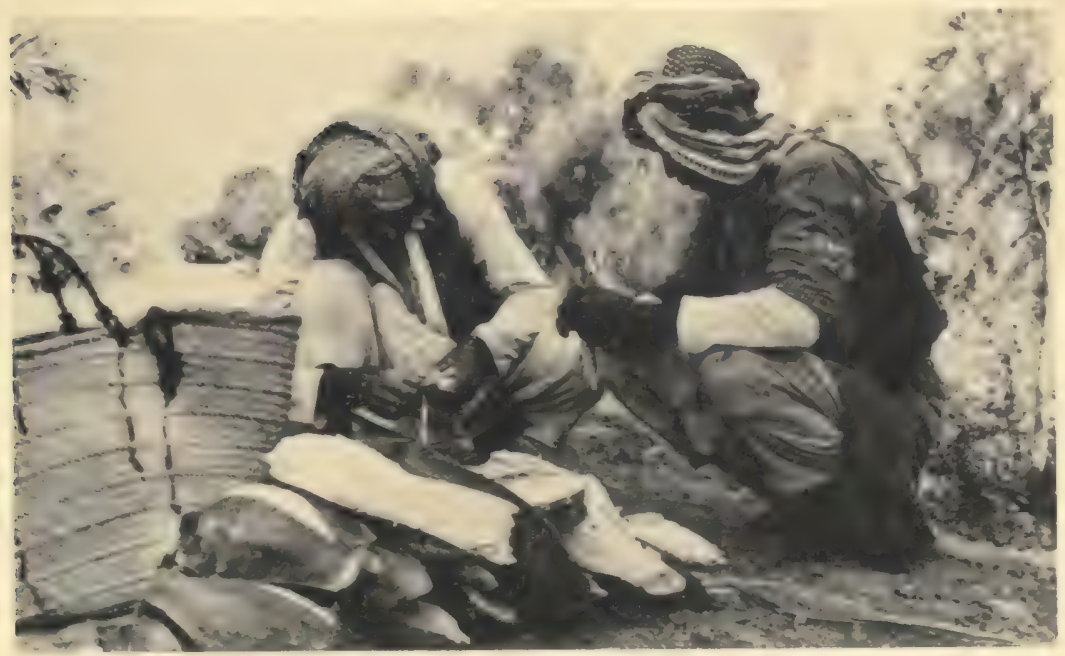

Fig. 2. Splitting into sprigs the staminate inflorescences of date palm 


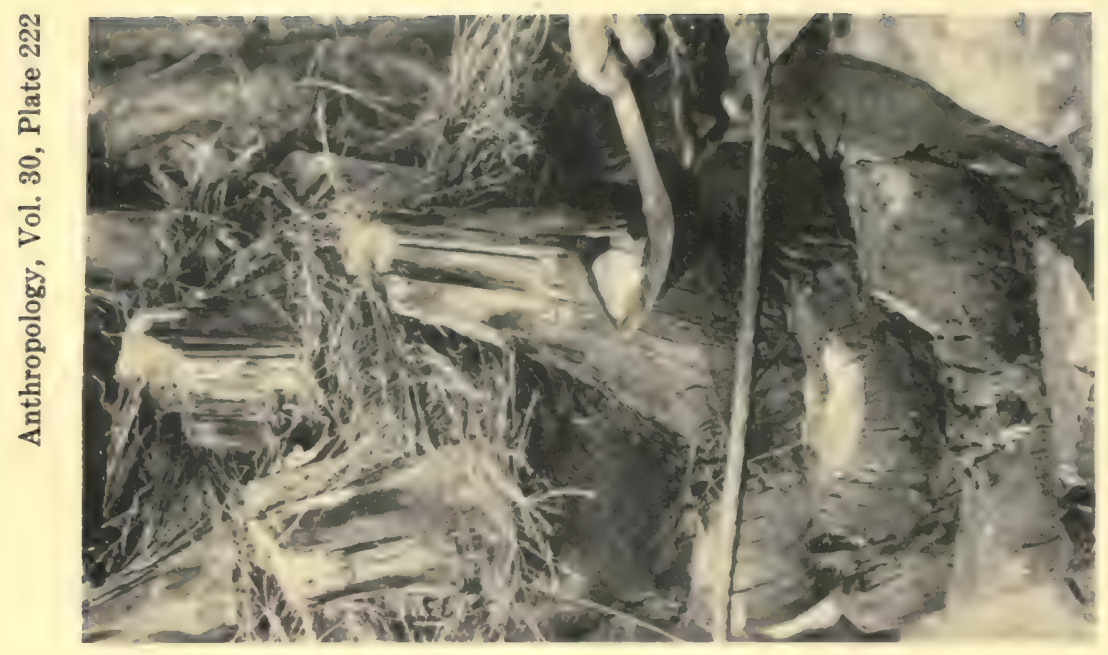

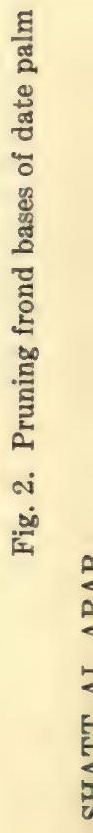

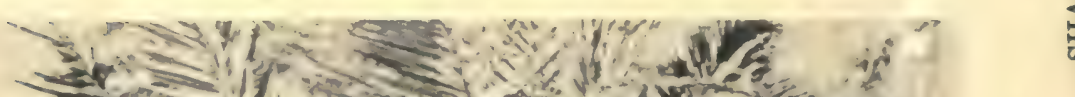

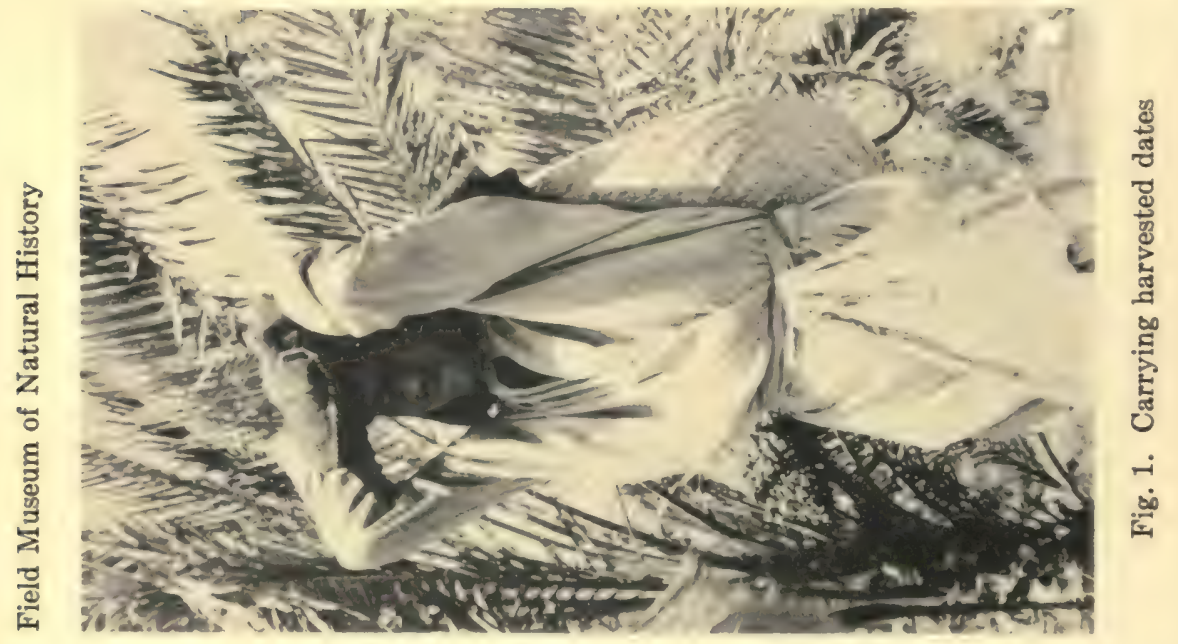




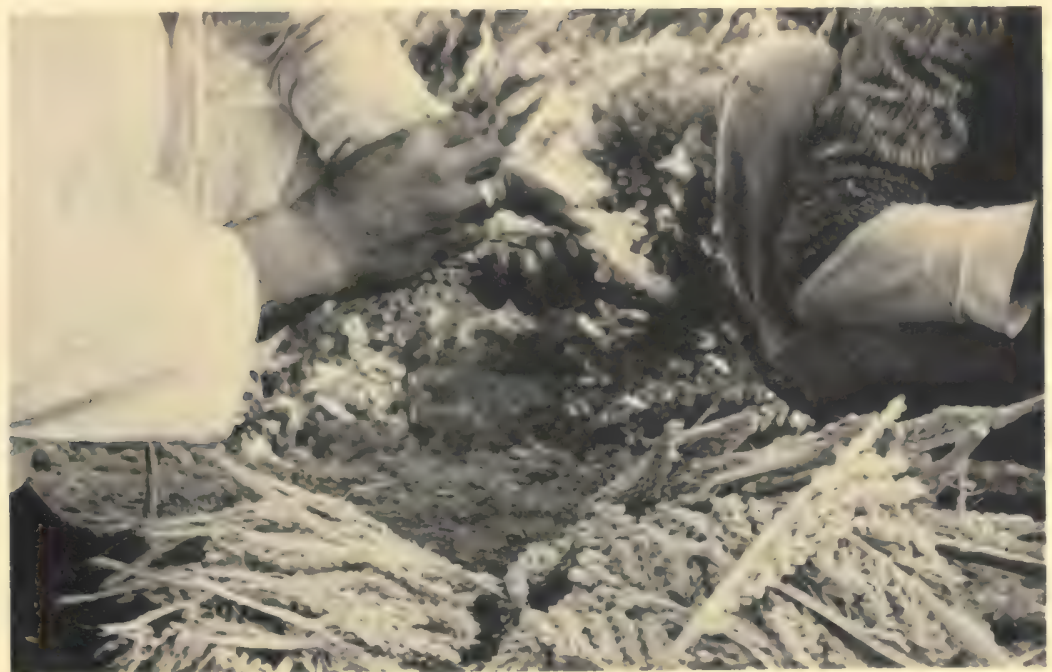

Fig. 1. Sprigs of staminate blossoms of date palm

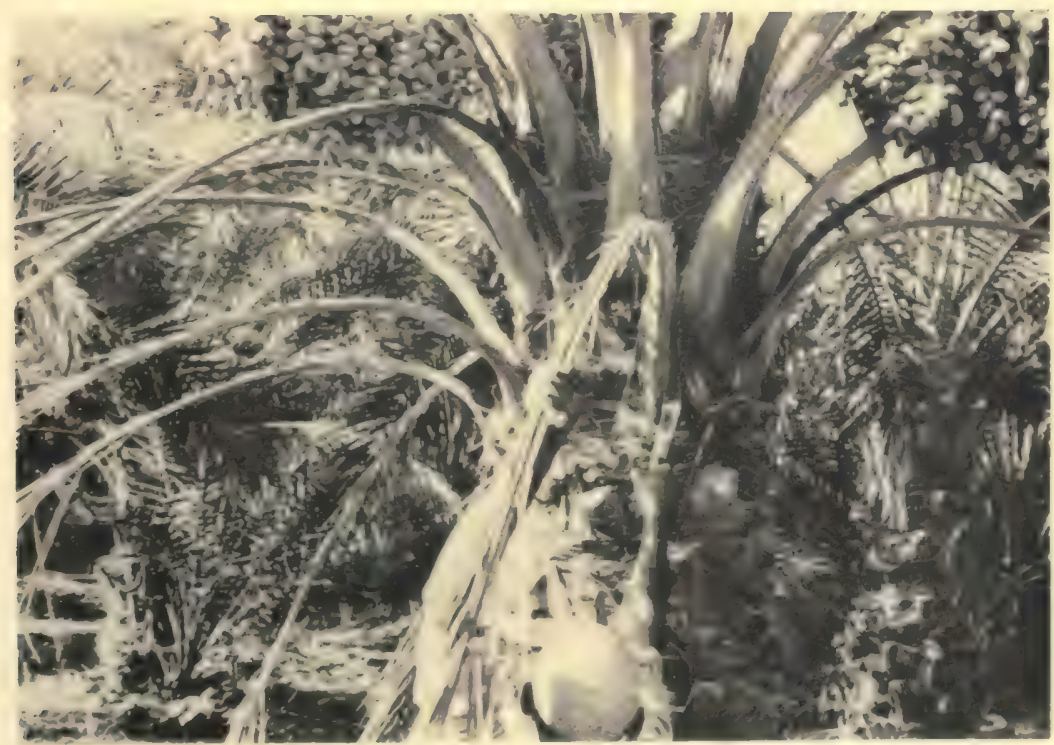

Fig. 2. Pruning fronds of date palm

SHATT AL ARAB 


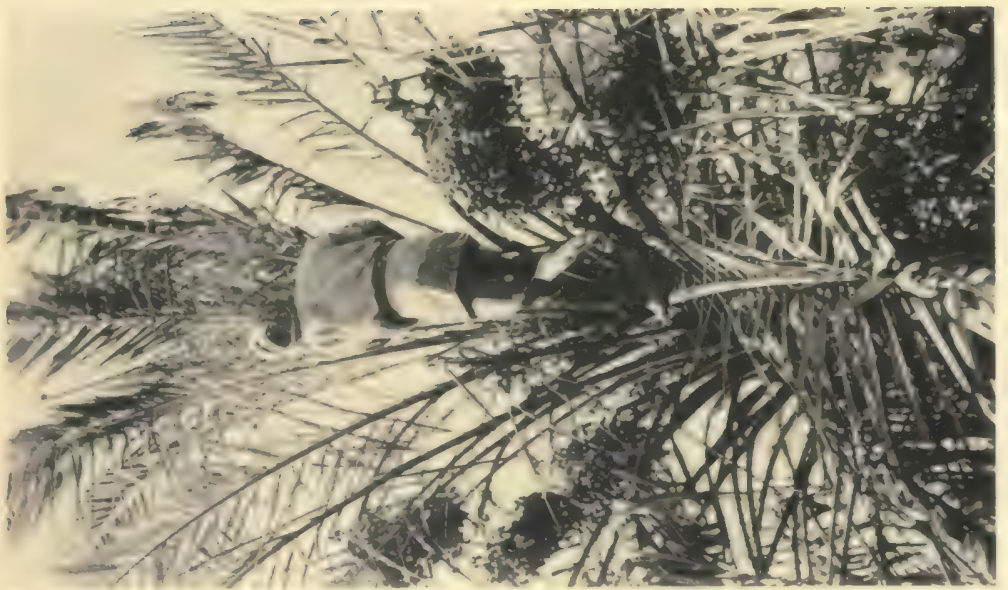

है
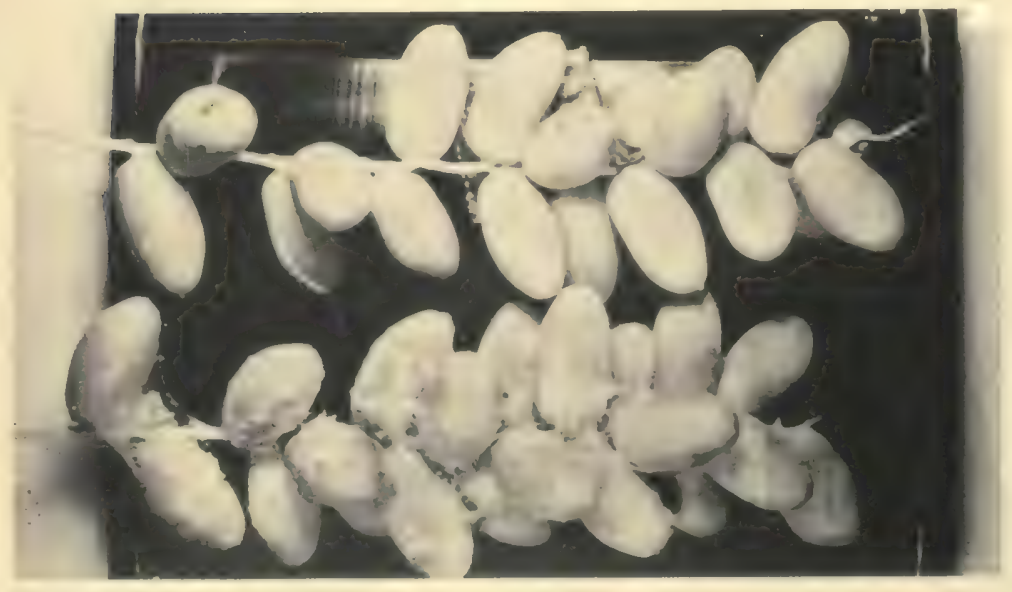

둥 क

党

एह

미

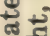

응

모

\$.

일

동

호을

두워

的

-

눈을 
Album No. 135

$$
\text { Neg. No. } 104418 \text { (all) }
$$

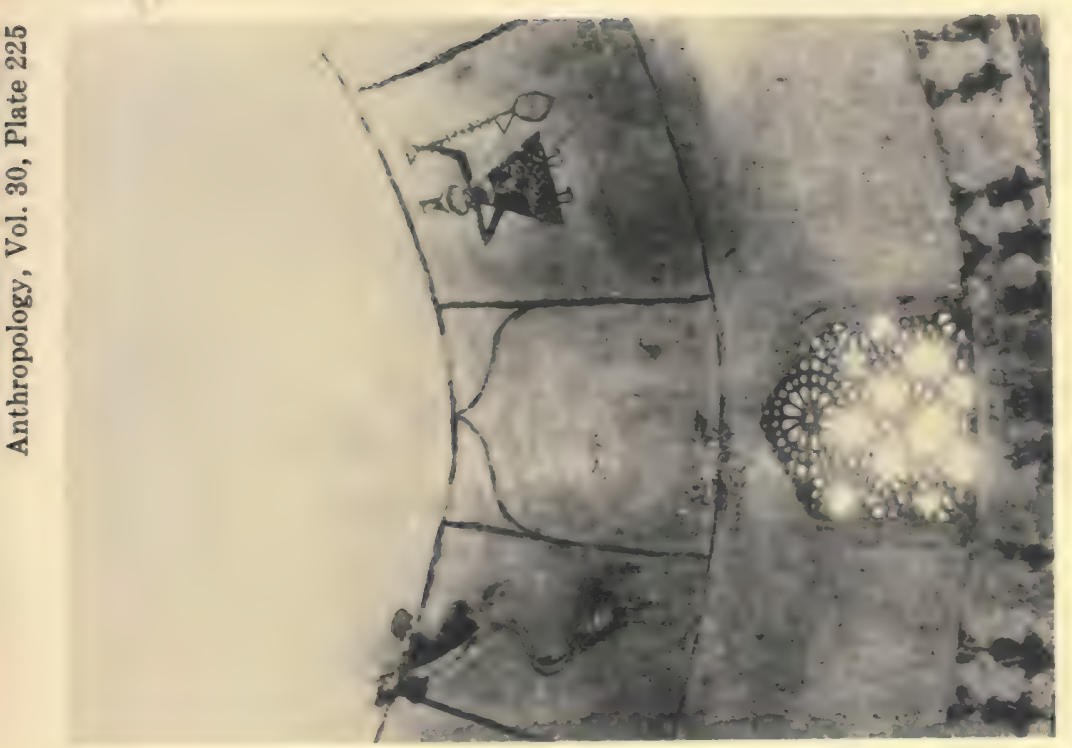

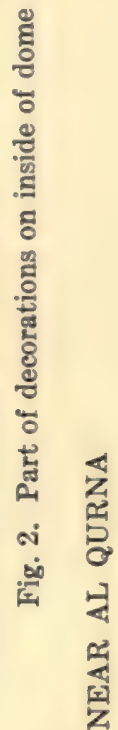

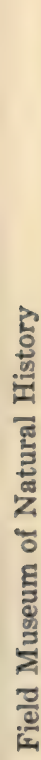

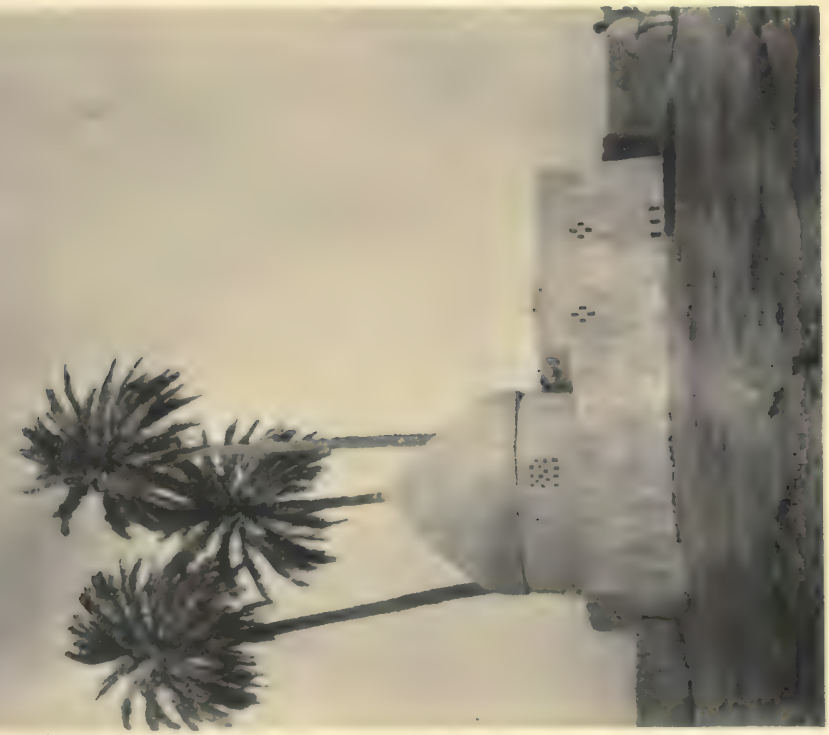

है

हैं

要
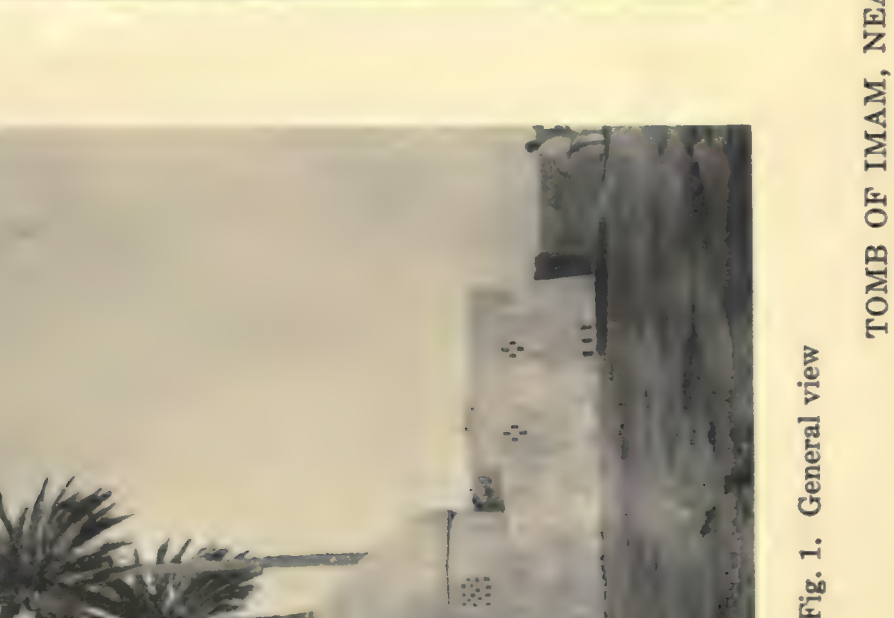


$$
\begin{aligned}
& \text { Al bum No.135 } \\
& \text { Neg. No. } 104374
\end{aligned}
$$

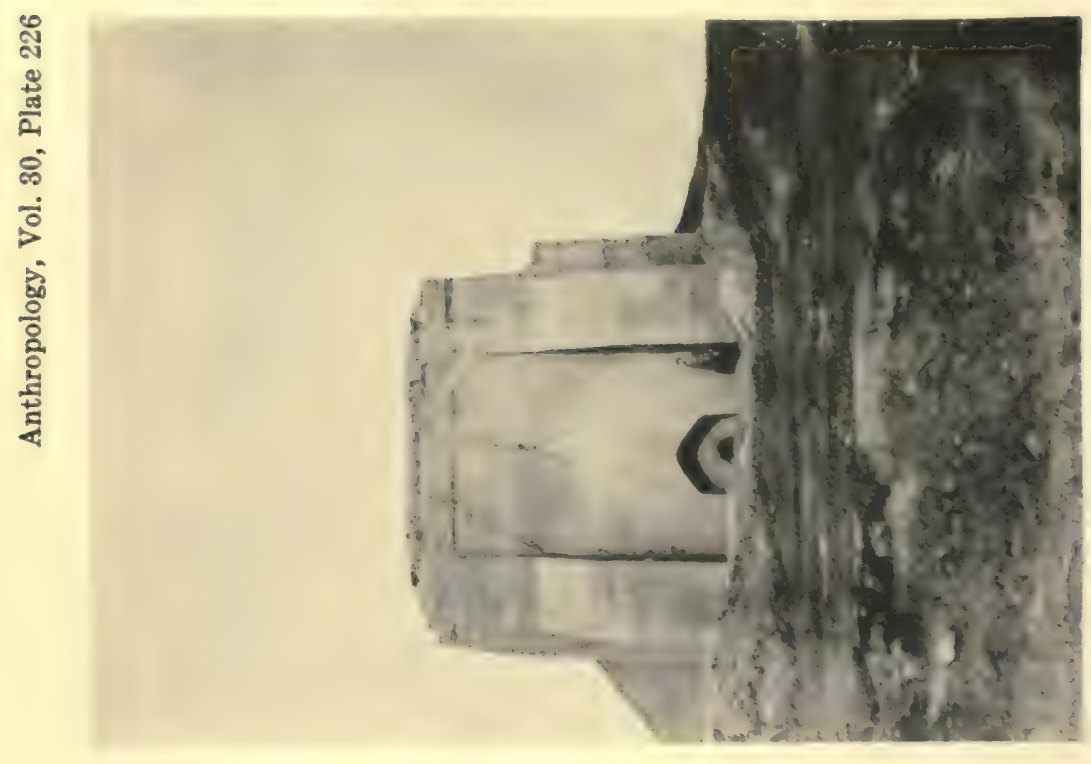

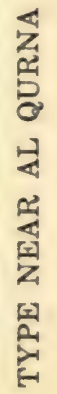

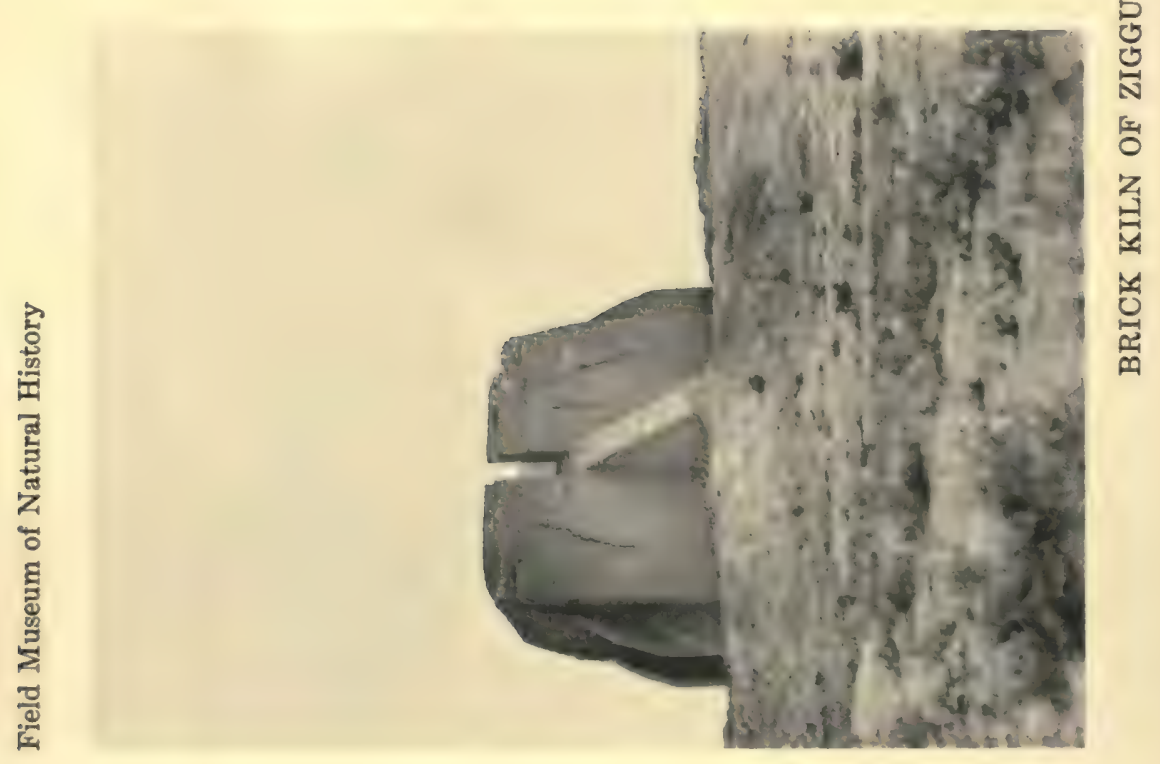




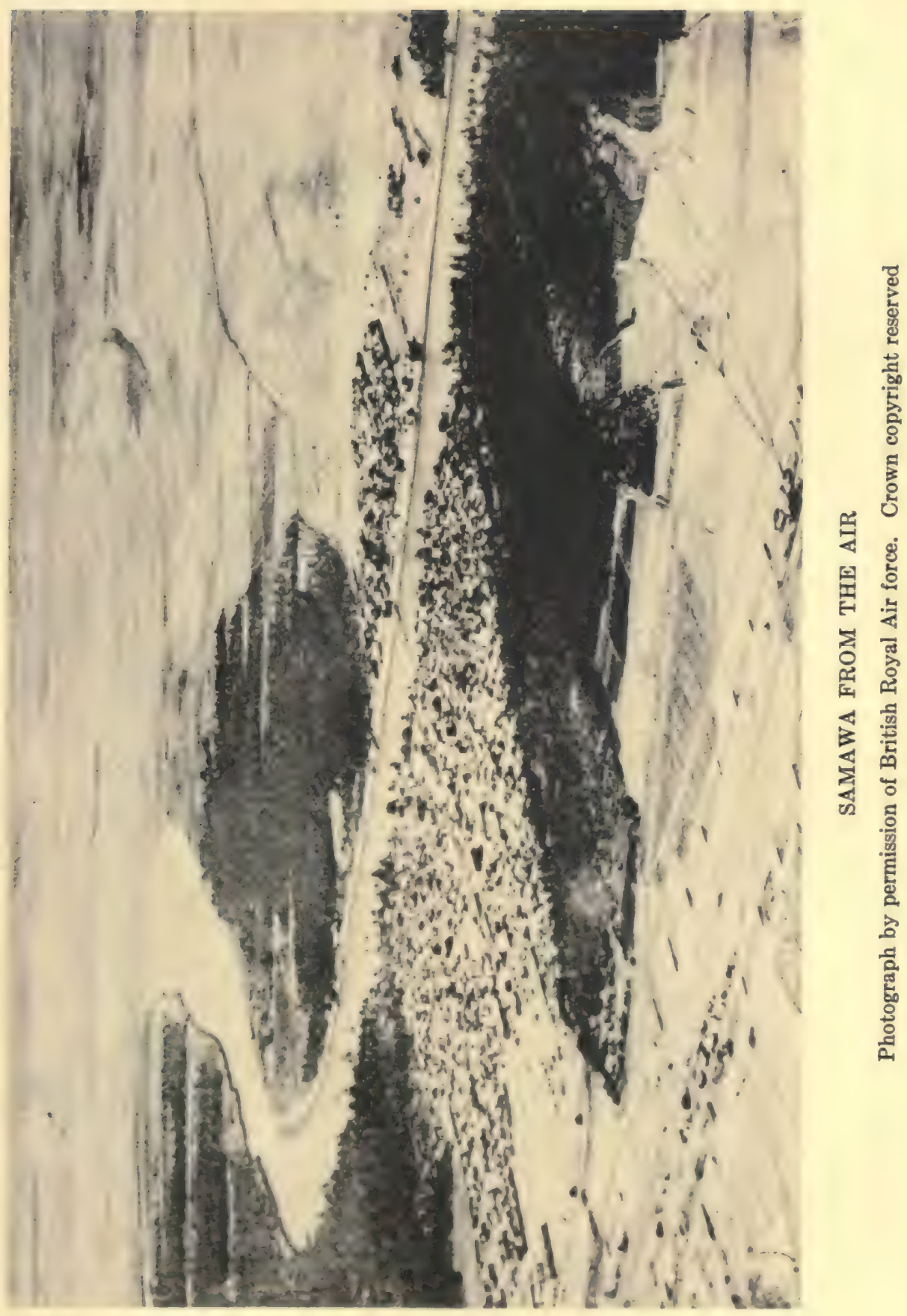




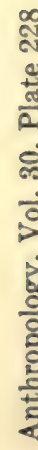
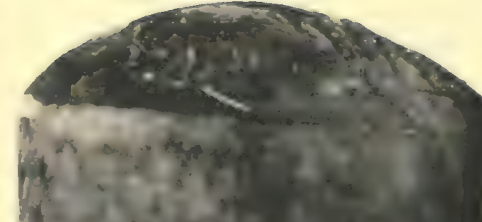

$k^{2}=2 x+2=0$

f. , ath - th

$\frac{8}{8}$

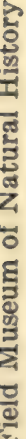

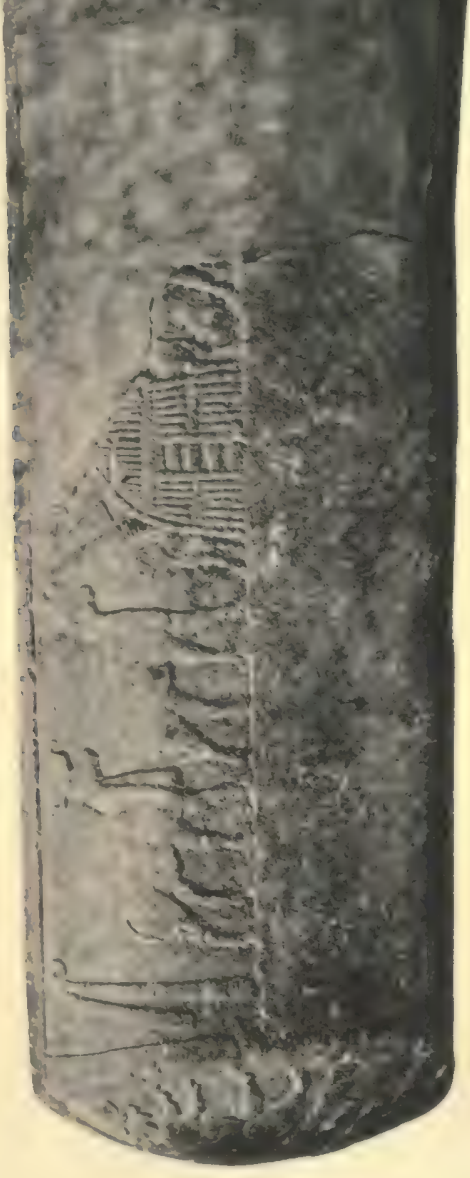

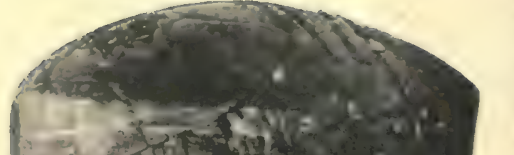

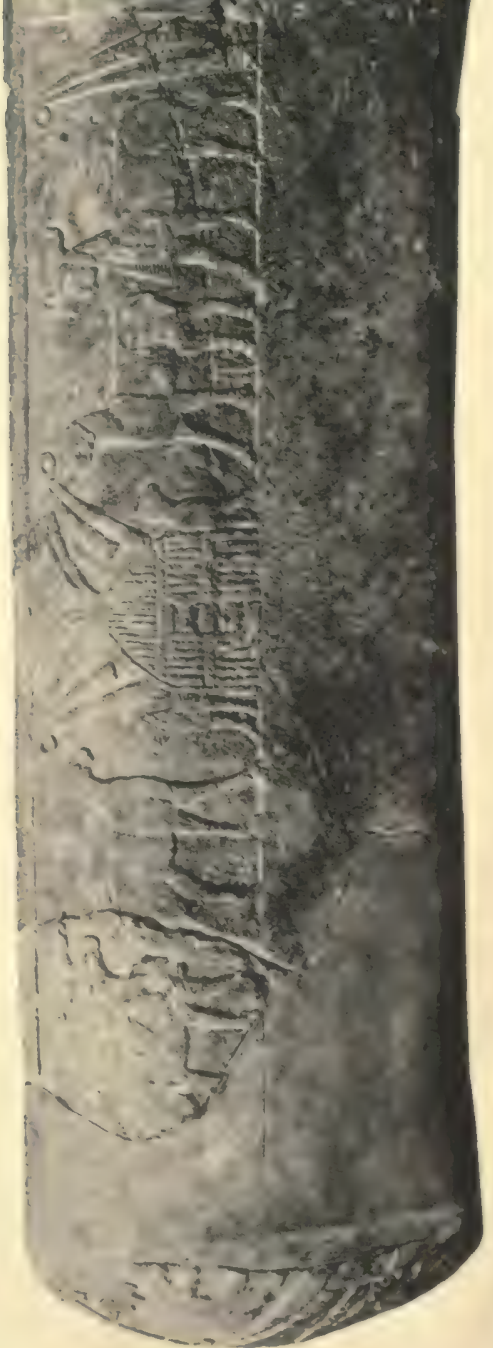





